\title{
EVALUATION, OPTIMIZATION, AND RELIABILITY OF NO-FLOW UNDERFILL PROCESS
}

\author{
A Thesis \\ Presented to \\ The Academic Faculty
}

by

Michael Colella

In Partial Fulfillment of the Requirements for the Degree

Master of Science

Georgia Institute of Technology

Jan 2004 
EVALUATION, OPTIMIZATION, AND RELIABILITY OF NO-FLOW UNDERFILL PROCESS

Date approved: 01/27/2004

Dr. Daniel F. Baldwin, Chairman

Dr. Suresh Sitaraman

Dr. Steven Danyluk 


\section{ACKNOWLEDGEMENTS}

I would like to thank my advisor, Dr. Daniel Baldwin for the opportunity to gain experience and marketable skills in the field of electronics packaging; the members of my thesis committee, Dr. Sitaraman, and Dr. Danyluk; Paul Houston, Brian Smith, and Brian Lewis, for their help and willingness to answer questions about equipment usage; and Jen Muncy for her help and cooperation with experimental work. 


\section{EVALUATION, OPTIMIZATION, AND RELIABILITY OF NO-FLOW} UNDERFILL PROCESS

\section{EVALUATION, OPTIMIZATION, AND RELIABILITY OF NO-FLOW} UNDERFILL PROCESS

ACKNOWLEDGEMENTS ........................................................................... ii

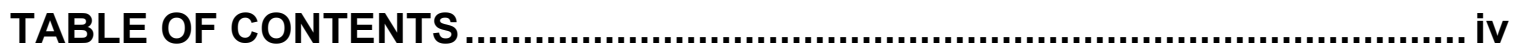

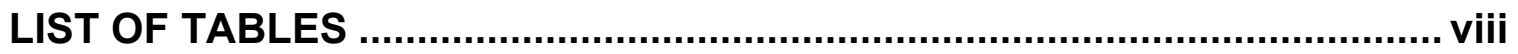

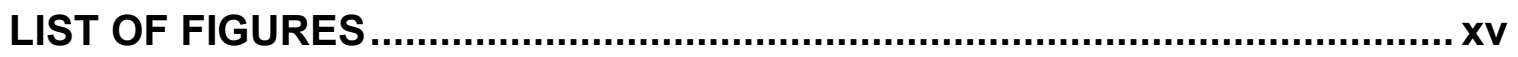

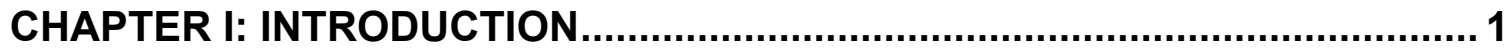

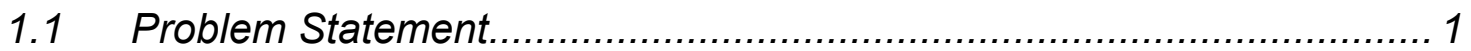

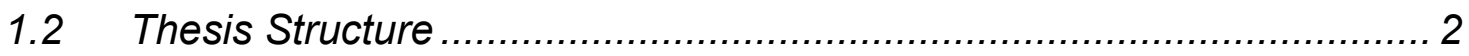

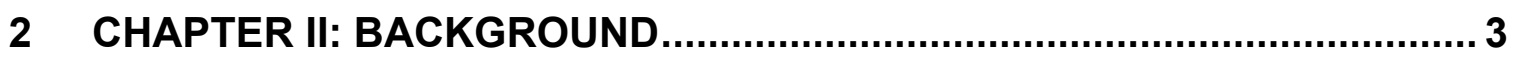

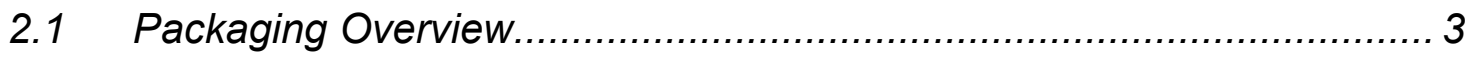

2.2 Advantages of Flip Chip Technology .............................................. 4

2.3 Disadvantages of Flip Chip Technology …..................................... 5

2.4 The Flip Chip Manufacturing Process ................................................. 7

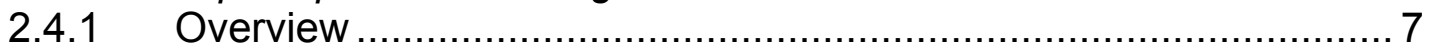

2.4.2 Flip Chip Processing Steps ................................................... 8

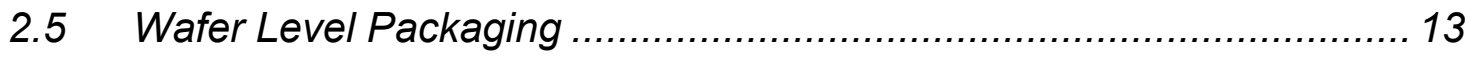

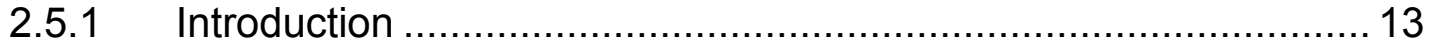

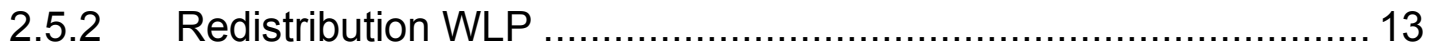

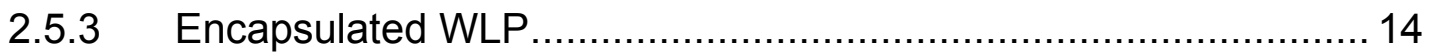

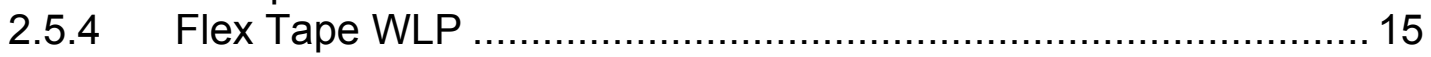

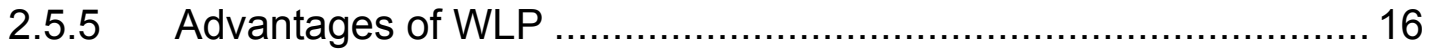

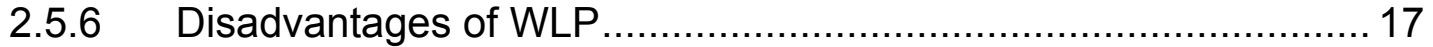

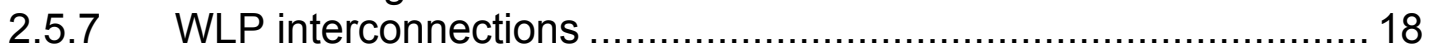

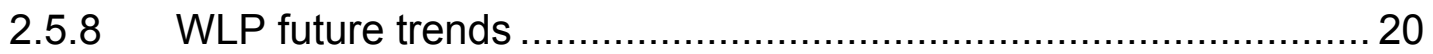

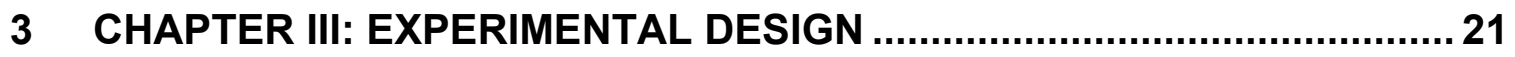

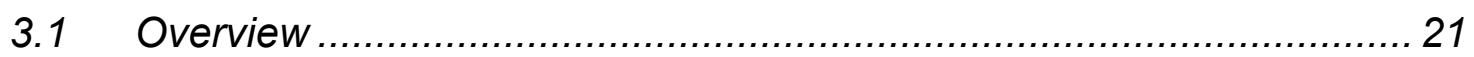

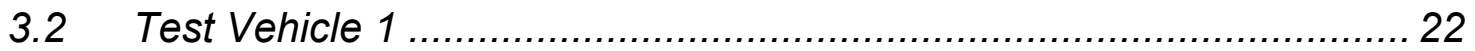

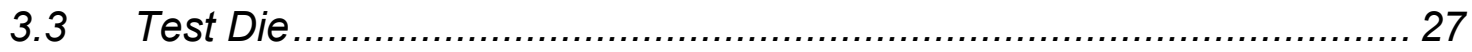

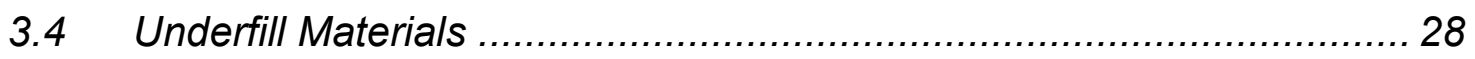




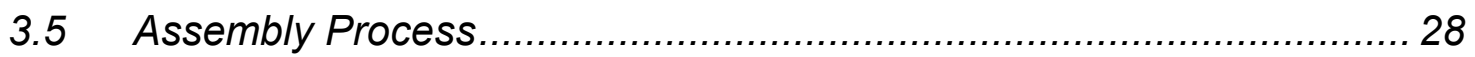

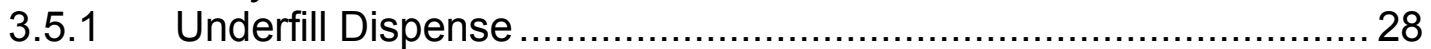

3.5.2 Pre-Assembly Moisture Removal ............................................ 32

3.5.3 General Reflow Information ............................................. 32

3.6 Design of Experiments \#1, Dispense Optimization ........................... 35

3.7 Design of Experiments \#2, Placement Optimization........................... 37

3.8 Line Placement Study ............................................................ 40

3.9 Parametric Reflow Optimization ................................................. 43

3.9.1 Reflow Profile Development ............................................... 45

3.9.2 Material A Reflow Profiles .................................................... 47

3.9.3 Material B Reflow Profiles .................................................... 48

3.9.4 Material C Reflow Profiles ................................................... 49

3.9.5 Material E Reflow Profiles ................................................. 51

3.9.6 Grain Size Determination Method …….................................... 53

3.10 C-Mode Scanning Acoustic Microscopy (C-SAM®) ........................... 55

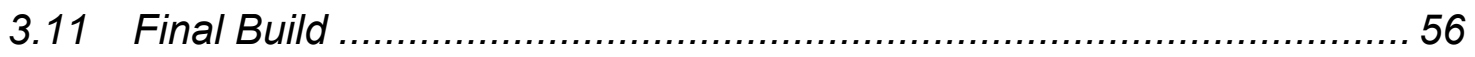

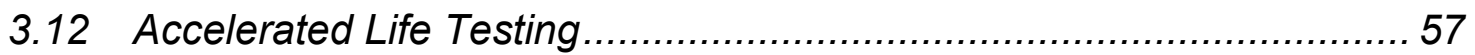

3.12.1 Air to Air Thermal Cycling (AATC) ............................................ 58

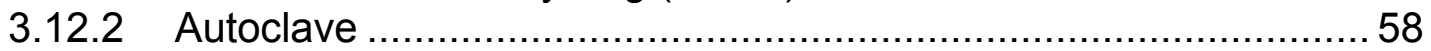

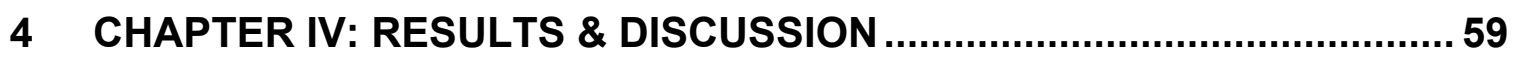

4.1 Results: Design of Experiments \# 1 .............................................. 59

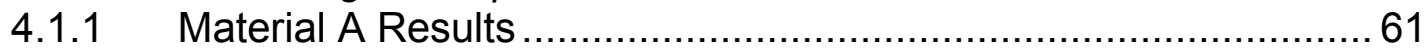

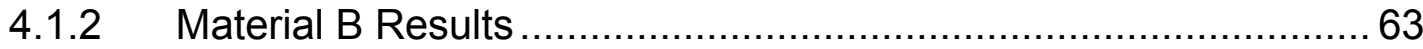

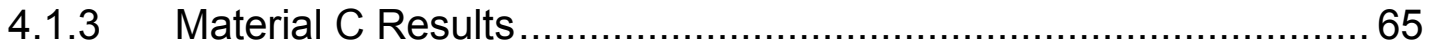

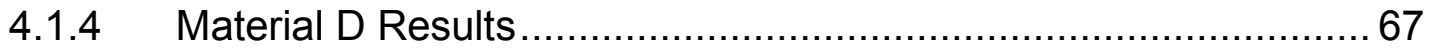

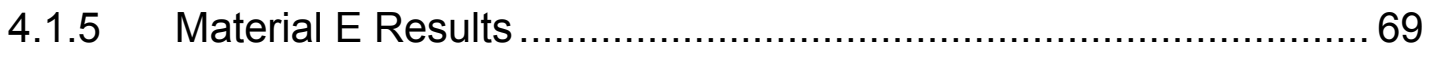

4.2 Discussion, Design of Experiments \# 1 .......................................... 71

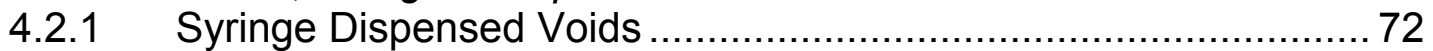

4.2.2 Pad Opening Voids From Dispense .......................................... 73

4.2.3 Pad Opening Voids Formed During Flow .................................. 77

4.2.4 Entrainment Voids from Flow ................................................. 81

4.2.5 Summary of DOE1 Conclusions................................................ 83

4.3 Results: Design of Experiments \#2 ............................................... 85

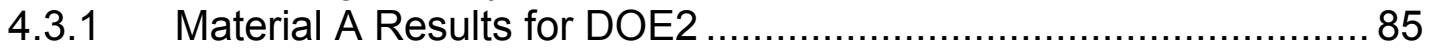

4.3.2 Material B Results for DOE2 ……..................................... 88

4.3.3 Material C Results for DOE2 …............................................ 90

4.3.4 Material D Results for DOE2 …........................................... 93

4.3.5 Material E Results for DOE2 …............................................. 96

4.4 Discussion: Design of Experiments \#2 ........................................... 99

4.4.1 Discussion of Interconnect Results for DOE2 …....................... 99

4.4.2 Discussion of Voiding Results for DOE2 ................................. 103 


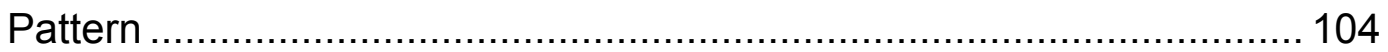

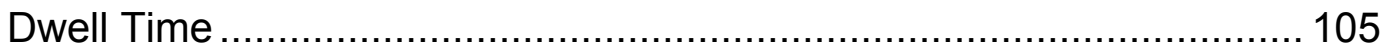

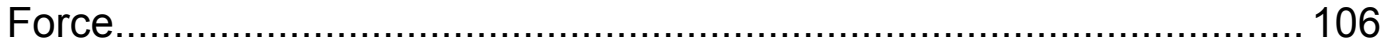

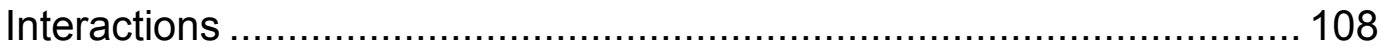

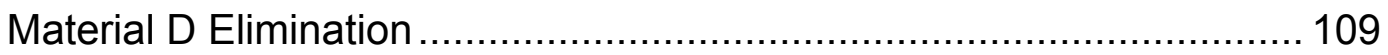

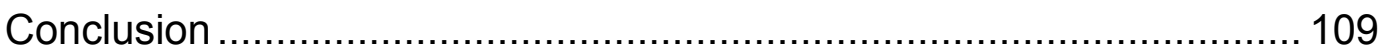

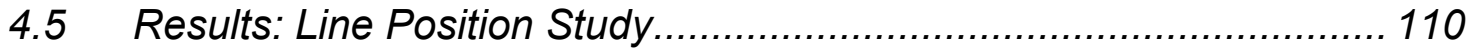

4.6 Discussion and Conclusions, Line Position Study ........................... 113

4.7 Results and Discussion: Parametric Reflow Characterization............. 115

4.7.1 Reflow Results, Material A ................................................... 115

4.7.2 Reflow Results, Material B ............................................... 117

4.7.3 Reflow Results, Material C .................................................. 118

4.7.4 Reflow Results, Material E .................................................. 119

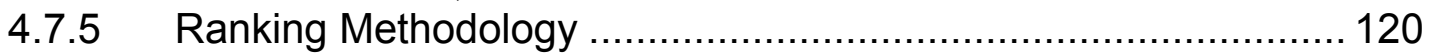

4.7.6 Reflow Profile Discussion and Conclusions ................................ 124

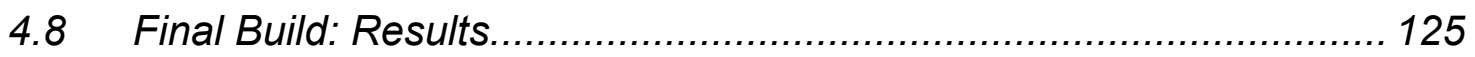

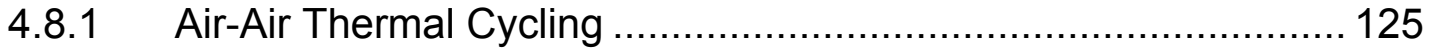

4.8.2 Autoclave Test .......................................................... 127

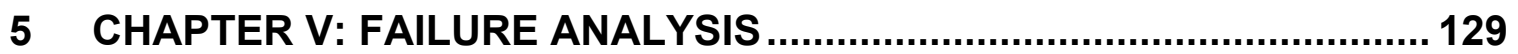

5.1 Observed Failure modes .......................................................... 129

5.1.1 Solder Fatigue Cracks........................................................ 130

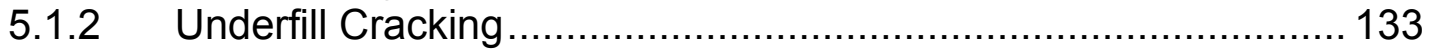

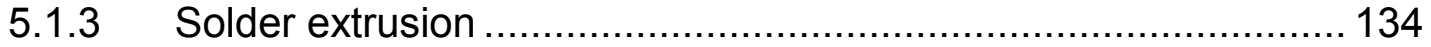

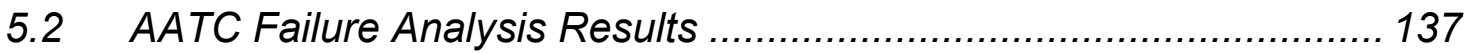

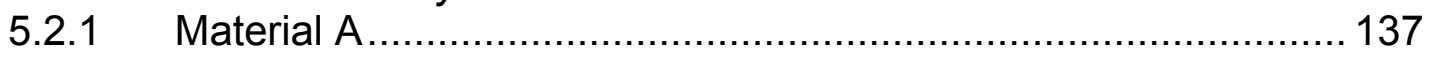

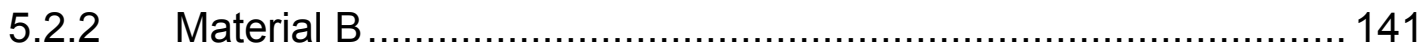

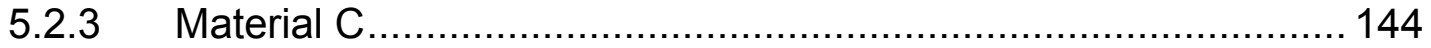

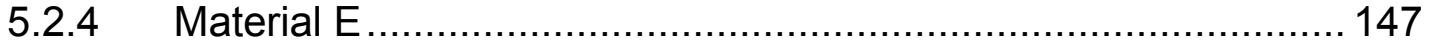

5.3 AATC Discussion and Conclusions ................................................. 150

5.4 Autoclave Failure Analysis Results .............................................. 152

5.5 Autoclave Discussion and Conclusions........................................ 157

6 CHAPTER VI: PROCESS MODELING AND DESIGN GUIDLINES ......... 158

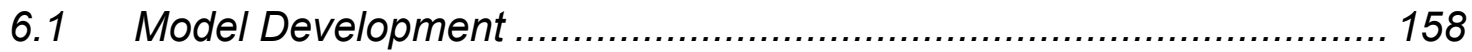

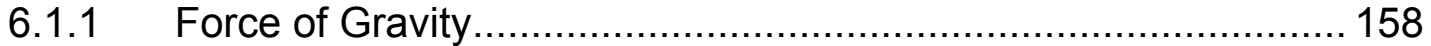

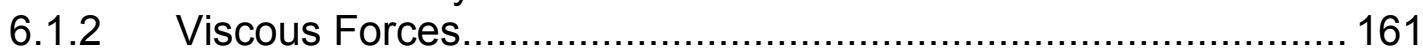

6.1.3 Surface Tension as a Driving Force .......................................... 162

6.1.4 Viscous Dissipation as a Retarding Force................................ 163

6.1.5 The Viscous Dissipation Hydrodynamic Model .......................... 163

6.2 Application of the Wetting Model.............................................. 168

6.2.1 Wetting Dynamics for FA10-2 Assembly ................................. 168 


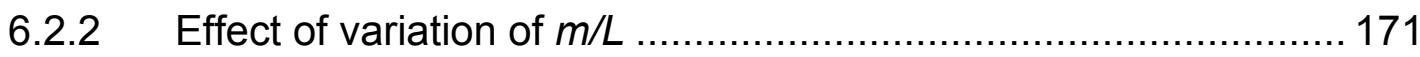

6.2.3 Effect of variation of viscosity ............................................. 175

6.2.4 Effect of variation of the fitting parameter................................ 177

6.2.5 Effect of variation in the equilibrium contact angle .................... 178

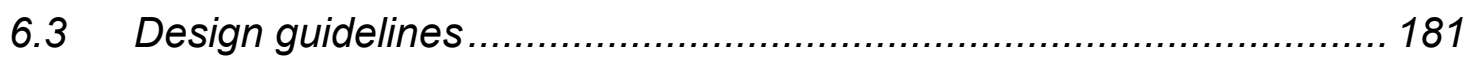

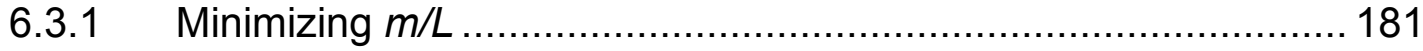

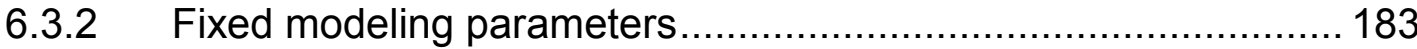

6.3.3 Design guidelines for area array test vehicles........................... 184

7 CHAPTER VI: CONCLUSIONS AND FUTURE WORK........................... 188

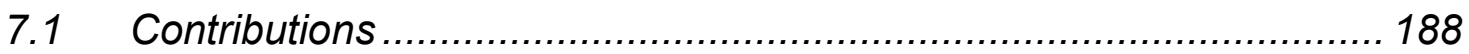

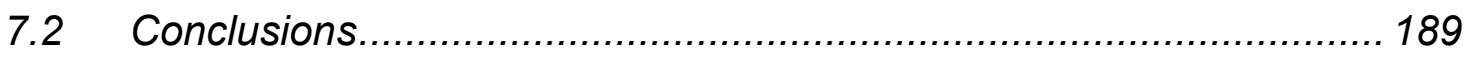

7.3 Recommendations and Future Work .......................................... 190

A. Appendix - Reflow Profiles....................................................... 191

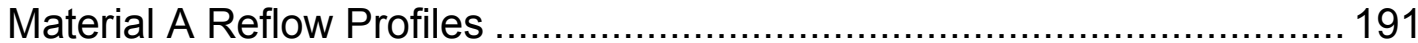

Material B Reflow Profiles .................................................................... 204

Material C Reflow Profiles ................................................................. 214

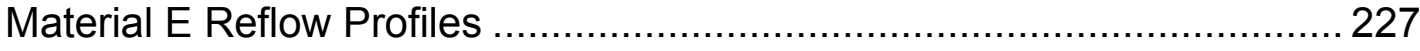

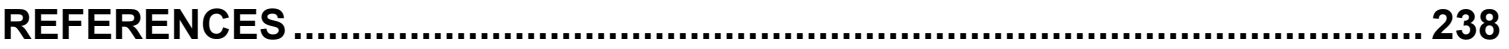




\section{LIST OF TABLES}

Table 3-1 No-Flow Fluxing Underfills Used and Material Properties ................. 28

Table 3-2 Underfill Dispense Program for Line Pattern .................................. 29

Table 3-3 FA10LINE.CAM Sub-Program for Line Pattern ............................... 29

Table 3-4 Underfill Dispense Program for Dot Pattern ................................... 30

Table 3-5 FA10DROP.CAM Sub-Program for Dot Pattern ............................... 30

Table 3-6 Underfill Dispense Program for Cross Pattern................................. 31

Table 3-7 FA10CRS.CAM Sub-Program for Cross Pattern .............................. 31

Table 3-8 Placement Experimental Matrix (DOE1) ....................................... 36

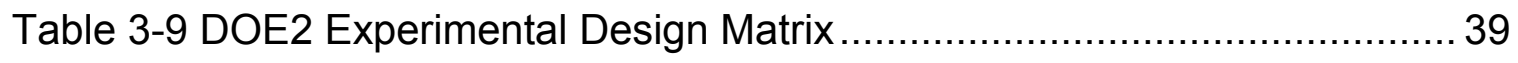

Table 3-10 Step Profile Parametric Matrix ................................................. 44

Table 3-11 Material A, Reflow Parameter Values........................................... 47

Table 3-12 Material B, Reflow Profile Parameter Values.................................. 49

Table 3-13 Material C, Reflow Profile Parameter Values ................................ 50

Table 3-14 Material E, Reflow Profile Parameter Values ..................................51

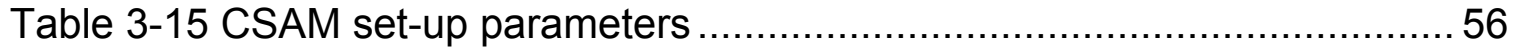

Table 3-16 Final Build Assembly Matrix ....................................................... 57

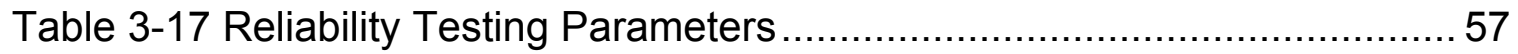

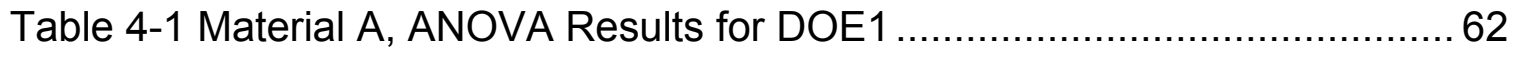

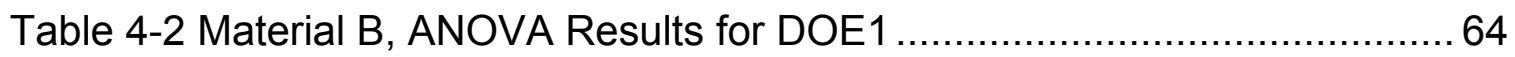

Table 4-3 Material C, ANOVA Results for DOE 1 ........................................ 66

Table 4-4 Material D, ANOVA Results for DOE1 ......................................... 68

Table 4-5 Material E, ANOVA Results for DOE1 _........................................... 70 
Table 4-6 Summary of Dispense Study Significance. 84

Table 4-7 Material A, ANOVA Results for DOE2 …....................................... 86

Table 4-8 Material B, ANOVA Results for DOE2 …...................................... 88

Table 4-9 Material C, ANOVA Results for DOE2 _........................................... 91

Table 4-10 Material D, ANOVA Results for DOE2 …...................................... 93

Table 4-11 Material E, ANOVA Results for DOE2 …...................................... 97

Table 4-12 Interconnect Yield for the 111 treatment (Dot, 1N, 0s) .................. 100

Table 4-13 Parameters Used for Figure 4-28 …........................................ 102

Table 4-14 Summary of Placement DOE Significance for Voiding .................. 104

Table 4-15 Material A, Line Position Voiding Results ................................... 110

Table 4-16 Material A, Reflow Profile Rankings ......................................... 116

Table 4-17 Material B, Reflow Profile Rankings ......................................... 117

Table 4-18 Material C, Reflow Profile Rankings .............................................. 118

Table 4-19 Material E, Reflow Profile Rankings …..................................... 119

Table 4-20 Autoclave Electrical Failure Summary ..................................... 128

Table 4-21 Autoclave Delamination Summary ........................................... 128

Table 6-1 Baseline Modeling Parameters (FA10-2) .................................... 169

Table 6-2 Linear Mass Density Values for Flip Chips .................................. 173

Table 6-3 Error of Prediction at Process Time-Scale (10 seconds) ................. 180

Table 6-4 Design Guidelines for FA10-2 Patterned Hybrid No-Flow Process .. 185

Table 6-5 Design Guidelines for FA10-4 Patterned Hybrid No-Flow Process .. 185

Table 6-6 Design Guidelines for FA(20x20) Patterned Hybrid No-Flow Process 
Table A-1 Material A, reflow parameters for Baseline profile ........................... 192

Table A-2 Material A, oven set points for Baseline profile ............................. 192

Table A-3 Material A, reflow parameters for Ramp Rate Low profile ................ 193

Table A-4 Material A, oven set points for Ramp Rate Low profile ................... 193

Table A-5 Material A, reflow parameters for Ramp Rate High profile ............... 194

Table A-6 Material A, oven set points for Ramp Rate High profile................... 194

Table A-7 Material A, reflow parameters for Soak Temperature Low profile .... 195

Table A-8 Material A, oven set points for Soak Temperature Low profile ......... 195

Table A-9 Material A, reflow parameters for Soak Temperature High profile ... 196

Table A-10 Material A, oven set points for Soak Temperature High profile ...... 196

Table A-11 Material A, reflow parameters for Soak Time Low profile .............. 197

Table A-12 Material A, oven set points for Soak Time High profile................... 197

Table A-13 Material A, reflow parameters for Soak Time High profile .............. 198

Table A-14 Material A, oven set points for Soak Time High profile ................... 198

Table A-15 Material A, reflow parameters for Time Above $183{ }^{\circ} \mathrm{C}$ Low profile 199

Table A-16 Material A, oven set points for Time Above $183{ }^{\circ} \mathrm{C}$ Low profile...... 199

Table A-17 reflow parameters for Time Above $183^{\circ} \mathrm{C}$ High profile ................. 200

Table A-18 Material A, oven set points for Time Above $183^{\circ} \mathrm{C}$ High profile..... 200

Table A-19 Material A, reflow parameters for Peak Temperature Low profile .. 201

Table A-20 Material A, oven set points for Peak Temperature Low profile....... 201

Table A-21 Material A, reflow parameters for Peak Temperature High profile . 202

Table A-22 Material A, oven set points for Peak Temperature High profile ...... 202

Table A-23 Material A, reflow parameters for Parametric Optimized profile ..... 203 
Table A-24 Material A, oven set points for Parametric Optimized profile. 203

Table A-25 Material B, reflow parameters for Baseline profile........................ 205

Table A-26 Material B, oven set points for Baseline profile …........................ 205

Table A-27 Material B, reflow parameters for Ramp Rate Low profile .............. 206

Table A-28 Material B, oven set points for Ramp Rate Low profile ................. 206

Table A-29 Material B, reflow parameters for Ramp Rate High profile ............. 207

Table A-30 Material B, oven set points for Ramp Rate High profile................. 207

Table A-31 Material B, reflow parameters for Time Above $183^{\circ} \mathrm{C}$ Low profile 208

Table A-32 Material B, oven set points for Time Above $183^{\circ} \mathrm{C}$ Low profile...... 208

Table A-33 Material B, reflow parameters for Time Above $183^{\circ} \mathrm{C}$ High profile 209

Table A-34 Material B, oven set points for Time Above $183^{\circ} \mathrm{C}$ High profile..... 209

Table A-35 Material B, reflow parameters for Peak Temperature Low profile .. 210

Table A-36 Material B, oven set points for Peak Temperature Low profile ....... 210

Table A-37 Material B, reflow parameters for Peak Temperature High profile . 211

Table A-38 Material B, oven set points for Peak Temperature High profile ...... 211

Table A-39 Material B, reflow parameters for Time to Peak Temperature Low

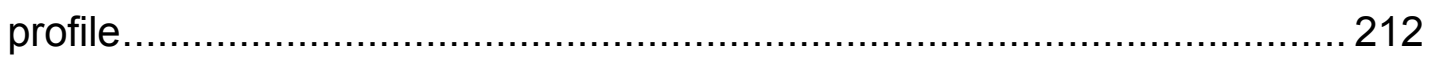

Table A-40 Material B, oven set points for Time to Peak Temperature Low profile

Table A-41 Material B, reflow parameters for Time to Peak Temperature High profile. 213

Table A-42 Material B, oven set points for Time to Peak Temperature High profile 213 
Table A-43 Material C, reflow parameters for Baseline profile........................ 215

Table A-44 Material C, oven setpoints for Baseline profile ........................... 215

Table A-45 Material C, reflow parameters for Ramp Rate Low profile.............. 216

Table A-46 Material C, oven set points for Ramp Rate Low profile ................. 216

Table A-47 Material C, reflow parameters for Ramp Rate High profile ............. 217

Table A-48 Material C, oven set points for Ramp Rate High profile …............. 217

Table A-49 Material C, reflow parameters for Soak Temperature Low profile .. 218

Table A-50 Material C, oven setpoints for Soak Temperature Low profile........ 218

Table A-51 Material C, reflow parameters for Soak Temperature High profile . 219

Table A-52 Material C, oven set points for Soak Temperature High profile ...... 219

Table A-53 Material C, reflow parameters for Soak Time Low profile............... 220

Table A-54 Material C, oven set points for Soak Time Low profile .................. 220

Table A-55 Material C, reflow parameters for Soak Time High profile.............. 221

Table A-56 Material C, oven set points for Soak Time High profile ................. 221

Table A-57 Material C, reflow parameters for Time Above $183^{\circ} \mathrm{C}$ Low profile. 222

Table A-58 Material C, oven set points for Time Above $183^{\circ} \mathrm{C}$ Low profile ..... 222

Table A-59 Material C, reflow parameters for Time Above $183^{\circ} \mathrm{C}$ High profile 223

Table A-60 Material C, oven set points for Time Above $183^{\circ} \mathrm{C}$ High profile..... 223

Table A-61 Material C, reflow parameters for Peak Temperature Low profile .. 224

Table A-62 Material C, oven set points for Peak Temperature Low profile....... 224

Table A-63 Material C, reflow parameters for Peak Temperature High profile . 225

Table A-64 Material C, oven set points for Peak Temperature High profile ...... 225

Table A-65 Material C, reflow parameters for Parametric Optimized profile ..... 226 
Table A-66 Material C, oven set points for Parametric Optimized profile 226

Table A-67 Material E, reflow parameters for Baseline profile........................ 228

Table A-68 Material E, oven set points for Baseline profile …....................... 228

Table A-69 Material E, reflow parameters for Ramp Rate Low profile .............. 229

Table A-70 Material E, oven set points for Ramp Rate Low profile ................. 229

Table A-71 Material E, reflow parameters for Ramp Rate High profile ............. 230

Table A-72 Material E, oven set points for Ramp Rate High profile................. 230

Table A-73 Material E, reflow parameters for Soak Time Low profile ............... 231

Table A-74 Material E, oven set points for Soak Time Low profile .................. 231

Table A-75 Material E, Reflow Parameters for Soak Time High Profile ............ 232

Table A-76 Material E, Oven Setpoints for Soak Time High Profile................. 232

Table A-77 Material E, Parameters for Time Above $183^{\circ} \mathrm{C}$ Low Reflow Profile233

Table A-78 Material E, Oven Setpoints for Time Above $183^{\circ} \mathrm{C}$ Low Reflow Profile 233

Table A-79 Material E, Parameters for Time Above $183{ }^{\circ} \mathrm{C}$ High Reflow Profile 234

Table A-80 Material E, Oven Setpoints, Time Above $183^{\circ} \mathrm{C}$ High Reflow Profile 234

Table A-81 Material E, Reflow Parameters for Peak Temperature Low Profile 235

Table A-82 Material E, Oven Setpoints for Peak Temperature Low Profile ...... 235

Table A-83 Material E, Reflow Parameters for Peak Temperature High Profile 236

Table A-84 Material E, Oven Setpoints for Peak Temperature High Profile ..... 236

Table A-85 Material E, Reflow Parameters for Parametric Optimized Profile ... 237 
Table A-86 Material E, Oven Setpoints for Parametric Optimized Profile ......... 237 


\section{LIST OF FIGURES}

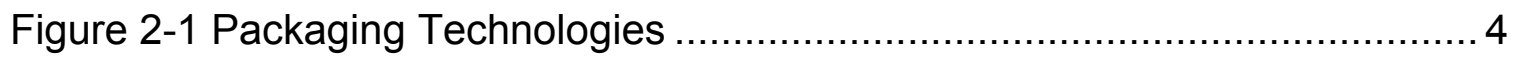

Figure 2-2 Traditional Capillary Underfill Process......................................... 6

Figure 2-3 Current No-Flow Process ..................................................... 7

Figure 2-4 Flip Chip UBM structure (Not to Scale) …................................... 8

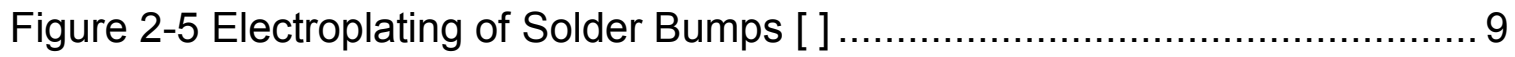

Figure 2-6 Bumped Chip (Pac Tech) …................................................... 10

Figure 2-7 Cross Section of a Redistribution Layer [Source: Fraunhofer IZM] ... 14

Figure 2-8 Shellcase ShellBGA WLP Technology (Source: Shellcase) ............. 15

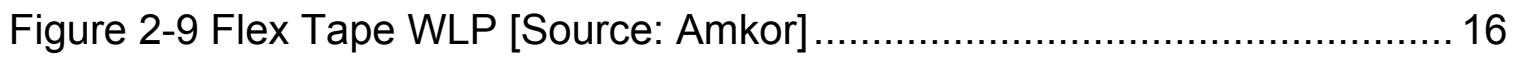

Figure 2-10 Compliant Lead Interconnect [Tummala 2001] ........................... 18

Figure 2-11 Stacked Solder Ball Interconnect [Tummala 2001] ...................... 19

Figure 2-12 Large Solder Ball Interconnect [Tummala 2001] .......................... 20

Figure 3-1 Test Vehicle 1, Six Bond Sites ............................................... 23

Figure 3-2 Test Vehicle 1 With Assembled Test Die ..................................... 23

Figure 3-3 Test Vehicle 1, Close Up of Trace Layout to One Bond Site............. 24

Figure 3-4 Test Vehicle 1, Optical Image of Daisy Chain Traces, Dimensions in

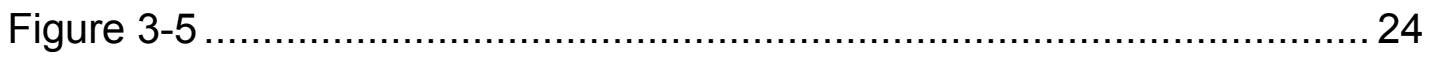

Figure 3-5 TV1, Top View of Substrate Pad Geometry ................................... 25

Figure 3-6 TV1, Trace and Mask Opening Geometry Profile .............................2 25

Figure 3-7 Cross Section of Solder Bump on Copper Trace …........................ 26

Figure 3-8 Cross Section of Assembly Showing Axis of Copper Trace .............. 26

Figure 3-9 FA10 2X2 Flip Chip Test Die Used for All Experiments................... 27 


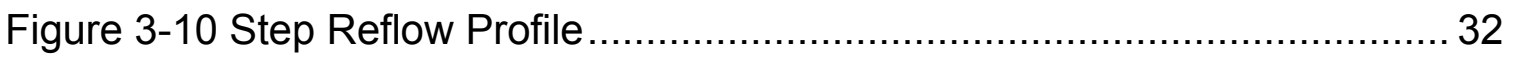

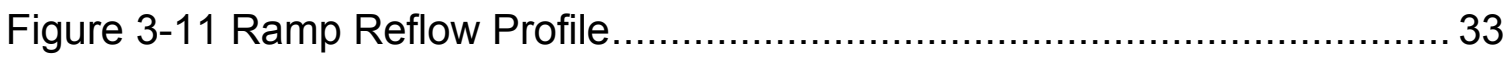

Figure 3-12 Dispense Patterns for DOE1 …............................................. 36

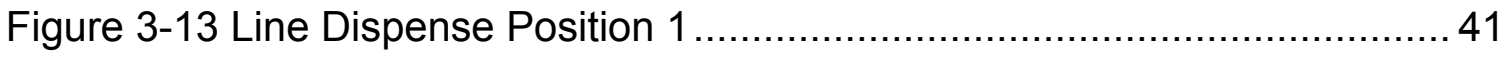

Figure 3-14 Line Dispense Position 3 .................................................. 42

Figure 3-15 Line Dispense Position 5 ................................................. 42

Figure 3-16 Variation of Profile Parameters off Baseline .................................. 45

Figure 3-17 Thermocouple Wiring for Reflow Profiling .................................. 46

Figure 3-18 Material A, Baseline Reflow Profile ........................................... 48

Figure 3-19 Material B, Baseline Reflow Profile ............................................. 49

Figure 3-20 Material C, Baseline Reflow Profile ............................................ 50

Figure 3-21 Material E, Baseline Reflow Profile ......................................... 52

Figure 3-22 Representation of Typical Two Phase Solder Alloy, Solid Lighter Areas Show Lead, Darker Surrounding Matrix is Eutectic (Sn-Pb)............. 54

Figure 3-23 Point Count Method, Relates Point Count Fraction to Volume

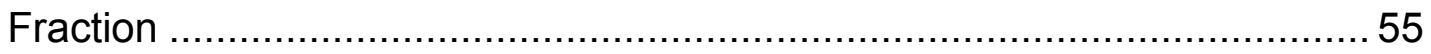

Figure 4-1 Material A, Main Effects Plots for DOE1 ........................................ 62

Figure 4-2 Material A, Interaction Effects Plot for DOE1 ................................ 63

Figure 4-3 Material B, Main Effects Plots for DOE1 .......................................... 64

Figure 4-4 Material B, Interaction Effects Plot for DOE1 ................................ 65

Figure 4-5 Material C, Main Effects Plots for DOE1 …..................................... 66

Figure 4-6 Material C, Interaction Effects Plot for DOE1 .................................. 67

Figure 4-7 Material D, Main Effects Plots for DOE1 ........................................68 
Figure 4-8 Material D, Interaction Effects Plot for DOE1 69

Figure 4-9 Material E, Main Effects Plots for DOE1 ...................................... 70

Figure 4-10 Material E, Interaction Effects Plot for DOE1 …........................... 71

Figure 4-11 Underfill Dispense Patterns .................................................... 73

Figure 4-12 Dot Dispense, Before Compression Flow................................... 78

Figure 4-13 Dot Dispense, During Compression Flow................................... 79

Figure 4-14 Capture Void, Region of Interest from Figure 4-13 ...................... 79

Figure 4-15 Capture Void Lift Out [Milner 2001] ............................................ 80

Figure 4-16 Capillary Flow Resulting in Complete Air Displacement................. 80

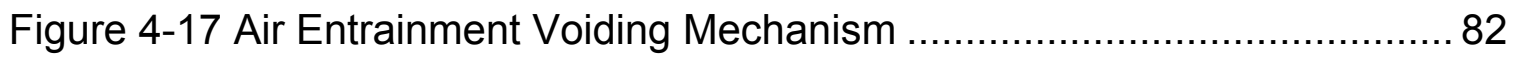

Figure 4-18 Material A, Main Effects Plots for DOE2 ...................................... 86

Figure 4-19 Material A, DOE2 Interaction Effects Plots including Pattern-Force,

Pattern-Dwell, and Force-Dwell Interactions …..................................... 87

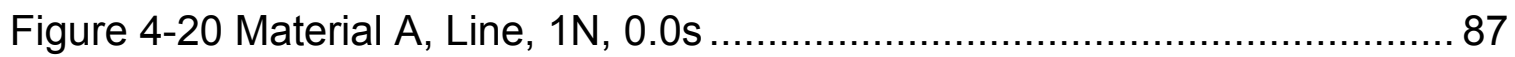

Figure 4-21 Material B, Main Effects Plots for DOE2 ...................................... 89

Figure 4-22 Material B, DOE2 Interaction Effects Plots including Pattern-Force, Pattern-Dwell, and Force-Dwell Interactions …........................................ 89

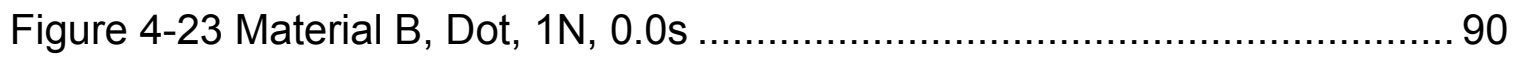

Figure 4-24 - Material C, Main Effects Plots for DOE2 …............................... 91

Figure 4-25 Material C, DOE2 Interaction Effects Plots including Pattern-Force,

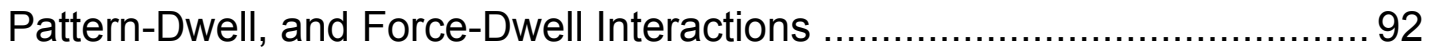

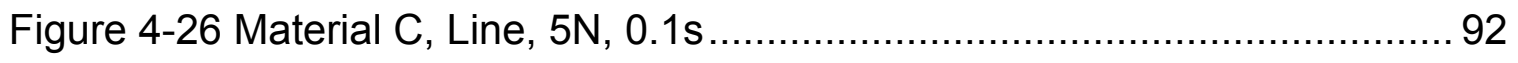

Figure 4-27 Material D, Main Effects Plots for DOE2 …................................. 94 
Figure 4-28 Material D, DOE2 Interaction Effects Plots including Pattern-Force, Pattern-Dwell, and Force-Dwell Interactions .......................................... 94

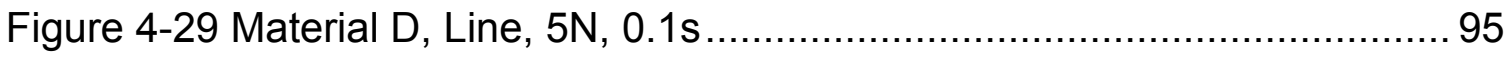

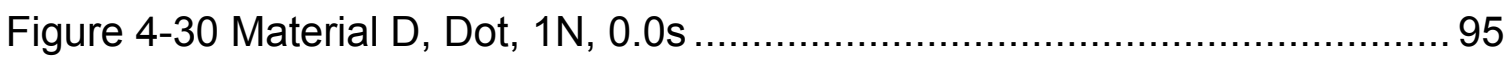

Figure 4-31 Material E, Main Effects Plots for DOE2 ..................................... 97

Figure 4-32 Material E, DOE2 Interaction Effects Plots including Pattern-Force, Pattern-Dwell, and Force-Dwell Interactions …...................................... 98

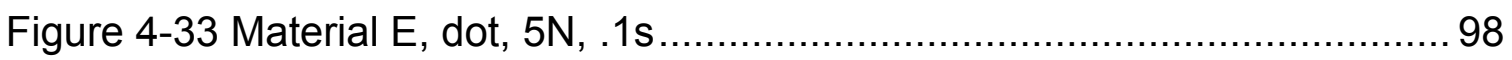

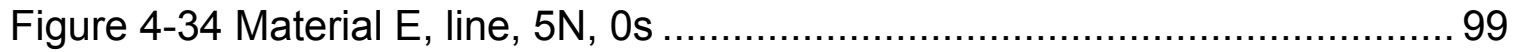

Figure 4-35 Materials A, B, C, D, and E, Force model for the 111 treatment ... 101

Figure 4-36 111 Treatment, Proposed Drift Mechanism for Yield Loss ............ 103

Figure 4-37 Material A, Line Position 1 .................................................. 111

Figure 4-38 Material A, Line Position 2 ................................................. 111

Figure 4-39 Material A, Line Position 3 ….............................................. 112

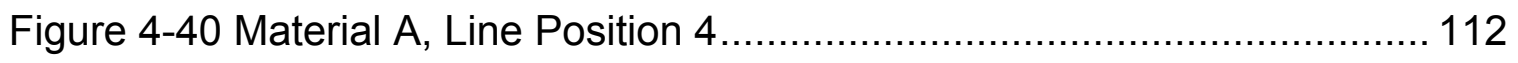

Figure 4-41 Material A, Line Position 5................................................... 113

Figure 4-42 Voiding vs. Non-Dimensional Line Position ................................ 114

Figure 4-43 Eutectic Microstructure, Relatively Evenly Dispersed Pb-Sn........ 121

Figure 4-44 SEM Image of a Cross Section to be Used for Phase Ratio Analysis 123

Figure 4-45 SEM Image With Phase Boundaries and a Partial Grid Overlay... 124

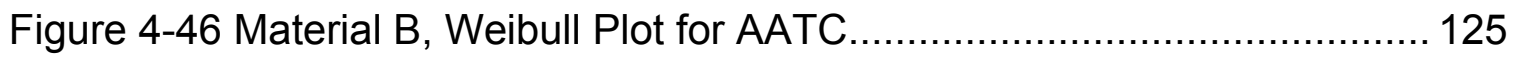

Figure 4-47 Material C, Weibull Plot for AATC …........................................ 126 
Figure 4-48 Material E, Weibull Plot for AATC ........................................... 126

Figure 5-1 Sequence of Failure Modes (Shading Indicates Electrical Failure) . 129

Figure 5-2 Fatigue Crack at the Top of a Bump........................................ 131

Figure 5-3 Locations of Fatigue Cracks ................................................... 132

Figure 5-4 Typical Crack Location Within a Solder Joint ............................... 132

Figure 5-5 Underfill cracks Between Solder Joints (Arrows Point to Cracks) ... 133

Figure 5-6 Underfill Void Between Solder Bumps.......................................... 135

Figure 5-7 Timescale for Solder Extrusion into an Underfill Void.................... 136

Figure 5-8 Solder Extrusion Into an Underfill Crack Causing a Short .............. 137

Figure 5-9 Material A, Best Case Delamination Progression, ........................ 138

Figure 5-10 Material A, Average Case Delamination Progression, .................. 139

Figure 5-11 Material A, Worst Case Delamination Progression, ..................... 139

Figure 5-12 Material A, Extensive Cracking Along Traces Without Significant

Extrusion, Part Removed From Test at 3500 Cycles.............................. 140

Figure 5-13 Material A, Partial Solder Extrusion Into a Crack, Part Removed

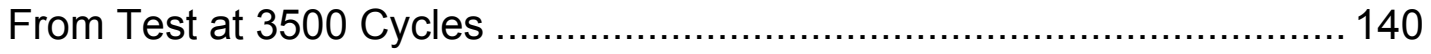

Figure 5-14 Material B, Best Case Delamination Progression........................ 141

Figure 5-15 Material B, Average Case of Delamination Progression, ,.............. 142

Figure 5-16 Material B, Worst Case Delamination Progression, ...................... 142

Figure 5-17 Material B, 1700 AATC cycles showing little cracking and no

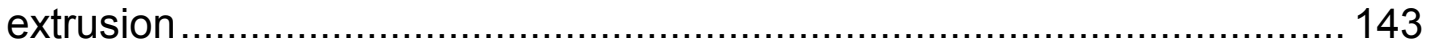

Figure 5-18 Material B, 3800 AATC cycles, extensive solder shorting …......... 143

Figure 5-19 Material B, 3800 AATC cycles, extrusion into delamination space 144 
Figure 5-20 Material C, Best Case Delamination Progression, Part Failed by Fatigue Cracking at 2700 cycles 145

Figure 5-21 Material C, Average Case Delamination Progression, Part Failed by

Fatigue Cracking at 2700 cycles 145

Figure 5-22 Material C, Worst Case Delamination Progression, Part Failed by

Fatigue Cracking at 2700 cycles 146

Figure 5-23 Material C, 2400 AATC cycles, No Visible Cracking, 146

Figure 5-24 Material C, Solder Extrusion Into Cracks at 3400 AATC cycles, ... 147

Figure 5-25 Material C, Best Case Delamination Progression, ...................... 148

Figure 5-26 Material C, Average Case Delamination Progression, ................ 148

Figure 5-27 Material E, Worst Case Delamination Progression, .................... 149

Figure 5-28 Material E, 3400 AATC cycles, Part Failed at 3400 Cycles........... 149

Figure 5-29 Material E, 3400 AATC cycles with extrusion shorts .................... 150

Figure 5-30 Material A, Typical CSAM Before Test Start .............................. 153

Figure 5-31 Material A, Typical CSAM After Testing 96 Hours....................... 153

Figure 5-32 Material B, Typical CSAM Before Test Start .............................. 154

Figure 5-33 Material B, Typical CSAM After 96 Hours Testing....................... 154

Figure 5-34 Material C, Typical CSAM Before Test Start .............................. 155

Figure 5-35 Material C, Typical CSAM After Testing 96 Hours........................ 155

Figure 5-36 Material E, Typical CSAM Before Test Start .............................. 156

Figure 5-37 Material E, Typical CSAM After 96 Hours Testing....................... 156

Figure 6-1 Modeling Geometry of Underfill Line Deposit ............................... 159

Figure 6-2 Surface Tension Forces at the Contact Line ............................... 162 
Figure 6-3 Modeling Geometry of Underfill Line Deposit .... 164

Figure 6-4 Contact Angle Relaxation for Baseline Parameter Values ............. 169

Figure 6-5 $r$ vs. $t$ of Underfill Cross Section for Baseline Parameter Values.... 170

Figure 6-6 Effect of $m / L$ on Wetting Radius Dynamics ................................ 172

Figure 6-7 Effect of $m / L$ on Wetting Radius Doubling Rate ......................... 174

Figure 6-8 Effect of Underfill Viscosity on Wetting Radius Dynamics .............. 175

Figure 6-9 Effect of Fitting Parameter $(\ell)$ on Wetting Radius Dynamics.......... 177

Figure 6-10 Effect of $\theta_{e q}$ on Wetting Radius Dynamics …............................. 179

Figure 6-11 Sensitivity of Wetting Radius Prediction to $\theta_{e q}$ Input Parameter.... 180

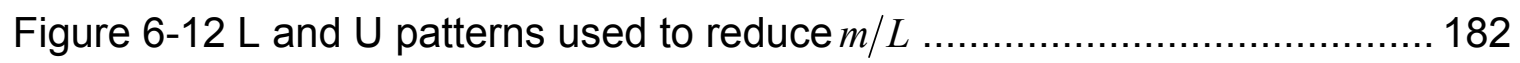

Figure 6-13 FA10-4 Assembled With a U-Pattern Underfill Dispense (No Voids) 183

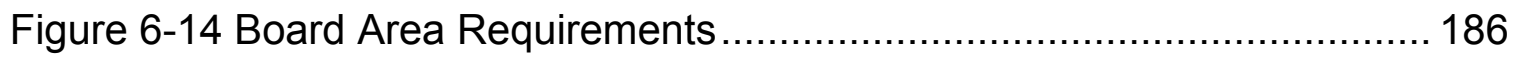

Figure A-1 Material A, Baseline profile ........................................................ 192

Figure A-2 Material A, Ramp Rate Low profile ............................................. 193

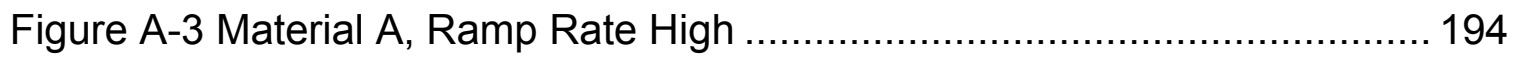

Figure A-4 Material A, Soak Temperature Low........................................... 195

Figure A-5 Material A, Soak Temperature High profile .................................. 196

Figure A-6 Material A, Soak Time Low profile ….......................................... 197

Figure A-7 Material A, Soak Time High profile ................................................ 198

Figure A-8 Material A, Time Above $183^{\circ} \mathrm{C}$ Low profile .................................. 199

Figure A-9 Material A, Time Above $183^{\circ} \mathrm{C}$ High profile................................. 200

Figure A-10 Material A, Peak Temperature Low profile .................................. 201 
Figure A-11 Material A, Peak Temperature High profile ................................ 202

Figure A-12 Material A, Parametric Optimized profile....................................203

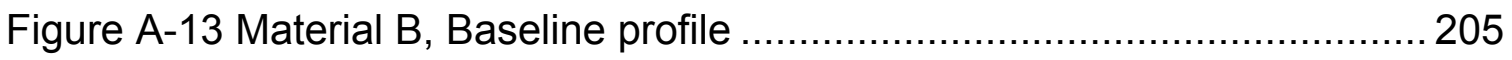

Figure A-14 Material B, Ramp Rate Low profile ........................................ 206

Figure A-15 Material B, Ramp Rate High profile......................................... 207

Figure A-16 Material B, Time Above $183^{\circ} \mathrm{C}$ Low profile ................................ 208

Figure A-17 Material B, Time Above $183^{\circ} \mathrm{C}$ High profile ................................. 209

Figure A-18 Material B, Peak Temperature Low profile ................................ 210

Figure A-19 Material B, Peak Temperature High profile ...............................2 211

Figure A-20 Material B, Time to Peak Temperature Low profile ...................... 212

Figure A-21 Time to Peak Temperature High profile ................................... 213

Figure A-22 Material C, Baseline profile …............................................ 215

Figure A-23 Material C, Ramp Rate Low profile ....................................... 216

Figure A-24 Material C, Ramp Rate High profile …...................................... 217

Figure A-25 Material C, Soak Temperature Low profile............................... 218

Figure A-26 Material C, Soak Temperature High profile ............................... 219

Figure A-27 Material C, Soak Time Low profile …....................................... 220

Figure A-28 Material C, Soak Time High profile ….................................... 221

Figure A-29 Material C, Time Above $183^{\circ} \mathrm{C}$ Low profile ................................. 222

Figure A-30 Material C, Time Above $183^{\circ} \mathrm{C}$ High profile .............................. 223

Figure A-31 Material C, Peak Temperature Low profile................................. 224

Figure A-32 Material C, Peak Temperature High profile ….............................. 225

Figure A-33 Material C, Parametric Optimized profile ................................... 226 
Figure A-34 Material E, Baseline Reflow profile ........................................ 228

Figure A-35 Material E, Ramp Rate Low reflow profile ................................. 229

Figure A-36 E, Ramp Rate High reflow profile .......................................... 230

Figure A-37 Material E, Soak Time Low reflow profile ….............................. 231

Figure A-38 Material E, Soak Time High Reflow Profile ................................ 232

Figure A-39 Material E, Time Above $183^{\circ} \mathrm{C}$ Low Reflow Profile ..................... 233

Figure A-40 Material E, Time Above $183^{\circ} \mathrm{C}$ Hlgh Reflow Profile ..................... 234

Figure A-41 Material E, Peak Temperature Low Reflow Profile....................... 235

Figure A-42 Material E, Peak Temperature Low Reflow Profile...................... 236

Figure A-43 Material E, Parametric Optimized Reflow Profile ........................ 237 


\section{CHAPTER I: INTRODUCTION}

\subsection{Problem Statement}

Previous researchers have investigated the no-flow fluxing underfill process in order to understand the feasibility of the process for common SMT machines and resolve some of the fundamental processing issues. The result has been the development of the current no-flow process, which utilizes compression flow of the dispensed material over the bond site as the chip is placed. This process has several potential problems, including increased voiding over traditional capillary flow processes as well as potential for interconnect yield problems due to triggering of the chip release before it has made contact with the substrate.

The goal of this research is to test the viability of a new no-flow process that uses the currently available no-flow underfills in a modified process that is a hybrid of the conventional no-flow and conventional capillary flow process. The experimentation investigates this process in relation to the conventional no-flow process and the results are analyzed with respect to key metrics known to influence reliability. Design of experiments is utilized to structure the evaluation within a statistically relevant framework. The resulting newly developed process for each underfill is then tested for reliability using industry standard AATC and Autoclave test conditions.

Finally, the initial stage of the newly developed process is modeled by utilizing a hydrodynamic approach to wetting. The model is developed to investigate key process parameters parametrically in order to develop a more 
complete understanding of the process wetting dynamics. The wetting dynamics knowledge from this model evaluation is then considered with respect to additional constraints imposed by a proposed use of the process in a typical manufacturing environment.

\subsection{Thesis Structure}

Chapter II summarizes flip chip technology, the flip chip manufacturing process, the advantages of flip chip packaging, and reviews wafer level packaging. Chapter III outlines the experimental methodology for all experimentation. Chapter IV contains the experimental results and discussion. Chapter $\mathrm{V}$ discusses the failure analysis of the reliability tested components. Chapter VI describes a process model and investigates the model parameters to develop processing guidelines. 


\section{CHAPTER II: BACKGROUND}

\subsection{Packaging Overview}

Traditionally, electronic component assembly involved the active side of the silicon chip facing up, away from the substrate. The I/O of the chip were then re-routed using wire bonding to a larger interconnect array around the perimeter of the device. This entire assembly was then encapsulated further to improve reliability. An example of this type of packaging assembly is the glob top component shown in Figure 2-1.

TAB (tape automated bonding) involves the attachment of a copper lead frame to a polyimide tape. The chip is then connected to the board through this lead frame. Like wire bonding, the active side of the chip faces away from the board as shown in Figure 2-1.

Flip chip components differ in several ways from traditional packaging technology. First, the I/O face downward and are connected to the substrate usually by solder bumps in a perimeter or area array $1 / O$ configuration. Secondly, the flip chip is a bare die, meaning that no additional packaging covers the silicon chip as shown in Figure 2-1.

Flip chips have been in existence for over 35 years. They were first seen in 1964 when IBM developed C4 (controlled collapse chip connection) technology for use in their mainframe computers. The C4 design used different UBM and solder bump metallization than is seen in current solder bumped flip chip designs. 


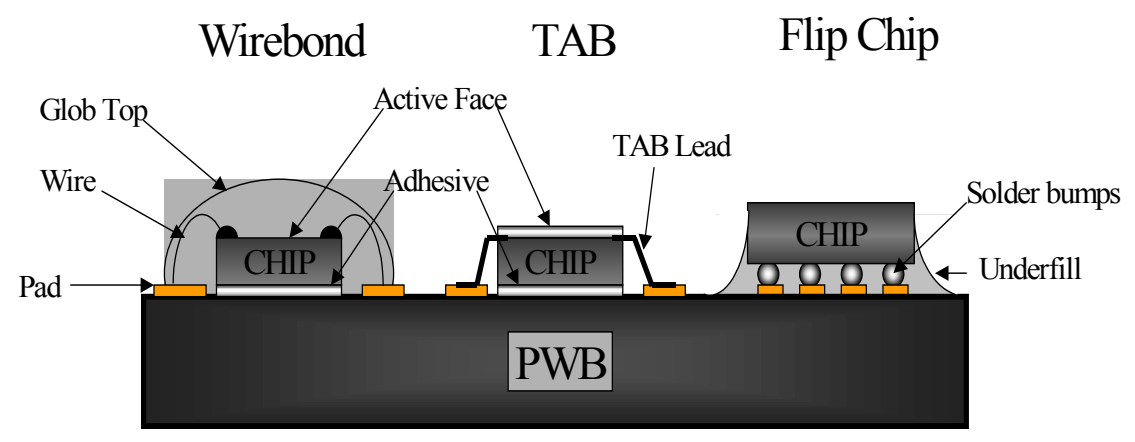

Figure 2-1 Packaging Technologies

\subsection{Advantages of Flip Chip Technology}

One advantage of flip chip technology is that the package solution offers the smallest size and weight possible. This is because no additional packaging is used; therefore, the flip chip takes up the least board real estate and adds the least amount of weight to the final assembly. This is extremely important for electronics manufacturers because of the ever increasing demand to miniaturize products or assemblies.

Flip chip technology also offers higher performance when compared to wirebonded assemblies. The connection involves only the distance through the solder bump, which minimizes the path length that the signal has to travel. Faster signal transmission means decreased cycle times for increased functionality.

I/O improvements - flip chips allow for more I/O on a given area of silicon because the $\mathrm{I} / \mathrm{O}$ can be placed in an area array. Wire bonding limits connections to the perimeter of the die. This is because the pads cannot be placed over 
active circuitry on the die due to subsurface damage that occurs during the ultrasonic bonding process. This limitation drives the die size higher quickly as more $\mathrm{I} / \mathrm{O}$ are required.

There is also a potential for improvement in process cycle time required for interconnect formation because flip chip is an area process, where wire bonding is a point to point process and processing time is dependent on the number of $\mathrm{I} / \mathrm{O}$.

\subsection{Disadvantages of Flip Chip Technology}

The large CTE mismatch between the silicon die and the PCB results in thermomechanical stresses in the assembly. These stresses threaten reliability of the package. The best solution to this problem involves polymer underfills that are used to couple the silicon to the PCB, effectively reducing the stresses. These underfills are expensive and they increase processing time considerably. Reworking an underfilled chip has traditionally been very difficult, so this results in increased waste and cost as well.

The traditional capillary flow underfill process is displayed in Figure 2-2. Some improvements to the traditional capillary flow underfill process are possible currently, such as No-flow underfill which eliminates the time consuming underfill flow process [Baldwin 2000, Lau 2000, Shi 2000, Thorpe 1999]. The current noflow process involves dispensing a fluxing underfill directly onto the bond site before placement as shown in Figure 2-3.

In the future, there are potentially new processes that could further improve on the underfill process. Wafer level underfill may become feasible, this involves 
underfilling the bumped wafer with a fluxing material and then dicing and placement of the die [Busch 2000, Nguyen 2002, Shi 1999].
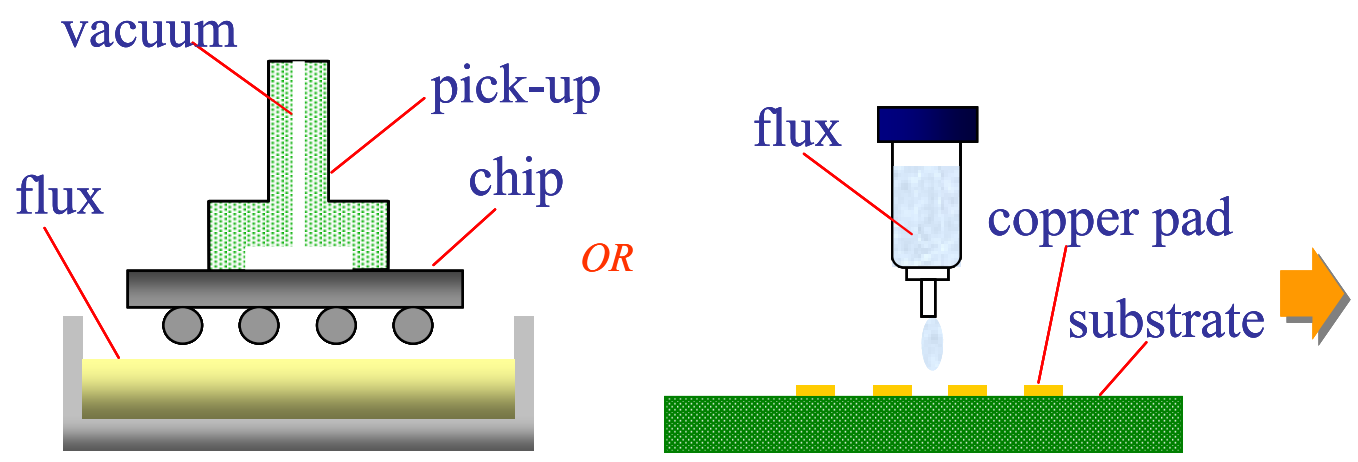

1- Dip Flux or Dispense Flux

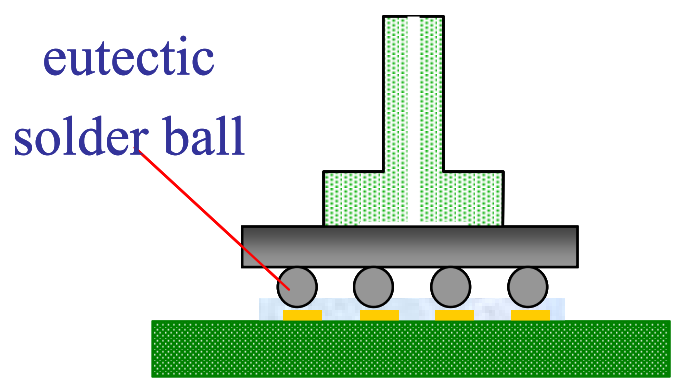

2- Place Chip

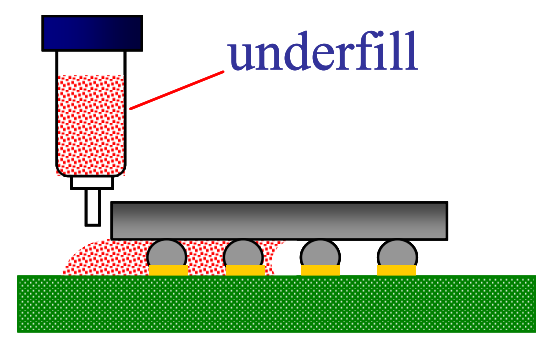

4- Dispense Underfill

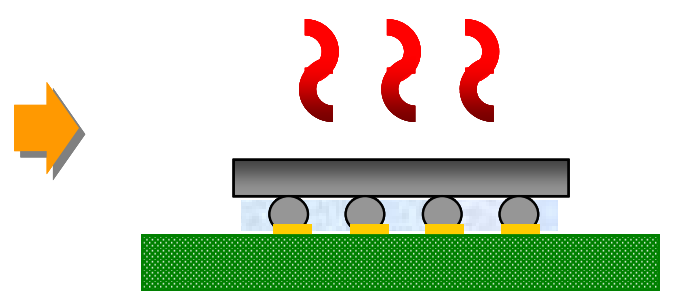

3- Reflow Solder

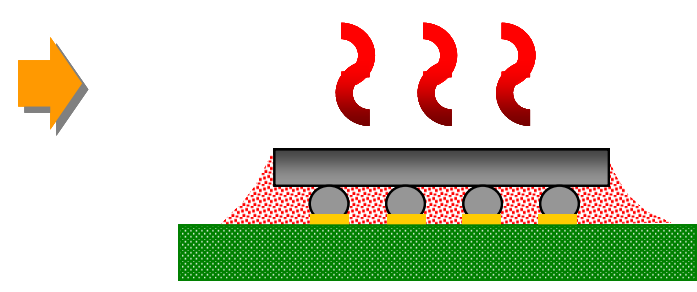

5- Cure Underfill

Figure 2-2 Traditional Capillary Underfill Process 


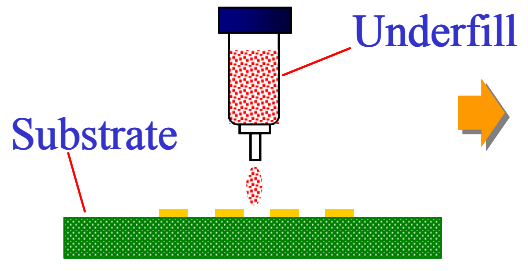

1- Dispense Underfill

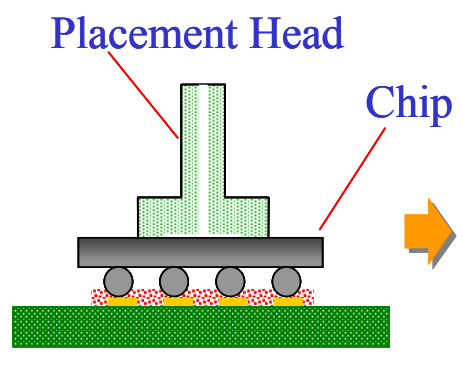

2- Place Chip

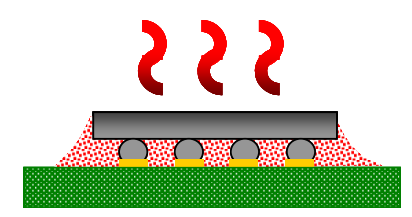

3- Reflow Solder + Cure Underfill

Figure 2-3 Current No-Flow Process

\subsection{The Flip Chip Manufacturing Process}

\subsubsection{Overview}

There are many steps needed to complete the transformation of a chip at wafer level into a singulated component ready for direct chip attach. These steps include: preparing the wafer for the bumping process by depositing metal layers, bumping the wafer with solder bumps, and finally dicing the wafer to form the individual flip chips.

After the forming the singulated chips, there are further processing steps involved in making the interconnection between the board and the chip. These steps include: picking of the die from a holder tray, fluxing of the die, placing of the die onto the board, reflow of the solder joints to form electrical interconnect, flux cleaning to remove remaining flux deposits, and underfilling the die to increase reliability.

The steps necessary for complete processing, from the wafer level through to component placement and underfill, are detailed in the following section. 


\subsubsection{Flip Chip Processing Steps}

Under Bump Metallization - The UBM is deposited in several layers each serving a purpose. The adhesion layer is the first layer deposited and must adhere well to the bond pad metallization and the silicon dioxide or silicon nitride passivation layer. Choices for the adhesion layer include Chromium, TitaniumTungsten, and others. A barrier layer is deposited to prevent diffusion of metals or ionic contaminants into the chip metallization. Barrier layer metallurgies can be Chromium, Tungsten, Chromium-Copper, Nickel, and others. A solder wettable layer is then deposited that is usually Copper. Other choices for the wetting layer include Nickel, Palladium, and others. Finally a protective thin layer of gold can be applied to prevent the formation of oxides. A schematic of a typical UBM structure is shown in Figure 2-4.

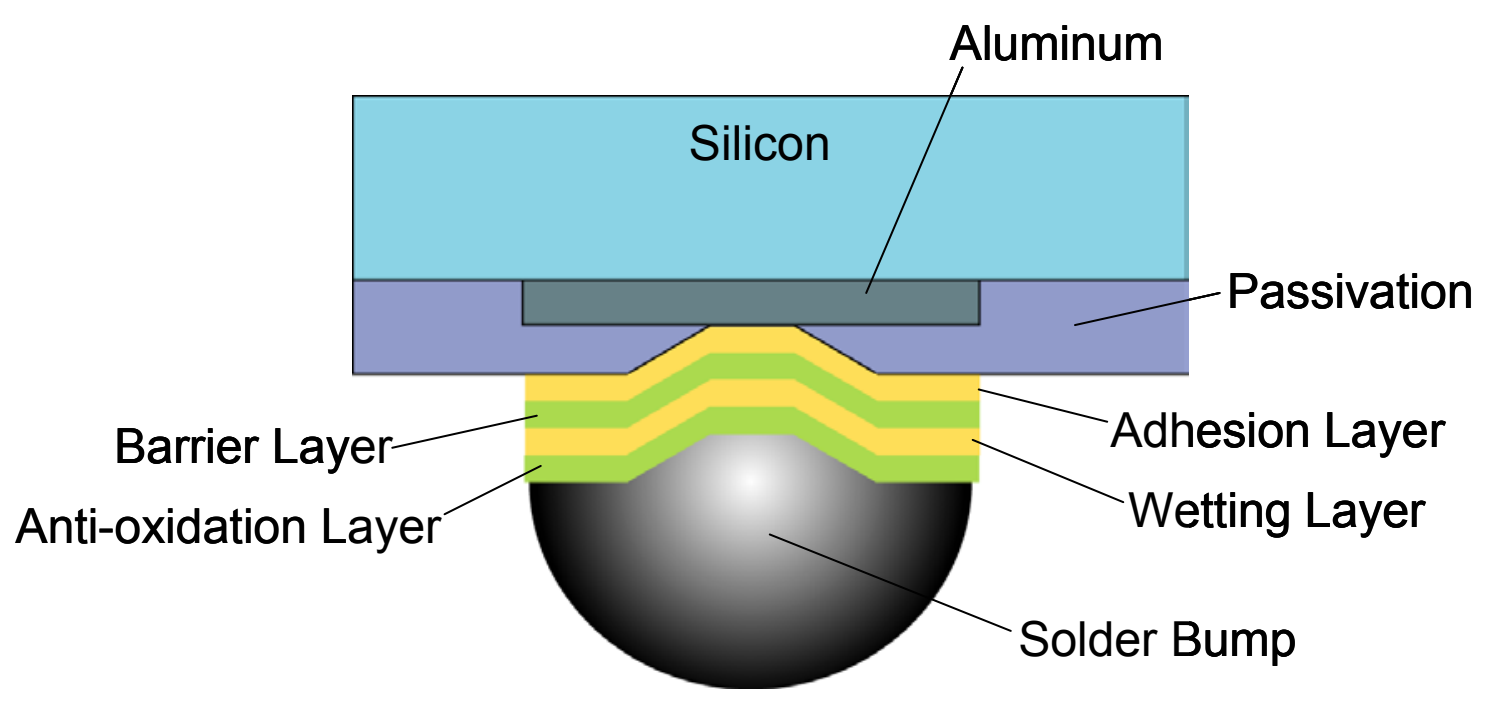

Figure 2-4 Flip Chip UBM structure (Not to Scale) 
Wafer Bumping - This process can be achieved in several different ways including evaporation, electroplating, screen printing, or stud bumping. A process diagram for electroplating solder bumps is shown in Figure 2-5.

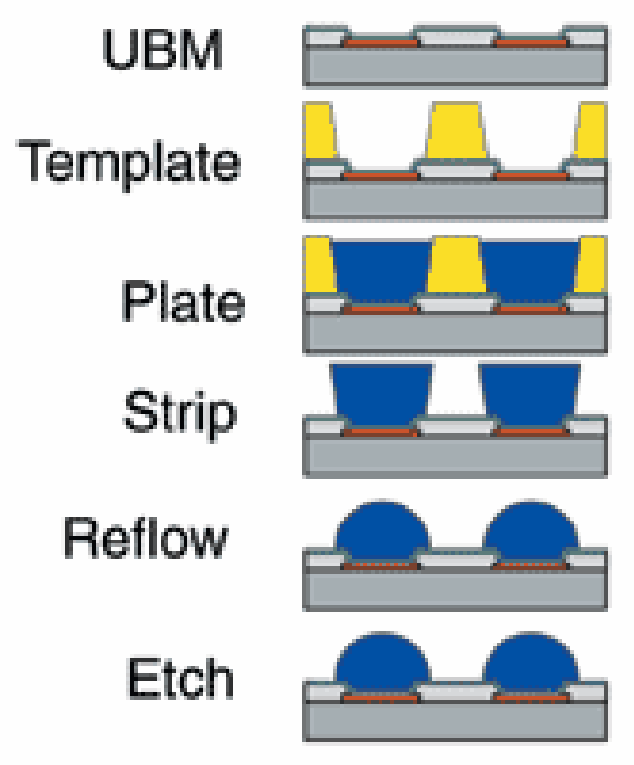

Figure 2-5 Electroplating of Solder Bumps [ ]

Electroplating is a bumping process that utilizes a resist pattern and a plating bath in which the wafer acts a cathode. First, a resist is overlaid onto a wafer that has already been prepared with a UBM. Then the resist is patterned to form a template for solder deposition. Next, copper and solder are electroplated to fill the resist openings; plating bath solutions and current densities must be carefully controlled to avoid variations in alloy composition and bump height across the wafer. The resist is then stripped, and the UBM surrounding the plated bumps is also removed with an etch. Finally, the wafer is reflowed to form the truncated sphere solder bumps. The key difference between this and wire 
bonding applications is that for wire bonding the wafer is diced first before the connections to the chip are made. An SEM image of a bumped wafer is shown in Figure 2-6.

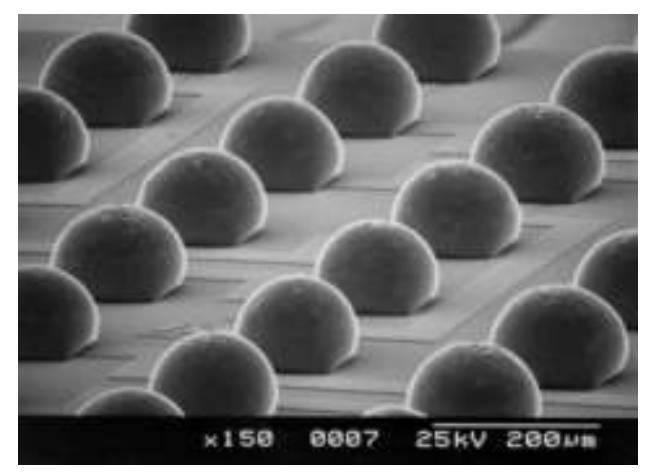

Figure 2-6 Bumped Chip (Pac Tech)

Dice Wafer and Die Packaging - The wafer is mounted to dicing tape to hold the wafer in place. Next, the wafer is diamond sawn into individual die. This process prepares singulated die for packaging. The singulated die can be packaged in standard waffle packs or in a tape and reel. Another option is shipping the diced wafer still attached to the dicing tape so that components can be picked and placed directly from the tape.

Pick and Place/ Flux - After the chips have been placed in a transport package such as waffle packs or a tape reel, they are loaded into a placement machine for high speed placement onto the substrate. If traditional capillary flow underfill is being used, flux must be applied to the bumps or substrate bond pads before reflow. The flux lowers the surface tension of the solder allowing for better wetting and removes oxides from the bond pads to insure good interconnection. 
There are many methods to apply flux, two of the most common are dip fluxing and dispense fluxing. Dip fluxing involves fluxing the chip by dipping the solder balls into a layer of flux that is at a controlled height, then the chip is placed onto the board site. Dispense flux involves dispensing a small amount of flux onto the board site itself, then as the die is placed the flux covers the solder balls. Another alternative is No-flow fluxing underfills, which include flux in the underfill chemistry. If this type of material is used, then fluxing occurs as the underfill coats the bond site. No-flow underfills are dispensed on the chip bond site before placement of the chip.

Reflow - A multi-zone reflow oven is used to bring the assembly through an appropriate reflow profile. The profile is designed to bring the assembly up to temperature slowly, then to remain at above the solder liquidous temperature $\left(183^{\circ} \mathrm{C}\right.$ for eutectic joints) for long enough to insure full wetting of all the bond pads and settling of the chip. The assembly is then cooled slowly.

Clean Flux - this step is necessary to clean any remaining flux residue from the assembly prior to underfill. The residue is cleaned with a solvent. The cleaning step is necessary because the residues can inhibit proper adhesion of the underfill to the solder joints or board or die interface. Improper adhesion is a reliability concern because good adhesion is necessary for proper thermomechanical stress distribution during the operation of the device.

Underfill - the traditional underfill process involves CUF (capillary underfills) which are dispensed on one or two sides of the die and allowed to flow by capillary action under the die. This process can be a production bottleneck 
taking up to $10-15 \mathrm{~min}$ for flow times, and then requiring cure times of $1 \mathrm{hr}$. Some of the newer fast flow and snap-cure underfills on the market may take only 5 minutes to flow and 10 minutes to cure. Although this is a substantial improvement, there is still a lot of room for improvement in this process.

Motorola pioneered a process that combined the underfill and flux into a single material. This process later became known as NUF (no-flow underfill), because the underfill is dispensed onto the site and flows quickly under compression when the die is placed. This process offers processing time advantages over CUF. The problem with this process is that the silica filler, that is normally added to CUF underfills can not be added to the NUF materials because it interferes with proper solder wetting and interconnect. Commercial NUF materials do not have fillers, and the resulting CTE is much higher than with filled CUF materials. The higher CTE's of no-flow underfills result in higher solder interconnect stresses and problems with delamination and cracking.

Wafer level underfill (WUF) is a potential improvement over either CUF or NUF that is currently being developed. It is unclear at this time whether the process will be a workable improvement over the current procedures. Other wafer level solutions fall under the broad category of wafer level packaging (WLP); some of the issues surrounding WLP are discussed in the next section. 


\subsection{Wafer Level Packaging}

\subsubsection{Introduction}

Wafer level packaging (WLP) is a term used to describe the packaging of an integrated circuit device (IC) at the wafer level. This means that any electrical pathways or environmental protection is applied when the ICs are still together as one wafer. This is in contrast to conventional packaging which may involve some processing steps at the wafer level, but with most of the packaging steps completed after the IC's are singulated into individual devices. Additionally, the WLP approach also includes wafer level test and burn-in which can potentially result in very favorable cost savings over the traditional test and burn-in of each package individually. The existing technologies under investigation for WLP can be broadly classified into three categories: Redistribution WLP, Encapsulated WLP, and Flex/tape WLP.

\subsubsection{Redistribution WLP}

The most common type of WLP in use today can be described as the redistribution type. A schematic of a redistribution layer is provided in Figure 2-7. One type of redistribution technology is the area array flip chip package, where the die pads are rerouted to an area array of solder bumps. Redistribution involves a secondary dielectric and metallization layer to reroute the typical peripheral pads to the area array configuration. The dielectric layer is often benzocyclobutene $(\mathrm{BCB})$ or polyimide $(\mathrm{PI})$ and the rerouting metallization is 
typically aluminum or copper. The polymer dielectric used in the redistribution layer provides environmental and mechanical protection for the IC.

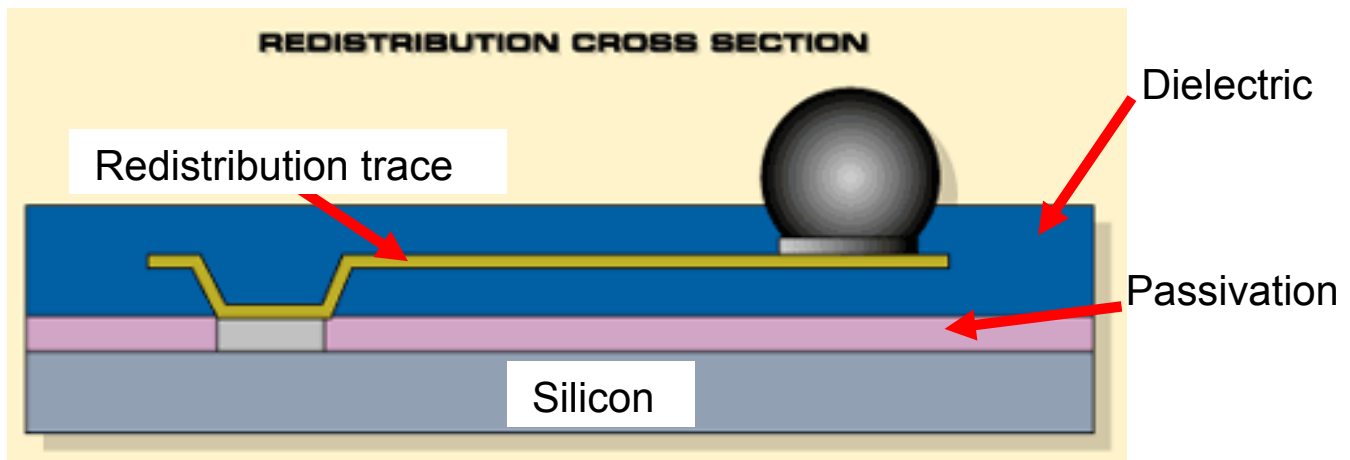

Figure 2-7 Cross Section of a Redistribution Layer [Source: Fraunhofer IZM]

\subsubsection{Encapsulated WLP}

The encapsulated approach involves sealing the IC between two protective layers. One type of encapsulated configuration that utilizes glass layers is depicted in Figure 2-8. The resulting encapsulated device has a footprint almost identical to the bare silicon and a thickness that can be even less than the original silicon. This thickness is possible because much of the silicon is removed from the inactive face of the wafer through a process called backgrinding. Through this process, the wafer is ground very then using diamond abrasive grinding wheels on rotary grinders. 


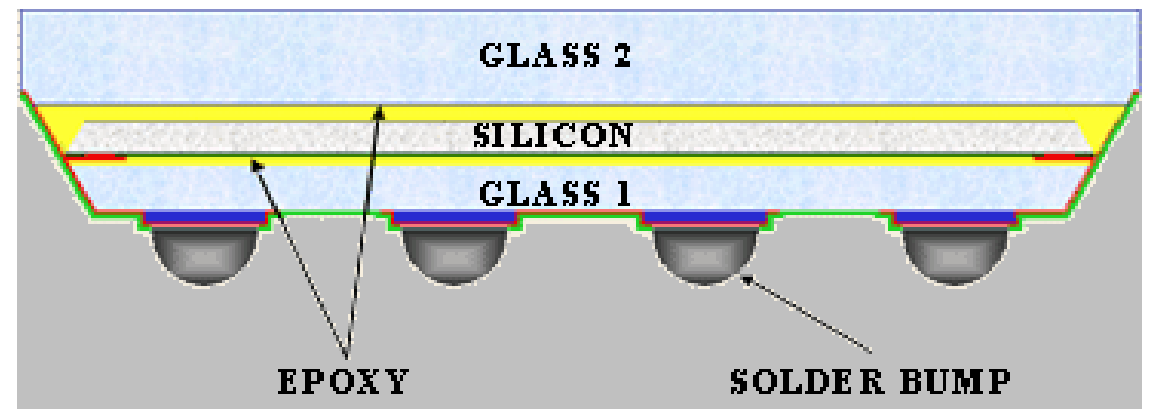

Figure 2-8 Shellcase ShellBGA WLP Technology (Source: Shellcase)

The key advantages to this technology are the ultra-thin thickness $(0.3-0.5 \mathrm{~mm})$, full encapsulation of the die, and assembly that does not require underfill. Underfill is not required because an organic compliant layer is placed under the bumps before the metallization is deposited. This compliant layer serves to reduce the stresses in the solder joints enough that underfill is not necessary for acceptable reliability.

\subsubsection{Flex Tape WLP}

The flex tape WLP utilizes a redistribution pattern that is formed on flexible copper-polyimide tape that is attached to the wafer with an adhesive. The IC is connected to the film by wirebonding from its pads. A liquid encapsulant is then used to seal and protect the wirebonds and bond pads. Finally, the rerouted pads are bumped with solder balls. An example of a flex based WLP is shown in Figure 2-9. 


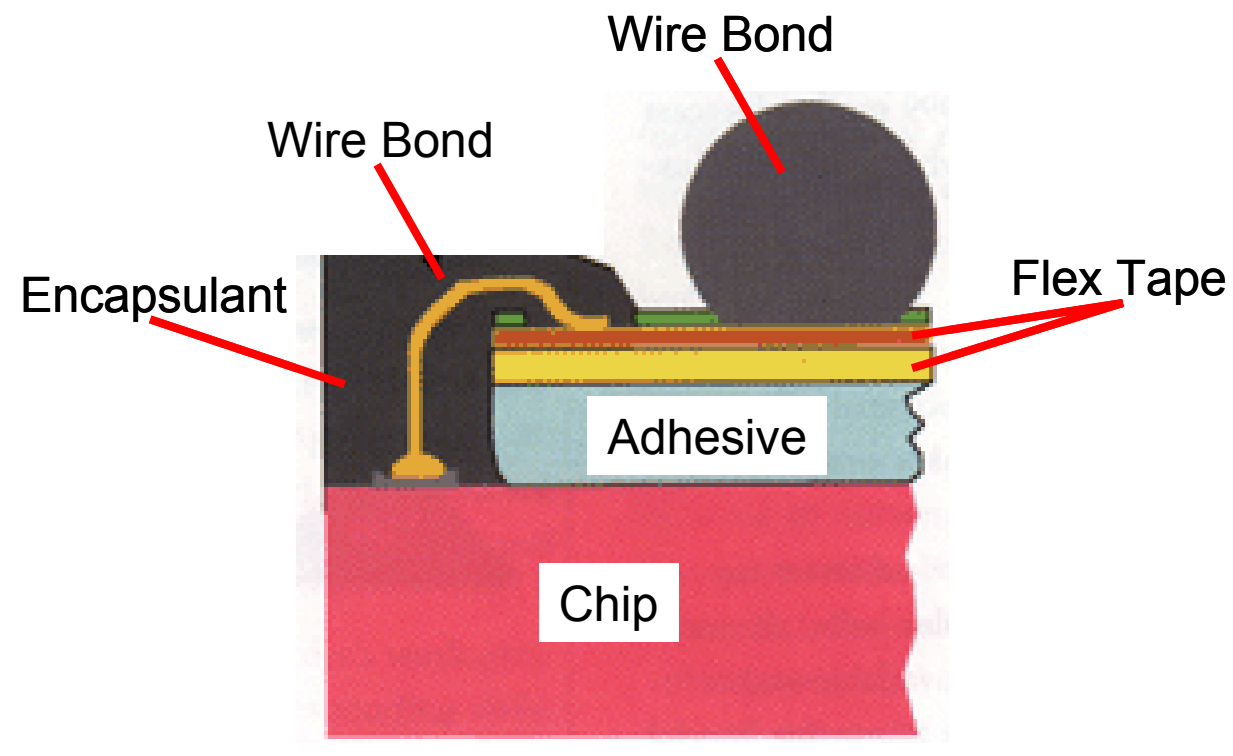

Figure 2-9 Flex Tape WLP [Source: Amkor]

There are numerous advantages to any of these WLP approaches, most importantly being lowest cost and smallest size. The advantages and disadvantages are discussed in the next sections.

\subsubsection{Advantages of WLP}

One of the primary advantages to WLP is that the resulting package is die sized, which results in a minimal size and weight packaging solution for a given IC. This means that WLP offers a potential solution for size critical components that are often found in many handheld consumer electronics products; the possibilities include mobile phones, cameras, bluetooth headsets, etc.

Another primary advantage to WLP is potential cost savings over traditional IC packaging. The main reason that WLP packaging has great potential as a low cost packaging alternative is that wafer processing costs 
remain about the same as wafer size increases and as scaling reduces the size of the ICs. The end result is that an increasing number of ICs can be packaged for about the same cost. This is a very different cost structure than that of singulated IC packaging, where packaging costs increase roughly linearly with increasing IC counts.

There are other advantages of WLP related to the electrical performance of the IC/board system. The leads are shorter than typical wirebonding and therefore offer more favorable inductance and resistance.

Additionally, redistribution allows for maximum pitch between I/Os which allows the use of the lowest cost substrate for interconnection.

\subsubsection{Disadvantages of WLP}

Because the solder interconnects must be located on the active side of the die, high I/O counts necessitate a very fine pitch of the solder balls. These fine pitch solder arrays then require a high density PWB to make the interconnection. These high density PWBs are currently very expensive. Additionally, because all the ICs are packaged together on the wafer, bad ICs are packaged along with the good ICs. This means that when yields are low wafer level packaging distributes the same cost over fewer die, therefore driving the cost per package higher. Therefore wafer level packaging may not be the best choice for relatively low yielding wafers.

Another potential problem exists in dicing and singulation. There is potential to damage the delicate structures in the redistribution layer during 
dicing. Problems can also occur with WLP materials causing a buildup on the saw blade during dicing.

\subsubsection{WLP interconnections}

The reliability of a package is dependant on the height or the compliancy of the connection between the IC and the substrate; therefore, many WLP interconnect solutions seek to provide this needed compliancy or height or interconnect [Tummala 2001].

One method is to provide a compliant spring like connection, which is also the reason that wirebonding results in good reliability. A schematic of the compliant lead WLP interconnect is presented in Figure 2-10.

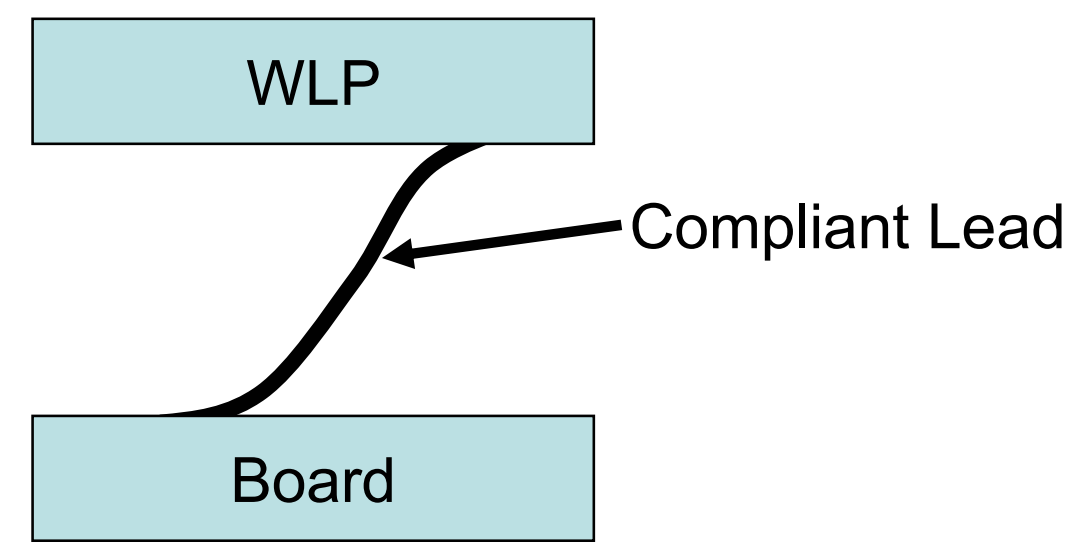

Figure 2-10 Compliant Lead Interconnect [Tummala 2001]

Examples of compliant lead packages include Form Factor's WLCSP product that utilizes the company's MicroSpring ${ }^{\mathrm{TM}}$ technology. Underfill is not needed with this approach because of the excellent compliance of the microsprings. Another approach using a complaint lead is the Tessera WAVE WLP. WAVE technology 
involves compliant beam leads on a flex based interconnect that are laminated using heat and pressure to $\mathrm{I} / \mathrm{O}$ pads of the individual die on the wafer.

Another approach involves stacking solder balls to provide more height. A schematic of this type of interconnect technology is provided in Figure 2-11. The double ball approach has been investigated by Fraunhofer IZM as a WLCSP technology [Töpper 2000]. They apply a stress compensation layer (SCL) over the first layer of high lead balls. The resulting structure is planarized by removing part of the SCL to expose the underlying bumps. Next, a high $\mathrm{Pb}$ solder

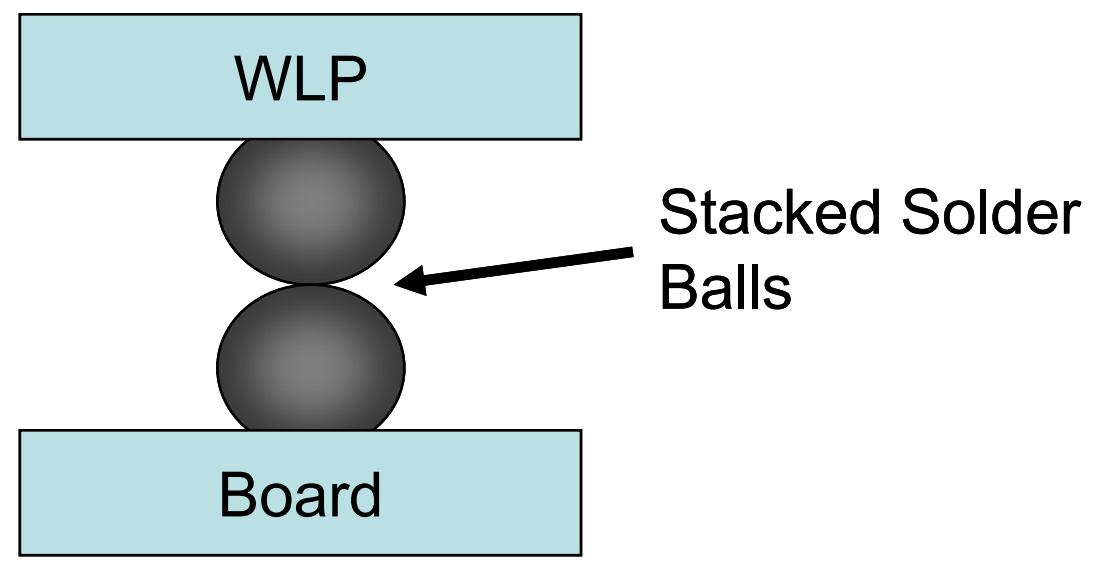

Figure 2-11 Stacked Solder Ball Interconnect [Tummala 2001]

is printed onto the base layer of bumps and reflowed to leave an array of stacked bumps. The result is an interconnect structure that is more compliant than a single layer of bumps, while maintaining the same pitch.

A third approach involves using larger solder balls to achieve the necessary height. A schematic of this technology is presented in Figure 2-12. 


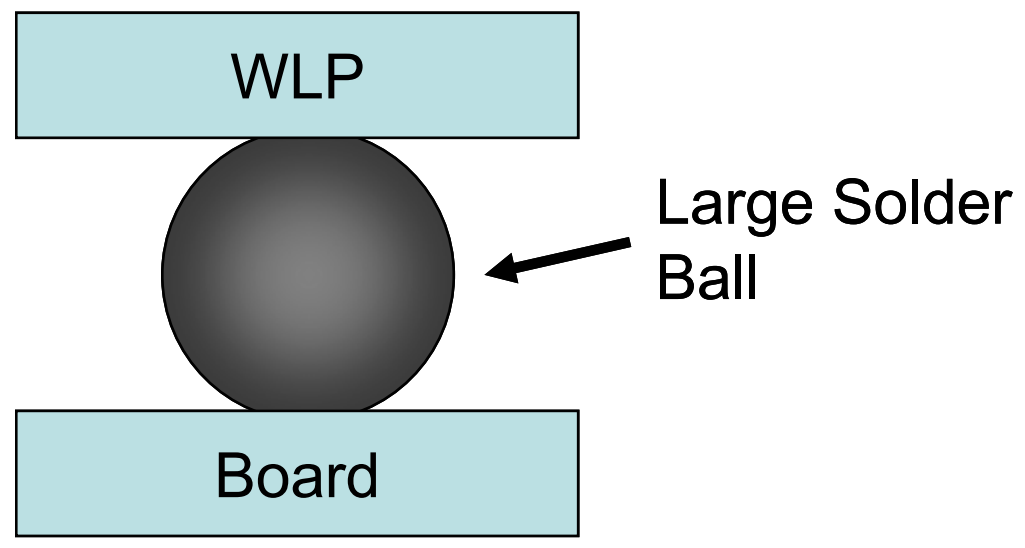

Figure 2-12 Large Solder Ball Interconnect [Tummala 2001]

An example of the large ball approach is the Ultra CSP ${ }^{\mathrm{TM}}$ by Flip Chip Technologies. Ultra CSP ${ }^{\mathrm{TM}}$ uses a two layer BCB dielectric system and a thin film redistribution layer of $\mathrm{Al} / \mathrm{NiV} / \mathrm{Cu}$. Solder ball height ranges from 250 to 400 $\mu \mathrm{m}$. The size of the bumps is much larger than the typical height for a flip chip of about $120 \mu \mathrm{m}$. The additional height provides the compliance necessary to make underfilling the assembly unnecessary.

\subsubsection{WLP future trends}

Wafer level packaging is predicted to have a compound annual growth rate of $210 \%$ through 2005 [Patterson 2002]. The devices that are most likely to drive this growth are integrated passives, flash and EEPROM memory devices, DRAM, SRAM, and others. As production volume increases for these WLP devices, the cost savings inherently possible with WLP will be realized. 


\section{CHAPTER III: EXPERIMENTAL DESIGN}

\subsection{Overview}

The primary goal of this thesis research was to develop and test the reliability of a novel hybrid no-flow underfill assembly process; this process used a capillary flow dynamic with an edge pattered dispense of no-flow fluxing underfill materials. The secondary goal of the research was to provide optimized processing parameters for 4 commercially available no-flow underfills as a consequence of the new hybrid process development; these materials were used to develop and verify the new hybrid process. To accomplish this goal a series of experiments were conducted. The general structure of the experimentation was as follows:

- An underfill dispense experiment, DOE1 (Design of Experiments $\# 1$ ), was conducted to determine the optimal underfill dispense parameters.

- A placement experiment, DOE 2, was performed to determine the optimal chip placement parameters.

- A line position study was conducted to gain a better understanding of how the placement of the line pattern affects processing.

- A parametric reflow study was completed to determine optimal reflow parameters, as well as to construct process windows for each underfill material. 
- Air to Air thermal cycling testing was conducted for each no-flow material to test the long term reliability of parts assembled with the newly developed final hybrid process.

- The high humidity, high pressure test (Autoclave) was performed to test the reliability of the final assemblies under extreme environmental conditions.

\subsection{Test Vehicle 1}

This TV1 (test vehicle 1) test vehicle was used for all thesis research. The TV1 flip chip carrier is composed of FR4 organic material with electroplated copper traces. The thickness of the copper traces was calculated as approximately 25 microns by SEM observation and appears in Figure 3-7. The substrate bond pads are a hybrid, mask defined on two sides and metal defined on two sides. The solder mask openings are circular.

This TV1 test vehicle was full area array with 317 flip chip pads (board to die interconnect). All bonding surfaces had an electroless nickel and immersion gold finish plate to preserve solderability. TV1 is illustrated in Figures 3-1 through 3-8. 


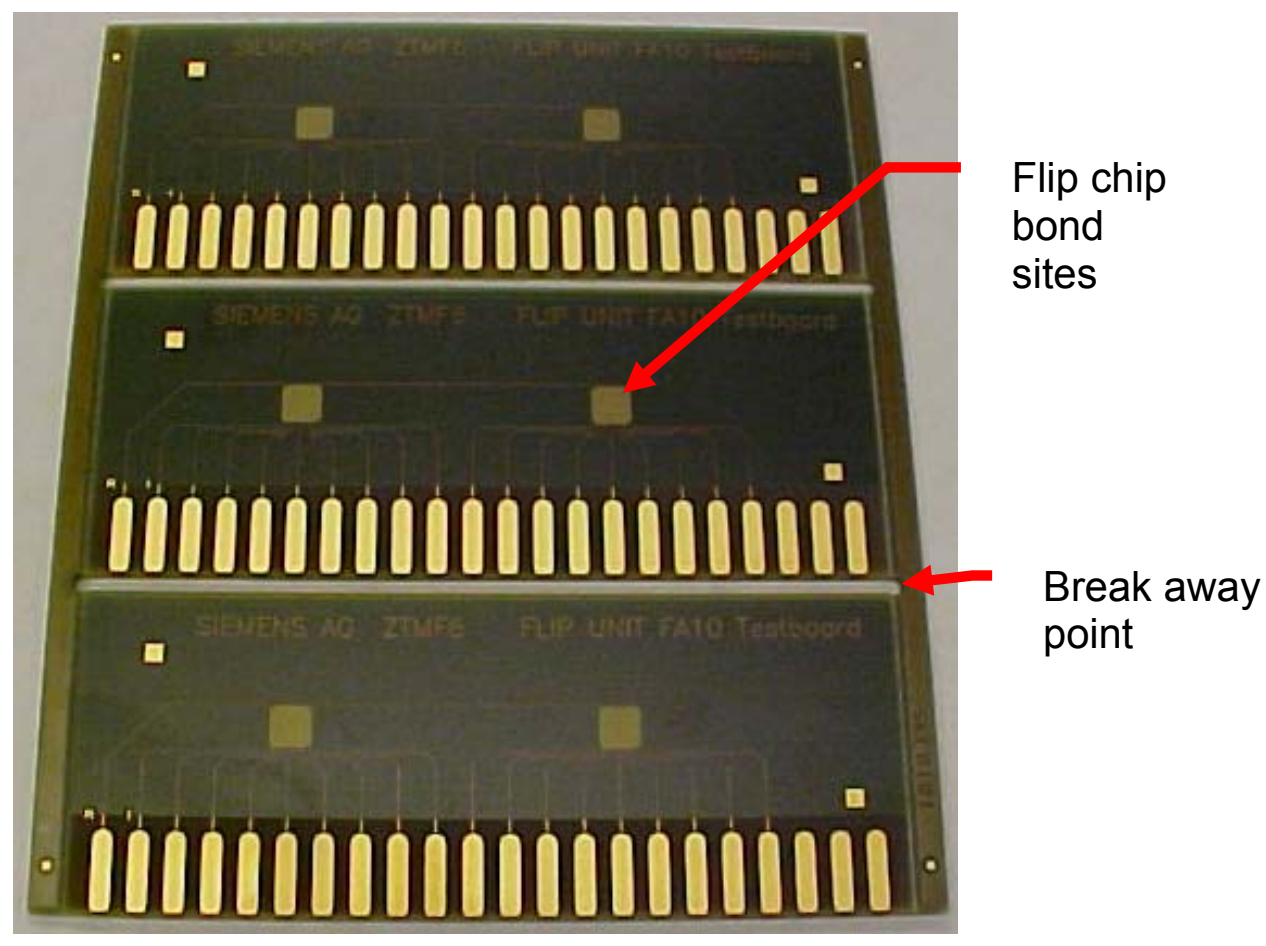

Figure 3-1 Test Vehicle 1, Six Bond Sites

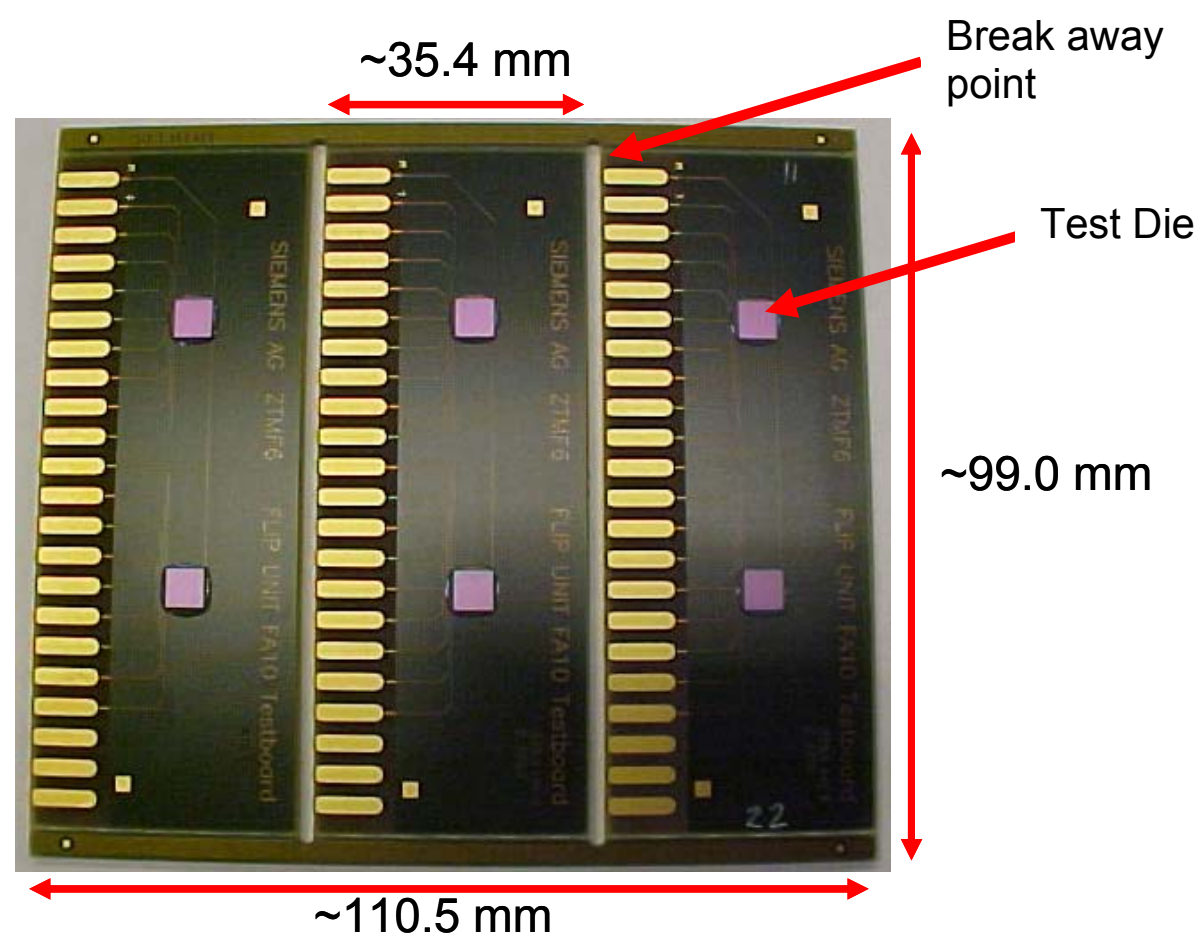

Figure 3-2 Test Vehicle 1 With Assembled Test Die 


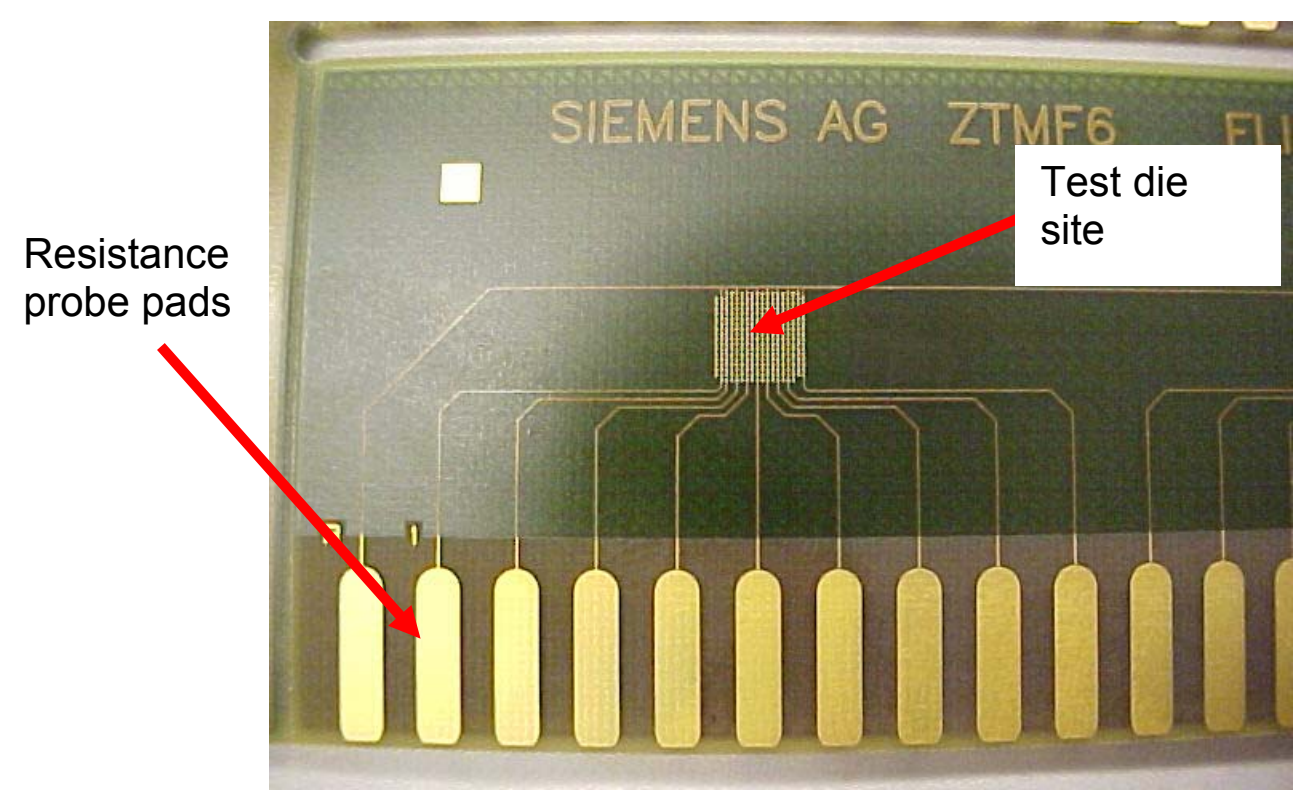

Figure 3-3 Test Vehicle 1, Close Up of Trace Layout to One Bond Site

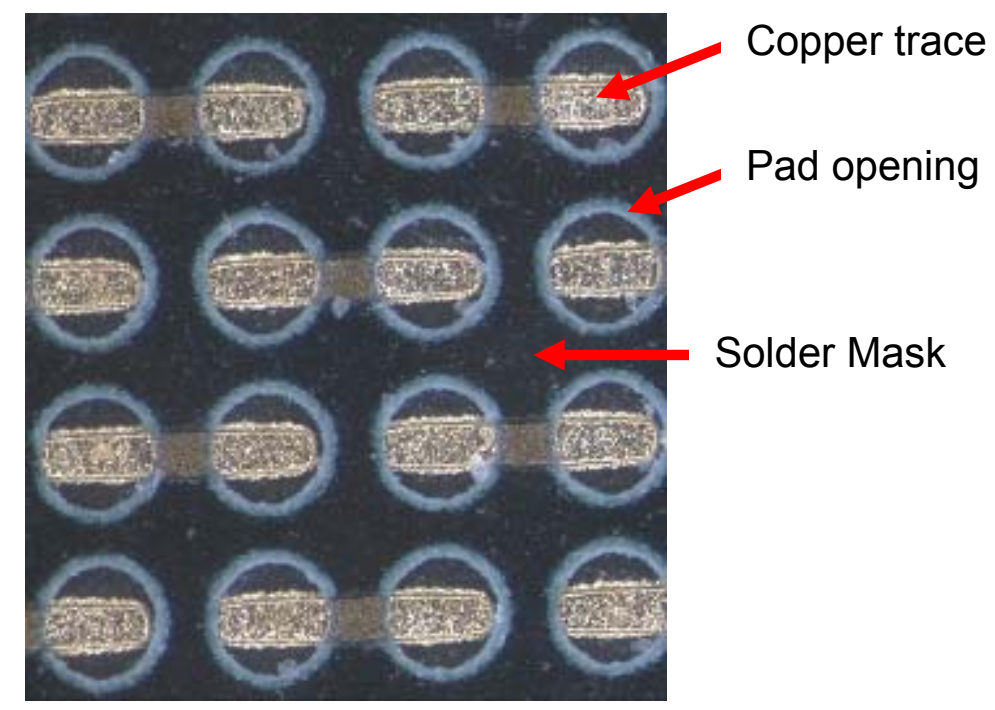

Figure 3-4 Test Vehicle 1, Optical Image of Daisy Chain Traces, Dimensions in Figure 3-5 


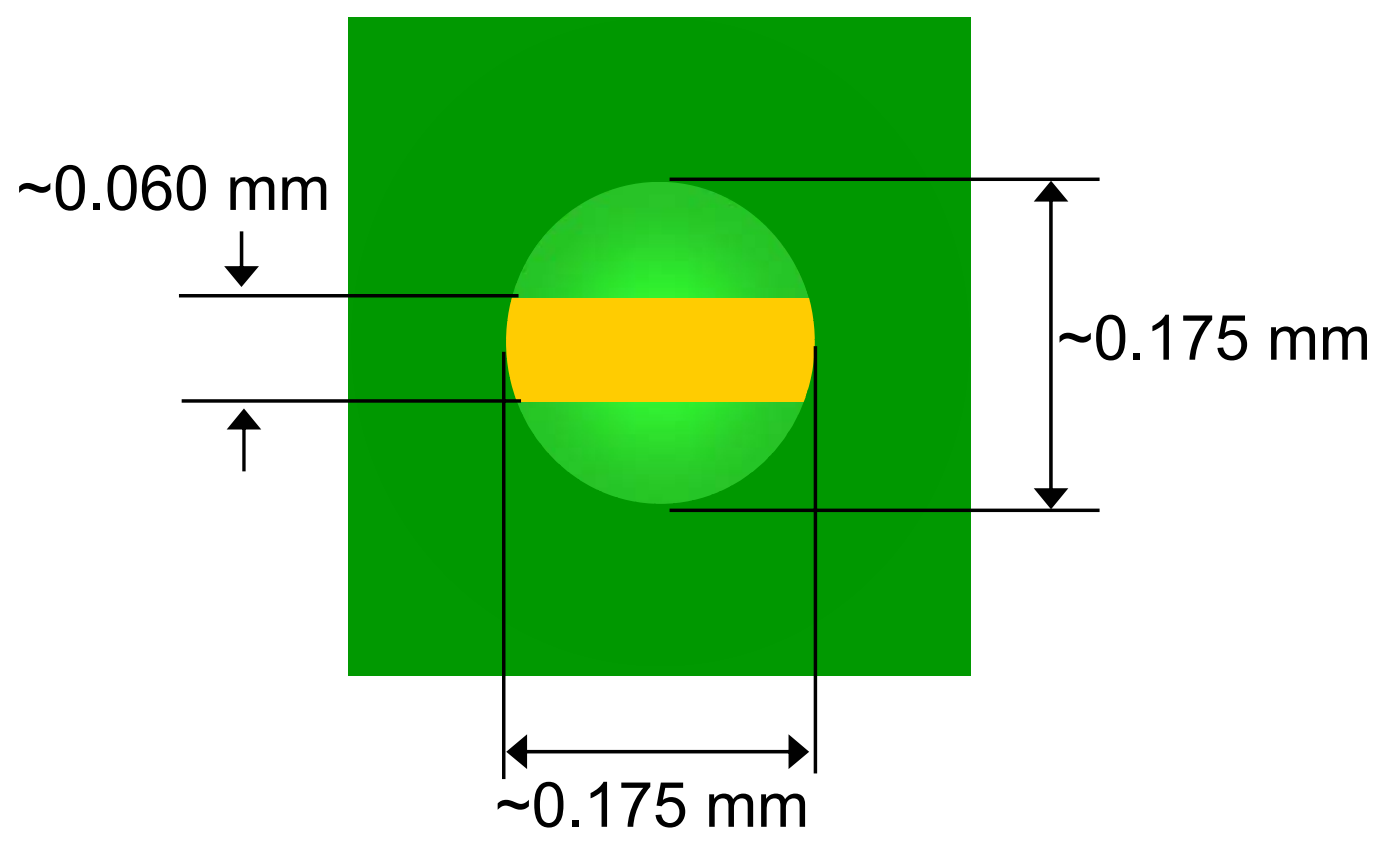

Figure 3-5 TV1, Top View of Substrate Pad Geometry

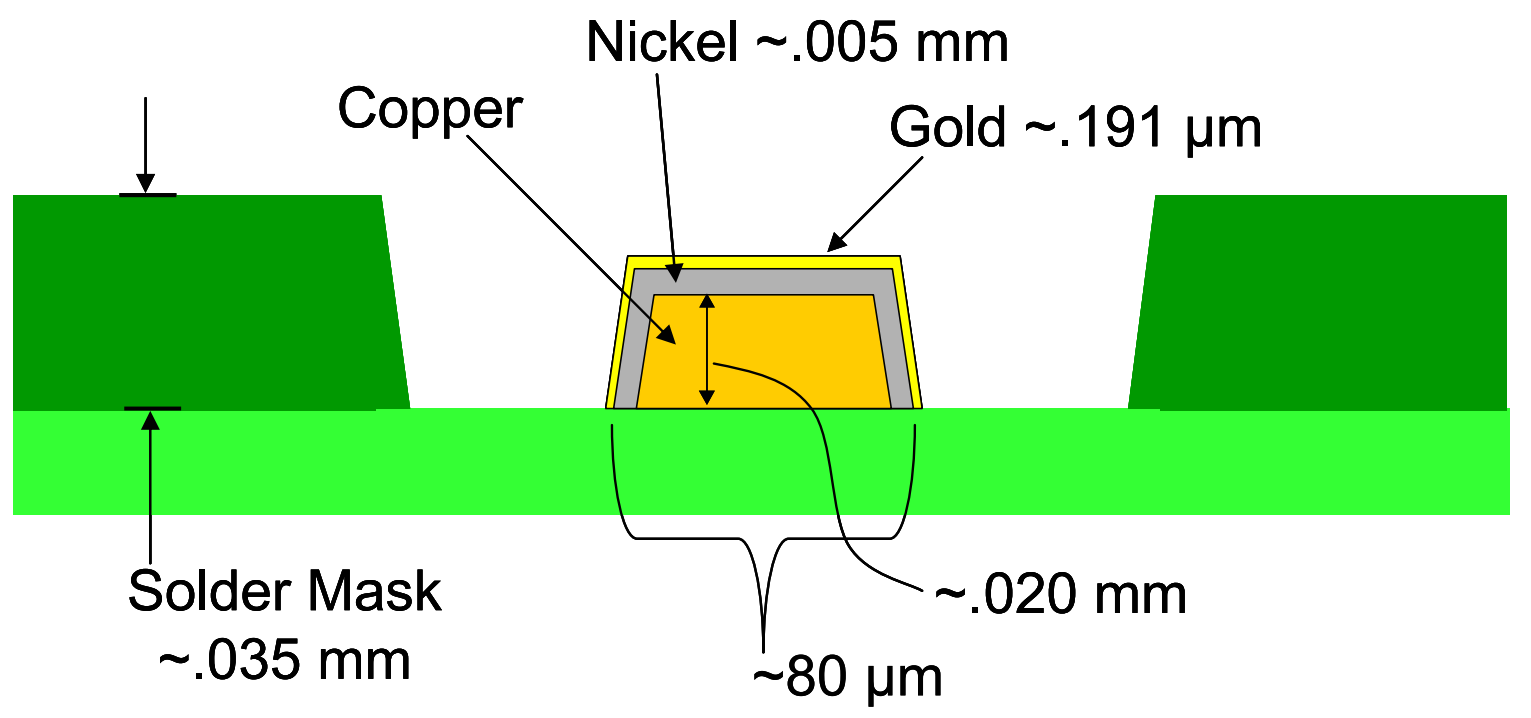

Figure 3-6 TV1, Trace and Mask Opening Geometry Profile 


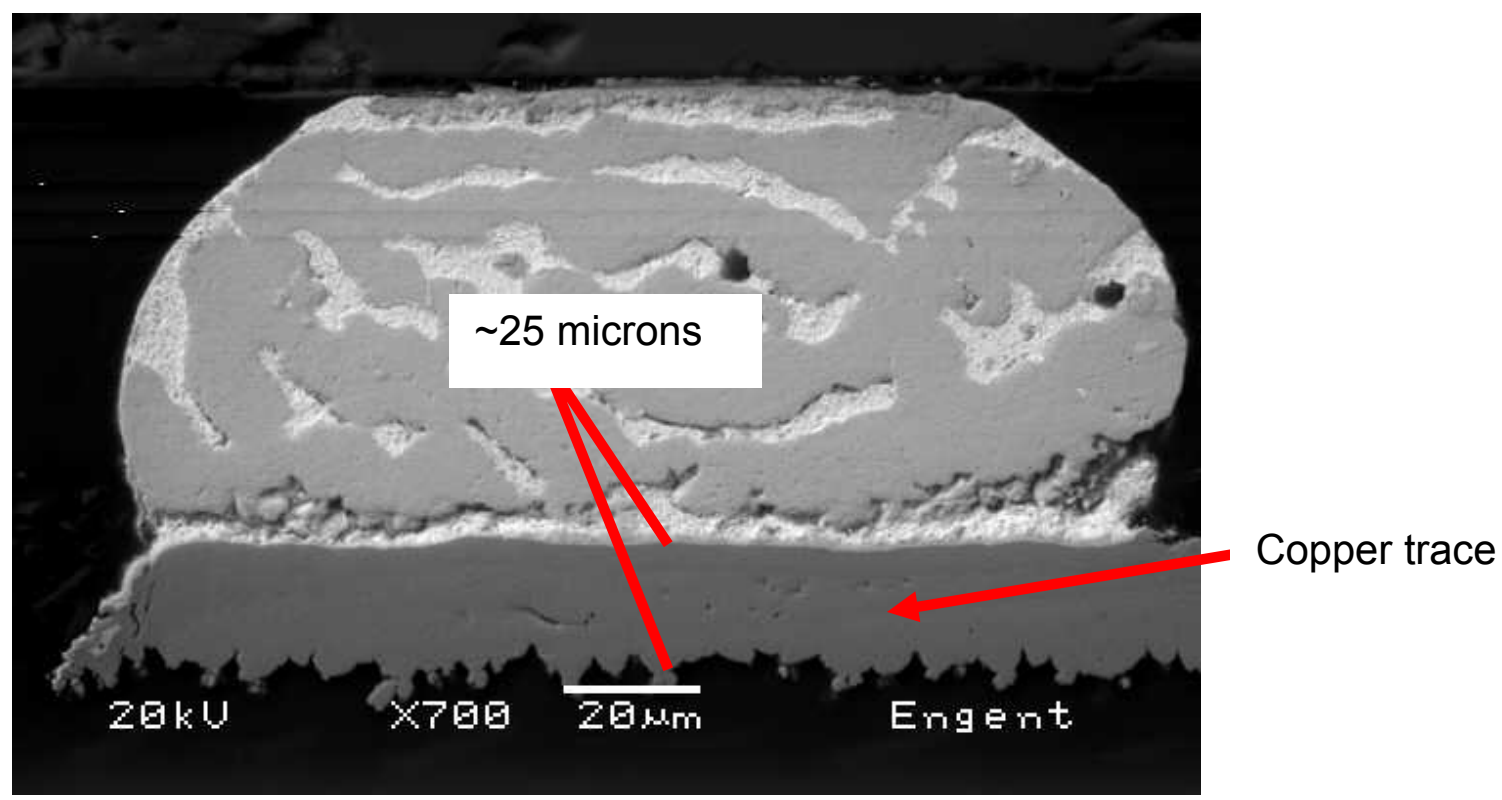

Figure 3-7 Cross Section of Solder Bump on Copper Trace

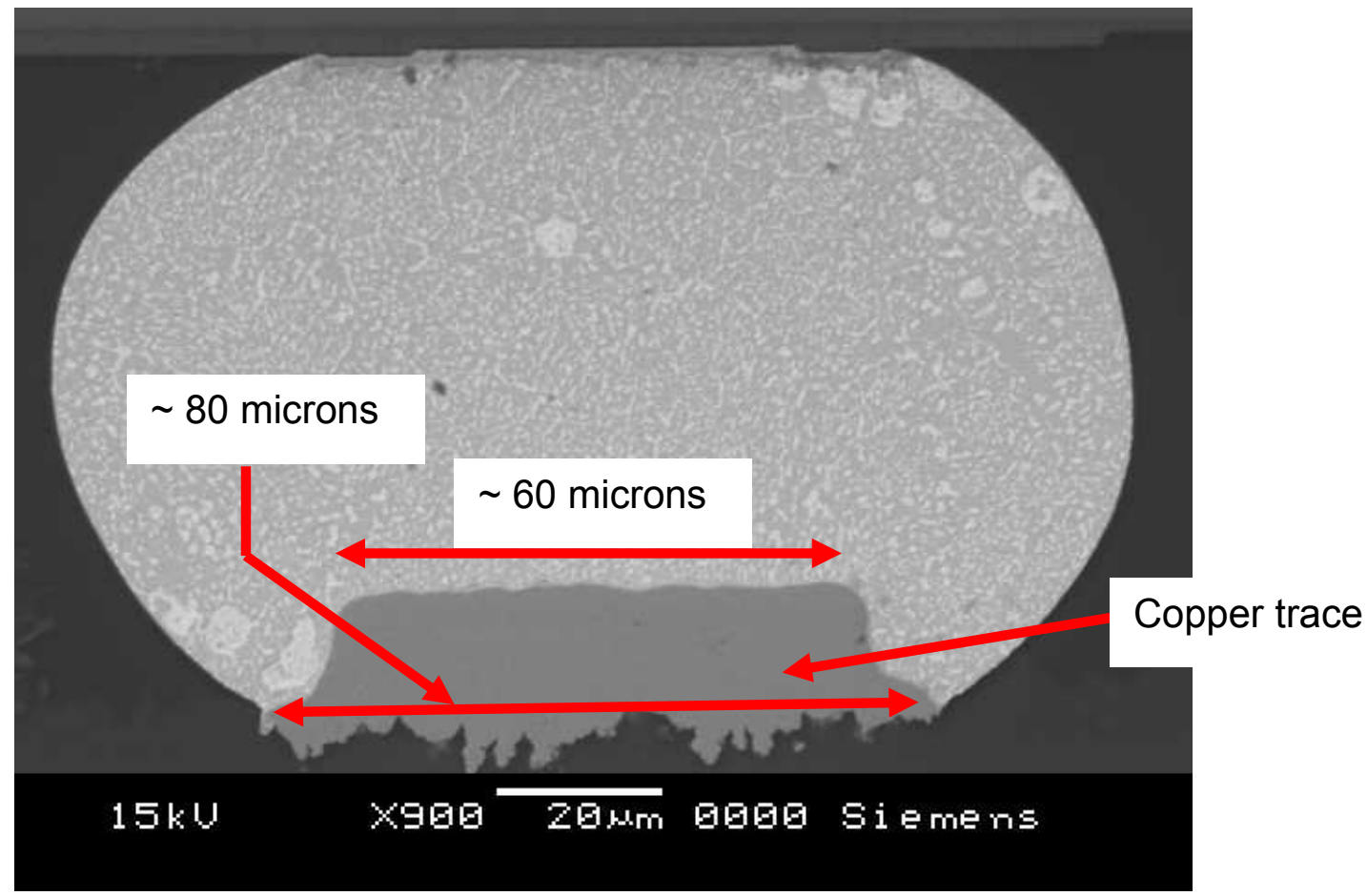

Figure 3-8 Cross Section of Assembly Showing Axis of Copper Trace 


\subsection{Test Die}

The only die used for this experimental work was the FA10 2x2 silicon die; all die were supplied through Flip Chip Technologies. The die were daisy-chained allowing for the assembly to be tested for interconnection by two point resistance measurement in groupings of two rows at a time. The square die measured $5.08 \mathrm{~mm} \times 5.08 \mathrm{~mm}(0.2 \mathrm{in} \times 0.2 \mathrm{in})$ in size and $0.60 \mathrm{~mm}(.22 \mathrm{in})$ in thickness. Each die has 317 eutectic $(\mathrm{Sn}-\mathrm{Pb})$ solder bumps that measured 135 microns in diameter and 120 microns in height, and the pitch of the bumps was 254 microns. The die has a passivation layer composed of silicon nitride and an under bump metallization of $\mathrm{Al} / \mathrm{NiV} / \mathrm{Cu}$. The trace and bump layout can be seen in Figure 3-9.

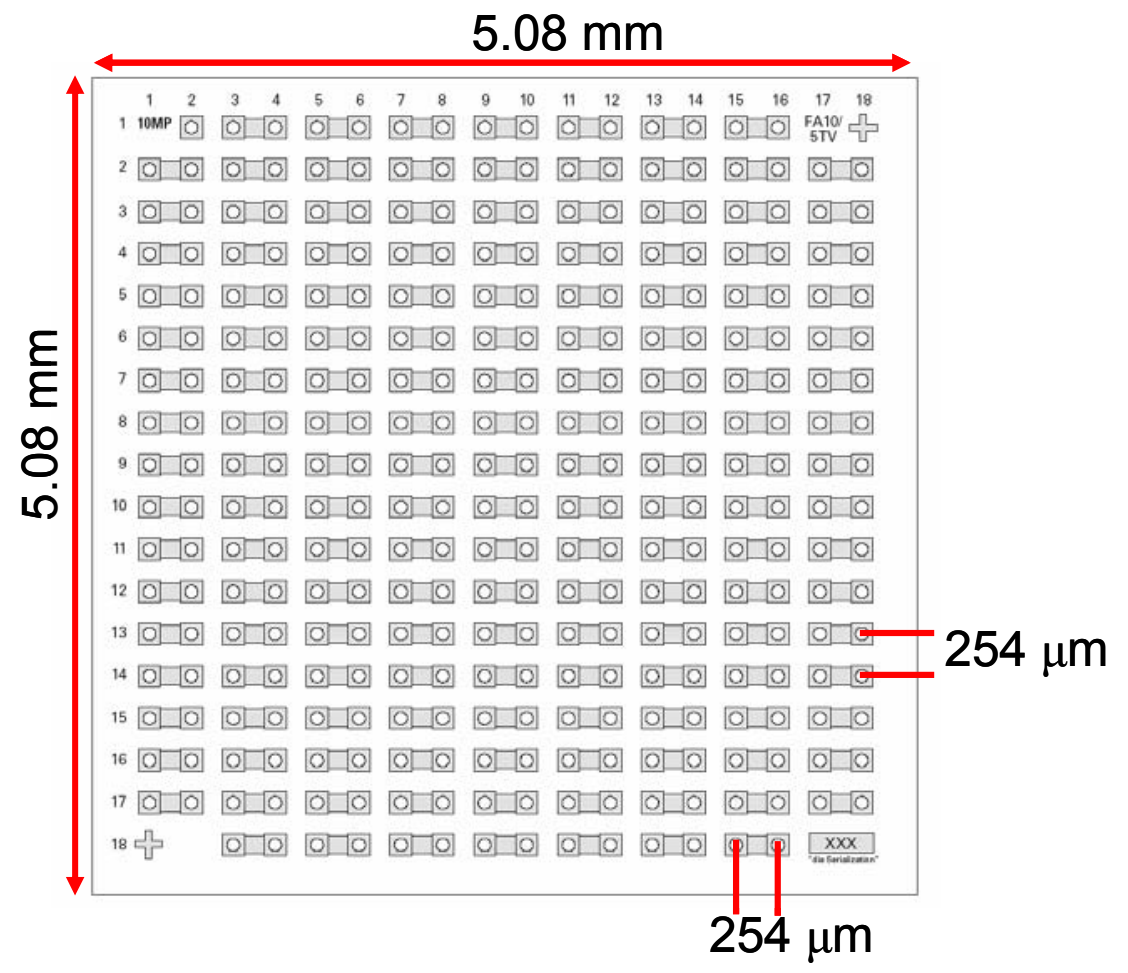

Figure 3-9 FA10 2X2 Flip Chip Test Die Used for All Experiments 


\subsection{Underfill Materials}

The underfill materials used for this experimental work were all commercially available no-flow fluxing underfills. The five underfills used during the dispense and placement DOEs are listed in Table 3-1 along with the material properties for each. The reflow experiment and the final build for reliability testing involved only materials $A, B, C$, and $E$. Material $D$ was eliminated from further testing after the placement study.

Table 3-1 No-Flow Fluxing Underfills Used and Material Properties

\begin{tabular}{|c|c|c|c|c|c|}
\hline Underfill & $\begin{array}{c}\mu @ 25^{\circ} \mathrm{C} \\
(\mathrm{cps})\end{array}$ & $\begin{array}{c}\mathrm{T}_{\mathrm{g}} \\
\left({ }^{\circ} \mathrm{C}\right) \\
\end{array}$ & $\begin{array}{c}\text { CTE @ T<Tg } \\
\left(\mathrm{ppm} /{ }^{\circ} \mathrm{C}\right)\end{array}$ & $\begin{array}{c}\mathrm{E} @ \mathrm{~T}<\mathrm{Tg} \\
(\mathrm{GPa})\end{array}$ & $\begin{array}{c}\text { Pot life @ } 25^{\circ} \mathrm{C} \\
\text { (hours) }\end{array}$ \\
\hline $\bar{A}$ & 3600 & 128 & 72 & 2.8 & 16 \\
\hline B & 2500 & 125 & 75 & 2.7 & 16 \\
\hline C & 9500 & 105 & 70 & 1.4 & 4 \\
\hline D & 2400 & $120-130$ & $70-90$ & 3.2 & 8 \\
\hline$E$ & 4500 & 120 & 75 & 2.6 & 8 \\
\hline
\end{tabular}

\subsection{Assembly Process}

\subsubsection{Underfill Dispense}

Underfill dispense was accomplished with a Speedline CAMALOT 3700 model dispense machine. The materials were stored at $-40{ }^{\circ} \mathrm{C}$ until 1 hour prior to use. This 1 hour time period is the recommended thaw time by the manufacturers, and it was sufficient to warm the materials to room temperature before dispensing. A 22 gauge needle was used to dispense for all of the experimental 
work presented here. The underfill dispense programs are presented in Tables 32 through 3-7.

Table 3-2 Underfill Dispense Program for Line Pattern

\begin{tabular}{|c|c|c|c|c|c|c|c|}
\hline Step & Command & $\mathbf{x}$ & $\mathbf{Y}$ & $\mathbf{v}$ & $\mathbf{s}$ & UP & DN \\
\hline$\overline{11}$ & REFPT & 8.185 & $\overline{c 4.440}$ & & & & \\
\hline 2 & REFPT & 4.611 & 1.417 & & & & \\
\hline 3 & MOVE & 4.819 & 3.835 & 1 & 4 & 2 & 1 \\
\hline 4 & CALL & \multicolumn{6}{|c|}{ FA10LINE.CAM } \\
\hline 5 & MOVE & 4.827 & 2.432 & 1 & 4 & 2 & 1 \\
\hline 6 & $\overline{\text { CALL }}$ & \multicolumn{6}{|c|}{ FA10LINE.CAM } \\
\hline 7 & MOVE & 6.298 & 3.837 & 1 & 4 & 2 & 1 \\
\hline 8 & CALL & \multicolumn{6}{|c|}{ FA10LINE.CAM } \\
\hline 9 & MOVE & 6.301 & 2.434 & 1 & 4 & 2 & 1 \\
\hline 10 & CALL & \multicolumn{6}{|c|}{ FA10LINE.CAM } \\
\hline 11 & MOVE & 7.773 & 3.840 & 1 & 4 & 2 & 1 \\
\hline 12 & CALL & \multicolumn{6}{|c|}{ FA10LINE.CAM } \\
\hline 13 & MOVE & 7.781 & 2.435 & 1 & 4 & 2 & 1 \\
\hline 14 & CALL & \multirow{2}{*}{\multicolumn{6}{|c|}{ FA10LINE.CAM }} \\
\hline 15 & END & & & & & & \\
\hline
\end{tabular}

Table 3-3 FA10LINE.CAM Sub-Program for Line Pattern

\begin{tabular}{cccccccc} 
Step & Command & $\mathbf{X}$ & $\mathbf{Y}$ & $\mathbf{V}$ & $\mathbf{S}$ & UP & DN \\
\hline \hline 1 & MOVE & 4.825 & 3.826 & 1 & 4 & 2 & 1 \\
\hline 2 & ZSENSE & 4.920 & 3.519 & 1 & 4 & 30 & 1 \\
\hline 3 & MOVE & 4.835 & 3.895 & 1 & 4 & 2 & 1 \\
\hline 4 & LINE & 5.018 & 3.898 & 1 & 2 & 2 & 1 \\
\hline 5 & LINE & 4.840 & 3.900 & 1 & 2 & 3 & 2 \\
\hline 6 & CLEAN & 4.864 & 3.898 & 1 & 2 & 4 & 3 \\
\hline 7 & END & & & & & & \\
\hline
\end{tabular}


Table 3-4 Underfill Dispense Program for Dot Pattern

\begin{tabular}{|c|c|c|c|c|c|c|c|}
\hline Step & Command & $\mathbf{x}$ & $\mathbf{Y}$ & $\mathbf{v}$ & $\mathbf{s}$ & UP & DN \\
\hline 1 & REFPT & 8.185 & 4.440 & & & & \\
\hline 2 & REFPT & 4.611 & 1.417 & & & & \\
\hline 3 & MOVE & 4.912 & 3.823 & 1 & 4 & 2 & 1 \\
\hline 4 & CALL & \multicolumn{6}{|c|}{ FA10DROP.CAM } \\
\hline 5 & MOVE & 4.922 & 2.431 & 1 & 4 & 2 & 1 \\
\hline 6 & CALL & \multicolumn{6}{|c|}{ FA10DROP.CAM } \\
\hline 7 & MOVE & 6.398 & 3.833 & 1 & 4 & 2 & 1 \\
\hline 8 & CALL & \multicolumn{6}{|c|}{ FA10DROP.CAM } \\
\hline 9 & MOVE & 6.398 & 2.429 & 1 & 4 & 2 & 1 \\
\hline 10 & CALL & \multicolumn{6}{|c|}{ FA10DROP.CAM } \\
\hline 11 & MOVE & 7.875 & 3.836 & 1 & 4 & 2 & 1 \\
\hline 12 & $\overline{\text { CALL }}$ & \multicolumn{6}{|c|}{ FA10DROP.CAM } \\
\hline 13 & MOVE & 7.878 & 2.429 & 1 & 4 & 2 & 1 \\
\hline 14 & CALL & \multirow{2}{*}{\multicolumn{6}{|c|}{ FA10DROP.CAM }} \\
\hline 15 & END & & & & & & \\
\hline
\end{tabular}

Table 3-5 FA10DROP.CAM Sub-Program for Dot Pattern

\begin{tabular}{cccccccc} 
Step & Command & $\mathbf{X}$ & $\mathbf{Y}$ & $\mathbf{V}$ & $\mathbf{S}$ & UP & DN \\
\hline \hline 1 & MOVE & 4.923 & 3.829 & 1 & 4 & 2 & 1 \\
\hline 2 & ZSENSE & 4.932 & 3.522 & 1 & 4 & 2 & 1 \\
\hline 3 & MOVE & 4.923 & 3.827 & 1 & 4 & 2 & 1 \\
\hline 4 & ZLINE & 4.924 & 3.827 & 1 & 3 & 3 & 1 \\
\hline 5 & END & & & & & & \\
\hline
\end{tabular}


Table 3-6 Underfill Dispense Program for Cross Pattern

\begin{tabular}{|c|c|c|c|c|c|c|c|}
\hline Step & Command & $\mathbf{x}$ & $\mathbf{Y}$ & v & $\mathbf{s}$ & UP & DN \\
\hline 1 & $\begin{array}{l}\text { REFPT } \\
\end{array}$ & 8.185 & 4.4 .440 & & & & \\
\hline 2 & REFPT & 4.611 & 1.417 & & & & \\
\hline 3 & MOVE & 4.826 & 3.914 & 1 & 4 & 2 & 1 \\
\hline 4 & CALL & \multicolumn{6}{|c|}{ FA10CRS.CAM } \\
\hline 5 & MOVE & 4.830 & 2.511 & 1 & 4 & 2 & 1 \\
\hline 6 & CALL & \multicolumn{6}{|c|}{ FA10CRS.CAM } \\
\hline 7 & MOVE & 6.304 & 3.917 & 1 & 4 & 2 & 1 \\
\hline 8 & CALL & \multicolumn{6}{|c|}{ FA10CRS.CAM } \\
\hline 9 & MOVE & 6.310 & 2.514 & 1 & 4 & 2 & 1 \\
\hline 10 & CALL & \multicolumn{6}{|c|}{ FA10CRS.CAM } \\
\hline 11 & MOVE & 7.781 & 3.921 & 1 & 4 & 2 & 1 \\
\hline 12 & CALL & \multicolumn{6}{|c|}{ FA10CRS.CAM } \\
\hline 13 & MOVE & 7.785 & 2.516 & 1 & 4 & 2 & 1 \\
\hline 14 & CALL & \multirow{2}{*}{\multicolumn{6}{|c|}{ FA10CRS.CAM }} \\
\hline 15 & END & & & & & & \\
\hline
\end{tabular}

Table 3-7 FA10CRS.CAM Sub-Program for Cross Pattern

\begin{tabular}{cccccccc} 
Step & Command & $\mathbf{X}$ & $\mathbf{Y}$ & $\mathbf{V}$ & $\mathbf{S}$ & UP & DN \\
\hline \hline 1 & ZSENSE & 4.838 & 3.908 & 1 & 4 & 30 & 1 \\
\hline 2 & MOVE & 4.838 & 3.908 & 1 & 4 & 2 & 1 \\
\hline 3 & LINE & 5.008 & 3.739 & 1 & 2 & 2 & 1 \\
\hline 4 & CLEAN & 5.000 & 3.756 & 1 & 4 & 2 & 1 \\
\hline 5 & MOVE & 4.835 & 3.743 & 1 & 2 & 2 & 1 \\
\hline 6 & LINE & 5.011 & 3.910 & 1 & 2 & 3 & 2 \\
\hline 7 & CLEAN & 4.989 & 3.883 & 1 & 4 & 3 & 2 \\
\hline 8 & END & & & & & & \\
\hline
\end{tabular}




\subsubsection{Pre-Assembly Moisture Removal}

Prior to assembly, all moisture was driven out of the boards with exposure to an isothermal environment at $125^{\circ} \mathrm{C}$ for 3 hours. This bakeout time was determined from a previous bakeout experiment, and was sufficient to avoid outgassing of the boards as described by [Lazarakis 2003; Wang, 2001]. The boards were then stored in a desiccant chamber after bakeout, for no more than 2 hours before assembly.

\subsubsection{General Reflow Information}

There are two distinct types of reflow profiles that were utilized in this experimental work; these types are described as either a step or a ramp profile. The general shape of these profiles is shown in Figures 3-10 and 3-11.

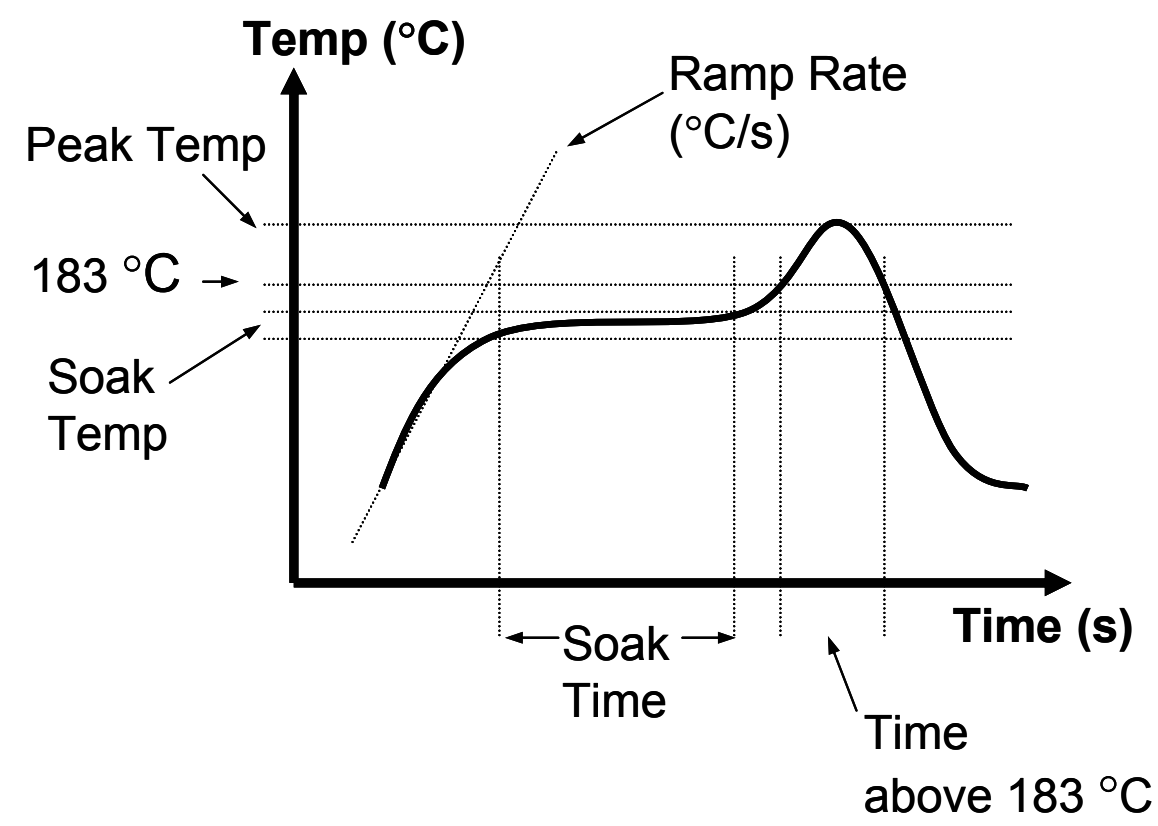

Figure 3-10 Step Reflow Profile 


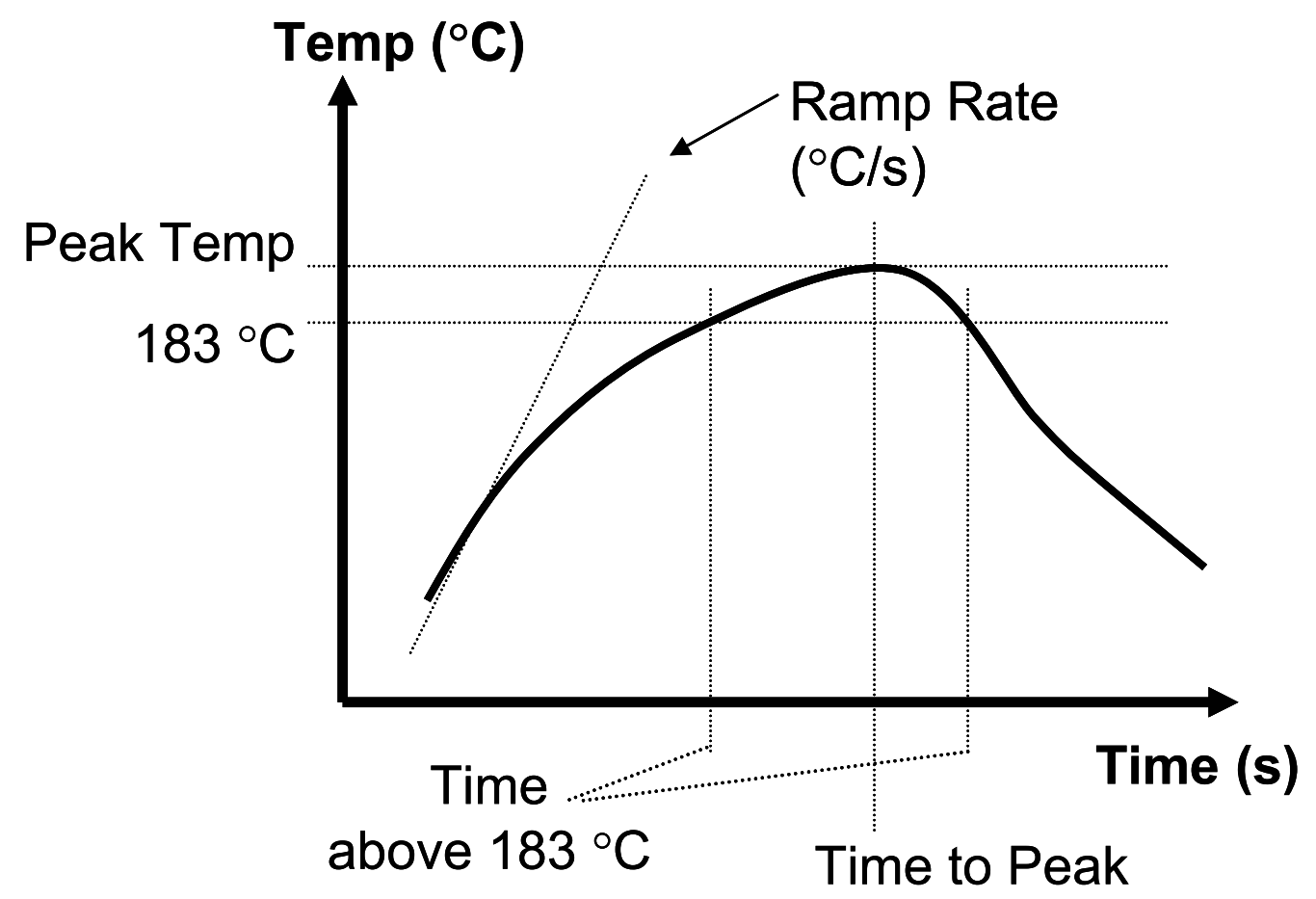

Figure 3-11 Ramp Reflow Profile

There are several important parameters that determine the temperature profile of a solder reflow process. These parameters include ramp rate, soak time, soak temp, time above $183^{\circ} \mathrm{C}$, peak temp, and time to peak, as defined in Figures 3-10 and 3-11. For no-flow applications, the reflow profile defined by these parameters must not only cause solder reflow, but also allow for activation of the flux and proper curing of the underfill material. Other researchers have identified these parameters as critically affecting the no-flow process; therefore, 
they are selected to vary for this experiment in order to best optimize the results. Reflow soak temperature and time has been shown to affect the viscosity and resulting fluxing action of no-flow underfills [Wong 1998]. Time to peak temperature is an important factor because it has a pronounced effect on the percentage cure of the underfill and therefore on the material properties. The effect of underfill material properties on flip chip reliability has been shown previously [Shi 2000]

The line dispense used in this research is particularly sensitive to reflow parameters, because the material must flow completely underneath the die before the flux becomes inactive or the material begins to set. In addition, the flow of the underfill during the first stages of reflow suggests that the elevated temperature will act to lower the viscosity of the underfill; this helps to explain why the underfill is able to successfully fill all the solder mask openings, thereby resulting in the extremely low voiding observed for the line pattern. These considerations suggest that the initial ramp rate $\left({ }^{\circ} \mathrm{C} / \mathrm{s}\right)$ and the soak temperature may be distinctively important reflow parameters for the line dispense.

The material suppliers provide a recommended profile, or process window, that can serve as a good starting point for further optimization. The reflow process window determination and optimization in this research was designed around these baseline profiles. 


\subsection{Design of Experiments \#1, Dispense Optimization}

Five different materials were separately evaluated for optimal dispense parameters. For each material, a full factorial design of experiment (DOE) was used with two variables. Dispense pattern was included with 3 levels: dot, line, and cross, see Figure 3-12. Placement speed was included with 2 levels: 70 $\mathrm{mm} / \mathrm{s}$, and $5 \mathrm{~mm} / \mathrm{s}$. All treatments were performed in replicates of 4 . Void formation was the primary metric. Fillet shape after cure, although not quantified, was also inspected. Based on the experimental results, an optimal dispensing process will be selected for use in the remaining experiments of this project.

All experiments were performed at the Georgia Institute of Technology, in the Center for Board Assembly Research and the Packaging Research Center process laboratories. Underfill dispense was accomplished with an Asymtek millennium using a 22 gauge needle. Placement was completed with a Siemens Siplace F5 DCA for speed $1(70 \mathrm{~mm} / \mathrm{s})$, and a K\&S 6900 for speed $2(5 \mathrm{~mm} / \mathrm{s})$. Both machines were calibrated for force and speed prior to running the DOE. The force used during the DOE was 500 grams $(\sim 5 \mathrm{~N})$. The dwell time used was 0.10 seconds.

Test Vehicle 1 boards were assembled according to the design matrix shown in Table 3-8, for each underfill A, B, C, D, and E. Each row of the matrix corresponds to one treatment in the DOE; four replicates were assembled for each treatment without randomization. Before assembly all boards were prebaked to remove moisture as described in Section 3.5.2. The target dispense weight was $8 \mathrm{mg}$; actual dispense weight varied between $7.5 \mathrm{mg}$ and $8.5 \mathrm{mg}$. 
The assemblies were low temperature cured at $130^{\circ} \mathrm{C}$ for 1 hour in an oven. The temperature was chosen to avoid reflow and any material volatility so that the effects of the factors included in the DOE could be studied in relative isolation from the reflow process.
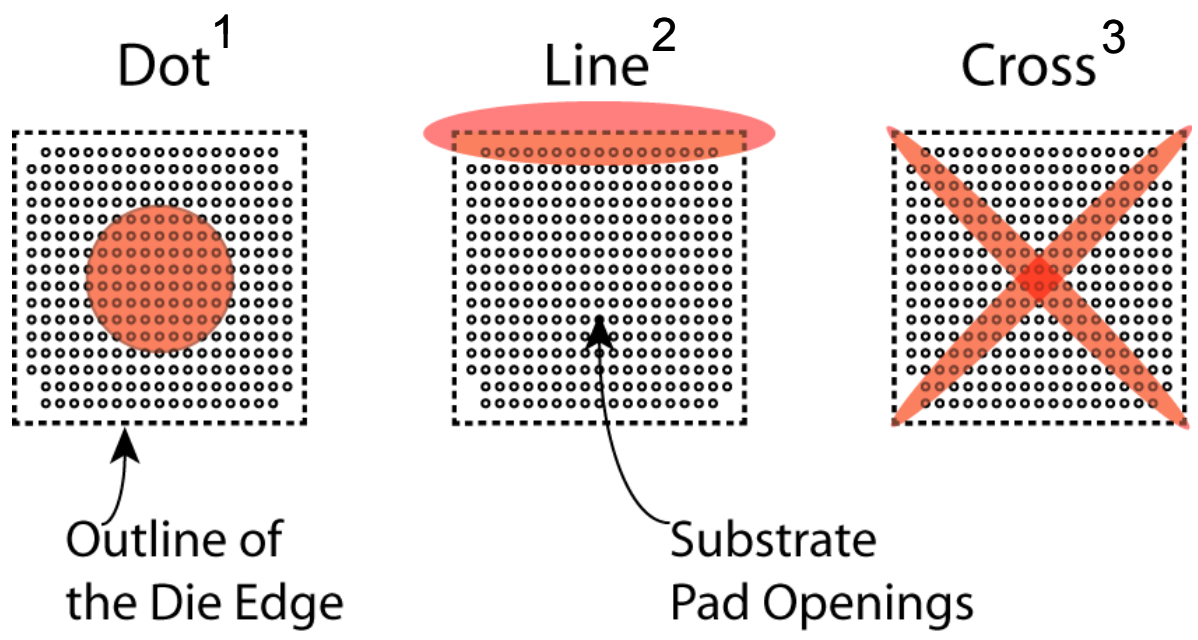

1 - Dot pattern was created using the program in Tables 3-4 and 3-5

2 - Line pattern was created using the program in Tables 3-2 and 3-3

3 - Cross pattern was created using the program in Tables 3-6 and 3-7

Figure 3-12 Dispense Patterns for DOE1

Table 3-8 Placement Experimental Matrix (DOE1)

\begin{tabular}{|c|c|}
\hline \multicolumn{2}{|c|}{ Underfill A, B, C, D, E } \\
\hline Pattern & Speed $(\mathrm{mm} / \mathrm{s})$ \\
\hline dot & 70 \\
\hline dot & 5 \\
\hline line & 70 \\
\hline line & 5 \\
\hline cross & 70 \\
\hline cross & 5 \\
\hline
\end{tabular}


Finally, the boards were scanned using acoustic microscopy (CSAM) to identify voids. The captured images were analyzed with digital image analysis (DIA) software to obtain voiding reported in percentage area. After all the parts were scanned, they were then planar cross sectioned and viewed optically under a microscope to determine if the CSAM image analysis was adequate for data analysis.

\subsection{Design of Experiments \#2, Placement Optimization}

Five different underfill materials were separately evaluated for optimal placement parameters. For each material, a 3 factor full factorial design of experiments (DOE) was conducted with 4 replicates for each treatment. The underfill dispense pattern was included with 2 levels: a dot and a line. The IC placement force was included at 2 levels: $1 \mathrm{~N}$ and $5 \mathrm{~N}$. The placement dwell time was included at 2 levels: no dwell (0.0s) and 0.1s. Flip chip interconnect yield percentage and underfill voiding were the primary metrics. Fillet shape was also inspected. Based on the experimental results, an optimal placement process for each underfill material will be selected. These optimal parameters will then be used in the remaining experiment for the reflow process. It should be noted that the process parameter settings for force and dwell are machine settings and not exact values. However, they are expected to be quite accurate. 
All experiments were performed at the Georgia Institute of Technology, in the Center for Board Assembly Research and the Packaging Research Center. Underfill dispense was conducted with a CAM/ALOT 3700 machine using a 22gauge needle. Please note that initial underfill dispense experimentation was conducted with an Asymtek Millennium M-2010 machine. The Siemens F5 DCA revolver head was used to place all flip chip ICs for this design of experiments. Reflow was accomplished using a BTU Paragon 7-zone reflow oven. The thermal profile for the experiment was developed with a KIC thermal profiling system.

Prior to assembly, all moisture was driven out of the boards with a 3 hour exposure of the boards to an isothermal environment of $125^{\circ} \mathrm{C}$. This bake time was determined from a previous weight loss experiment, and was sufficient to avoid outgassing of the boards during assembly. The boards were stored in a desiccant chamber after bakeout, for no more than 2 hours prior to assembly.

Boards were assembled according to the design matrix shown in Table 39, for each underfill A, B, C, D, and E. Each row of the matrix corresponds to one treatment in the DOE; four replicates were assembled for each treatment without randomization. The target dispense weight was $8 \mathrm{mg}$; actual dispense weight varied between $7.5 \mathrm{mg}$ and $8.5 \mathrm{mg}$. The assemblies were reflowed according to a baseline process determined for each material in preliminary testing. The profiles were determined based on the material suppliers recommendations and were determined to yield $100 \%$ reliably when using both the dot or line pattern with force of $5 \mathrm{~N}$ and 0.5 seconds dwell. 
Table 3-9 DOE2 Experimental Design Matrix

\begin{tabular}{|c|c|c|}
\hline \multicolumn{3}{|c|}{ Underfill A, B, C, D, E } \\
\hline Pattern & Force (N) & Dwell (s) \\
\hline dot & 1 & 0 \\
\hline dot & 1 & 0.1 \\
\hline dot & 5 & 0 \\
\hline dot & 5 & 0.1 \\
\hline line & 1 & 0 \\
\hline line & 1 & 0.1 \\
\hline line & 5 & 0 \\
\hline line & 5 & 0.1 \\
\hline
\end{tabular}

After the boards were assembled according to the parameters in Table $3-9$, electrical continuity tests were performed to determine the percent interconnect yield. Percent interconnect yield is defined as the percent of testable circuits that are found to be within $\pm 10 \%$ of the nominal resistance value; each trace has a different nominal value that was determined by the initial build used to verify the manufacturers recommended profile. The results were analyzed using Minitab statistical software with percent voiding as the response variable. Interconnect yield was tabulated, but was not evaluated statistically because the results did not have enough variation for a statistical analysis to be useful.

The boards were then scanned using acoustic microscopy (CSAM) to identify underfill voids. The captured images were analyzed with digital image analysis (DIA) software to obtain voiding reported in percent of total die area. The results were analyzed using Minitab statistical software with voiding percent area as the response. 


\subsection{Line Placement Study}

After reviewing the results, presented in Chapter 4 , of the dispense pattern experiment and the placement experiment, it is clear that the line pattern of underfill dispense gives voiding results far better than either the dot or the cross pattern. As a response to these results, it was decided to conduct an experiment that further investigates the line pattern.

This experiment investigates the location of the line in relation to the edge of the die and substrate bond site. Only one material, Material A, was selected for evaluation. The results for this material are expected to be qualitatively similar to potential studies with the remaining materials. Builds were completed with TV1, replicates of 2 were assembled for each line position, and the profile used for reflow was the baseline profile for Material A.

Underfill dispense was conducted with a CAM/ALOT 3700 machine using a 22-gauge needle. A line was dispensed along 5 different positions with the target dispense weight of $8 \mathrm{mg}$. Each dispense pattern was programmed by modifying the Y-coordinates of the program displayed in Table 3-2 and 3-3. Positions 1, 3,

and 5 are shown in Figures 3-13, 3-14, and 3-15 respectively. The figures show a cross section of the dispensed line at approximately 2 seconds after the finish of the dispense; because the line keeps spreading for quite some time after this, these figures can be considered snapshots at an instant in time.

After the sites were assembled, electrical continuity tests were performed to determine the percent interconnect yield. The boards were then scanned using acoustic microscopy (CSAM) to identify underfill voids. The captured images 
were analyzed with digital image analysis (DIA) software to obtain voiding reported in percent of total die area.

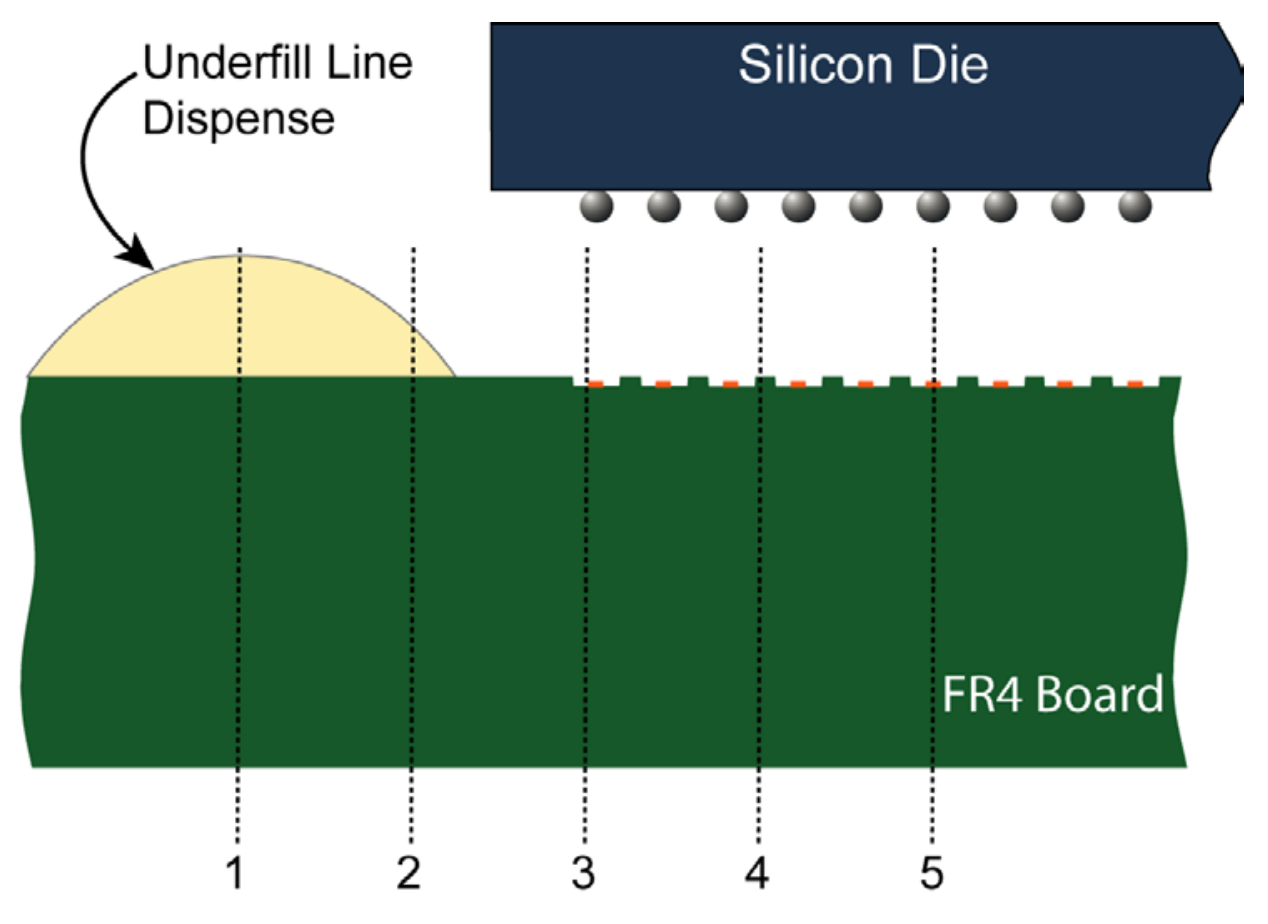

Figure 3-13 Line Dispense Position 1 


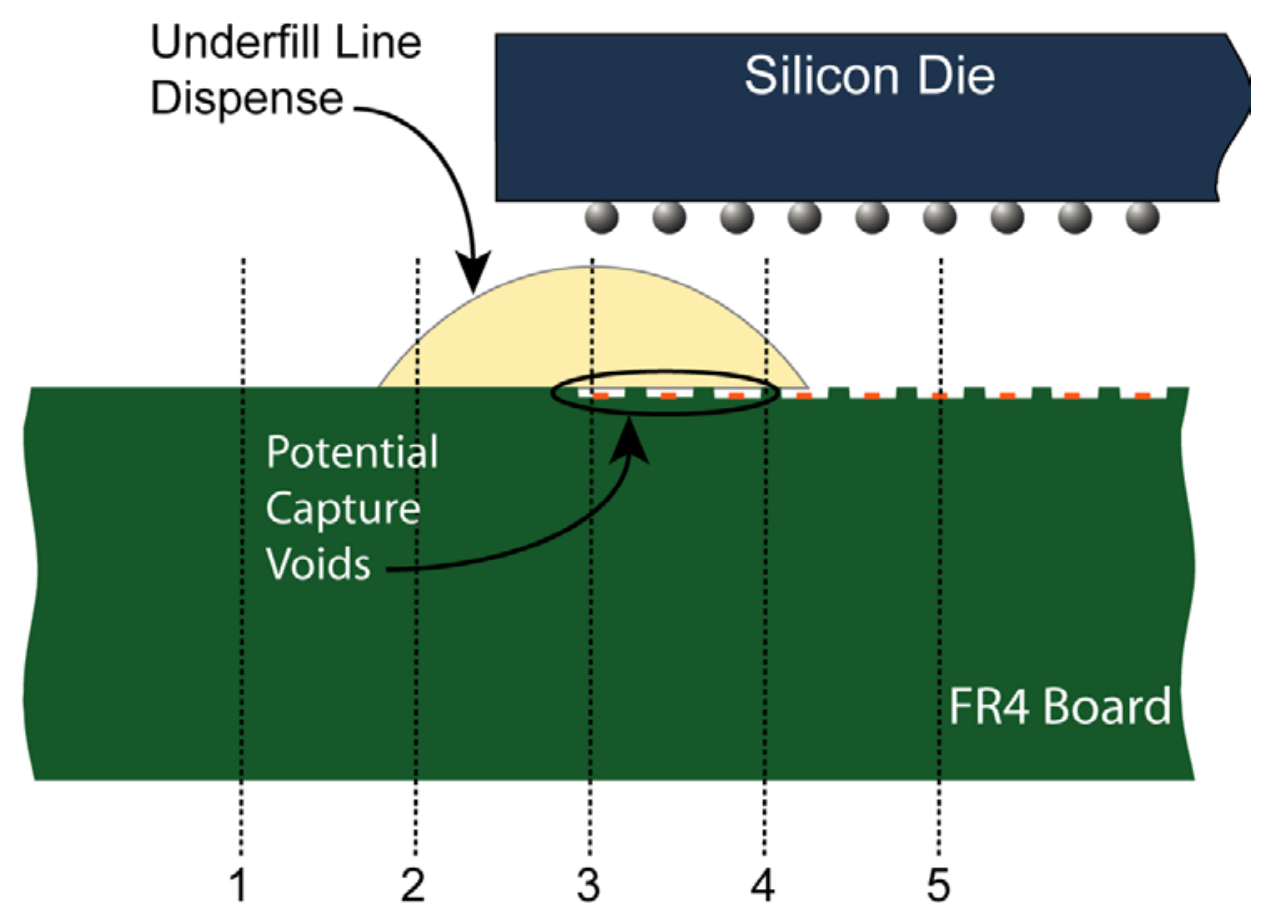

Figure 3-14 Line Dispense Position 3

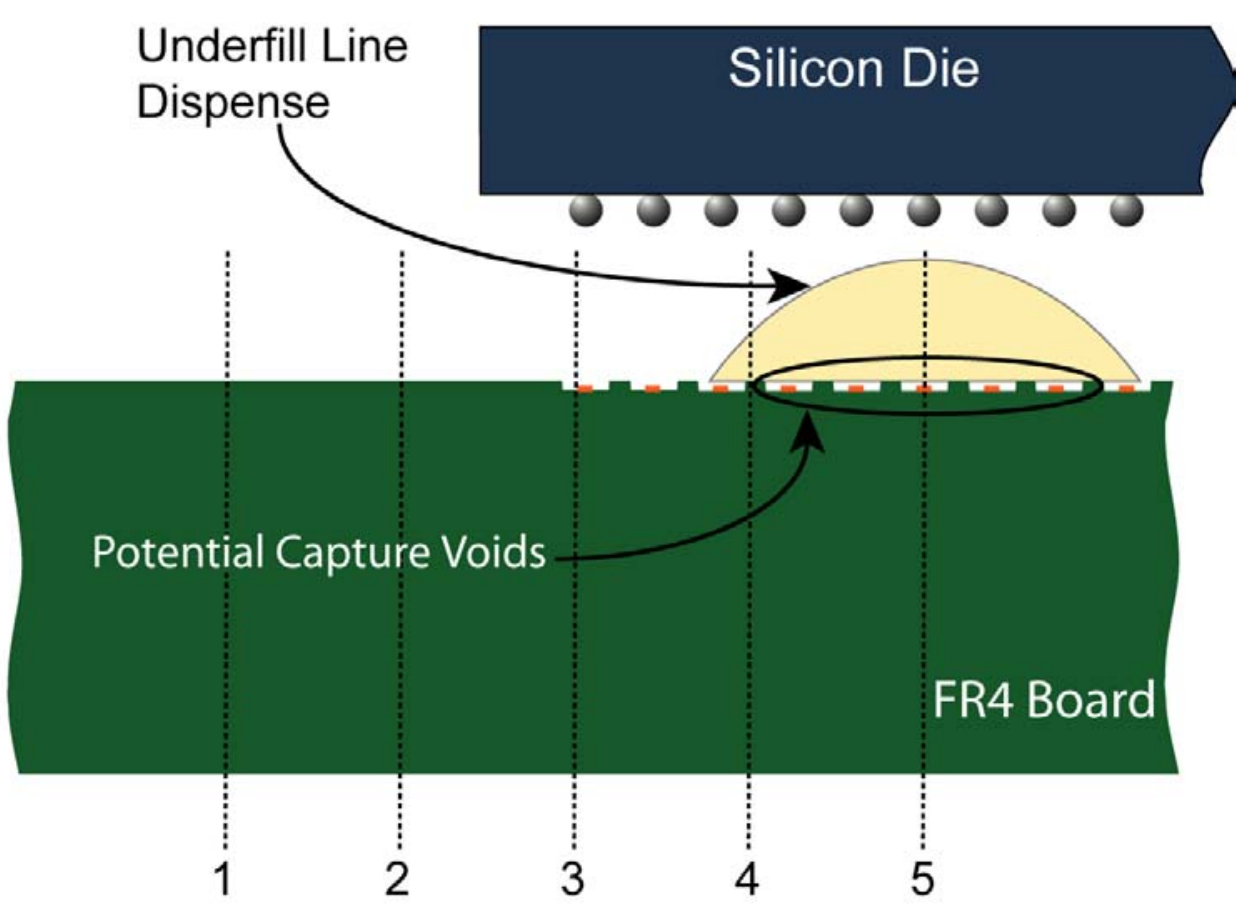

Figure 3-15 Line Dispense Position 5 


\subsection{Parametric Reflow Optimization}

There were two main goals of this experiment, to determine the optimal reflow profile for each material, and to define a reflow process window for each material. The experimental design was chosen to be a parametric study due to limitations on time and materials, as the requirements for a full factorial DOE would have been excessive; a 5 factor, 2 level design would consist of 32 separate profile treatments for each material under test.

A baseline reflow profile was developed for each material based on the manufacturers suggested profile. This profile was validated by placing 4 die and sending the assembly through reflow. The assemblies were then checked for

continuity by resistance measurement. After a baseline profile was established, new profiles were generated by varying each of the profile parameters individually by an amount higher or lower than that of the baseline parameter value, while keeping all other parameters at or near their baseline value.

Note that it is difficult to change one parameter without changing some or all of the other parameters. For instance, a high peak temperature will cause an increase in the time above $183^{\circ} \mathrm{C}$ as a consequence; this results because the oven can not ramp up to a high peak and back down as quickly as it could for a lower temperature excursion. As a response to the parameters acting in this coupled manner, a window of about $\pm 10 \%$ off baseline was adopted for parameters that were supposed to stay as close to baseline as possible. This 
allowed for an adequate variation of the parameter of interest for any particular profile. The implication of this imperfect experimental design is that there may be effects present for a particular profile that are due to the "constant" baseline parameters instead of the parameter of interest; this is unavoidable given the equipment, time, and materials constraints in place for this research.

An example of the various profiles that are created from a baseline step profile using this parametric method is shown in Table 3-10. This variation is illustrated graphically for two parameters (ramp rate, soak temperature) in Figure 3-16.

Table 3-10 Step Profile Parametric Matrix

\begin{tabular}{|l|c|c|c|c|c|}
\hline Profile & $\begin{array}{c}\text { Ramp } \\
\text { Rate }\end{array}$ & $\begin{array}{c}\text { Soak } \\
\text { Temp }\end{array}$ & $\begin{array}{c}\text { Soak } \\
\text { Time }\end{array}$ & $\begin{array}{c}\text { Time Above } \\
183^{\circ} \mathrm{C}\end{array}$ & $\begin{array}{c}\text { Peak } \\
\text { Temp }\end{array}$ \\
\hline Baseline & B & B & B & B & B \\
\hline Ramp Rate + & + & B & B & B & B \\
\hline Ramp Rate - & - & B & B & B & B \\
\hline Soak Temp + & B & + & B & B & B \\
\hline Soak Temp - & B & - & B & B & B \\
\hline Soak Time + & B & B & + & B & B \\
\hline Soak Time - & B & B & - & B & B \\
\hline $\begin{array}{l}\text { Time Above } \\
183^{\circ} \text { C }+\end{array}$ & B & B & B & + & B \\
\hline $\begin{array}{l}\text { Time Above } \\
183^{\circ} \text { C - }\end{array}$ & B & B & B & - & B \\
\hline Peak Temp + & B & B & B & B & + \\
\hline Peak Temp - & B & B & B & B & - \\
\hline
\end{tabular}

${ }^{*}(+)$ and $(-)$ values are $10-20 \%$ off baseline values ${ }^{*} \mathrm{~B}=$ baseline parameter value 


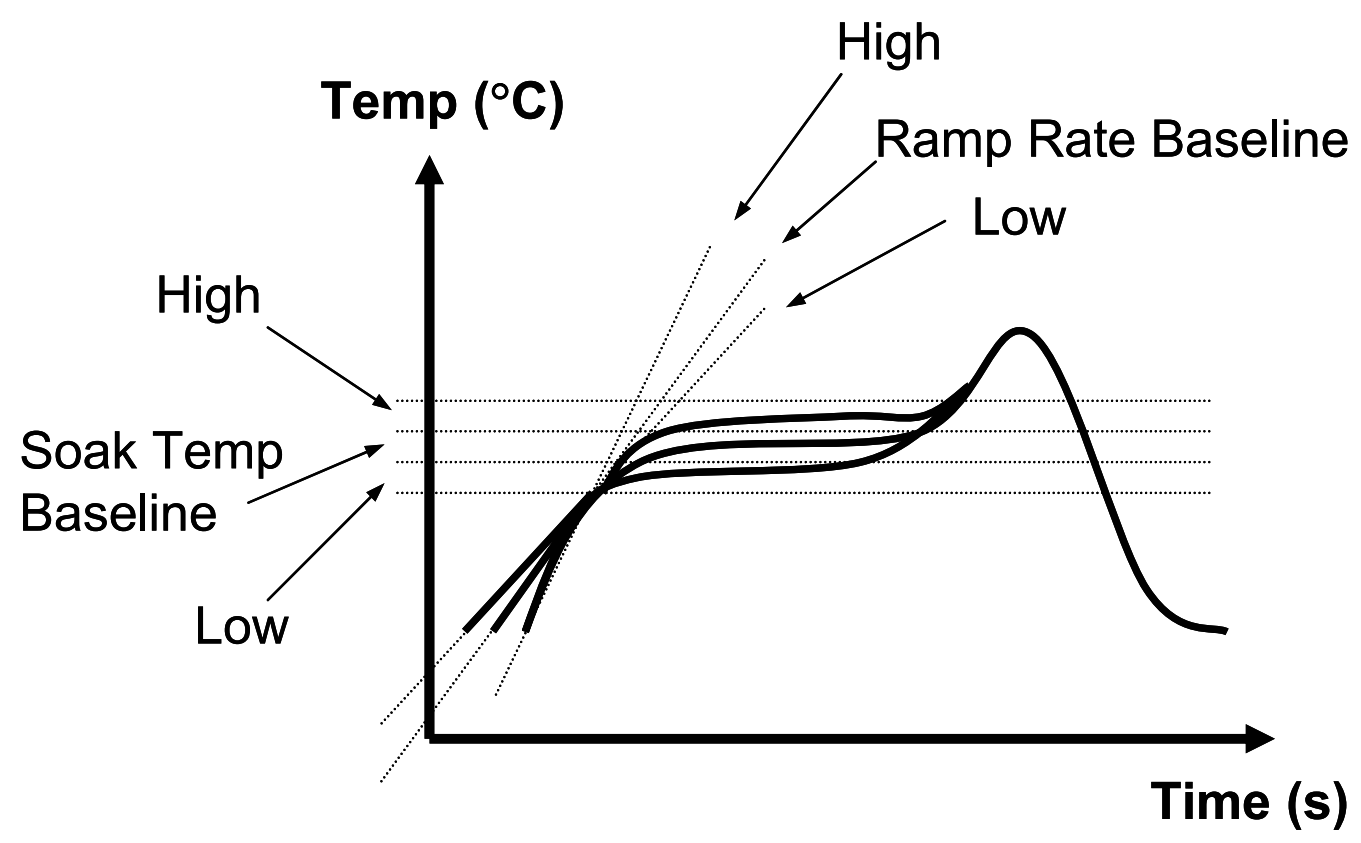

Figure 3-16 Variation of Profile Parameters off Baseline

\subsubsection{Reflow Profile Development}

All reflow profiling was performed utilizing the KIC 2000 thermal profiling system on a BTU Paragon 98 forced convection 7-zone reflow oven.

Thermocouples were attached to a populated test vehicle with Kapton® thermal tape as depicted in Figure 3-17. One thermocouple junction was positioned next to the die against the underfill fillet, therefore measuring close to the actual temperature that the solder joints experience during reflow. A second thermocouple was positioned with the junction location of 1 inch in front of the edge, and 1 inch above the surface of the test vehicle; this thermocouple served as an air reference temperature, which allowed the $\mathrm{KIC}$ software to calculate improved oven setpoints for a desired profile. Omega Engineering, K-type, 
thermocouples were used throughout all experimentation and they are accurate to +2.2 or $-2.2^{\circ} \mathrm{C}$.

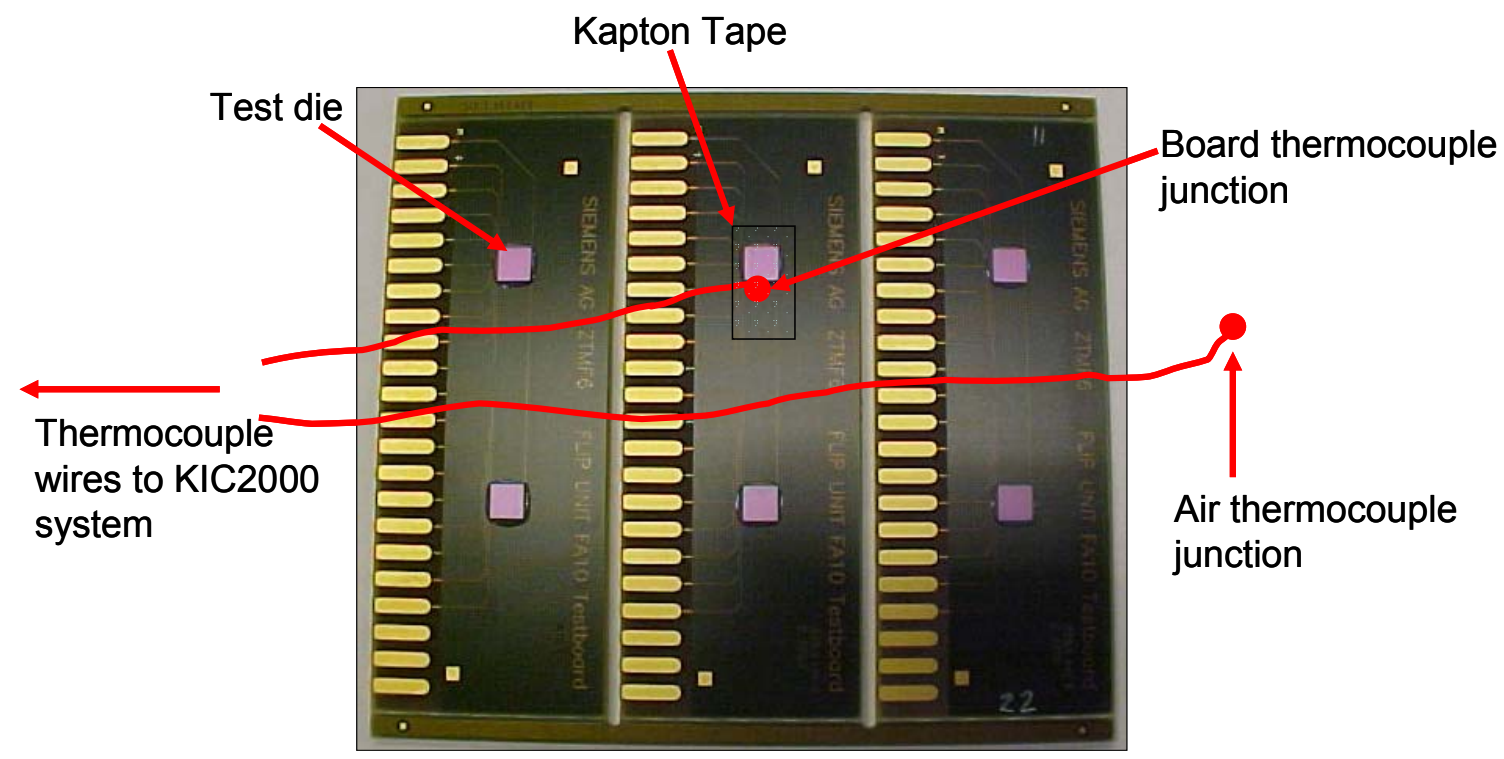

Figure 3-17 Thermocouple Wiring for Reflow Profiling

The BTU International Paragon 98 reflow oven has seven programmable zones, inert nitrogen environment capability to $2 \mathrm{ppm}$ Oxygen, temperature uniformity to $+/-2^{\circ} \mathrm{C}$, and adjustable conveyor speed of $10-60$ inches $/$ min, as stated by the manufacturer specifications. The heated length of the oven is 98 inches, and the cooling length is 28 inches. 


\subsubsection{Material A Reflow Profiles}

The reflow profile characterization for Material A used a step type profile (Figure 3-10) as the basis for investigation. The defining parameters for the 12 profiles used for experimentation are presented in Table 3-11, and a plot of the Baseline profile is presented in Figure 3-18. Full details for these profiles including plots, parameter values, and oven setpoints can be found in Appendix A. Replicates of 4 die were assembled for each profile, and these assemblies were analyzed for underfill voiding, resistance, and phase ratio.

Table 3-11 Material A, Reflow Parameter Values

\begin{tabular}{l|c|c|c|c|c}
\multicolumn{1}{c|}{ Profile } & $\begin{array}{c}\text { Ramp Rate } \\
\left({ }^{\circ} \mathrm{C} / \mathrm{s}\right)\end{array}$ & $\begin{array}{c}\text { Soak Temp } \\
\left({ }^{\circ} \mathrm{C}\right)\end{array}$ & $\begin{array}{c}\text { Soak Time } \\
(\mathrm{s})\end{array}$ & $\begin{array}{c}\text { Time above } 183{ }^{\circ} \mathrm{C} \\
(\mathrm{s})\end{array}$ & $\begin{array}{c}\text { Peak Temp } \\
\left({ }^{\circ} \mathrm{C}\right)\end{array}$ \\
\hline \hline Baseline & 2 & 150 & 119.7 & 60.9 & 220.1 \\
Soak Temp High & 2 & 165 & 115.8 & 62 & 218 \\
Soak Temp Low & 2.2 & 130 & 118.2 & 62.7 & 220.6 \\
Soak Time High & 2.1 & 150 & 148.8 & 64.9 & 221.5 \\
Soak Time Low & 2.1 & 150 & 100.6 & 61.4 & 216.6 \\
Time Above 183 oC High & 2 & 150 & 119.2 & 80.4 & 218.9 \\
Time Above 183 oC Low & 2.1 & 150 & 113.6 & 49.3 & 214.2 \\
Peak Temp High & 2 & 150 & 114.9 & 64.2 & 232.8 \\
Peak Temp Low & 1.9 & 150 & 121.5 & 64.3 & 211 \\
Ramp Rate High & 2.5 & 150 & 125.1 & 62.6 & 217.3 \\
Ramp Rate Low & 2 & 150 & 127.3 & 60.7 & 218.3 \\
Parametric Optimization & 2 & 140 & 153.6 & 68.7 & 219.2
\end{tabular}




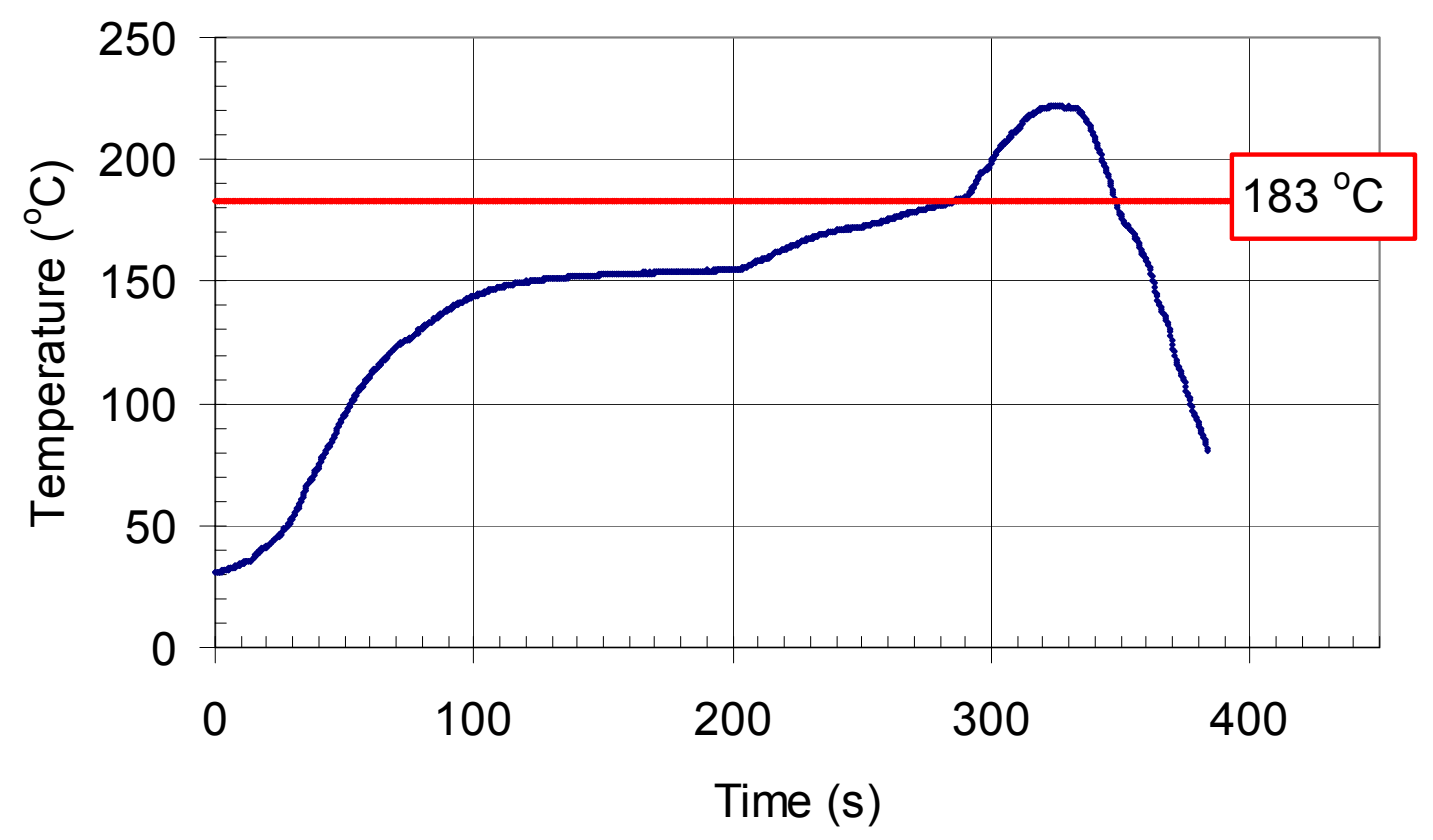

Figure 3-18 Material A, Baseline Reflow Profile

\subsubsection{Material B Reflow Profiles}

The reflow profile characterization for Material B used a ramp type profile (Figure 3-11) as the basis for investigation. The defining parameters for the 9 profiles used for experimentation are presented in Table 3-12, and a plot of the Baseline profile is presented in Figure 3-19. Full details for these profiles including plots, parameter values, and oven setpoints can be found in Appendix A. Replicates of 4 die were assembled for each profile, and these assemblies were analyzed for underfill voiding, resistance, and phase ratio. 
Table 3-12 Material B, Reflow Profile Parameter Values

\begin{tabular}{l|c|c|c|c}
\multicolumn{1}{c|}{ Profile } & $\begin{array}{c}\text { Ramp Rate } \\
\left({ }^{\circ} \mathrm{C} / \mathrm{s}\right)\end{array}$ & $\begin{array}{c}\text { Time Above } 183{ }^{\circ} \mathrm{C} \\
(\mathrm{s})\end{array}$ & $\begin{array}{c}\text { Peak Temperature } \\
\left({ }^{\circ} \mathrm{C}\right)\end{array}$ & $\begin{array}{c}\text { Time to Peak Temperature } \\
(\mathrm{s})\end{array}$ \\
\hline \hline Time to peak high & 1.2 & 87.9 & 229.7 & 245.3 \\
Time to peak low & 1.4 & 82.9 & 232.8 & 195.3 \\
Time Above $183^{\circ} \mathrm{C}$ High & 1.2 & 120 & 229 & 261.7 \\
Time Above $183^{\circ} \mathrm{C}$ Low & 1.2 & 73.7 & 228 & 213 \\
Peak Temp High & 1.2 & 88.1 & 225.7 & 221.3 \\
Peak Temp Low & 1.2 & 91.3 & 229.9 & 232 \\
Ramp Rate High & 1.4 & 94 & 229.7 & 252 \\
Ramp Rate Low & 1.1 & 92.4 & 220.6 & 277.7
\end{tabular}

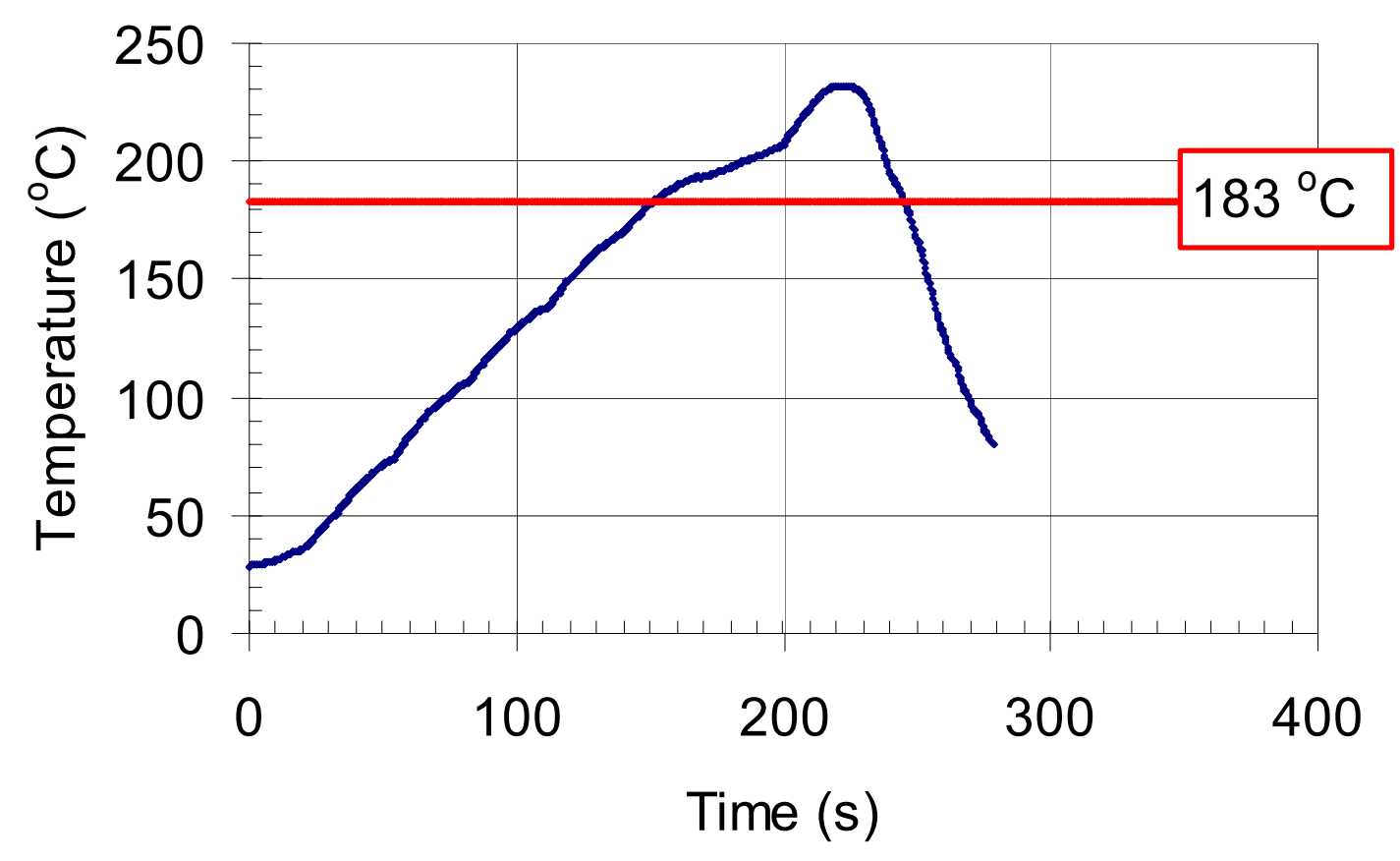

Figure 3-19 Material B, Baseline Reflow Profile

\subsubsection{Material C Reflow Profiles}

The reflow profile characterization for Material C used a step type profile (Figure 3-10) as the basis for investigation. The defining parameters for the 12 profiles used for experimentation are presented in Table 3-13, and a plot of the Baseline profile is presented in Figure 3-20. Full details for these profiles 
including plots, parameter values, and oven setpoints can be found in Appendix A. Replicates of 4 die were assembled for each profile, and these assemblies were analyzed for underfill voiding, resistance, and phase ratio.

Table 3-13 Material C, Reflow Profile Parameter Values

\begin{tabular}{l|c|c|c|c|c}
\multicolumn{1}{c|}{ Profile } & $\begin{array}{c}\text { Ramp Rate } \\
\left({ }^{\circ} \mathrm{C} / \mathrm{s}\right)\end{array}$ & $\begin{array}{c}\text { Soak Temp } \\
\left({ }^{\circ} \mathrm{C}\right)\end{array}$ & $\begin{array}{c}\text { Soak Time } \\
(\mathrm{s})\end{array}$ & $\begin{array}{c}\text { Time above } 183^{\circ} \mathrm{C} \\
(\mathrm{s})\end{array}$ & $\begin{array}{c}\text { Peak Temp } \\
\left({ }^{\circ} \mathrm{C}\right)\end{array}$ \\
\hline \hline Baseline & 2 & 140 & 42.2 & 99.2 & 226 \\
Soak Temp High & 2.1 & 140 & 43 & 98.4 & 227.3 \\
Soak Temp Low & 2 & 140 & 41.3 & 94.6 & 228.8 \\
Soak Time High & 2.1 & 140 & 63.2 & 104.7 & 226.2 \\
Soak Time Low & 2 & 140 & 29.1 & 98.7 & 228.4 \\
Time Above 183 oC High & 1.9 & 140 & 45.3 & 125.6 & 229 \\
Time Above 183 oC Low & 2.2 & 140 & 35.6 & 90.5 & 228 \\
Peak Temp High & 2 & 140 & 43.6 & 102.4 & 236 \\
Peak Temp Low & 1.9 & 140 & 40.6 & 96.5 & 218.1 \\
Ramp Rate High & 2.5 & 140 & 51.5 & 97 & 229.6 \\
Ramp Rate Low & 1.5 & 140 & 41.1 & 103.3 & 231.6 \\
Parametric Optimization & 1.5 & 140 & 55.7 & 122.3 & 233.2
\end{tabular}

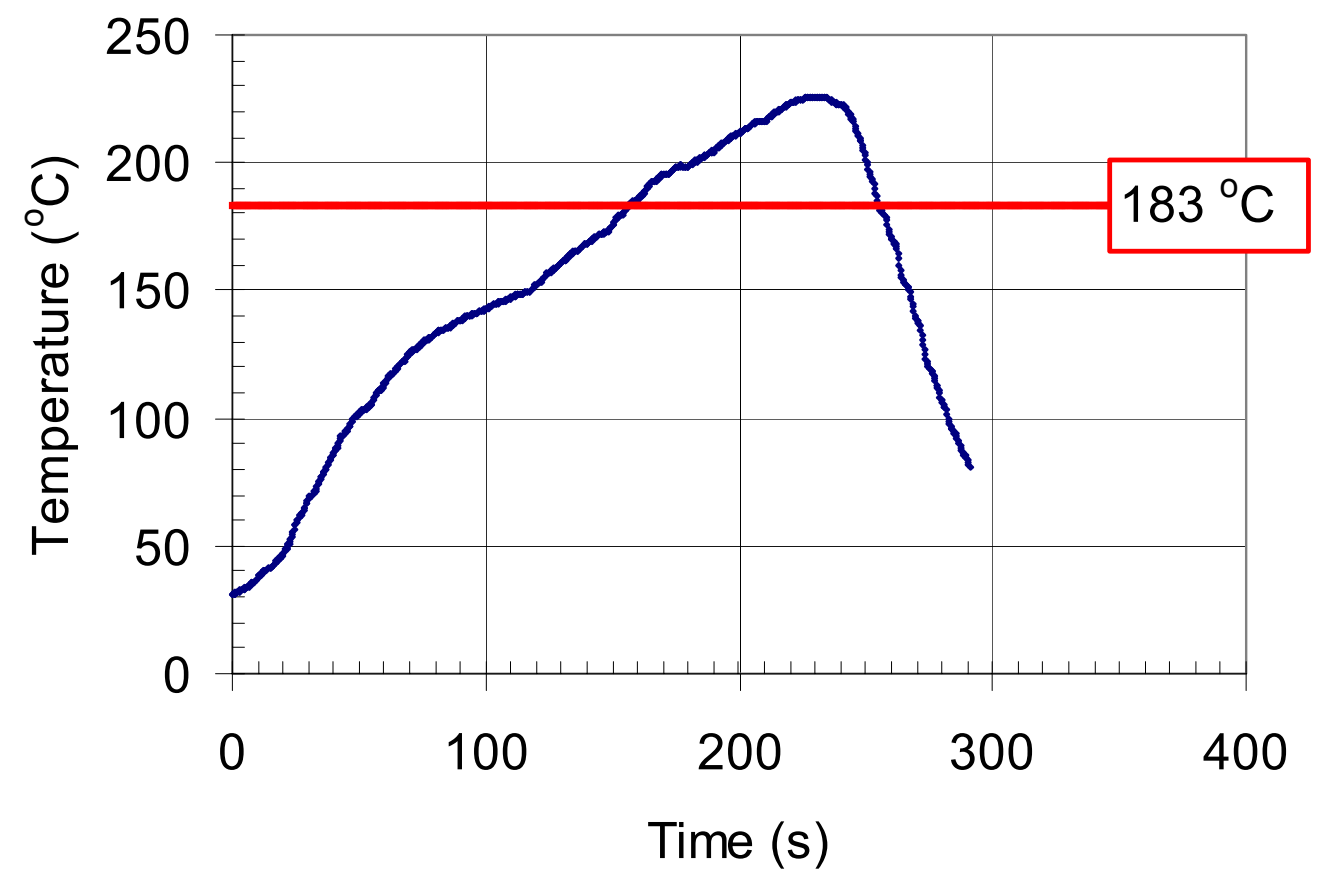

Figure 3-20 Material C, Baseline Reflow Profile 


\subsubsection{Material E Reflow Profiles}

The reflow profile characterization for Material E used a ramp type profile (Figure 3-11) as the basis for investigation. The defining parameters for the 10 profiles used for experimentation are presented in Table 3-14, and a plot of the Baseline profile is presented in Figure 3-21. Full details for these profiles including plots, parameter values, and oven setpoints can be found in Appendix A. Replicates of 4 die were assembled for each profile, and these assemblies were analyzed for underfill voiding, resistance, and phase ratio.

Table 3-14 Material E, Reflow Profile Parameter Values

\begin{tabular}{l|c|c|c|c|c}
\multicolumn{1}{c|}{ Profile } & $\begin{array}{c}\text { Ramp Rate } \\
\left({ }^{\circ} \mathrm{C} / \mathrm{s}\right)\end{array}$ & $\begin{array}{c}\text { Soak Temp } \\
\left({ }^{\circ} \mathrm{C}\right)\end{array}$ & $\begin{array}{c}\text { Soak Time } \\
(\mathrm{s})\end{array}$ & $\begin{array}{c}\text { Time above } 183{ }^{\circ} \mathrm{C} \\
(\mathrm{s})\end{array}$ & $\begin{array}{c}\text { Peak Temp } \\
\left({ }^{\circ} \mathrm{C}\right)\end{array}$ \\
\hline \hline Baseline & 1.8 & 165 & 71.5 & 67.2 & 225.2 \\
Soak Time High & 1.8 & 165 & 85.1 & 71.2 & 226.2 \\
Soak Time Low & 1.8 & 165 & 56.1 & 67.3 & 224.7 \\
Time Above $183{ }^{\circ} \mathrm{C}$ High & 1.8 & 165 & 70 & 89.3 & 224.9 \\
Time Above $183{ }^{\circ} \mathrm{C}$ Low & 1.8 & 165 & 65.7 & 62.9 & 222.4 \\
Peak Temp High & 1.8 & 165 & 67.7 & 72 & 228.5 \\
Peak Temp Low & 1.8 & 165 & 70.2 & 69.5 & 215.8 \\
Ramp Rate High & 2 & 165 & 67.7 & 71.9 & 223.8 \\
Ramp Rate Low & 1.6 & 165 & 69.3 & 72.3 & 223.7 \\
Parametric Optimization & 1.5 & 165 & 83.2 & 87.7 & 228.9
\end{tabular}




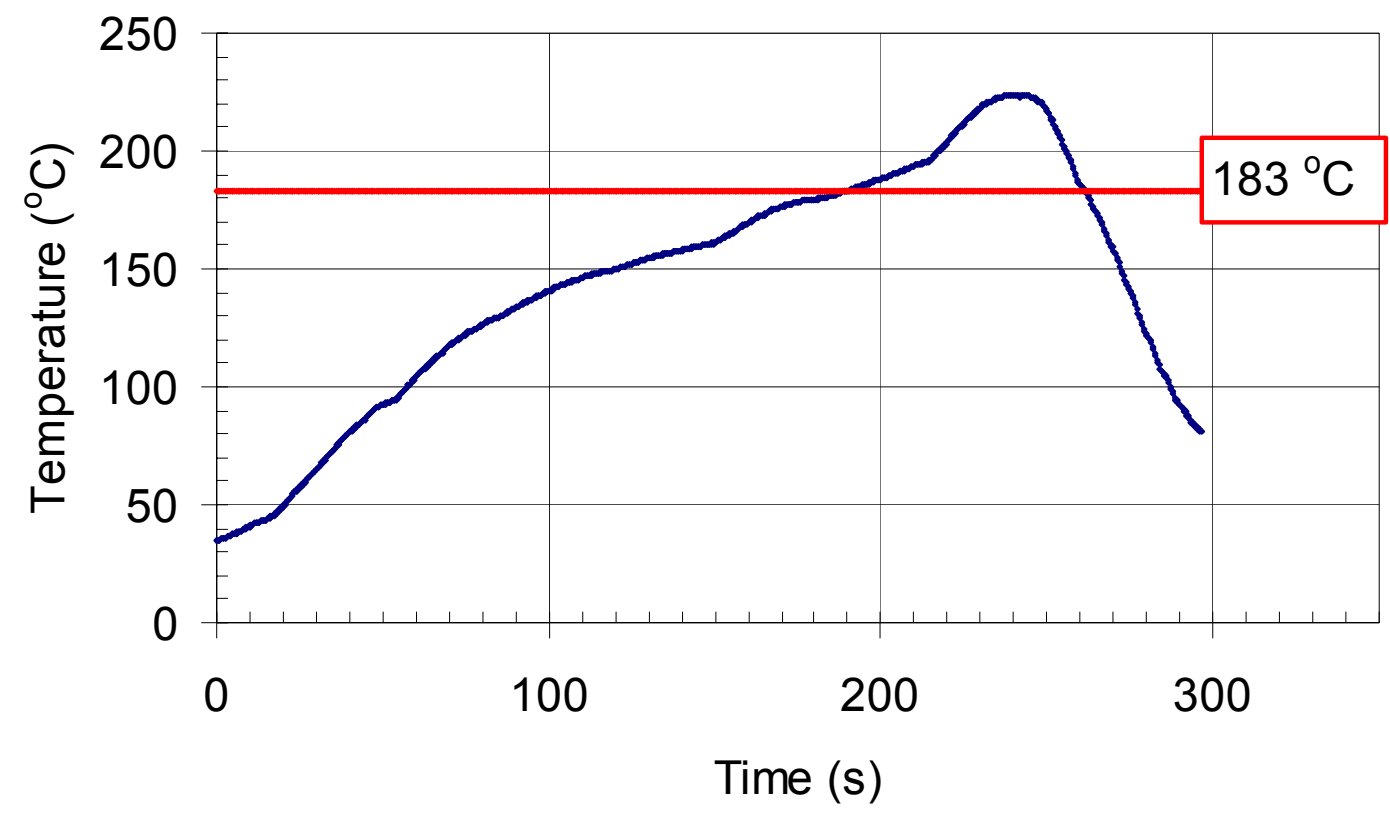

Figure 3-21 Material E, Baseline Reflow Profile 


\subsubsection{Grain Size Determination Method}

The cross sectional microstructure of a two phase solder alloy, when viewed by electron microscopy, shows a light phase surrounded by a dark colored eutectic matrix, as shown in Figure 3-22. There are many methods for estimating grain size of a two phase alloy, including area fraction, lineal fraction, and the point count method [Smallman, 1999]. For these experiments, the point count method was employed.

A regular grid of points is laid over the field of interest, then all the points are counted for which the grid intersections coincide with the light colored high lead phase $(P)$, see Figure 3-23. The total number of points in the region is then calculated $\left(P_{T}\right)$. Finally, a ratio is created to give a point count fraction $P_{P}$. Shown in Equation 3-1. The accuracy of this method is dependent on the choice of the

$$
P_{P}=\frac{P}{P_{T}}=\frac{13}{49}=0.27
$$

grid size used for the analysis. The size of the grid for this analysis was chosen to limit the error to about $10 \%$ from the true area fraction. This means that the grid in Figure 3-23 is not drawn to scale. For the analysis, the grid actually is a much finer mesh than what appears in the Figure. 


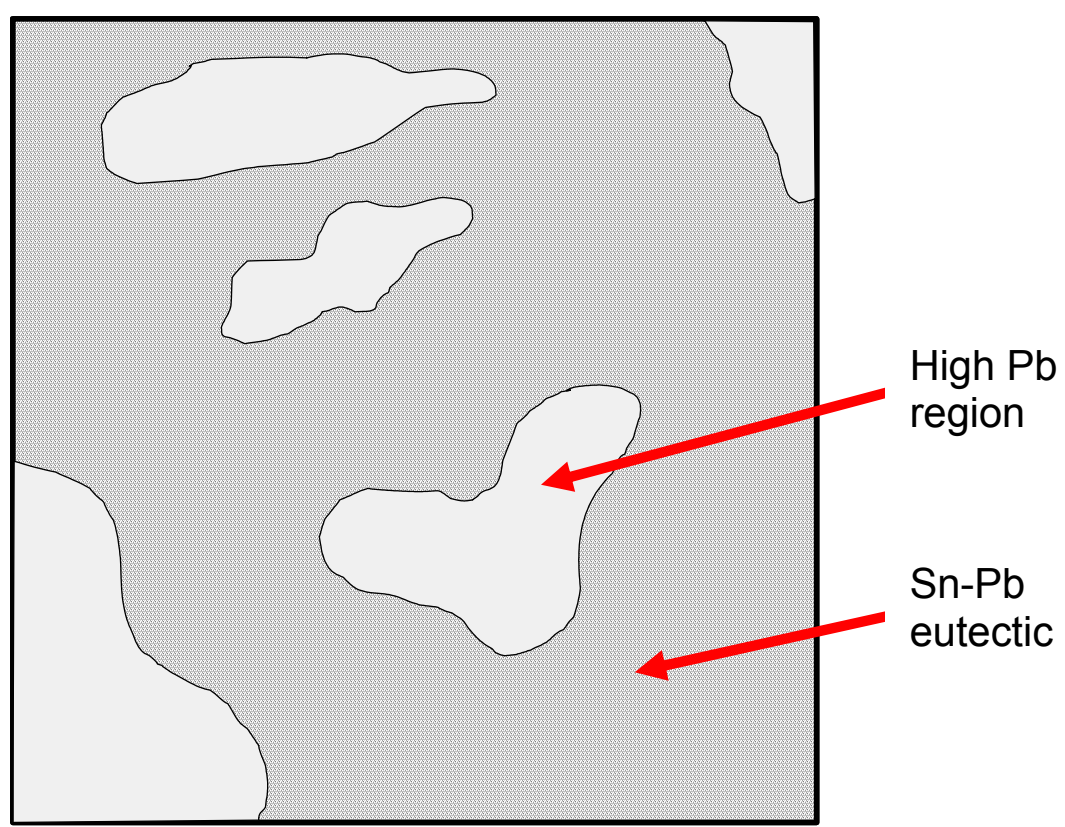

Figure 3-22 Representation of Typical Two Phase Solder Alloy, Solid Lighter Areas Show Lead, Darker Surrounding Matrix is Eutectic ( $\mathrm{Sn}-\mathrm{Pb})$

For this experimental work, the assemblies from each reflow profile were cross-sectioned and polished to expose the solder joints for analysis. Scanning Electron Microscopy was used to create digital images of the exposed solder joints. For each reflow profile, four solder bumps were analyzed using the point count method to determine the relative concentration of high lead regions. This grain ratio data was then incorporated into the reflow profile rankings. 


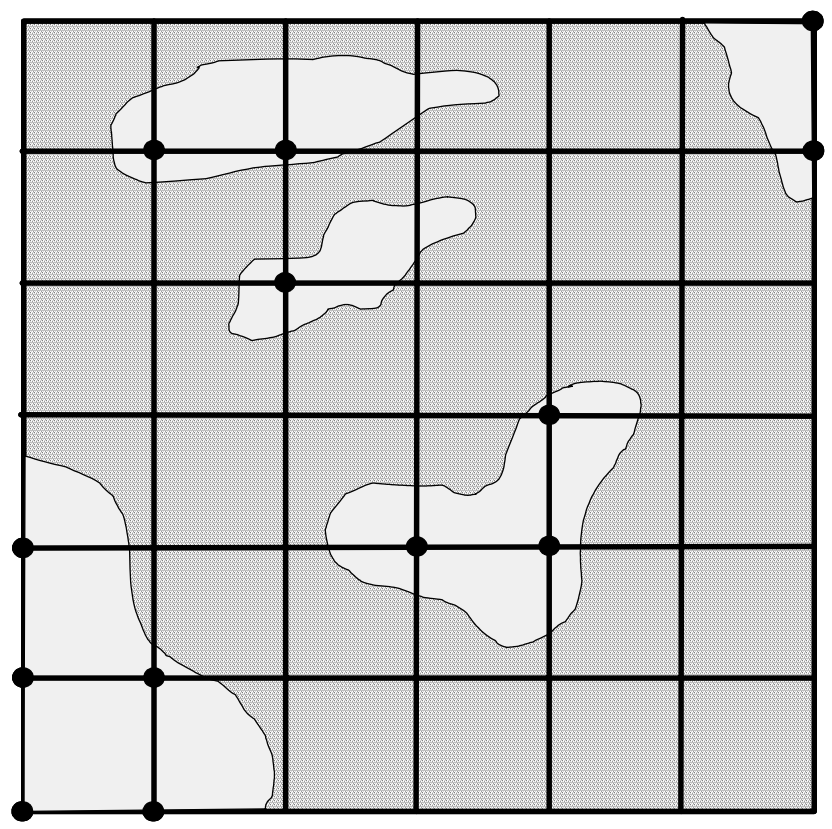

Figure 3-23 Point Count Method, Relates Point Count Fraction to Volume Fraction

\subsection{0 $\underline{\text { C-Mode Scanning Acoustic Microscopy (C-SAM®) }}$}

Scanning acoustic microscopy is capable of viewing cracks or delamination on the die/underfill interface as well as the underfill/board interface. A transducer above the sample emits ultrasound and then receives the return echoes. The return signal is gated/filtered to select an image at the desired depth within the sample. The CSAM set-up parameters used during experimentation are detailed in Table 3-15. 
Table 3-15 CSAM set-up parameters

\begin{tabular}{c|c} 
Parameter & Setting \\
\hline \hline Trigger & 0.715 \\
\hline Frequency & $100 \mathrm{MHz}$ \\
\hline Focal Length & $0.50 "$ \\
\hline Delay & 19.418 \\
\hline Amplitude & $47.5 \mathrm{~dB}$
\end{tabular}

\subsection{Final Build}

After analyzing the data from each of the process experiments, an optimal process was selected for each material. This process was then used to create assemblies for final reliability testing. A summary of the final build is presented in Table 3-16.

Note: Material $D$ was removed from testing before the final build due to poor performance in DOE1 and DOE2. Based on the results presented in Chapter 4, the Line pattern was selected to be used for all final build assemblies in Table 3-16. The reflow process parameters for the profiles presented in Table 3-16 can be found in Tables 3-11 through 3-14. 
Table 3-16 Final Build Assembly Matrix

\begin{tabular}{|c|c|c|c|c|c|c|}
\hline \multicolumn{7}{|c|}{ FINAL BUILD ASSEMBLY PARAMETERS } \\
\hline $\begin{array}{c}\text { ASSEMBLY } \\
\text { TYPE }\end{array}$ & UNDERFILL & $\begin{array}{c}\text { UNDERFILL } \\
\text { MASS (mg) }\end{array}$ & $\begin{array}{c}\text { FORCE } \\
\text { (N) }\end{array}$ & $\begin{array}{c}\text { DWELL } \\
\text { TIME (s) }\end{array}$ & $\begin{array}{c}\text { REFLOW } \\
\text { PROFILE }\end{array}$ & $\begin{array}{c}\text { ASSEMBLED } \\
\text { DIE }\end{array}$ \\
\hline \hline $\begin{array}{c}\text { TV1 } \\
\text { FA10-2 Ni-Au }\end{array}$ & A & $8.0 \pm .5$ & 5 & 0 & $\begin{array}{c}\text { Soak Time } \\
\text { High }\end{array}$ & 60 \\
\hline $\begin{array}{c}\text { TV1 } \\
\text { FA10-2 Ni-Au }\end{array}$ & B & $8.0 \pm .5$ & 5 & 0 & $\begin{array}{c}\text { Parametric } \\
\text { Optimized }\end{array}$ & 60 \\
\hline $\begin{array}{c}\text { TV1 } \\
\text { FA10-2 Ni-Au }\end{array}$ & C & $8.0 \pm .5$ & 5 & 0 & $\begin{array}{c}\text { Soak Temp } \\
\text { High }\end{array}$ & 60 \\
\hline $\begin{array}{c}\text { TV1 } \\
\text { FA10-2 Ni-Au }\end{array}$ & E & $8.0 \pm .5$ & 5 & 0 & $\begin{array}{c}\text { Parametric } \\
\text { Optimized }\end{array}$ & 60 \\
\hline
\end{tabular}

\subsection{Accelerated Life Testing}

Two standard reliability tests were employed to evaluate the underfill materials and the unique process developed for each material. The tests and testing parameters are displayed in Table 3-17. Note: Material D was removed from testing before the final build due to poor performance in DOE1 and DOE2.

Table 3-17 Reliability Testing Parameters

\begin{tabular}{c|c|c|c} 
Reliability Test & Industry Standard & Test Conditions & Cycle Time \\
\hline $\begin{array}{c}\text { Air to Air Thermal } \\
\text { Cycling }\end{array}$ & JESD22-A104-B & $-40^{\circ} \mathrm{C}$ to $125^{\circ} \mathrm{C}$ & 24 min \\
\hline Autoclave & JESD22-A102-C & $121^{\circ} \mathrm{C}, 2 \mathrm{~atm}$ & $\begin{array}{c}96 \text { hours total } \\
\text { test time }\end{array}$
\end{tabular}




\subsubsection{Air to Air Thermal Cycling (AATC)}

An ESPEC brand cycling machine was used to subject the test vehicles to air to air thermal cycling. The ESPEC Control System has two air chambers that can be set to different cycling temperatures. The chambers were set at $-40{ }^{\circ} \mathrm{C}$ and $125^{\circ} \mathrm{C}$. An air to air cycle consisted of a 12 minute dwell in each of the chambers. Typically, substrates were subjected to 200 consecutive cycles and then removed for electrical probing and visual inspection. CSAM analysis was completed approximately every 400 cycles. A total of 30 replicates were tested for each of the four final underfill materials: $A, B, C$, and $E$.

\subsubsection{Autoclave}

An ESPEC brand Autoclave was used to subject the test vehicles to a high pressure and high humidity environment. The machine has one chamber that can be programmed to hold a specific temperature and humidity for a specified time period. The chamber was set at $121^{\circ} \mathrm{C}$ and 2 atm at $100 \%$ humidity (noncondensing). The full duration of the test is 96 hours, but all test assemblies were removed every 24 hours for electrical probing and CSAM analysis. A total of 30 replicates were tested for each of the four final underfill materials: A, B, C, and E. 


\section{CHAPTER IV: RESULTS \& DISCUSSION}

The primary goal of this thesis research was to develop optimal processing parameters for five commercially available no-flow underfills. The results of the experiments outlined in Chapter 3 will be detailed and discussed in this chapter. The outline of these experimental results is:

- DOE \#1, the data collection and statistical results are presented.

- DOE \#2, the data collection and statistical results are presented.

- The results of the Line Placement Study are presented.

- The results of the parametric reflow study are presented, including the process window and optimal profile for each material.

- The results of the Air-Air thermal cycling tests are presented.

- The Autoclave (high humidity and high pressure) test results are also presented.

\subsection{Results: Design of Experiments \# 1}

Digital image analysis (DIA) software that comes bundled with the

Sonoscan machine was utilized to perform voiding analysis for all materials. This decision was made after comparing some CSAM images to the cross sectioned images and verifying that sonoscan and DIA software analysis could produce equivalent response data for analysis. The software output gives the percentage by area that is occupied by the projection of the voids onto a cross-sectional plane through the underfill layer; the projection plane is parallel to the plane of 
the die or the board. Therefore the voiding response for all materials is presented in percent area. Percent area voiding is defined as displayed in Equation (4.1). Note also, that the remaining voiding analysis for any subsequent experimental work is presented in percent area as well.

$$
\text { Percent area voiding }=\left(\frac{\text { Area of voids }}{\text { Area of Die }}\right) \cdot 100
$$

The following sections present the statistical analysis for each underfill, performed using Minitab ${ }^{\mathrm{TM}}$ 13.32. The Analysis of Variance (ANOVA) technique is used to analyze the data; the idea behind this technique is to compare the treatment means of the experimental design to test the hypothesis that they are all equal. This hypothesis test involves the F-Ratio, which is a ratio of mean squares. The test also results in a p-value for each factor which is simply the probability that the mean responses of the individual levels for that factor are all equal. Therefore, a low $p$-value for a particular factor, means that the factor has a statistically significant effect on the response metric. A more detailed look at the data is necessary to determine the magnitude and the exact nature of the effect. It should be noted that a low p-value does not signify a large difference in mean response between the levels of a particular factor. The $p$-value is a measure of the statistical significance of an effect, rather than the magnitude of the effect.

The ANOVA tables presented in the rest of this chapter also contain the degrees of freedom (DF), the Sequential Sum of Squares (Seq SS), the Adjusted 
Sum of Squares (Adj SS), the Adjusted Mean Squares (Adj MS). These terms are explained along with the full theory behind the ANOVA technique in any text dealing with Design of Experiments and many Statistics texts also [Box 1978].

\subsubsection{Material A Results}

Material A shows a minimum voiding response when using a line dispense pattern, with the factor level mean of only 0.01 percent area voiding. The Dot and Cross dispense patterns resulted in extensive voiding with factor level means of 1.82 and 1.87 percent area voiding respectively.

Speed is a factor at 0.10 significance level, with $5 \mathrm{~mm} / \mathrm{s}$ yielding a mean response of 1.11 percent area voiding, and $70 \mathrm{~mm} / \mathrm{s}$ resulting in a mean response of 1.35 percent area voiding. The p-value of 0.069 is a borderline result, indicating that Speed might be a statistically significant factor influencing voiding.

The full ANOVA results for Material A are displayed in Table 4-1. The main effects and interactions plots are shown in Figures 4-1 and 4-2 respectively. 
Table 4-1 Material A, ANOVA Results for DOE1

\begin{tabular}{c|c|c|c|c|c|c} 
Source & DF & \multicolumn{1}{c}{ Seq SS } & Adj SS & Adj MS & \multicolumn{2}{c}{ F Ratio P-Value } \\
\hline speed & 1 & 0.36 & 0.36 & 0.36 & 3.75 & 0.069 \\
\hline pattern & 2 & 18.01 & 18.01 & 9.00 & 93.16 & $<.001$ \\
\hline speed*pattern $^{*}$ & 2 & 0.20 & 0.20 & 0.10 & 1.01 & 0.383 \\
\hline Error & 18 & 1.74 & 1.74 & 0.10 & & \\
\hline Total & 23 & 20.31 & & & &
\end{tabular}

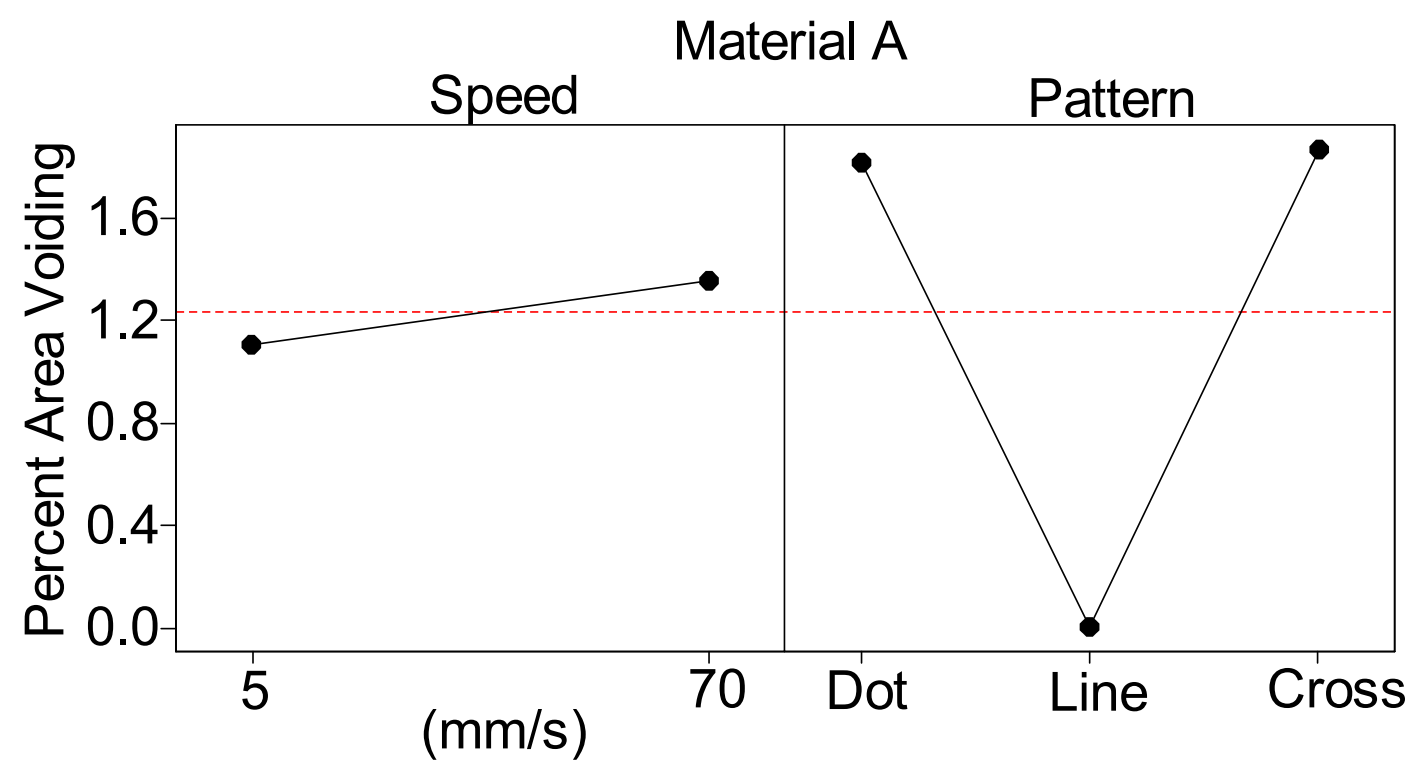

Figure 4-1 Material A, Main Effects Plots for DOE1 


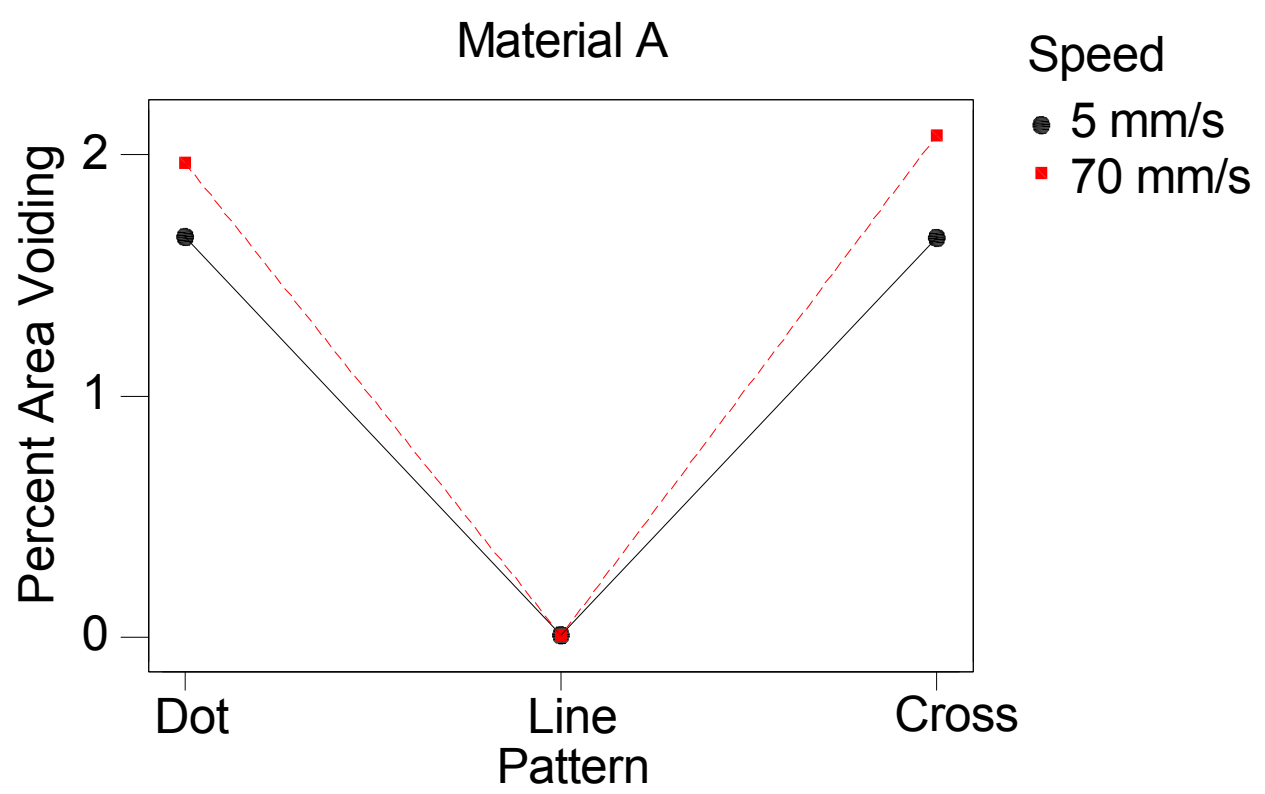

Figure 4-2 Material A, Interaction Effects Plot for DOE1

\subsubsection{Material B Results}

Material B shows a minimum voiding response when using a line dispense pattern, with the factor level mean of 0.07 percent area voiding. Even more so than Material A, the Dot and Cross dispense patterns resulted in extensive voiding with factor level means of 4.45 and 3.85 percent area voiding respectively.

Speed is a factor at .05 significance level, with $5 \mathrm{~mm} / \mathrm{s}$ yielding a mean response 2.55 percent area voiding, and $70 \mathrm{~mm} / \mathrm{s}$ a mean response of 3.03 percent area voiding. 
The $p$-value of 0.013 indicates a fairly strong result; therefore, speed appears to be a statistically significant factor influencing voiding for Material B.

The full ANOVA results for Material B are displayed in Table 4-2. The main effects and interactions plots are shown in Figures 4-3 and 4-4, respectively.

Table 4-2 Material B, ANOVA Results for DOE1

\begin{tabular}{|c|c|c|c|c|c|c|}
\hline Source & DF & Seq SS & Adj SS & Adj MS & F Ratio & P-Value \\
\hline speed & 1 & 1.41 & 1.41 & 1.41 & 7.54 & 0.013 \\
\hline pattern & 2 & 90.00 & 90.00 & 45.00 & 241.4 & $<.001$ \\
\hline speed $^{*}$ pattern & 2 & 0.97 & 0.97 & 0.49 & 2.61 & 0.101 \\
\hline Error & 18 & 3.36 & 3.36 & 0.19 & & \\
\hline Total & 23 & 95.74 & & & & \\
\hline
\end{tabular}

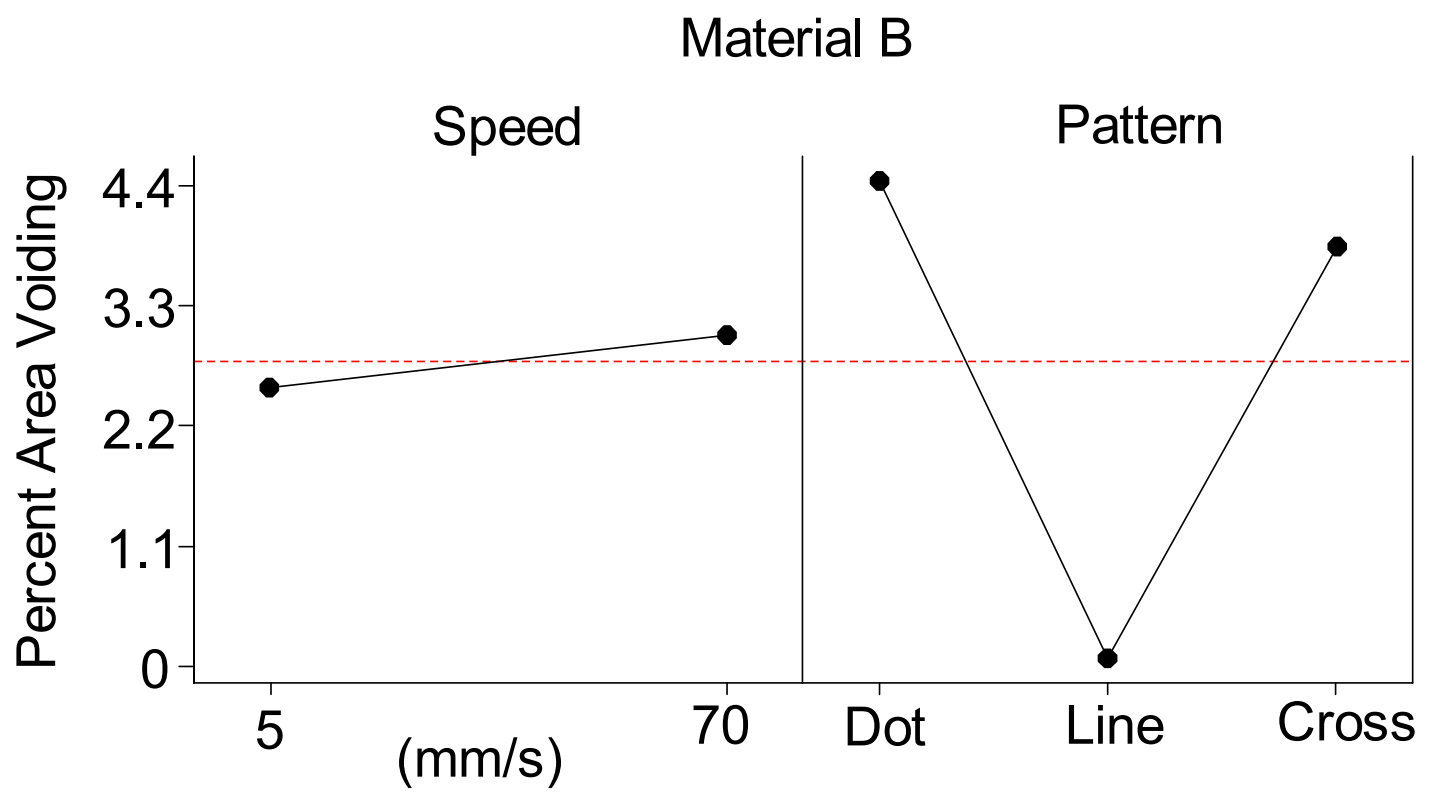

Figure 4-3 Material B, Main Effects Plots for DOE1 


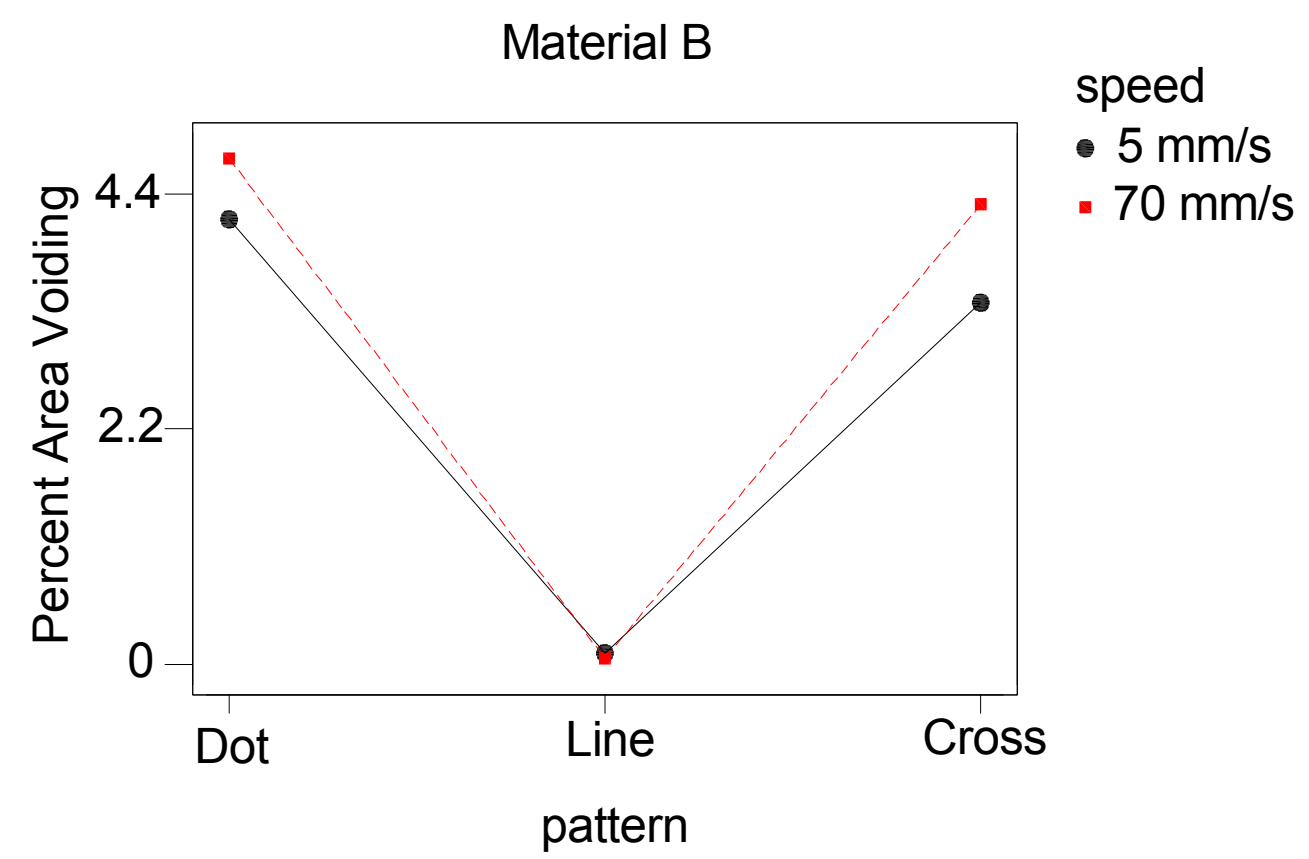

Figure 4-4 Material B, Interaction Effects Plot for DOE1

\subsubsection{Material C Results}

Material $\mathrm{C}$ also shows a minimum voiding response when using a line dispense pattern, with the factor level mean of 0.165 percent area voiding. The Dot and Cross dispense patterns resulted in extensive voiding, similar to Materials A and B, with factor level means of 2.60 percent area voiding and 3.05 percent area voiding respectively. 
Speed does not appear as a statistically significant factor $(p=0.362)$, with $5 \mathrm{~mm} / \mathrm{s}$ yielding a mean response 1.77 percent area voiding, and $70 \mathrm{~mm} / \mathrm{s} \mathrm{a}$ mean response of 2.10 percent area voiding.

The full ANOVA results for Material $\mathrm{C}$ are displayed in Table 4-3. The main effects and interactions plots are shown in Figures 4-5 and 4-6 respectively.

Table 4-3 Material C, ANOVA Results for DOE 1

\begin{tabular}{|c|c|c|c|c|c|c|}
\hline Source & DF & Seq SS & Adj SS & Adj MS & F Ratio & P-Value \\
\hline speed & 1 & 0.65 & 0.65 & 0.65 & 0.88 & 0.362 \\
\hline pattern & 2 & 38.58 & 38.58 & 19.29 & 26.14 & $<.001$ \\
\hline speed $^{*}$ pattern & 2 & 1.24 & 1.24 & 0.62 & 0.84 & 0.448 \\
\hline Error & 18 & 13.28 & 13.28 & 0.74 & & \\
\hline Total & 23 & 53.74 & & & & \\
\hline
\end{tabular}

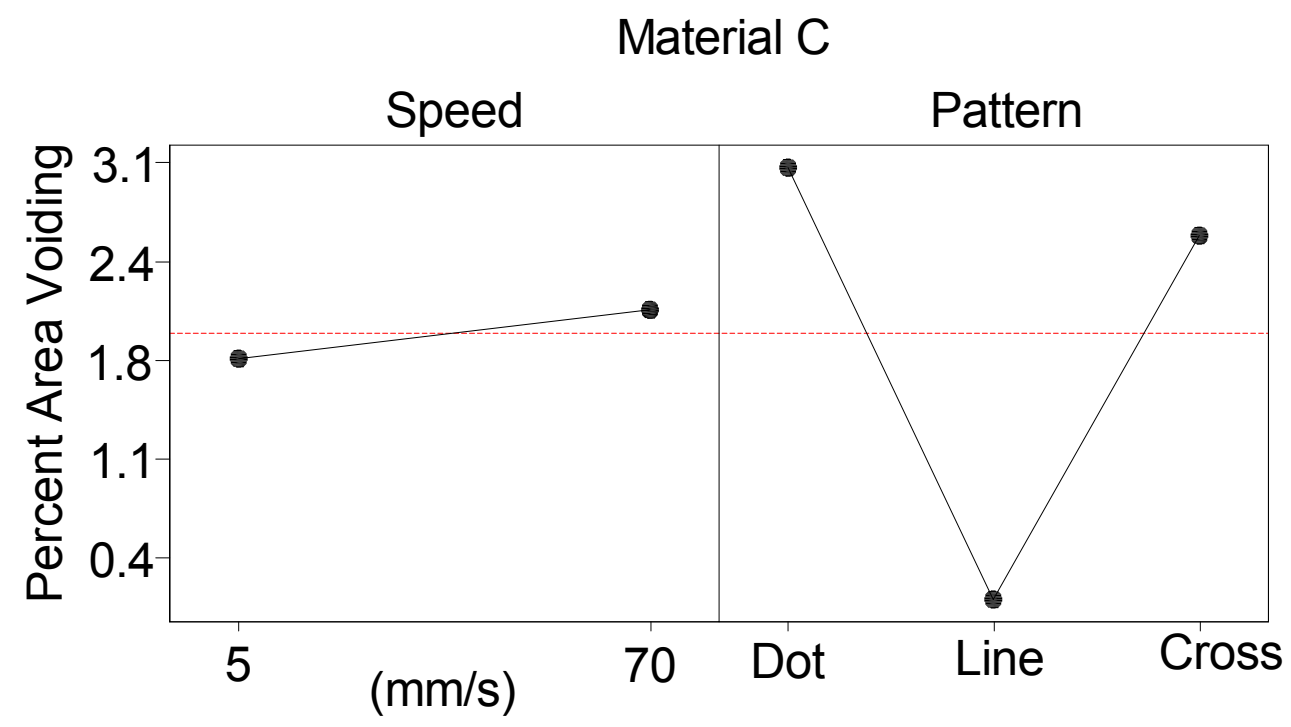

Figure 4-5 Material C, Main Effects Plots for DOE1 


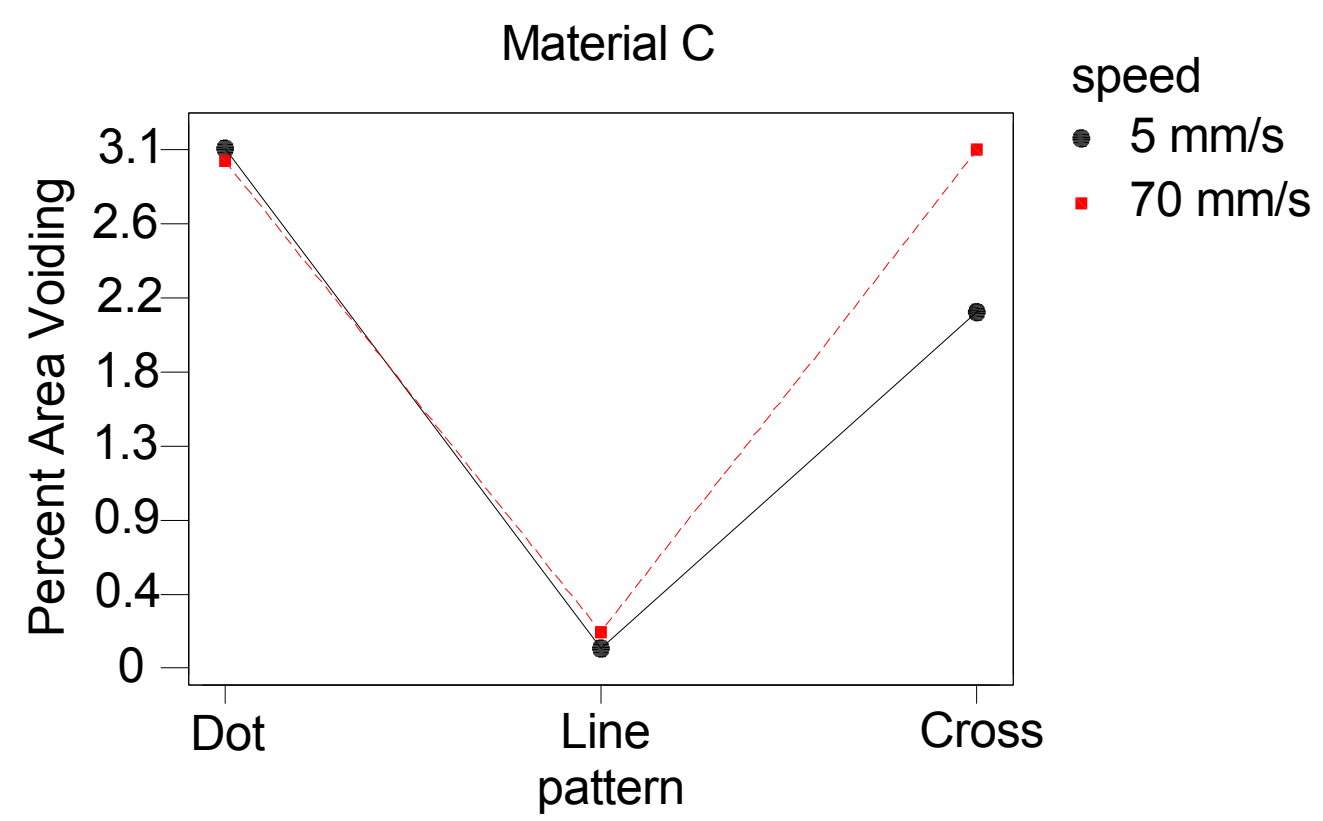

Figure 4-6 Material C, Interaction Effects Plot for DOE1

\subsubsection{Material D Results}

Material $D$ also shows a minimum voiding response when using a line dispense pattern, with the factor level mean of 0.44 percent area voiding. The Dot and Cross dispense patterns resulted once again in greater voiding, with factor level means of 0.73 percent area voiding and 0.72 percent area voiding respectively.

Speed does not appear as a statistically significant factor $(p=0.170)$, with $5 \mathrm{~mm} / \mathrm{s}$ yielding a mean response 0.59 percent area voiding, and $70 \mathrm{~mm} / \mathrm{s}$ a mean response of 0.67 percent area voiding. 
The full ANOVA results for Material D are displayed in Table 4-4. The main effects and interactions plots are shown in Figures 4-7 and 4-8 respectively.

Table 4-4 Material D, ANOVA Results for DOE1

\begin{tabular}{c|c|c|c|c|c|c} 
Source & DF & Seq SS & \multicolumn{1}{c}{ Adj SS } & \multicolumn{1}{c}{ Adj MS } & F Ratio & P-Value \\
\hline speed & 1 & 0.0392 & 0.0392 & 0.0392 & 2.04 & 0.170 \\
\hline pattern & 2 & 0.4259 & 0.4259 & 0.2129 & 11.07 & 0.001 \\
\hline speed $^{\star}$ pattern & 2 & 0.0111 & 0.0111 & 0.0055 & 0.29 & 0.754 \\
\hline Error & 18 & 0.3462 & 0.3462 & 0.0192 & & \\
\hline Total & 23 & 0.8223 & & & &
\end{tabular}

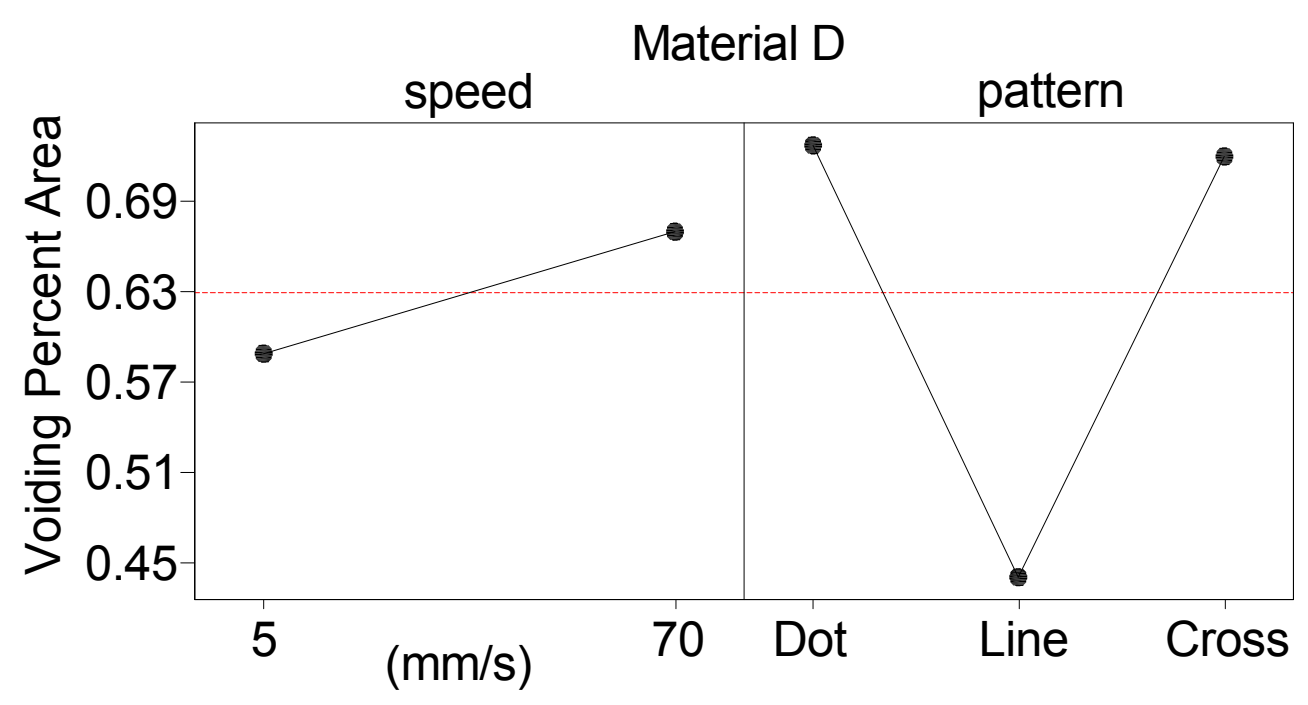

Figure 4-7 Material D, Main Effects Plots for DOE1 


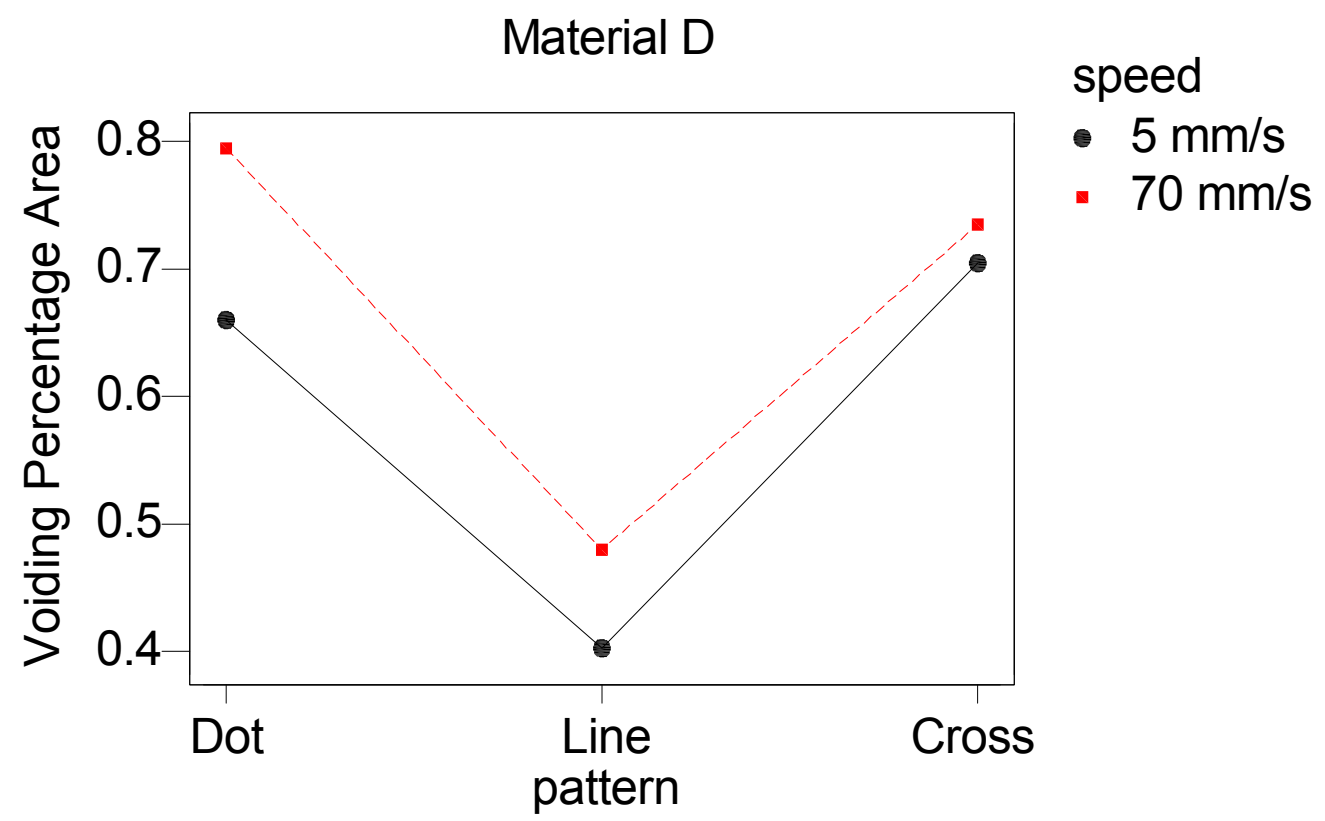

Figure 4-8 Material D, Interaction Effects Plot for DOE1

\subsubsection{Material E Results}

Material E also shows a minimum voiding response when using a line dispense pattern, with the factor level mean of 0.04 percent area voiding. The Dot and Cross dispense patterns resulted once again in significantly higher voiding, with factor level means of 0.39 voids and 0.64 voids respectively.

Speed does not appear as a statistically significant factor $(p=0.725)$, with $5 \mathrm{~mm} / \mathrm{s}$ yielding a mean response 0.38 percent area voiding, and $70 \mathrm{~mm} / \mathrm{s}$ a mean response of 0.33 percent area voiding. 
The full ANOVA results for Material E are displayed in Table 4-5. The main effects and interactions plots are shown in Figures 4-9 and 4-10, respectively.

Table 4-5 Material E, ANOVA Results for DOE1

\begin{tabular}{c|ccc|c|c|c} 
Source & DF & Seq SS & \multicolumn{1}{c}{ Adj SS } & Adj MS & F Ratio & P-Value \\
\hline speed & 1 & 0.0104 & 0.0104 & 0.0104 & 0.13 & 0.725 \\
\hline pattern & 2 & 1.4269 & 1.4269 & 0.7135 & 8.78 & 0.002 \\
\hline speed $^{*}$ pattern & 2 & 0.0289 & 0.0289 & 0.0145 & 0.18 & 0.838 \\
\hline Error & 18 & 1.4632 & 1.4632 & 0.0813 & & \\
\hline Total & 23 & 2.9294 & & & &
\end{tabular}

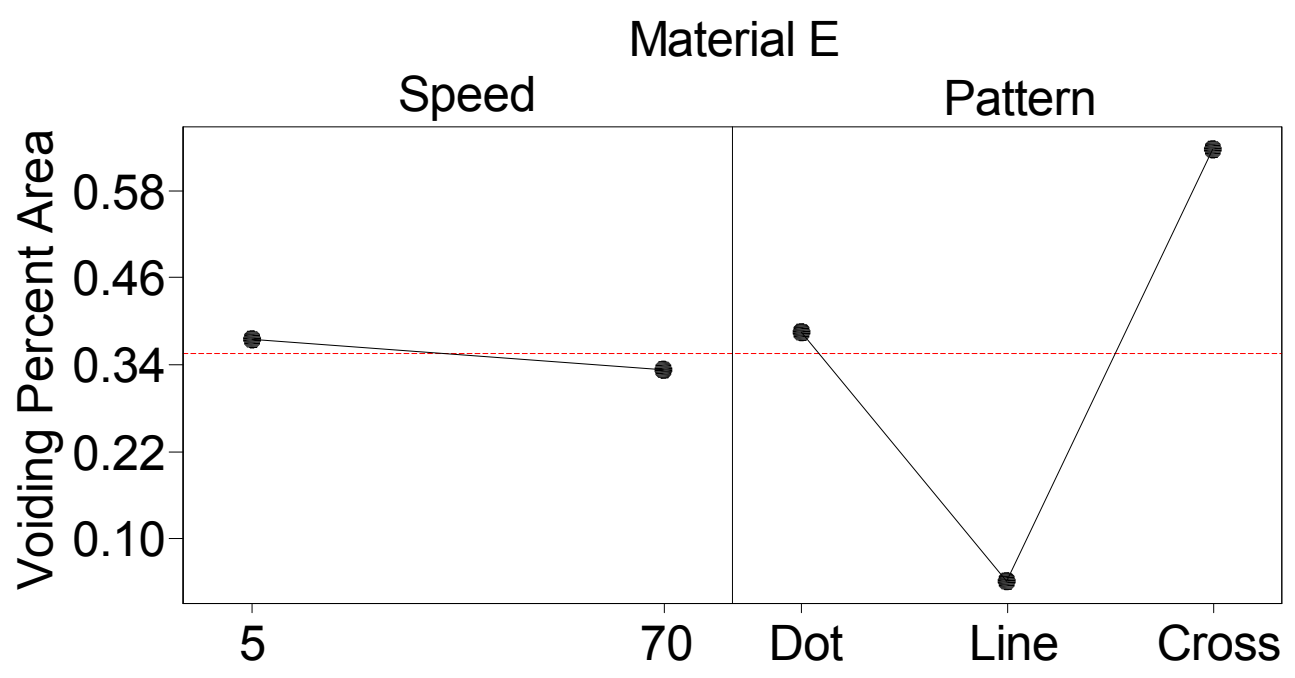

Figure 4-9 Material E, Main Effects Plots for DOE1 


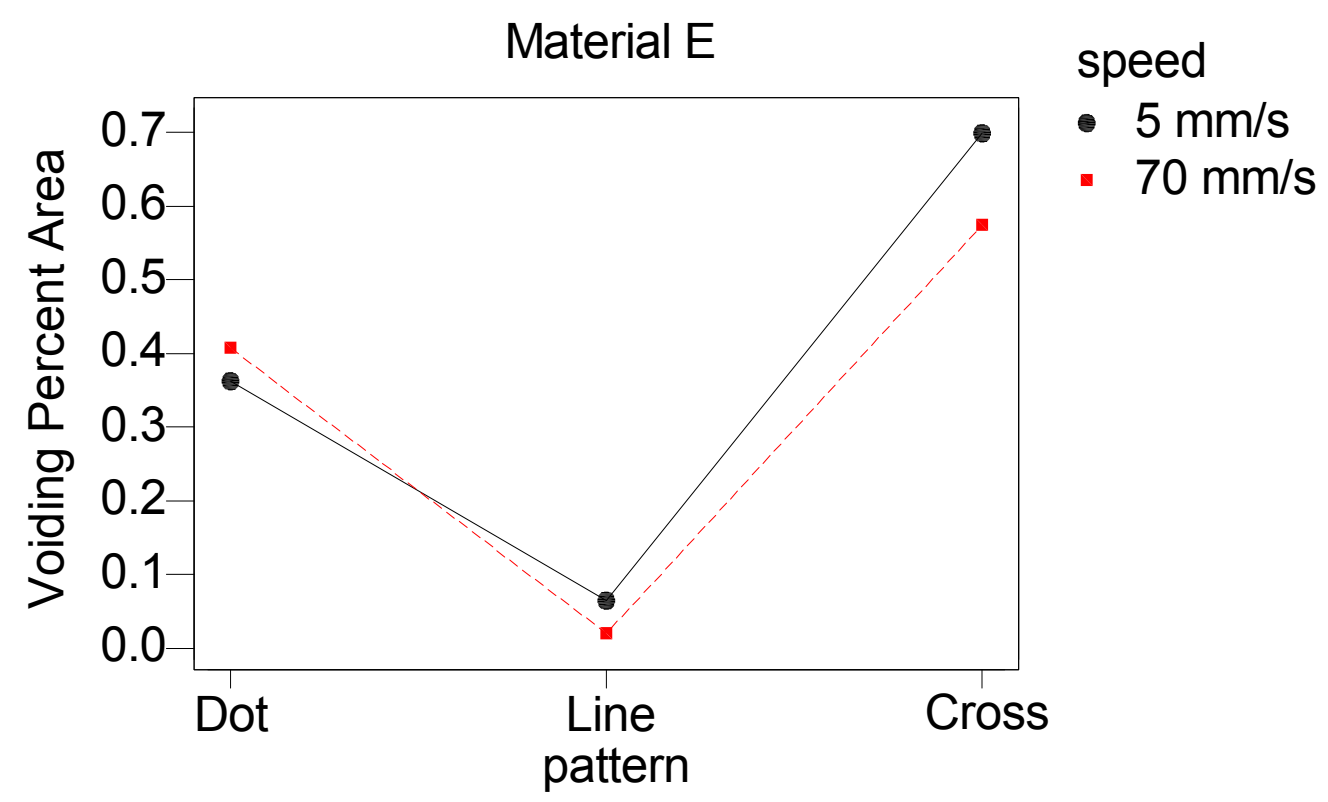

Figure 4-10 Material E, Interaction Effects Plot for DOE1

\subsection{Discussion, Design of Experiments \# 1}

The very low $p$-values (<.001) for dispense pattern, observed for all underfills, indicate that the underfill dispense pattern is a significant factor affecting the percent area voiding occurring during placement. The potential reason for this effect can be understood most easily by considering each of several voiding mechanisms separately. The mechanisms are: syringe dispensed, pad opening voids from dispense, pad opening voids from flow, and entrainment voids from flow. These voiding mechanisms, and the interactions with the dot, line, and cross dispense patterns are presented in the sections that follow. 


\subsubsection{Syringe Dispensed Voids}

Air contained in the dispense syringe could be a potential source of voiding. Entrapped air near the syringe needle may end up in the dispensed underfill after the dispensing is complete. It should be noted that the syringe is held in position with the needle pointing downward, so most likely any air in the syringe would float to the top and therefore not end up in the dispensed material.

If there was air present in the dispensed material, the Line pattern would offer an advantage over the Dot and Cross patterns. The advantage stems from the fact that the Dot and Cross Patterns are both dispensed onto the substrate bond site in such a way that the die covers the material after placement, while the Line is dispensed so that it is centered on the side of the die. Thus, for the Dot and Cross patterns, any voids present in the material from the dispensing are likely to end up trapped under the die, and therefore can end up in the final assembly. This is especially true when considering these dispense patterns for a high volume production process where the transfer time from the dispense machine to the die placement machine will be as short as possible, leaving little time for any dispensed voids to rise through the viscous underfill to escape at the surface.

Because the capillary flow process happens slowly from the side of the die, the Line pattern acts to provide additional time after dispense to allow for any air dispensed with the material to escape the underfill. Therefore, if voids are 
contributed to the process via the syringe dispense, the line pattern offers an advantage and may result in less voiding than the dot or cross patterns.

\subsubsection{Pad Opening Voids From Dispense}

Air contained in the substrate pad openings is a likely source for voids caused by dispense of the underfill directly onto the openings. In other words, the underfill could essentially seal off the pad openings as it impacts the substrate during the dispense process. The dispense pattern is expected to have a definite influence over this type of voiding because each pattern will potentially dispense underfill directly over a different number of pads. This is evident when reviewing the dispense patterns provided again as Figure 4-11.
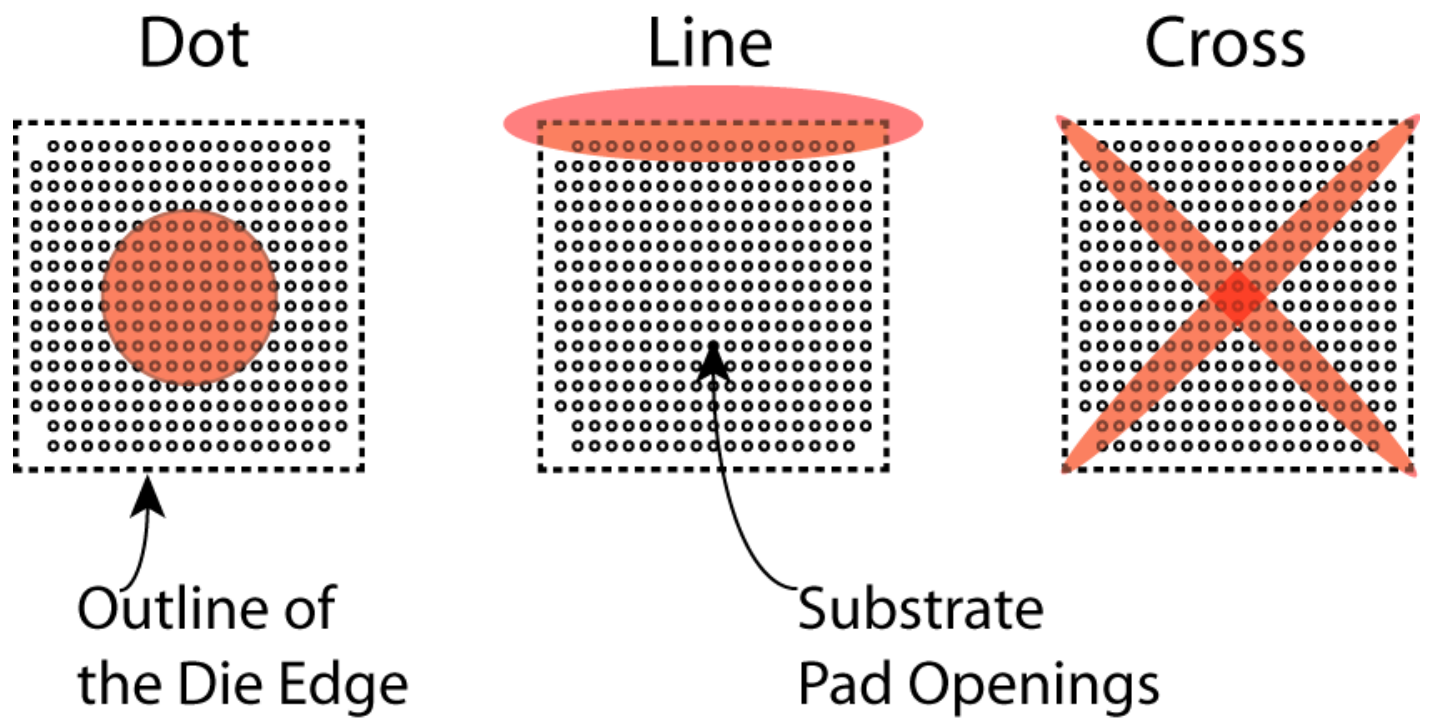

Figure 4-11 Underfill Dispense Patterns 
The line pattern is actually positioned so that it is centered along the edge of the die as it is placed onto the substrate; this means that the initial material that touches the substrate will be positioned outside of the area that is populated with pad openings. Therefore, no material is deposited directly over any pad openings. After the material sits for a few seconds it does have a chance to wet out onto the solder mask. At this point the flow does encounter pad openings, but the material is wetting out slowly by capillary action which has been empirically verified, as discussed in Section 4.2.3, to rather easily fill the pad openings. Thus, any pad openings that the flow front encounters should not contribute to percent area voiding because the air is displaced by underfill instead of trapped to form voids.

The Dot and Cross patterns are expected to exhibit this voiding mechanism as a result of the positioning of each pattern directly over the pad openings. We can estimate the potential of each pattern to cause voiding by using a simple analysis. The 22-gauge dispense needle has an inside diameter of $\sim 0.400 \mathrm{~mm}$. Assume that the underfill is deposited onto the substrate in a line or dot with the same width. Next, assume that voids created during dispense are limited to only the pad openings where the material is dispensed directly overhead. To find an estimate of voiding, take the projected area of the dispense path and multiply by the area density of the pad openings, Equation (4.2). The result is the number of pads covered by direct underfill deposition during the dispense.

$$
n_{p}=\left(A_{\text {path }}\right)\left(\rho_{\text {pads }}\right)
$$


Where $n_{p}$ is the number of pads covered by the dispense, $A_{p a t h}$ is the projected area of the dispense path onto the substrate, and $\rho_{\text {pads }}$ is the area density of the pad openings. The substrate specific constant $\rho_{\text {pads }}$ is defined in Equation (4.3).

$$
\rho_{\text {pads }}=\frac{n_{\text {total }}}{A_{\text {die }}}
$$

Where $n_{\text {total }}$ is the total number of pad openings per bond site, and $A_{\text {die }}$ is the projected area of the die onto the substrate. The calculation of $\rho_{\text {pads }}$ for TV1 used in this experimental work is given in Equation (4.4).

$$
\rho_{\text {pads }}=\frac{317}{(5.04 \mathrm{~mm})^{2}}=12.48 \frac{\mathrm{pads}}{\mathrm{mm}^{2}}
$$

The calculation of $A_{\text {path }}$ for the Dot pattern is presented in Equation (4.5) and the total number of pads covered $\left(n_{p}\right)$ is displayed in Equation (4.6).

$$
\begin{gathered}
\frac{\pi}{4} d^{2}=0.126 \mathrm{~mm}^{2} \\
\left(0.126 \mathrm{~mm}^{2}\right)\left(12.48 \frac{\text { pads }}{\mathrm{mm}^{2}}\right)=1.57 \text { pads }
\end{gathered}
$$


The calculation of $A_{\text {path }}$ for the Cross pattern is presented in Equation (4.7) and the total number of pads covered $\left(n_{p}\right)$ is displayed in Equation (4.8).

$$
\begin{aligned}
& \sqrt{2}(5.04 \mathrm{~mm})(0.400 \mathrm{~mm})(2)=5.70 \mathrm{~mm}^{2} \\
& \left(5.70 \mathrm{~mm}^{2}\right)\left(12.48 \frac{\text { pads }}{\mathrm{mm}^{2}}\right)=71.14 \text { pads }
\end{aligned}
$$

The results of this simple analysis indicate that this voiding mechanism could very likely be a significant source of voids for the Cross pattern, potentially trapping the air contained in $\sim 70$ pad openings. The number of pad openings covered during underfill dispense provides an estimate for the relative contribution to total percent area voiding that this mechanism is likely to produce. Consider that there are 317 total pad openings per bond site for TV1. It is clear that for the Cross pattern, this mechanism could potentially result in $70 / 317$ or about $22 \%$ of the total possible voiding due to the air encasing the pad geometry.

The dot pattern analysis indicates that although the material is dispensed directly over the bond site, this mechanism is unlikely to be a significant source of voids for the Dot Pattern; because the needle stays in place in the $x-y$ plane during the Dot dispense, the projected area of the direct underfill deposition is small. The final size of the underfill dot on the bond site is much larger the 
projected dispense needle area; however, the underfill wets slowly out to the final area by capillary action, without trapping the air in the process.

Because the Line dispense process deposits underfill along the side of the die instead of directly over pad openings, the Line pattern minimizes voids

created by this mechanism. Additionally, following the reasoning in Section 4.2.1, the voids trapped by this mechanism when using the Dot or Cross dispense may not have time to surface before die placement. The end result is that this mechanism will result in an increase in percent area voiding in the final assembly for the Dot or Cross patterns.

\subsubsection{Pad Opening Voids Formed During Flow}

Similar to Section 4.2.2, the air encasing the substrate pad openings is a likely source for voids caused by the flow of the underfill over the pad openings during and after placement. The dispense pattern is expected to have a definite influence over this type of voiding, because the dynamics of the material flow is a direct result of the placement of the pattern. Two very different types of flow result; compression flow for the Dot and the Cross patterns, and capillary flow for the Line pattern. Additionally, it is expected that speed of placement will have an effect on voiding by this mechanism.

The potential mechanism for void formation during compression flow can be seen in Figures 4-13 through 4-15. The Dot and Cross patterns are likely to exhibit this mechanism of voiding. A complete understanding of the fluid dynamics surrounding this flow is quite complicated; however, it is likely that the 
flow front shape and velocity, and therefore placement speed, are potential factors affecting this mechanism [Milner 2001]. Other factors would include underfill viscosity, the pad opening radius of curvature, and the detailed geometry of the copper trace.

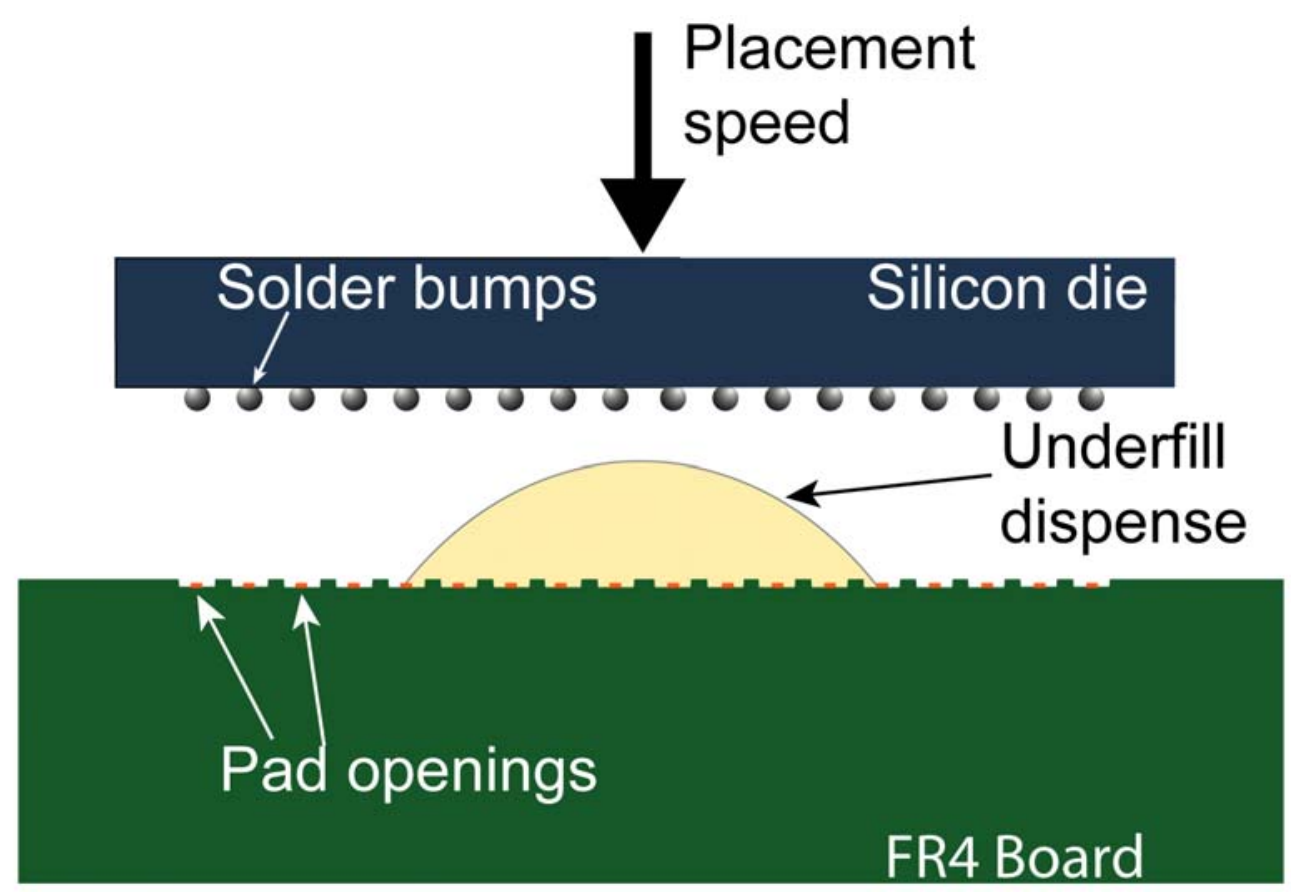

Figure 4-12 Dot Dispense, Before Compression Flow 


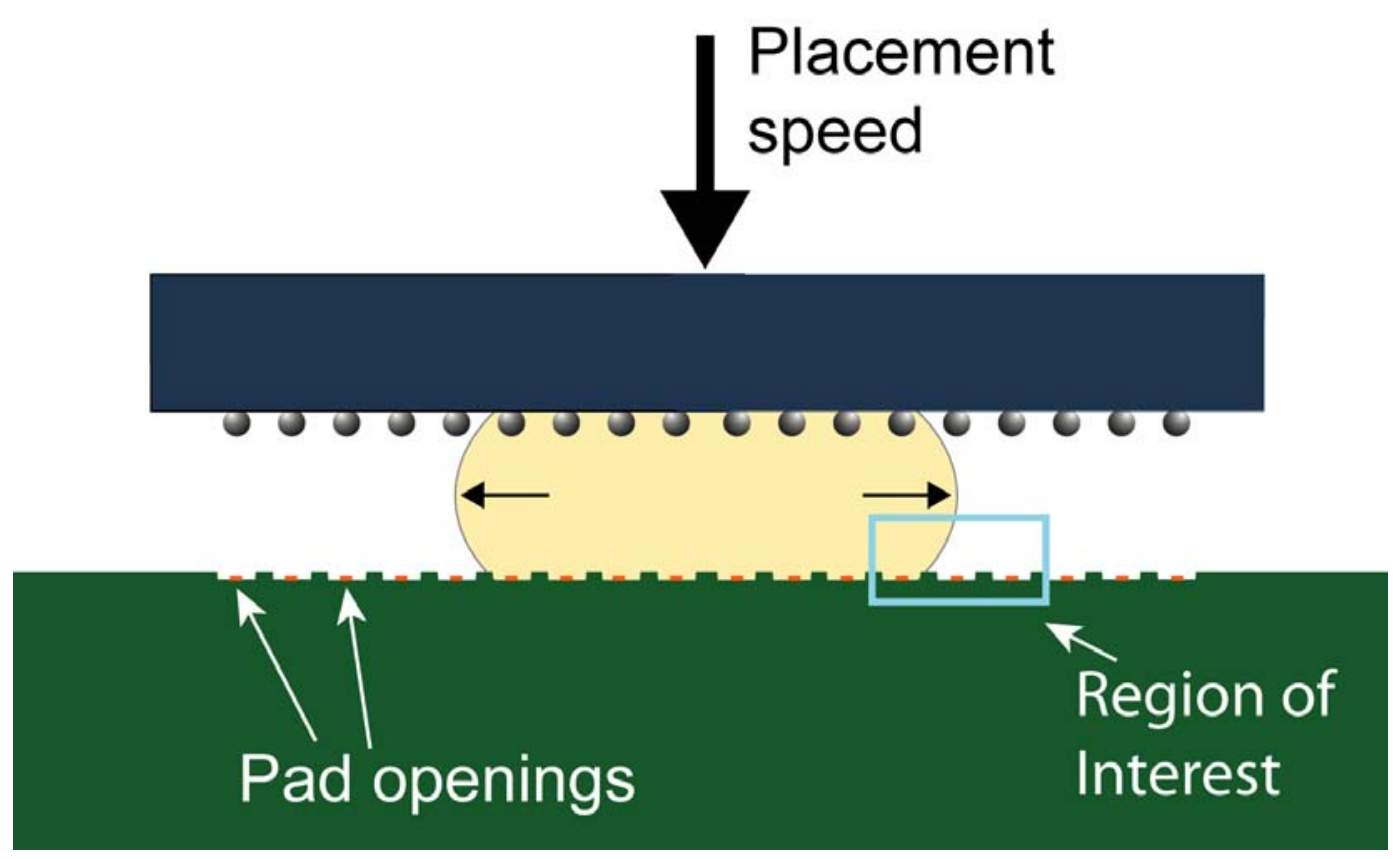

Figure 4-13 Dot Dispense, During Compression Flow

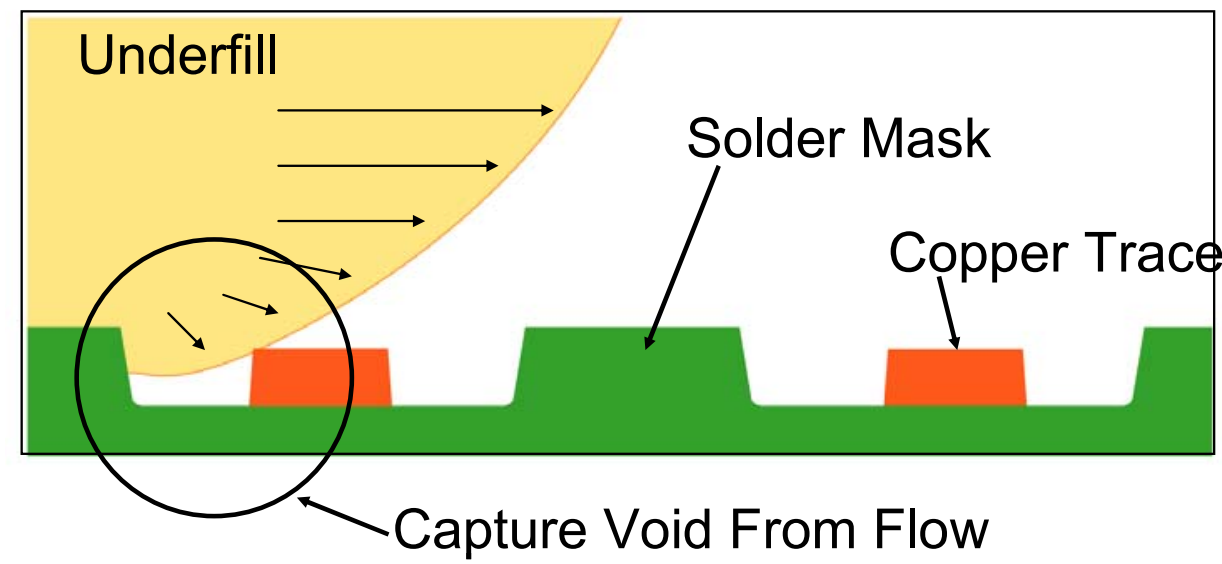

Figure 4-14 Capture Void, Region of Interest from Figure 4-13 


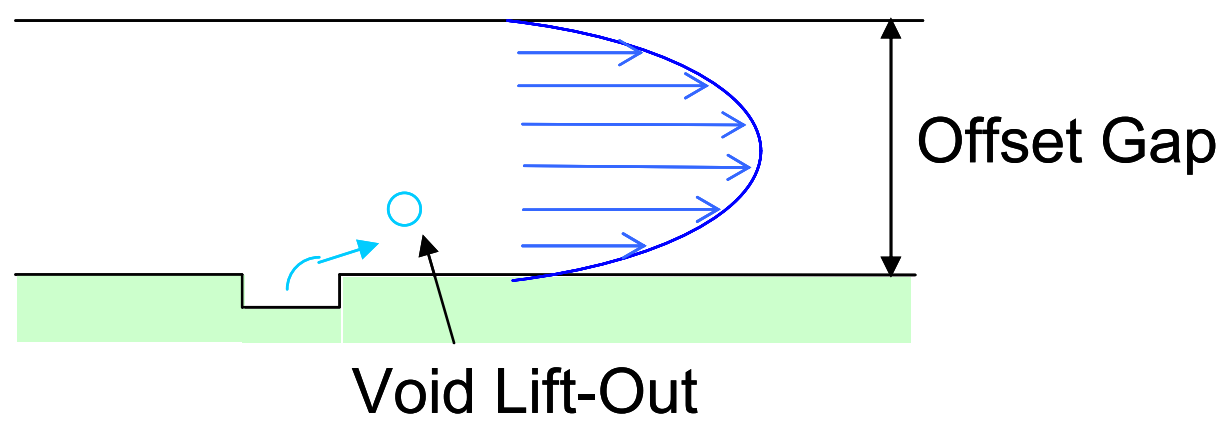

Figure 4-15 Capture Void Lift Out [Milner 2001]

Since every material tested has the lowest voiding when using the Line pattern, it seems likely that the capillary flow process associated with the Line pattern is better at filling the solder mask openings without capturing voids during the process. The wetting dynamics of the capillary process are very different than the compression dynamics illustrated in $4-13$. The material wets slowly allowing the flow to creep into the pad openings and displace the air for complete wetting. This flow dynamic is depicted in Figure 4-16.

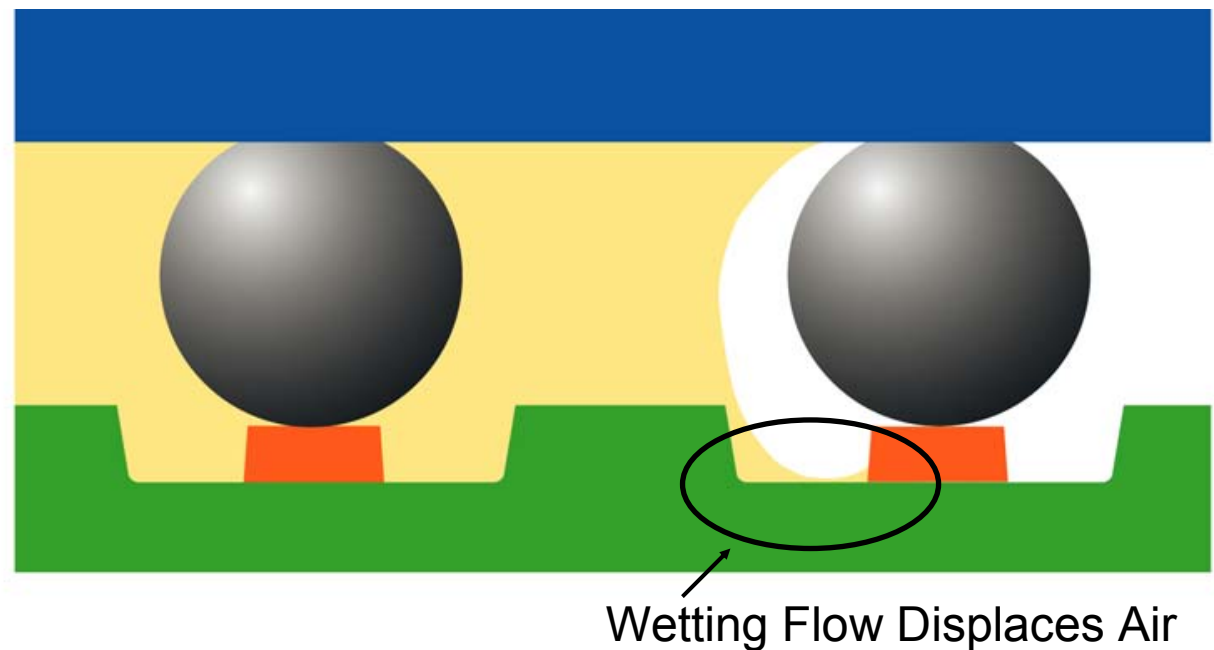

Figure 4-16 Capillary Flow Resulting in Complete Air Displacement 
Another factor affecting the capillary process, or Line pattern, is the lowered viscosity of the material due to heating in the early stages of reflow. The underfill material first undergoes a change to lower viscosity due to heating before finally starting to cross-link, and rapidly increasing in viscosity in the later stages of reflow. This heating of the material can have a significant influence on voiding results even for a standard dot dispense on the bond site. Researchers have studied this temperature effect for a no-flow underfill and test die similar to those presented here [Wang 2001]. Their results indicate that either heating of the substrate or heating of the placement head will result in lower voiding. Considering [Wang 2001] and the voiding results presented here, it is likely that the increased temperature during the capillary flow is at least partially the reason the Line pattern displays such favorable results.

\subsubsection{Entrainment Voids from Flow}

During the compression flow of the underfill for the Dot and Cross patterns, one final voiding mechanism could occur. It is possible that air becomes entrained in the flow simply because the material can not wet the solder mask surface quickly enough. This voiding mechanism does not involve the pad openings, but simply the solder mask surface roughness and rapid flow of the material between the die and the board as depicted in Figure 4-17. 


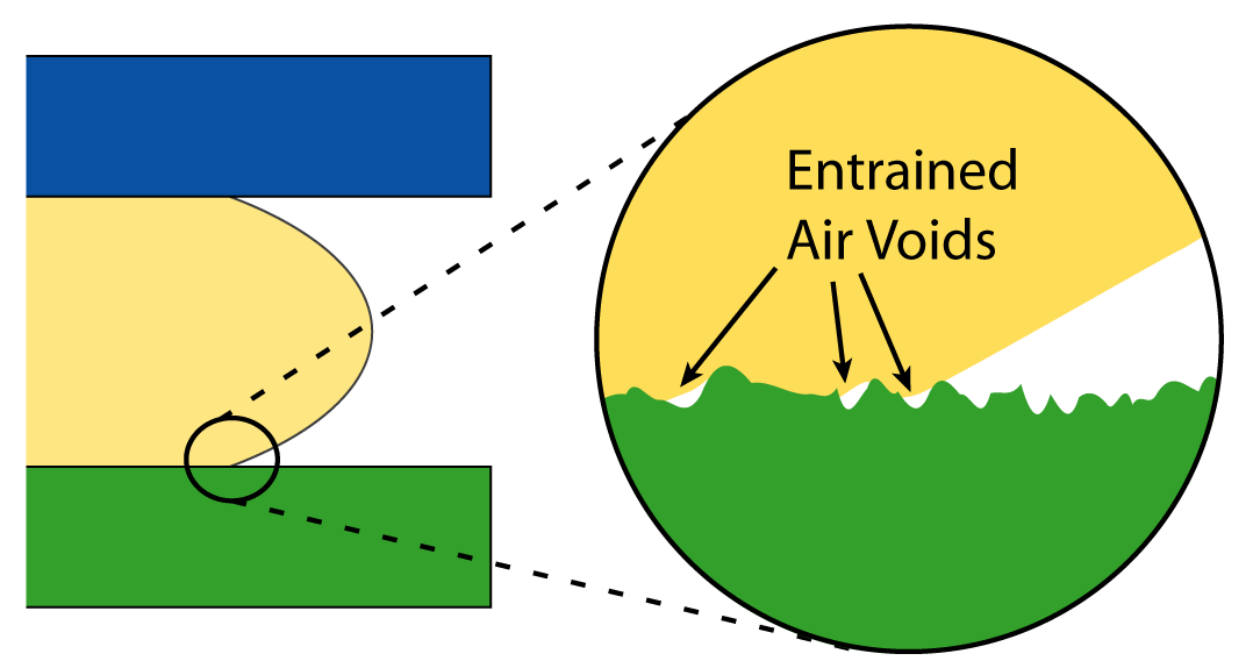

Figure 4-17 Air Entrainment Voiding Mechanism

This mechanism may explain a small amount of the total voiding observed for both the Dot and Cross patterns. Once again, the capillary flow for the Line dispense will minimize the effects of this mechanism by allowing the flow front to track the surface more closely and displace more of the air contained in the recesses defined by the surface asperities. This argument is based on considering the surface profile in 2 dimensions only as displayed in Figure 4-17, however the true surface is actually $3 \mathrm{D}$. A consideration of the 3D surface indicates that the trapped voids as shown in Figure 4-17 could possibly escape along a path that is perpendicular to the cross-section shown. The voids could travel along pathways at the surface of the board until reaching the perimeter of the underfill dispense and finally escaping completely. This escape route might be possible for some of the air trapped beneath the underfill flow, especially for air trapped near the edge of the die; however, it seems unlikely that there would not be some air remaining that was trapped by this mechanism. This is because the underfill would be likely to block off some of these escape passages as the 
material sunk into the surface under the influence of gravity after the initial compression flow finished covering the solder mask surface. Thus, this mechanism could contribute to the overall percent area voiding, although the magnitude of the contribution may be very small.

\subsubsection{Summary of DOE1 Conclusions}

The significance of the factors for each material is presented in Table 4-6. Speed does not show a clear effect as a significant factor for all 5 materials tested. It does show a weak conclusion for 2 materials indicating that increasing speed might increase voiding. A more detailed experiment would be necessary to reach a stronger conclusion, preferably involving more levels and replicates. Other researchers [Milner 2001, Wang 2001], have demonstrated that speed can be a significant factor affecting voiding. However, the range of their experiments, $0.6 \mathrm{~mm} / \mathrm{s}$ and $2 \mathrm{~mm} / \mathrm{s}$ respectively, extended well below the lowest value ( 5 $\mathrm{mm} / \mathrm{s}$ ) used during this research. This suggests that there is possibly a speed threshold value, less than $5 \mathrm{~mm} / \mathrm{s}$, and above which any increase in speed results in a negligible increase in voiding. This concept makes sense qualitatively when considering the flow of the material over the pad openings. It is easy to imagine that after the material is flowing fast enough, it will essentially just capture all of the air contained in the pad openings and any further increase in speed will have no noticeable effect. Because the results of this experimental work do not clearly indicate that the $5 \mathrm{~mm} / \mathrm{s}$ speed results in a lower percent area voiding than the $70 \mathrm{~mm} / \mathrm{s}$ speed, the $70 \mathrm{~mm} / \mathrm{s}$ speed was selected for any 
remaining experiments based on practical concerns. The faster placement speed allows for a decreased cycle time, which is desirable in a high volume production environment. Thus, speed does not appear as part of the design for any further experimental designs included in this research.

Table 4-6 Summary of Dispense Study Significance

\begin{tabular}{|l||c|c|c|}
\hline & Pattern & Speed & Speed*Pattern \\
\hline \hline Material A & +++ & + & \\
\hline Material B & +++ & ++ & \\
\hline Material C & +++ & & \\
\hline Material D & +++ & & \\
\hline Material E & +++ & & \\
+ & $=<0.10$ ANOVA p-value \\
++ & $=<0.05$ ANOVA p-value \\
+++ & $=<0.01$ ANOVA p-value
\end{tabular}

Pattern clearly shows as a significant factor for all the underfills tested, and therefore it will be investigated further in additional experiments. The pattern factor shows a strong conclusion $(p<.01)$ for all materials. This implies that the pattern effect is relatively unrelated to the variation in specific material properties such as density or viscosity. Because the results of the Line pattern were so favorable, it was decided for verification purposes to investigate the Line pattern again in comparison to the Dot pattern only in the next DOE. 


\subsection{Results: Design of Experiments \#2}

The assemblies for this placement DOE were reflowed according to the manufacturer baseline process for each material (Chapter 3), and yield and voiding are the primary response metrics. The statistics for yield are not included, because for every material, all of the treatments produced 100 percent yield except for the 111 treatment (Dot, $1 \mathrm{~N}, 0.0 \mathrm{~s})$. A summary of the interconnect results for the 111 treatment will be presented in section 4.4 along with a discussion of the probable cause.

The statistical results presented in 4.3.1 through 4.3.5 are based on underfill voiding as the response metric. The analysis for each underfill was performed using Minitab Statistical Software release 13.32. The response variable is underfill voiding percent area, determined by DIA software, for each main effects plot.

\subsubsection{Material A Results for DOE2}

The voiding ANOVA results for Material A are displayed in Table 4-7. The main effects plots are shown in Figure 4-18 and interactions plots are shown in Figure 4-19. As in the previous DOE, the line pattern clearly results in the least voiding, a sample is shown in Figure 4-20. 
Table 4-7 Material A, ANOVA Results for DOE2

\begin{tabular}{l|cccc|c|c} 
Source & \multicolumn{2}{|c}{ DF } & Seq SS & Adj SS & \multicolumn{1}{c}{ Adj MS } & \multicolumn{2}{c}{ F-Ratio } & p-value \\
\hline Pattern & 1 & 10.3513 & 10.3513 & 10.3513 & 30.88 & $<.001$ \\
\cline { 2 - 7 } Force & 1 & 0.0312 & 0.0312 & 0.0312 & 0.09 & 0.763 \\
\cline { 2 - 7 } Dwell & 1 & 0.005 & 0.005 & 0.005 & 0.01 & 0.904 \\
Pattern*Force & 1 & 0.4512 & 0.4512 & 0.4512 & 1.35 & 0.257 \\
Pattern*Dwell & 1 & 0.045 & 0.045 & 0.045 & 0.13 & 0.717 \\
\cline { 2 - 7 } Force*Dwell & 1 & 0.845 & 0.845 & 0.845 & 2.52 & 0.125 \\
Error & 25 & 8.38 & 8.38 & 0.3352 & & \\
Total & 31 & 20.1088 & & & &
\end{tabular}

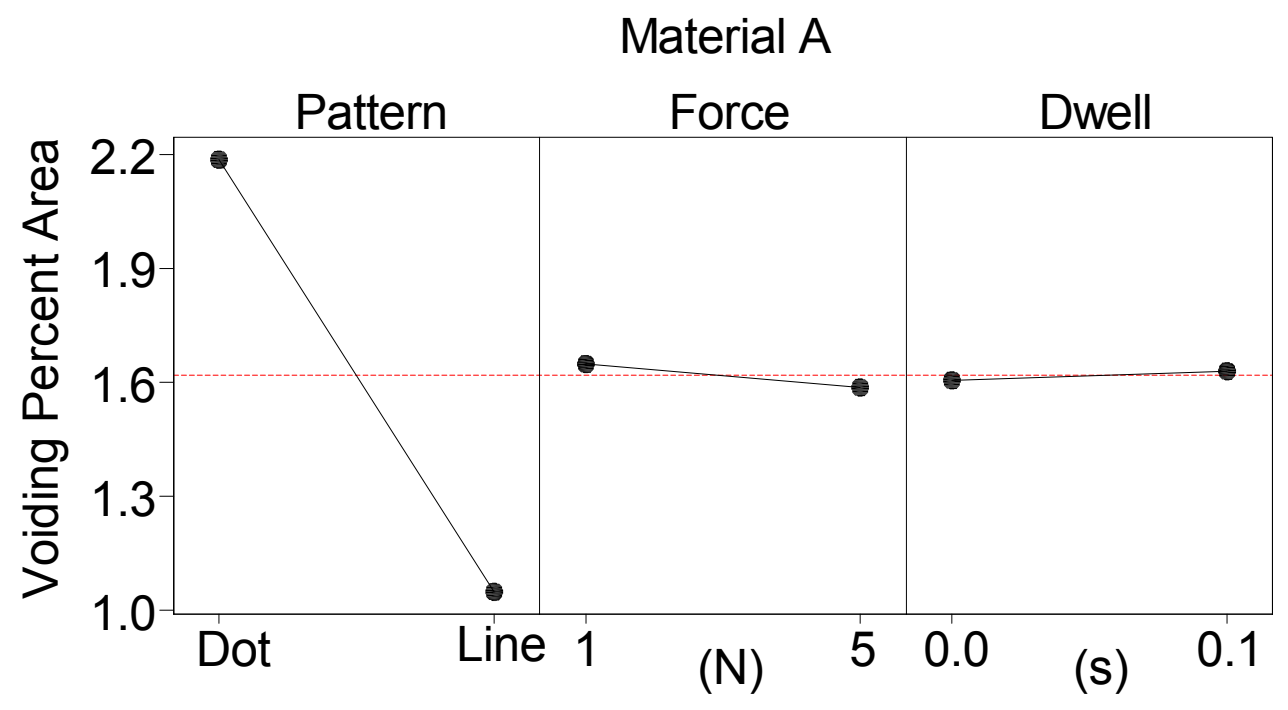

Figure 4-18 Material A, Main Effects Plots for DOE2 


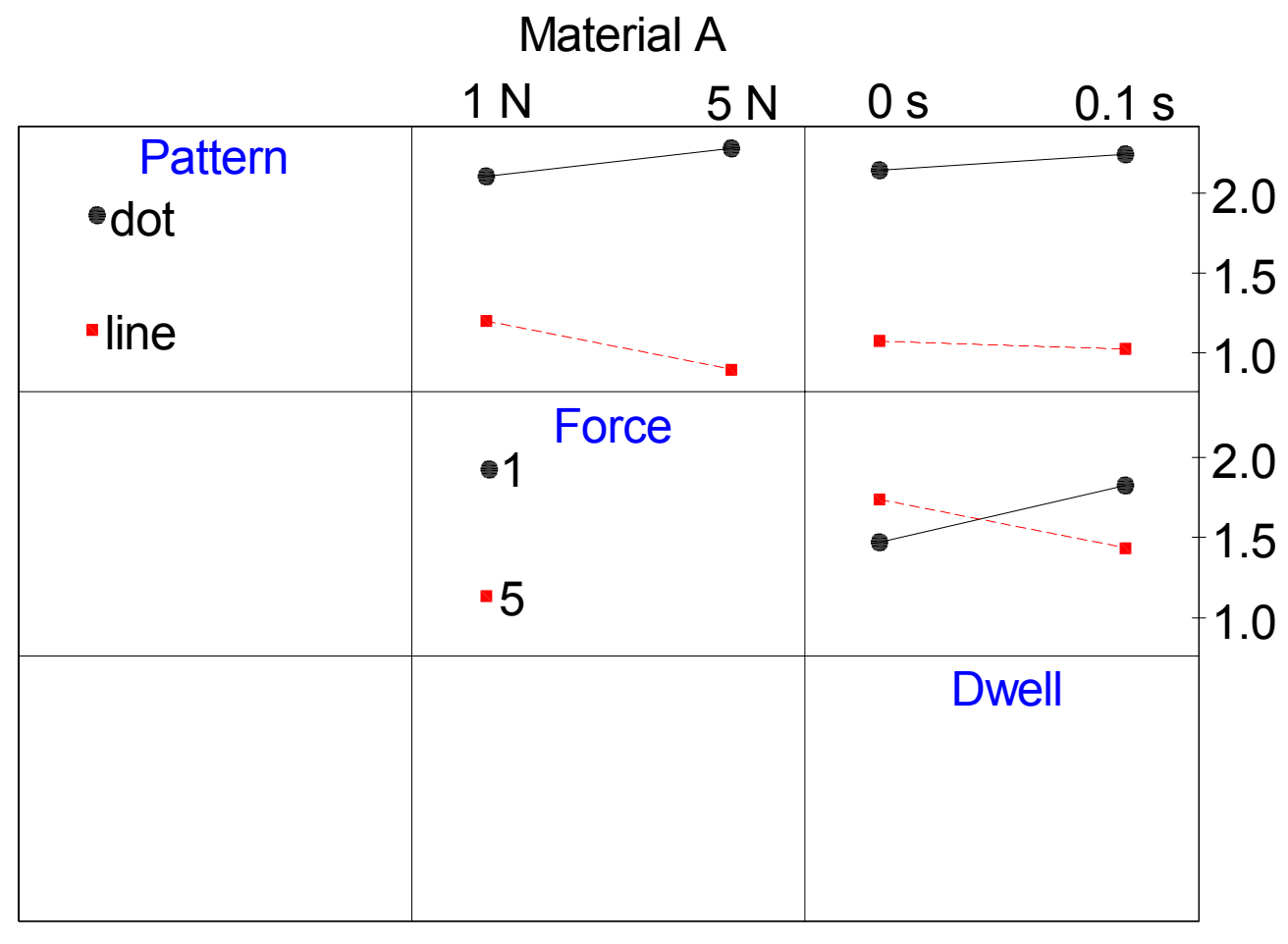

Figure 4-19 Material A, DOE2 Interaction Effects Plots including Pattern-Force, Pattern-Dwell, and Force-Dwell Interactions

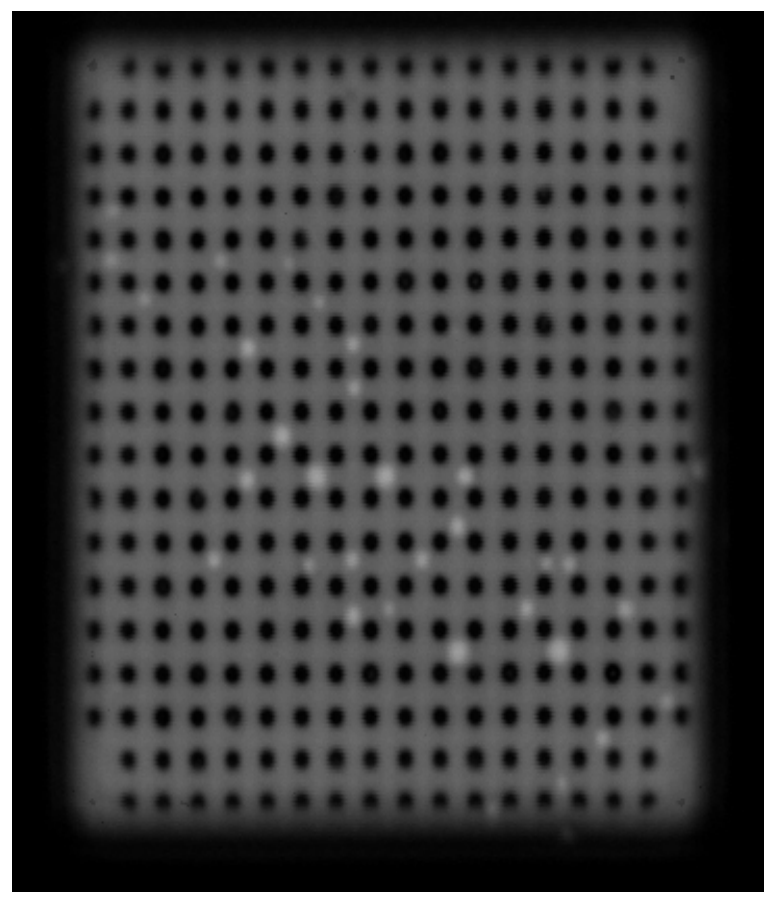

Figure 4-20 Material $\mathrm{A}$, Line, $1 \mathrm{~N}, 0.0 \mathrm{~s}$ 


\subsubsection{Material B Results for DOE2}

The voiding ANOVA results for Material B are displayed in Table 4-8. The main effects plots are shown in Figure 4-21. Interaction effects are shown in Figure 4-22. The p-value for pattern appears at the 0.05 significance level. An increase in force is seen to increase voiding, and the p-value $(<.001)$ indicates that this effect is significant. A pattern-force interaction shows up at the 0.05 significance level. A sample CSAM image is shown in Figure 4-23.

Table 4-8 Material B, ANOVA Results for DOE2

\begin{tabular}{|c|c|c|c|c|c|c|}
\hline Source & DF & Seq SS & Adj SS & Adj MS & F-Ratio & $p$-value \\
\hline Pattern & 1 & 2.1144 & 1.8003 & 1.8003 & 4.51 & 0.045 \\
\hline Force & 1 & 11.2853 & 11.8946 & 11.8946 & 29.78 & $<.001$ \\
\hline Dwell & 1 & 0.5081 & 0.5841 & 0.5841 & 1.46 & 0.239 \\
\hline Pattern*Force & 1 & 2.3775 & 2.3746 & 2.3746 & 5.95 & 0.023 \\
\hline Pattern*Dwell & 1 & 0.4849 & 0.4849 & 0.4849 & 1.21 & 0.282 \\
\hline Force*Dwell & 1 & 0.0018 & 0.0018 & 0.0018 & 0.00 & 0.948 \\
\hline Error & 23 & 9.1866 & 9.1866 & 0.3994 & & \\
\hline Total & 29 & 25.9587 & & & & \\
\hline
\end{tabular}




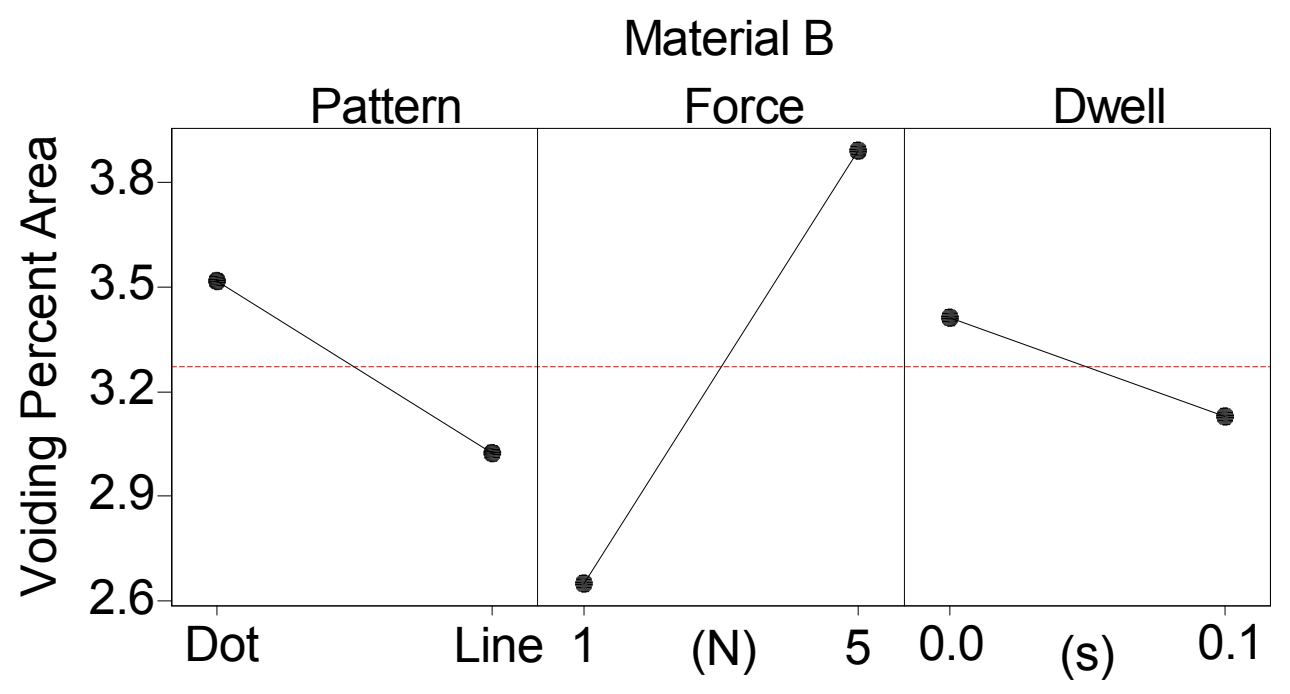

Figure 4-21 Material B, Main Effects Plots for DOE2

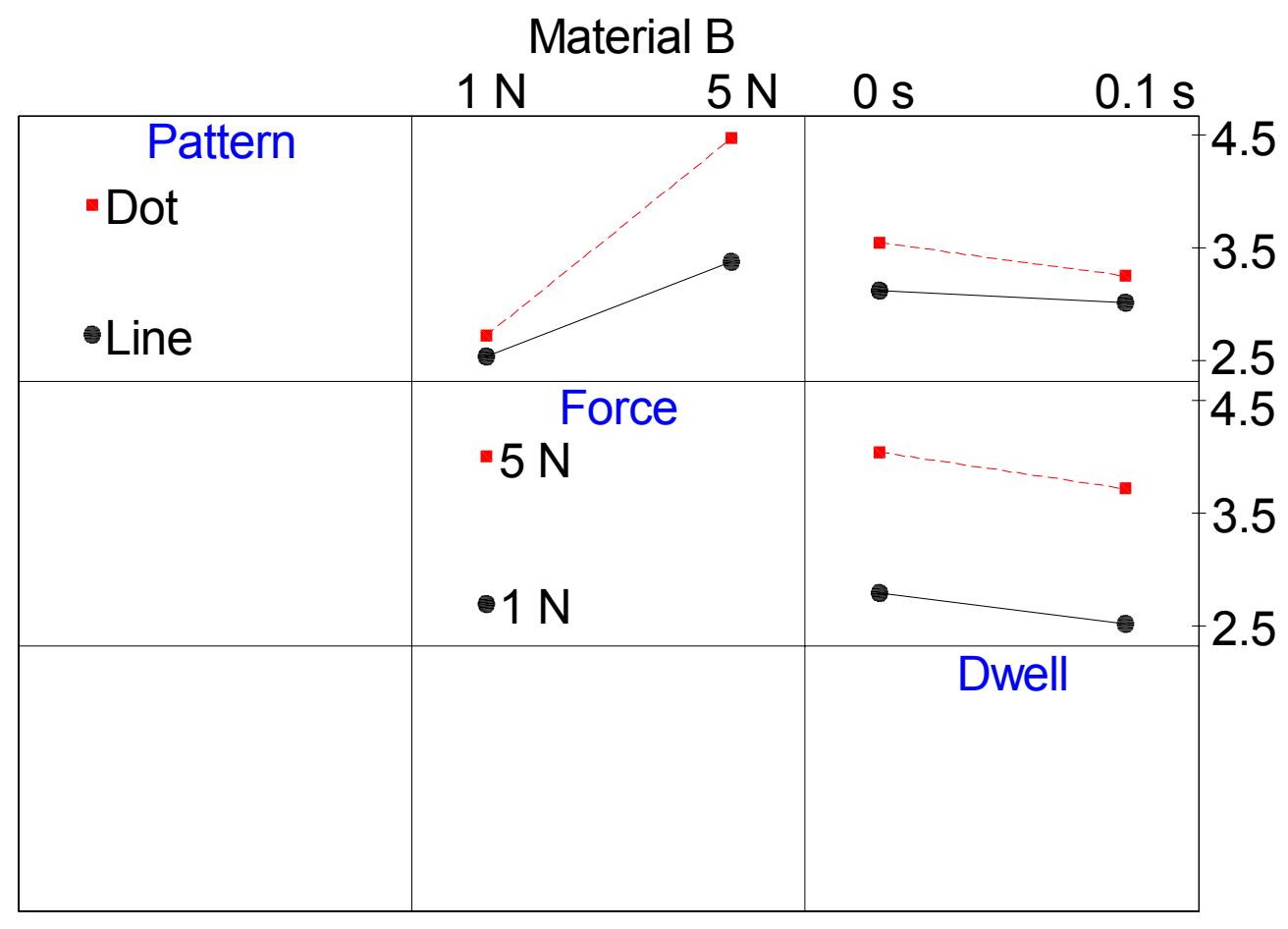

Figure 4-22 Material B, DOE2 Interaction Effects Plots including Pattern-Force, Pattern-Dwell, and Force-Dwell Interactions 


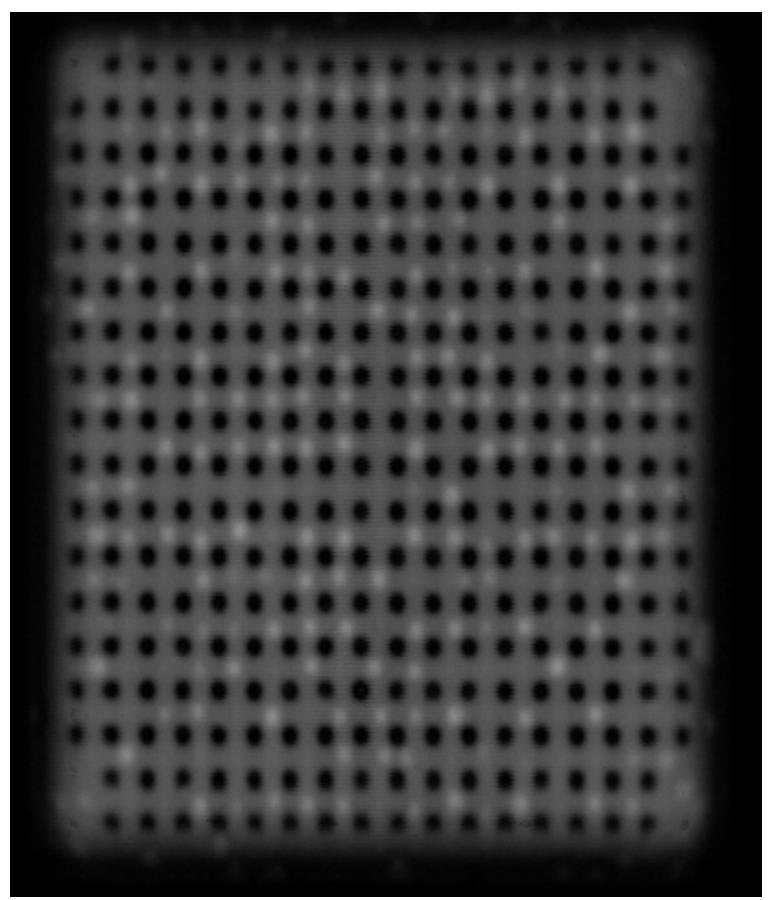

Figure 4-23 Material B, Dot, $1 \mathrm{~N}, 0.0 \mathrm{~s}$

\subsubsection{Material C Results for DOE2}

The voiding ANOVA results for Material $C$ are displayed in Table 4-9. The main effects plots are shown in Figure 4-24. Interaction effects are shown in Figure 4-25. The p-value for pattern does not appear at a significant level for this material. Similar to Material B results, an increase in force is seen to increase voiding, and the $p$-value (<.001) indicates that this effect is significant. Furthermore, a pattern-force interaction shows up once again, this time at the 0.10 significance level. A sample CSAM image is shown in Figure 4-26. 
Table 4-9 Material C, ANOVA Results for DOE2

\begin{tabular}{|c|c|c|c|c|c|c|}
\hline Source & DF & Seq SS & Adj SS & Adj MS & F-Ratio & $p$-value \\
\hline$\overline{\text { Pattern }}$ & 1 & 0.4753 & 0.4753 & 0.4753 & 2.10 & 0.159 \\
\hline Force & 1 & 5.2003 & 5.2003 & 5.2003 & 23.03 & $<.001$ \\
\hline Dwell & 1 & 0.3003 & 0.3003 & 0.3003 & 1.33 & 0.260 \\
\hline Pattern*Force & 1 & 0.8128 & 0.8128 & 0.8128 & 3.60 & 0.069 \\
\hline Pattern*Dwell & 1 & 0.0078 & 0.0078 & 0.0078 & 0.03 & 0.854 \\
\hline Force*Dwell & 1 & 0.1378 & 0.1378 & 0.1378 & 0.61 & 0.442 \\
\hline Error & 25 & 5.6453 & 5.6453 & 0.2258 & & \\
\hline Total & 31 & 12.5797 & & & & \\
\hline
\end{tabular}

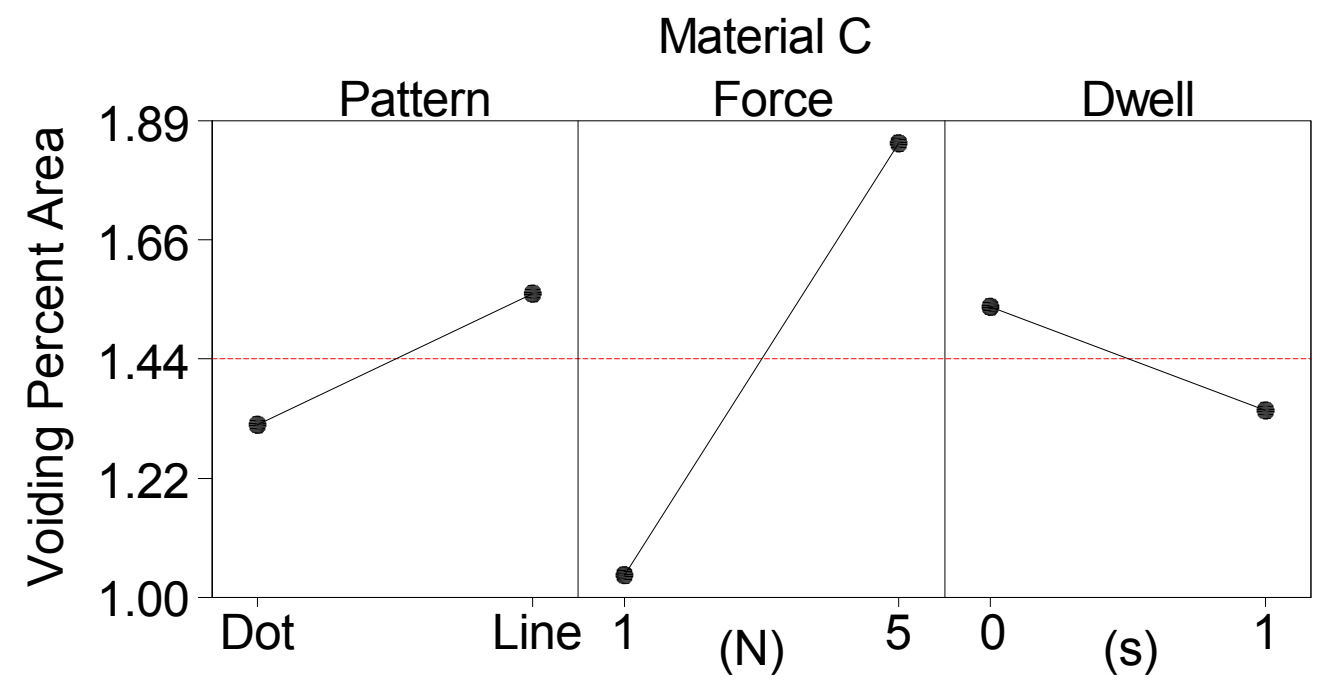

Figure 4-24 - Material C, Main Effects Plots for DOE2 


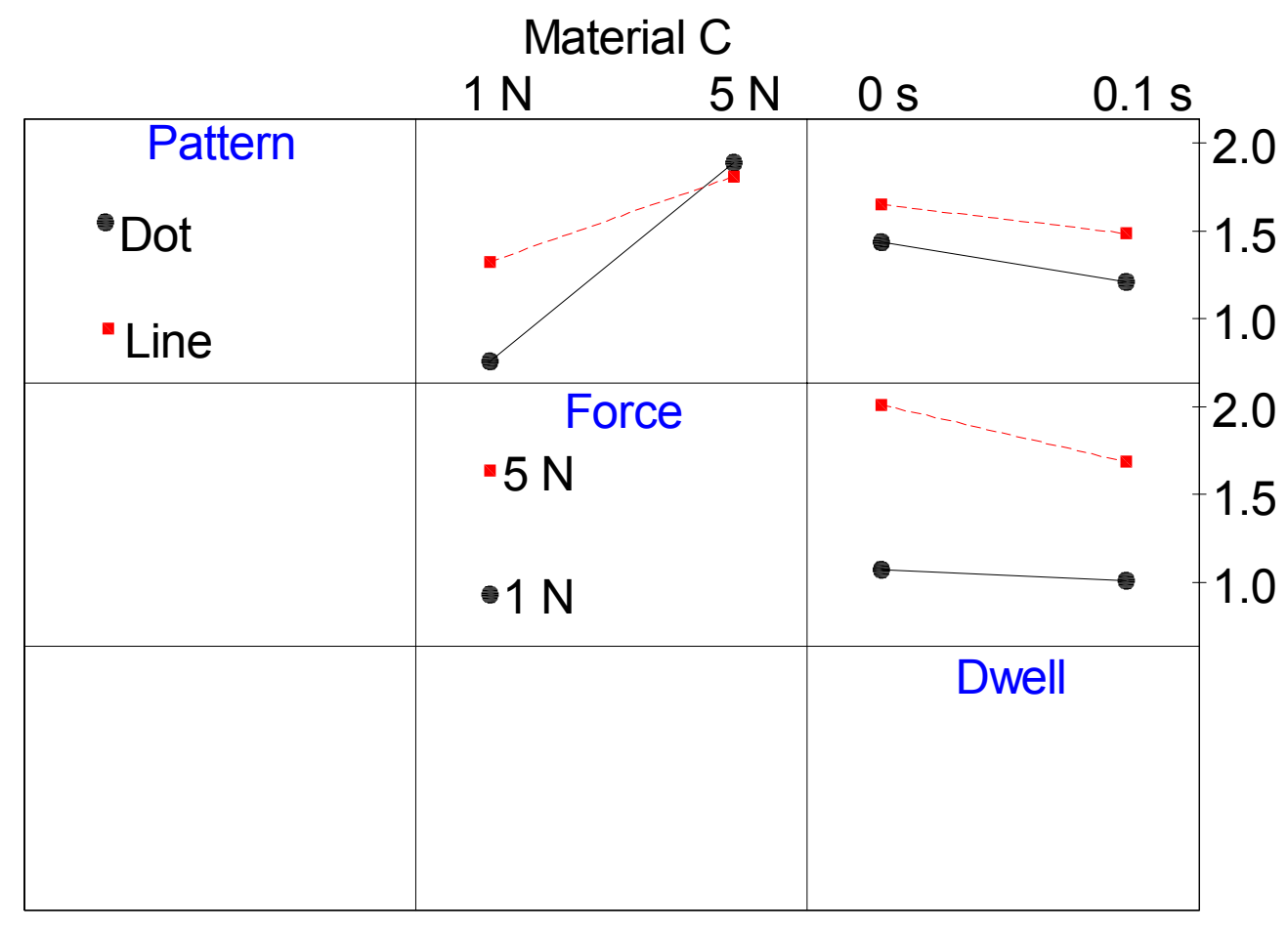

Figure 4-25 Material C, DOE2 Interaction Effects Plots including Pattern-Force, Pattern-Dwell, and Force-Dwell Interactions

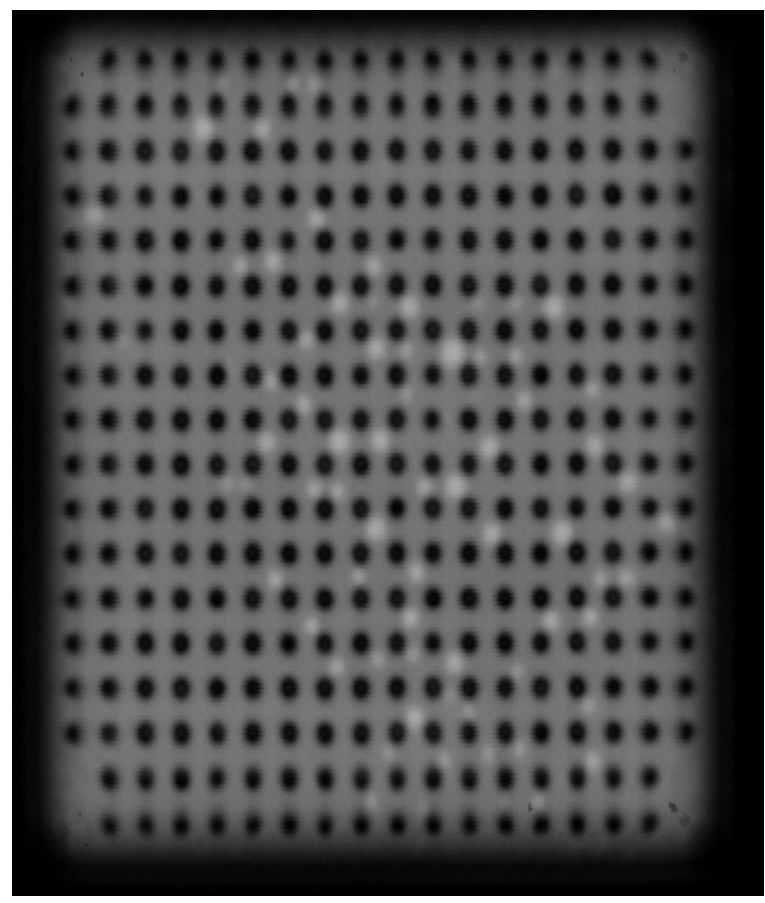

Figure 4-26 Material C, Line, 5N, 0.1s 


\subsubsection{Material D Results for DOE2}

The voiding ANOVA results for Material D are displayed in Table 4-10. The main effects plots are shown in Figures 4-27. Interaction effects are shown in Figure 4-28. The $p$-value for pattern is $<.001$, indicating a statistically significant result. Both pattern-force and force-dwell interactions show up at the 0.10 and 0.05 significance level respectively. Sample CSAM images are shown in Figures 4-29 and 4-30.

Table 4-10 Material D, ANOVA Results for DOE2

\begin{tabular}{|c|c|c|c|c|c|c|}
\hline Source & DF & Seq SS & Adj SS & Adj MS & F-Ratio & $p$-value \\
\hline$\overline{\text { Pattern }}$ & 1 & 415.440 & 415.440 & 415.440 & 110.57 & $<.001$ \\
\hline Force & 1 & 0.165 & 0.165 & 0.165 & 0.04 & 0.836 \\
\hline Dwell & 1 & 5.528 & 5.528 & 5.528 & 1.47 & 0.236 \\
\hline Pattern*Force & 1 & 6.390 & 6.390 & 6.390 & 1.70 & 0.204 \\
\hline Pattern*Dwell & 1 & 14.178 & 14.178 & 14.178 & 3.77 & 0.063 \\
\hline Force ${ }^{\star}$ Dwell & 1 & 20.003 & 20.003 & 20.003 & 5.32 & 0.030 \\
\hline Error & 25 & 93.930 & 93.930 & 3.757 & & \\
\hline Total & 31 & 555.635 & & & & \\
\hline
\end{tabular}




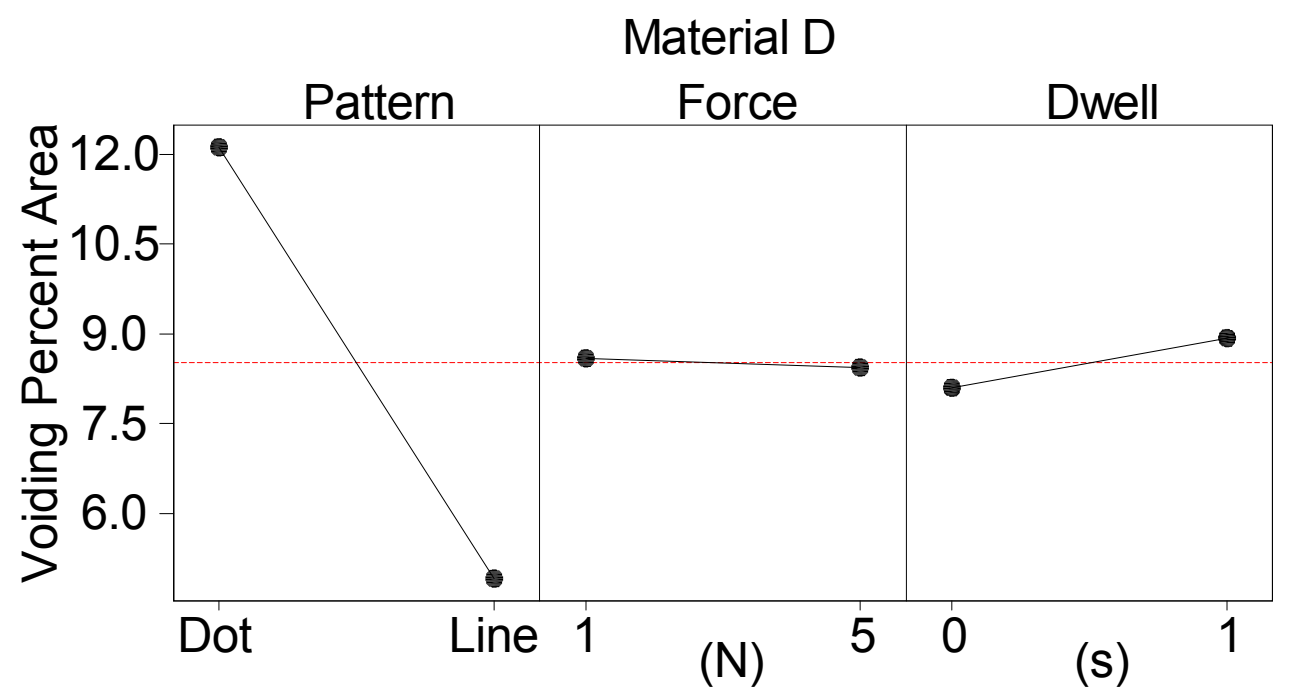

Figure 4-27 Material D, Main Effects Plots for DOE2

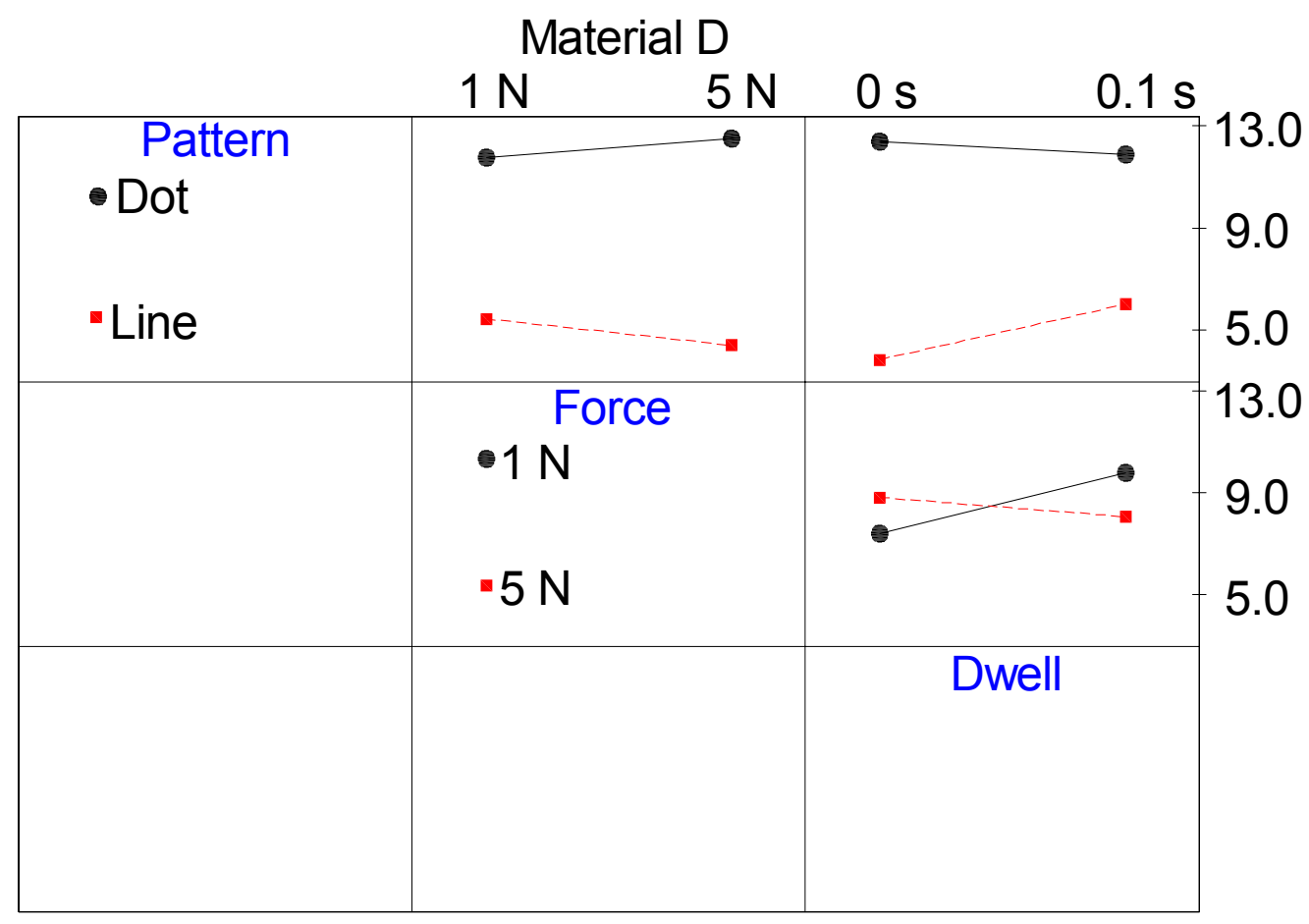

Figure 4-28 Material D, DOE2 Interaction Effects Plots including Pattern-Force, Pattern-Dwell, and Force-Dwell Interactions 


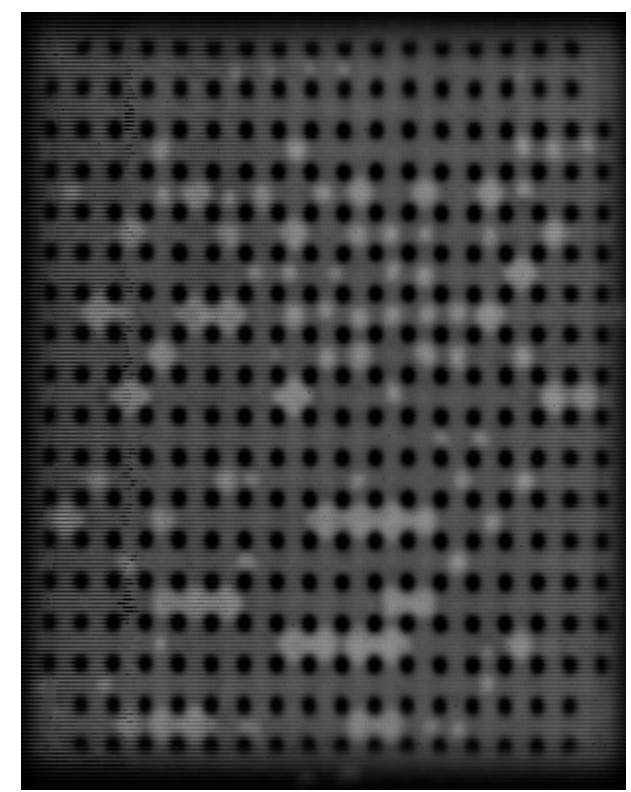

Figure 4-29 Material D, Line, 5N, 0.1s

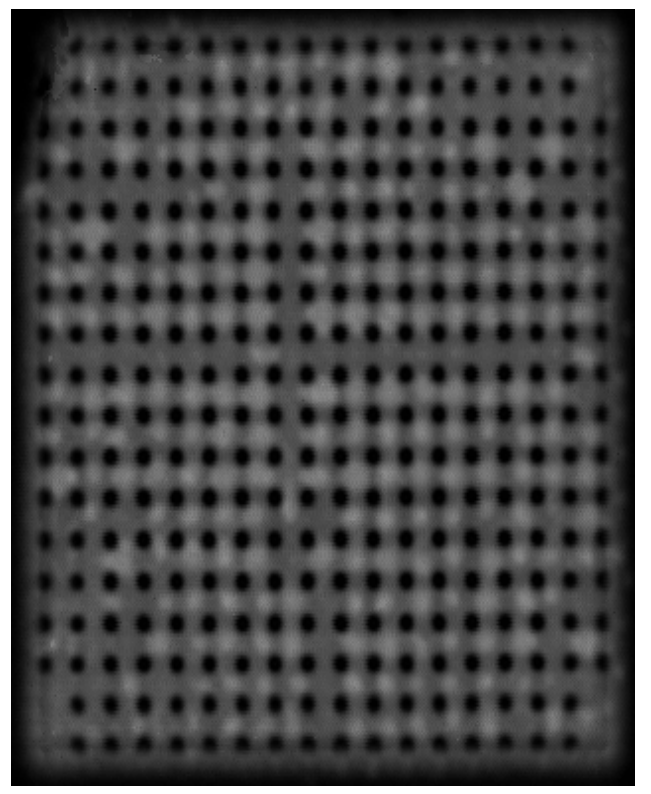

Figure 4-30 Material D, Dot, $1 \mathrm{~N}, 0.0 \mathrm{~s}$ 


\subsubsection{Material E Results for DOE2}

The voiding ANOVA results for Material E are displayed in Table 4-11. The main effects plots are shown in Figures 4-31. Interaction effects are shown in Figure 4-32. The p-value for pattern appears at the 0.05 significance level. An increase in force appears to decrease voiding, in contrast to Materials A and B, and the p-value (.05) indicates that this effect may be statistically significant. Representative CSAM images appear in Figures 4-33 and 4-34. 
Table 4-11 Material E, ANOVA Results for DOE2

\begin{tabular}{|c|c|c|c|c|c|c|}
\hline Source & DF & Seq SS & Adj SS & Adj MS & F-Ratio & $p$-value \\
\hline$\overline{\text { Pattern }}$ & 1 & 2.365 & 2.365 & 2.365 & 5.22 & 0.031 \\
\hline Force & 1 & 1.950 & 1.950 & 1.950 & 4.30 & 0.048 \\
\hline Dwell & 1 & 0.165 & 0.165 & 0.165 & 0.36 & 0.551 \\
\hline Pattern*Force & 1 & 0.525 & 0.525 & 0.525 & 1.16 & 0.292 \\
\hline Pattern*Dwell & 1 & 0.113 & 0.113 & 0.113 & 0.25 & 0.622 \\
\hline Force*Dwell & 1 & 1.088 & 1.088 & 1.088 & 2.40 & 0.134 \\
\hline Error & 25 & 11.328 & 11.328 & 0.453 & & \\
\hline Total & 31 & 17.535 & & & & \\
\hline
\end{tabular}

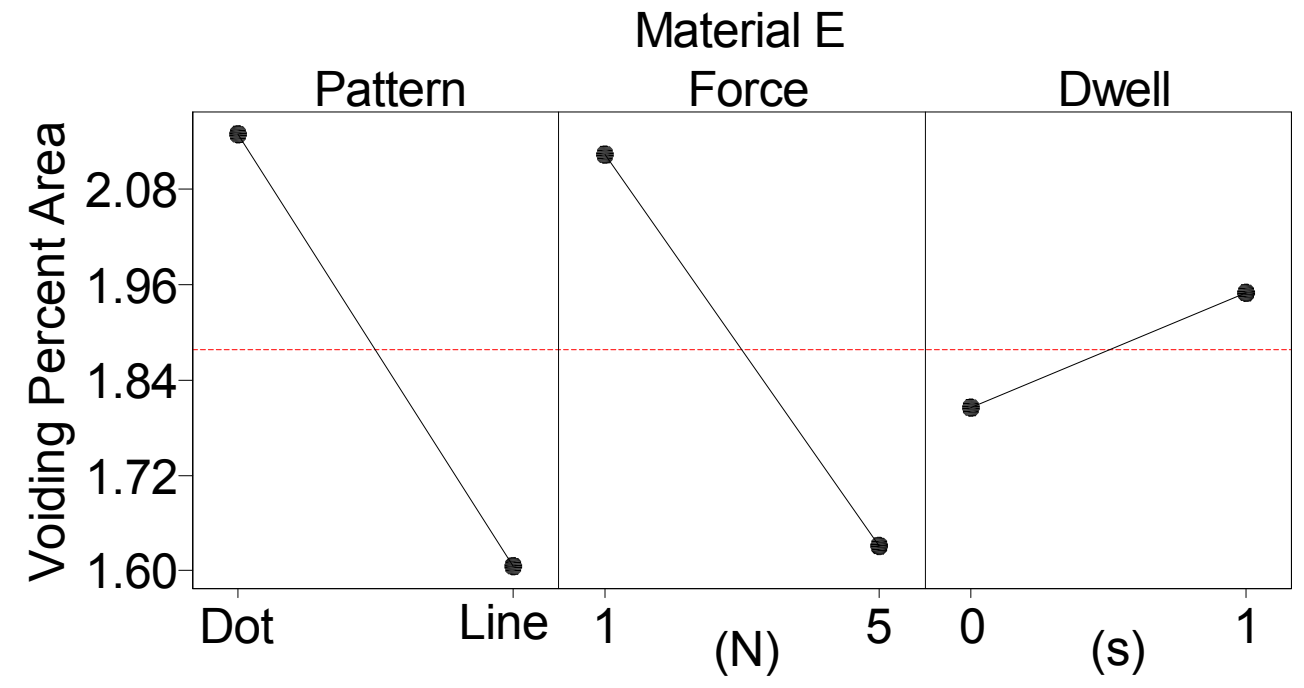

Figure 4-31 Material E, Main Effects Plots for DOE2 


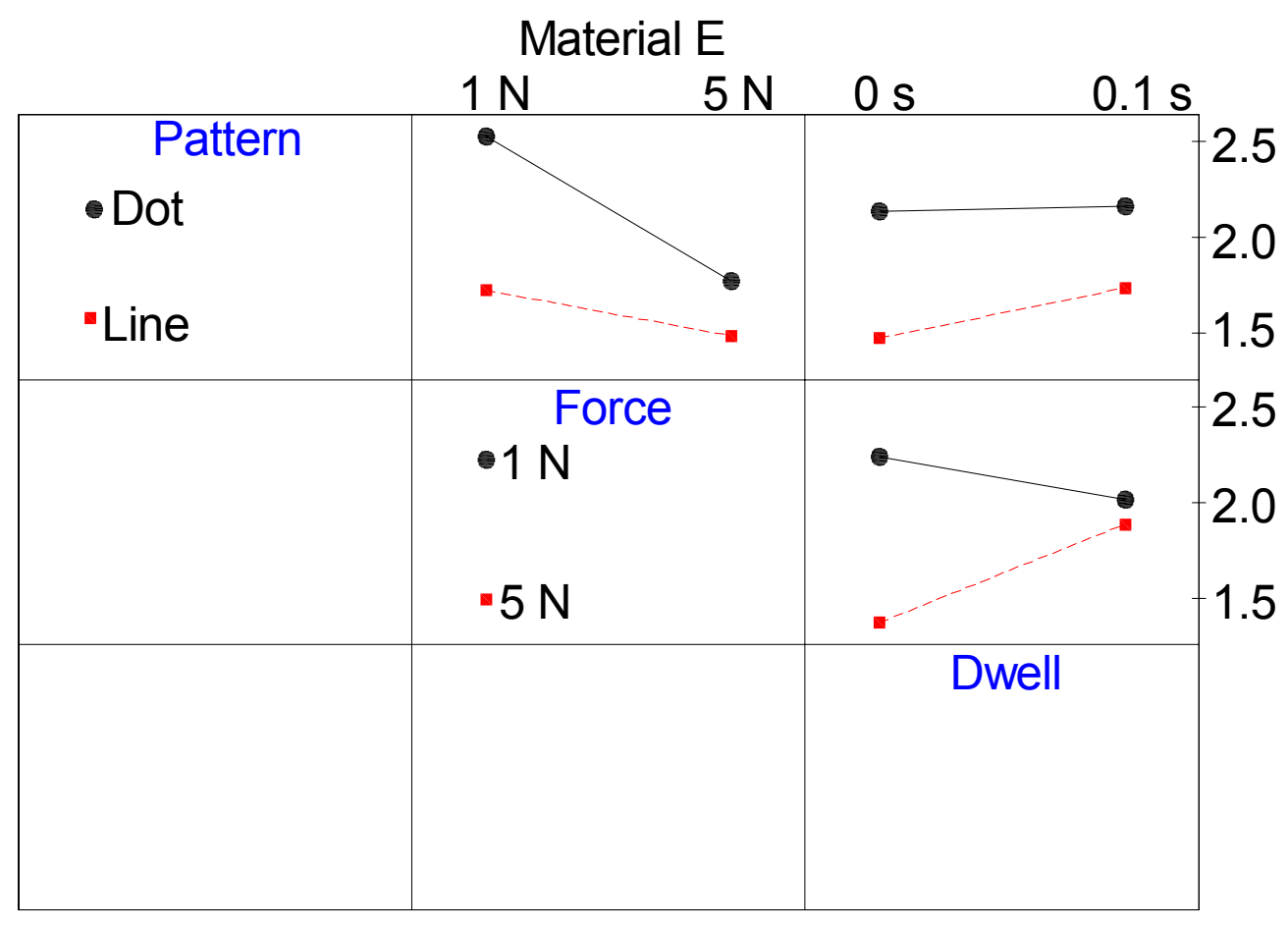

Figure 4-32 Material E, DOE2 Interaction Effects Plots including Pattern-Force, Pattern-Dwell, and Force-Dwell Interactions

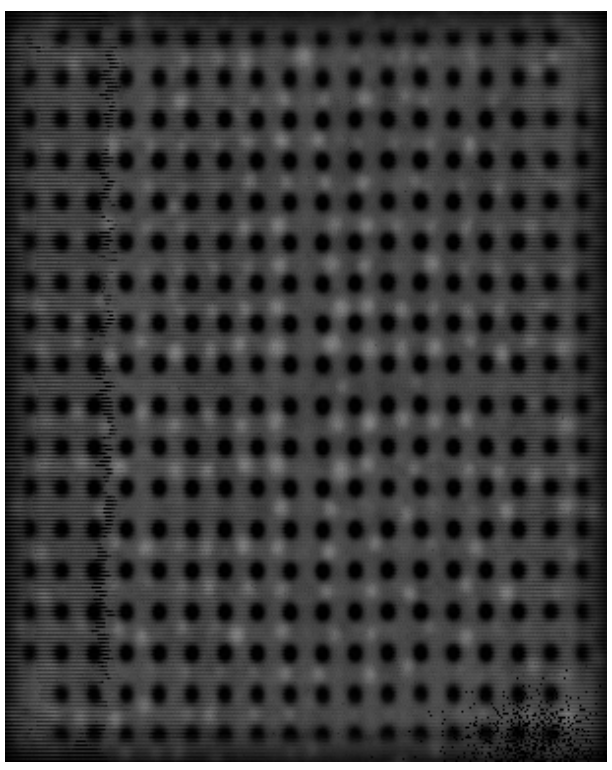

Figure 4-33 Material E, dot, $5 \mathrm{~N}, .1 \mathrm{~s}$ 


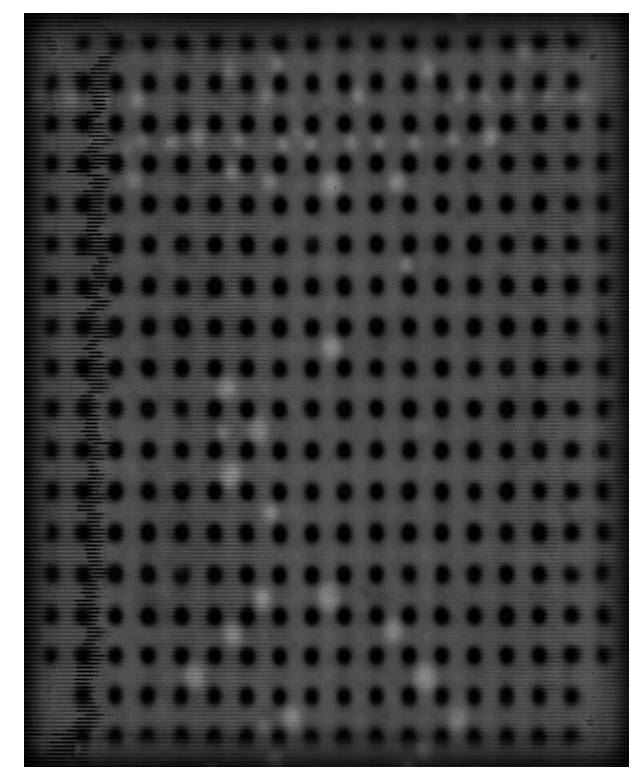

Figure 4-34 Material E, line, 5N, 0s

\subsection{Discussion: Design of Experiments \#2}

\subsubsection{Discussion of Interconnect Results for DOE2}

All of the treatments resulted in 100 percent interconnect yield except for the 111 treatment (dot, $1 \mathrm{~N}, 0.0 \mathrm{~s})$. Yield summary results for this treatment are shown in Table 4-12. The treatment was expected to potentially have yield problems because the chip is being placed onto a dot of underfill with a relatively small force and with no dwell time after the placement machine force limit is triggered. This combination is likely to result in the release of the chip before it 
makes contact with the substrate, and this hypothesis will be investigated by employing a processing model discussed here.

Table 4-12 Interconnect Yield for the 111 treatment (Dot, 1N, 0s)

\begin{tabular}{c||c}
\multicolumn{1}{c||}{ Material } & Yield \\
\hline \hline A & $25 \%$ \\
\hline B & $25 \%$ \\
\hline C & $0 \%$ \\
\hline D & $50 \%$ \\
\hline E & $25 \%$
\end{tabular}

The force required to place the chip through a dot of underfill has been estimated by several researchers [Pascarella 1998, Milner 2001]. The methods employed use a squeeze flow analysis based on earlier work [Leider 1974].

As a means to understanding the interconnect results of the 111 treatment presented earlier, the equations presented by Pascarella will be adopted here, substituting the geometry and placement speed utilized for this research. The equation of interest is the simplified version, for Newtonian flow, the force acting over the surface of the chip is given by equation (4.6).

$$
F=\frac{3 \pi \mu v_{p}}{h^{3}}\left(\frac{V}{\pi h_{o}}\right)^{2}
$$


The Siemens F5 placement machine is hard-coded to work by moving the chip toward the substrate at $70 \mathrm{~mm} / \mathrm{s}$ until the force on the placement head reaches the programmed force limit. For the 111 treatment of interest (Dot, $1 \mathrm{~N}, 0$ dwell), this force limit is $1 \mathrm{~N}$. Once the force limit is triggered, the chip is placed under constant force for the time specified as the dwell time. For the 111 treatment the dwell time is 0 , so the chip is immediately released when the force is $1 \mathrm{~N}$. The force of placement vs. standoff gap reduction as the chip lowers toward the substrate is shown in Figure 4-35. The initial conditions used to create the plot in Figure 4-35 are displayed in Table 4-13.

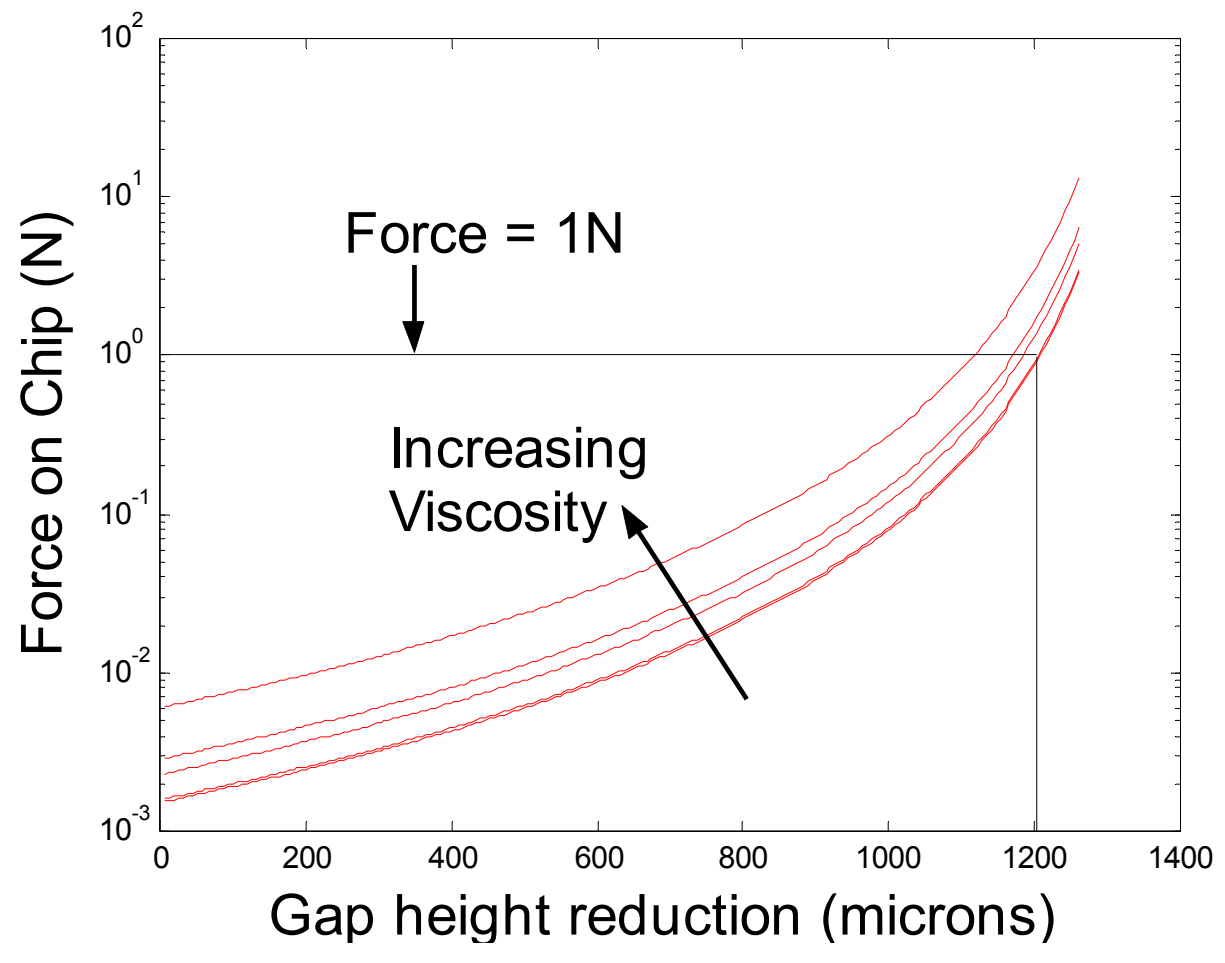

Figure 4-35 Materials A, B, C, D, and E, Force model for the 111 treatment 
Table 4-13 Parameters Used for Figure 4-28

\begin{tabular}{|c|c|}
\hline \multicolumn{2}{|c|}{ Simulation Parameters for Placement Force Estimate } \\
\hline $\mathrm{V}=$ Volume of Underfill Dispensed & $8 \mathrm{mg}$ \\
\hline $\mathrm{vp}=$ Placement Velocity & $70 \mathrm{~mm} / \mathrm{s}$ \\
\hline$\mu=$ Undefill Viscosity (Varied) & $2400-9500 \mathrm{cP}$ \\
\hline ho $=$ Initial height of Underfill Slug & $1.4 \mathrm{~mm}$ \\
\hline
\end{tabular}

The parameter $h_{\circ}$ was determined by assuming that the initial volume of underfill was in the form of a cylindrical slug of radius $1.25 \mathrm{~mm}$ when the chip first impacts the material. The underfill would actually be much closer in shape to a truncated spherical cap, however for the purposes of this analysis the distinction is unimportant because we are concerned only with the forces developed at some later time during placement when the underfill can be assumed to be in fully developed squeeze flow closely approximated by the curves shown in Figure 435.

Considering the curves shown in Figure 4-35, we can begin to understand the cause of the poor interconnect results for the 111 treatment. When viewing the line drawn at the release force of $1 \mathrm{~N}$, it can be seen that even for the underfill with the lowest viscosity, this model predicts that a gap height reduction of only about 1200 microns is possible before the machine will release the chip. Comparing this value to the initial gap height, equal to the initial height of the underfill or 1400 microns, we see that this model predicts that the chip release will happen at approximately 200 microns above the substrate. With a gap height of about 100 microns corresponding to when the bumps touch the pads, it is then 
estimated that the chip will have 100 microns to "free fall" though the underfill deposit. The result is then, that the chip may drift and settle on the substrate shifted slightly from the intended placement position. This misplacement was confirmed via x-ray analysis for the assemblies that did not yield after reflow (Figure 4-36).

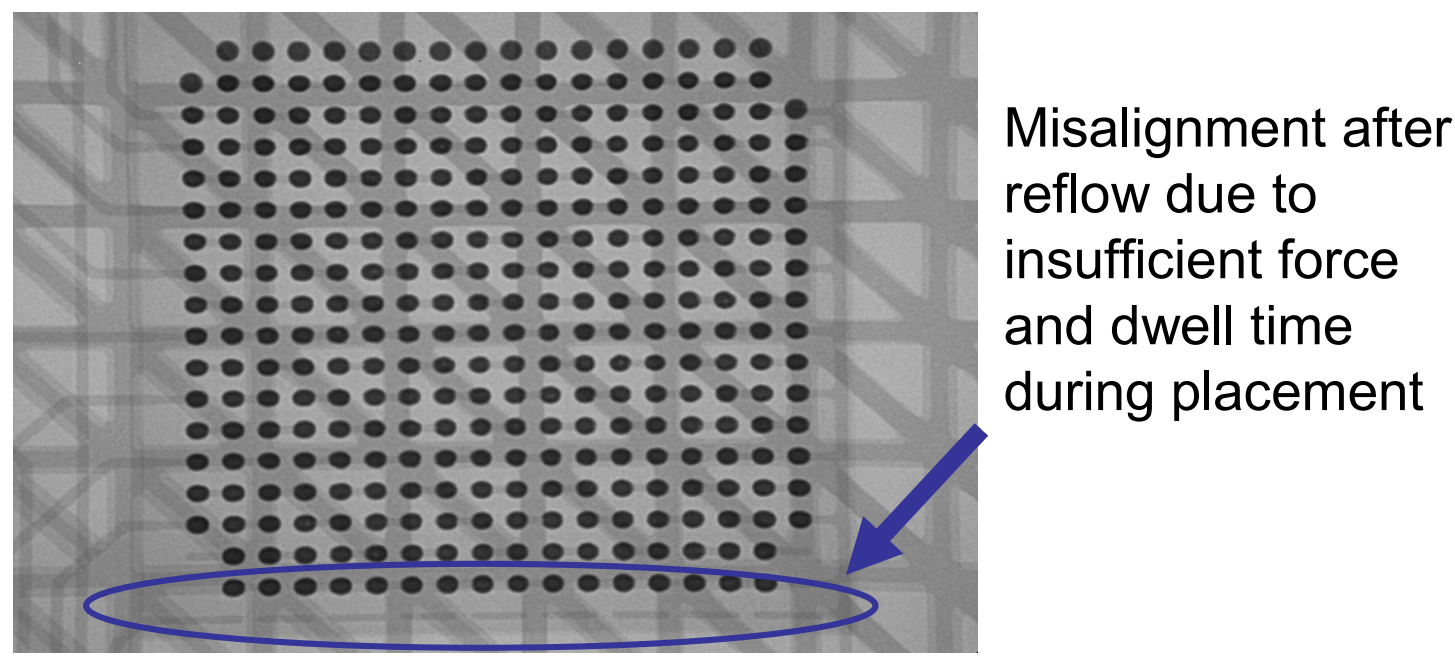

Figure 4-36 111 Treatment, Proposed Drift Mechanism for Yield Loss

\subsubsection{Discussion of Voiding Results for DOE2}

A summary of the statistical analysis for voiding is presented in Table 414. The specific findings will be discussed here, along with the recommendation for optimal processing parameters based on these results. The discussion topics are organized according to the following Sections: Pattern, Dwell Time, Force, Interactions, Material D elimination, and Conclusion. 
Table 4-14 Summary of Placement DOE Significance for Voiding

\begin{tabular}{|c|c|c|c|c|c|c|}
\hline & Pattern & Force & Dwell & Pattern*Force & Pattern*Dwell & Force*Dwel \\
\hline Material A & t+++ & & & & & \\
\hline Material B & ++ & +++ & & ++ & & \\
\hline Material C & & +++ & & + & & \\
\hline Material D & +++ & & & & + & ++ \\
\hline Material E & ++ & ++ & & & & \\
\hline
\end{tabular}

\section{Pattern}

The voiding results for pattern follow the same trend that was seen in DOE1. The very low $p$-values for pattern indicate that the line pattern is clearly the best choice for the remaining reflow experiment and final build for reliability testing.

The material $\mathrm{C}$ assemblies do not show a statistically significant result for pattern. The reason for this result is not clear, however, there is one reasonable possibility. Material $\mathrm{C}$ does have a significantly higher viscosity than all of the other underfills. This high viscosity is expected to make it more difficult for Material $\mathrm{C}$ to easily flow into the pad openings during the capillary flow when using the line pattern. More replicates would be necessary to fully investigate this result in order to determine if it is an anomaly or representative of the usual behavior of this underfill. Limitations on boards and chips restrict this research from a more in depth study of this result for material C. 
Some fillet non-uniformity was observed for both line and dot patterns. The fillet data was not strictly quantified, but the line pattern does appear to result in a difference of about 20 percent volume between the dispense side of the chip and the opposite side. However, both sides have well shaped fillets and therefore the line pattern, based on the voiding statistics, is selected as the best pattern to be used in the remaining experiment.

\section{Dwell Time}

Considering Table 4-14, dwell time does not appear as a significant factor effecting voiding for any material and it is therefore recommended that a dwell time of $0.0 \mathrm{~s}$ is used in future builds. This recommendation is possible because the line pattern has already been selected; therefore, we do not have to be concerned with the interconnect results presented in section 4.4.1. This decision is supported based on two considerations. First, with the pattern of choice for further experimentation being the line pattern it makes sense that the dwell time should not be a critical factor because the chip is placed with very little contact onto the dispensed underfill. This makes a dwell time unnecessary to avoid release above the substrate, as is possible with a dot dispense. Secondly, the dwell time of 0.0 s is desirable when considering the viability of this process for a high volume manufacturing environment. The reduced dwell time results in better throughput and therefore is more desirable from a practical standpoint.

Other researchers have investigated a die "floating" phenomenon that can sometimes be a concern for interconnect yield in flip chip assemblies [Thorpe 2001, Kim 2003]. The die floating phenomenon is created when the buoyancy 
force from the underfill is greater than the total of the weight of the die combined with the surface tension forces acting around the perimeter of the die. There are numerous factors that determine whether a die will float after placement. Underfill related factors include amount, surface tension, viscosity, and density. The die geometry is also a determining factor for chip floating. Note that the line pattern yielded $100 \%$ for all treatments, including the treatments with no dwell time; therefore, the chip floating phenomenon does not pose a concern for the die/board/underfill combinations used in this research. Thus, no dwell time is selected as a process parameter for the remaining experimental work.

\section{$\underline{\text { Force }}$}

The effects of Force on voiding are mixed based on the experimental results. For two materials (A and D) force does not appear as a significant factor. While for materials $B$ and $C$ force appears significant with a higher force resulting in increased voiding. Finally, in contrast, Material E displays better performance (lower voiding percentage) with the higher force setting of $5 \mathrm{~N}$.

When considering the placement dynamics described in section 4.4 .1 , as well as the underfill flow voiding mechanism described in Section 4.2.3, we can develop an understanding for the trend seen for materials B and C. For a Newtonian material, at the leading edge of the flow front, in the center of the narrowing standoff gap, the radial velocity of the material under compression flow can be described by Equation (4.7). This follows directly from [Pascarella 1998, Milner 2001] with the assumptions above, or $n=1$ and $z=0$. 


$$
v_{r}=\frac{3 v_{p} r}{h^{2}}
$$

$v_{r}=$ radial velocity of the material, $v_{p}=$ placement speed, $r=$ the

instantaneous underfill flowfront radius, and $h=$ the instantaneous standoff height. As $h$ decreases, $r$ must increase to maintain continuity of mass, specifically $r \propto h^{-1 / 2}$. Considering this, it is seen that as $h$ decreases, the radial velocity of the material must increase as $v_{r} \propto \mathrm{h}^{-5 / 2}$. As explained in Section 4.4.1, the placement machine will only maintain the placement velocity until the force limit is triggered. After the force limit is triggered, the placement velocity will slow to maintain the constant placement force for the required dwell time. Considering the $1 \mathrm{~N}$ and $5 \mathrm{~N}$ force limits and the force vs. standoff gap curves shown in Figure 4-35, it is seen that the $5 \mathrm{~N}$ force limit will accommodate a smaller standoff gap before slowing. Therefore, the radial velocity of the underfill will keep increasing according to Equation (4.7). In fact, one of the main influences over the amount of voiding seen as a result of the mechanisms described in sections 4.2.3 and 4.2.4 is thought to be the radial velocity of the flow front, by the reasoning presented in those sections and by consideration of the shape of the flow front curvature as described by [Milner 2001].

The result obtained for underfill $E$ is not easily reasoned. The results show decreased voiding with the higher force value. There is nothing significantly different about underfill $E$ that would lead to a better understanding of this result. In light of this, there is some concern here with the data as it was collected. This 
anomaly could be further investigated with more replicates and a fully

randomized experimental design. This task was not undertaken for this research, however, because the dot pattern is not investigated further. The force is unimportant in terms of its effect on voiding for the line pattern.

Force can only operate to increase voiding when using the dot or cross pattern because the material is fully under the die flowing by compression flow. The line pattern voiding results are not affected by the placement force because the flow over the pad openings happens slowly after placement. Thus, it is not necessary to consider this effect when using the line pattern. It is recommended that a force of $5 \mathrm{~N}$ be used in further builds for all materials since the materials do not display better performance with a force of $1 \mathrm{~N}$; therefore, we might as well chose the higher force to ensure good contact with the bond pads.

\section{Interactions}

The interaction results summary shown in Table 4-14 does not indicate any clear trend in the data. Several somewhat statistically significant results show up but no clear trend in any one interaction across all the materials. This result provides no basis for a strong conclusion about any of the interactions in Table 4-14. It can often be difficult to determine interaction effects because the magnitude of the effect itself is often fairly small in comparison to the main effects. This means that unless there are many replicates included in the experimental design, the variation in the data will often cloud the interaction effect and the ANOVA result will show a relatively high p-value. It is difficult to say that there are no interaction effects for the process parameters under 
investigation; however, it is possible to conclude with reasonable certainty that if present, the magnitude of an interaction is small in comparison to the main effect for Pattern which easily showed up in the ANOVA.

\section{Material D Elimination}

Material D performed poorly with a mean \% voiding area of 8.5 . This is about $160 \%$ more than the underfill with the second worst voiding performance. There are several possibilities for this result. A "bad" syringe of material could have been used for the build; if there was some problem with the chemistry of the material it could have caused gaseous products during the time in the reflow oven. The boards could have reabsorbed moisture during the time between the pre-bake and the assembly. The pre-bake oven may have malfunctioned resulting in an incomplete moisture removal to begin with. There is no way of distinguishing between a material problem or an equipment problem from the data. Based on this anomalously high voiding result, underfill $D$ was removed from the remaining process development experiments.

\section{Conclusion}

A primary goal of this research was to develop an optimized process for each material; therefore, a decision must be made concerning what dispense and placement process parameters are to be used in the remaining line position experiment, reflow experiment, and the final reliability build. Based on the results from DOE1 and DOE2, and the discussion that followed, the dispense and placement parameters suggested for the remaining experimental work are:

\section{Line Pattern, 5N Force, and 0.0s Dwell Time.}




\subsection{Results: Line Position Study}

All five line positions resulted in $100 \%$ interconnect yield for each part assembled. The fillet results appear to be comparable for each line position, with a small difference in the size of the fillets for the dispense side and side opposite the dispense. The primary goal of this experiment was to determine the line position threshold that determines when significant voiding results due to the flow of the material over the pads or by direct dispense onto the pads. The effect of the line position on voiding is discussed in this section.

The voiding percentage of each assembly was determined by digital image analysis. The voiding results are presented as the mean of the 2 replicates assembled for each position. Percent area voiding and the standard deviation for each line position is displayed in Table 4-15. A representative CSAM image of an assembly for each line placement is shown in Figures 4-37 through 4-41.

Table 4-15 Material A, Line Position Voiding Results

\begin{tabular}{c|c|c}
$\begin{array}{c}\text { Line } \\
\text { Position }\end{array}$ & $\begin{array}{c}\text { Voiding } \\
\text { Percentage }\end{array}$ & $\begin{array}{c}\text { Standard } \\
\text { Deviation }\end{array}$ \\
\hline \hline 1 & 0.00 & 0.00 \\
\hline 2 & 0.00 & 0.00 \\
\hline 3 & 0.28 & 0.11 \\
\hline 4 & 1.36 & 0.24 \\
\hline 5 & 2.31 & 0.29
\end{tabular}




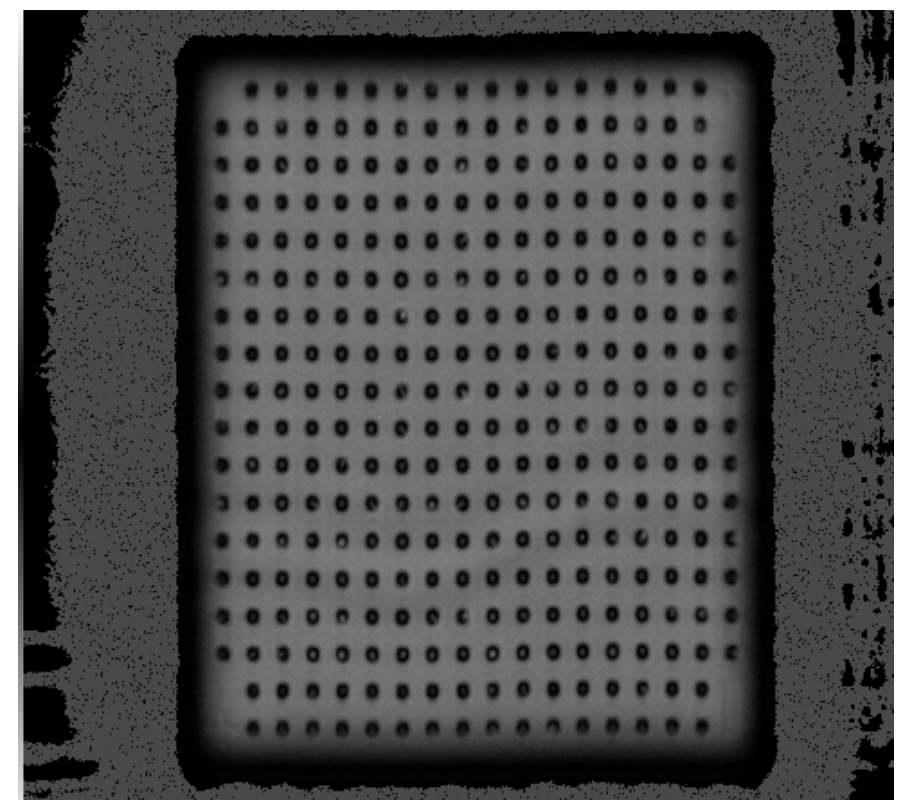

Figure 4-37 Material A, Line Position 1

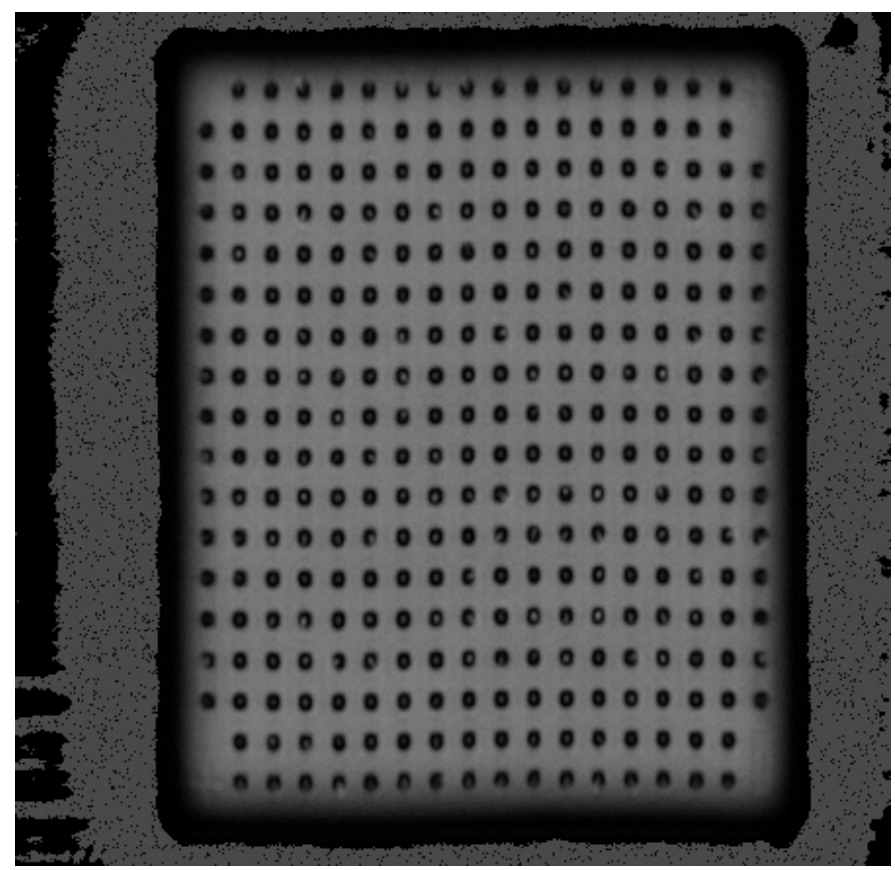

Figure 4-38 Material A, Line Position 2 


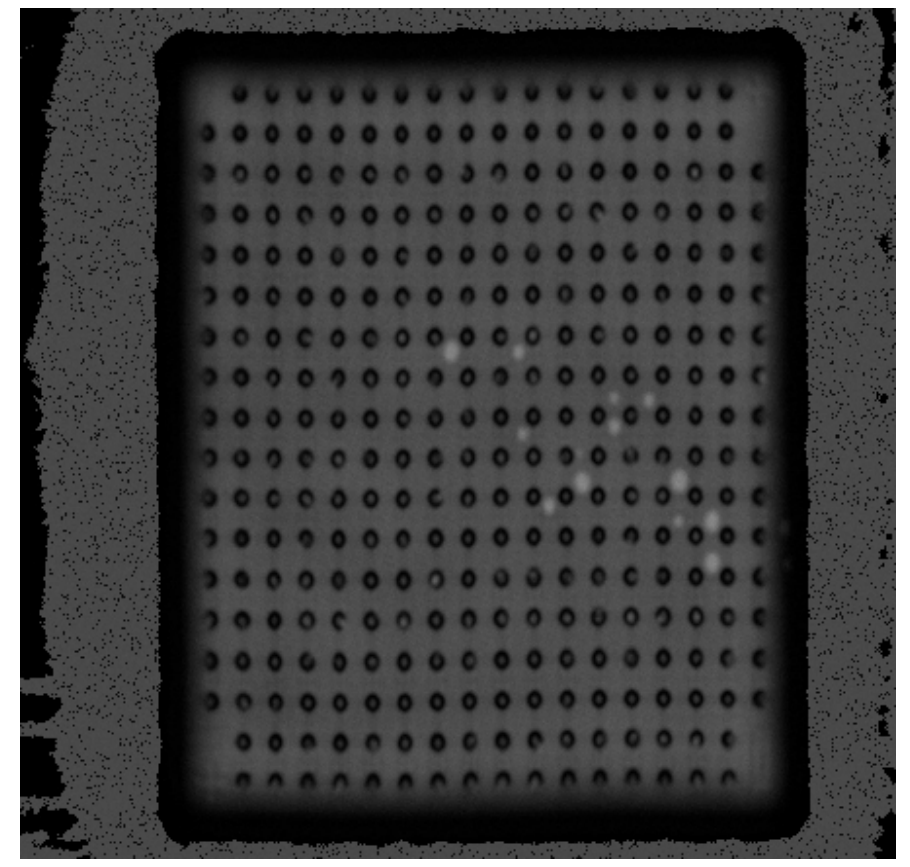

Figure 4-39 Material A, Line Position 3

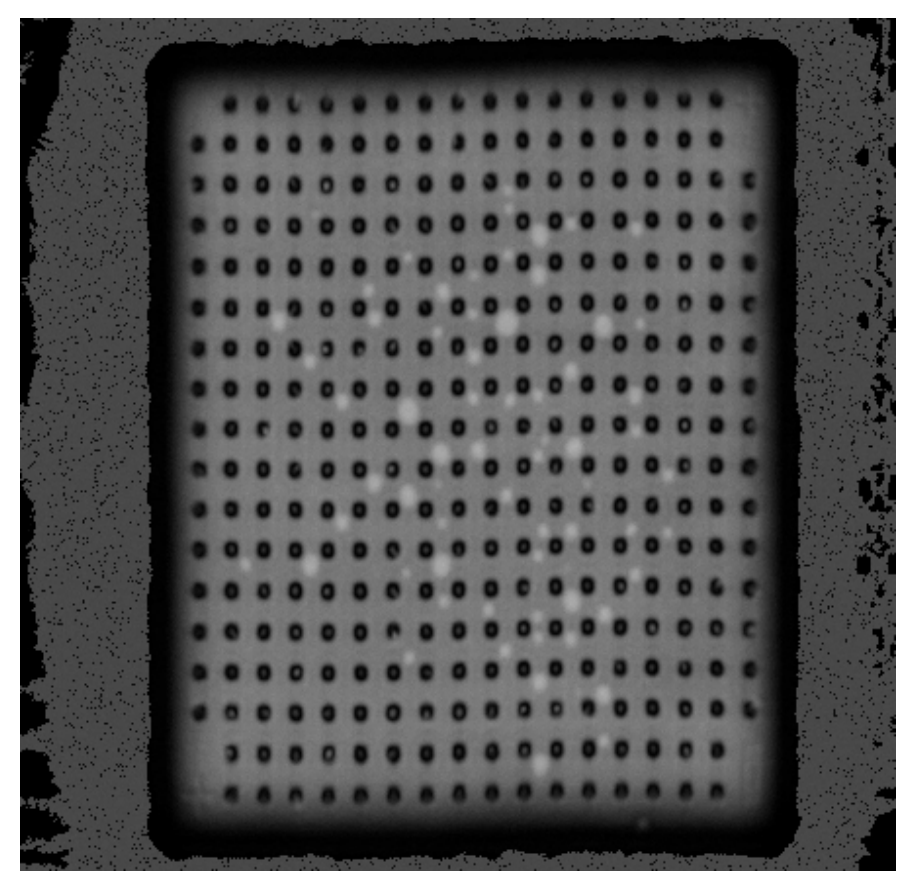

Figure 4-40 Material A, Line Position 4 


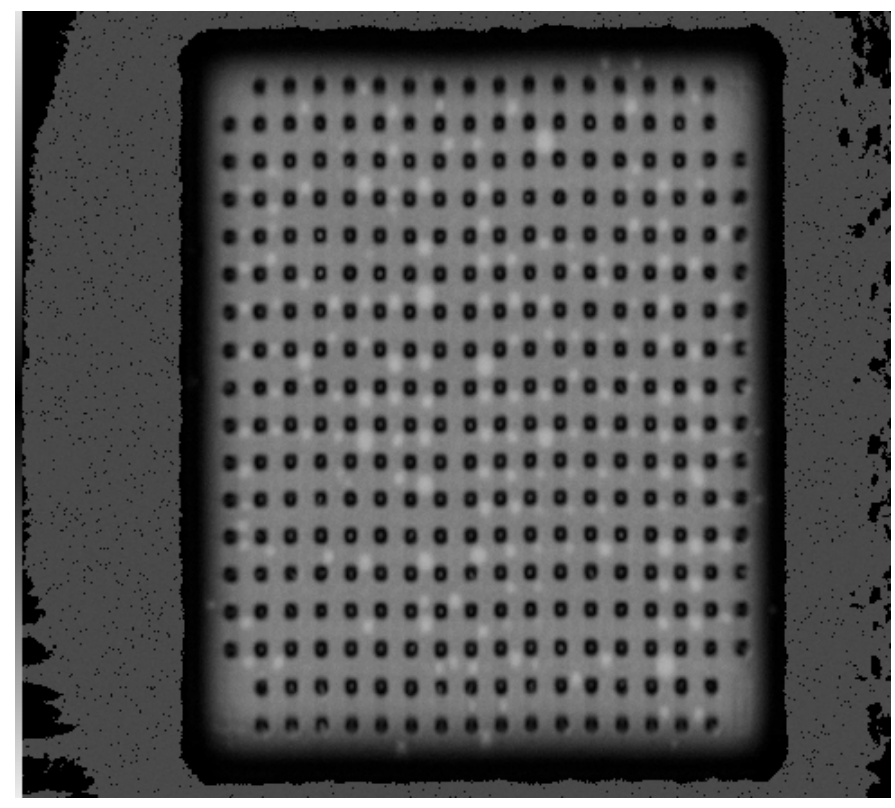

Figure 4-41 Material A, Line Position 5

\subsection{Discussion and Conclusions, Line Position Study}

The position of the dispense line in relation to the edge of the substrate bond site has a clear effect on the percentage voiding of the underfill. A nondimensional position ratio was employed to uncouple the specific device geometry from the results of the study. The non-dimensional ratio $X_{\text {edge }} / h_{\text {bump }}$ was selected to create a ratio that is normalized by a characteristic length of the device. $X_{\text {edge }}$ is the distance from the die edge to the axis of the dispense line, with positive values falling underneath the die. $h_{\text {bump }}$ is the height of the solder bump before reflow (120 $\mu \mathrm{m}$ for FA10-2 die). The non-dimensional voiding results are displayed graphically in Figure 4-42 with the shaded area of the plot corresponding to the region under the die. 


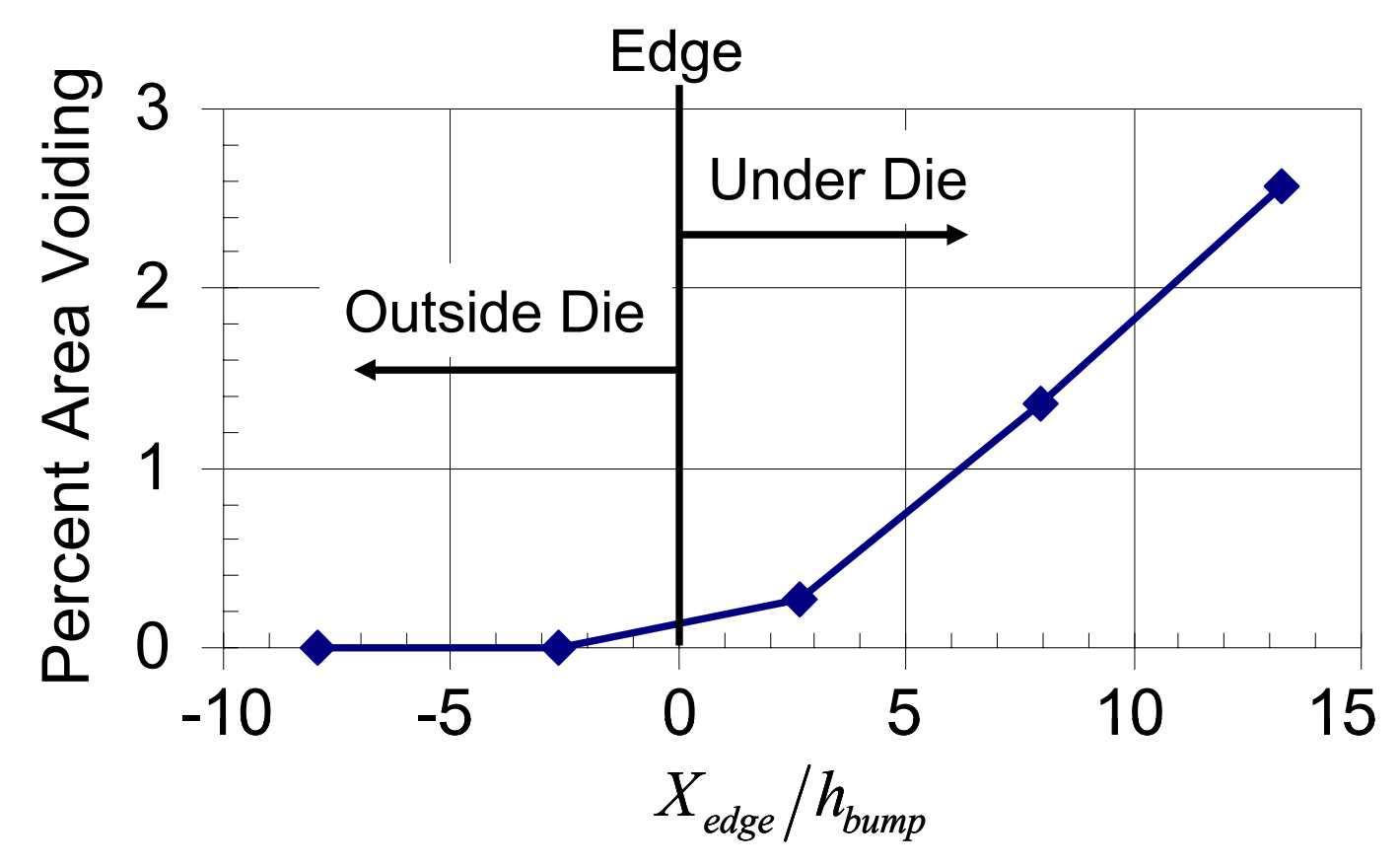

Figure 4-42 Voiding vs. Non-Dimensional Line Position

It is clear from Figure 4-42 that there are regions where the line can be positioned such that no voiding is present in the final assemblies. This region extends from about the edge of the die to a location that is approximately 8 nondimensional units to the outside of the die edge. This indicates that the capillary flow dynamic of the assembly process does not inherently produce voids as the material flows under the die. Thus, any voids present in earlier experiments are most likely due to placement of the line too close to the pad openings which can result in trapped air due to the dispense or to voids forming due to a partial compression flow dynamic of the material over the pads during placement. Note, a more detailed discussion of voids caused by direct dispense onto pads is presented in Section 4.2.2. 
The results of would be expected to begin to show up based on where the center line of the dispense would intersect the substrate, and the dimension of the needle diameter. These results then make intuitive sense and the small sample size $(n=2)$ for this experiment does not pose much of a concern.

In summary, the effect of line placement on voiding shows a relatively clear cutoff for where the line must be placed in relation to the outermost pad openings on the substrate. This critical placement position is located somewhere within the region between position 2 and position 3 , for which a more exact value could be determined empirically without much difficulty.

\subsection{Results and Discussion: Parametric Reflow Characterization}

The reflow profile results are presented for each material in Sections 4.7.1 through 4.7.4. The methodology used to assign the profile rankings is presented in Section 4.7.5, and a discussion of the results is presented in Section 4.7.6.

\subsubsection{Reflow Results, Material A}

The relative rankings of all the profiles for material A are listed in Table 416. Three of the profiles did not yield $100 \%$ and therefore are not assigned a rank because yield must be $100 \%$ to make the profile worth considering in terms of the other metrics. 
Table 4-16 Material A, Reflow Profile Rankings

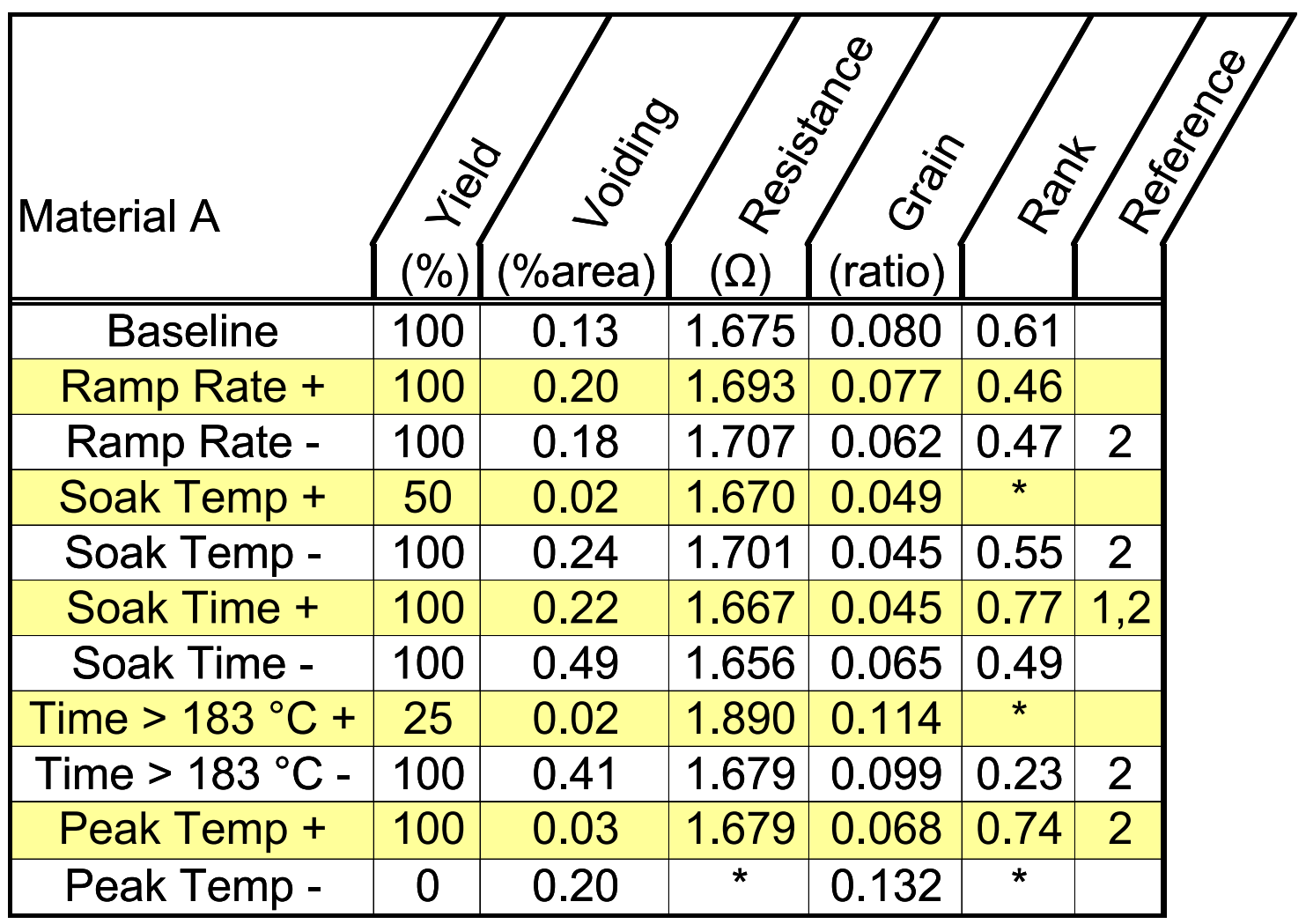

1 - Highest ranked profile

2 - Highest ranked of the $+/$ - levels for each parameter of interest. 


\subsubsection{Reflow Results, Material B}

The relative rankings of all the profiles for material B are listed in Table 4-

17. One of the profiles did not yield $100 \%$ and therefore is not assigned a rank because yield must be $100 \%$ to make the profile worth considering in terms of the other metrics.

Table 4-17 Material B, Reflow Profile Rankings

\begin{tabular}{|c|c|c|c|c|c|c|}
\hline Material B & $(\%)$ & (\%area) & $(\Omega)$ & (ratio) & & \\
\hline Baseline & 100 & 0.38 & 1.704 & 0.058 & 0.37 & \\
\hline Ramp Rate + & 100 & 0.27 & 1.698 & 0.062 & 0.48 & 2 \\
\hline Ramp Rate - & 100 & 0.36 & 1.721 & 0.069 & 0.27 & \\
\hline Time $>183^{\circ} \mathrm{C}+$ & 100 & 0.35 & 1.673 & 0.057 & 0.49 & \\
\hline Time $>183^{\circ} \mathrm{C}-$ & 100 & 0.14 & 1.664 & 0.050 & 0.79 & 2 \\
\hline Peak Temp + & 100 & 0.39 & 1.759 & 0.031 & 0.41 & \\
\hline Peak Temp - & 100 & 0.30 & 1.689 & 0.030 & 0.70 & 2 \\
\hline Time to Peak + & 100 & 0.49 & 1.637 & 0.073 & 0.30 & 2 \\
\hline Time to Peak - & 75 & 0.38 & 1.640 & 0.037 & * & \\
\hline Optimized & 100 & 0.00 & 1.724 & 0.049 & 0.81 & 1 \\
\hline
\end{tabular}

1 - Highest ranked profile

2 - Highest ranked of the +/- levels for each parameter of interest. 


\subsubsection{Reflow Results, Material C}

The relative rankings of all the profiles for material $\mathrm{C}$ are listed in Table 418. All profiles yielded $100 \%$.

Table 4-18 Material C, Reflow Profile Rankings

\begin{tabular}{|c|c|c|c|c|c|c|}
\hline Material C & $(\%)$ & & $(\Omega)$ & (ratio) & & \\
\hline Baseline & 100 & 1.05 & 1.707 & 0.037 & 0.462 & \\
\hline Ramp Rate + & 100 & 0.828 & 1.714 & 0.043 & 0.437 & \\
\hline Ramp Rate - & 100 & 0.675 & 1.713 & 0.044 & 0.480 & 2 \\
\hline Soak Temp + & 100 & 0.493 & 1.676 & 0.033 & 0.819 & 1,2 \\
\hline Soak Temp - & 100 & 0.863 & 1.677 & 0.028 & 0.746 & \\
\hline Soak Time + & 100 & 0.558 & 1.711 & 0.039 & 0.573 & 2 \\
\hline Soak Time - & 100 & 1.085 & 1.726 & 0.053 & 0.207 & \\
\hline Time $>183{ }^{\circ} \mathrm{C}+$ & 100 & 0.27 & 1.680 & 0.042 & 0.782 & 2 \\
\hline Time $>183^{\circ} \mathrm{C}-$ & 100 & 0.68 & 1.705 & 0.059 & 0.373 & \\
\hline Peak Temp + & 100 & 0.743 & 1.674 & 0.042 & 0.660 & 2 \\
\hline Peak Temp - & 100 & 1.553 & 1.662 & 0.038 & 0.501 & \\
\hline Optimized & 100 & 0.178 & 1.728 & 0.03 & 0.700 & \\
\hline
\end{tabular}




\subsubsection{Reflow Results, Material E}

The relative rankings of all the profiles for material $\mathrm{E}$ are listed in Table 4-

19. One of the profiles did not yield $100 \%$ and therefore is not assigned a rank because yield must be $100 \%$ to make the profile worth considering in terms of the other metrics.

Table 4-19 Material E, Reflow Profile Rankings

\begin{tabular}{|c|c|c|c|c|c|c|}
\hline Material E & & (\%area) & & (ratio) & & \\
\hline Baseline & 100 & 3.90 & 1.708 & 0.037 & 0.580 & \\
\hline Ramp Rate + & 100 & 2.27 & 1.734 & 0.078 & 0.520 & \\
\hline Ramp Rate - & 100 & 0.45 & 1.710 & 0.081 & 0.787 & 2 \\
\hline Soak Time + & 100 & 1.52 & 1.766 & 0.049 & 0.557 & 2 \\
\hline Soak Time - & 100 & 1.74 & 1.757 & 0.138 & 0.305 & \\
\hline Time $>183^{\circ} \mathrm{C}+$ & 100 & 1.61 & 1.689 & 0.044 & 0.863 & 1,2 \\
\hline Time $>183^{\circ} \mathrm{C}-$ & 100 & 2.90 & 1.692 & 0.082 & 0.609 & \\
\hline Peak Temp + & 100 & 4.44 & 1.736 & 0.055 & 0.363 & 2 \\
\hline Peak Temp - & 75 & 2.10 & 1.713 & 0.061 & * & \\
\hline Optimized & 100 & 1.24 & 1.683 & 0.055 & 0.890 & \\
\hline
\end{tabular}

1 - Highest ranked profile

2 - Highest ranked of the $+/$ - levels for each parameter of interest. 


\subsubsection{Ranking Methodology}

A ranking was developed for each material based on the observable metrics: interconnect yield, underfill material voiding, two point daisy chain resistance, and a phase size ratio. While the motivation behind an interconnect yield metric is obvious, the motivation behind the other metrics can also be validated by reference to the literature and additional physical reasoning.

The emphasis on underfill voiding as a metric throughout this research can be understood by considering the results of [Schubert, 2000]. His finite element modeling investigation involving the effect of voiding on fatigue life predicted little effect; however, his experimental failure analysis work has led to the conclusion that flip chip devices subjected to thermal cycling are seen to initiate delamination at the site of voids in the underfill. Once initiated, this delamination propagates along the passivation-underfill interface to ultimately render the underfill incapable of sufficiently coupling the die to the board, and thus to fatigue failure of the joint. Additionally, other no-flow underfill research has shown that solder extrusion will occur during thermal cycling [Thorpe 2000]. The path of least resistance to this extrusion is into a void adjacent to the solder bump. This extrusion is undesirable, both because it can cause electrical shorting failures and because it compromises the integrity of the solder joint from which the solder is extruded. Based on these arguments, voiding is the metric of primary concern.

The inclusion of phase size ratio, as described in section 3.9.6, is made based on the observation that fatigue cracks often propagate along the 
boundaries of the $\mathrm{Pb}$ rich regions. It is expected then that in order to maximize the fatigue life of the assemblies, it may be desirable to reduce the incidence of these boundaries with the joint, preferring instead the uniform eutectic microstructure shown as an SEM image in Figure 4-43.

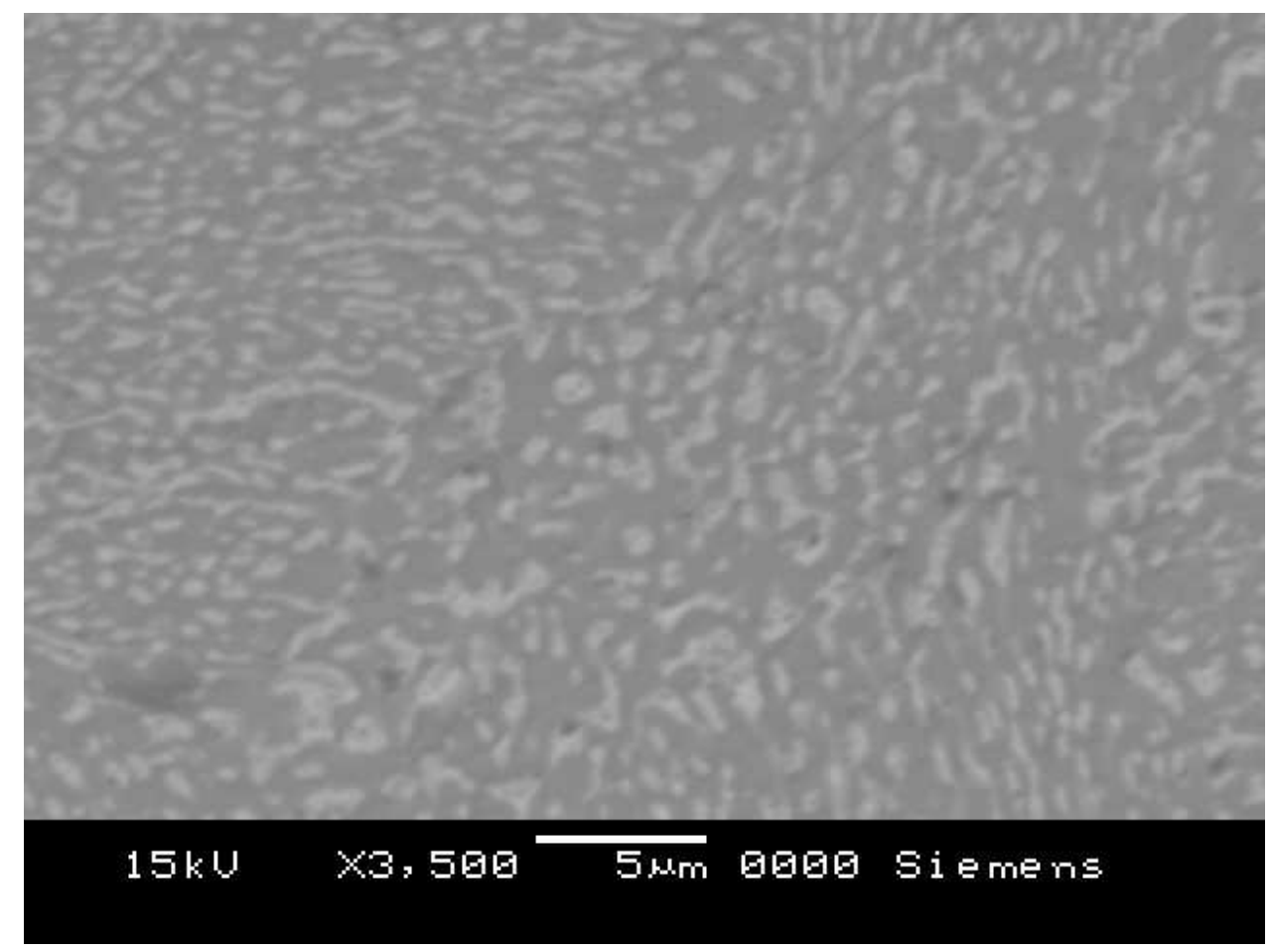

Figure 4-43 Eutectic Microstructure, Relatively Evenly Dispersed Pb-Sn

Finally, resistance is selected as a metric based partly on the results of Fan, who showed experimentally that for PBGA solder joints the smaller the resistance of the joints, the larger the shear strength [Fan, 1998]. Additionally, we know that the resistance will be related to the relative areas of contact between the bump, and the bond pads of both the chip and the substrate. We expect that 
an increase in this area will act to lower the measured resistance, and that this would also correspond to longer fatigue life.

A weighted ranking system was chosen to place 40 percent weight on the underfill voiding data, and 30 percent each on the resistance and grain ratio data. These weighting coefficients were selected based roughly on the amount of attention each metric has received in the literature in respect to its effect on reliability. The selection is somewhat arbitrary in the sense that an argument could be made for slightly different coefficients based on some specific finding or bias. However, the ranking is employed here not as an exact method, but as a practical means with sound reasoning behind the choice of metrics.

The data for each material was scaled using the high and low values of voiding associated with each metric. This is shown in equation (4-8).

$$
\operatorname{Rank}=0.4 \frac{\left(V_{h i}-V\right)}{V_{h i}-V_{\text {low }}}+0.3 \frac{\left(R_{h i}-R\right)}{R_{h i}-R_{\text {low }}}+0.3 \frac{\left(G_{h i}-G\right)}{G_{h i}-G_{\text {low }}}
$$

The values for $V, R$, and $G$, are in respect to the particular profile to be ranked. $V=$ Underfill voiding area as a percentage $R=$ Two point electrical resistance of the daisy chain structure $\mathrm{G}=$ Phase ratio $\mathrm{Pb} / \mathrm{Tn}$

The voiding percent area was determined using the DIA software as in DOE1 and DOE2. The resistance data was taken by summing the resistance 
measurements from individual trace measurements for each die. The phase data was determined using an area ratio technique, where a grid was overlaid onto SEM images (Figures 4-44 and 4-45) and the ratio of points was calculated that fell inside of the large phase boundaries, explained in more detail in section 3.9.6. The ranking in Equation (4.8) gives a weighted score from 0 to 1, with the higher number corresponding to low (desirable) values of voiding, resistance, and grain ratio.

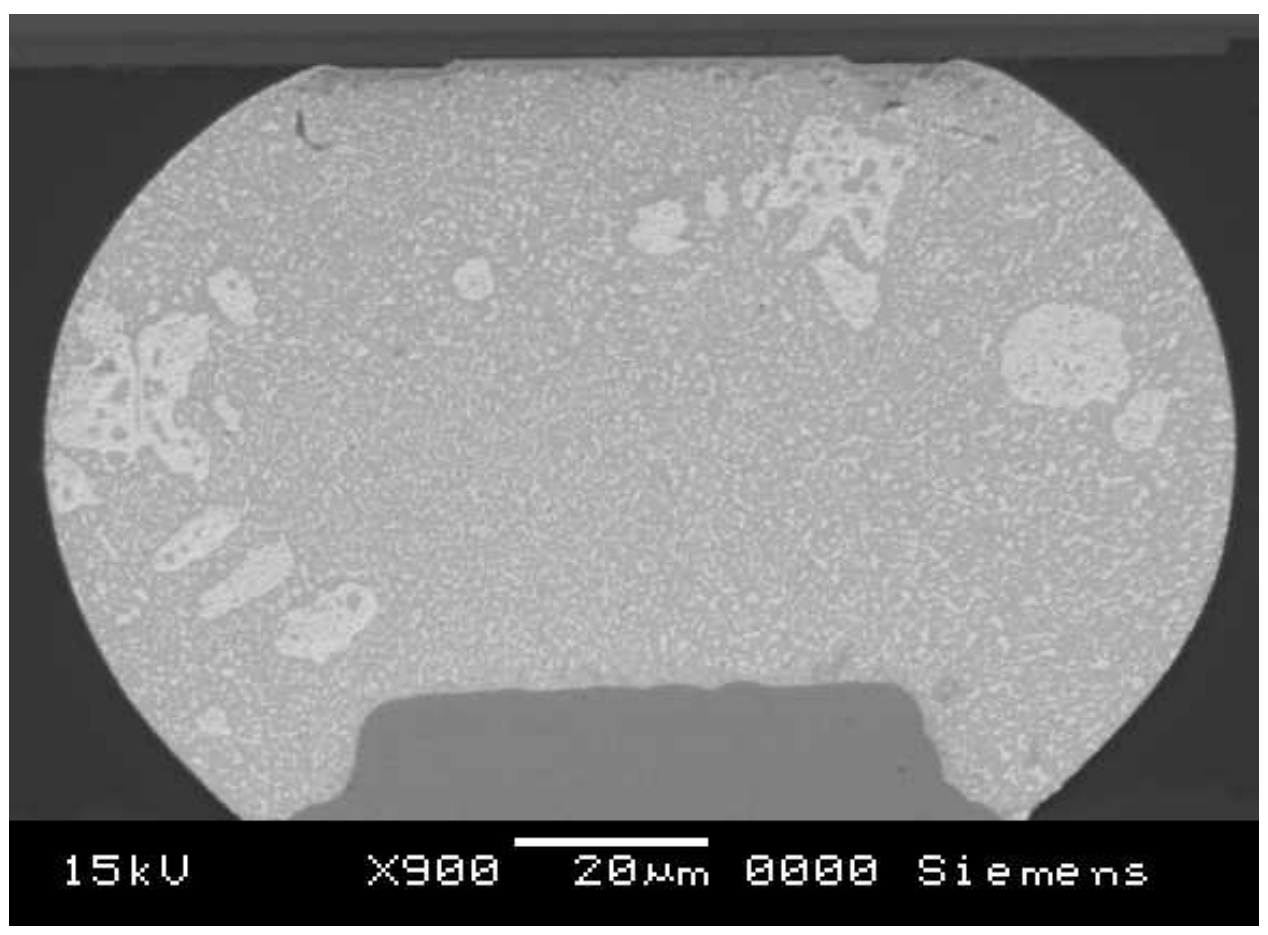

Figure 4-44 SEM Image of a Cross Section to be Used for Phase Ratio Analysis 


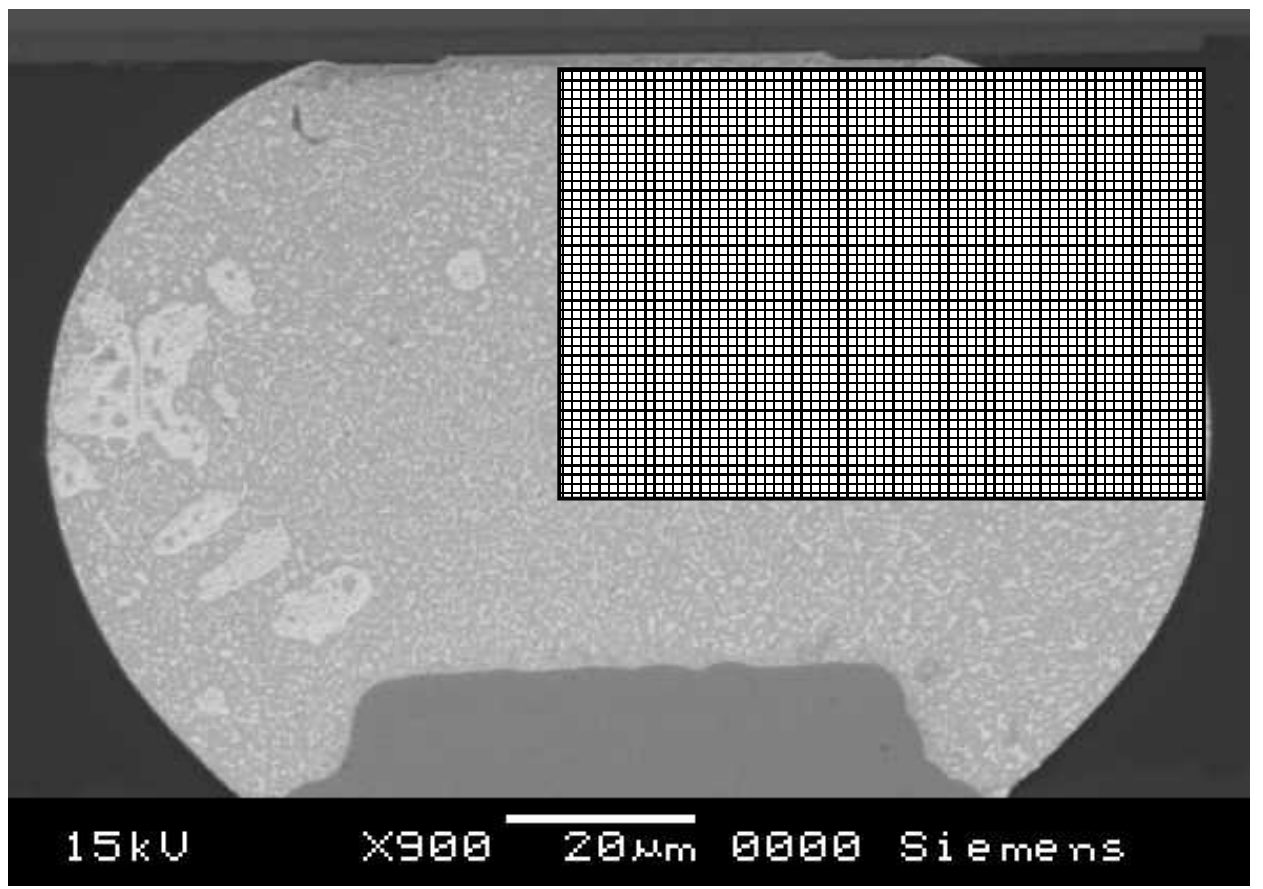

Figure 4-45 SEM Image With Phase Boundaries and a Partial Grid Overlay.

For each material, the highest ranking profile was selected for use in the final reliability build of 30 replicates. The data used to create the rankings as well as the results of the ranking can be found in sections 4.7.1 through 4.7.4.

\subsubsection{Reflow Profile Discussion and Conclusions}

The Soak Time + profile was chosen for the final build with material A. The Parametric Optimized profile was chosen for the final build with material B. The Soak Temp + profile was chosen for the final build with material C. The Time > $183^{\circ} \mathrm{C}+$ profile was chosen for the final build with material $\mathrm{E}$. 


\subsection{Final Build: Results}

\subsubsection{Air-Air Thermal Cycling}

The results for the Air-Air thermal cycling test are presented here in the form of Weibull plots for materials B, C, and E for which complete failure data was obtained. The plots appear in Figures 4-46 through 4-48. The material A assemblies were removed from test at 3500 cycles before a first failure was observed. This decision was made based on the separate testing of a smaller sample of assemblies also processed with material A; this sample of 6 chips was cycled for 5000 cycles before finding the first electrical failure. The materials were removed from test in order to investigate the extent of solder extrusion present before an electrical "open" failure develops. A complete discussion of the reliability results and failure modes is presented in Chapter 5.

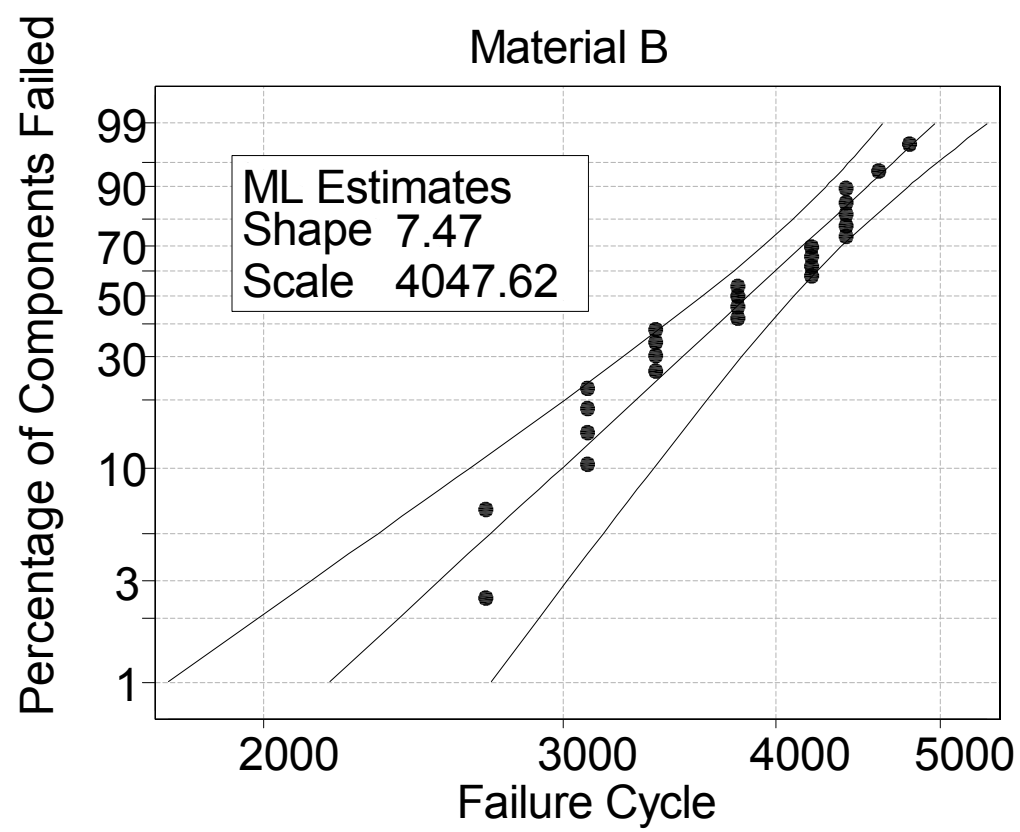

Figure 4-46 Material B, Weibull Plot for AATC 


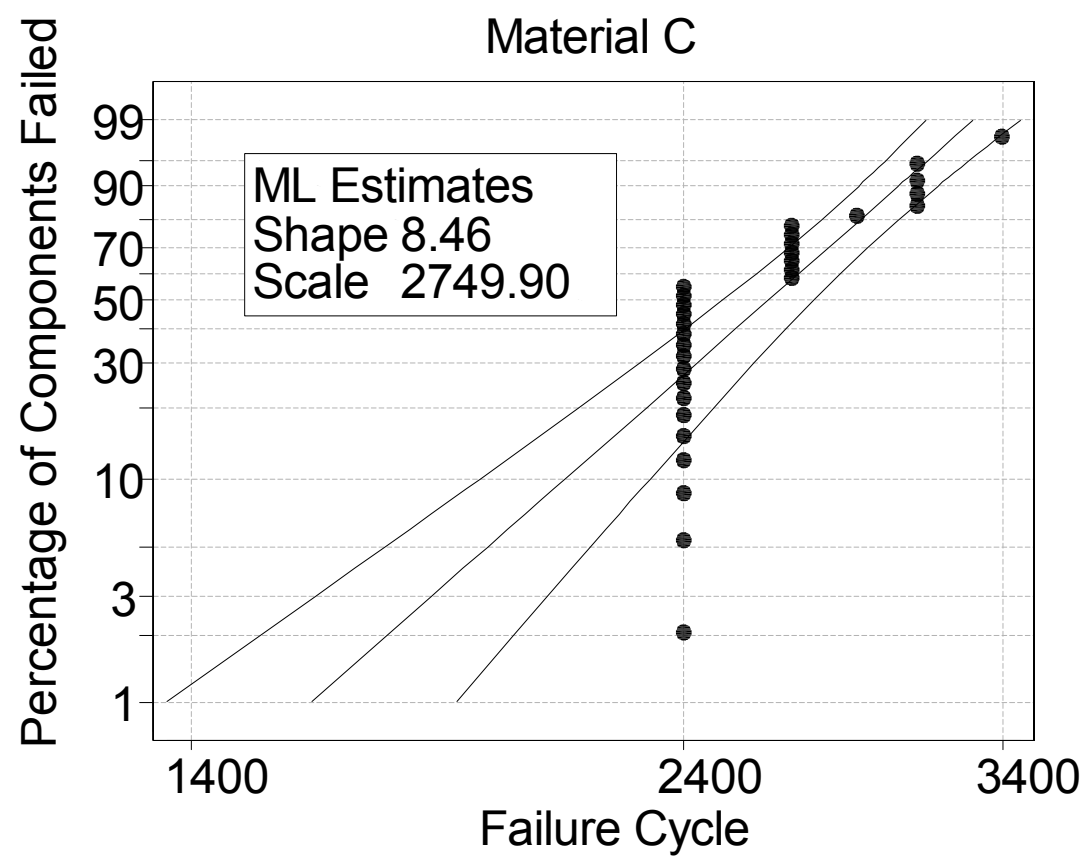

Figure 4-47 Material C, Weibull Plot for AATC

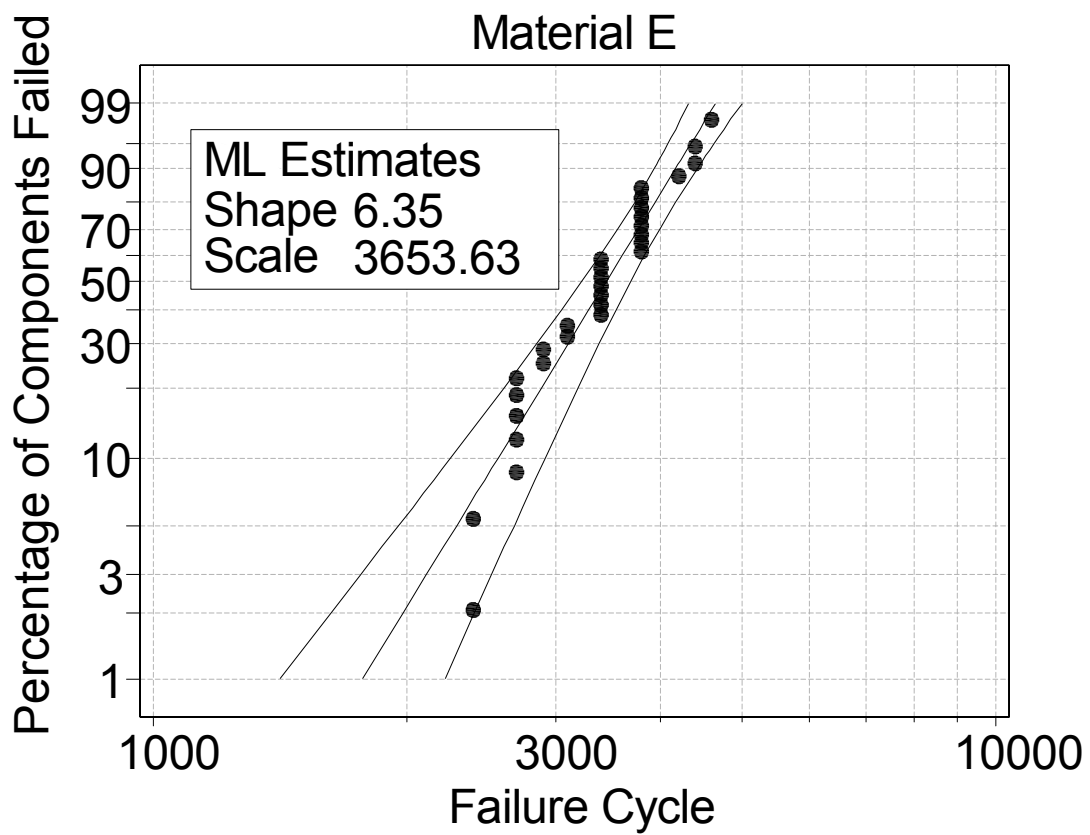

Figure 4-48 Material E, Weibull Plot for AATC 


\subsubsection{Autoclave Test}

The Autoclave test results are presented here in Tables 4-20 and 4-21. All of the materials passed 96 hours of testing under the test conditions of $121^{\circ} \mathrm{C}$ and $2 \mathrm{~atm}$. Although not required by the JESD22-A-102-C, the assemblies were monitored for delamination by CSAM at 24 hour intervals. A complete discussion of the reliability results and failure modes is presented in Chapter 5. 
Table 4-20 Autoclave Electrical Failure Summary

\begin{tabular}{|l||l|c|c|c|c|}
\hline \multicolumn{5}{|c|}{ Autoclave (JESD22-A-102-C) } \\
\cline { 2 - 6 } & Test Condition 24 hrs 48 hrs & 72 hrs & \multirow{2}{*}{96 hrs } \\
\hline \hline Material A & $121^{\circ} \mathrm{C}, 2 \mathrm{~atm}$ & $0 / 30$ & $0 / 30$ & $0 / 30$ & $0 / 30$ \\
\cline { 2 - 6 } Material B & $121^{\circ} \mathrm{C}, 2 \mathrm{~atm}$ & $0 / 30$ & $0 / 30$ & $0 / 30$ & $0 / 30$ \\
\cline { 2 - 6 } Material C & $121^{\circ} \mathrm{C}, 2 \mathrm{~atm}$ & $0 / 30$ & $0 / 30$ & $0 / 30$ & $0 / 30$ \\
\cline { 2 - 6 } Material E & $121^{\circ} \mathrm{C}, 2 \mathrm{~atm}$ & $0 / 30$ & $0 / 30$ & $0 / 30$ & $0 / 30$ \\
\hline
\end{tabular}

* Shows (\#Failed/\#Tested )

* Failure defined as $\pm 10 \%$ change from nominal resistance

Table 4-21 Autoclave Delamination Summary

\begin{tabular}{|c||l|c|c|c|c|}
\hline \multicolumn{6}{|c|}{ Autoclave (JESD22-A-102-C) } \\
\cline { 1 - 6 } & \multicolumn{1}{||}{ Test Condition $24 \mathrm{hrs}$} & $48 \mathrm{hrs}$ & $72 \mathrm{hrs}$ & \multirow{2}{*}{$96 \mathrm{hrs}$} \\
\hline \hline Material A & $121^{\circ} \mathrm{C}, 2 \mathrm{~atm}$ & $0 / 30$ & $0 / 30$ & $0 / 30$ & $0 / 30$ \\
Material B & $121^{\circ} \mathrm{C}, 2 \mathrm{~atm}$ & $0 / 30$ & $2 / 30$ & $7 / 30$ & $7 / 30$ \\
\cline { 2 - 6 } Material C & $121^{\circ} \mathrm{C}, 2 \mathrm{~atm}$ & $1 / 30$ & $3 / 30$ & $21 / 30$ & $27 / 30$ \\
Material E & $121^{\circ} \mathrm{C}, 2 \mathrm{~atm}$ & $0 / 30$ & $0 / 30$ & $6 / 30$ & $11 / 30$ \\
\hline
\end{tabular}

* Shows ( \#Failed/\#Tested )

${ }^{*}$ Failure defined as greater than $0 \%$ delamination 


\section{CHAPTER V: FAILURE ANALYSIS}

Failure analysis was performed for a sample of the assemblies from the final build; the findings for each material are presented here. Section 5.1 presents a description of the failure modes observed. Section 5.2 presents the failure mode results for the AATC test of each material. Section 5.3 presents a discussion of the AATC failure mode results. Section 5.4 presents the failure mode results for the Autoclave test of each material. Section 5.5 presents a discussion of the Autoclave test results for each material.

\subsection{Observed Failure modes}

Analysis of failed assemblies identified four primary modes of failure which can be broadly classified as follows: delamination at the chip/underfill interface, solder fatigue cracks, underfill cracks, and solder extrusion. The sequence of these failure modes is shown in Figure 5-1.
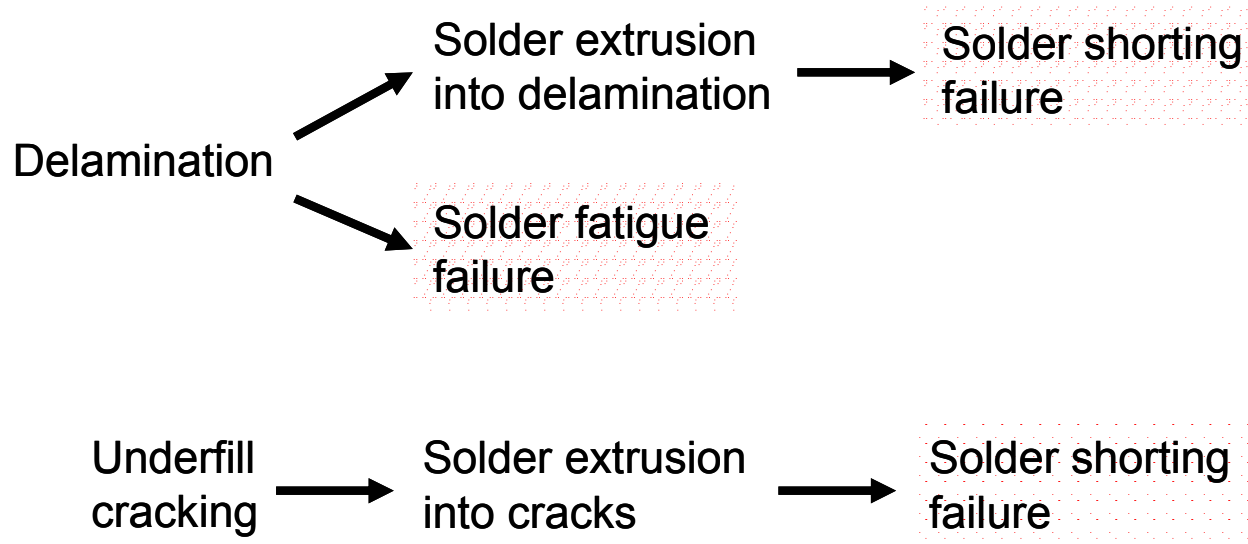

Figure 5-1 Sequence of Failure Modes (Shading Indicates Electrical Failure) 
These failure modes are discussed in detail in the sections that follow.

\subsubsection{Solder Fatigue Cracks}

Solder fatigue cracks were the primary failure modes observed for the AATC tested assemblies for all underfill materials. The parts are subjected to cyclic thermo-mechanical stresses that result in crack initiation. The cracks propagate through the solder joints as the cycles continue. The cracks are detected through increased resistance readings of the daisy chain or open electrical loops in the tested assemblies. Solder fatigue cracks are typically initiated near the die side of the joint and can propagate through the intermetallic layer or through the bulk solder.

Propagation through the intermetallic layer typically indicates that the quality of the joint is compromised by brittle intermetallic compounds. There are two common compounds that occur when $\mathrm{Sn}-\mathrm{Pb}$ solders wet copper: $\mathrm{Cu}_{3} \mathrm{Sn}$ and $\mathrm{Cu}_{6} \mathrm{Sn}_{5}$. For eutectic $\mathrm{Sn}-\mathrm{Pb}$ solder joints, the $\mathrm{Cu}_{6} \mathrm{Sn}_{5}$ species forms preferentially [Frear 1994]. Other brittle intermetallics can form in the presence of $\mathrm{Ni}$ and $\mathrm{Au}$, such as $\mathrm{Ni}_{3} \mathrm{Sn}_{4}$ and $\mathrm{AuSn}_{4}$. The common quality of all these intermetallics is that the hardness of each is much higher than that of the base metals. Therefore, they are less ductile and less resistant to fatigue cracking under a thermomechanical sttress.

The failed interconnects were most clearly observed through scanning electron microscopy (SEM) of cross-sectioned samples to identify the exact crack sizes and locations. An example of a fatigue crack resulting in a failed 
interconnect is demonstrated in Figure 5-2. This SEM image is representative of the location and appearance of fatigue cracks found in assemblies for each of the underfills tested. The particular crack in Figure 5-2 appears to have originated at the upper right corner of the joint and then propagated through the solder near the top of the joint. This is an indication that the intermetallic layer is not excessively brittle.

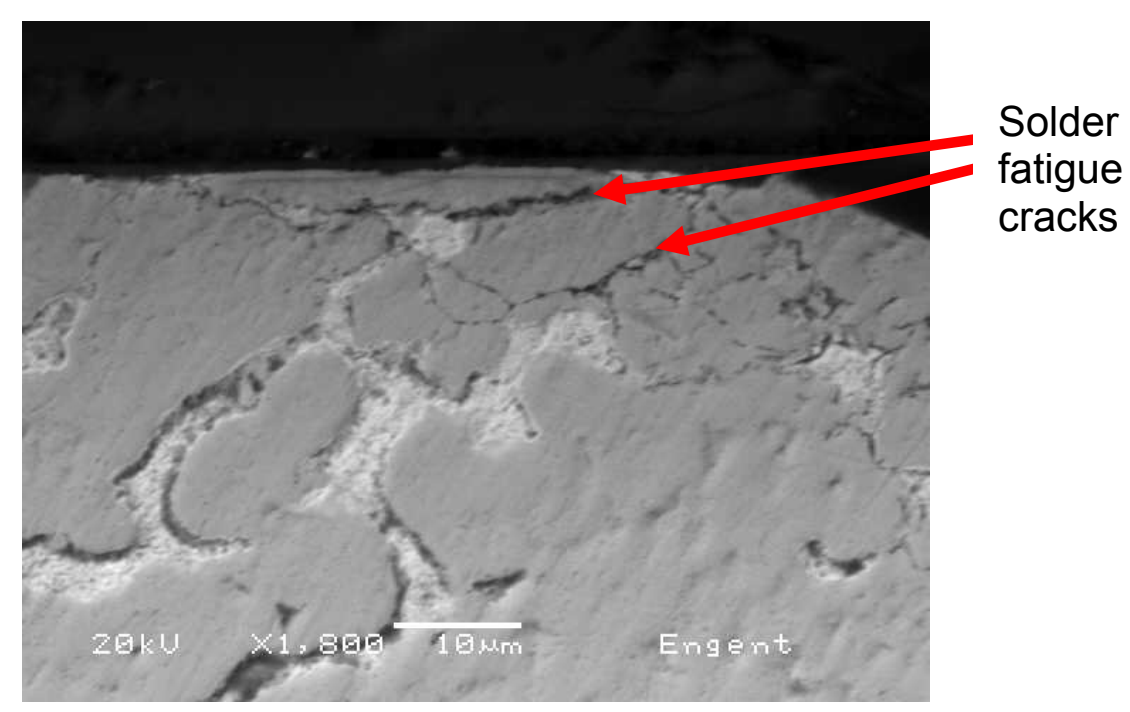

Figure 5-2 Fatigue Crack at the Top of a Bump

Typical locations for solder fatigue cracks were in the edge rows of bumps near the corner of the die as shown in Figure 5-3. All the cracks found for the parts assembled during this research originated near the top of the joint. The cracks typically propagated along the top of the joint although some cracks do propagate downward into the bulk solder. A schematic of the typical crack location within the joint is provided in Figure 5-4. 


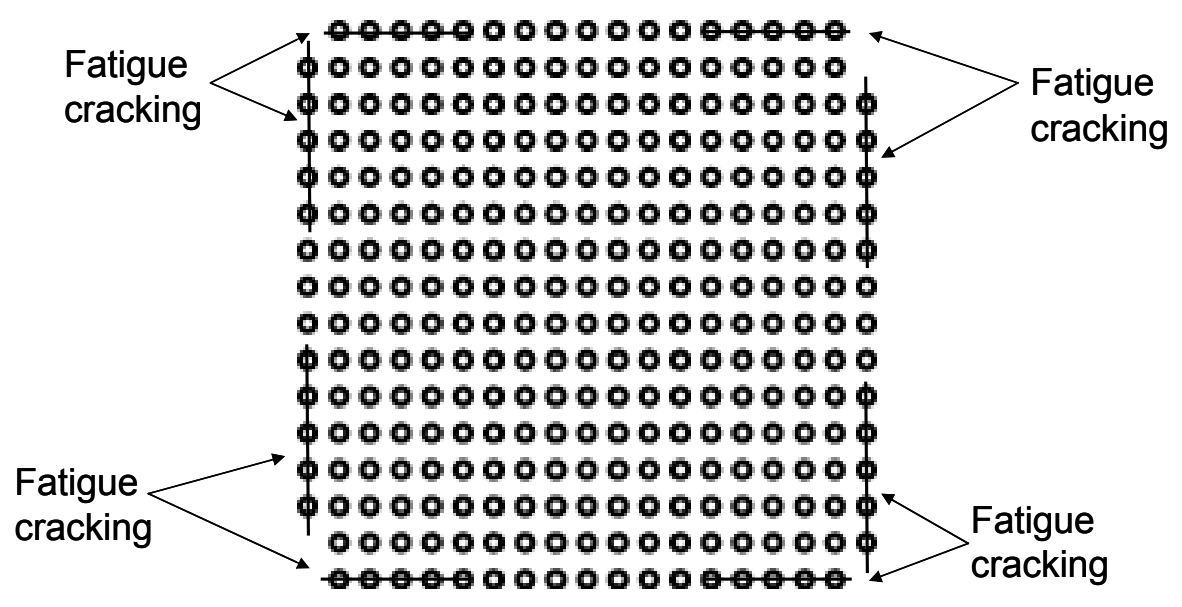

Figure 5-3 Locations of Fatigue Cracks

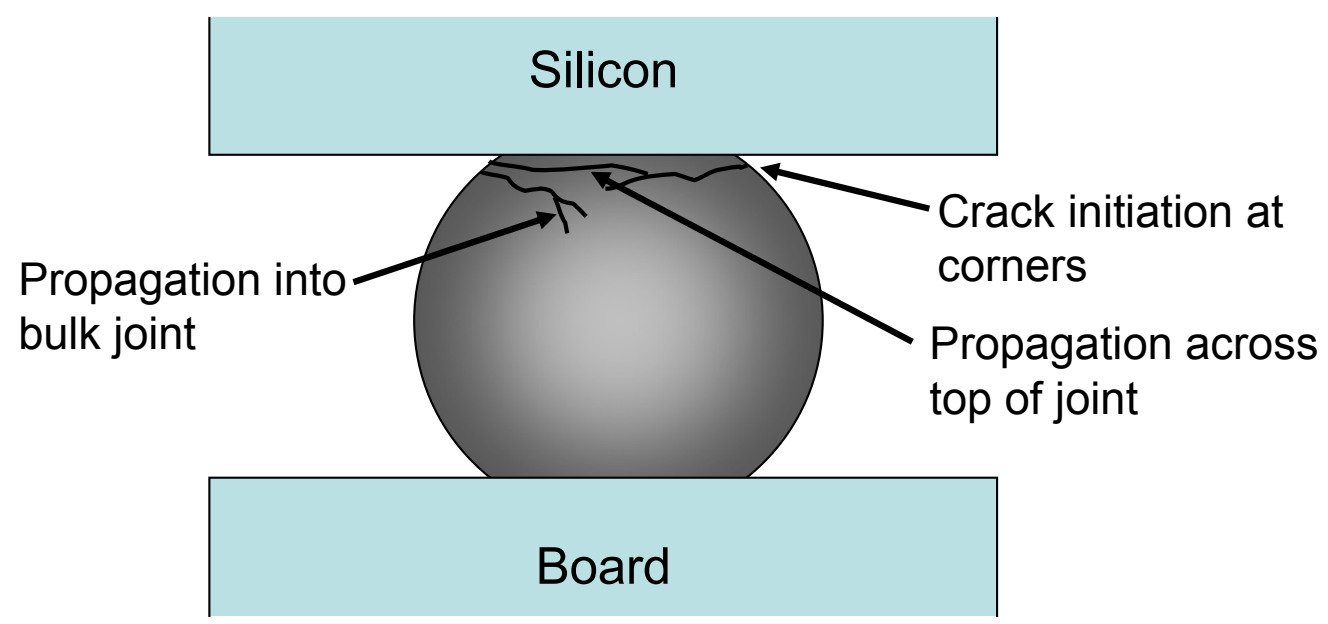

Figure 5-4 Typical Crack Location Within a Solder Joint

None of the solder joints sampled for fatigue crack analysis were found to fail near the substrate side of the solder joint. This is fairly typical for flip chip mounted onto FR4 substrate. The reason for this is that there is a greater mismatch in CTE between the silicon and the solder than there is between the the FR4 and the solder. Thus, the top of the joint near the silicon is exposed to greater shear stresses under thermo-mechanical loading, which results in fatigue cracks near the top of the joint. 


\subsubsection{Underfill Cracking}

Underfill cracking can be observed in the bulk material between solder bumps. These cracks tend to propagate along the substrate copper traces, but can be observed between bumps in any direction. The cracks are visible by optical microscopy after cross-sectioning of the assemblies. An example of underfill cracking is shown in Figure 5-5.

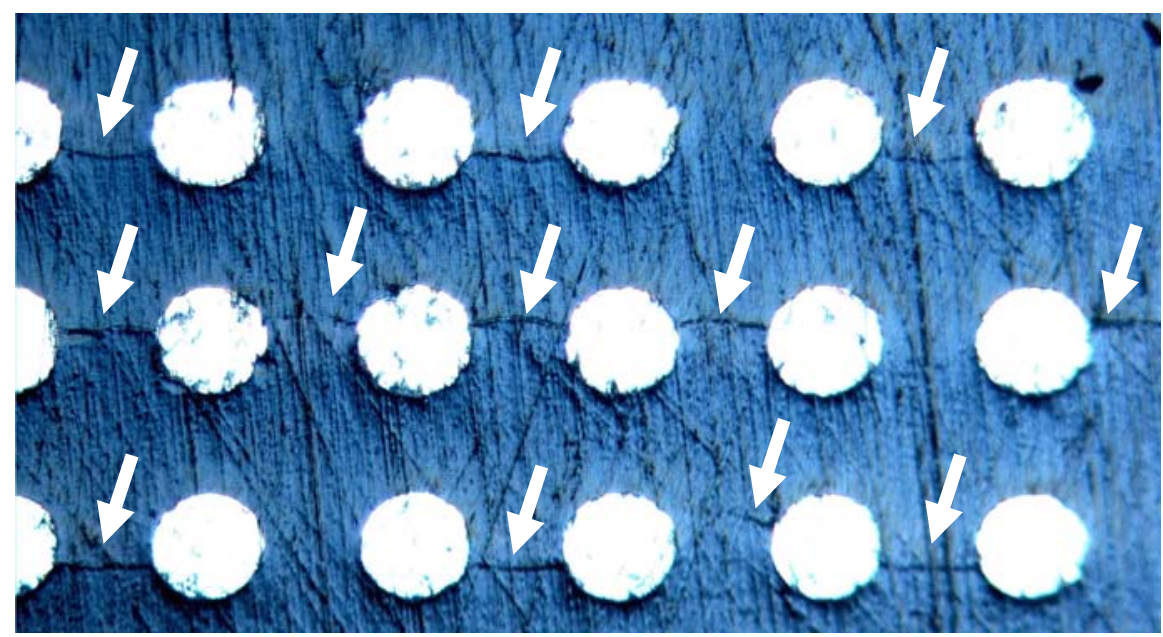

Figure 5-5 Underfill cracks Between Solder Joints (Arrows Point to Cracks)

There is no way to determine exactly when these underfill cracks begin forming or how long they take to propagate. This is because in order to find the cracks, the assemblies must be destructively cross-sectioned for analysis. This was not performed at regular intervals because the primary goal of the reliability testing was to evaluate the reliability of the assemblies in terms of electrical continuity of the daisy chain circuit. Therefore, the assemblies could not be evaluated for underfill cracking until they failed electrically. The first underfill 
cracking found in this research was at 2400 cycles, which was the point of first electrical failure for Materials $\mathrm{C}$ and $\mathrm{E}$.

\subsubsection{Solder extrusion}

Solder extrusion is a solder joint shape deformation observed with optical microscopy of cross-sectioned samples. Over time and under cyclic thermal stresses, solder extends into underfill voids, delaminations, or underfill cracks adjacent the solder interconnect. The driving force behind this extrusion is the cyclic compression of the solder by the underfill surrounding the joint. During the cold side temperature excursion, the higher CTE of the underfill results in the compressive stresses on the solder joint. The physics is somewhat analogous to hydrostatic extrusion because the pressure required for the extrusion is supplied by the surrounding medium. A complete analysis of the extrusion mechanics would involve considering the ideal work, frictional work, and redundant work. Ideal work is a function of only the yield stress and the true strain. Frictional work comes from the necessary energy to overcome the friction of the solder flowing over the underfill interface. The redundant work arises from any inhomogeneous deformation of the material.

Solder extrusion between two solder joints often leads to solder joint bridging (electrical shorting). This results in lowered resistance readings of the daisy chain structure. The test vehicles used for this research are not designed to easily detect a shorting failure. The failures can be determined, however, if the short happens between two rows of the daisy chain circuit. 
Solder extrusion into an underfill void is the most likely type of extrusion to cause the earliest electrical failures of the components. The type of voiding that can result in an early extrusion failure is shown in Figure 5-6. Because this type of extrusion can involve relatively large volumes of solder, it is sometimes possible to monitor the extrusion dynamic by X-ray inspection. The series of images shown in Figure 5-7 illustrates the potential time scale for this type of extrusion and ultimate failure by shorting.

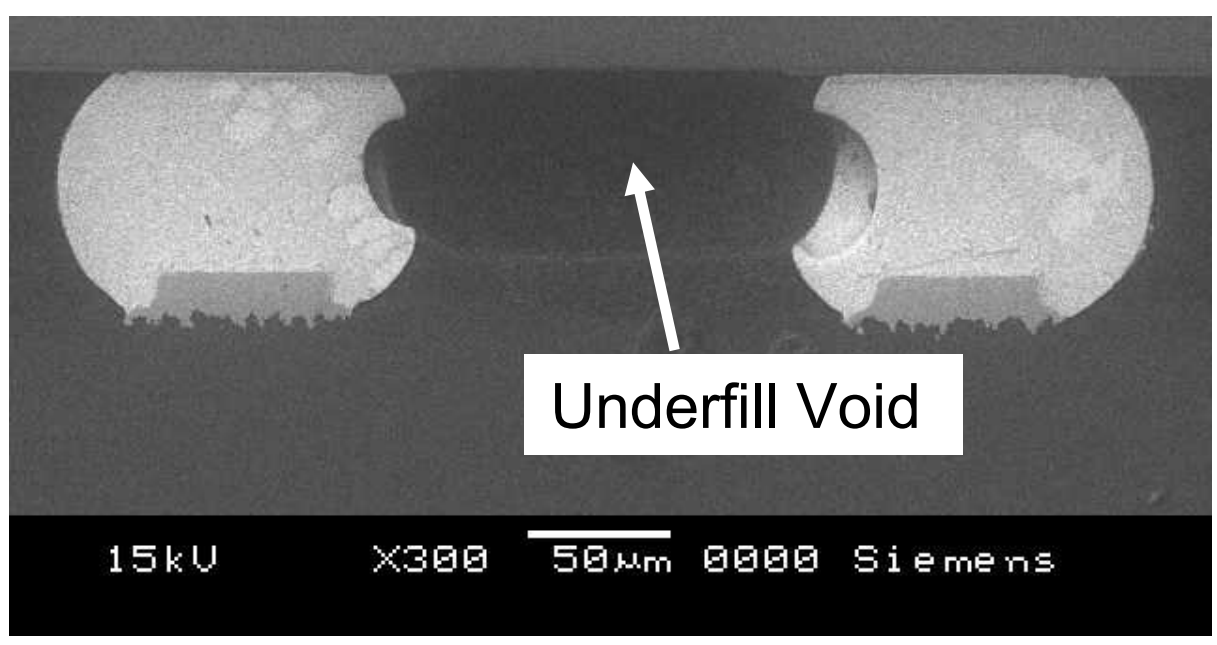

Figure 5-6 Underfill Void Between Solder Bumps 


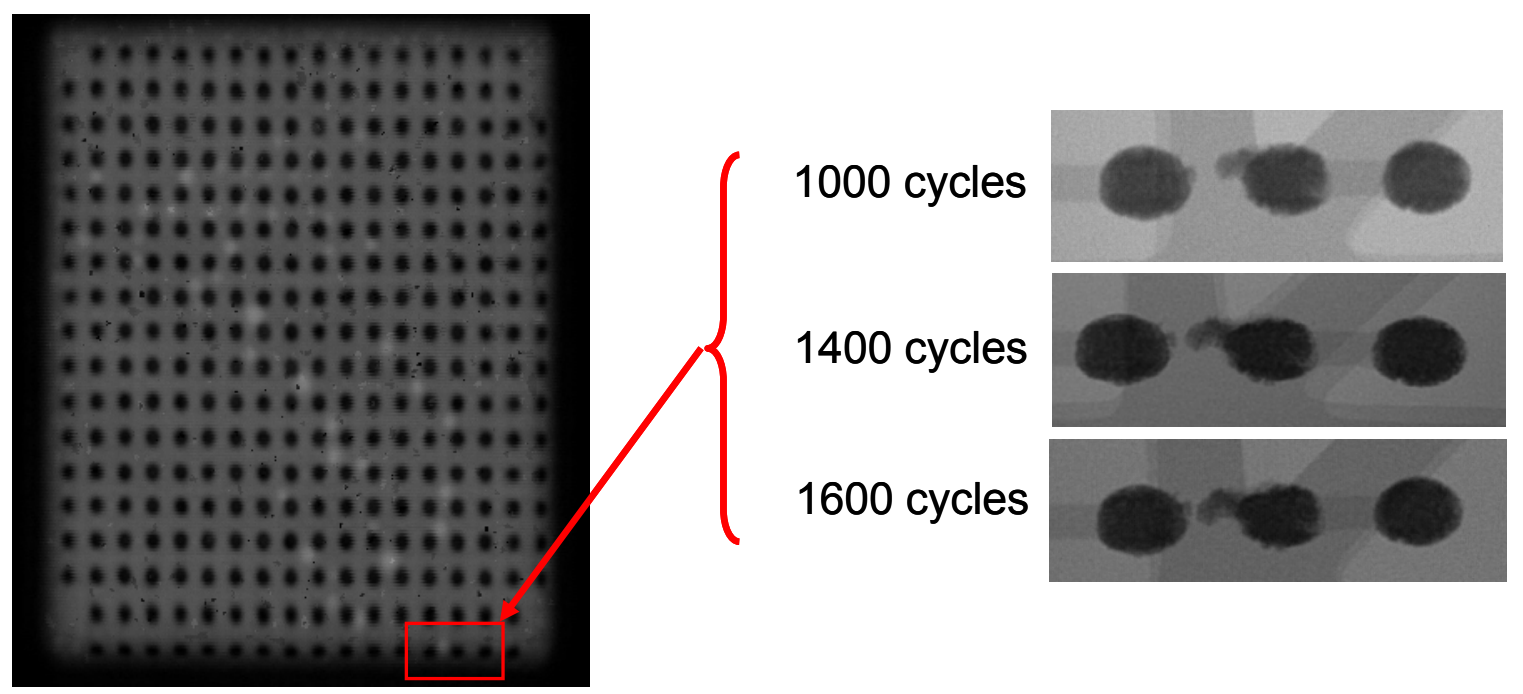

Figure 5-7 Timescale for Solder Extrusion into an Underfill Void

Solder extrusion into underfill cracks was found to occur for all the materials tested. The only way to determine this type of extrusion is through a planar cross-sectional analysis. Therefore, the assemblies could not be evaluated until they failed electrically. The first extrusion into cracks found in this research was at 2400 cycles, which was the point of first electrical failure for Materials $\mathrm{C}$ and $\mathrm{E}$. Extrusion into cracks can produce an electrical failure if the solder extrudes enough to contact another solder bump as shown in Figure 5-8. 


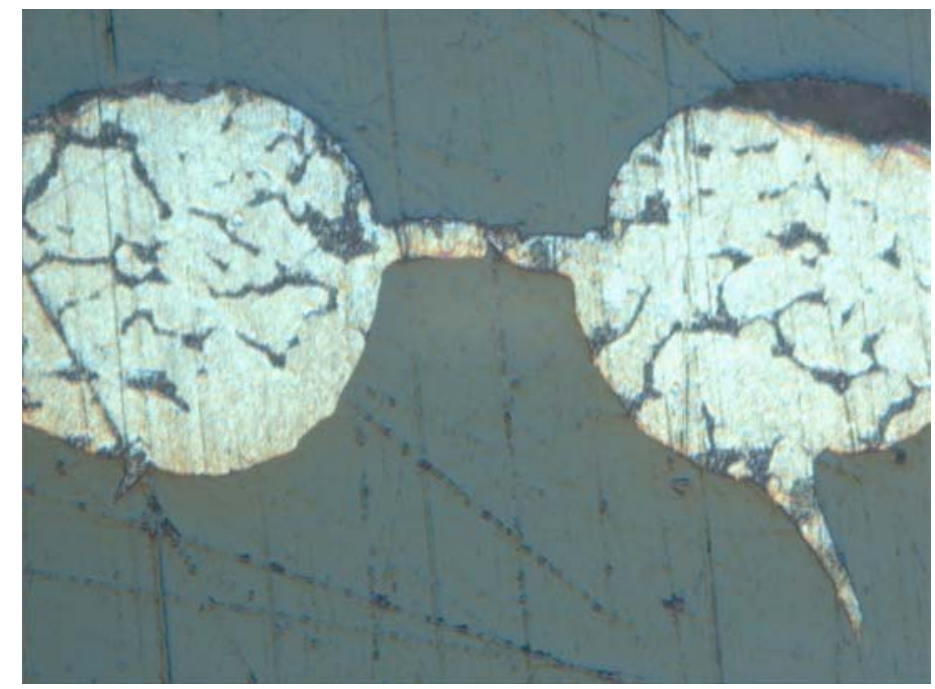

Figure 5-8 Solder Extrusion Into an Underfill Crack Causing a Short

\subsection{AATC Failure Analysis Results}

There were two electrical failure mechanisms observed for the AATC assemblies: fatigue crack failures resulting in an open circuit and solder extrusion resulting in a short circuit failure. Delamination and underfill cracking were found as preliminary failure mechanisms before actual electrical failures. A failure was defined by a change of $\pm 10 \%$ from the baseline resistance value. The baseline resistance value was determined for each daisy chain trace individually by two point resistance measurement immediately after assembly and before the start of the test.

\subsubsection{Material A}

Material A displayed excellent adhesion as evidenced by the delamination results. Delamination was first observed at 3500 cycles. The best case 
delamination progression is shown in Figure 5-9. The average case delamination progression is shown in Figure 5-10. The images in Figure 5-11 is representative of the worst delamination observed for Material A. The delamination appears to be distributed about the interior region of the die rather than around the outer edges. Most (>80\%) of the assemblies display no delamination at all, even at 3500 cycles. Therefore, these assemblies remained well protected against fatigue throughout the 3500 cycles. This explains why no failures were observed before the parts were pulled from testing at 3500 cycles.
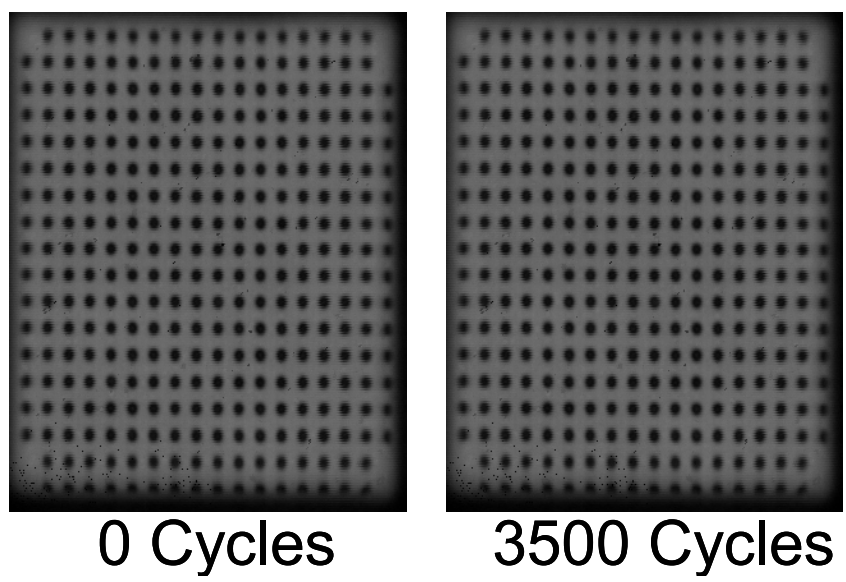

Figure 5-9 Material A, Best Case Delamination Progression, Part Removed From Test at 3500 Cycles 


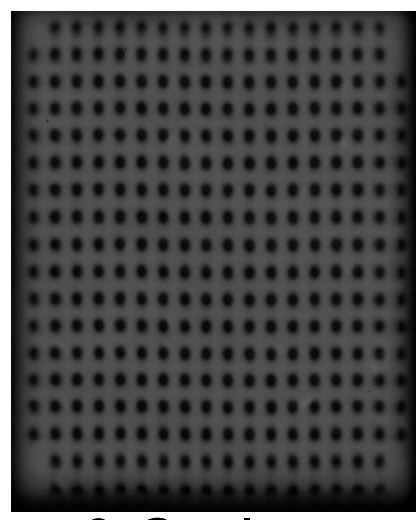

0 Cycles

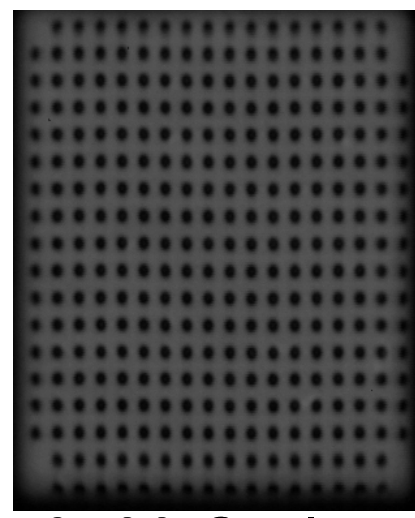

3500 Cycles

Figure 5-10 Material A, Average Case Delamination Progression, Part Removed From Test at 3500 Cycles

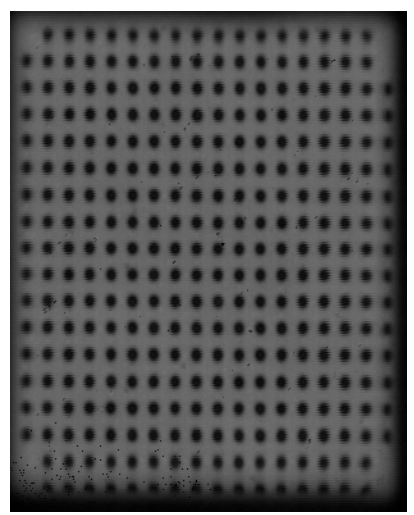

0 Cycles

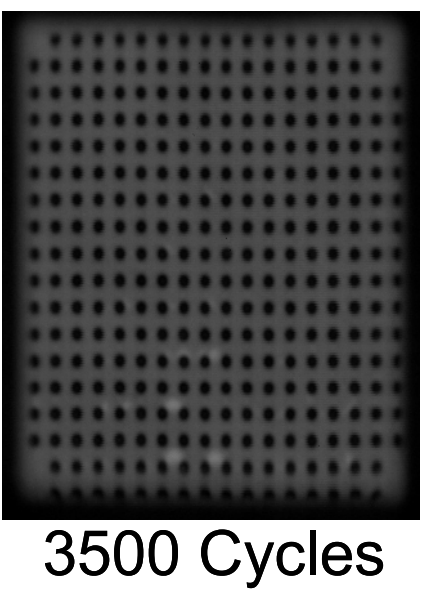

Figure 5-11 Material A, Worst Case Delamination Progression, Part Removed From Test at 3500 Cycles

In order to determine if these assemblies had underfill cracking and solder extrusion, a sample of the parts was planar cross-sectioned to reveal the region just below the active side of the silicon die. This procedure leaves the underfill and solder bumps visible for easy optical microscopy. The assemblies exhibit 
very little solder extrusion even though there is extensive cracking of the underfill between the solder bumps as seen in Figures 5-12. Some solder extrusion was found to extend part way into underfill cracks as shown in Figure 5-13.

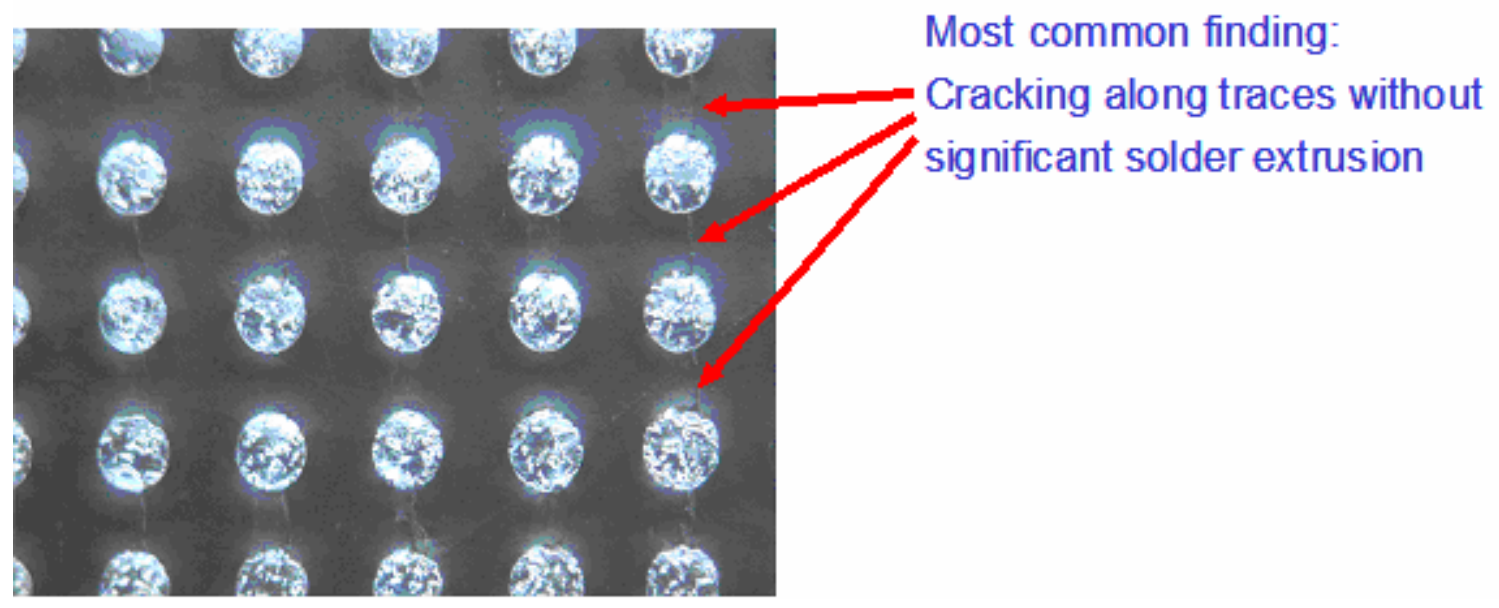

Figure 5-12 Material A, Extensive Cracking Along Traces Without Significant Extrusion, Part Removed From Test at 3500 Cycles

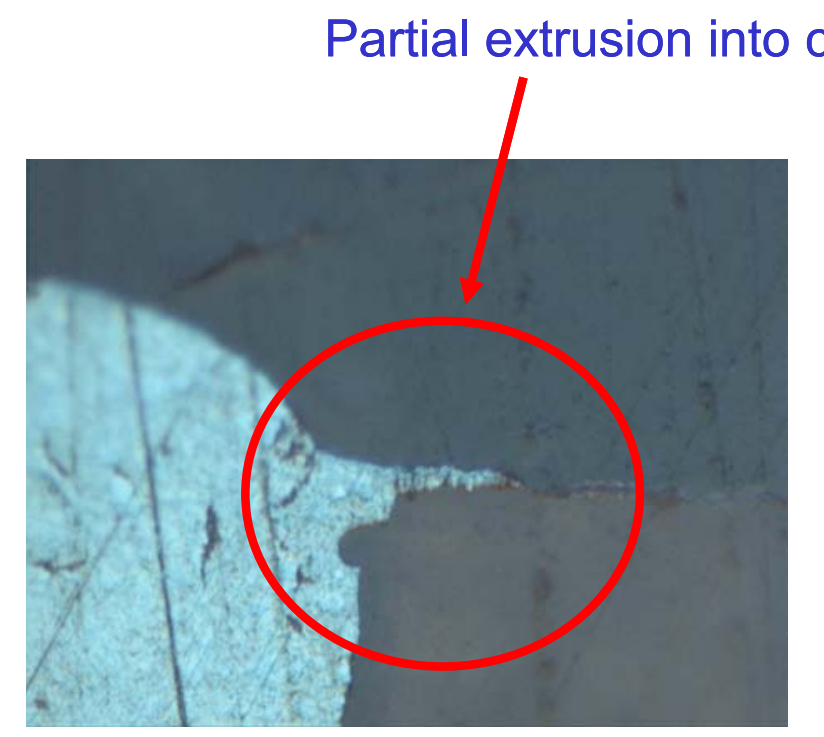

Figure 5-13 Material A, Partial Solder Extrusion Into a Crack, Part Removed From Test at 3500 Cycles 


\subsubsection{Material B}

Material B exhibited the worst delamination performance out of all of the underfills tested. Delamination was first observed at about 1400 cycles. A best case progression of the delamination is shown in Figure 5-14. The best case resulted in no visible delamination by 2800 cycles; only one die out of 30 showed this result. The average case progression is shown in Figure 5-15. A worst case progression of this delamination for one test die is depicted in Figures 5-16. The delamination appears to originate in the interior portion of the chip and then progresses to cover all areas. The images show that the delamination begins around 1600 cycles and has progressed to about $50 \%$ the area of the die by 2800 cycles. Parts typically fail about $400-600$ cycles after delamination reaches a point similar to the 2800 cycle image in Figure $5-16$. This indicates that fatigue cracks rapidly initiate and propagate after the die and board are significantly uncoupled by the delamination.

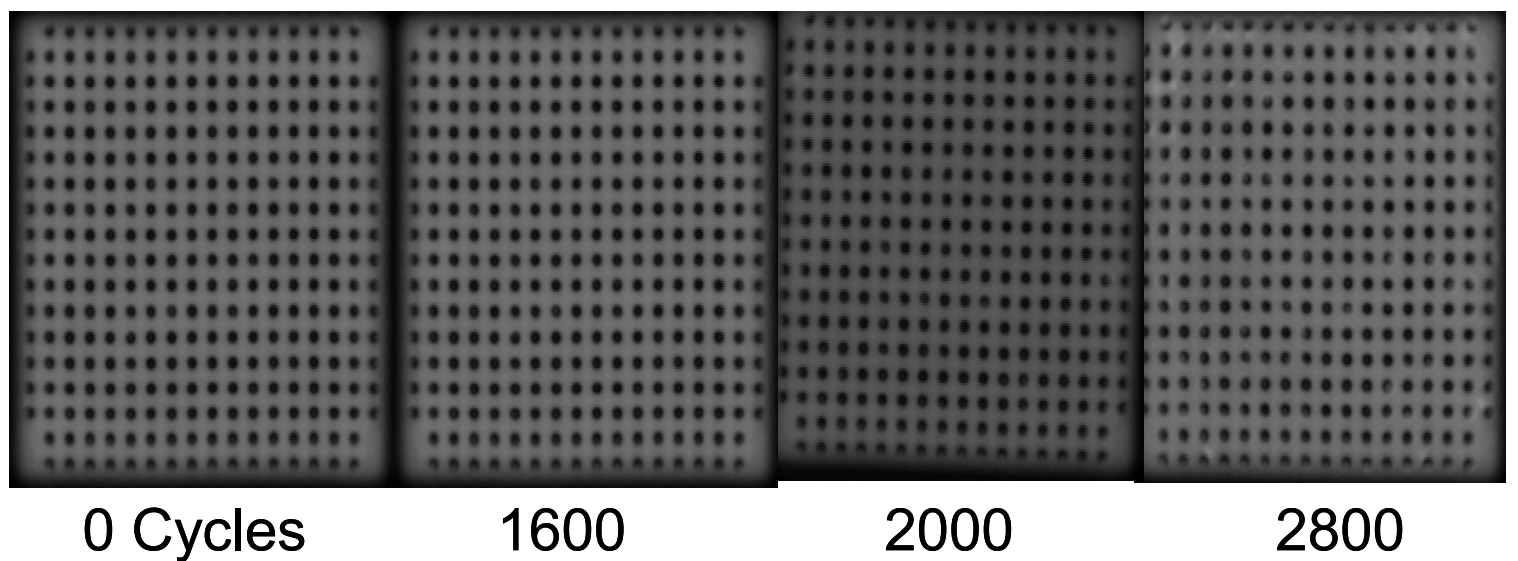

Figure 5-14 Material B, Best Case Delamination Progression 


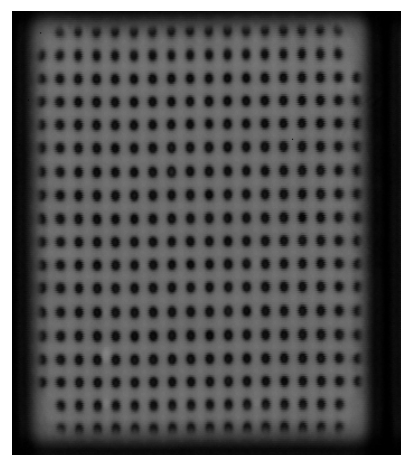

0 Cycles

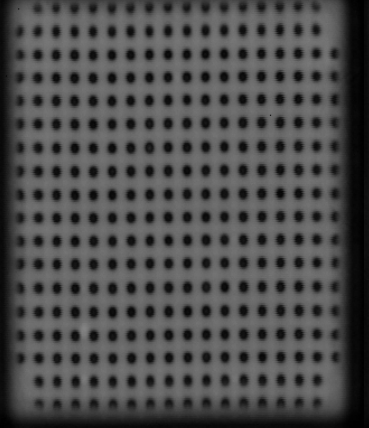

1600

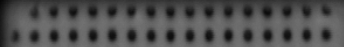

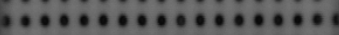

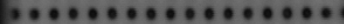

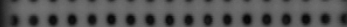

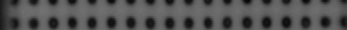

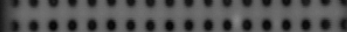

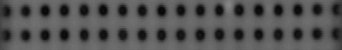

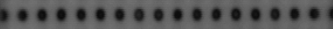
, .

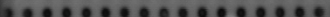
bots द

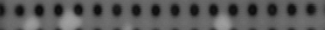
,$\bullet \bullet \bullet \bullet \bullet \bullet \bullet \bullet \bullet \bullet \bullet \bullet \bullet \bullet$ $\bullet \bullet \bullet \bullet \bullet \bullet \bullet \bullet \bullet \bullet \bullet \bullet \bullet \bullet \bullet$ $, \cdots, \ldots, \ldots, \ldots, 0^{\circ}$

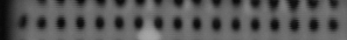

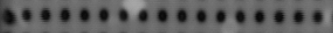

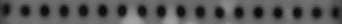
$\bullet \bullet \bullet \bullet \bullet \bullet \bullet \bullet \bullet \bullet \bullet \bullet \bullet \bullet \bullet$

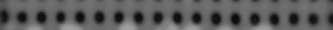

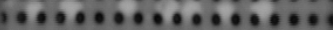

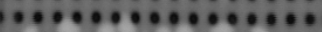

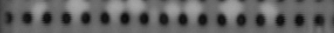
,$\bullet \bullet \bullet \bullet \bullet \bullet \bullet \bullet \bullet \bullet \bullet \bullet \bullet \bullet$

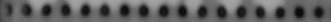

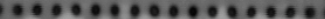

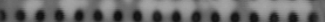

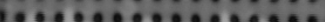

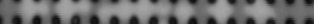
,

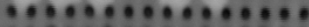

Figure 5-15 Material B, Average Case of Delamination Progression,

Light Areas Show Delamination

$\left[\begin{array}{ll}2 \\ 2\end{array}\right.$

\section{$\begin{array}{llll}0 & \text { Cycles } & 1600 & 2000\end{array}$}

Figure 5-16 Material B, Worst Case Delamination Progression,

Light Areas Show Delamination

Material $\mathrm{B}$ was the worst performing underfill in terms of solder extrusion and underfill cracking. Representative cross sections are displayed in Figures 517 through 5-19. 


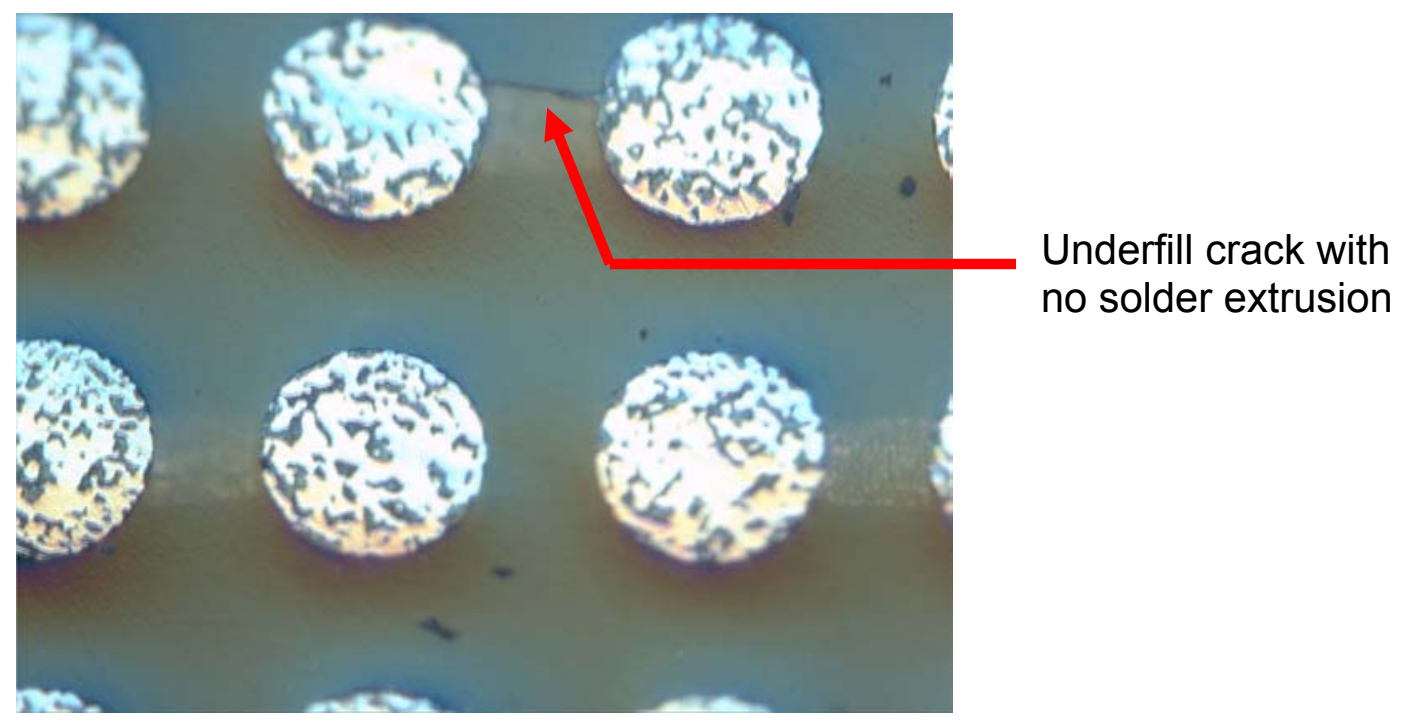

Figure 5-17 Material B, 1700 AATC cycles showing little cracking and no extrusion

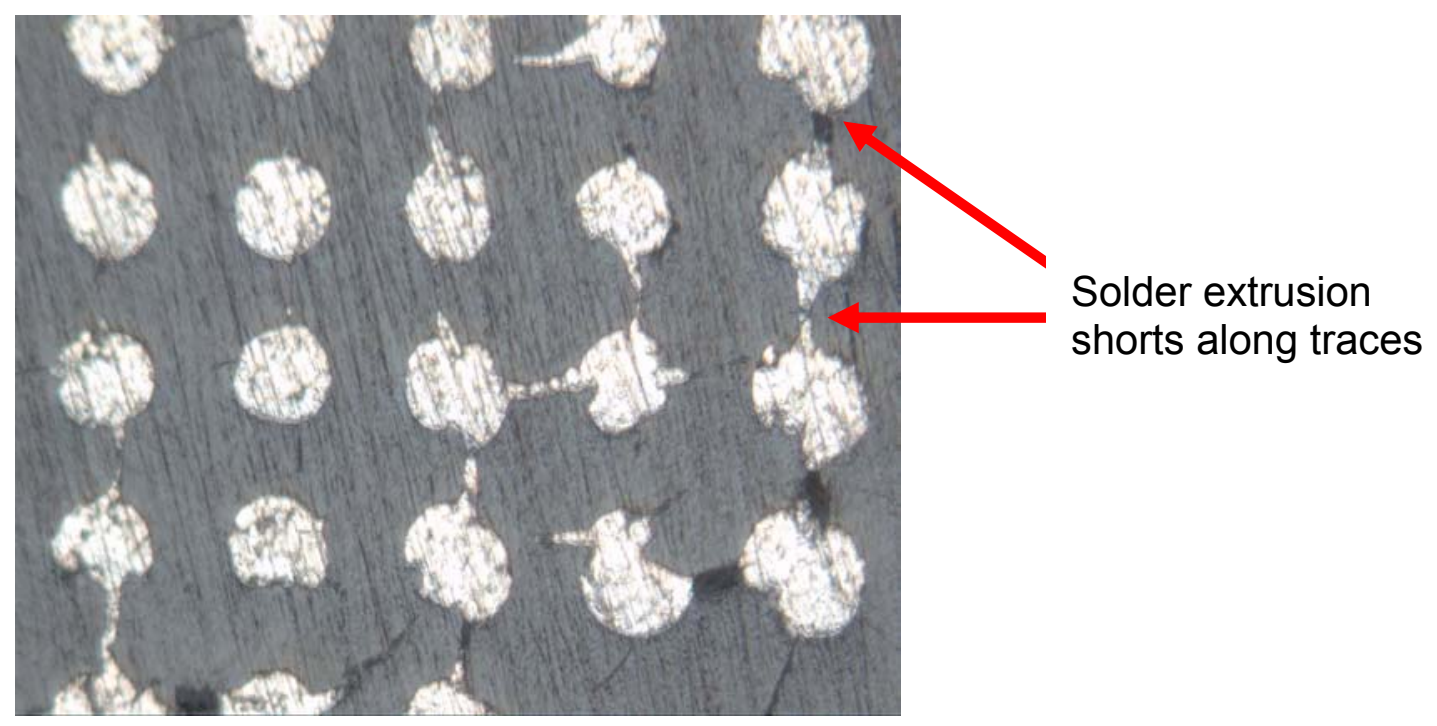

Figure 5-18 Material B, 3800 AATC cycles, extensive solder shorting 


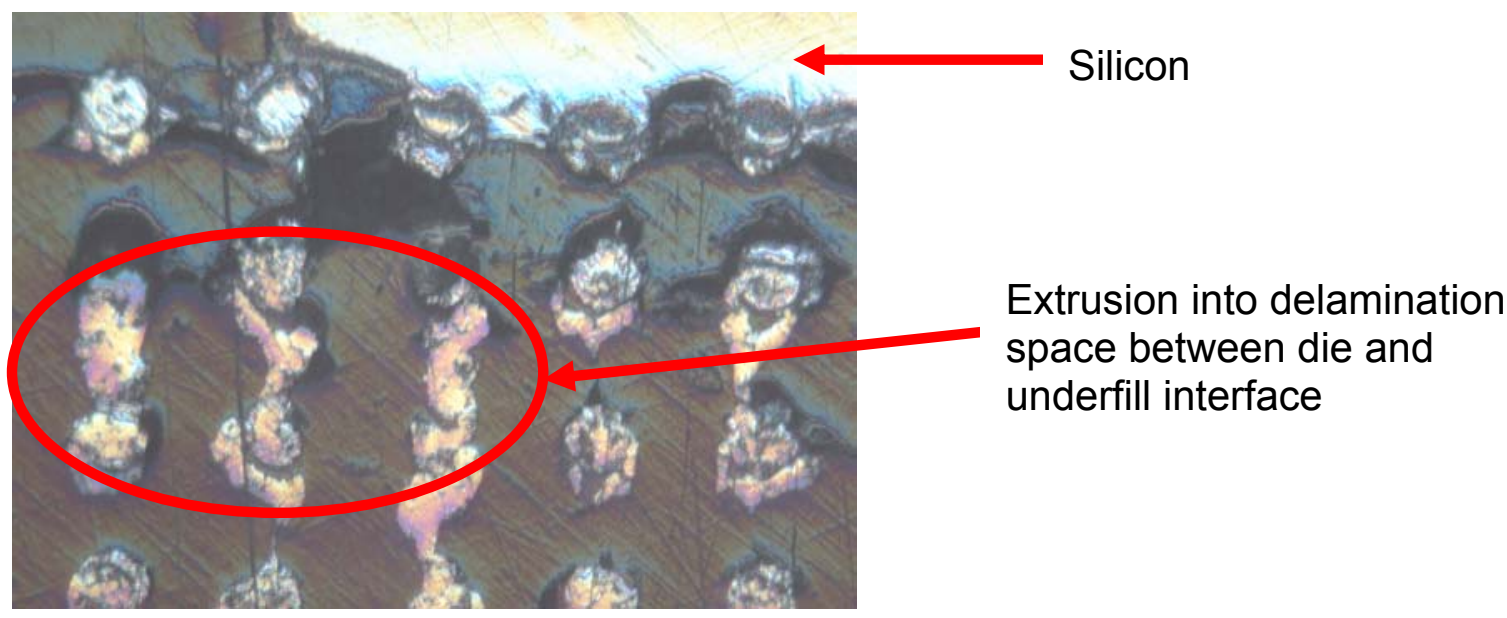

Figure 5-19 Material B, 3800 AATC cycles, extrusion into delamination space

\subsubsection{Material C}

Material C exhibited very good delamination performance, with only slight delamination present in a few parts by 2700 cycles. Delamination was first observed at 2700 cycles. The best case delamination progression shows no visible delamination up to failure of the part as shown in Figure 5-20. The average case delamination progression is shown in Figure 5-21. A worst case delamination progression is displayed in Figure 5-22. The delamination appears to originate in the interior regions of the chip. 


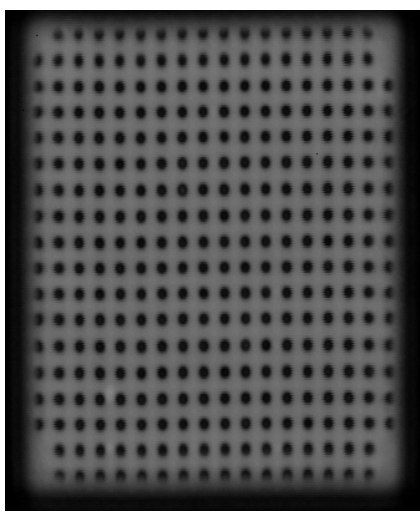

0 Cycles

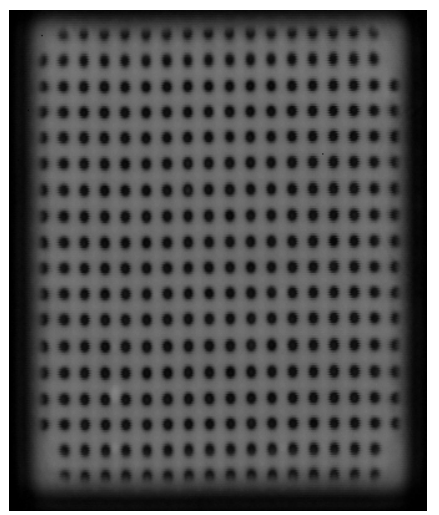

2300 Cycles

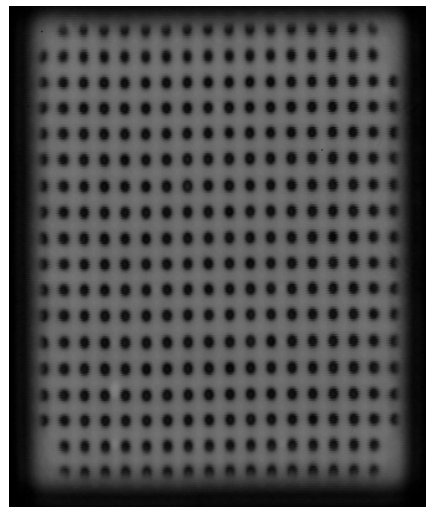

2700 Cycles

Figure 5-20 Material C, Best Case Delamination Progression, Part Failed by Fatigue Cracking at 2700 cycles

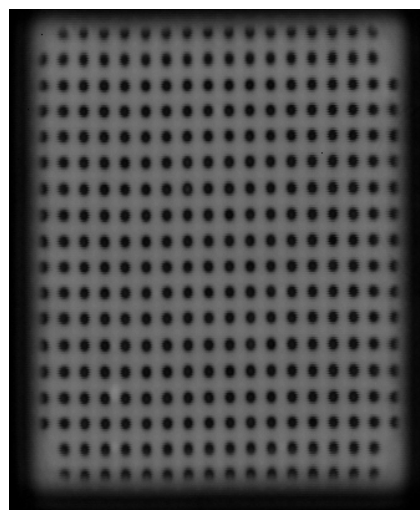

0 Cycles

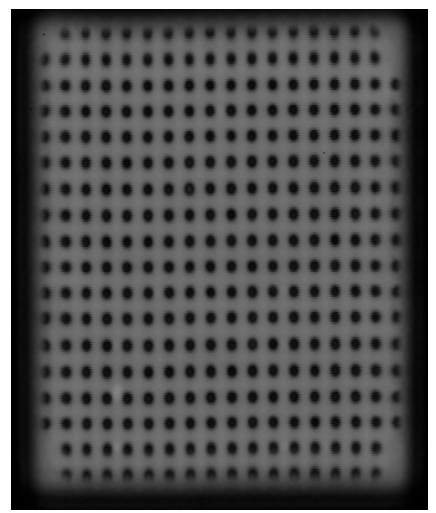

2300 Cycles

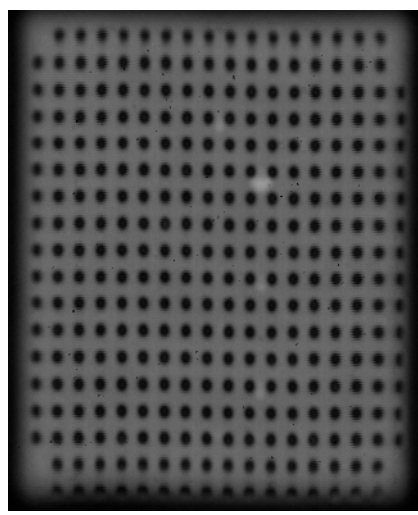

2700 Cycles

Figure 5-21 Material C, Average Case Delamination Progression, Part Failed by Fatigue Cracking at 2700 cycles 


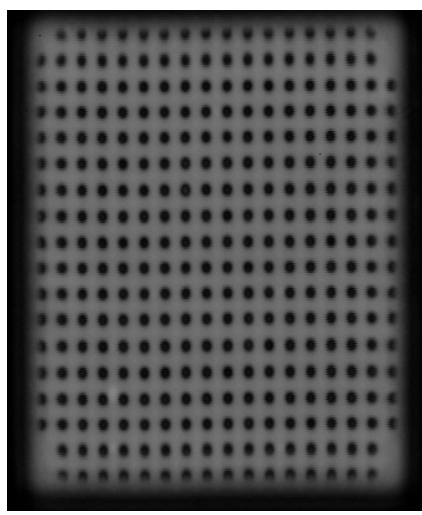

0 Cycles

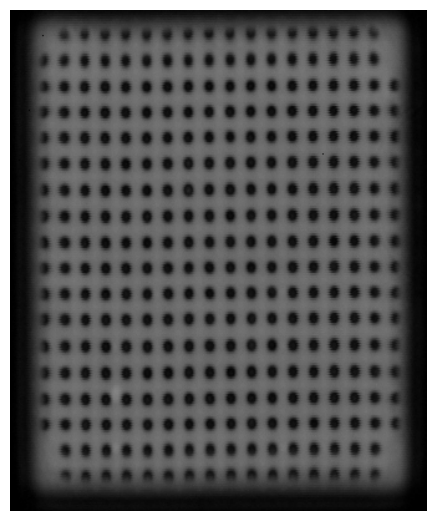

2300 Cycles

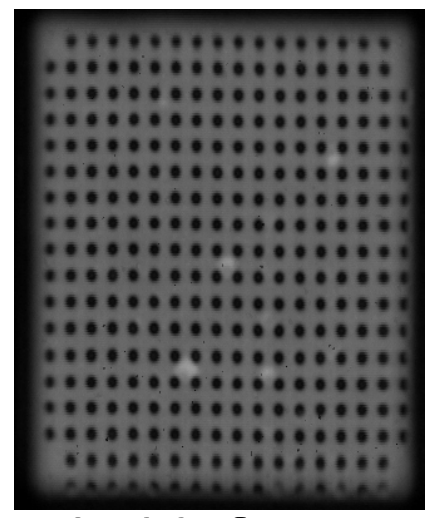

2700 Cycles

Figure 5-22 Material C, Worst Case Delamination Progression, Part Failed by Fatigue Cracking at 2700 cycles

'Material $\mathrm{C}$ demonstrated good resistance to solder extrusion with very little cracking observed by 2400 cycles as displayed in Figure 5-23. Note that later cross-sections do show extrusion into cracks as in Figure 5-24.

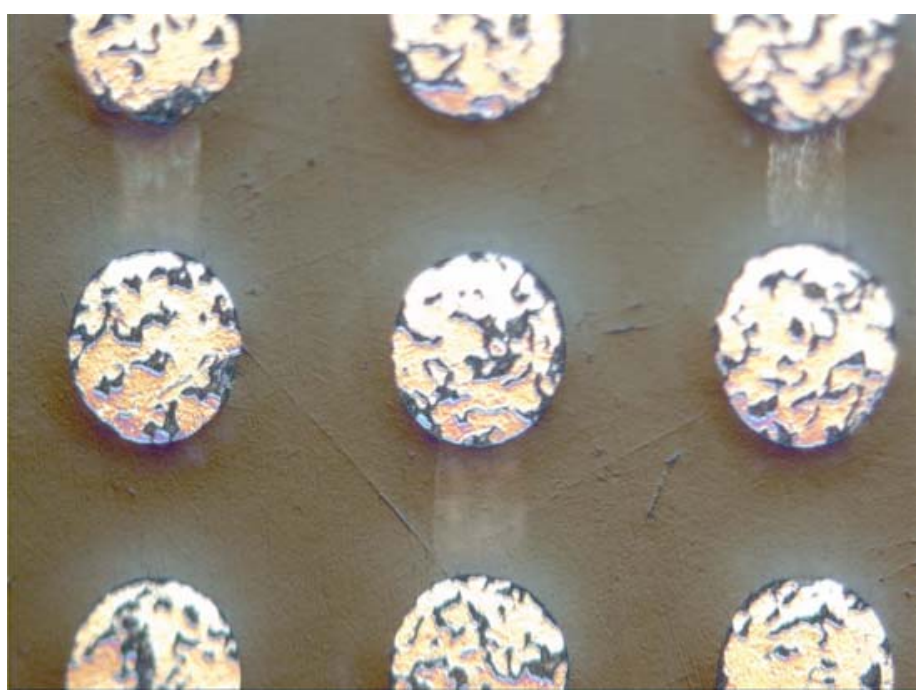

Figure 5-23 Material C, 2400 AATC cycles, No Visible Cracking,

Part Failed at 2400 Cycles 


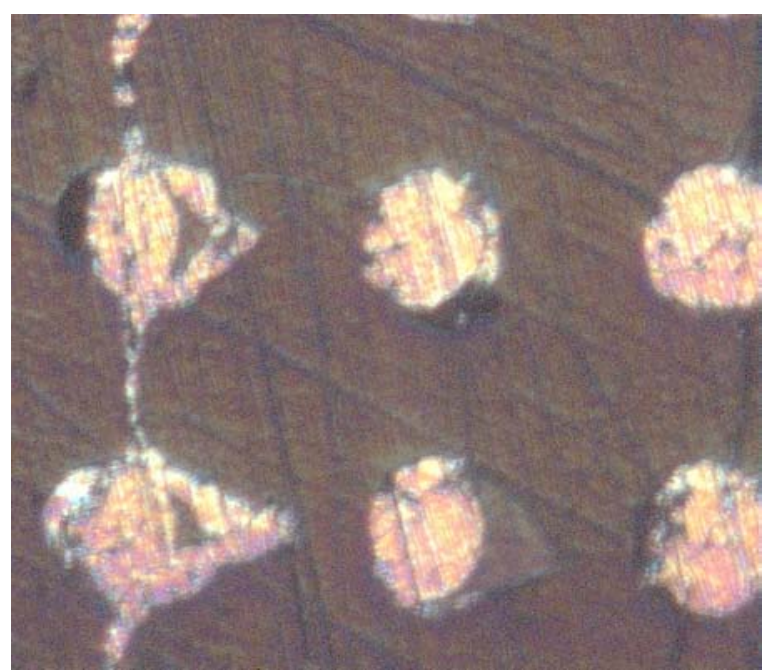

Figure 5-24 Material C, Solder Extrusion Into Cracks at 3400 AATC cycles, Part Failed at 3400 Cycles

\subsubsection{Material E}

Material E did not perform well in terms of delamination results.

Delamination was first observed at about 1600 cycles. At 1800 cycles most assemblies had little delamination if any at all. By 2700 cycles most assemblies had significant delamination around the outer edges of the die. The best case delamination progression is shown in Figure 5-25. The Average case delamination progression is shown in Figure 5-26. The worst case delamination progression is shown in Figure 5-27. The delamination appears to originate around the outer edges of the chip. 


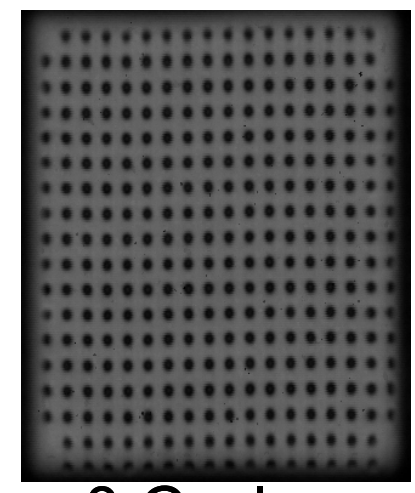

0 Cycles
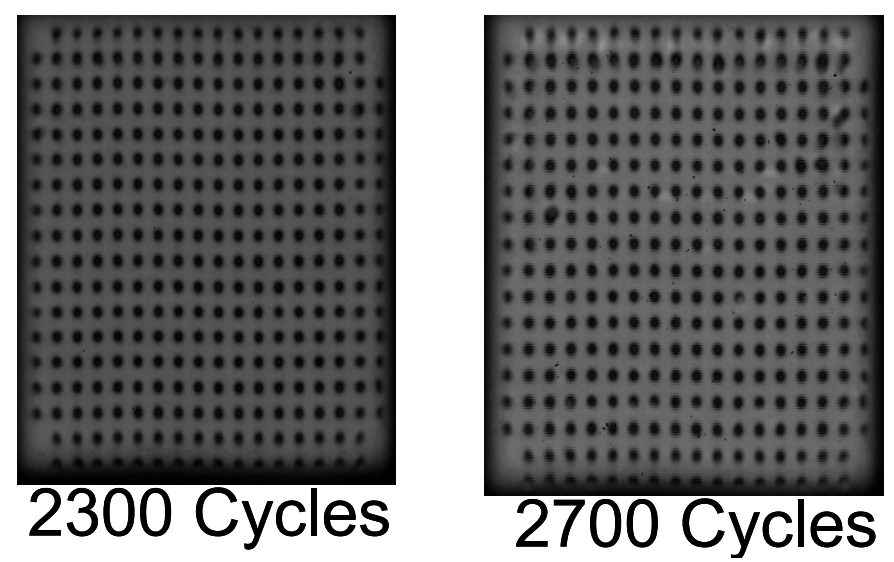

Figure 5-25 Material C, Best Case Delamination Progression, Part Failed at 2700 Cycles

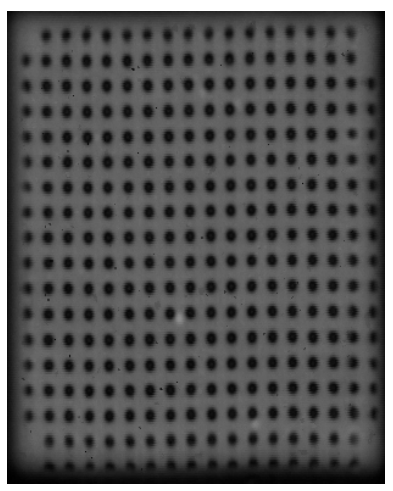

0 Cycles

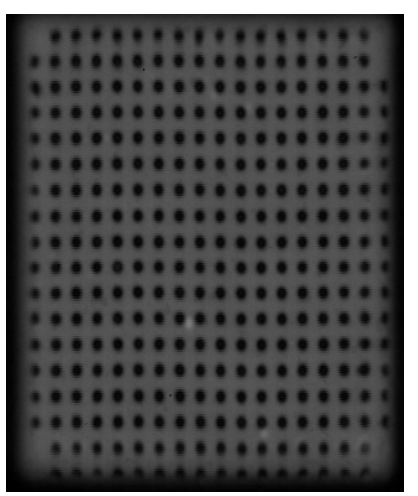

2300 Cycles

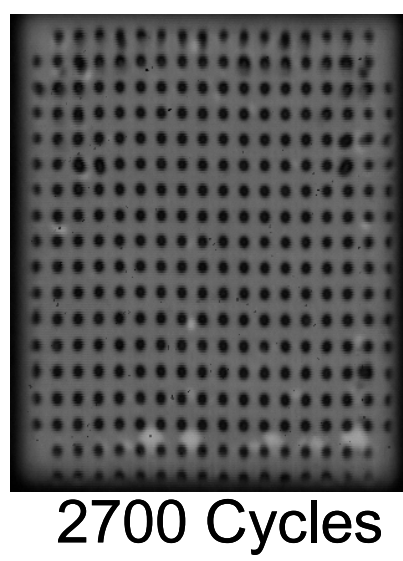

Figure 5-26 Material C, Average Case Delamination Progression, Part Failed at 2700 Cycles 


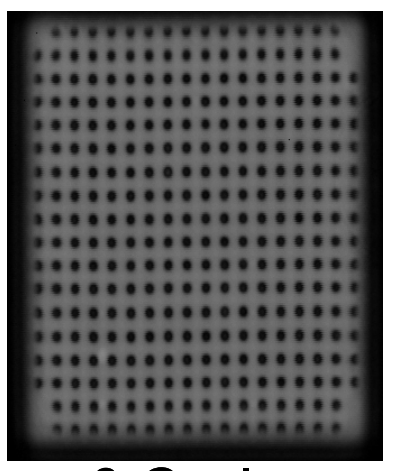

0 Cycles

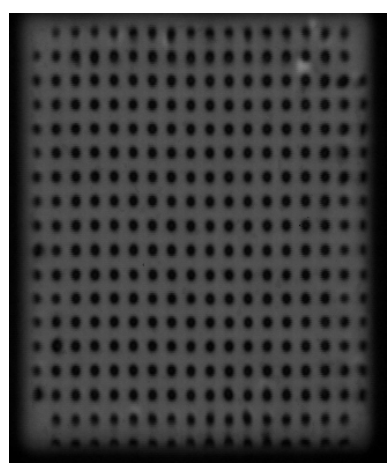

2300 Cycles

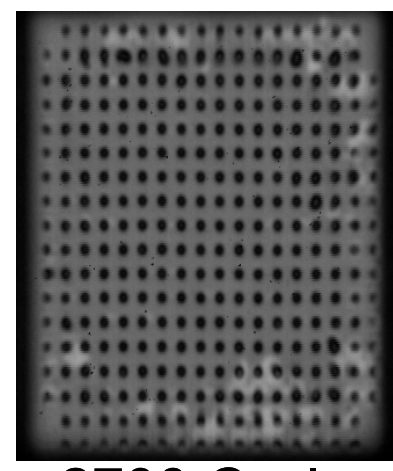

2700 Cycles

Figure 5-27 Material E, Worst Case Delamination Progression,

Part Failed at 2700 Cycles

Solder extrusion shorts were present in all assemblies that failed resistance measurement. Most of the assemblies show extensive shorting as presented in Figures 5-28 and 5-29. The extrusion was more prevalent around the die edges, specifically the outer two rows.

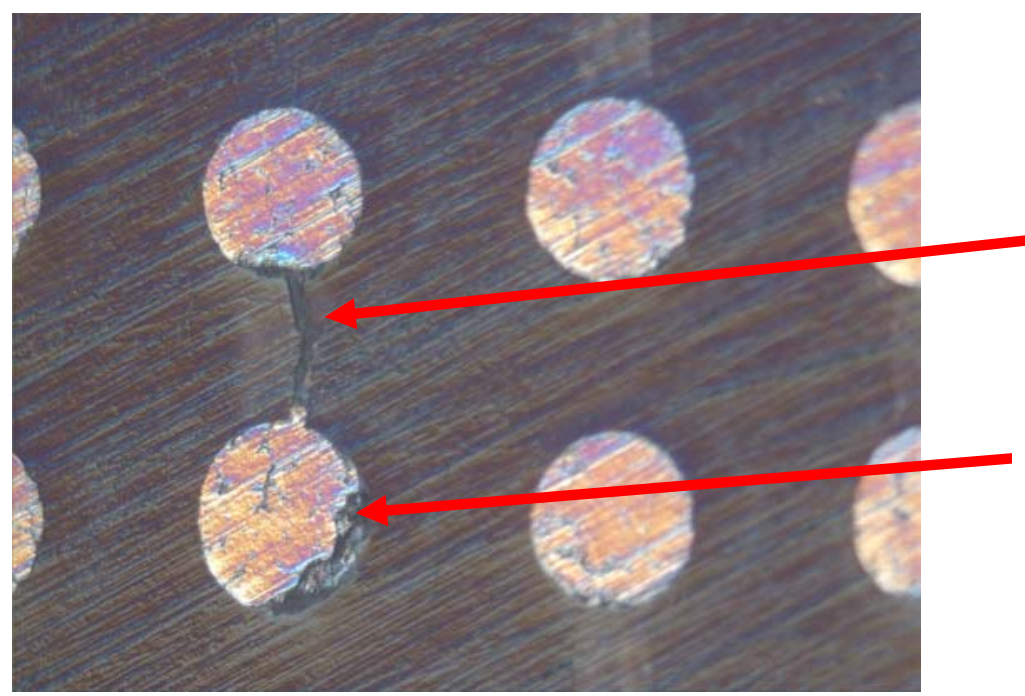

Underfill crack

Solder missing from joint due to extrusion

Figure 5-28 Material E, 3400 AATC cycles, Part Failed at 3400 Cycles 


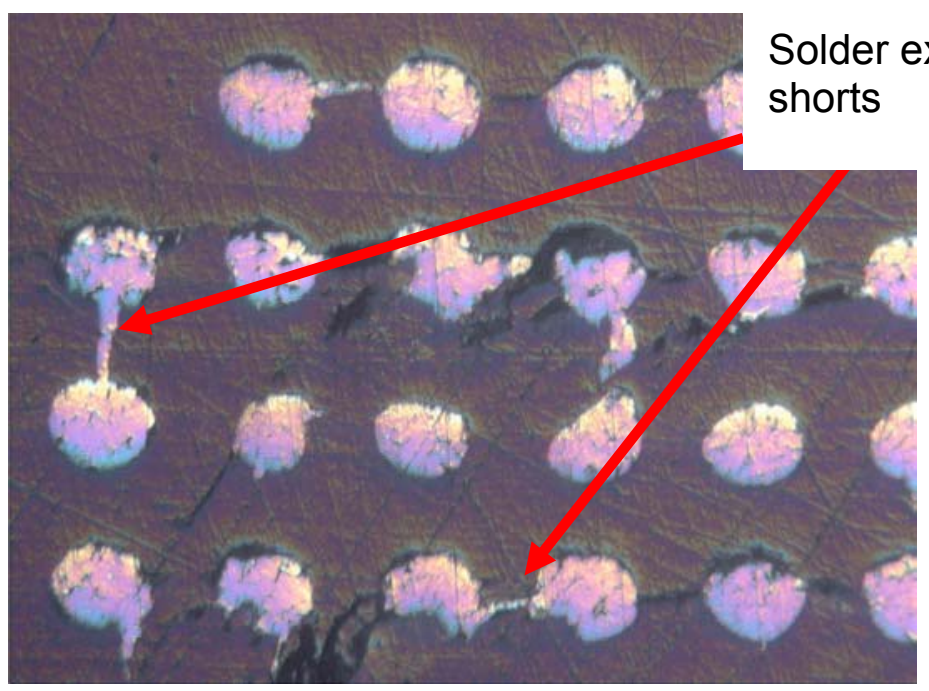

Figure 5-29 Material E, 3400 AATC cycles with extrusion shorts

\subsection{AATC Discussion and Conclusions}

Material A was the top performing material out of the four materials tested for final reliability. The performance can be attributed to the excellent adhesion performance of the underfill. This is evident from the CSAM images taken at regular intervals (200-400 cycles) during cycling. Cross-sectional inspection of the assemblies at 3500 cycles reveals that the material also exhibited excellent resistance to solder extrusion shorts, evidently from either a better resistance to crack initiation or crack opening because the assemblies do show numerous hairline cracks without extrusion. It is unclear whether the cracks started forming later than the other materials or if they formed on a similar timescale and remained relatively closed to solder extrusion; this determination could only be made by a properly designed experiment to monitor extrusion with samples cross-sectioned at regular intervals. 
The poor delamination performance of Material B resulted in equally poor solder extrusion performance. This is the only material where it was possible to observe extrusion along the die/underfill interface after the underfill had delaminated from the underside of the die. The poor adhesion of Material B makes it a bad choice for assemblies requiring reliability beyond about 2000 cycles. This is based on the delamination results that show fairly significant delamination by 2000 cycles. It is assumed that solder extrusion begins along the delamination interface by this point and the reliability of the assemblies could be compromised. This determination could only be made by a properly designed experiment to monitor extrusion with samples cross-sectioned at regular intervals.

For Material C, approximately $50 \%$ of the parts failed by fatigue at 2400 cycles. A review of Figures 5-20, 5-21, and 5-22, indicates that delamination does not play a significant role in accelerating failures for these assemblies, because very little delamination is present by 2700 cycles. The relatively low modulus (1.4 GPa) for this material results in many fatigue failures by 2400 cycles which is relatively early compared to the parts built with other underfills. This is because a lower modulus results in more of the stress being transferred to the joints. The higher stress during each cycle results in relatively low fatigue life. These early failures coupled with the relatively few underfill cracks and no extrusion shorts present by 2400 cycles as displayed in Figure 5-23, indicate that Material $\mathrm{C}$ assemblies failed first by fatigue of the solder joints. This is in contrast 
to other materials which are often failed from solder shorting, although undetected, before the fatigue failure is manifested by resistance measurements. Material E displayed extensive shorting by the time the assemblies failed by resistance measurement. This indicates that a more detailed study of this extrusion evolution would be necessary to properly define the reliable life of parts assembled with Material E.

\subsection{Autoclave Failure Analysis Results}

All the materials performed very well in Autoclave testing, with each passing 96 hours without any electrical failures. The assemblies were also monitored for delamination by CSAM, and the results of the test are presented here.

Representative CSAMs for each material are presented in Figures 5-30 through 5-37, with discussion following in Section 5.5. 


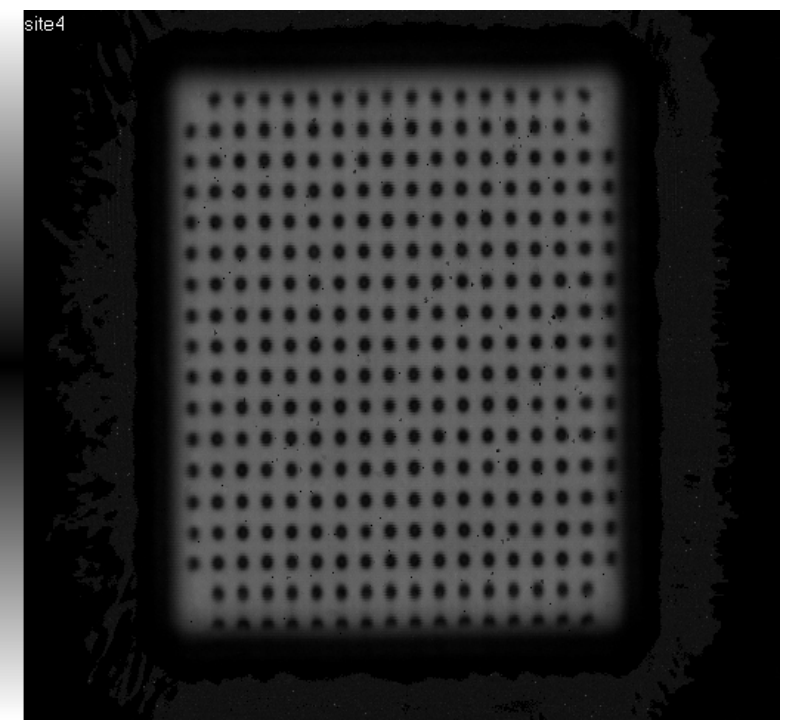

Figure 5-30 Material A, Typical CSAM Before Test Start

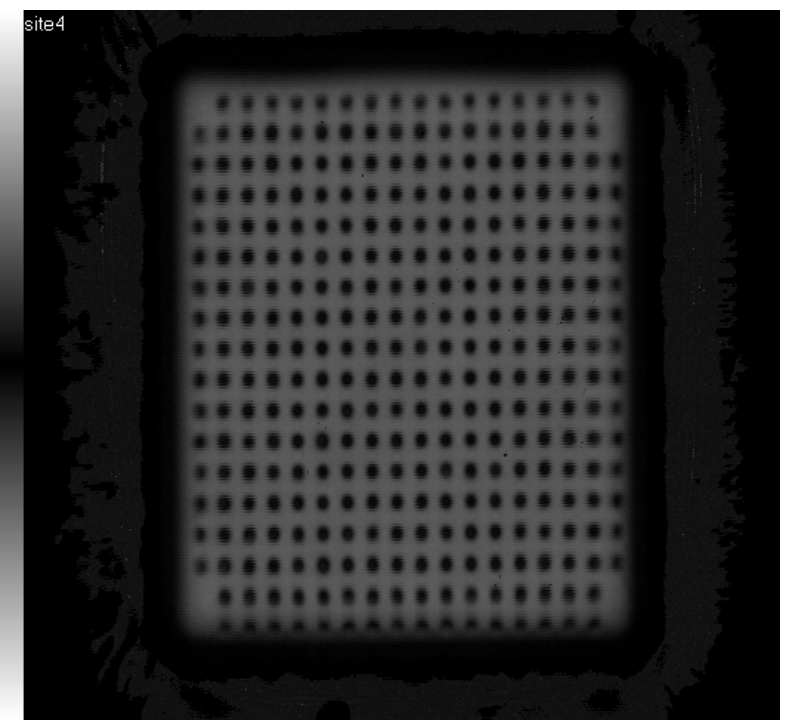

Figure 5-31 Material A, Typical CSAM After Testing 96 Hours 


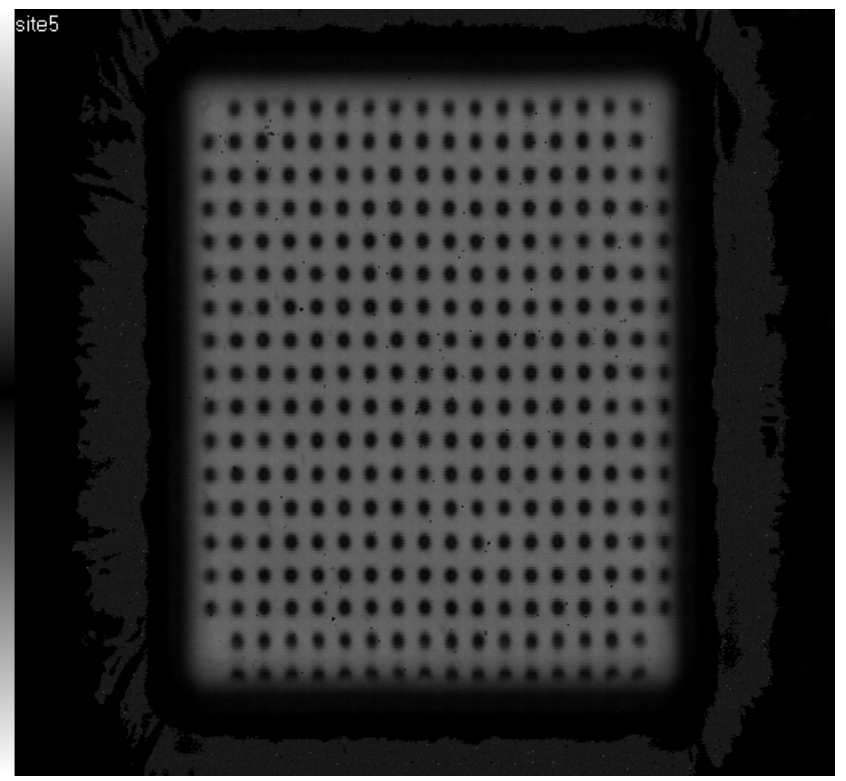

Figure 5-32 Material B, Typical CSAM Before Test Start

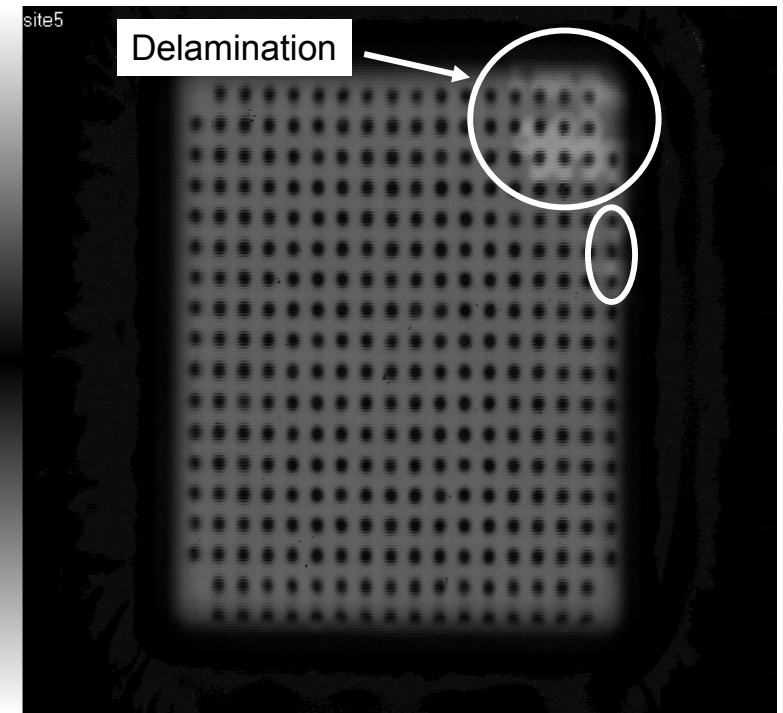

Figure 5-33 Material B, Typical CSAM After 96 Hours Testing 


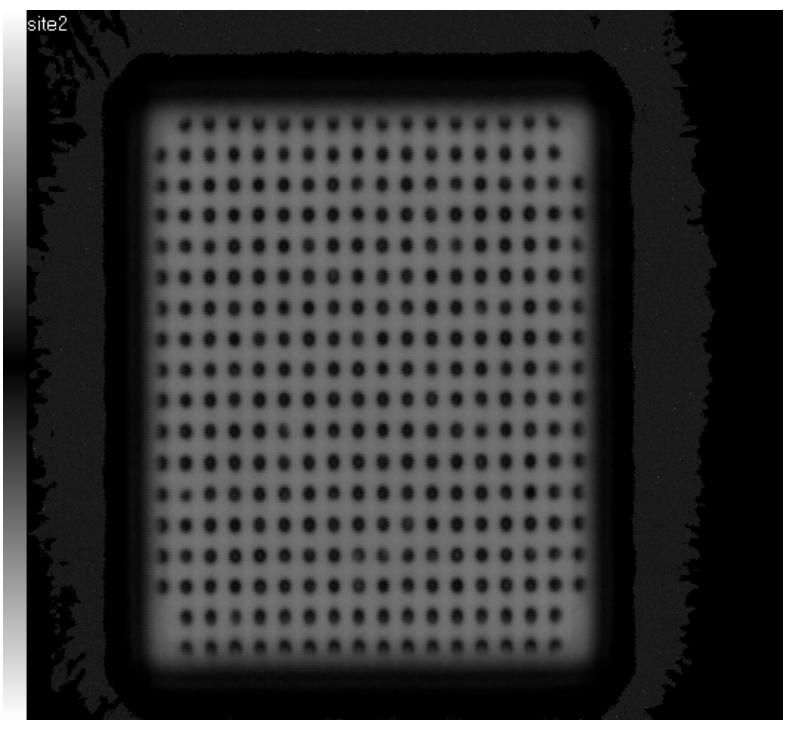

Figure 5-34 Material C, Typical CSAM Before Test Start

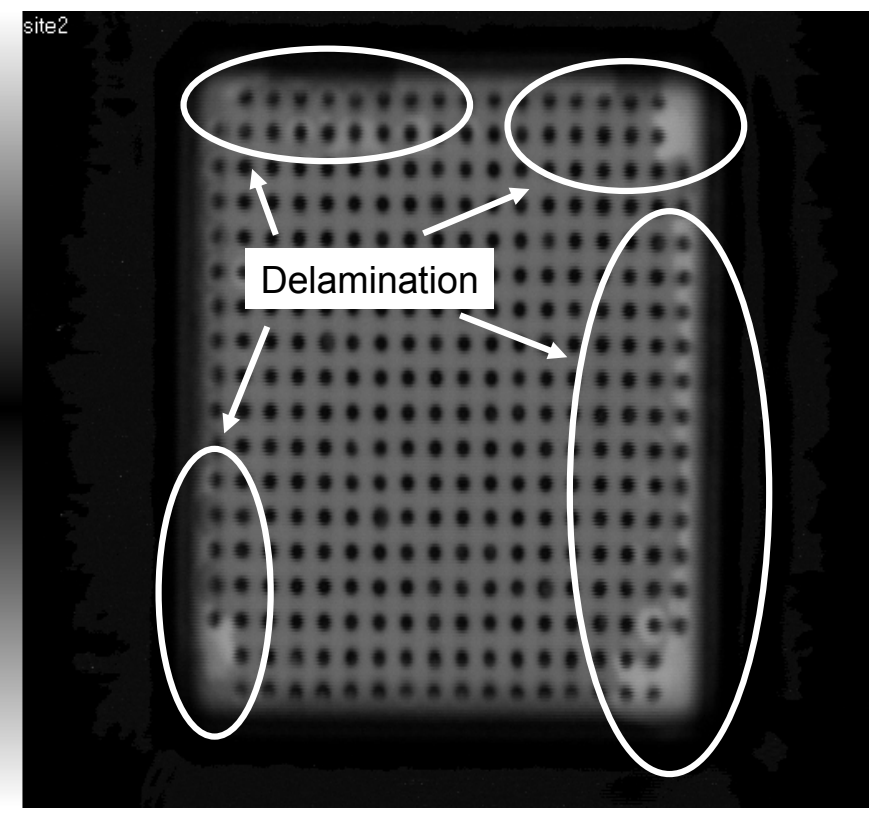

Figure 5-35 Material C, Typical CSAM After Testing 96 Hours 


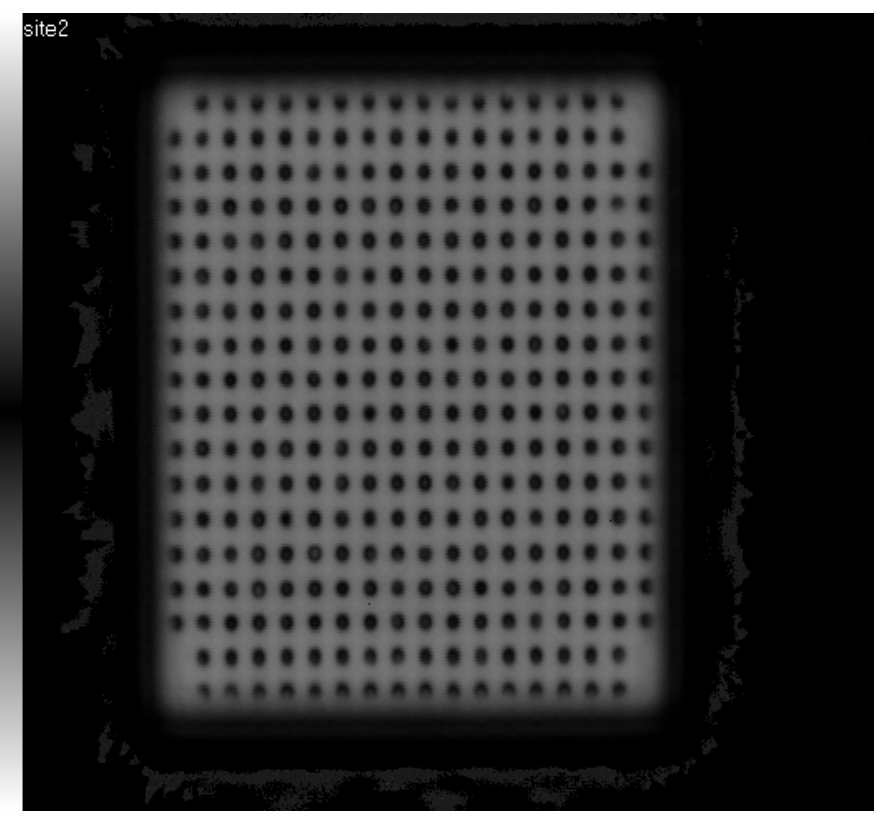

Figure 5-36 Material E, Typical CSAM Before Test Start

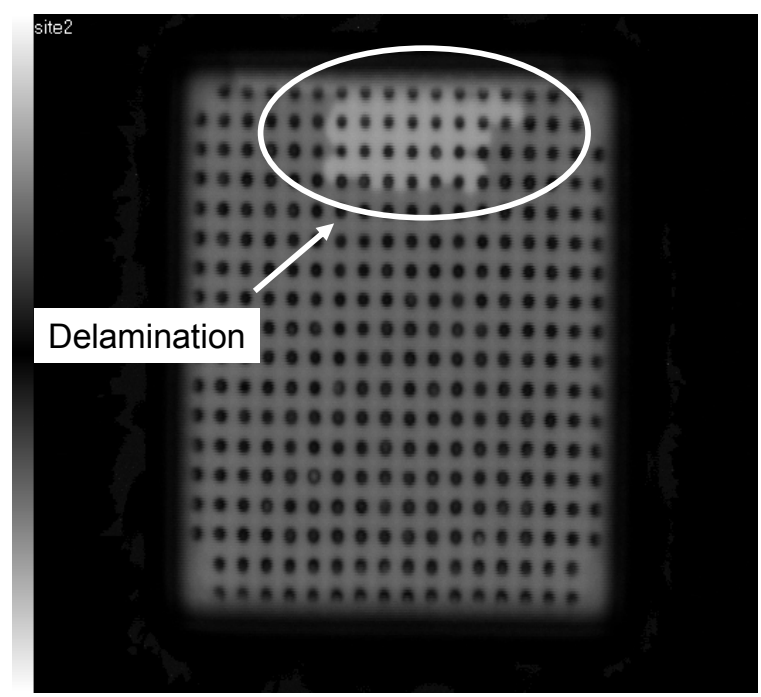

Figure 5-37 Material E, Typical CSAM After 96 Hours Testing 


\subsection{Autoclave Discussion and Conclusions}

The driving factors behind autoclave induced delamination are different than for AATC tested components. The high humidity environment causes moisture to permeate the underfill material. When the moisture reaches the die/underfill interface, the water molecules can disrupt the bonding between the polymer and the die passivation which results in a loss of adhesion. The mechanism involves the substitution of water molecules into the polymer bonds, effectively oxidizing the polymer.

Reviewing Figures 5-30 through 5-37 it is clear that the materials do not rank the same for Autoclave delamination as they do for AATC delamination performance. Material A performs the best once again, but Material $\mathrm{C}$ clearly performs the worst in contrast to the results of AATC delamination in which Material B performed the worst. These results indicate that Material $\mathrm{C}$ is more sensitive to the high humidity and high pressure environment of the Autoclave test. This may be a concern if choosing this material for a use condition that would encounter similar environmental stresses, but should not be a concern for typical normal operating conditions of consumer electronics. Materials $B$ and $E$ performed about the same in terms of delamination for this test. 


\section{CHAPTER VI: PROCESS MODELING AND DESIGN GUIDLINES}

\subsection{Model Development}

Considerable research has been done to investigate the wetting dynamics of a small volume of liquid onto a solid surface; surface tension and gravity are most commonly assumed to drive the movement of the fluid. An application of this theory to the wetting dynamics of the line dispense pattern used in this research will be investigated in this section. The goal of the modeling effort will be to develop design guidelines for the dispensing of the line next to a chip bond site. The geometrical constraints imposed by neighboring components or substrate features will drive the design guidelines.

\subsubsection{Force of Gravity}

The force due to gravity is generally ignored in the wetting of a small liquid droplet; it will be shown here that this simplification is also applicable to the cylindrical segment geometry of interest here. The non-dimensional Bond number $(B o)$, which is the ratio of gravitational force to surface tension force, is commonly used to estimate the potential effects due to gravity.

$$
B o=\frac{\text { Gravity energy }}{\text { Surface energy }}=\frac{m g h_{b}}{\gamma A}
$$

The geometry of the line dispense cross-section is taken to be a half cylinder at the start of the analysis $(t=0)$. The half cylinder geometry has a contact angle of $90^{\circ}$. The true contact angle begins at near $180^{\circ}$ as the material touches the 
substrate, and then decreases with time to a final value equal to the equilibrium contact angle. Thus, at some point in the evolution of the contact angle the crosssection is a half cylinder; this point in time is defined as time $=0$ for the model.

The Bond number variables for this geometry are the following: $h_{b}$ is the vertical height of the center of mass of the half cylinder, $A$ is the surface area, $m$ is the mass, $\gamma$ is the surface tension between the liquid and air, and $g$ is the acceleration due to gravity. The cross-sectional geometry of the line dispense is displayed in Figure 6-1.

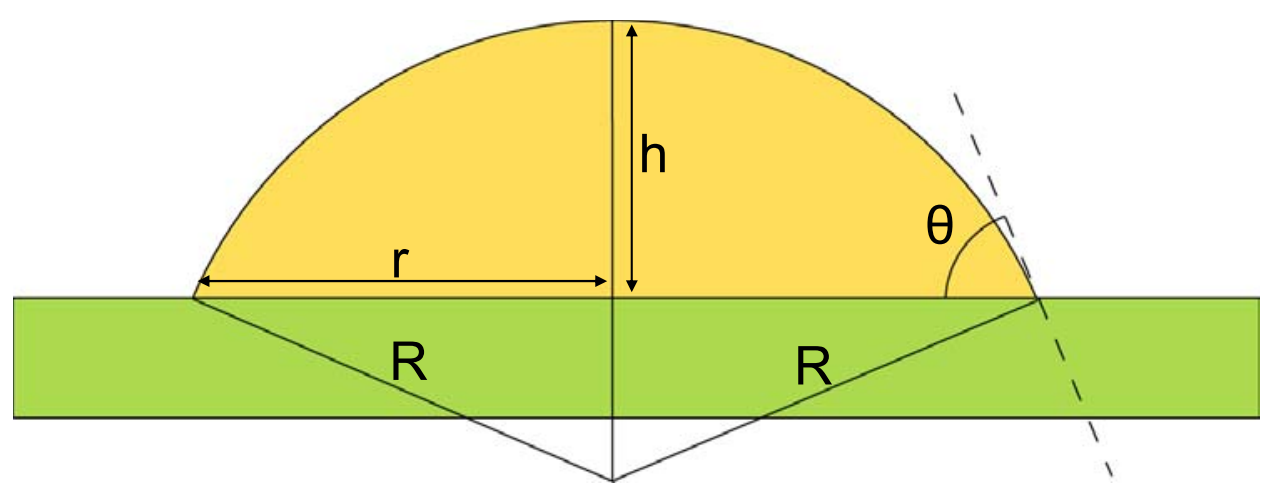

Figure 6-1 Modeling Geometry of Underfill Line Deposit

Considering Figure 6-1 at time $=0$, the geometric constraint $\left(\theta=90^{\circ}\right)$ results in $h=r$. The half cylinder cross-sectional area is $\frac{\pi}{2} r^{2}$. Also, $A=V / L$, the volume of underfill divided by the length of the dispense. Solving for $r$ gives Equation 6.2. 


$$
r=\sqrt{\frac{2 V}{\pi L}}
$$

Thus, the variables for the Bond number calculation have the following values:

$$
\begin{aligned}
& h_{b} \approx h / 2=r / 2=\sqrt{\frac{V}{2 \pi L}}=\sqrt{\frac{m}{2 \pi \rho L}}=0.42 \mathrm{~mm} \\
& A \approx \pi r L=\pi(.84 \mathrm{~mm})(5.08 \mathrm{~mm})=13.2 \mathrm{~mm}^{2} \\
& m=8 m g \\
& \gamma=.025 \mathrm{~N} / \mathrm{m} \\
& g=9.8 \mathrm{~m} / \mathrm{s}^{2}
\end{aligned}
$$

Where $A$ and $h_{b}$ are approximations that will tend to make the resulting Bond number calculation an upper bound. The $\pi r L$ value does not take into account the area of the "end caps" that close off the ends of the simplified modeling geometry; therefore, the true value of $A$ is larger than $\pi r L$. The $h / 2$ approximation for $h_{b}$ overestimates the height of the center of mass because the true center of mass is obviously below $h / 2$. A small value for $A$ and a large value for $h_{b}$ results in an upper bound for the true Bond number, as evidenced by Equation 6.2. A substitution of these values into Equation (6.1) yields a Bond number of 0.10 . Furthermore, as the line spreads, the surface area will increase and the height of the center of mass will decrease; therefore, the Bond number 
will remain below 0.1 during the wetting of the line. For this reason, gravity effects are neglected in this modeling.

\subsubsection{Viscous Forces}

The Capillary number $(\mathrm{Ca})$ provides a non-dimensional ratio of the viscous forces and the surface tension forces that are acting on a volume of fluid.

$$
C a=\frac{\text { viscous forces }}{\text { surface tension forces }}=\frac{\mu \nu}{\gamma}
$$

If $C a$ is much less than 1 , then the magnitude of the surface forces is much greater than the magnitude of the viscous forces. For the case of $\mathrm{Ca}$ much less than 1 , viscous forces can be ignored as a first approximation. This is desirable because it often allows for a simplified approach when developing an analytical model of the dynamics for a specific geometry of fluid. The capillary number for the line dispense flow dynamic is approximately 0.05 . The Reynolds number has also been calculated as 0.00005 which shows that viscous forces are much larger than inertial forces. This is quite a bit different from the compression flow dynamic which has a Reynolds number of about 0.125 , which is over 1000 times as large. This result for the capillary number and Reynolds number coupled with the result of the Bond number calculation in the previous section allow for use of the Cox wetting model introduced in Section 6.1.5. 


\subsubsection{Surface Tension as a Driving Force}

The role of surface tension as a driving force in wetting was first established by [Young 1855] by considering the imbalance of forces at the triple contact line (Figure 6-2).

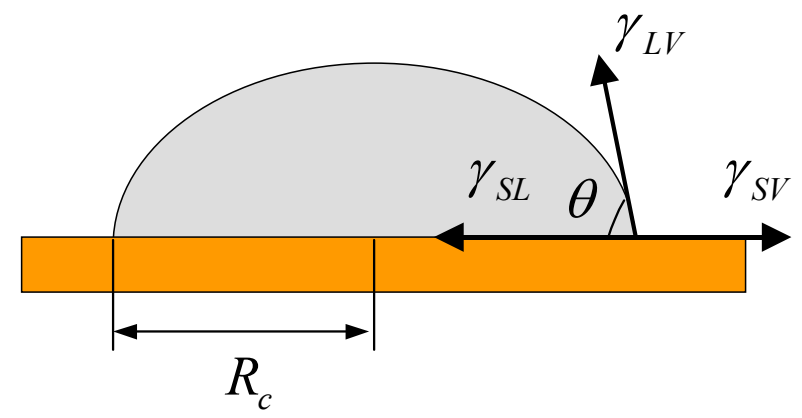

Figure 6-2 Surface Tension Forces at the Contact Line

This driving force $F_{d}$ is expressed in terms of the surface tension components in Equation (6.4).

$$
F_{d}=\gamma_{S V}-\gamma_{S L}-\gamma_{L V} \cos \theta
$$

After the liquid has wet to its equilibrium contact angle $\theta_{e q}$, we take $F_{d}=0$, which results in Young's equation (6.5).

$$
\gamma_{S V}-\gamma_{S L}=\gamma_{L V} \cos \theta_{e q}
$$

Then, substituting back into Equation (6.4) yields the expression for the driving force due to surface tension at some angle $\theta$ :

$$
F_{d}=\gamma_{L V}\left(\cos \theta_{e q}-\cos \theta\right)
$$




\subsubsection{Viscous Dissipation as a Retarding Force}

For non-reactive wetting, many researchers consider viscous dissipation within the fluid to be the dominant mechanism by which forces opposing the driving force are created [de Gennes 1985, Cox 1986]; this will be assumed for the underfill-substrate combination in this research. This conventional hydrodynamic approach encounters a singularity at the triple contact line due to a conflict between the classical no-slip boundary condition and the moving contact line. This difficulty has been circumvented by truncating the analysis at a small distance from the wetting line, first by Voinov and then later by many others employing the hydrodynamic approach [Voinov 1976, Cox 1986]. A variation of the Cox model will be employed here.

\subsubsection{The Viscous Dissipation Hydrodynamic Model}

The analysis of wetting is based on viscous dissipation within the expanding underfill line. The viscous dissipation rate balanced with the power of the driving force (Equation 6-6) will determine the velocity of the wetting line. Using this approach, if the capillary number is small and the contact angle is less than $3 \pi / 4$, Cox derived (Equation 6-7) the approximate relation between the dynamic contact angle and the velocity of the wetting line.

$$
\theta^{3}=\left(\theta_{e q}\right)^{3}+9 \frac{v \mu}{\gamma_{L V}} \ln \left(\frac{R_{c}}{s}\right)
$$

Where $v$ is the radial velocity of the contact line, $\mu$ is the viscosity of the liquid, $R_{c}$ is the characteristic length of the fluid, $s$ is the "slip length", and $\theta, \theta_{e q}$, and 
$\gamma_{L V}$ are as shown in Figure 6-2. The slip length corresponds to the length scale where continuum theory breaks down and is related to the molecular dimensions and surface properties of the solid. Specific values for $s$ can vary widely, and have been estimated at between $1 \mathrm{~nm}$ and $100 \mu \mathrm{m}$ [Kistler 1993]. Values toward the larger end of that range are not uncommon for polymer melts [de Gennes 1985].

From Section 6.1.1 it is known that for the line pattern geometry and volume of fluid, the gravitational potential energy is much less than the surface energy (Bo much less than 1). This result indicates that as an approximation, the effect of gravity on the shape of the cross section can be neglected. Furthermore, the surface energy is expected to dominate the shape of the cross-section. Therefore, for the purpose of this analysis, the minimum surface energy shape will be assumed. The geometry of a cylindrical segment is that of a circular segment when considered in 2D, Figure 6-3. The geometry of such a segment is described by Equations (6.8)-(6.10).

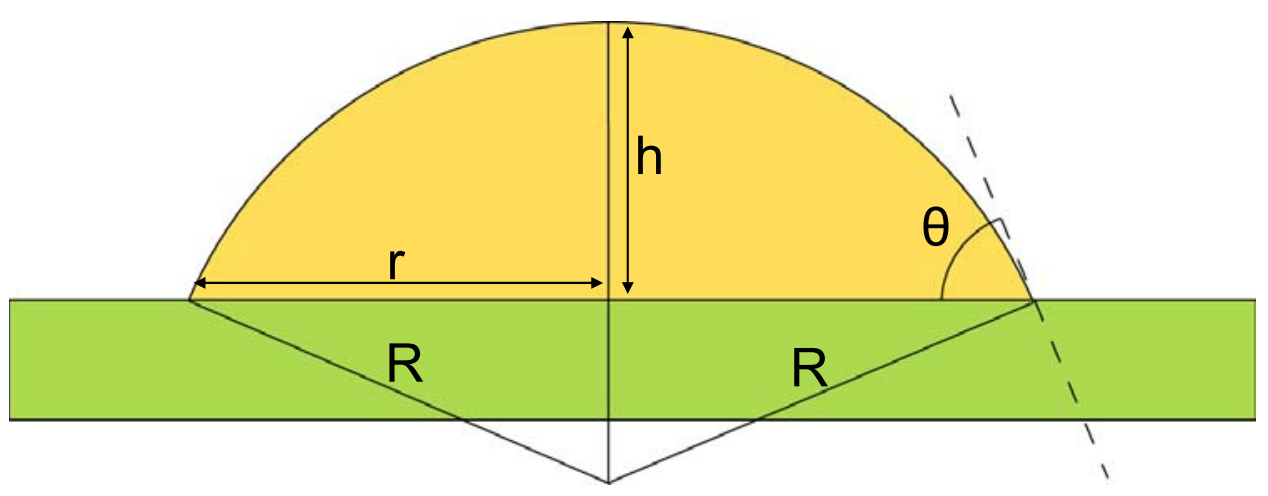

Figure 6-3 Modeling Geometry of Underfill Line Deposit 


$$
\begin{gathered}
A=R^{2} \cos ^{-1}\left(\frac{R-h}{R}\right)-(R-h) \sqrt{2 R h-h^{2}} \\
A=\frac{r^{2}}{\sin ^{2} \theta}(\theta-\sin \theta \cos \theta) \\
r=\frac{A^{1 / 2} \sin \theta}{(\theta-\sin \theta \cos \theta)^{1 / 2}}
\end{gathered}
$$

Where $A$ is the cross sectional area of the dispensed underfill line. This analysis will assume that this cross sectional area remains constant, meaning that the length of the line remains roughly constant during the relaxation of the contact angle.

For constant volume, and using the chain rule of derivatives, we have the relation given in Equation (6.11).

$$
\frac{d r}{d t}=\frac{d r}{d \theta} \frac{d \theta}{d t}
$$

Now, differentiating Equation (6.10) with respect to $t$ and using the relation in Equation (6.11) results in the following:

$$
\frac{d r}{d t}=v=\left(-\frac{d \theta}{d t}\right) A^{1 / 2}\left[\frac{2 \cos \theta(\theta-\sin \theta \cos \theta)+\sin \theta(\cos (2 \theta)-1)}{2(\theta-\sin \theta \cos \theta)^{3 / 2}}\right]
$$


We can now combine this volumetric continuity constraint (Equation 6.12) with the hydrodynamic condition of Equation (6.7), and obtain an expression for the time derivative of the contact angle, Equation (6.13).

$$
\frac{d \theta}{d t}=\frac{1}{A^{1 / 2}\left(\frac{9 \mu}{\gamma_{L V}}\right) \ln \left(\frac{R_{c}}{s}\right)}\left[\frac{2(\theta-\sin \theta \cos \theta)^{3 / 2}\left(\theta^{3}-\theta_{e q}^{3}\right)}{2 \cos \theta(\theta-\sin \theta \cos \theta)+\sin \theta(\cos (2 \theta)-1)}\right]
$$

Where $A$ is easily determined for a given volume of underfill and chip length ( $A=V / L)$, and $\mu$ at room temperature $\left(25^{\circ} \mathrm{C}\right.$ ) can be obtained from the underfill manufacturers specs. In this analysis, values of $\gamma_{L V}, \theta_{e q}$, and the slip fitting parameter $\ell=\ln \left(R_{c} / s\right)$ will be investigated parametrically centered around some values obtained experimentally by other researchers [Kim 2003, Sze 2000].

We wish to obtain the time evolution of the contact line along the substrate in order to better understand processing issues that may arise when implementing the line pattern no-flow dispense that was developed as a result of the experimental work detailed in Chapters 3 and 4. A Matlab program was created to investigate the relevant parameters of the wetting model. The initial value problem was solved using Euler's Method as described in Equation 6.14.

$$
\theta_{i+1}=\theta_{i}+\left(\frac{d \theta}{d t}\right)_{i} \Delta t
$$

Then the initial values and time step were selected as 


$$
\begin{aligned}
& \theta_{o}=\frac{\pi}{2} \\
& \left(\frac{d \theta}{d t}\right)_{o}=\left(\frac{d \theta}{d t}\right)_{\theta_{o}} \\
& \Delta t=0.001 \mathrm{~s}
\end{aligned}
$$




\subsection{Application of the Wetting Model}

\subsubsection{Wetting Dynamics for FA10-2 Assembly}

The baseline parameters for use in the simulation are displayed in Table 6-1. The values in Table 6-1 for $m, \rho, \mu$, and $L$ come from the experimental work presented in Chapters 3 and 4 . The remaining values for $\gamma_{L V}, \ell$, and $\theta_{e q}$, were selected from the literature [Kim 2003]. The values for $\ell$ and $\theta_{e q}$ were determined by Kim experimentally. Recall that the slip fitting parameter is defined as $\ell \equiv \ln \left(R_{c} / s\right) . R_{c}$ is the characteristic length of the fluid, and $s$ is the "slip length". The slip length corresponds to the length scale where continuum theory breaks down and is related to the molecular dimensions and surface properties of the solid. It is important to note that $s$ or $\ell$ are curve fitting parameters and must be determined experimentally. Kim determined $\theta_{e q}$ by optical inspection, as the contact angle of a small drop of underfill at 24 hours after dispense. The $\gamma_{L V}$ value was also taken from Kim. Plots of contact angle vs. time and wetting radius vs. time, created with the simulation parameters in Table 6-1, are shown in Figures 6-4 and 6-5. 
Table 6-1 Baseline Modeling Parameters (FA10-2)

\begin{tabular}{l||c}
\multicolumn{1}{c||}{ Parameter } & Value \\
\hline \hline Underfill surface tension, $\quad \gamma_{L V}$ & $25 \mathrm{mN} / \mathrm{m}$ \\
\hline Underfill mass, $m$ & $8 \mathrm{mg}$ \\
\hline Underfill density, $\rho$ & $1.2 \mathrm{~g} / \mathrm{mL}$ \\
\hline Underfill viscosity (average), $\mu$ & $6000 \mathrm{cP}$ \\
\hline Slip fitting parameter, $\quad \ell$ & 2.14 \\
\hline Length of the chip, $L$ & $5 \mathrm{~mm}$ \\
\hline Equilibrium contact angle, $\theta_{e q}$ & $22^{\circ}$
\end{tabular}

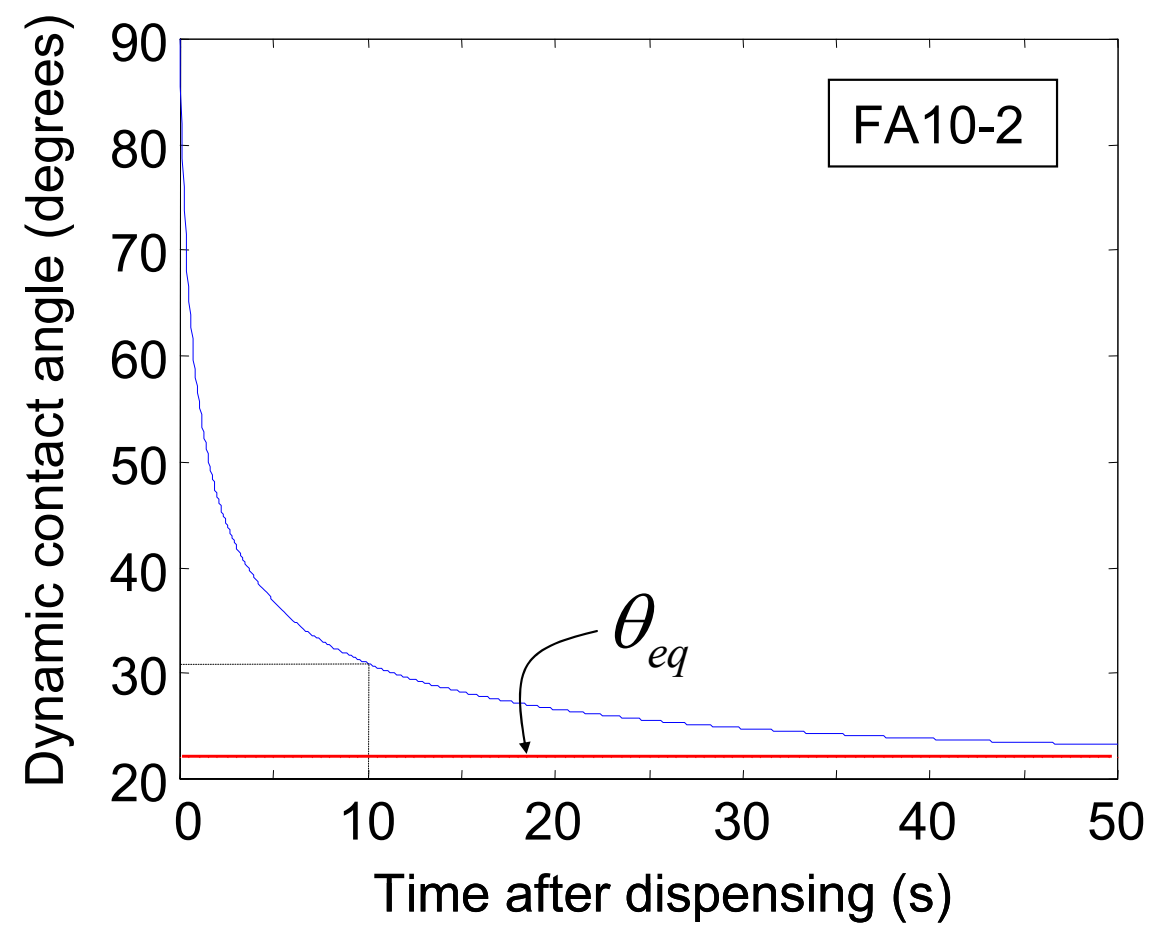

Figure 6-4 Contact Angle Relaxation for Baseline Parameter Values 


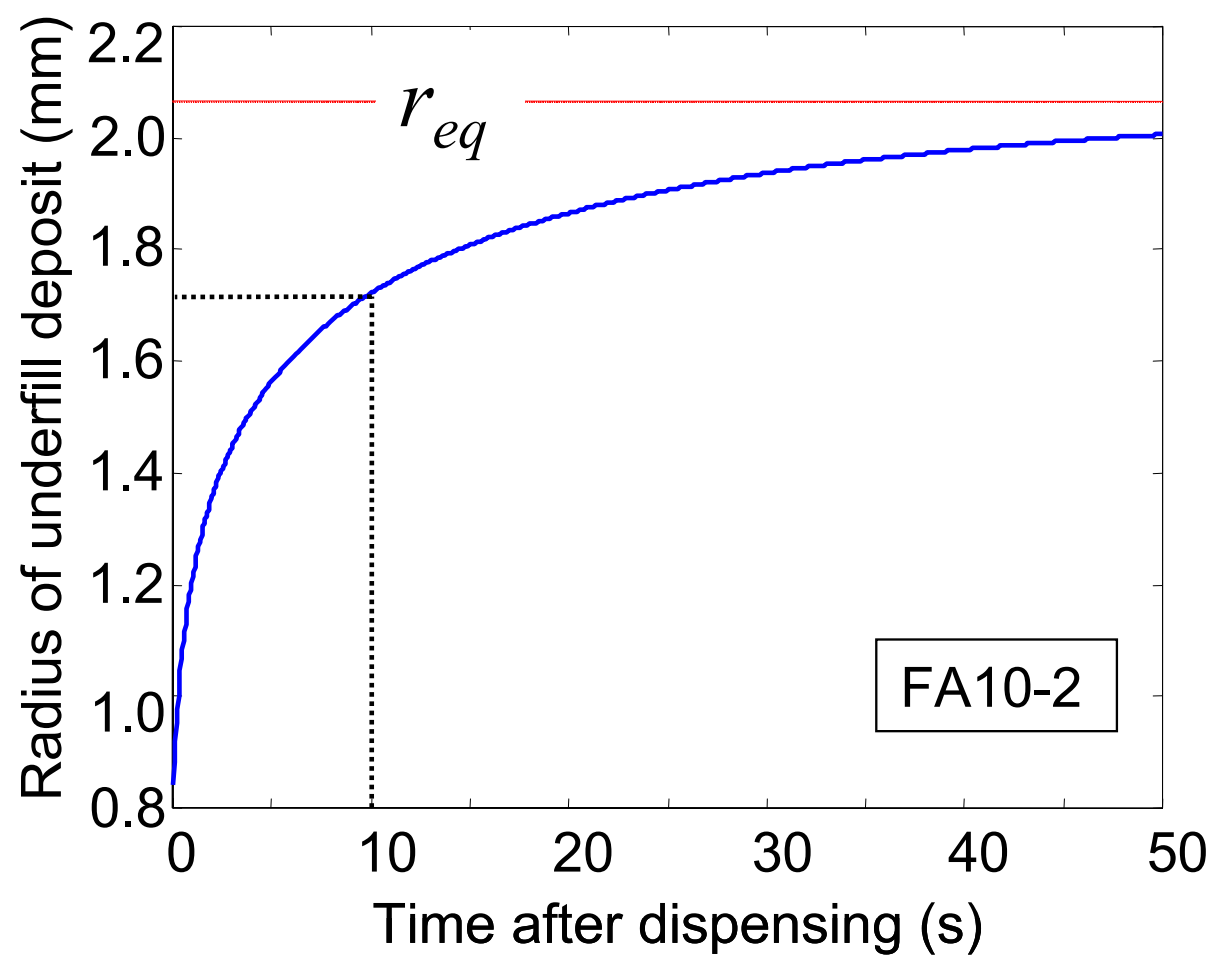

Figure 6-5 $r$ vs. $t$ of Underfill Cross Section for Baseline Parameter Values

The plots in Figure 6-4 and 6-5 show that at about 10 seconds after the line is dispensed, the radius is predicted to extend to more than double the size of the initial line. While this wetting rate was not monitored during the experimental work for this research, a simple observation of the wetting dynamics confirms a wetting rate similar to the predicted results. For purposes of this analysis, 10 seconds will be used as the time scale of interest based on an estimate of the time required to move a circuit board from the dispense machine and into the placement machine for chip placement. Therefore, for the baseline 
parameters, we can predict that the underfill cross section will extend to approximately $3.4 \mathrm{~mm}$ across by the time the chip is actually placed. It is important to note, that if the axis of the dispended line lies at the edge of the die, as was the case for the experimental work outlined in sections 3.6 and 3.7, then as much as half of this wetting will extend over the chip bond site and will not be a potential problem for adjacent substrate features. Considering that the die is only $5 \mathrm{~mm}$ across, it is clear that there is some concern with the extension of the contact line to $\sim 1.7 \mathrm{~mm}$ outside of the bond site. Direct chip attach is often used in size critical applications such as cell phones or lap top computers. These applications require tightly spaced components on a circuit board in order to pack the most functionality into the smallest possible space. Therefore, it is desired that a no-flow process for flip chip attach will require as little board space as possible in excess of the chip area. This requirement will be investigated further in the discussion on design guidelines.

The model will now be applied, while parametrically varying $m / L, \mu, \ell$, and $\theta_{e q}$ parameter values while holding all parameters other than the parameter of interest at the baseline values displayed in Table (6-1). The results will be usually be displayed using the normalized non-dimensional wetting radius $r / r_{o}$.

\subsubsection{Effect of variation of $m / L$}

The ratio $m / L$ is selected for analysis because these values will typically not change independent of one another. The ratio can be related to common flip chip geometries and a determination of the viability of the process for packages 
other than FA10-2 assembly can be made. The parametric results are displayed in Figure 6-6, where as might be expected, there is a strong effect of the linear mass density on the extension of the wetting line. Note that the ratio $m / L$ is calculated in $(\mathrm{g} / \mathrm{m})$.

To better understand the dynamics for actual flip chip devices we can calculate the linear mass density necessary to adequately underfill flip chips of known geometries. These values are displayed in Table 6-2, and they assume that the line is dispensed on one side of the chip only. It is obvious then, by Figure 6-6, that for larger devices we will begin to see wetting to distances that will likely be unacceptable considering neighboring components.

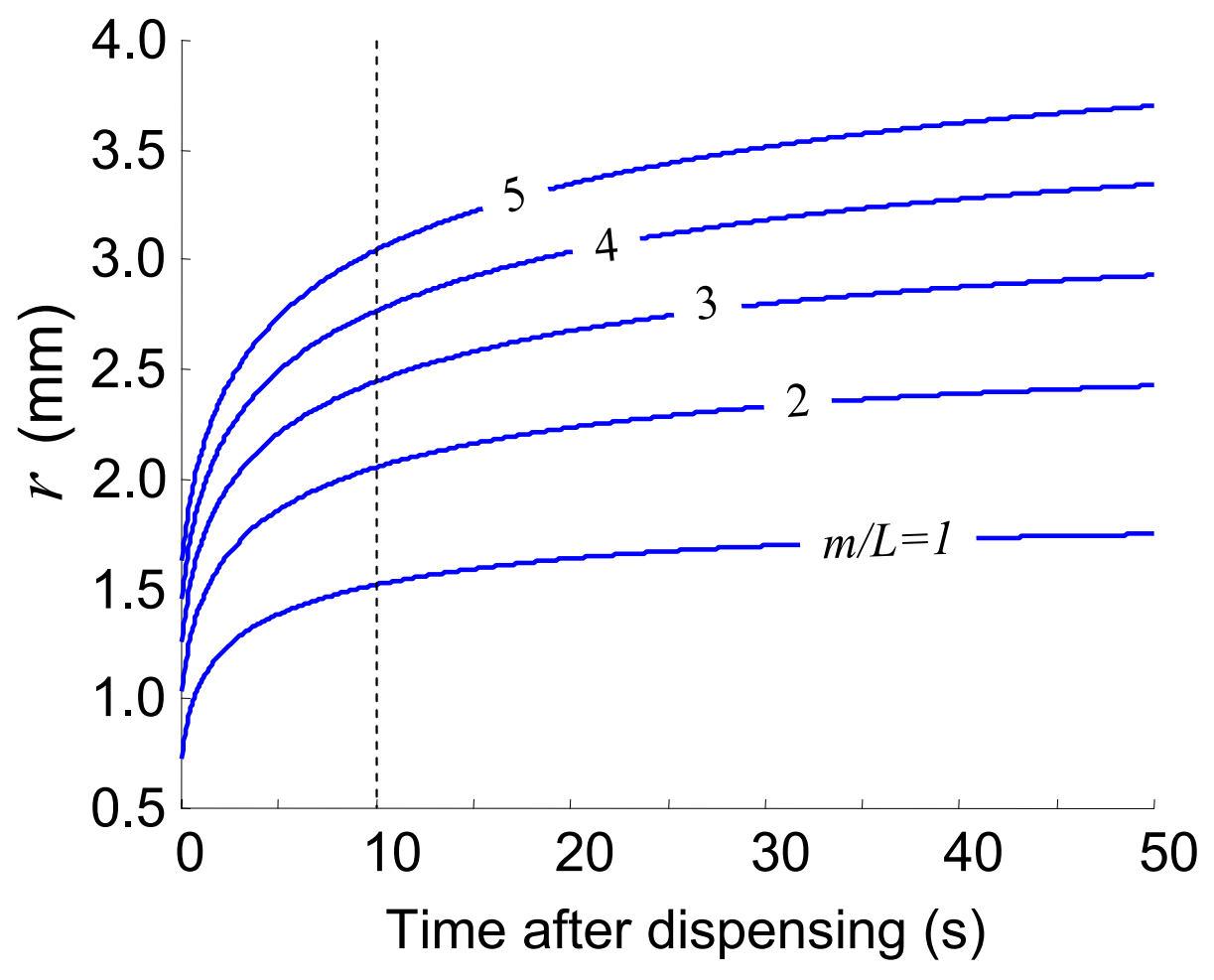

Figure 6-6 Effect of $m / L$ on Wetting Radius Dynamics 
Table 6-2 Linear Mass Density Values for Flip Chips

\begin{tabular}{cc} 
Package Type & $m / L(\mathrm{~g} / \mathrm{m})$ \\
\hline \hline FA10-2 & 1.6 \\
FA10-4 & 2.1 \\
FA-20x20mm & 2.8
\end{tabular}

A plot of the non-dimensional wetting radius $\left(r / r_{o}\right)$ vs. time, for the same $m / L$ values, is displayed in Figure 6-7. All of the curves approach the same nondimensional equilibrium radius $r_{e q} / r_{o}$ because they are based on the same $\theta_{e q}$. This plot provides a useful perspective on the wetting dynamic for lines of various linear mass densities; it can be seen that the wetting of the lines does not follow the same "doubling time" even though the "equilibrium multiplier" $(\sim 2.4)$ is the same for each case.

This result can be understood by a re-examination of the constitutive equations used in constructing the model. First, recognizing that the wetting time toward $r_{e q}$ will depend on $d \theta / d t$ rather than $d r / d t$, an understanding of this doubling time discrepancy can be obtained by reviewing Equation (6.13); note that for the curves of Figure 6-7, the only parameter that changes is the $A^{1 / 2}$ in the denominator. For larger values of $m / L$, there is a corresponding increase in $A$, with the resulting decrease in $d \theta / d t$. While this provides a mathematical explanation of Figure 6-7, it is possible to arrive at a better understanding through a look at the underlying model assumptions. Recall that the driving force 
behind the advance of the line is force per unit length which is given by Equation 6-6. This means that as $m / L$ increases the driving force associated with the increasing cross-section area will remain constant. In the de Gennes framework, the retarding force from viscous dissipation is obtained by assuming a Poiseuille type velocity profile over the wedge shaped cross section of the advancing fluid. This results in a larger dissipation force per unit length as the cross-sectional area is increased. Thus, for increasing $m / L$ there is a larger retarding force to contend with the unchanged driving force from surface tension, and this explains why lines dispensed with higher values of $m / L$ will approach $r_{e q}$ at a slower rate.

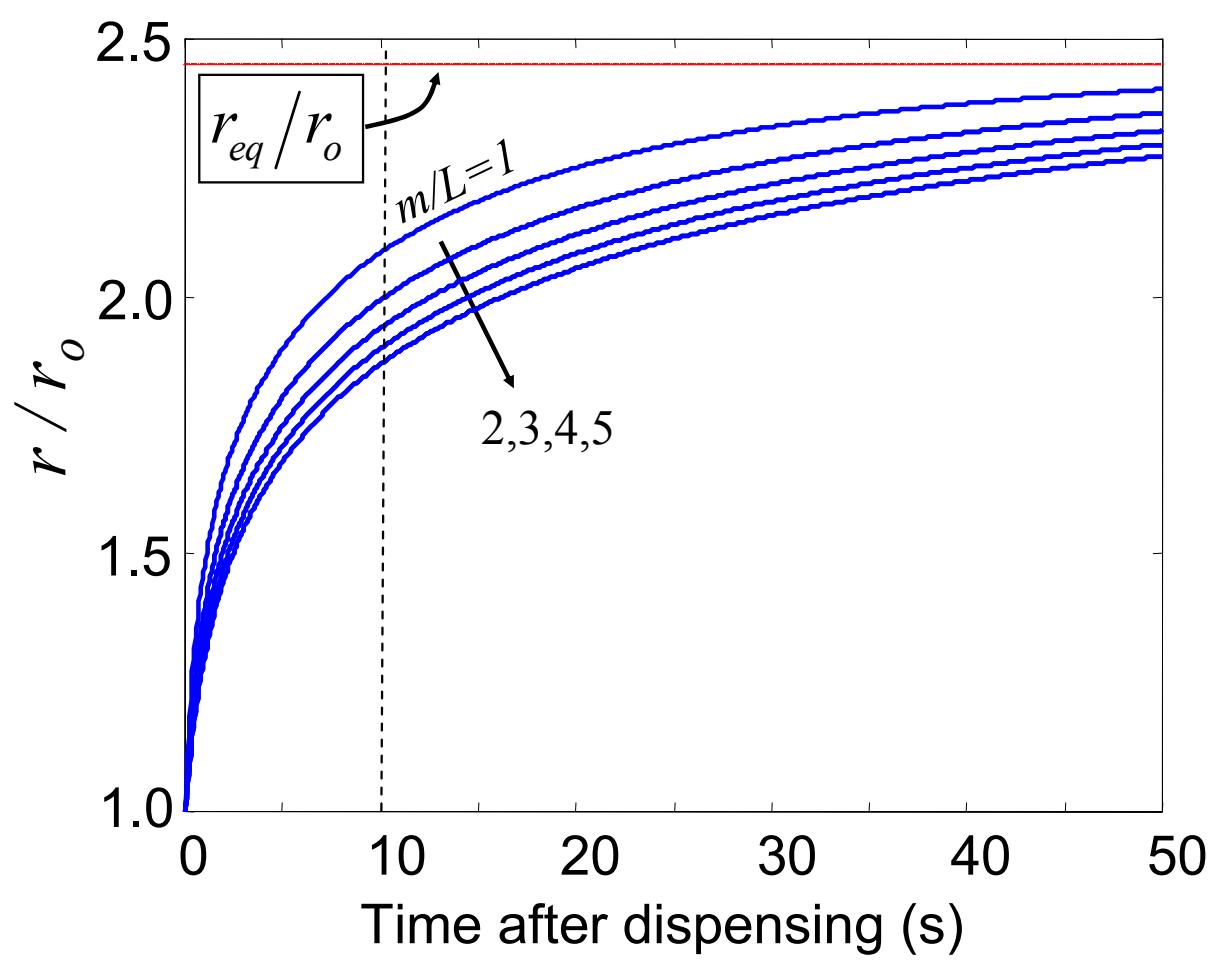

Figure 6-7 Effect of $m / L$ on Wetting Radius Doubling Rate 


\subsubsection{Effect of variation of viscosity}

The curves in Figure 6-8 show the effect of varying the viscosity of the underfill from a value of $\mu=2 \mathrm{~Pa} \cdot \mathrm{s}$ to $20 \mathrm{~Pa} \cdot \mathrm{s}$. These values roughly correspond to the range of viscosities encountered when using no-flow underfills throughout the range of their pot-life. It is apparent that there is a significant effect on the wetting dynamics, with a higher viscosity resulting in less spreading for a given amount of time. This result is not surprising, as the viscosity is incorporated into the viscous dissipation component of the model and is qualitatively expected to increase the retarding force. The model allows for a more exact, quantitative determination of this effect. For instance, it can be seen from Figure 6-8 that at $t=10$ s after dispense, an underfill with a viscosity of $2 \mathrm{~Pa} \cdot \mathrm{s}$ will wet out to about

$2.3 \cdot r_{o}$, while a viscosity of $20 \mathrm{~Pa} \cdot \mathrm{s}$ would result in a spread to only about $1.7 \cdot r_{o}$.

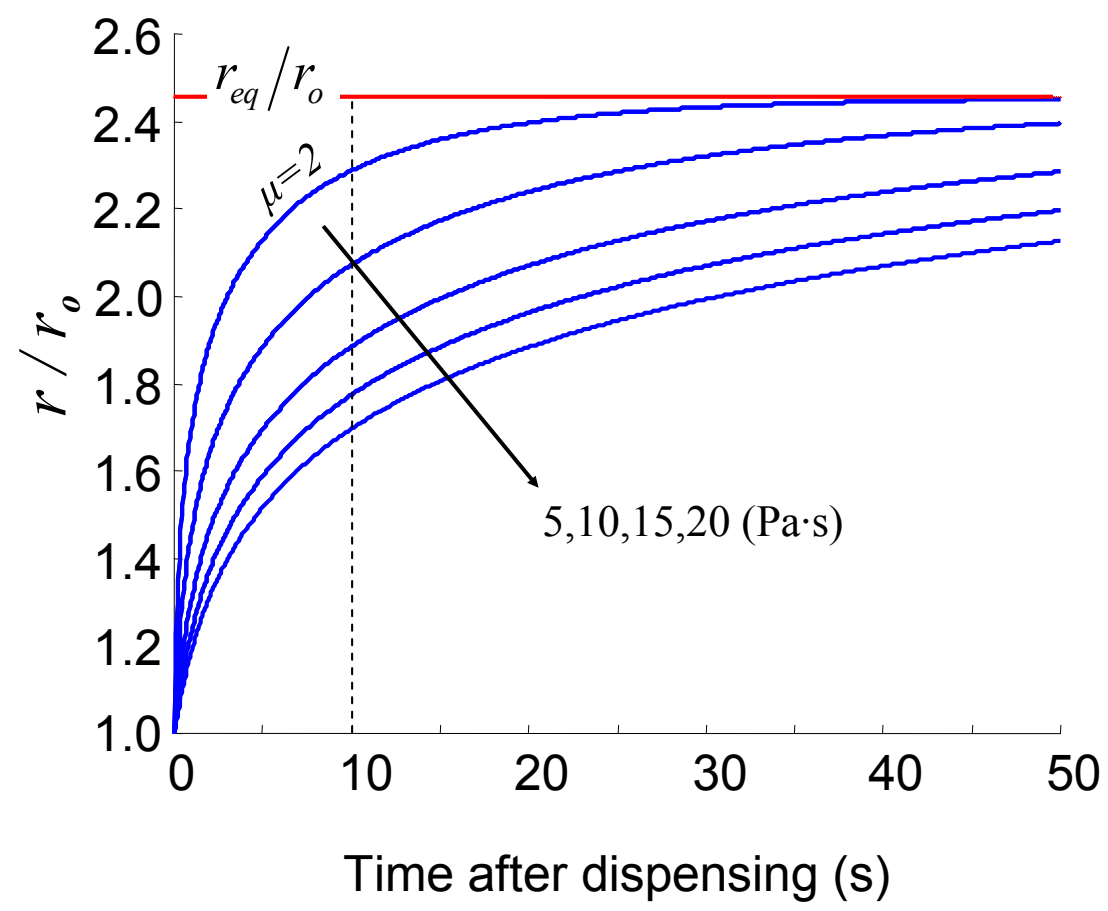

Figure 6-8 Effect of Underfill Viscosity on Wetting Radius Dynamics 
This is an appreciable difference and is an indication that it will be necessary to carefully consider, for a given application, whether it will be possible to use one of the lower viscosity materials given board population design constraints. Therefore, it is recommended that whenever possible, higher viscosity materials should be selected to avoid the potential of the underfill line to wet out excessively and encounter nearby substrate features. Another option is to consider holding underfills at room temperature for a period of time in order to increase the viscosity before processing. Although it is clear that there is a preference for a high viscosity material in this initial stage of the process before chip placement, there are additional concerns with such a material.

First, there are potential dispensing issues with a high viscosity material. Time spent in the lab working with Underfill $\mathrm{C}$ of this experimental work indicates that there may be difficulty in obtaining consistent line dispenses using materials with viscosity near the high end of those investigated in the modeling effort. A potential solution to this problem would be a more detailed examination of factors such as gap height during dispense, needle gauge, and dispense speed.

Next, there is potential for a high viscosity material to perform poorly during the next stage of the process where the material flows underneath the die to complete the underfill. The effect of a high viscosity material on the capillary flow process is difficult to predict because the flow does not happen in an isothermal environment. Therefore, the material undergoes large changes in viscosity during the flow process. The viscosity for similar underfill materials has 
been shown to decrease by an order of magnitude under temperature changes from $40{ }^{\circ} \mathrm{C}$ to $110^{\circ} \mathrm{C}$ [Han 1996]. This temperature range is very similar to the temperature range expected during the flow that happens as an assembly is in the first stages of the reflow oven. This result allows some confidence that a high viscosity material will perform adequately during the capillary flow.

\subsubsection{Effect of variation of the fitting parameter}

The effect of variation in the fitting parameter can be seen in Figure 6-9, where the values for $\ell$ were increased from the baseline value because the literature reports values typically in a range higher than that reported by Kim for no-flow on solder mask [Kim 2003].

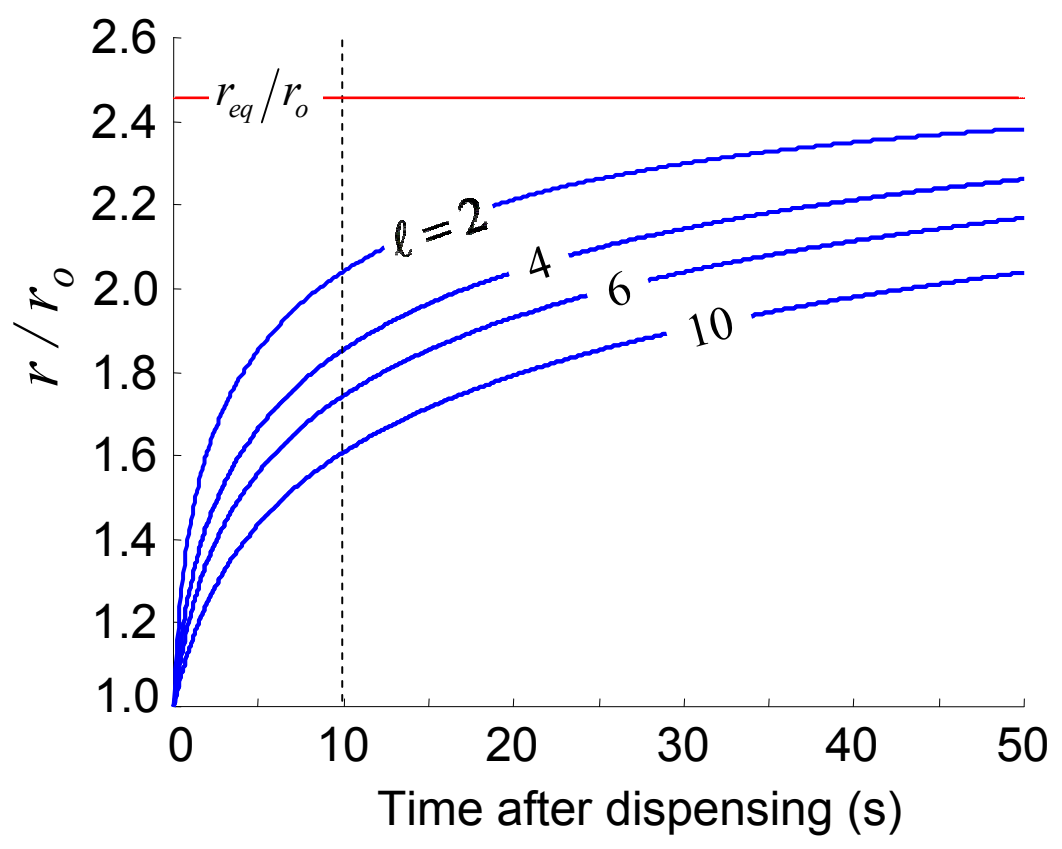

Figure 6-9 Effect of Fitting Parameter $(\ell)$ on Wetting Radius Dynamics 
The parameter $\ell$ is a property of the substrate-underfill interaction, and can only be determined by an experimental fit to data. Kim determined this value for a specific no-flow underfill on solder mask system. In order to more fully understand the wetting dynamics of a no-flow material on other types of substrate finishes, it would be required to conduct fundamental wetting studies with the material systems of interest. Additionally, it cannot be assumed that all types of solder mask coatings would result in the same $\ell$ as the 2.14 value found by Kim. This is because surface roughness can have a large influence on the result.

\subsubsection{Effect of variation in the equilibrium contact angle}

The equilibrium contact angle used as a baseline for this model was taken from the literature as $22^{\circ}$ [Kim 2003]. However, the true value remains somewhat uncertain, as a value of $18^{\circ}$ has been reported by [Milner 2001]. These values were both determined experimentally for no-flow underfill on solder mask, although it is not clear if either the solder mask finish or underfill was identical in both cases. Fortunately, the curves in Figure 6-10 indicate that for the 10 second time scale of interest, there is relatively little difference in the predicted radius of the underfill cross section. 


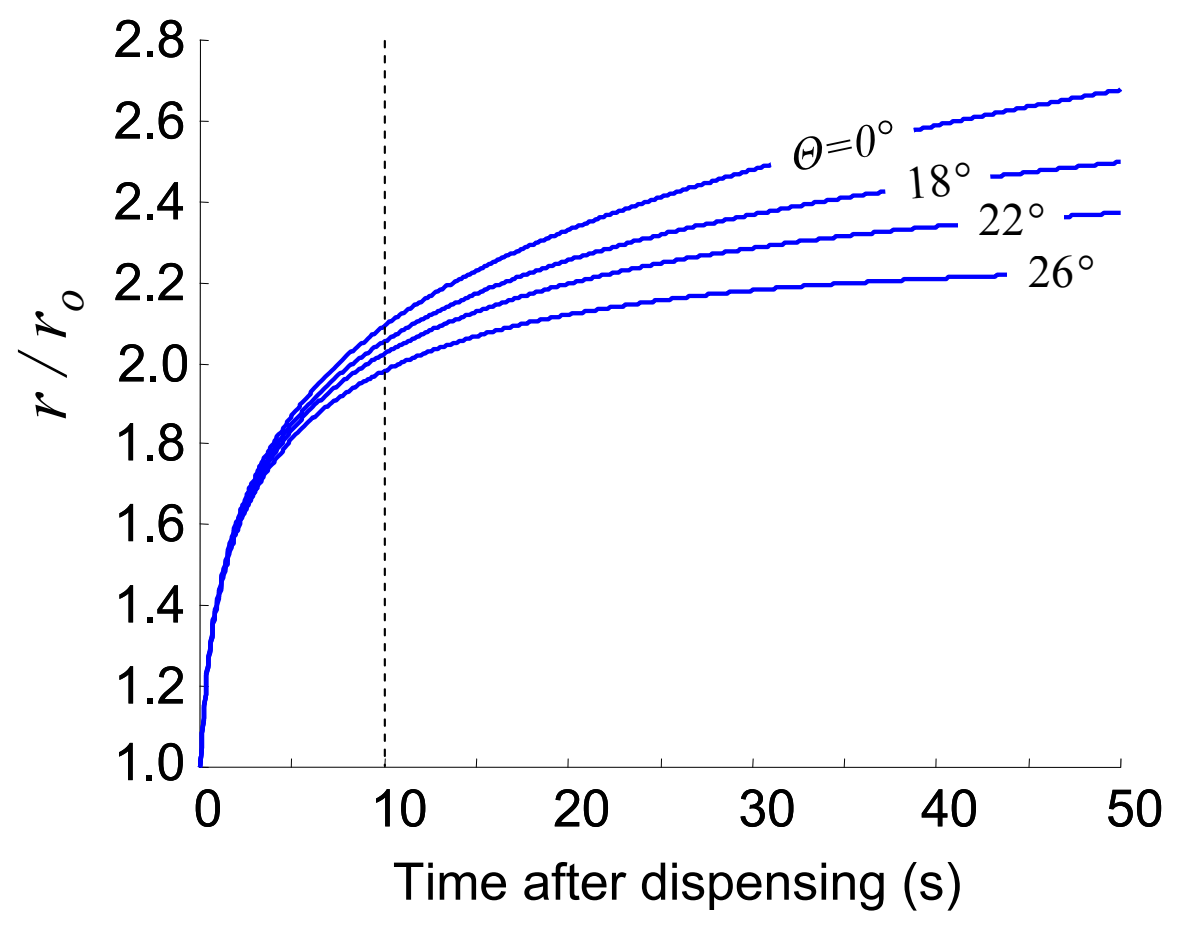

Figure 6-10 Effect of $\theta_{e q}$ on Wetting Radius Dynamics

In fact, as Figure 6-11 and Table 6-3 indicate, the error is only $\pm 2 \%$ in predicted radius when assuming a true contact angle of either $18^{\circ}$ or $26^{\circ}$, which are values $\pm 20 \%$ from the $22^{\circ}$ reported by Kim. This finding indicates that the modeling effort is relatively robust against error in the input $\theta_{e q}$ parameter. This can be understood when considering again the driving force of Equation (6.6), where the $\theta_{e q}$ only appears in the $\cos \left(\theta_{e q}\right)$ term. For small angles, $\cos \left(\theta_{e q}\right)$ will be approximately 1 , for example $\cos \left(26^{\circ}\right) \sim 0.90$ and therefore any equilibrium angle less than $26^{\circ}$ will result in a driving force that is at most about $10 \%$ larger than the force the material experiences with $\theta_{e q}=26^{\circ}$. Thus, we see only small wetting dynamics differences due to $\theta_{e q}$ variation when considering relatively short timescales. 


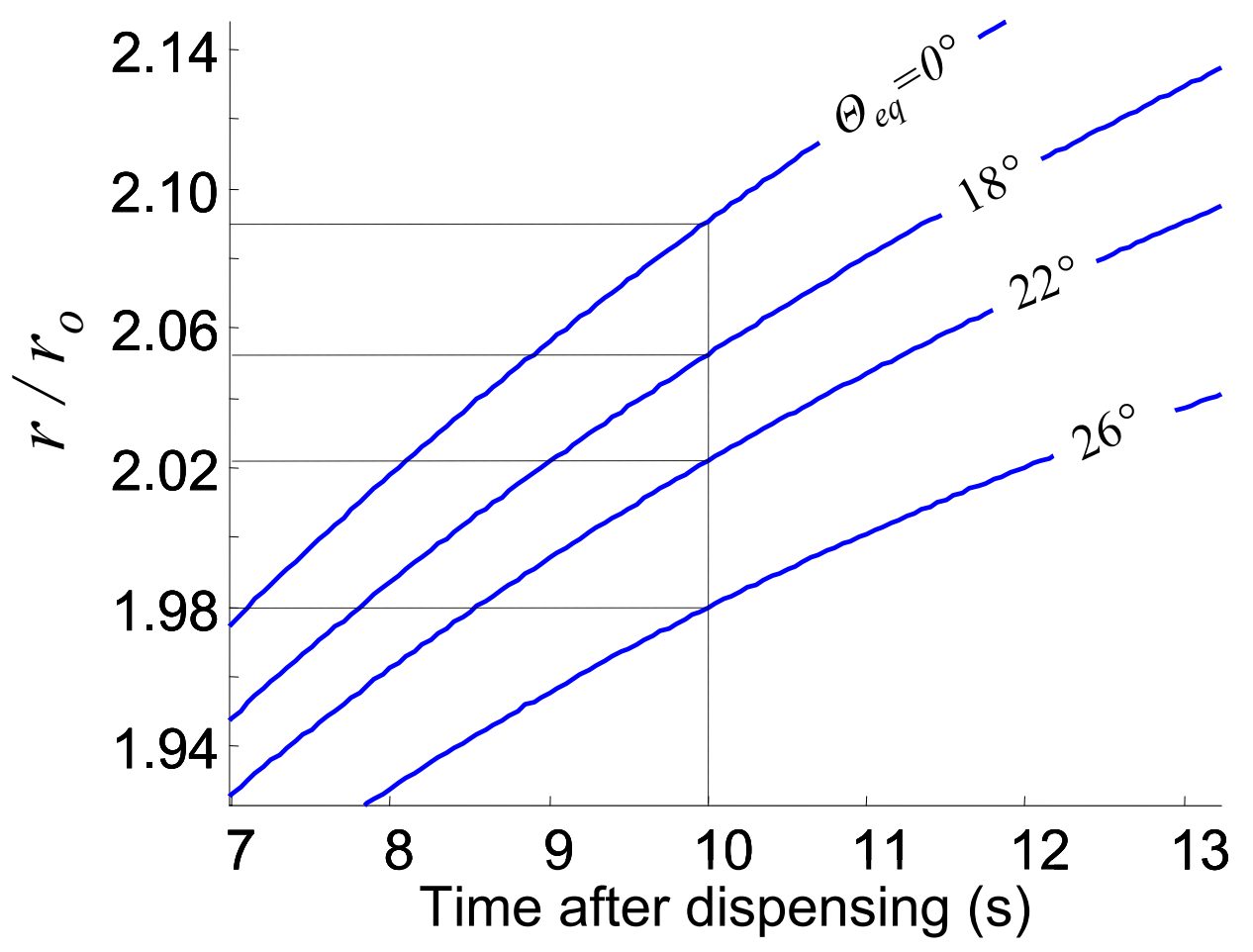

Figure 6-11 Sensitivity of Wetting Radius Prediction to $\theta_{e q}$ Input Parameter

Table 6-3 Error of Prediction at Process Time-Scale (10 seconds)

\begin{tabular}{ccc} 
Curve & $\mathrm{r} / \mathrm{r}_{\mathrm{o}} @ 10 \mathrm{~s}$ & Error \\
\hline \hline$r_{0^{\circ}}$ & 2.09 & 0.04 \\
$r_{18^{\circ}}$ & 2.05 & 0.02 \\
$r_{22^{\circ}}$ & 2.02 & 0.00 \\
$r_{26^{\circ}}$ & 1.98 & -0.02
\end{tabular}




\subsection{Design guidelines}

The goal of this section will be to develop guidelines for the line dispense process that will meet the manufacturing requirement that this process can be implemented with closely spaced neighboring substrate features commonly found on high density assemblies. This will be accomplished by considering specific flip chip packages with two points of interest in mind. First, the wetting radius of the underfill deposit after 10 seconds, which is considered here to be the characteristic time-scale of the transfer time into the next step in the process. Second, the equilibrium wetting radius is considered, which is of interest as an upper bound, and will provide insight into a worst case situation where the underfill is dispensed and the board does not move quickly into the placement machine.

\subsubsection{Minimizing $m / L$}

It is clear from Figure 6-6 that it is desirable to decrease $m / L$ for a line dispense process. Two special cases will be considered here. First, reduce $m$ and keep $L$ the same, and second, increase $L$ and keep $m$ constant.

Decreasing $m$ can lead to inadequate underfill material for the proper forming of fillets. However, it is expected that $m$ could be reduced by $15 \%$ or so and the resulting assemblies would still form reasonable fillets. This is useful to keep in mind as a means to refining wetting radius estimates later on if needed

The analysis to follow will be based on the premise that it makes sense to first increase $L$ as much as possible for any given package. This can be 
accomplished by employing an extended line pattern, either in the shape of an $\mathrm{L}$ or a $\mathrm{U}$, as seen in Figure 6-12.

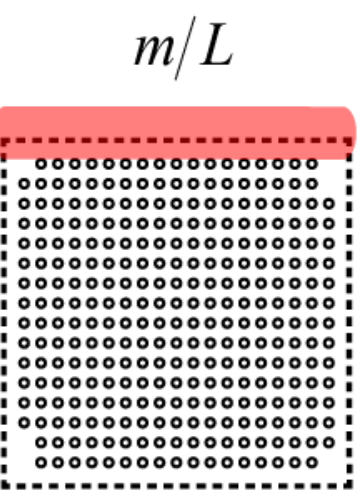

L pattern

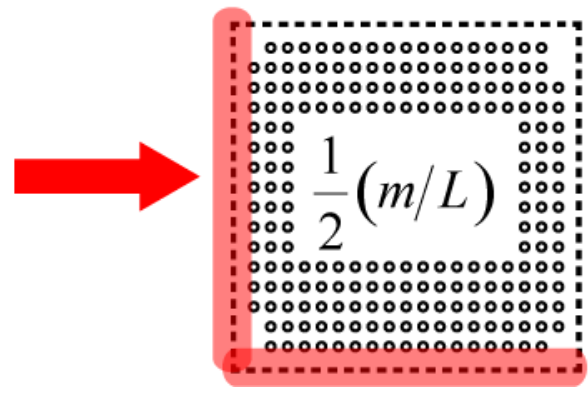

U pattern

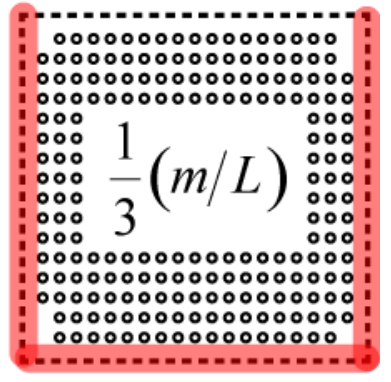

Figure 6-12 $L$ and $U$ patterns used to reduce $m / L$

These patterns were verified to produce void free assemblies with either FA10-2 or FA10-4 test chips. The verification was completed by assembling 4 replicates for each pattern; all assemblies resulted in $100 \%$ interconnect yield as well as no visible voiding. See Figure 6-13 for an example. 


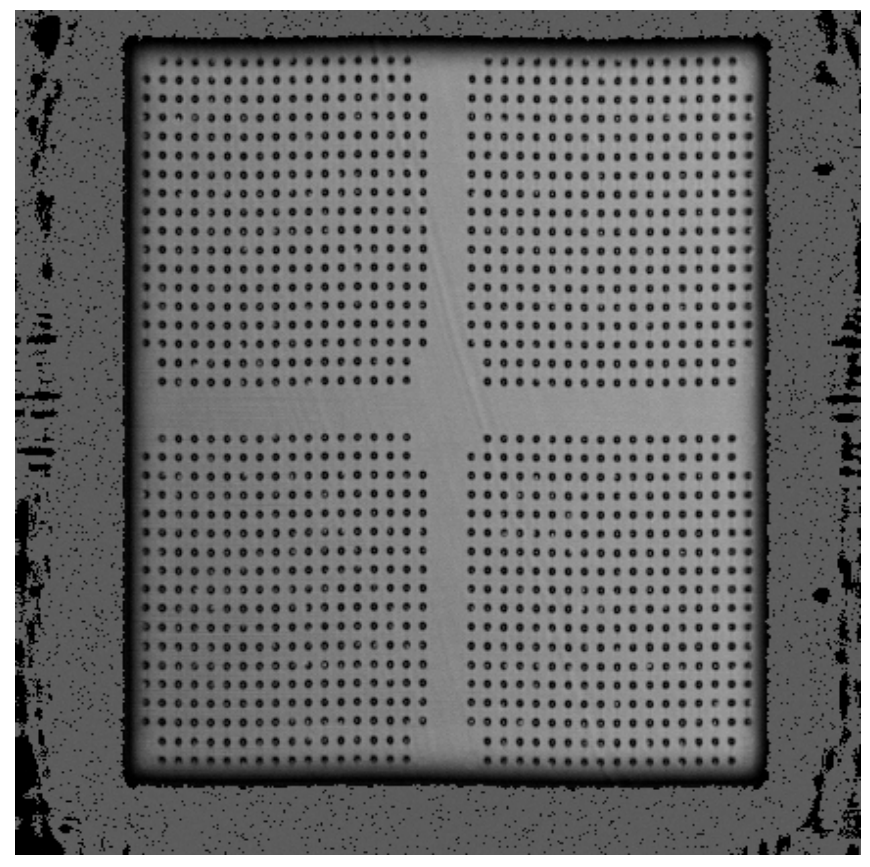

Figure 6-13 FA10-4 Assembled With a U-Pattern Underfill Dispense (No Voids)

The following section will discuss some design guidelines for typical flip chip area array devices.

\subsubsection{Fixed modeling parameters}

The modeling parameters $\ell$ and $\theta_{e q}$ will be considered fixed for the purposes of developing design guidelines in the next section for specific components. The values from Kim will be used as presented in Table 6-1. The analysis in 6.2 .5 showed that the results should be relatively insensitive to the true value of $\theta_{e q}$ and therefore it will remain fixed here. It is true that the parameter $\ell$ does have an appreciable effect on the wetting radius estimates; however, only Kim's value for FR4 will be assumed here. This limits the process design guidelines to FR4, which is still quite useful since no-flow underfills find 
the majority of applications in flip chip on FR4, due to the necessity of coupling the board and die under such a large mismatch in CTE.

\subsubsection{Design guidelines for area array test vehicles}

The model results are displayed in Tables 6-4 through 6-6 for FA10-2, FA104 , and for a hypothetical $20 \times 20 \mathrm{~mm}$ full area array chip, respectively. For each component, the viscosity requirements for two separate wetting radii are presented at time of 10 seconds after dispensing. The viscosities listed in the Tables correspond to the limiting viscosity that will result in either the $1 \mathrm{~mm}$ or 1.5mm wetting radii @ 10s after dispense. This means that for a viscosity higher than is listed in the Tables, the wetting radius would be smaller than either the $1 \mathrm{~mm}$ or $1.5 \mathrm{~mm}$ depending on which column of the table the viscosity is listed. For instance, using Table 6-4 it can be determined for an FA10-2 assembly using the L-pattern, that an underfill with a viscosity greater than $2.6 \mathrm{~Pa} \cdot \mathrm{s}$ will result in a wetting radius extension of less than 1.5mm @ 10s after dispense. The two wetting radii considered in the Tables are $1 \mathrm{~mm}$ and $1.5 \mathrm{~mm}$, because these radii

are somewhat reasonable in terms of board space requirements. The 10 second timescale is estimated as the interval between the end of the dispensing process and chip placement, assuming that only 1 chip will be placed. The equilibrium radius is also given in Tables 6-4 through 6-6, and this value is useful for the case of many components on a board, or one component that will not be transported immediately into placement. 
Table 6-4 Design Guidelines for FA10-2 Patterned Hybrid No-Flow Process

\begin{tabular}{|c|c|c|c|}
\hline \multicolumn{4}{|c|}{ FA10-2 } \\
\hline $\begin{array}{c}\text { Pattern } \\
(m / L \text { in } \mathrm{g} / \mathrm{m})\end{array}$ & $\begin{array}{c}\mu \text { required for } \\
r(10 \mathrm{~s})=1 \mathrm{~mm}\end{array}$ & $\begin{array}{c}\mu \text { required for } \\
r(10 \mathrm{~s})=1.5 \mathrm{~mm}\end{array}$ & $r_{e q}(\mathrm{~mm})$ \\
\hline $\mathrm{L}(.80)$ & $52 \mathrm{~Pa} \cdot \mathrm{s}$ & $2.6 \mathrm{~Pa} \cdot \mathrm{s}$ & 1.6 \\
\hline $\mathrm{U}(.53)$ & $17.2 \mathrm{~Pa} \cdot \mathrm{s}$ & $0 \mathrm{~Pa} \cdot \mathrm{s}^{*}$ & 1.3 \\
\hline
\end{tabular}

- Shaded cells show viscosities within the pot-life limits of commercial underfills

* $r_{e q}$ is less than $1.5 \mathrm{~mm}$

Table 6-5 Design Guidelines for FA10-4 Patterned Hybrid No-Flow Process

\begin{tabular}{|c|c|c|c|}
\hline \multicolumn{4}{|c|}{ FA10-4 } \\
\hline $\begin{array}{c}\text { Pattern } \\
(m / L \text { in } \mathrm{g} / \mathrm{m})\end{array}$ & $\begin{array}{c}\mu \text { required for } \\
r(10 \mathrm{~s})=1 \mathrm{~mm}\end{array}$ & $\begin{array}{c}\mu \text { required for } \\
r(10 \mathrm{~s})=1.5 \mathrm{~mm}\end{array}$ & $r_{e q}(\mathrm{~mm})$ \\
\hline $\mathrm{L}(1.05)$ & $110 \mathrm{~Pa} \cdot \mathrm{s}$ & $7.8 \mathrm{~Pa} \cdot \mathrm{s}$ & 1.83 \\
\hline $\mathrm{U}(.70)$ & $37.2 \mathrm{~Pa} \cdot \mathrm{s}$ & $0 \mathrm{~Pa} \cdot \mathrm{s}^{*}$ & 1.49 \\
\hline
\end{tabular}

- Shaded cells show viscosities within the pot-life limits of commercial underfills

${ }^{*} r_{e q}$ is less than $1.5 \mathrm{~mm}$

Table 6-6 Design Guidelines for FA(20x20) Patterned Hybrid No-Flow Process

\begin{tabular}{|c|c|c|c|}
\hline \multicolumn{4}{|c|}{ FA (20x20mm) } \\
\hline $\begin{array}{c}\text { Pattern } \\
(m / L \text { in } \mathrm{g} / \mathrm{m})\end{array}$ & $\begin{array}{c}\mu \text { required for } \\
r(10 \mathrm{~s})=1 \mathrm{~mm}\end{array}$ & $\begin{array}{c}\mu \text { required for } \\
r(10 \mathrm{~s})=1.5 \mathrm{~mm}\end{array}$ & $r_{e q}(\mathrm{~mm})$ \\
\hline $\mathrm{L}(1.40)$ & $280 \mathrm{~Pa} \cdot \mathrm{s}$ & $18.4 \mathrm{~Pa} \cdot \mathrm{s}$ & 2.11 \\
\hline $\mathrm{U}(.93)$ & $78.3 \mathrm{~Pa} \cdot \mathrm{s}$ & $5.1 \mathrm{~Pa} \cdot \mathrm{s}$ & 1.72 \\
\hline
\end{tabular}

- Shaded cells show viscosities within the pot-life limits of commercial underfills 
The results here have been presented in a format that allows wetting radius requirements to drive decisions on material selection with a specific component in mind. However, the result for a specific configuration from Tables 6-4 through 6-6 should also be compared in a meaningful way to a conventional no-flow process.

The driving metric behind all of the analysis up to this point has been board area required for assembly. The results here are therefore best compared against the area required for a conventional no-flow process. The equilibrium radius is selected for an area comparison because it will provide an upper bound on the required area for the process. An area comparison for both conventional no-flow and a U-pattern hybrid process is shown in Figure 6-14. The conventional process is assumed to have a fillet size of $1 \mathrm{~mm}$ past the chip edge on all sides, this was verified by measuring fillet sizes with an optical microscope for typical assemblies built with the conventional process. .
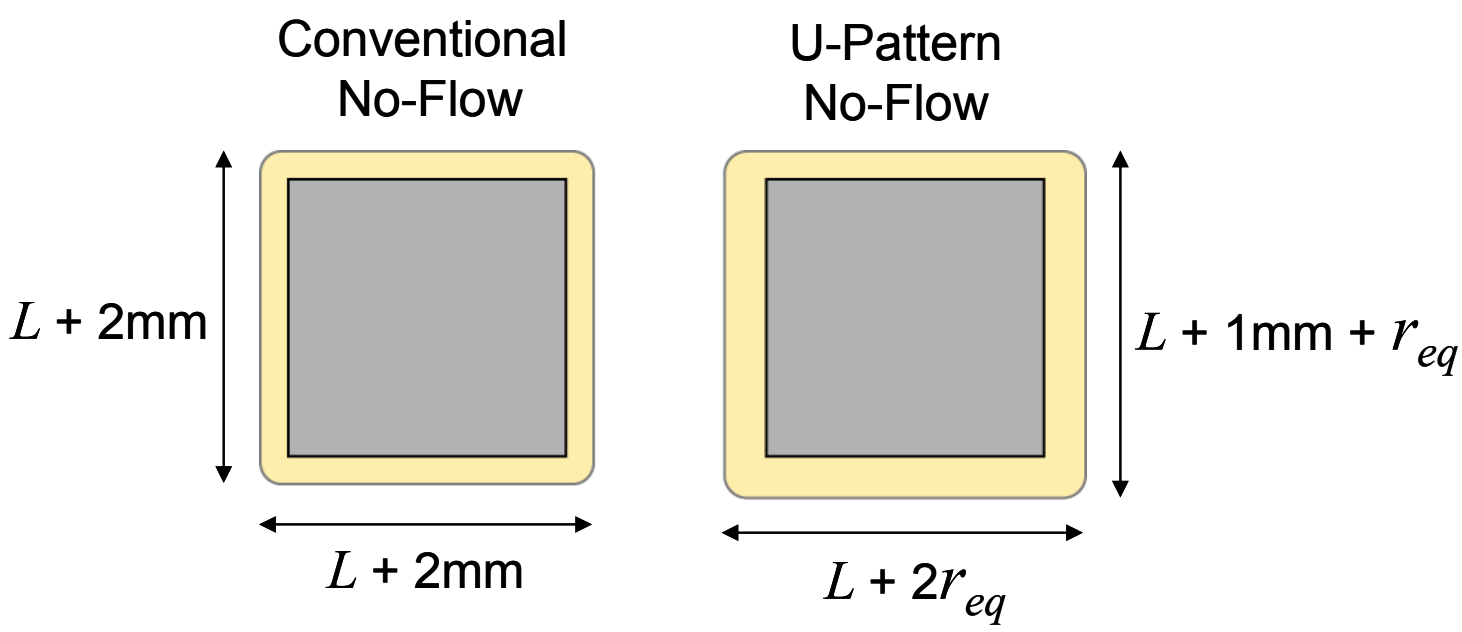

Figure 6-14 Board Area Requirements 
A survey of Table 6-4 indicates that any of the commercial materials tested in Chapters 3 and 4 can be used with an FA10-2 component to yield a wetting radius of $1.5 \mathrm{~mm}$ at $t=10 \mathrm{~s}$ with either the $\mathrm{L}$ or $U$ pattern. This configuration is not very practical for an actual manufacturing application because the chip size is only $5 \mathrm{~mm}$ square. The U-pattern would result in a required board area of 60 $\mathrm{mm}^{2}$, or an increase of $22 \%$ over the conventional process area of $49 \mathrm{~mm}^{2}$.

Table 6-5 indicates that for a $U$ dispense pattern and the FA10-4 configuration, any of the materials from earlier chapters can be used to obtain a wetting radius of $1.5 \mathrm{~mm}$ at $\mathrm{t}=10 \mathrm{~s}$ and even for any time $\mathrm{t}$ because the equilibrium radius is below $1.5 \mathrm{~mm}$. This would result in a required board area of $162.5 \mathrm{~mm}^{2}$, or $13 \%$ more than the conventional no-flow process area.

Similarly for the $20 \mathrm{~mm}$ chip, the $U$ dispense will provide a process solution that takes up only about $10 \%$ more board area than a conventional no-flow process. It is interesting to note the trend that larger die size result in a smaller percentage increase in area when using the U-pattern process; this is a result of the chip area growing faster than the fillet area.

In conclusion, the $U$ dispense process may be a good choice for implementation. The trade off would be that slightly more board area consumed, but with void free assemblies. If extrusion failures were of primary concern, then the $U$ process could be selected without giving up much board space. 


\section{CHAPTER VI: CONCLUSIONS AND FUTURE WORK}

\subsection{Contributions}

The following contributions were made to the study of no-flow fluxing underfill processing for flip chip on organic substrate use:

- Detailed four potential voiding mechanisms for no flow underfill processing and provided engineering analysis to draw conclusions about the potential of each mechanism to influence voiding for specific underfill dispense patterns.

- Determined the effect of the reflow process on solder grain size, electrical resistance, and void formation, to incorporate into a physics based ranking system that was utilized to select an optimal reflow profile.

- Characterized the AATC reliability performance of four separate die/board/material systems assembled using the highest ranking reflow profiles.

- Developed process windows for four commercially available no-flow underfills.

- Developed a void free no-flow process that can be used successfully with a wide range of no-flow underfills.

- Provided an engineering analysis to develop a model of the wetting dynamics of the line dispense pattern. 
- Modeled the effects of varying input parameters on the wetting dynamics of the line dispense in order to develop design guidelines for the manufacturing process.

\subsection{Conclusions}

The process design of experiments clearly indicate that the line dispense pattern results in the least voiding of any of the dispense patterns included in the experimental design. This performance has been explained by considering each of the four potential voiding mechanisms possible during processing. The line pattern was also shown to be robust against variations in placement force or dwell times, this is in contrast to the conventional no-flow dispense which does exhibit yield losses under certain force-dwell time combinations. This performance has been reasoned by employing the compression flow model in order to estimate the position of the chip upon release for the parameters of interst. A ranking system was developed based on a literature survey of potential reliability predictors and by a physics based reasoning of the solder joint mechanics. A model was developed for the wetting of the underfill line onto FR4 substrate. The model was then applied parametrically to the relevant parameters affecting wetting in order to gain a more complete understanding of the processing issues associated with the initial dispense and spreading of the underfill line. 


\subsection{Recommendations and Future Work}

The process developed during this experimental work is ultimately intended to be a viable manufacturing process in a high volume production environment. In order to fully understand the capabilities of the process in such an environment it will be necessary to gain a better understanding of several key parts of the process: capillary flow during early stages of reflow, and extrusion failures after thermal cycling.

The next step after the placement of the chip involves the flow of the material by capillary action to completely underfill the chip. Because the majority of this flow actually happens during reflow, it is necessary to further investigate the dynamics of this process. Ideally a modeling effort would relate the flow time of the underfill to the temperature dependant viscosity and DSC data. The goal would be to determine for the process, any limits on die size or reflow profile parameters in order to ensure that the underfill fully underfilled the chip before setting due to curing.

Many of the assemblies are observed to encompass solder extrusion failures before they actually fail by electrical resistance test. A better understanding of the initiation of the underfill cracks as well as the time progression of the extrusion failures would enable improved design of both underfill materials and package-board combinations. 


\section{A. Appendix - Reflow Profiles}

\section{Material A Reflow Profiles}

The reflow profile characterization for Material A used a step type profile as the basis for investigation. The 12 profiles used for experimentation are presented in Figures A-1 through A-12. The reflow parameters and The BTU Paragon oven setpoints that describe these profiles are presented in Tables A-1 through A-24. Replicates of 4 die were assembled for each profile, and these assemblies were analyzed for underfill voiding, resistance, and phase ratio. 


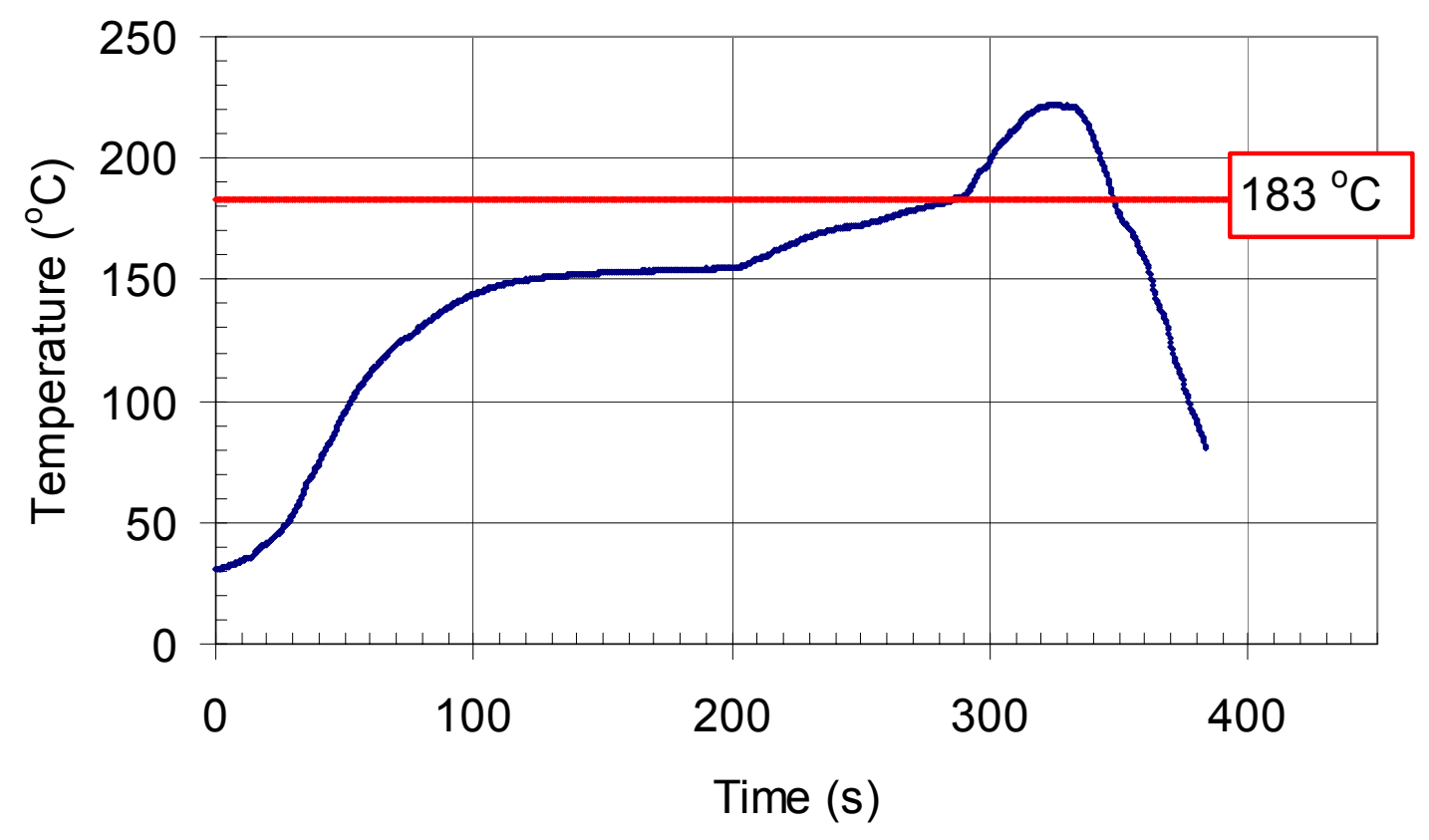

Figure A-1 Material A, Baseline profile

Table A-1 Material A, reflow parameters for Baseline profile

\begin{tabular}{c|c|c|c|c}
$\begin{array}{c}\text { Ramp Rate } \\
\left({ }^{\circ} \mathrm{C} / \mathrm{s}\right)\end{array}$ & $\begin{array}{c}\text { Soak Temp } \\
\left({ }^{\circ} \mathrm{C}\right)\end{array}$ & $\begin{array}{c}\text { Soak Time } \\
(\mathrm{s})\end{array}$ & $\begin{array}{c}\text { Time above } 183{ }^{\circ} \mathrm{C} \\
(\mathrm{s})\end{array}$ & $\begin{array}{c}\text { Peak Temp } \\
\left({ }^{\circ} \mathrm{C}\right)\end{array}$ \\
\hline \hline 2 & 150 & 119.7 & 60.9 & 220.1
\end{tabular}

Table A-2 Material A, oven set points for Baseline profile

\begin{tabular}{c|c|c|c|c|c|c|c}
$\begin{array}{c}\text { Zone \#1 } \\
\left({ }^{\circ} \mathrm{C}\right)\end{array}$ & $\begin{array}{c}\text { Zone \#2 } \\
\left({ }^{\circ} \mathrm{C}\right)\end{array}$ & $\begin{array}{c}\text { Zone \#3 } \\
\left({ }^{\circ} \mathrm{C}\right)\end{array}$ & $\begin{array}{c}\text { Zone \#4 } \\
\left({ }^{\circ} \mathrm{C}\right)\end{array}$ & $\begin{array}{c}\text { Zone \#5 } \\
\left({ }^{\circ} \mathrm{C}\right)\end{array}$ & $\begin{array}{c}\text { Zone \#6 } \\
\left({ }^{\circ} \mathrm{C}\right)\end{array}$ & $\begin{array}{c}\text { Zone \#7 } \\
\left({ }^{\circ} \mathrm{C}\right)\end{array}$ & $\begin{array}{c}\text { Belt Speed } \\
(\text { in/min })\end{array}$ \\
\hline \hline 148 & 159 & 155 & 155 & 188 & 188 & 263 & 19.4
\end{tabular}




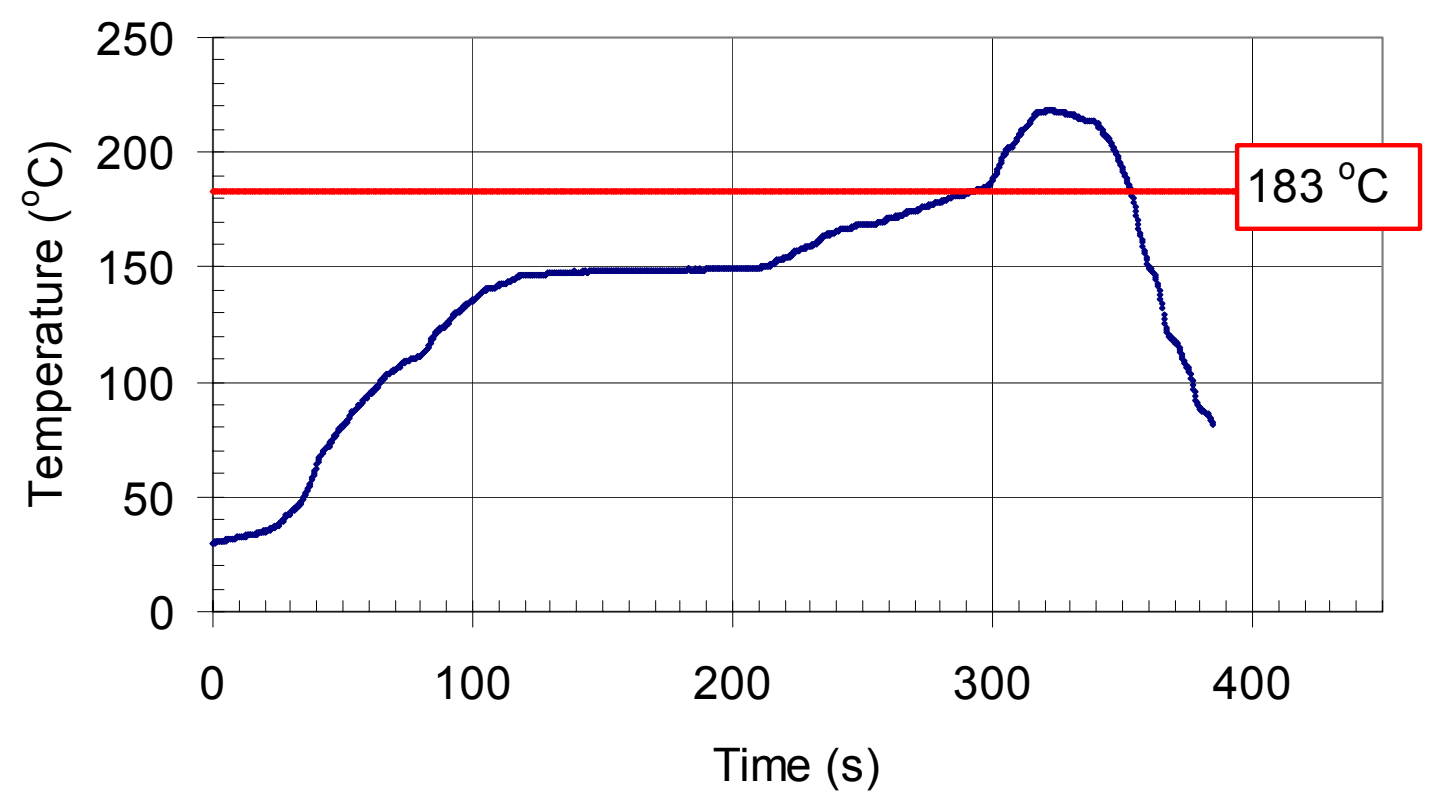

Figure A-2 Material A, Ramp Rate Low profile

Table A-3 Material A, reflow parameters for Ramp Rate Low profile

\begin{tabular}{c|c|c|c|c}
$\begin{array}{c}\text { Ramp Rate } \\
\left({ }^{\circ} \mathrm{C} / \mathrm{s}\right)\end{array}$ & $\begin{array}{c}\text { Soak Temp } \\
\left({ }^{\circ} \mathrm{C}\right)\end{array}$ & $\begin{array}{c}\text { Soak Time } \\
(\mathrm{s})\end{array}$ & $\begin{array}{c}\text { Time above } 183^{\circ} \mathrm{C} \\
(\mathrm{s})\end{array}$ & $\begin{array}{c}\text { Peak Temp } \\
\left({ }^{\circ} \mathrm{C}\right)\end{array}$ \\
\hline \hline 2 & 150 & 127.3 & 60.7 & 218.3
\end{tabular}

Table A-4 Material A, oven set points for Ramp Rate Low profile

\begin{tabular}{c|c|c|c|c|c|c|c}
$\begin{array}{c}\text { Zone \#1 } \\
\left({ }^{\circ} \mathrm{C}\right)\end{array}$ & $\begin{array}{c}\text { Zone \#2 } \\
\left({ }^{\circ} \mathrm{C}\right)\end{array}$ & $\begin{array}{c}\text { Zone \#3 } \\
\left({ }^{\circ} \mathrm{C}\right)\end{array}$ & $\begin{array}{c}\text { Zone \#4 } \\
\left({ }^{\circ} \mathrm{C}\right)\end{array}$ & $\begin{array}{c}\text { Zone \#5 } \\
\left({ }^{\circ} \mathrm{C}\right)\end{array}$ & $\begin{array}{c}\text { Zone \#6 } \\
\left({ }^{\circ} \mathrm{C}\right)\end{array}$ & $\begin{array}{c}\text { Zone \#7 } \\
\left({ }^{\circ} \mathrm{C}\right)\end{array}$ & $\begin{array}{c}\text { Belt Speed } \\
(\text { in/min })\end{array}$ \\
\hline \hline 125 & 162 & 150 & 150 & 183 & 188 & 266 & 19.2
\end{tabular}




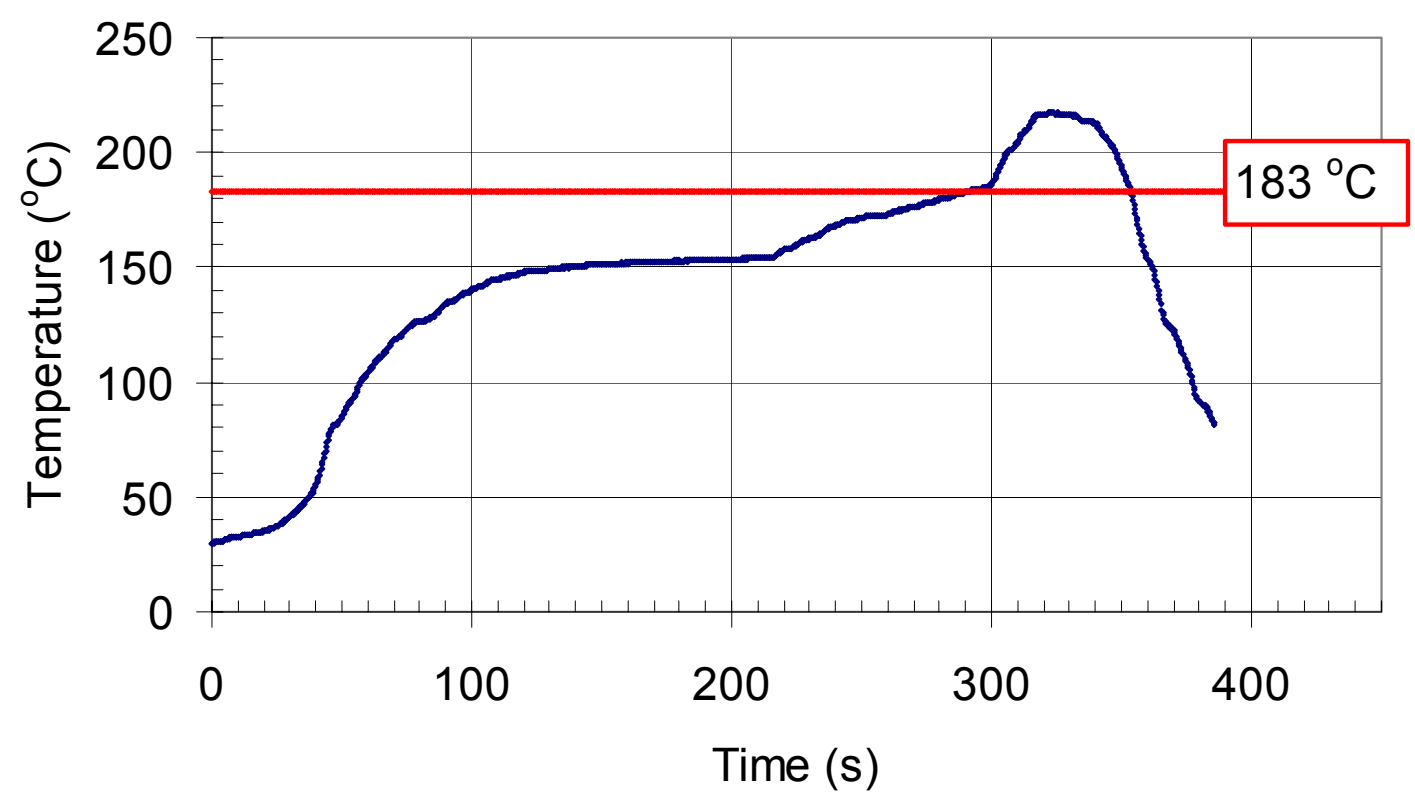

Figure A-3 Material A, Ramp Rate High

Table A-5 Material A, reflow parameters for Ramp Rate High profile

\begin{tabular}{c|c|c|c|c}
$\begin{array}{c}\text { Ramp Rate } \\
\left({ }^{\circ} \mathrm{C} / \mathrm{s}\right)\end{array}$ & $\begin{array}{c}\text { Soak Temp } \\
\left({ }^{\circ} \mathrm{C}\right)\end{array}$ & $\begin{array}{c}\text { Soak Time } \\
(\mathrm{s})\end{array}$ & $\begin{array}{c}\text { Time above } 183{ }^{\circ} \mathrm{C} \\
(\mathrm{s})\end{array}$ & $\begin{array}{c}\text { Peak Temp } \\
\left({ }^{\circ} \mathrm{C}\right)\end{array}$ \\
\hline \hline 2.5 & 150 & 125.1 & 62.6 & 217.3
\end{tabular}

Table A-6 Material A, oven set points for Ramp Rate High profile

\begin{tabular}{c|c|c|c|c|c|c|c}
$\begin{array}{c}\text { Zone \#1 } \\
\left({ }^{\circ} \mathrm{C}\right)\end{array}$ & $\begin{array}{c}\text { Zone \#2 } \\
\left({ }^{\circ} \mathrm{C}\right)\end{array}$ & $\begin{array}{c}\text { Zone \#3 } \\
\left({ }^{\circ} \mathrm{C}\right)\end{array}$ & $\begin{array}{c}\text { Zone \#4 } \\
\left({ }^{\circ} \mathrm{C}\right)\end{array}$ & $\begin{array}{c}\text { Zone \#5 } \\
\left({ }^{\circ} \mathrm{C}\right)\end{array}$ & $\begin{array}{c}\text { Zone \#6 } \\
\left({ }^{\circ} \mathrm{C}\right)\end{array}$ & $\begin{array}{c}\text { Zone \#7 } \\
\left({ }^{\circ} \mathrm{C}\right)\end{array}$ & $\begin{array}{c}\text { Belt Speed } \\
(\text { in/min })\end{array}$ \\
\hline \hline 150 & 159 & 155 & 155 & 188 & 188 & 265 & 19.4
\end{tabular}




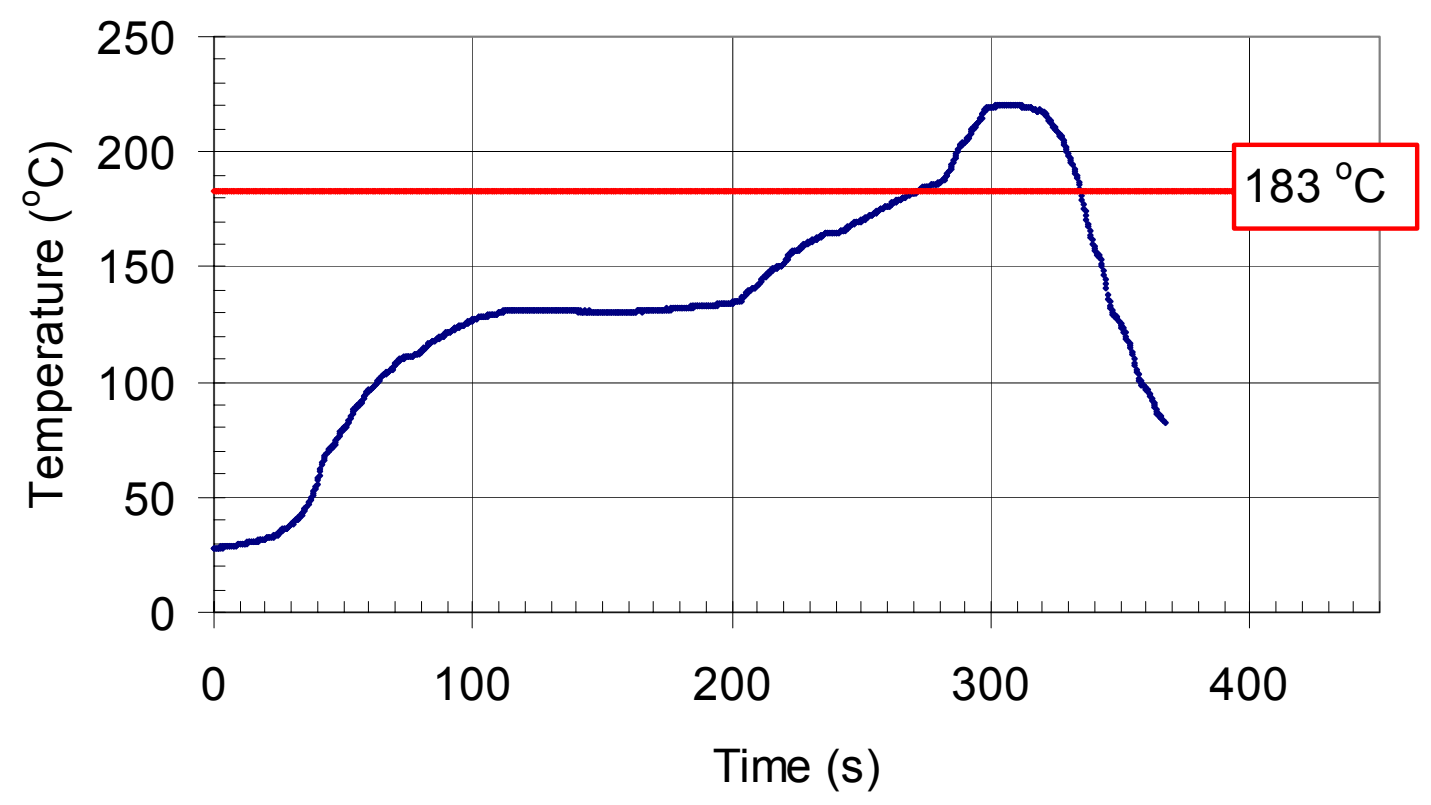

Figure A-4 Material A, Soak Temperature Low

Table A-7 Material A, reflow parameters for Soak Temperature Low profile

\begin{tabular}{c|c|c|c|c}
$\begin{array}{c}\text { Ramp Rate } \\
\left({ }^{\circ} \mathrm{C} / \mathrm{s}\right)\end{array}$ & $\begin{array}{c}\text { Soak Temp } \\
\left({ }^{\circ} \mathrm{C}\right)\end{array}$ & $\begin{array}{c}\text { Soak Time } \\
(\mathrm{s})\end{array}$ & $\begin{array}{c}\text { Time above } 183{ }^{\circ} \mathrm{C} \\
(\mathrm{s})\end{array}$ & $\begin{array}{c}\text { Peak Temp } \\
\left({ }^{\circ} \mathrm{C}\right)\end{array}$ \\
\hline \hline 2.2 & 130 & 118.2 & 62.7 & 220.6
\end{tabular}

Table A-8 Material A, oven set points for Soak Temperature Low profile \begin{tabular}{c|c|c|c|c|c|c|c}
$\begin{array}{c}\text { Zone \#1 } \\
\left({ }^{\circ} \mathrm{C}\right)\end{array}$ & $\begin{array}{c}\text { Zone \#2 } \\
\left({ }^{\circ} \mathrm{C}\right)\end{array}$ & $\begin{array}{c}\text { Zone \#3 } \\
\left({ }^{\circ} \mathrm{C}\right)\end{array}$ & $\begin{array}{c}\text { Zone \#4 } \\
\left({ }^{\circ} \mathrm{C}\right)\end{array}$ & $\begin{array}{c}\text { Zone \#5 } \\
\left({ }^{\circ} \mathrm{C}\right)\end{array}$ & $\begin{array}{c}\text { Zone \#6 } \\
\left({ }^{\circ} \mathrm{C}\right)\end{array}$ & $\begin{array}{c}\text { Zone \#7 } \\
\left({ }^{\circ} \mathrm{C}\right)\end{array}$ & $\begin{array}{c}\text { Belt Speed } \\
(\text { in/min })\end{array}$ \\
\hline \hline 133 & 141 & 130 & 135 & 190 & 195 & 273 & 20
\end{tabular} 


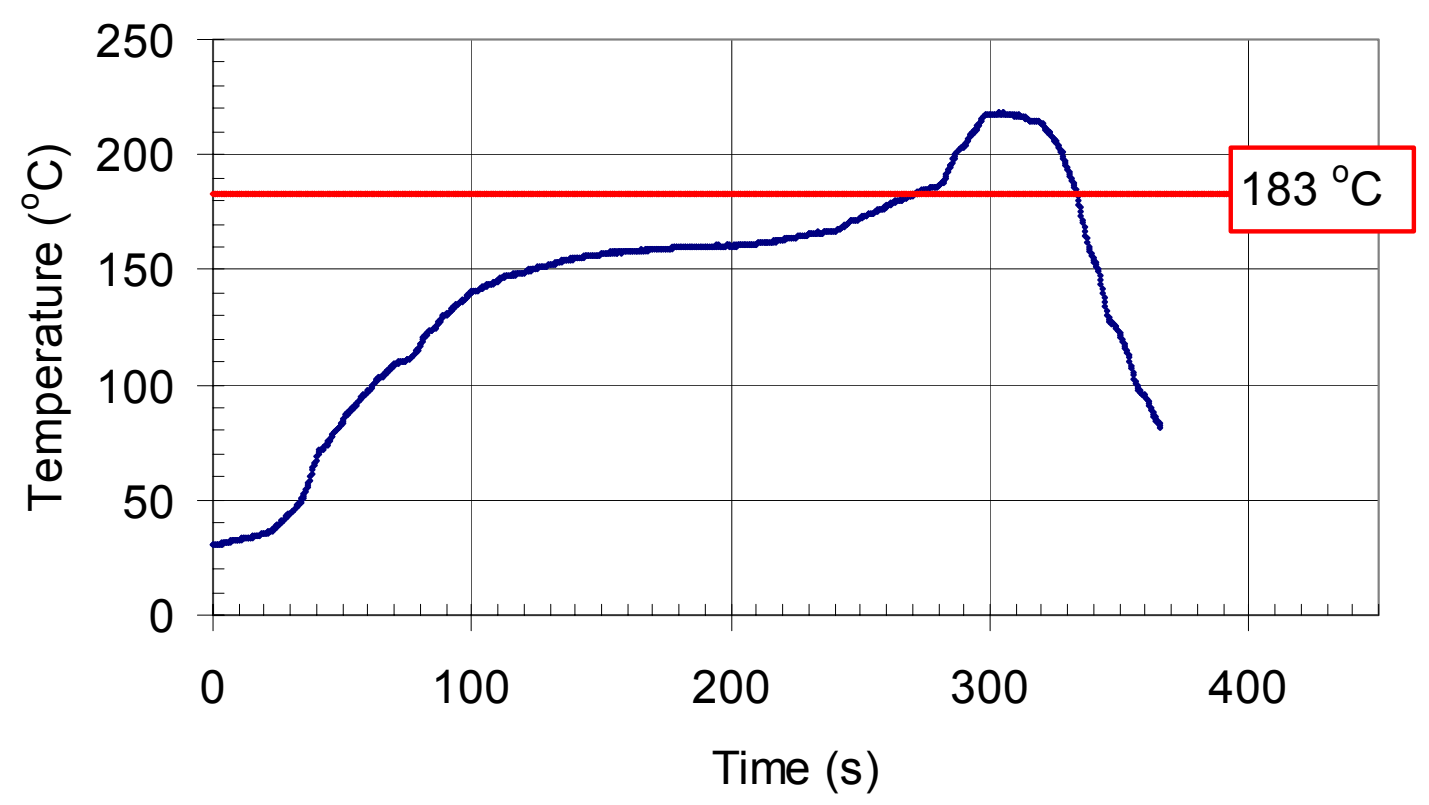

Figure A-5 Material A, Soak Temperature High profile

Table A-9 Material A, reflow parameters for Soak Temperature High profile

\begin{tabular}{c|c|c|c|c}
$\begin{array}{c}\text { Ramp Rate } \\
\left({ }^{\circ} \mathrm{C} / \mathrm{s}\right)\end{array}$ & $\begin{array}{c}\text { Soak Temp } \\
\left({ }^{\circ} \mathrm{C}\right)\end{array}$ & $\begin{array}{c}\text { Soak Time } \\
(\mathrm{s})\end{array}$ & $\begin{array}{c}\text { Time above } 183{ }^{\circ} \mathrm{C} \\
(\mathrm{s})\end{array}$ & $\begin{array}{c}\text { Peak Temp } \\
\left({ }^{\circ} \mathrm{C}\right)\end{array}$ \\
\hline \hline 2 & 165 & 115.8 & 62 & 218
\end{tabular}

Table A-10 Material A, oven set points for Soak Temperature High profile

\begin{tabular}{c|c|c|c|c|c|c|c}
$\begin{array}{c}\text { Zone \#1 } \\
\left({ }^{\circ} \mathrm{C}\right)\end{array}$ & $\begin{array}{c}\text { Zone \#2 } \\
\left({ }^{\circ} \mathrm{C}\right)\end{array}$ & $\begin{array}{c}\text { Zone \#3 } \\
\left({ }^{\circ} \mathrm{C}\right)\end{array}$ & $\begin{array}{c}\text { Zone \#4 } \\
\left({ }^{\circ} \mathrm{C}\right)\end{array}$ & $\begin{array}{c}\text { Zone \#5 } \\
\left({ }^{\circ} \mathrm{C}\right)\end{array}$ & $\begin{array}{c}\text { Zone \#6 } \\
\left({ }^{\circ} \mathrm{C}\right)\end{array}$ & $\begin{array}{c}\text { Zone \#7 } \\
\left({ }^{\circ} \mathrm{C}\right)\end{array}$ & $\begin{array}{c}\text { Belt Speed } \\
(\text { in/min })\end{array}$ \\
\hline \hline 128 & 165 & 163 & 163 & 170 & 193 & 267 & 20
\end{tabular}




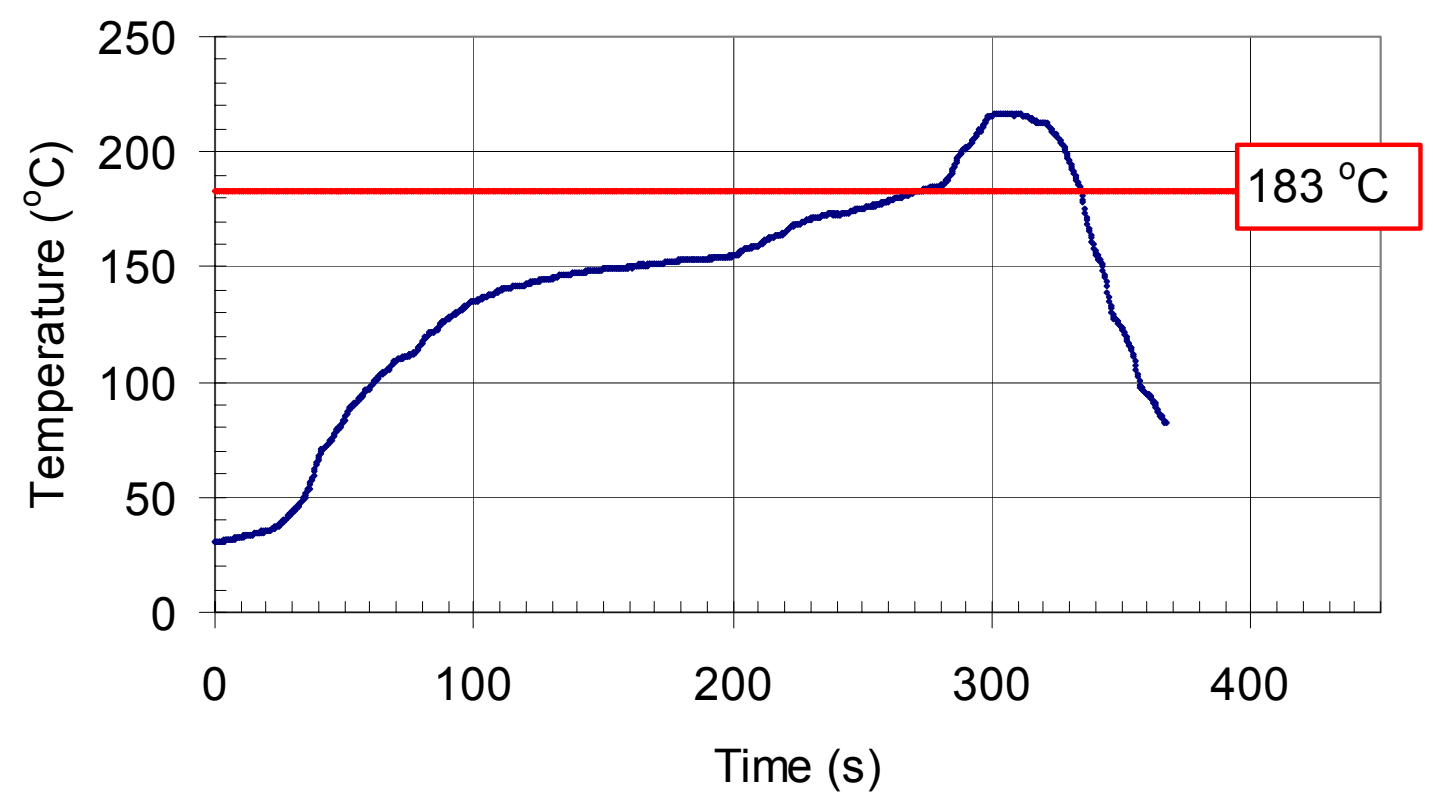

Figure A-6 Material A, Soak Time Low profile

Table A-11 Material A, reflow parameters for Soak Time Low profile

\begin{tabular}{c|c|c|c|c}
$\begin{array}{c}\text { Ramp Rate } \\
\left({ }^{\circ} \mathrm{C} / \mathrm{s}\right)\end{array}$ & $\begin{array}{c}\text { Soak Temp } \\
\left({ }^{\circ} \mathrm{C}\right)\end{array}$ & $\begin{array}{c}\text { Soak Time } \\
(\mathrm{s})\end{array}$ & $\begin{array}{c}\text { Time above } 183{ }^{\circ} \mathrm{C} \\
(\mathrm{s})\end{array}$ & $\begin{array}{c}\text { Peak Temp } \\
\left({ }^{\circ} \mathrm{C}\right)\end{array}$ \\
\hline \hline 2.1 & 150 & 100.6 & 61.4 & 216.6
\end{tabular}

Table A-12 Material A, oven set points for Soak Time High profile

\begin{tabular}{c|c|c|c|c|c|c|c}
$\begin{array}{c}\text { Zone \#1 } \\
\left({ }^{\circ} \mathrm{C}\right)\end{array}$ & $\begin{array}{c}\text { Zone \#2 } \\
\left({ }^{\circ} \mathrm{C}\right)\end{array}$ & $\begin{array}{c}\text { Zone \#3 } \\
\left({ }^{\circ} \mathrm{C}\right)\end{array}$ & $\begin{array}{c}\text { Zone \#4 } \\
\left({ }^{\circ} \mathrm{C}\right)\end{array}$ & $\begin{array}{c}\text { Zone \#5 } \\
\left({ }^{\circ} \mathrm{C}\right)\end{array}$ & $\begin{array}{c}\text { Zone \#6 } \\
\left({ }^{\circ} \mathrm{C}\right)\end{array}$ & $\begin{array}{c}\text { Zone \#7 } \\
\left({ }^{\circ} \mathrm{C}\right)\end{array}$ & $\begin{array}{c}\text { Belt Speed } \\
(\text { in/min })\end{array}$ \\
\hline \hline 130.2 & 155 & 154.3 & 156.6 & 189.7 & 189.1 & 265.1 & 20
\end{tabular}




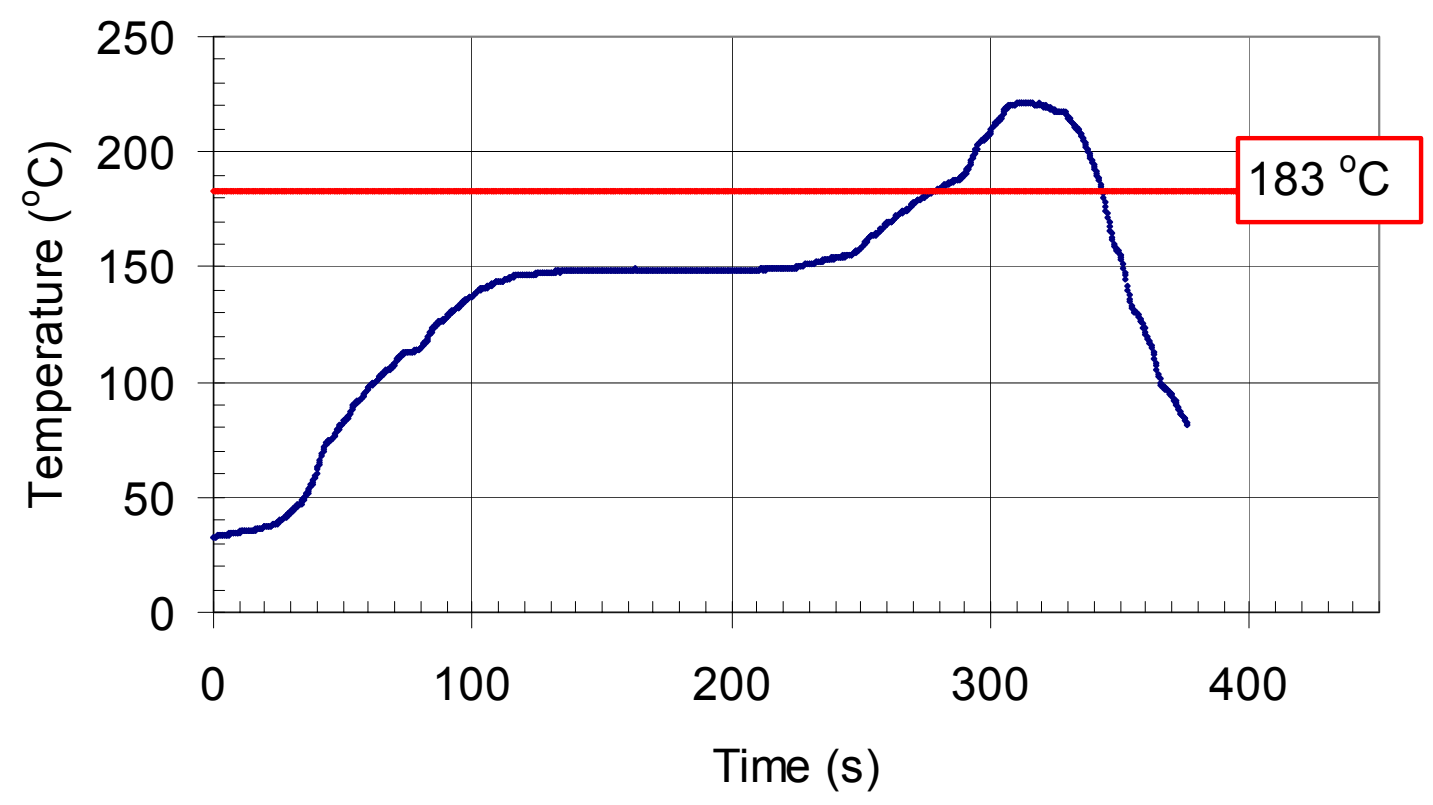

Figure A-7 Material A, Soak Time High profile

Table A-13 Material A, reflow parameters for Soak Time High profile

\begin{tabular}{c|c|c|c|c}
$\begin{array}{c}\text { Ramp Rate } \\
\left({ }^{\circ} \mathrm{C} / \mathrm{s}\right)\end{array}$ & $\begin{array}{c}\text { Soak Temp } \\
\left({ }^{\circ} \mathrm{C}\right)\end{array}$ & $\begin{array}{c}\text { Soak Time } \\
(\mathrm{s})\end{array}$ & $\begin{array}{c}\text { Time above } 183^{\circ} \mathrm{C} \\
(\mathrm{s})\end{array}$ & $\begin{array}{c}\text { Peak Temp } \\
\left({ }^{\circ} \mathrm{C}\right)\end{array}$ \\
\hline \hline 2.1 & 150 & 148.8 & 64.9 & 221.5
\end{tabular}

Table A-14 Material A, oven set points for Soak Time High profile

\begin{tabular}{c|c|c|c|c|c|c|c}
$\begin{array}{c}\text { Zone \#1 } \\
\left({ }^{\circ} \mathrm{C}\right)\end{array}$ & $\begin{array}{c}\text { Zone \#2 } \\
\left({ }^{\circ} \mathrm{C}\right)\end{array}$ & $\begin{array}{c}\text { Zone \#3 } \\
\left({ }^{\circ} \mathrm{C}\right)\end{array}$ & $\begin{array}{c}\text { Zone \#4 } \\
\left({ }^{\circ} \mathrm{C}\right)\end{array}$ & $\begin{array}{c}\text { Zone \#5 } \\
\left({ }^{\circ} \mathrm{C}\right)\end{array}$ & $\begin{array}{c}\text { Zone \#6 } \\
\left({ }^{\circ} \mathrm{C}\right)\end{array}$ & $\begin{array}{c}\text { Zone \#7 } \\
\left({ }^{\circ} \mathrm{C}\right)\end{array}$ & $\begin{array}{c}\text { Belt Speed } \\
(\text { in/min })\end{array}$ \\
\hline \hline 130 & 163 & 150 & 150 & 154 & 200 & 271 & 20
\end{tabular}




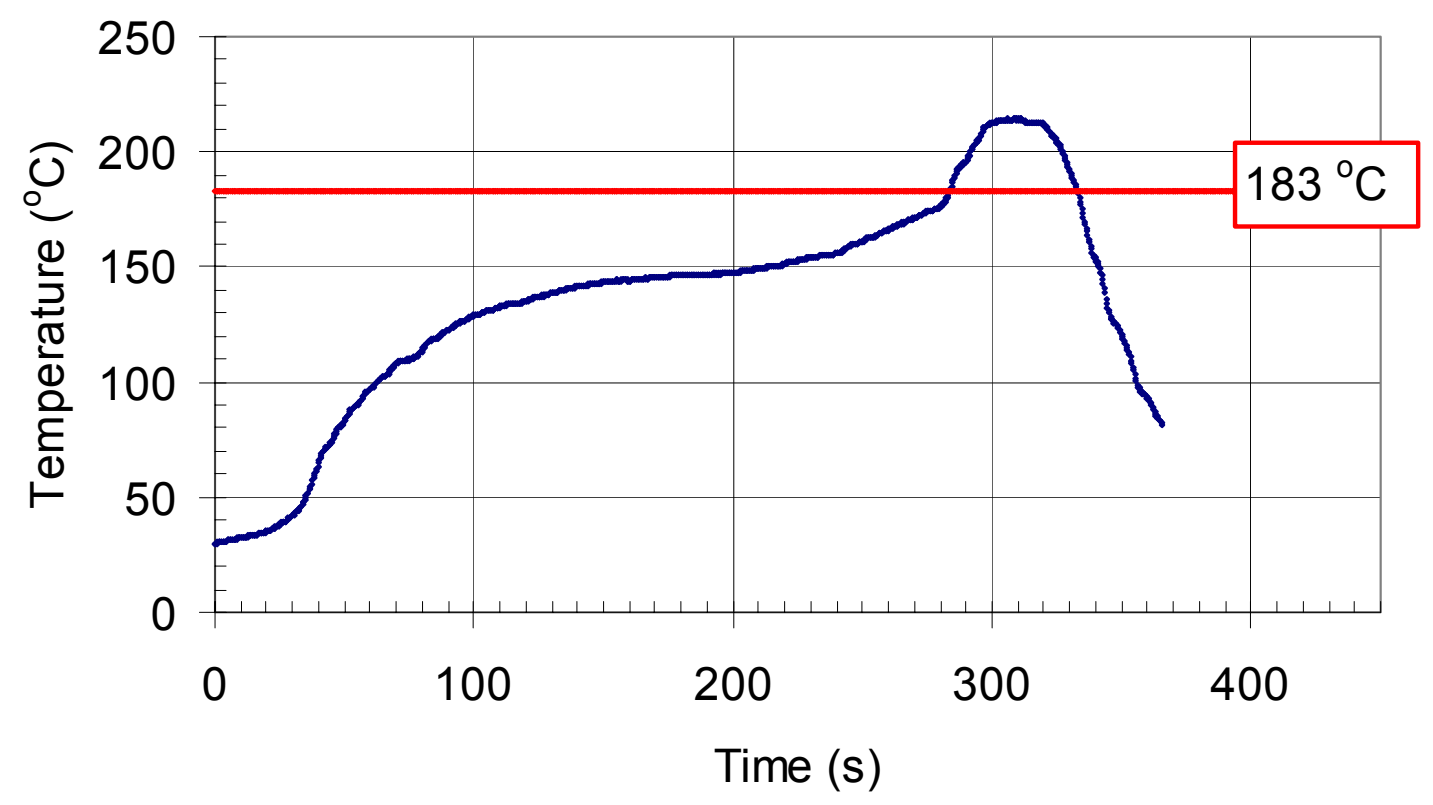

Figure A-8 Material A, Time Above $183^{\circ} \mathrm{C}$ Low profile

Table A-15 Material A, reflow parameters for Time Above $183^{\circ} \mathrm{C}$ Low profile

\begin{tabular}{c|c|c|c|c}
$\begin{array}{c}\text { Ramp Rate } \\
\left({ }^{\circ} \mathrm{C} / \mathrm{s}\right)\end{array}$ & $\begin{array}{c}\text { Soak Temp } \\
\left({ }^{\circ} \mathrm{C}\right)\end{array}$ & $\begin{array}{c}\text { Soak Time } \\
(\mathrm{s})\end{array}$ & $\begin{array}{c}\text { Time above } 183{ }^{\circ} \mathrm{C} \\
(\mathrm{s})\end{array}$ & $\begin{array}{c}\text { Peak Temp } \\
\left({ }^{\circ} \mathrm{C}\right)\end{array}$ \\
\hline \hline 2.1 & 150 & 113.6 & 49.3 & 214.2
\end{tabular}

Table A-16 Material A, oven set points for Time Above $183{ }^{\circ} \mathrm{C}$ Low profile

\begin{tabular}{c|c|c|c|c|c|c|c}
$\begin{array}{c}\text { Zone \#1 } \\
\left({ }^{\circ} \mathrm{C}\right)\end{array}$ & $\begin{array}{c}\text { Zone \#2 } \\
\left({ }^{\circ} \mathrm{C}\right)\end{array}$ & $\begin{array}{c}\text { Zone \#3 } \\
\left({ }^{\circ} \mathrm{C}\right)\end{array}$ & $\begin{array}{c}\text { Zone \#4 } \\
\left({ }^{\circ} \mathrm{C}\right)\end{array}$ & $\begin{array}{c}\text { Zone \#5 } \\
\left({ }^{\circ} \mathrm{C}\right)\end{array}$ & $\begin{array}{c}\text { Zone \#6 } \\
\left({ }^{\circ} \mathrm{C}\right)\end{array}$ & $\begin{array}{c}\text { Zone \#7 } \\
\left({ }^{\circ} \mathrm{C}\right)\end{array}$ & $\begin{array}{c}\text { Belt Speed } \\
(\mathrm{in} / \mathrm{min})\end{array}$ \\
\hline \hline 128.7 & 145 & 150 & 150 & 160 & 180 & 270 & 20
\end{tabular}




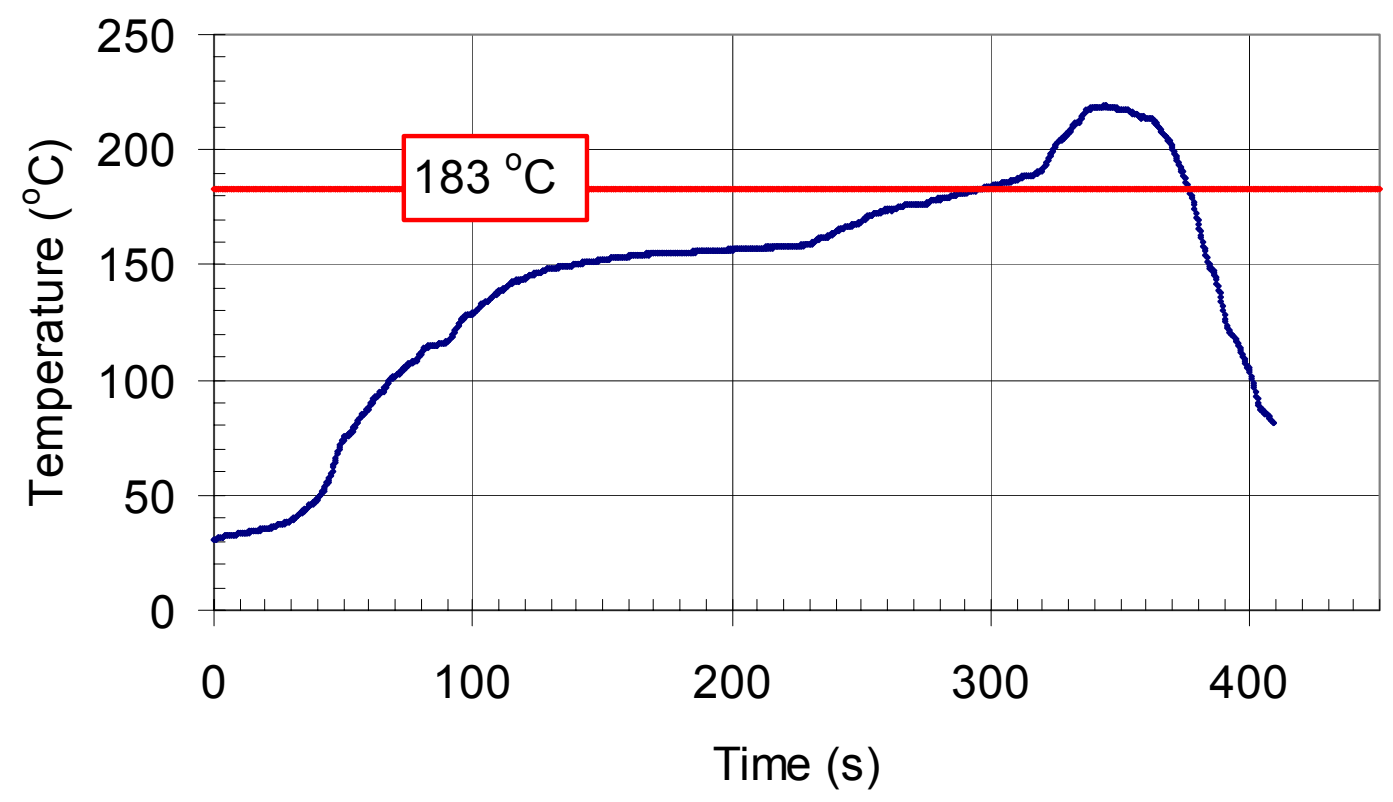

Figure A-9 Material A, Time Above $183^{\circ} \mathrm{C}$ High profile

Table A-17 reflow parameters for Time Above $183^{\circ} \mathrm{C}$ High profile

\begin{tabular}{c|c|c|c|c}
$\begin{array}{c}\text { Ramp Rate } \\
\left({ }^{\circ} \mathrm{C} / \mathrm{s}\right)\end{array}$ & $\begin{array}{c}\text { Soak Temp } \\
\left({ }^{\circ} \mathrm{C}\right)\end{array}$ & $\begin{array}{c}\text { Soak Time } \\
(\mathrm{s})\end{array}$ & $\begin{array}{c}\text { Time above } 183{ }^{\circ} \mathrm{C} \\
(\mathrm{s})\end{array}$ & $\begin{array}{c}\text { Peak Temp } \\
\left({ }^{\circ} \mathrm{C}\right)\end{array}$ \\
\hline \hline 2 & 150 & 119.2 & 80.4 & 218.9
\end{tabular}

Table A-18 Material A, oven set points for Time Above $183^{\circ} \mathrm{C}$ High profile \begin{tabular}{c|c|c|c|c|c|c|c}
$\begin{array}{c}\text { Zone \#1 } \\
\left({ }^{\circ} \mathrm{C}\right)\end{array}$ & $\begin{array}{c}\text { Zone \#2 } \\
\left({ }^{\circ} \mathrm{C}\right)\end{array}$ & $\begin{array}{c}\text { Zone \#3 } \\
\left({ }^{\circ} \mathrm{C}\right)\end{array}$ & $\begin{array}{c}\text { Zone \#4 } \\
\left({ }^{\circ} \mathrm{C}\right)\end{array}$ & $\begin{array}{c}\text { Zone \#5 } \\
\left({ }^{\circ} \mathrm{C}\right)\end{array}$ & $\begin{array}{c}\text { Zone \#6 } \\
\left({ }^{\circ} \mathrm{C}\right)\end{array}$ & $\begin{array}{c}\text { Zone \#7 } \\
\left({ }^{\circ} \mathrm{C}\right)\end{array}$ & $\begin{array}{c}\text { Belt Speed } \\
(\mathrm{in} / \mathrm{min})\end{array}$ \\
\hline \hline 128.8 & 162.8 & 158.1 & 160 & 191.3 & 192 & 261.8 & 17.8
\end{tabular} 


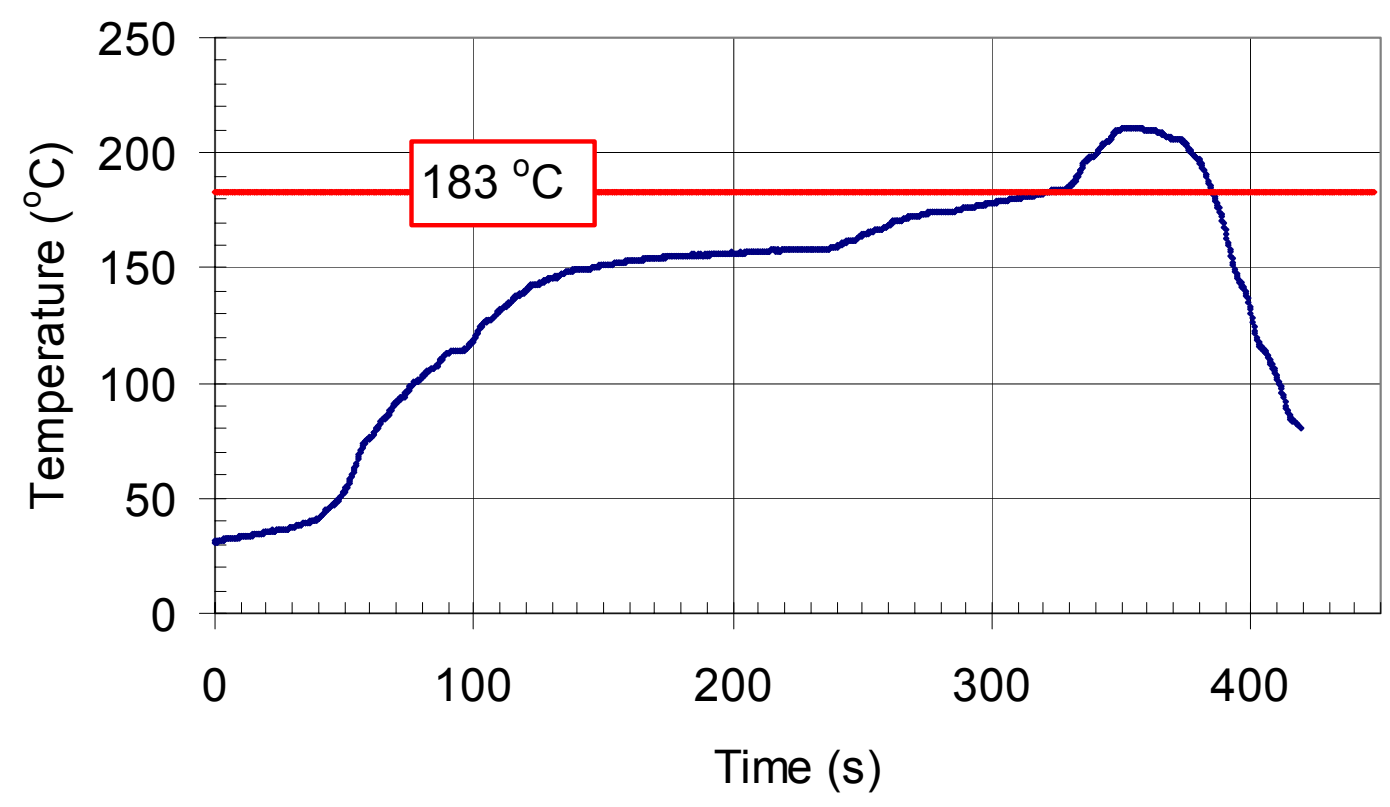

Figure A-10 Material A, Peak Temperature Low profile

Table A-19 Material A, reflow parameters for Peak Temperature Low profile

\begin{tabular}{c|c|c|c|c}
$\begin{array}{c}\text { Ramp Rate } \\
\left({ }^{\circ} \mathrm{C} / \mathrm{s}\right)\end{array}$ & $\begin{array}{c}\text { Soak Temp } \\
\left({ }^{\circ} \mathrm{C}\right)\end{array}$ & $\begin{array}{c}\text { Soak Time } \\
(\mathrm{s})\end{array}$ & $\begin{array}{c}\text { Time above } 183{ }^{\circ} \mathrm{C} \\
(\mathrm{s})\end{array}$ & $\begin{array}{c}\text { Peak Temp } \\
\left({ }^{\circ} \mathrm{C}\right)\end{array}$ \\
\hline \hline 1.9 & 150 & 121.5 & 64.3 & 211
\end{tabular}

Table A-20 Material A, oven set points for Peak Temperature Low profile

\begin{tabular}{c|c|c|c|c|c|c|c}
$\begin{array}{c}\text { Zone \#1 } \\
\left({ }^{\circ} \mathrm{C}\right)\end{array}$ & $\begin{array}{c}\text { Zone \#2 } \\
\left({ }^{\circ} \mathrm{C}\right)\end{array}$ & $\begin{array}{c}\text { Zone \#3 } \\
\left({ }^{\circ} \mathrm{C}\right)\end{array}$ & $\begin{array}{c}\text { Zone \#4 } \\
\left({ }^{\circ} \mathrm{C}\right)\end{array}$ & $\begin{array}{c}\text { Zone \#5 } \\
\left({ }^{\circ} \mathrm{C}\right)\end{array}$ & $\begin{array}{c}\text { Zone \#6 } \\
\left({ }^{\circ} \mathrm{C}\right)\end{array}$ & $\begin{array}{c}\text { Zone \#7 } \\
\left({ }^{\circ} \mathrm{C}\right)\end{array}$ & $\begin{array}{c}\text { Belt Speed } \\
(\mathrm{in} / \mathrm{min})\end{array}$ \\
\hline \hline 127.5 & 163.5 & 159.1 & 159.5 & 188 & 185.8 & 250.1 & 17.7
\end{tabular}




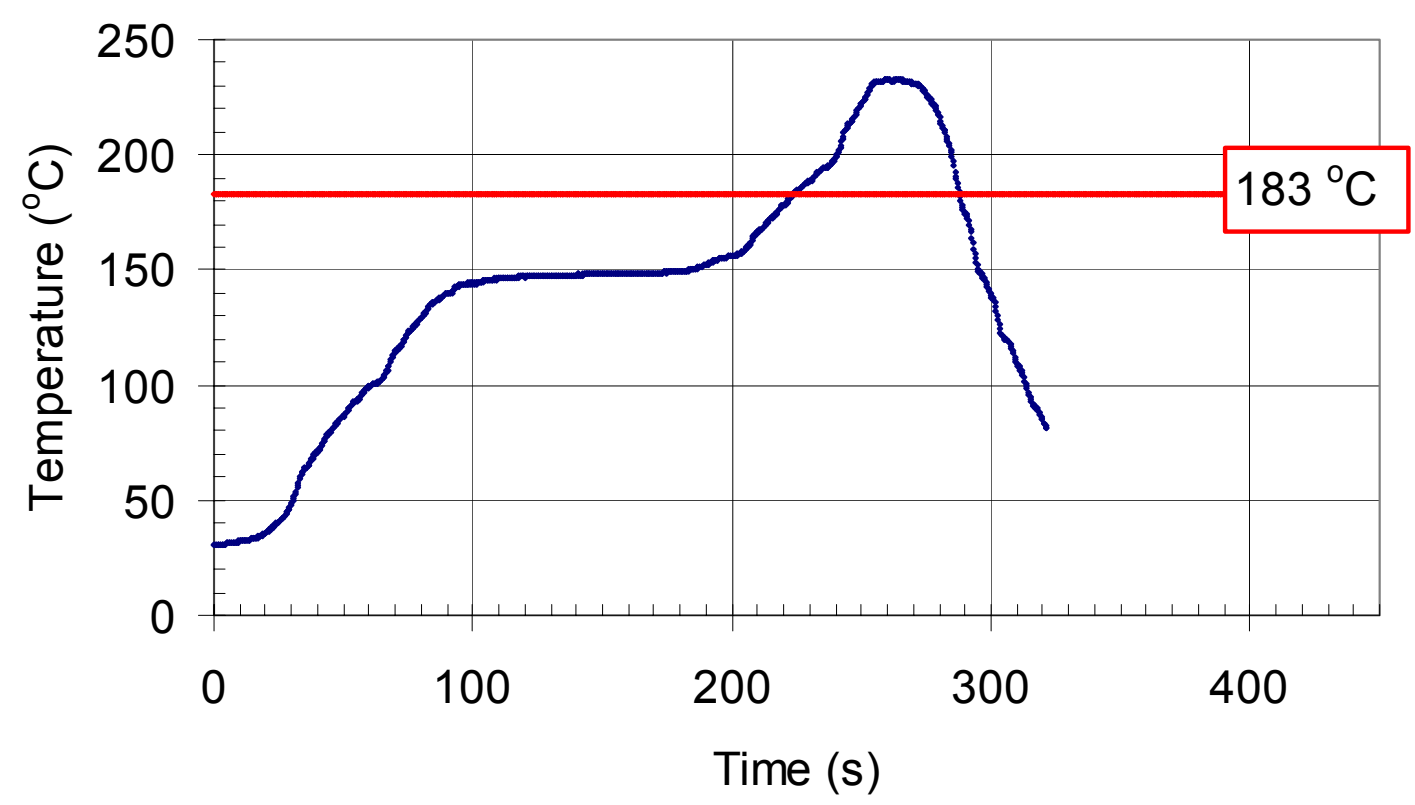

Figure A-11 Material A, Peak Temperature High profile

Table A-21 Material A, reflow parameters for Peak Temperature High profile

\begin{tabular}{c|c|c|c|c}
$\begin{array}{c}\text { Ramp Rate } \\
\left({ }^{\circ} \mathrm{C} / \mathrm{s}\right)\end{array}$ & $\begin{array}{c}\text { Soak Temp } \\
\left({ }^{\circ} \mathrm{C}\right)\end{array}$ & $\begin{array}{c}\text { Soak Time } \\
(\mathrm{s})\end{array}$ & $\begin{array}{c}\text { Time above } 183{ }^{\circ} \mathrm{C} \\
(\mathrm{s})\end{array}$ & $\begin{array}{c}\text { Peak Temp } \\
\left({ }^{\circ} \mathrm{C}\right)\end{array}$ \\
\hline \hline 2 & 150 & 114.9 & 64.2 & 232.8
\end{tabular}

Table A-22 Material A, oven set points for Peak Temperature High profile

\begin{tabular}{c|c|c|c|c|c|c|c}
$\begin{array}{c}\text { Zone \#1 } \\
\left({ }^{\circ} \mathrm{C}\right)\end{array}$ & $\begin{array}{c}\text { Zone \#2 } \\
\left({ }^{\circ} \mathrm{C}\right)\end{array}$ & $\begin{array}{c}\text { Zone \#3 } \\
\left({ }^{\circ} \mathrm{C}\right)\end{array}$ & $\begin{array}{c}\text { Zone \#4 } \\
\left({ }^{\circ} \mathrm{C}\right)\end{array}$ & $\begin{array}{c}\text { Zone \#5 } \\
\left({ }^{\circ} \mathrm{C}\right)\end{array}$ & $\begin{array}{c}\text { Zone \#6 } \\
\left({ }^{\circ} \mathrm{C}\right)\end{array}$ & $\begin{array}{c}\text { Zone \#7 } \\
\left({ }^{\circ} \mathrm{C}\right)\end{array}$ & $\begin{array}{c}\text { Belt Speed } \\
(\text { in/min })\end{array}$ \\
\hline \hline 120 & 170 & 150 & 150 & 155 & 215 & 295 & 24
\end{tabular}




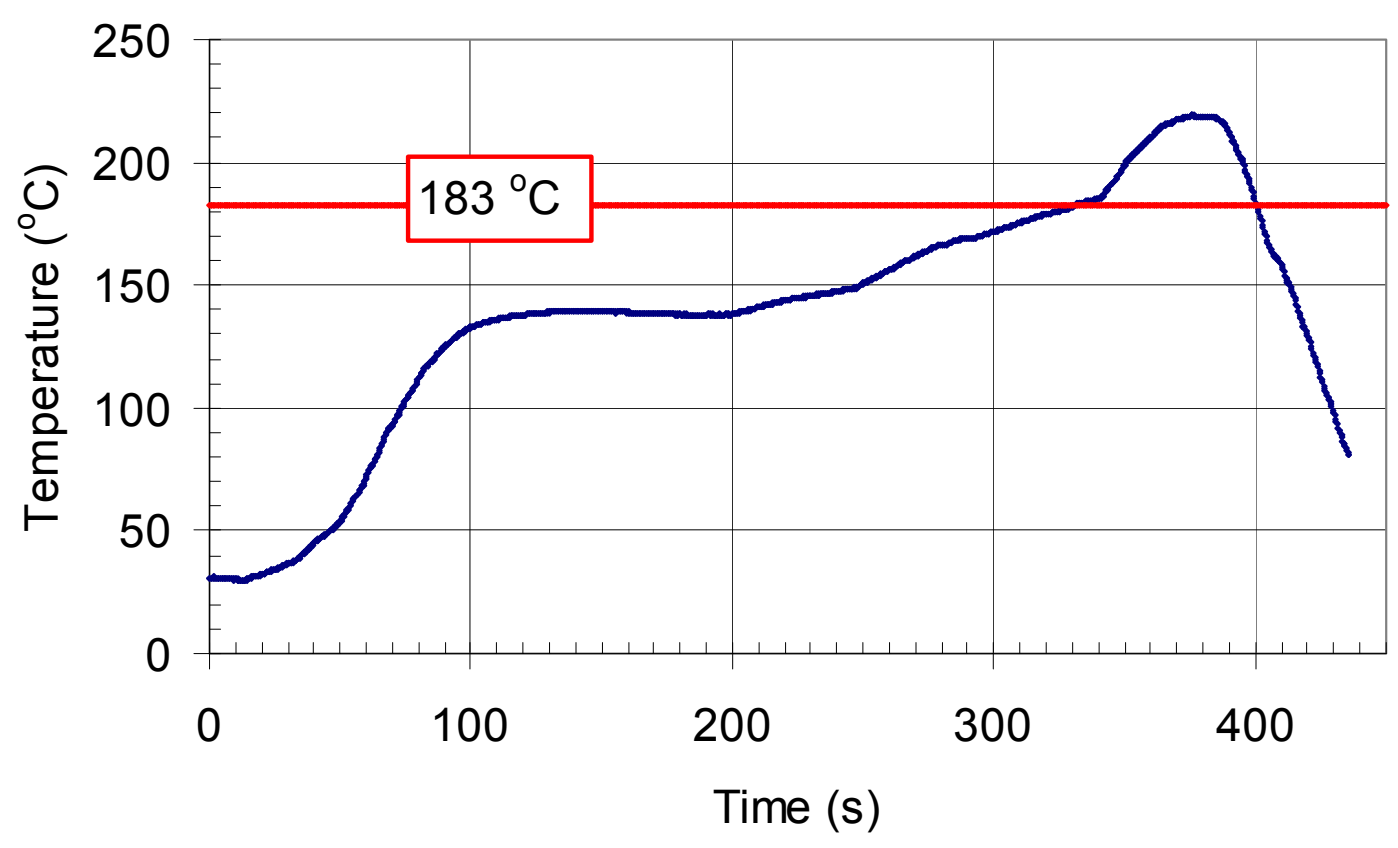

Figure A-12 Material A, Parametric Optimized profile

Table A-23 Material A, reflow parameters for Parametric Optimized profile

\begin{tabular}{c|c|c|c|c}
$\begin{array}{c}\text { Ramp Rate } \\
\left({ }^{\circ} \mathrm{C} / \mathrm{s}\right)\end{array}$ & $\begin{array}{c}\text { Soak Temp } \\
\left({ }^{\circ} \mathrm{C}\right)\end{array}$ & $\begin{array}{c}\text { Soak Time } \\
(\mathrm{s})\end{array}$ & $\begin{array}{c}\text { Time above } 183{ }^{\circ} \mathrm{C} \\
(\mathrm{s})\end{array}$ & $\begin{array}{c}\text { Peak Temp } \\
\left({ }^{\circ} \mathrm{C}\right)\end{array}$ \\
\hline \hline 2 & 140 & 153.6 & 68.7 & 219.2
\end{tabular}

Table A-24 Material A, oven set points for Parametric Optimized profile

\begin{tabular}{c|c|c|c|c|c|c|c}
$\begin{array}{c}\text { Zone \#1 } \\
\left({ }^{\circ} \mathrm{C}\right)\end{array}$ & $\begin{array}{c}\text { Zone \#2 } \\
\left({ }^{\circ} \mathrm{C}\right)\end{array}$ & $\begin{array}{c}\text { Zone \#3 } \\
\left({ }^{\circ} \mathrm{C}\right)\end{array}$ & $\begin{array}{c}\text { Zone \#4 } \\
\left({ }^{\circ} \mathrm{C}\right)\end{array}$ & $\begin{array}{c}\text { Zone \#5 } \\
\left({ }^{\circ} \mathrm{C}\right)\end{array}$ & $\begin{array}{c}\text { Zone \#6 } \\
\left({ }^{\circ} \mathrm{C}\right)\end{array}$ & $\begin{array}{c}\text { Zone \#7 } \\
\left({ }^{\circ} \mathrm{C}\right)\end{array}$ & $\begin{array}{c}\text { Belt Speed } \\
(\mathrm{in} / \mathrm{min})\end{array}$ \\
\hline \hline 160.5 & 140 & 137.2 & 151.6 & 190.2 & 189.5 & 252 & 17.8
\end{tabular}




\section{Material B Reflow Profiles}

The reflow profile characterization for Material B used a ramp type profile as the basis for investigation. The 9 profiles used for experimentation are presented in Figures A-13 through A-21. The reflow parameters and The BTU Paragon oven setpoints that describe these profiles are presented in Tables A-25 through A-42. Replicates of 4 die were assembled for each profile, and these assemblies were analyzed for underfill voiding, resistance, and phase ratio. 


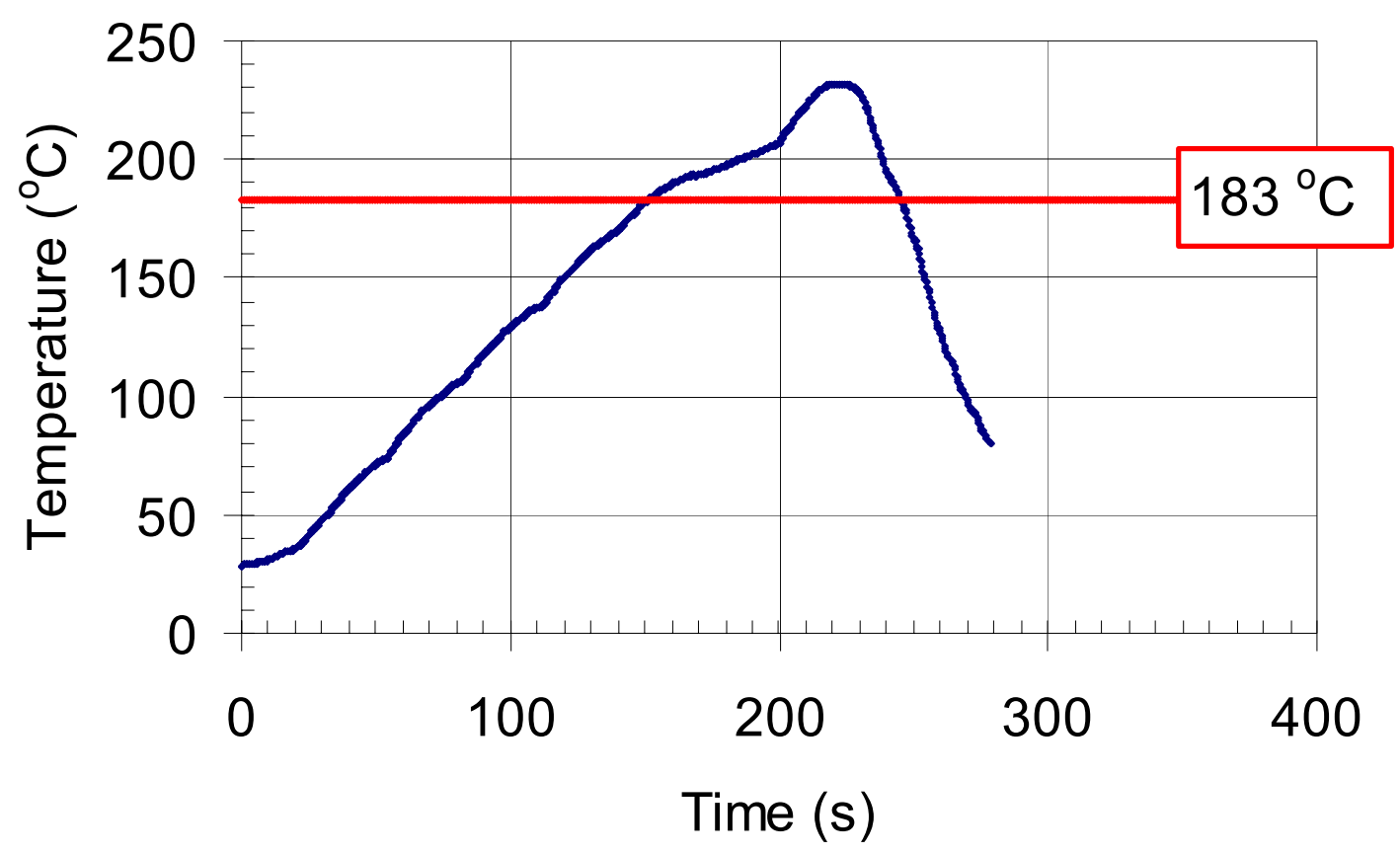

Figure A-13 Material B, Baseline profile

Table A-25 Material B, reflow parameters for Baseline profile

\begin{tabular}{c|c|c|c}
$\begin{array}{c}\text { Ramp Rate } \\
\left({ }^{\circ} \mathrm{C} / \mathrm{s}\right)\end{array}$ & $\begin{array}{c}\text { Time above } 183{ }^{\circ} \mathrm{C} \\
(\mathrm{s})\end{array}$ & $\begin{array}{c}\text { Peak Temperature } \\
\left({ }^{\circ} \mathrm{C}\right)\end{array}$ & $\begin{array}{c}\text { Time to Peak Temperature } \\
(\mathrm{s})\end{array}$ \\
\hline \hline 1.3 & 94 & 232.1 & 221
\end{tabular}

Table A-26 Material B, oven set points for Baseline profile

\begin{tabular}{c|c|c|c|c|c|c|c}
$\begin{array}{c}\text { Zone \#1 } \\
\left({ }^{\circ} \mathrm{C}\right)\end{array}$ & $\begin{array}{c}\text { Zone \#2 } \\
\left({ }^{\circ} \mathrm{C}\right)\end{array}$ & $\begin{array}{c}\text { Zone \#3 } \\
\left({ }^{\circ} \mathrm{C}\right)\end{array}$ & $\begin{array}{c}\text { Zone \#4 } \\
\left({ }^{\circ} \mathrm{C}\right)\end{array}$ & $\begin{array}{c}\text { Zone \#5 } \\
\left({ }^{\circ} \mathrm{C}\right)\end{array}$ & $\begin{array}{c}\text { Zone \#6 } \\
\left({ }^{\circ} \mathrm{C}\right)\end{array}$ & $\begin{array}{c}\text { Zone \#7 } \\
\left({ }^{\circ} \mathrm{C}\right)\end{array}$ & $\begin{array}{c}\text { Belt Speed } \\
(\mathrm{in} / \mathrm{min})\end{array}$ \\
\hline \hline 90.6 & 125.2 & 155.2 & 193.5 & 226 & 214.7 & 277.5 & 28.6
\end{tabular}




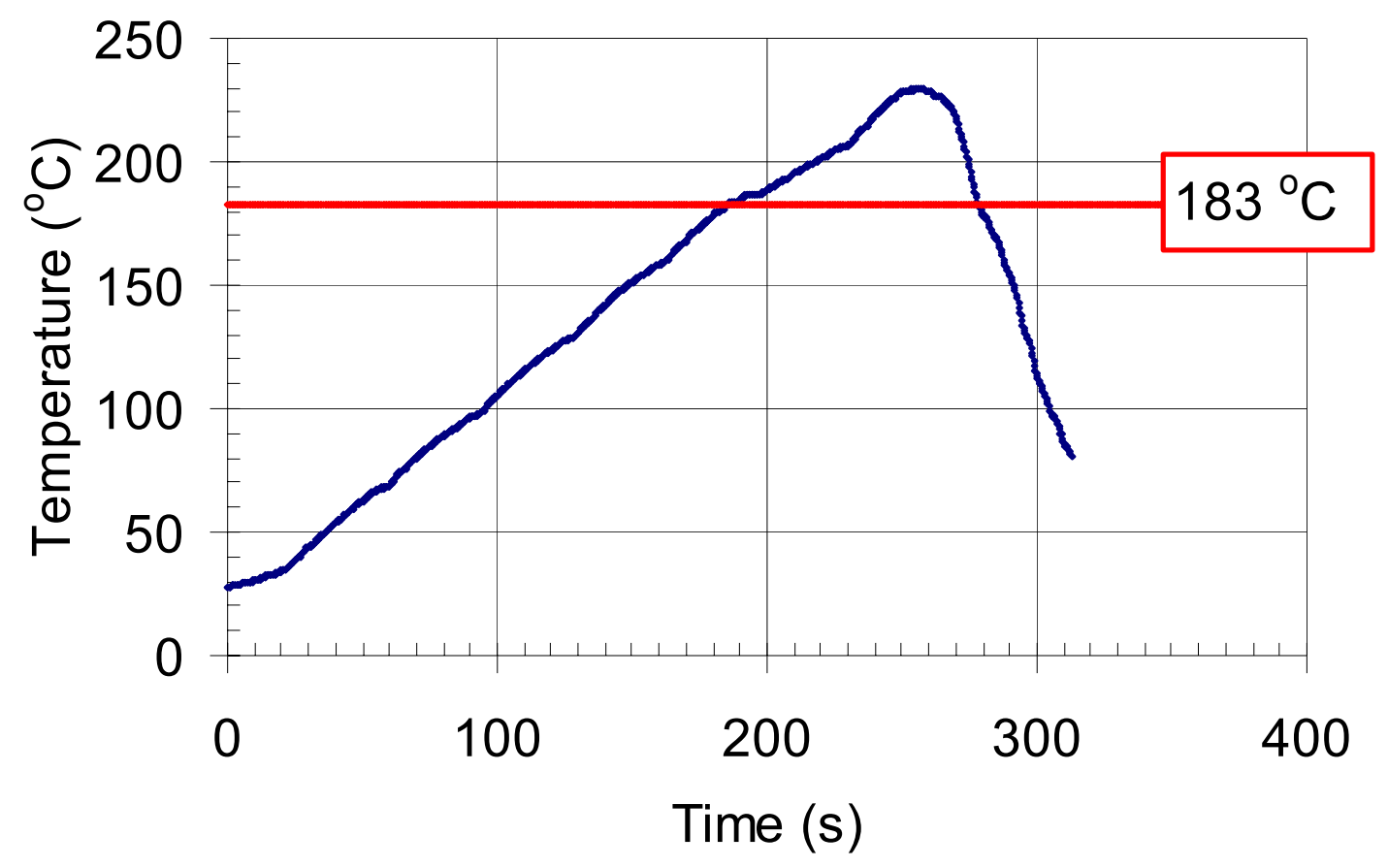

Figure A-14 Material B, Ramp Rate Low profile

Table A-27 Material B, reflow parameters for Ramp Rate Low profile

\begin{tabular}{c|c|c|c}
$\begin{array}{c}\text { Ramp Rate } \\
\left({ }^{\circ} \mathrm{C} / \mathrm{s}\right)\end{array}$ & $\begin{array}{c}\text { Time above } 183^{\circ} \mathrm{C} \\
(\mathrm{s})\end{array}$ & $\begin{array}{c}\text { Peak Temperature } \\
\left({ }^{\circ} \mathrm{C}\right)\end{array}$ & $\begin{array}{c}\text { Time to Peak Temperature } \\
(\mathrm{s})\end{array}$ \\
\hline \hline 1.1 & 92.4 & 229.7 & 252
\end{tabular}

Table A-28 Material B, oven set points for Ramp Rate Low profile \begin{tabular}{c|c|c|c|c|c|c|c}
$\begin{array}{c}\text { Zone \#1 } \\
\left({ }^{\circ} \mathrm{C}\right)\end{array}$ & $\begin{array}{c}\text { Zone \#2 } \\
\left({ }^{\circ} \mathrm{C}\right)\end{array}$ & $\begin{array}{c}\text { Zone \#3 } \\
\left({ }^{\circ} \mathrm{C}\right)\end{array}$ & $\begin{array}{c}\text { Zone \#4 } \\
\left({ }^{\circ} \mathrm{C}\right)\end{array}$ & $\begin{array}{c}\text { Zone \#5 } \\
\left({ }^{\circ} \mathrm{C}\right)\end{array}$ & $\begin{array}{c}\text { Zone \#6 } \\
\left({ }^{\circ} \mathrm{C}\right)\end{array}$ & $\begin{array}{c}\text { Zone \#7 } \\
\left({ }^{\circ} \mathrm{C}\right)\end{array}$ & $\begin{array}{c}\text { Belt Speed } \\
(\mathrm{in} / \mathrm{min})\end{array}$ \\
\hline \hline 79.3 & 109.8 & 140.9 & 176.3 & 219 & 218.4 & 266.9 & 24.4
\end{tabular} 


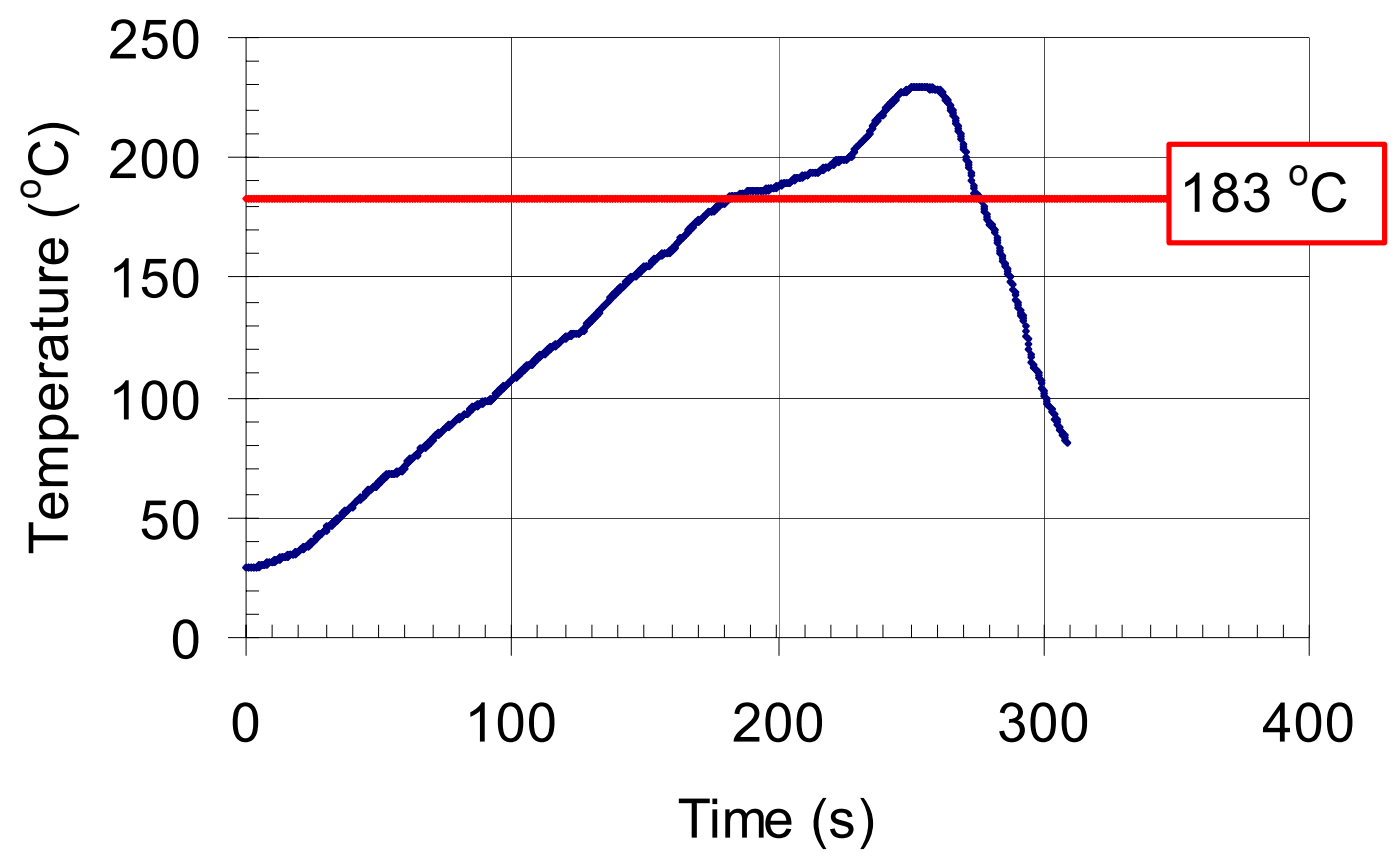

Figure A-15 Material B, Ramp Rate High profile

Table A-29 Material B, reflow parameters for Ramp Rate High profile \begin{tabular}{c|c|c|c}
$\begin{array}{c}\text { Ramp Rate } \\
\left({ }^{\circ} \mathrm{C} / \mathrm{s}\right)\end{array}$ & $\begin{array}{c}\text { Time above } 183^{\circ} \mathrm{C} \\
(\mathrm{s})\end{array}$ & $\begin{array}{c}\text { Peak Temperature } \\
\left({ }^{\circ} \mathrm{C}\right)\end{array}$ & $\begin{array}{c}\text { Time to Peak Temperature } \\
(\mathrm{s})\end{array}$ \\
\hline \hline 1.4 & 94 & 229.9 & 251.7
\end{tabular}

Table A-30 Material B, oven set points for Ramp Rate High profile \begin{tabular}{c|c|c|c|c|c|c|c}
$\begin{array}{c}\text { Zone \#1 } \\
\left({ }^{\circ} \mathrm{C}\right)\end{array}$ & $\begin{array}{c}\text { Zone \#2 } \\
\left({ }^{\circ} \mathrm{C}\right)\end{array}$ & $\begin{array}{c}\text { Zone \#3 } \\
\left({ }^{\circ} \mathrm{C}\right)\end{array}$ & $\begin{array}{c}\text { Zone \#4 } \\
\left({ }^{\circ} \mathrm{C}\right)\end{array}$ & $\begin{array}{c}\text { Zone \#5 } \\
\left({ }^{\circ} \mathrm{C}\right)\end{array}$ & $\begin{array}{c}\text { Zone \#6 } \\
\left({ }^{\circ} \mathrm{C}\right)\end{array}$ & $\begin{array}{c}\text { Zone \#7 } \\
\left({ }^{\circ} \mathrm{C}\right)\end{array}$ & $\begin{array}{c}\text { Belt Speed } \\
(\text { in/min })\end{array}$ \\
\hline \hline 78.9 & 109.3 & 137.8 & 178.2 & 218.5 & 205.8 & 274.1 & 24.7
\end{tabular} 


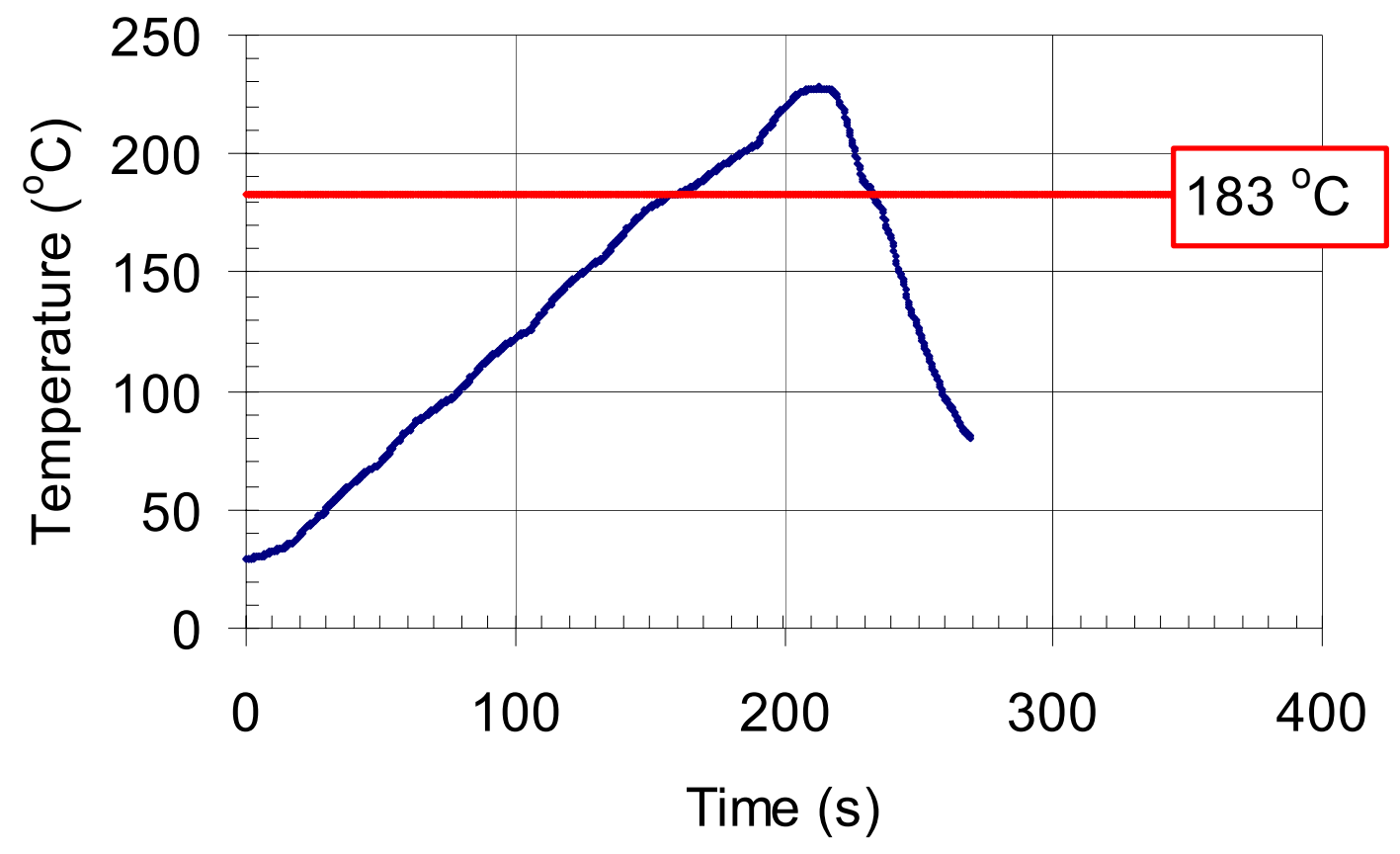

Figure A-16 Material B, Time Above $183^{\circ} \mathrm{C}$ Low profile

Table A-31 Material B, reflow parameters for Time Above $183^{\circ} \mathrm{C}$ Low profile

\begin{tabular}{c|c|c|c}
$\begin{array}{c}\text { Ramp Rate } \\
\left({ }^{\circ} \mathrm{C} / \mathrm{s}\right)\end{array}$ & $\begin{array}{c}\text { Time above } 183{ }^{\circ} \mathrm{C} \\
(\mathrm{s})\end{array}$ & $\begin{array}{c}\text { Peak Temperature } \\
\left({ }^{\circ} \mathrm{C}\right)\end{array}$ & $\begin{array}{c}\text { Time to Peak Temperature } \\
(\mathrm{s})\end{array}$ \\
\hline \hline 1.2 & 73.7 & 228 & 213
\end{tabular}

Table A-32 Material B, oven set points for Time Above $183{ }^{\circ} \mathrm{C}$ Low profile

\begin{tabular}{c|c|c|c|c|c|c|c}
$\begin{array}{c}\text { Zone \#1 } \\
\left({ }^{\circ} \mathrm{C}\right)\end{array}$ & $\begin{array}{c}\text { Zone \#2 } \\
\left({ }^{\circ} \mathrm{C}\right)\end{array}$ & $\begin{array}{c}\text { Zone \#3 } \\
\left({ }^{\circ} \mathrm{C}\right)\end{array}$ & $\begin{array}{c}\text { Zone \#4 } \\
\left({ }^{\circ} \mathrm{C}\right)\end{array}$ & $\begin{array}{c}\text { Zone \#5 } \\
\left({ }^{\circ} \mathrm{C}\right)\end{array}$ & $\begin{array}{c}\text { Zone \#6 } \\
\left({ }^{\circ} \mathrm{C}\right)\end{array}$ & $\begin{array}{c}\text { Zone \#7 } \\
\left({ }^{\circ} \mathrm{C}\right)\end{array}$ & $\begin{array}{c}\text { Belt Speed } \\
(\text { in/min })\end{array}$ \\
\hline \hline 83.6 & 113.4 & 141.2 & 177.9 & 221.7 & 221.1 & 270.7 & 29.5
\end{tabular}




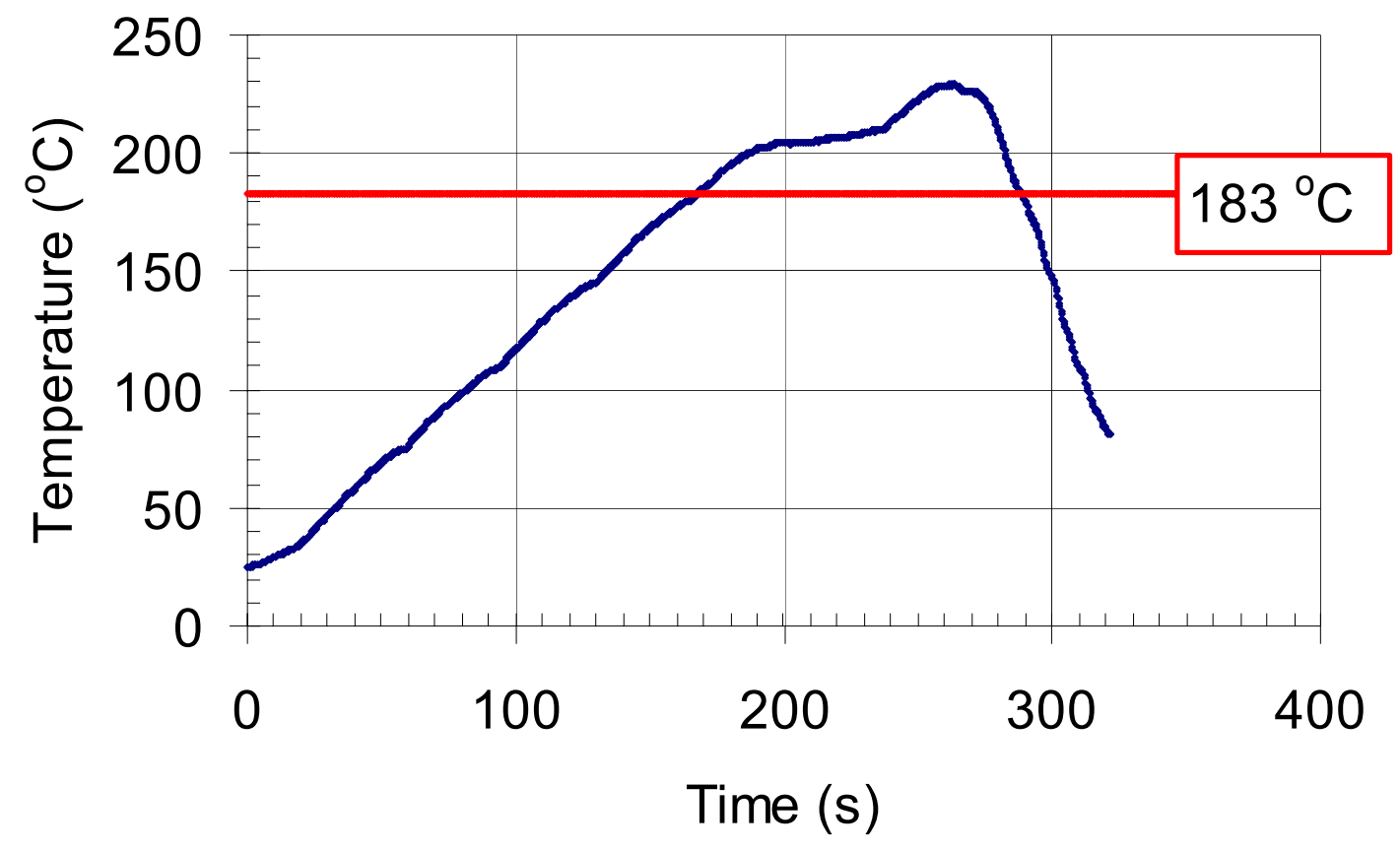

Figure A-17 Material B, Time Above $183^{\circ} \mathrm{C}$ High profile

Table A-33 Material B, reflow parameters for Time Above $183^{\circ} \mathrm{C}$ High profile \begin{tabular}{c|c|c|c}
$\begin{array}{c}\text { Ramp Rate } \\
\left({ }^{\circ} \mathrm{C} / \mathrm{s}\right)\end{array}$ & $\begin{array}{c}\text { Time above } 183^{\circ} \mathrm{C} \\
(\mathrm{s})\end{array}$ & $\begin{array}{c}\text { Peak Temperature } \\
\left({ }^{\circ} \mathrm{C}\right)\end{array}$ & $\begin{array}{c}\text { Time to Peak Temperature } \\
(\mathrm{s})\end{array}$ \\
\hline \hline 1.2 & 120 & 229 & 261.7
\end{tabular}

Table A-34 Material B, oven set points for Time Above $183^{\circ} \mathrm{C}$ High profile \begin{tabular}{c|c|c|c|c|c|c|c}
$\begin{array}{c}\text { Zone \#1 } \\
\left({ }^{\circ} \mathrm{C}\right)\end{array}$ & $\begin{array}{c}\text { Zone \#2 } \\
\left({ }^{\circ} \mathrm{C}\right)\end{array}$ & $\begin{array}{c}\text { Zone \#3 } \\
\left({ }^{\circ} \mathrm{C}\right)\end{array}$ & $\begin{array}{c}\text { Zone \#4 } \\
\left({ }^{\circ} \mathrm{C}\right)\end{array}$ & $\begin{array}{c}\text { Zone \#5 } \\
\left({ }^{\circ} \mathrm{C}\right)\end{array}$ & $\begin{array}{c}\text { Zone \#6 } \\
\left({ }^{\circ} \mathrm{C}\right)\end{array}$ & $\begin{array}{c}\text { Zone \#7 } \\
\left({ }^{\circ} \mathrm{C}\right)\end{array}$ & $\begin{array}{c}\text { Belt Speed } \\
(\text { in/min })\end{array}$ \\
\hline \hline 86.1 & 121.3 & 159.3 & 198.6 & 236.3 & 207.6 & 260.5 & 23.5
\end{tabular} 


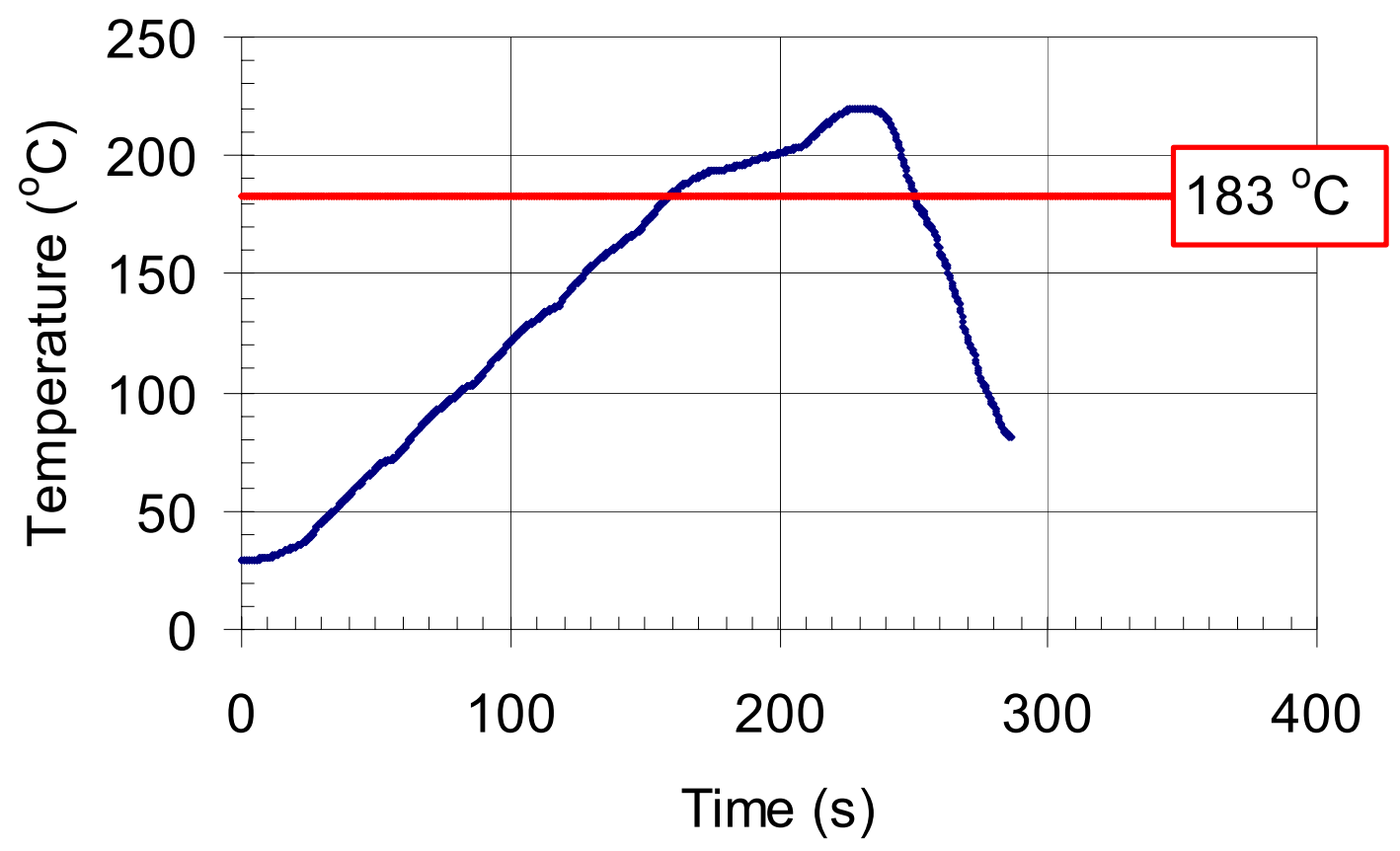

Figure A-18 Material B, Peak Temperature Low profile

Table A-35 Material B, reflow parameters for Peak Temperature Low profile

\begin{tabular}{c|c|c|c}
$\begin{array}{c}\text { Ramp Rate } \\
\left({ }^{\circ} \mathrm{C} / \mathrm{s}\right)\end{array}$ & $\begin{array}{c}\text { Time above } 183{ }^{\circ} \mathrm{C} \\
(\mathrm{s})\end{array}$ & $\begin{array}{c}\text { Peak Temperature } \\
\left({ }^{\circ} \mathrm{C}\right)\end{array}$ & $\begin{array}{c}\text { Time to Peak Temperature } \\
(\mathrm{s})\end{array}$ \\
\hline \hline 1.2 & 91.3 & 220.1 & 232
\end{tabular}

Table A-36 Material B, oven set points for Peak Temperature Low profile

\begin{tabular}{c|c|c|c|c|c|c|c}
$\begin{array}{c}\text { Zone \#1 } \\
\left({ }^{\circ} \mathrm{C}\right)\end{array}$ & $\begin{array}{c}\text { Zone \#2 } \\
\left({ }^{\circ} \mathrm{C}\right)\end{array}$ & $\begin{array}{c}\text { Zone \#3 } \\
\left({ }^{\circ} \mathrm{C}\right)\end{array}$ & $\begin{array}{c}\text { Zone \#4 } \\
\left({ }^{\circ} \mathrm{C}\right)\end{array}$ & $\begin{array}{c}\text { Zone \#5 } \\
\left({ }^{\circ} \mathrm{C}\right)\end{array}$ & $\begin{array}{c}\text { Zone \#6 } \\
\left({ }^{\circ} \mathrm{C}\right)\end{array}$ & $\begin{array}{c}\text { Zone \#7 } \\
\left({ }^{\circ} \mathrm{C}\right)\end{array}$ & $\begin{array}{c}\text { Belt Speed } \\
(\mathrm{in} / \mathrm{min})\end{array}$ \\
\hline \hline 86.2 & 118.5 & 151.6 & 187.5 & 231.7 & 209.5 & 252.2 & 27.3
\end{tabular}




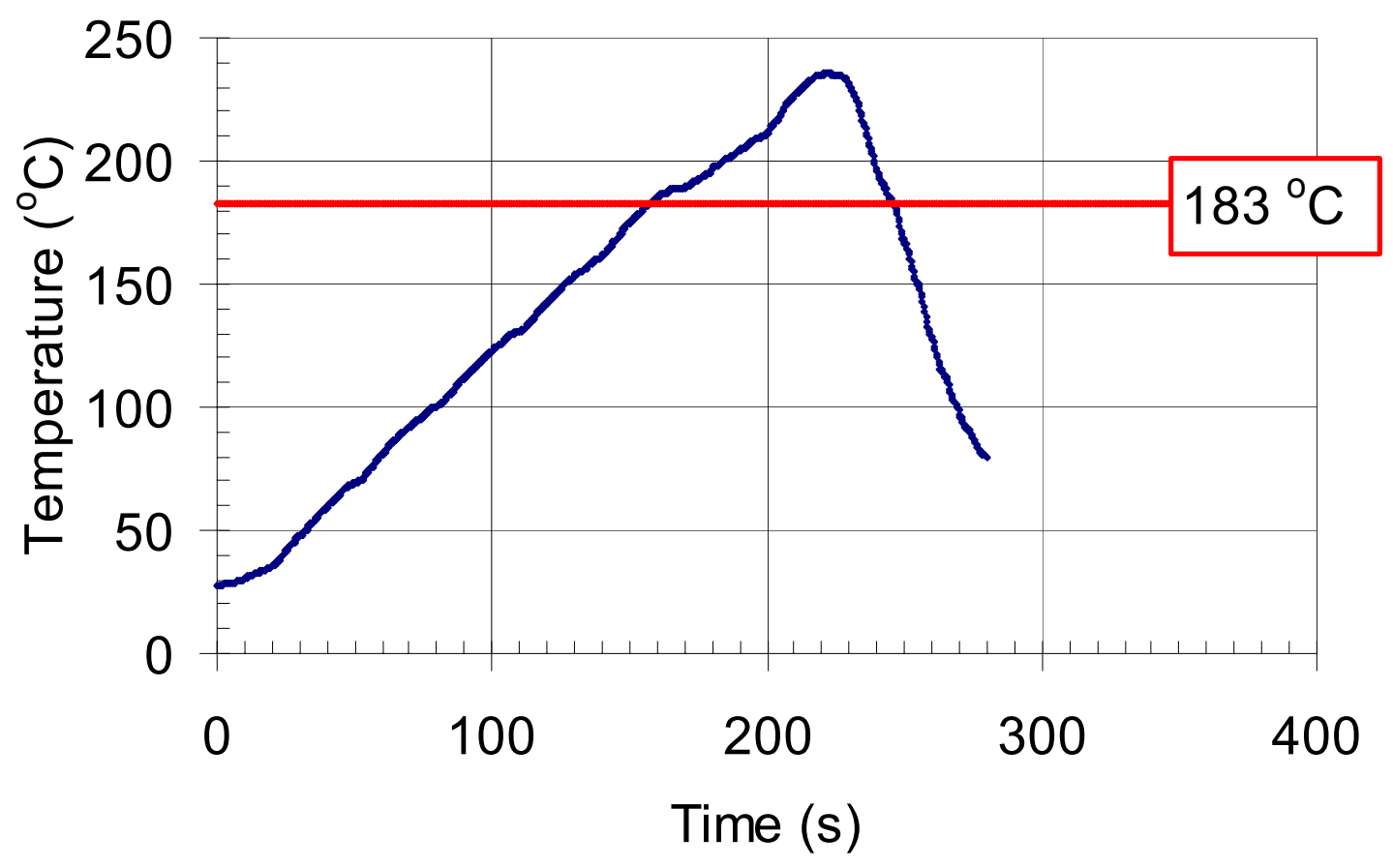

Figure A-19 Material B, Peak Temperature High profile

Table A-37 Material B, reflow parameters for Peak Temperature High profile \begin{tabular}{l|l|l|l} 
Ramp Rate & Time above $183^{\circ} \mathrm{C}$ & Peak Temperature & Time to Peak Temperature
\end{tabular}

\begin{tabular}{c|c|c|c}
$\left({ }^{\circ} \mathrm{C} / \mathrm{s}\right)$ & $(\mathrm{s})$ & $\left({ }^{\circ} \mathrm{C}\right)$ & $(\mathrm{s})$ \\
\hline \hline 1.2 & 88.1 & 235.7 & 221.3
\end{tabular}

Table A-38 Material B, oven set points for Peak Temperature High profile

\begin{tabular}{c|c|c|c|c|c|c|c}
$\begin{array}{c}\text { Zone \#1 } \\
\left({ }^{\circ} \mathrm{C}\right)\end{array}$ & $\begin{array}{c}\text { Zone \#2 } \\
\left({ }^{\circ} \mathrm{C}\right)\end{array}$ & $\begin{array}{c}\text { Zone \#3 } \\
\left({ }^{\circ} \mathrm{C}\right)\end{array}$ & $\begin{array}{c}\text { Zone \#4 } \\
\left({ }^{\circ} \mathrm{C}\right)\end{array}$ & $\begin{array}{c}\text { Zone \#5 } \\
\left({ }^{\circ} \mathrm{C}\right)\end{array}$ & $\begin{array}{c}\text { Zone \#6 } \\
\left({ }^{\circ} \mathrm{C}\right)\end{array}$ & $\begin{array}{c}\text { Zone \#7 } \\
\left({ }^{\circ} \mathrm{C}\right)\end{array}$ & $\begin{array}{c}\text { Belt Speed } \\
(\text { in/min })\end{array}$ \\
\hline \hline 86.2 & 117.6 & 147.7 & 182.7 & 227.7 & 226.2 & 278.8 & 28.3
\end{tabular}




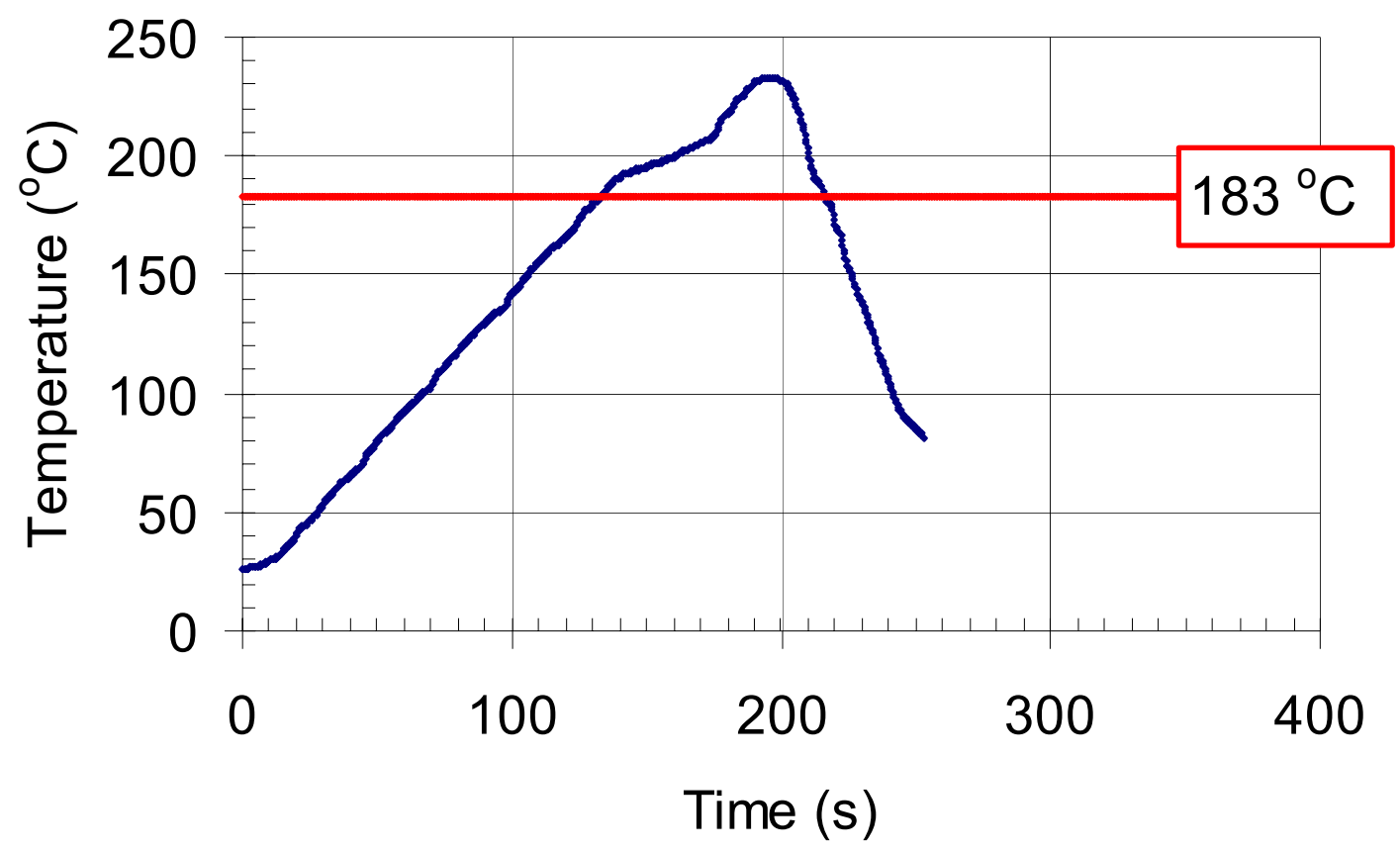

Figure A-20 Material B, Time to Peak Temperature Low profile

Table A-39 Material B, reflow parameters for Time to Peak Temperature Low profile

\begin{tabular}{c|c|c|c}
$\begin{array}{c}\text { Ramp Rate } \\
\left({ }^{\circ} \mathrm{C} / \mathrm{s}\right)\end{array}$ & $\begin{array}{c}\text { Time above } 183{ }^{\circ} \mathrm{C} \\
(\mathrm{s})\end{array}$ & $\begin{array}{c}\text { Peak Temperature } \\
\left({ }^{\circ} \mathrm{C}\right)\end{array}$ & $\begin{array}{c}\text { Time to Peak Temperature } \\
(\mathrm{s})\end{array}$ \\
\hline \hline 1.4 & 82.9 & 232.8 & 195.3
\end{tabular}

Table A-40 Material B, oven set points for Time to Peak Temperature Low profile

\begin{tabular}{c|c|c|c|c|c|c|c}
$\begin{array}{c}\text { Zone \#1 } \\
\left({ }^{\circ} \mathrm{C}\right)\end{array}$ & $\begin{array}{c}\text { Zone \#2 } \\
\left({ }^{\circ} \mathrm{C}\right)\end{array}$ & $\begin{array}{c}\text { Zone \#3 } \\
\left({ }^{\circ} \mathrm{C}\right)\end{array}$ & $\begin{array}{c}\text { Zone \#4 } \\
\left({ }^{\circ} \mathrm{C}\right)\end{array}$ & $\begin{array}{c}\text { Zone \#5 } \\
\left({ }^{\circ} \mathrm{C}\right)\end{array}$ & $\begin{array}{c}\text { Zone \#6 } \\
\left({ }^{\circ} \mathrm{C}\right)\end{array}$ & $\begin{array}{c}\text { Zone \#7 } \\
\left({ }^{\circ} \mathrm{C}\right)\end{array}$ & $\begin{array}{c}\text { Belt Speed } \\
(\text { in/min })\end{array}$ \\
\hline \hline 88.5 & 123.1 & 154 & 192.3 & 239 & 218.1 & 280 & 32
\end{tabular}




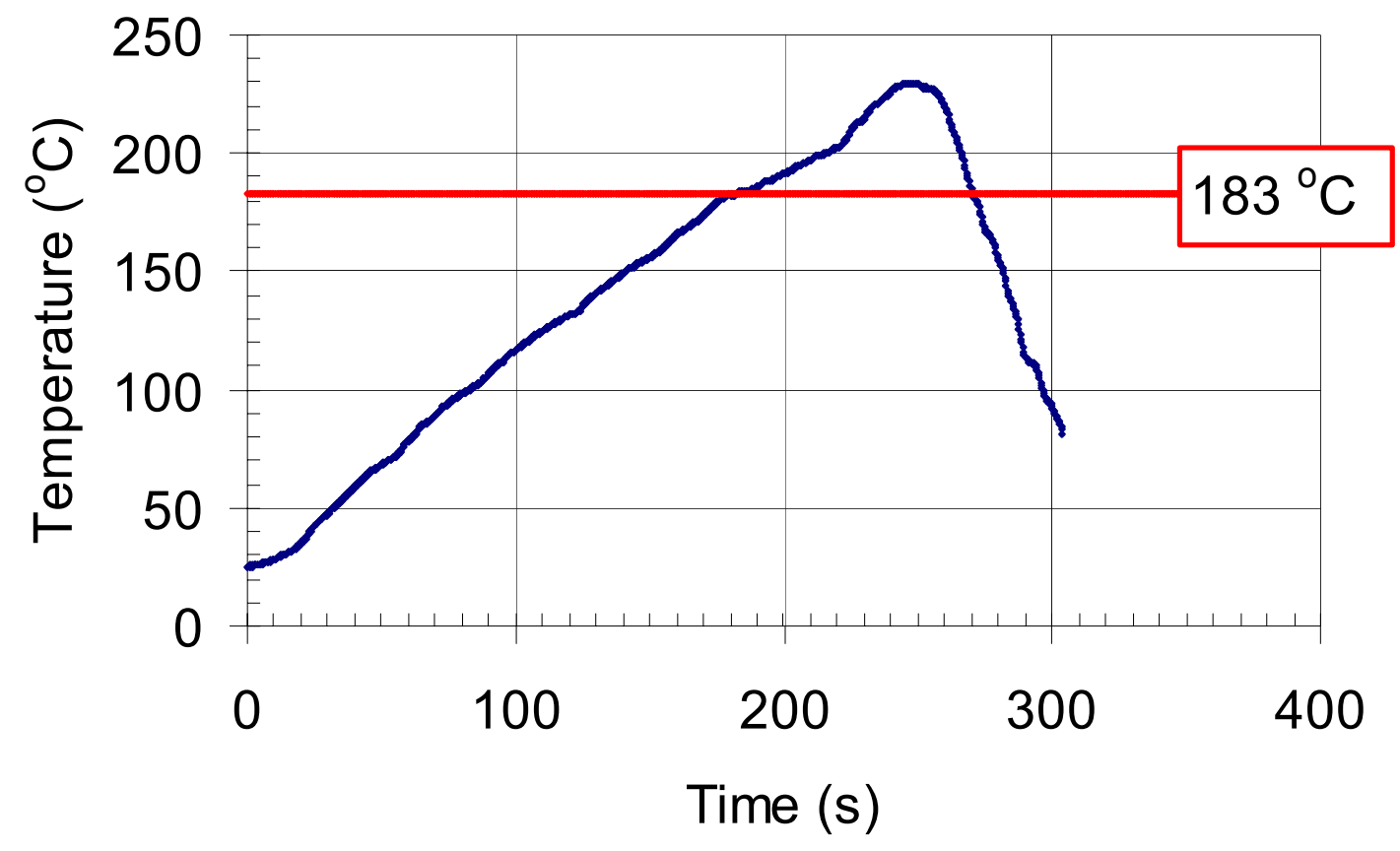

Figure A-21 Time to Peak Temperature High profile

Table A-41 Material B, reflow parameters for Time to Peak Temperature High profile

\begin{tabular}{c|c|c|c}
$\begin{array}{c}\text { Ramp Rate } \\
\left({ }^{\circ} \mathrm{C} / \mathrm{s}\right)\end{array}$ & $\begin{array}{c}\text { Time above } 183{ }^{\circ} \mathrm{C} \\
(\mathrm{s})\end{array}$ & $\begin{array}{c}\text { Peak Temperature } \\
\left({ }^{\circ} \mathrm{C}\right)\end{array}$ & $\begin{array}{c}\text { Time to Peak Temperature } \\
(\mathrm{s})\end{array}$ \\
\hline \hline 1.2 & 87.9 & 229.7 & 245.3
\end{tabular}

Table A-42 Material B, oven set points for Time to Peak Temperature High profile

\begin{tabular}{c|c|c|c|c|c|c|c}
$\begin{array}{c}\text { Zone \#1 } \\
\left({ }^{\circ} \mathrm{C}\right)\end{array}$ & $\begin{array}{c}\text { Zone \#2 } \\
\left({ }^{\circ} \mathrm{C}\right)\end{array}$ & $\begin{array}{c}\text { Zone \#3 } \\
\left({ }^{\circ} \mathrm{C}\right)\end{array}$ & $\begin{array}{c}\text { Zone \#4 } \\
\left({ }^{\circ} \mathrm{C}\right)\end{array}$ & $\begin{array}{c}\text { Zone \#5 } \\
\left({ }^{\circ} \mathrm{C}\right)\end{array}$ & $\begin{array}{c}\text { Zone \#6 } \\
\left({ }^{\circ} \mathrm{C}\right)\end{array}$ & $\begin{array}{c}\text { Zone \#7 } \\
\left({ }^{\circ} \mathrm{C}\right)\end{array}$ & $\begin{array}{c}\text { Belt Speed } \\
(\mathrm{in} / \mathrm{min})\end{array}$ \\
\hline 84.8 & 117.7 & 143.7 & 172.6 & 215.6 & 214 & 268 & 25.1
\end{tabular}




\section{Material C Reflow Profiles}

The reflow profile characterization for Material C used a step type profile as the basis for investigation. The 12 profiles used for experimentation are presented in Figures A-22 through A-33. The reflow parameters and The BTU Paragon oven setpoints that describe these profiles are presented in Tables A-43 through A-66. Replicates of 4 die were assembled for each profile, and these assemblies were analyzed for underfill voiding, resistance, and phase ratio. 


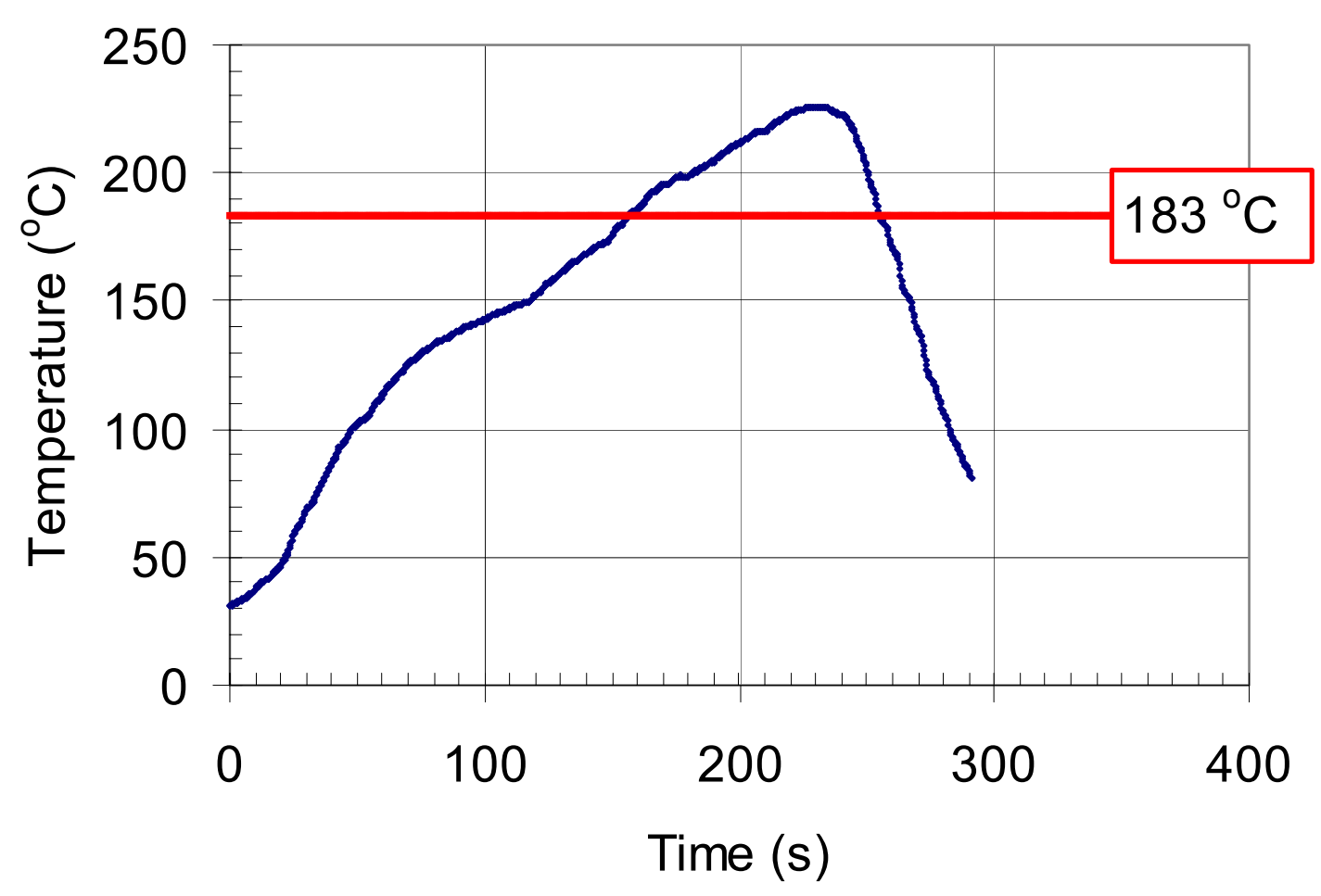

Figure A-22 Material C, Baseline profile

Table A-43 Material C, reflow parameters for Baseline profile

\begin{tabular}{c|c|c|c|c}
$\begin{array}{c}\text { Ramp Rate } \\
\left({ }^{\circ} \mathrm{C} / \mathrm{s}\right)\end{array}$ & $\begin{array}{c}\text { Soak Temp } \\
\left({ }^{\circ} \mathrm{C}\right)\end{array}$ & $\begin{array}{c}\text { Soak Time } \\
(\mathrm{s})\end{array}$ & $\begin{array}{c}\text { Time above } 183{ }^{\circ} \mathrm{C} \\
(\mathrm{s})\end{array}$ & $\begin{array}{c}\text { Peak Temp } \\
\left({ }^{\circ} \mathrm{C}\right)\end{array}$ \\
\hline \hline 2 & 140 & 42.2 & 99.2 & 226
\end{tabular}

Table A-44 Material C, oven setpoints for Baseline profile

\begin{tabular}{c|c|c|c|c|c|c|c}
$\begin{array}{c}\text { Zone \#1 } \\
\left({ }^{\circ} \mathrm{C}\right)\end{array}$ & $\begin{array}{c}\text { Zone \#2 } \\
\left({ }^{\circ} \mathrm{C}\right)\end{array}$ & $\begin{array}{c}\text { Zone \#3 } \\
\left({ }^{\circ} \mathrm{C}\right)\end{array}$ & $\begin{array}{c}\text { Zone \#4 } \\
\left({ }^{\circ} \mathrm{C}\right)\end{array}$ & $\begin{array}{c}\text { Zone \#5 } \\
\left({ }^{\circ} \mathrm{C}\right)\end{array}$ & $\begin{array}{c}\text { Zone \#6 } \\
\left({ }^{\circ} \mathrm{C}\right)\end{array}$ & $\begin{array}{c}\text { Zone \#7 } \\
\left({ }^{\circ} \mathrm{C}\right)\end{array}$ & $\begin{array}{c}\text { Belt Speed } \\
(\text { in/min })\end{array}$ \\
\hline \hline 134.1 & 155 & 155.2 & 188.4 & 234.2 & 232.7 & 247.8 & 26.5
\end{tabular}




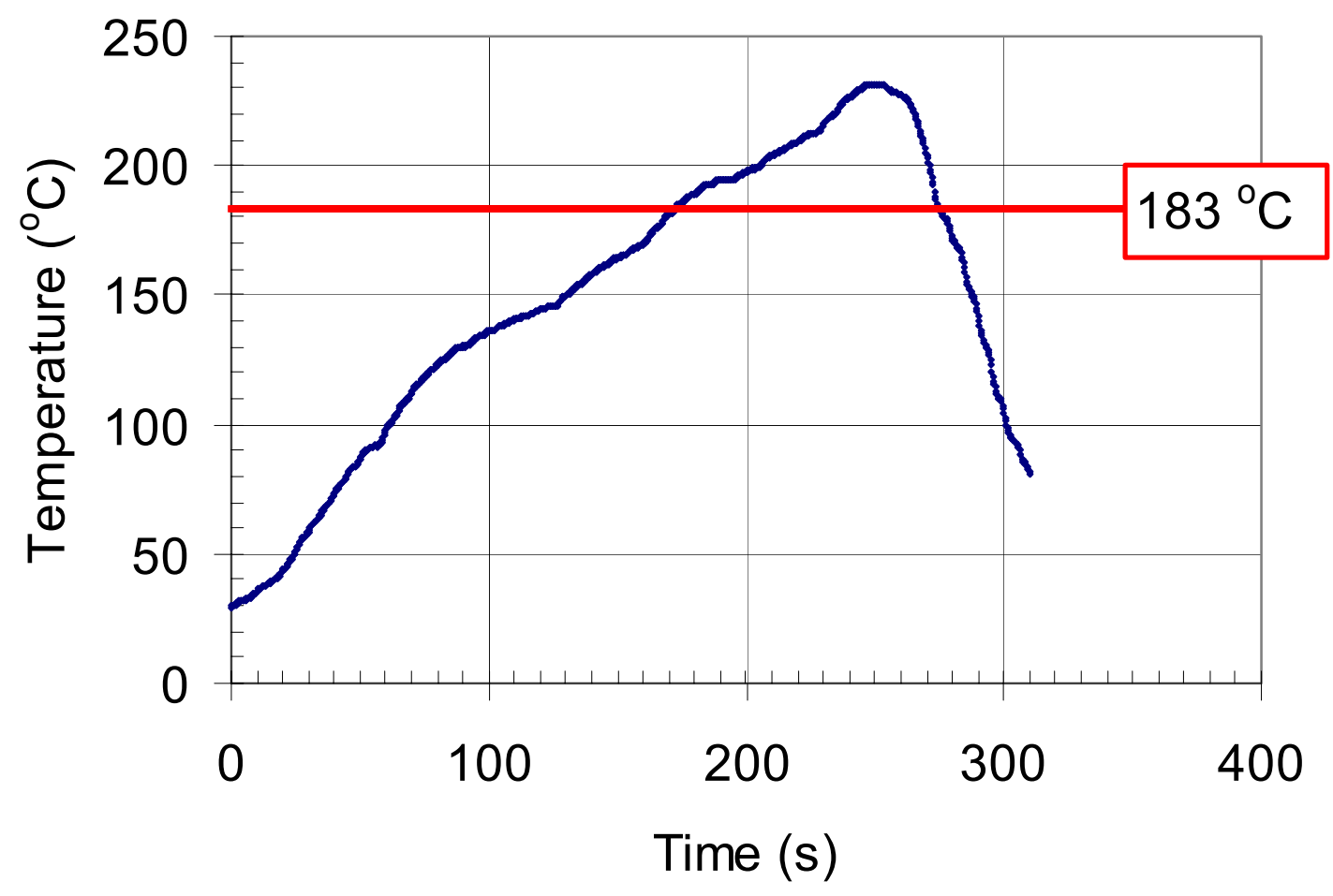

Figure A-23 Material C, Ramp Rate Low profile

Table A-45 Material C, reflow parameters for Ramp Rate Low profile

\begin{tabular}{c|c|c|c|c}
$\begin{array}{c}\text { Ramp Rate } \\
\left({ }^{\circ} \mathrm{C} / \mathrm{s}\right)\end{array}$ & $\begin{array}{c}\text { Soak Temp } \\
\left({ }^{\circ} \mathrm{C}\right)\end{array}$ & $\begin{array}{c}\text { Soak Time } \\
(\mathrm{s})\end{array}$ & $\begin{array}{c}\text { Time above } 183{ }^{\circ} \mathrm{C} \\
(\mathrm{s})\end{array}$ & $\begin{array}{c}\text { Peak Temp } \\
\left({ }^{\circ} \mathrm{C}\right)\end{array}$ \\
\hline \hline 1.5 & 140 & 41.1 & 103.3 & 231.6
\end{tabular}

Table A-46 Material C, oven set points for Ramp Rate Low profile

\begin{tabular}{c|c|c|c|c|c|c|c}
$\begin{array}{c}\text { Zone \#1 } \\
\left({ }^{\circ} \mathrm{C}\right)\end{array}$ & $\begin{array}{c}\text { Zone \#2 } \\
\left({ }^{\circ} \mathrm{C}\right)\end{array}$ & $\begin{array}{c}\text { Zone \#3 } \\
\left({ }^{\circ} \mathrm{C}\right)\end{array}$ & $\begin{array}{c}\text { Zone \#4 } \\
\left({ }^{\circ} \mathrm{C}\right)\end{array}$ & $\begin{array}{c}\text { Zone \#5 } \\
\left({ }^{\circ} \mathrm{C}\right)\end{array}$ & $\begin{array}{c}\text { Zone \#6 } \\
\left({ }^{\circ} \mathrm{C}\right)\end{array}$ & $\begin{array}{c}\text { Zone \#7 } \\
\left({ }^{\circ} \mathrm{C}\right)\end{array}$ & $\begin{array}{c}\text { Belt Speed } \\
(\mathrm{in} / \mathrm{min})\end{array}$ \\
\hline \hline 108 & 149.7 & 151.2 & 180.2 & 224.6 & 224 & 264.5 & 24.5
\end{tabular}




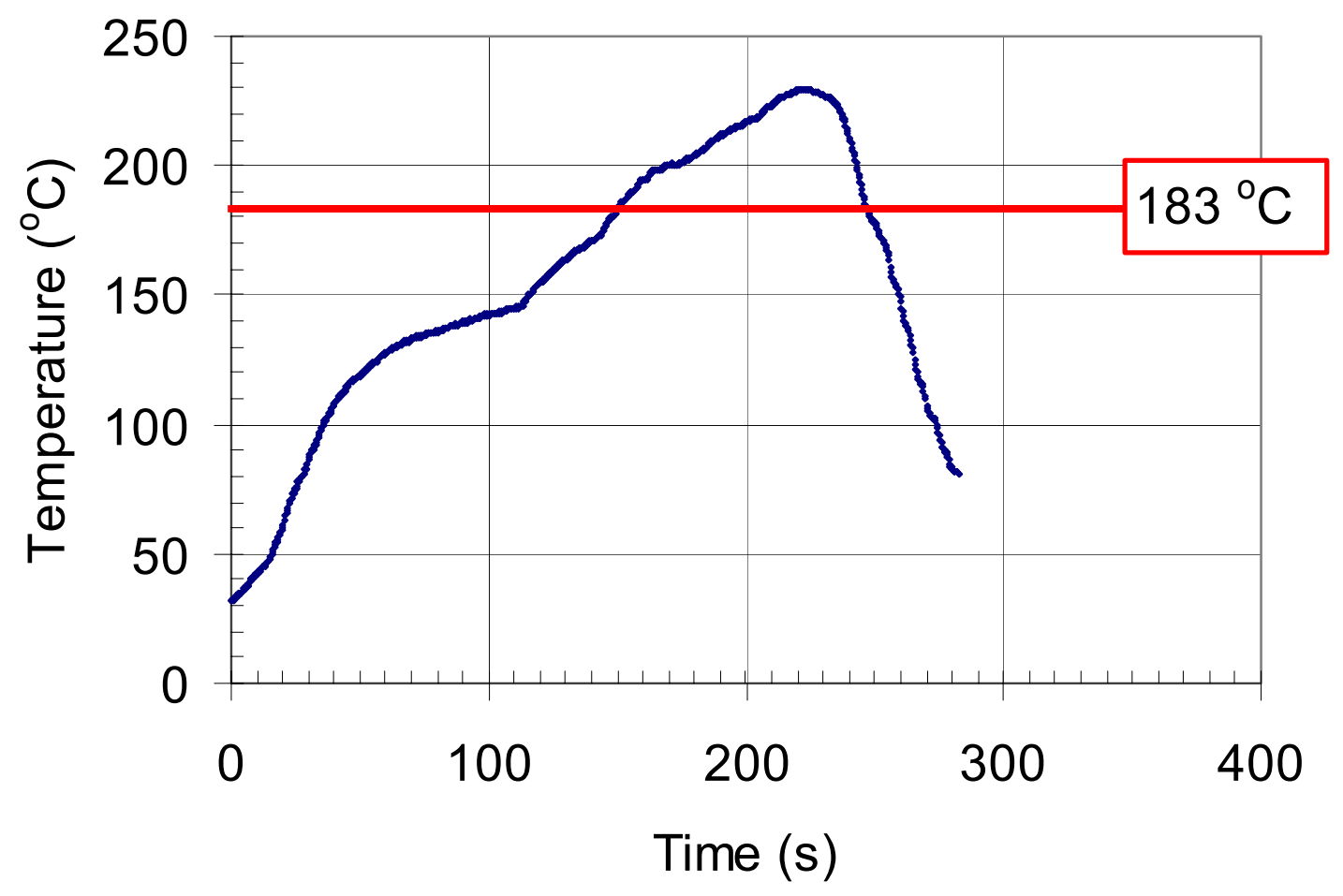

Figure A-24 Material C, Ramp Rate High profile

Table A-47 Material C, reflow parameters for Ramp Rate High profile

\begin{tabular}{c|c|c|c|c}
$\begin{array}{c}\text { Ramp Rate } \\
\left({ }^{\circ} \mathrm{C} / \mathrm{s}\right)\end{array}$ & $\begin{array}{c}\text { Soak Temp } \\
\left({ }^{\circ} \mathrm{C}\right)\end{array}$ & $\begin{array}{c}\text { Soak Time } \\
(\mathrm{s})\end{array}$ & $\begin{array}{c}\text { Time above } 183{ }^{\circ} \mathrm{C} \\
(\mathrm{s})\end{array}$ & $\begin{array}{c}\text { Peak Temp } \\
\left({ }^{\circ} \mathrm{C}\right)\end{array}$ \\
\hline \hline 2.5 & 140 & 51.5 & 97 & 229.6
\end{tabular}

Table A-48 Material C, oven set points for Ramp Rate High profile

\begin{tabular}{c|c|c|c|c|c|c|c}
$\begin{array}{c}\text { Zone \#1 } \\
\left({ }^{\circ} \mathrm{C}\right)\end{array}$ & $\begin{array}{c}\text { Zone \#2 } \\
\left({ }^{\circ} \mathrm{C}\right)\end{array}$ & $\begin{array}{c}\text { Zone \#3 } \\
\left({ }^{\circ} \mathrm{C}\right)\end{array}$ & $\begin{array}{c}\text { Zone \#4 } \\
\left({ }^{\circ} \mathrm{C}\right)\end{array}$ & $\begin{array}{c}\text { Zone \#5 } \\
\left({ }^{\circ} \mathrm{C}\right)\end{array}$ & $\begin{array}{c}\text { Zone \#6 } \\
\left({ }^{\circ} \mathrm{C}\right)\end{array}$ & $\begin{array}{c}\text { Zone \#7 } \\
\left({ }^{\circ} \mathrm{C}\right)\end{array}$ & $\begin{array}{c}\text { Belt Speed } \\
(\text { in/min })\end{array}$ \\
\hline \hline 157.7 & 145.2 & 145.9 & 189.8 & 235.2 & 234.4 & 253.9 & 27.2
\end{tabular}




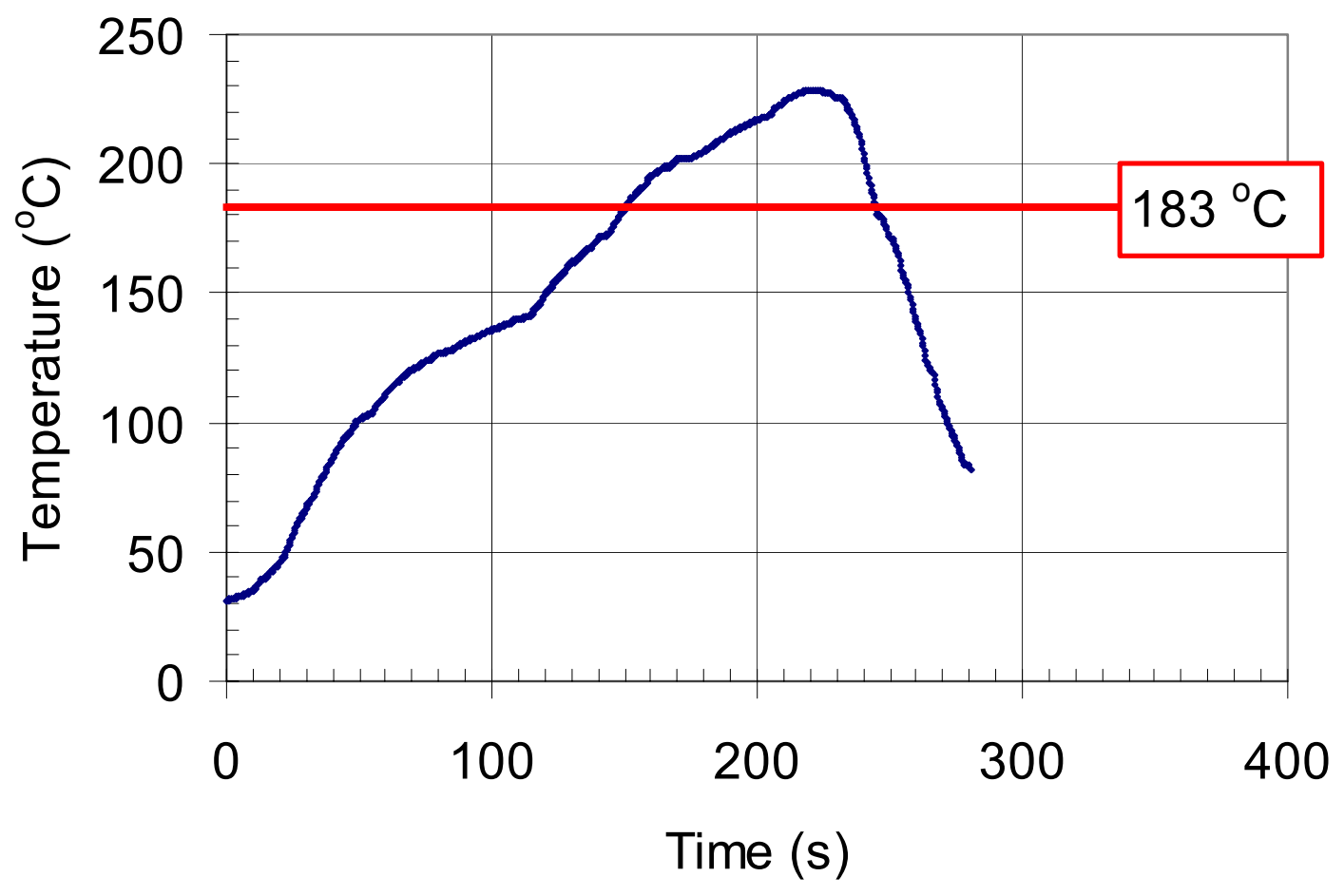

Figure A-25 Material C, Soak Temperature Low profile

Table A-49 Material C, reflow parameters for Soak Temperature Low profile

\begin{tabular}{c|c|c|c|c}
$\begin{array}{c}\text { Ramp Rate } \\
\left({ }^{\circ} \mathrm{C} / \mathrm{s}\right)\end{array}$ & $\begin{array}{c}\text { Soak Temp } \\
\left({ }^{\circ} \mathrm{C}\right)\end{array}$ & $\begin{array}{c}\text { Soak Time } \\
(\mathrm{s})\end{array}$ & $\begin{array}{c}\text { Time above } 183{ }^{\circ} \mathrm{C} \\
(\mathrm{s})\end{array}$ & $\begin{array}{c}\text { Peak Temp } \\
\left({ }^{\circ} \mathrm{C}\right)\end{array}$ \\
\hline \hline 2 & 140 & 41.3 & 94.6 & 228.8
\end{tabular}

Table A-50 Material C, oven setpoints for Soak Temperature Low profile \begin{tabular}{c|c|c|c|c|c|c|c}
$\begin{array}{c}\text { Zone \#1 } \\
\left({ }^{\circ} \mathrm{C}\right)\end{array}$ & $\begin{array}{c}\text { Zone \#2 } \\
\left({ }^{\circ} \mathrm{C}\right)\end{array}$ & $\begin{array}{c}\text { Zone \#3 } \\
\left({ }^{\circ} \mathrm{C}\right)\end{array}$ & $\begin{array}{c}\text { Zone \#4 } \\
\left({ }^{\circ} \mathrm{C}\right)\end{array}$ & $\begin{array}{c}\text { Zone \#5 } \\
\left({ }^{\circ} \mathrm{C}\right)\end{array}$ & $\begin{array}{c}\text { Zone \#6 } \\
\left({ }^{\circ} \mathrm{C}\right)\end{array}$ & $\begin{array}{c}\text { Zone \#7 } \\
\left({ }^{\circ} \mathrm{C}\right)\end{array}$ & $\begin{array}{c}\text { Belt Speed } \\
(\text { in/min })\end{array}$ \\
\hline \hline 134 & 141.2 & 142.1 & 194 & 240.1 & 234 & 252.6 & 27.9
\end{tabular} 


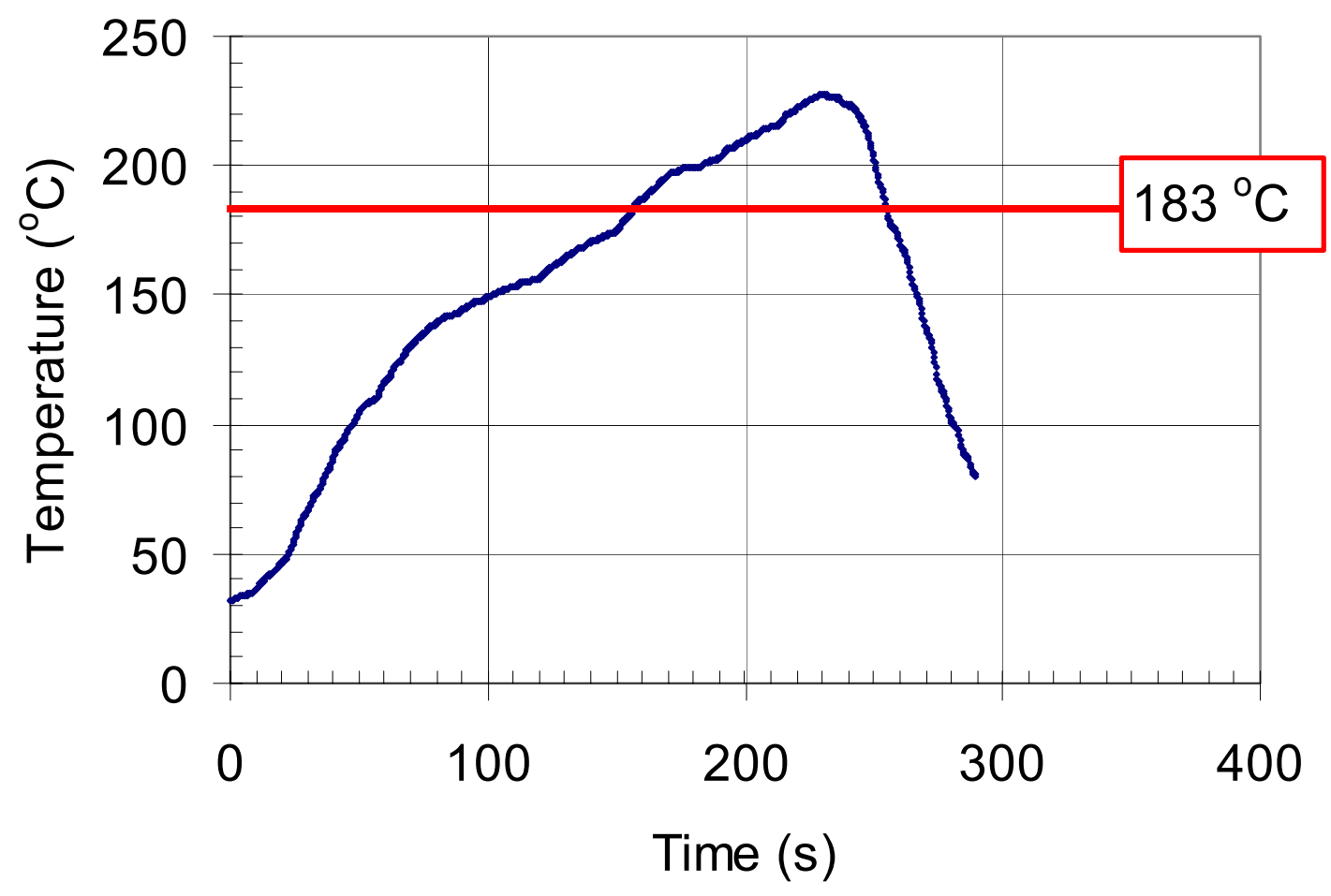

Figure A-26 Material C, Soak Temperature High profile

Table A-51 Material C, reflow parameters for Soak Temperature High profile

\begin{tabular}{c|c|c|c|c}
$\begin{array}{c}\text { Ramp Rate } \\
\left({ }^{\circ} \mathrm{C} / \mathrm{s}\right)\end{array}$ & $\begin{array}{c}\text { Soak Temp } \\
\left({ }^{\circ} \mathrm{C}\right)\end{array}$ & $\begin{array}{c}\text { Soak Time } \\
(\mathrm{s})\end{array}$ & $\begin{array}{c}\text { Time above } 183{ }^{\circ} \mathrm{C} \\
(\mathrm{s})\end{array}$ & $\begin{array}{c}\text { Peak Temp } \\
\left({ }^{\circ} \mathrm{C}\right)\end{array}$ \\
\hline \hline 2.1 & 140 & 43 & 98.4 & 227.3
\end{tabular}

Table A-52 Material C, oven set points for Soak Temperature High profile

\begin{tabular}{c|c|c|c|c|c|c|c}
$\begin{array}{c}\text { Zone \#1 } \\
\left({ }^{\circ} \mathrm{C}\right)\end{array}$ & $\begin{array}{c}\text { Zone \#2 } \\
\left({ }^{\circ} \mathrm{C}\right)\end{array}$ & $\begin{array}{c}\text { Zone \#3 } \\
\left({ }^{\circ} \mathrm{C}\right)\end{array}$ & $\begin{array}{c}\text { Zone \#4 } \\
\left({ }^{\circ} \mathrm{C}\right)\end{array}$ & $\begin{array}{c}\text { Zone \#5 } \\
\left({ }^{\circ} \mathrm{C}\right)\end{array}$ & $\begin{array}{c}\text { Zone \#6 } \\
\left({ }^{\circ} \mathrm{C}\right)\end{array}$ & $\begin{array}{c}\text { Zone \#7 } \\
\left({ }^{\circ} \mathrm{C}\right)\end{array}$ & $\begin{array}{c}\text { Belt Speed } \\
(\mathrm{in} / \mathrm{min})\end{array}$ \\
\hline \hline 137.9 & 161.5 & 161.7 & 185.7 & 230.3 & 229.5 & 251.9 & 26.8
\end{tabular}




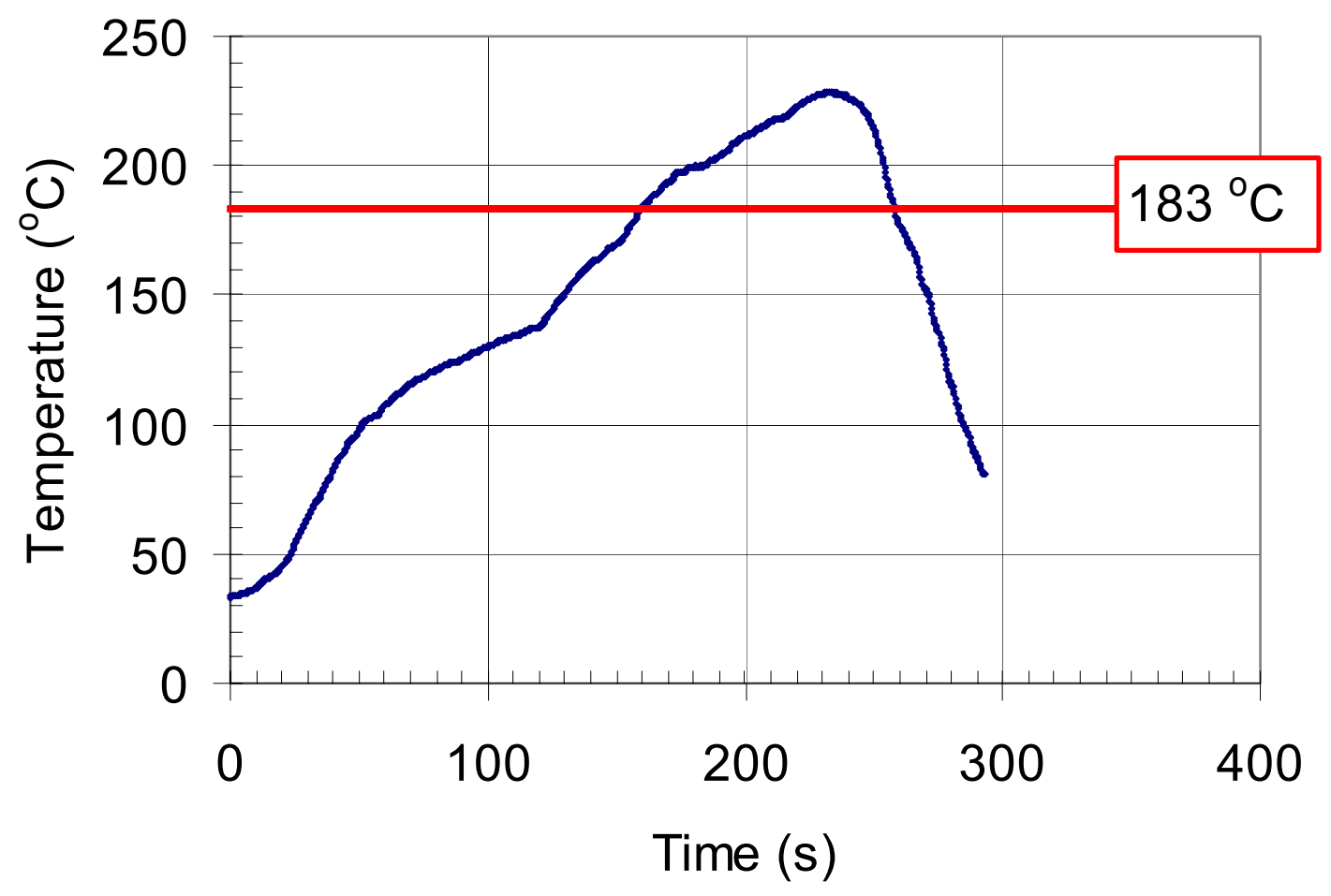

Figure A-27 Material C, Soak Time Low profile

Table A-53 Material C, reflow parameters for Soak Time Low profile

\begin{tabular}{c|c|c|c|c}
$\begin{array}{c}\text { Ramp Rate } \\
\left({ }^{\circ} \mathrm{C} / \mathrm{s}\right)\end{array}$ & $\begin{array}{c}\text { Soak Temp } \\
\left({ }^{\circ} \mathrm{C}\right)\end{array}$ & $\begin{array}{c}\text { Soak Time } \\
(\mathrm{s})\end{array}$ & $\begin{array}{c}\text { Time above } 183{ }^{\circ} \mathrm{C} \\
(\mathrm{s})\end{array}$ & $\begin{array}{c}\text { Peak Temp } \\
\left({ }^{\circ} \mathrm{C}\right)\end{array}$ \\
\hline \hline 2 & 140 & 29.1 & 98.7 & 228.4
\end{tabular}

Table A-54 Material C, oven set points for Soak Time Low profile

\begin{tabular}{c|c|c|c|c|c|c|c}
$\begin{array}{c}\text { Zone \#1 } \\
\left({ }^{\circ} \mathrm{C}\right)\end{array}$ & $\begin{array}{c}\text { Zone \#2 } \\
\left({ }^{\circ} \mathrm{C}\right)\end{array}$ & $\begin{array}{c}\text { Zone \#3 } \\
\left({ }^{\circ} \mathrm{C}\right)\end{array}$ & $\begin{array}{c}\text { Zone \#4 } \\
\left({ }^{\circ} \mathrm{C}\right)\end{array}$ & $\begin{array}{c}\text { Zone \#5 } \\
\left({ }^{\circ} \mathrm{C}\right)\end{array}$ & $\begin{array}{c}\text { Zone \#6 } \\
\left({ }^{\circ} \mathrm{C}\right)\end{array}$ & $\begin{array}{c}\text { Zone \#7 } \\
\left({ }^{\circ} \mathrm{C}\right)\end{array}$ & $\begin{array}{c}\text { Belt Speed } \\
(\mathrm{in} / \mathrm{min})\end{array}$ \\
\hline \hline 131 & 134 & 141 & 190.3 & 236.3 & 235.2 & 249.3 & 26.4
\end{tabular}




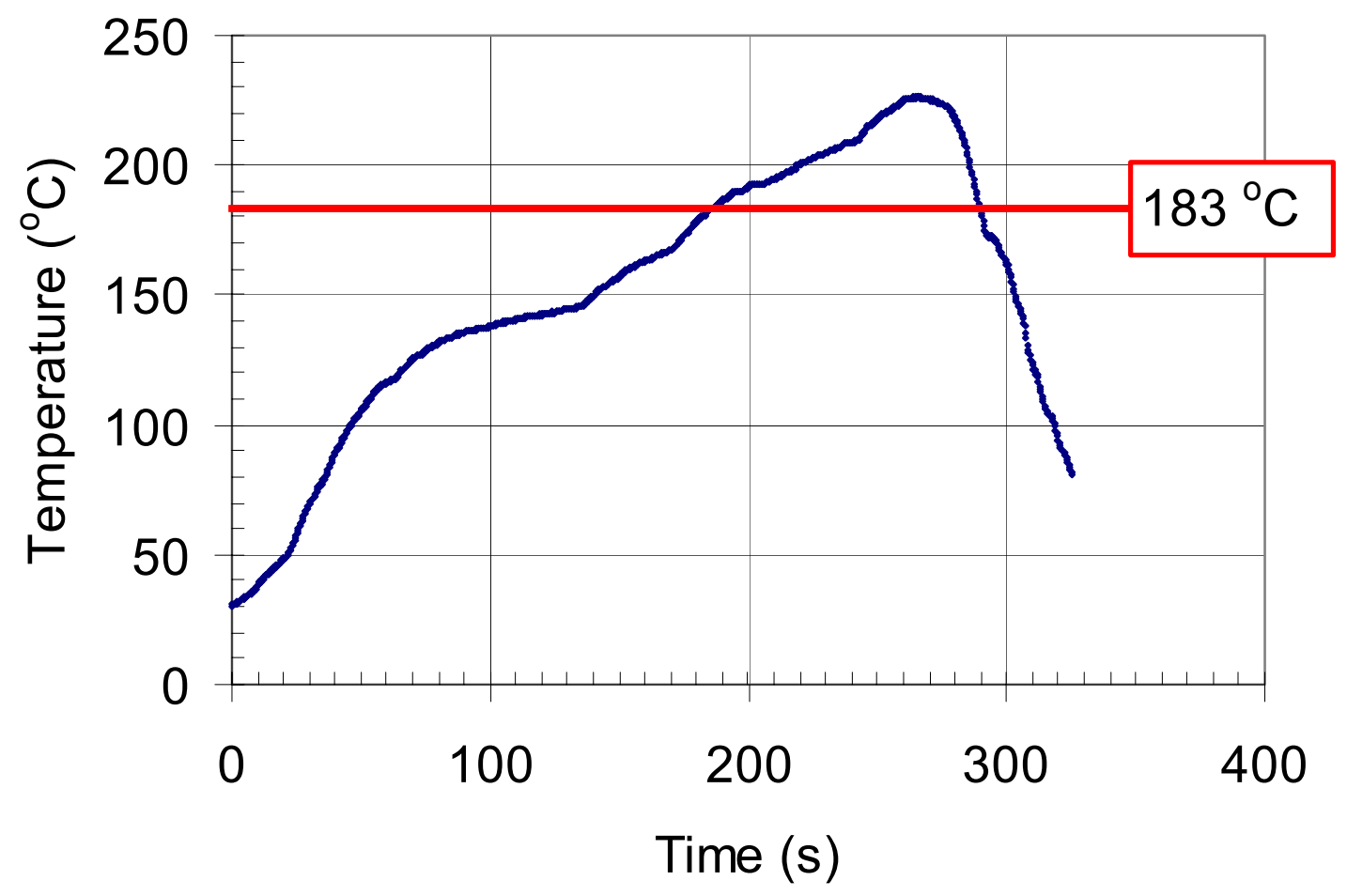

Figure A-28 Material C, Soak Time High profile

Table A-55 Material C, reflow parameters for Soak Time High profile

\begin{tabular}{c|c|c|c|c}
$\begin{array}{c}\text { Ramp Rate } \\
\left({ }^{\circ} \mathrm{C} / \mathrm{s}\right)\end{array}$ & $\begin{array}{c}\text { Soak Temp } \\
\left({ }^{\circ} \mathrm{C}\right)\end{array}$ & $\begin{array}{c}\text { Soak Time } \\
(\mathrm{s})\end{array}$ & $\begin{array}{c}\text { Time above } 183{ }^{\circ} \mathrm{C} \\
(\mathrm{s})\end{array}$ & $\begin{array}{c}\text { Peak Temp } \\
\left({ }^{\circ} \mathrm{C}\right)\end{array}$ \\
\hline \hline 2.1 & 140 & 63.2 & 104.7 & 226.2
\end{tabular}

Table A-56 Material C, oven set points for Soak Time High profile

\begin{tabular}{c|c|c|c|c|c|c|c}
$\begin{array}{c}\text { Zone \#1 } \\
\left({ }^{\circ} \mathrm{C}\right)\end{array}$ & $\begin{array}{c}\text { Zone \#2 } \\
\left({ }^{\circ} \mathrm{C}\right)\end{array}$ & $\begin{array}{c}\text { Zone \#3 } \\
\left({ }^{\circ} \mathrm{C}\right)\end{array}$ & $\begin{array}{c}\text { Zone \#4 } \\
\left({ }^{\circ} \mathrm{C}\right)\end{array}$ & $\begin{array}{c}\text { Zone \#5 } \\
\left({ }^{\circ} \mathrm{C}\right)\end{array}$ & $\begin{array}{c}\text { Zone \#6 } \\
\left({ }^{\circ} \mathrm{C}\right)\end{array}$ & $\begin{array}{c}\text { Zone \#7 } \\
\left({ }^{\circ} \mathrm{C}\right)\end{array}$ & $\begin{array}{c}\text { Belt Speed } \\
(\text { in/min })\end{array}$ \\
\hline \hline 144.9 & 146.1 & 146.5 & 177.8 & 221.1 & 220 & 253.6 & 23.2
\end{tabular}




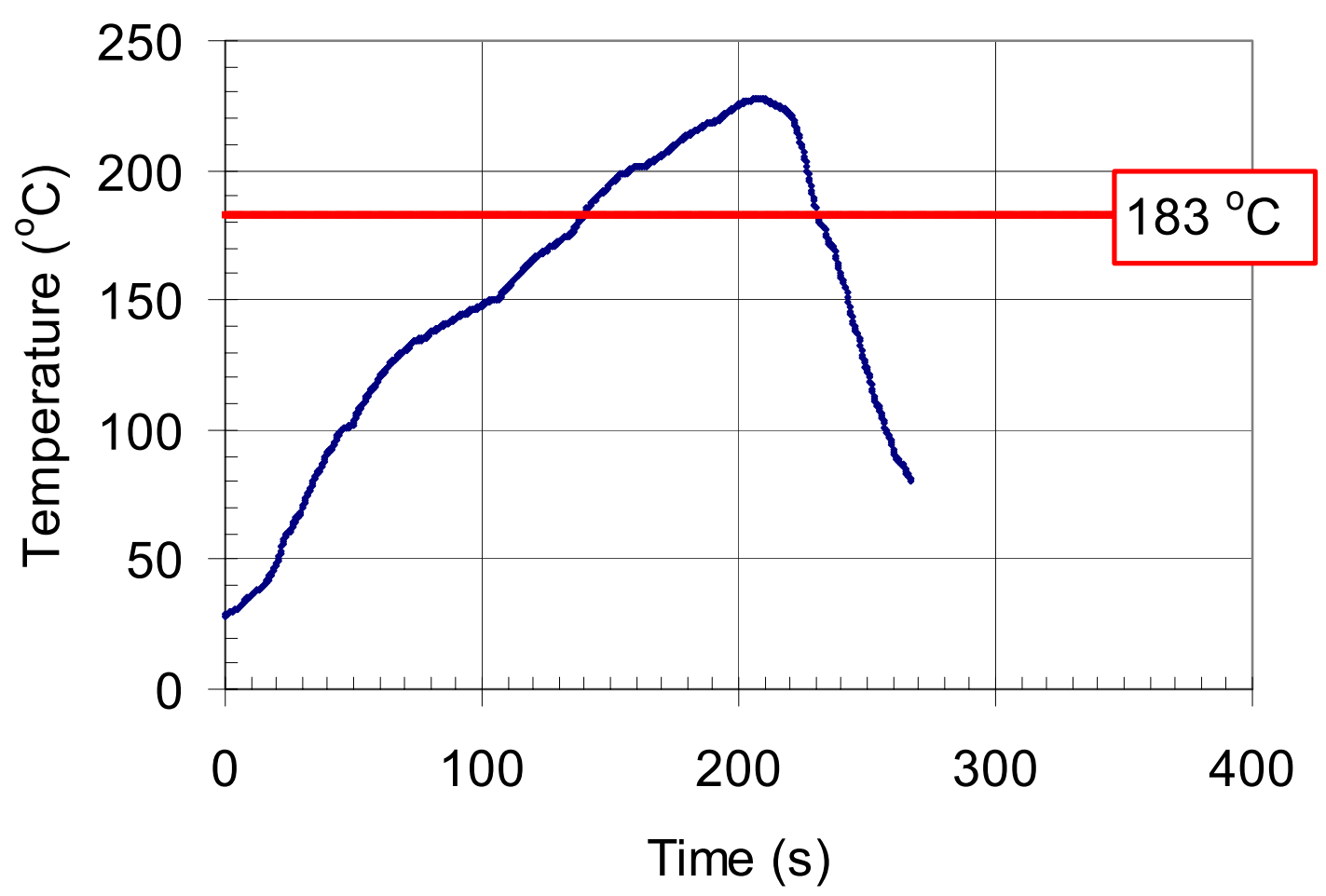

Figure A-29 Material C, Time Above $183^{\circ} \mathrm{C}$ Low profile

Table A-57 Material C, reflow parameters for Time Above $183^{\circ} \mathrm{C}$ Low profile \begin{tabular}{c|c|c|c|c}
$\begin{array}{c}\text { Ramp Rate } \\
\left({ }^{\circ} \mathrm{C} / \mathrm{s}\right)\end{array}$ & $\begin{array}{c}\text { Soak Temp } \\
\left({ }^{\circ} \mathrm{C}\right)\end{array}$ & $\begin{array}{c}\text { Soak Time } \\
(\mathrm{s})\end{array}$ & $\begin{array}{c}\text { Time above } 183^{\circ} \mathrm{C} \\
(\mathrm{s})\end{array}$ & $\begin{array}{c}\text { Peak Temp } \\
\left({ }^{\circ} \mathrm{C}\right)\end{array}$ \\
\hline \hline 2.2 & 140 & 35.6 & 90.5 & 228
\end{tabular}

Table A-58 Material C, oven set points for Time Above $183^{\circ} \mathrm{C}$ Low profile \begin{tabular}{c|c|c|c|c|c|c|c}
$\begin{array}{c}\text { Zone \#1 } \\
\left({ }^{\circ} \mathrm{C}\right)\end{array}$ & $\begin{array}{c}\text { Zone \#2 } \\
\left({ }^{\circ} \mathrm{C}\right)\end{array}$ & $\begin{array}{c}\text { Zone \#3 } \\
\left({ }^{\circ} \mathrm{C}\right)\end{array}$ & $\begin{array}{c}\text { Zone \#4 } \\
\left({ }^{\circ} \mathrm{C}\right)\end{array}$ & $\begin{array}{c}\text { Zone \#5 } \\
\left({ }^{\circ} \mathrm{C}\right)\end{array}$ & $\begin{array}{c}\text { Zone \#6 } \\
\left({ }^{\circ} \mathrm{C}\right)\end{array}$ & $\begin{array}{c}\text { Zone \#7 } \\
\left({ }^{\circ} \mathrm{C}\right)\end{array}$ & $\begin{array}{c}\text { Belt Speed } \\
(\text { in/min })\end{array}$ \\
\hline \hline 130.7 & 155.7 & 156.1 & 191.1 & 237.1 & 235.7 & 247.7 & 29.5
\end{tabular} 


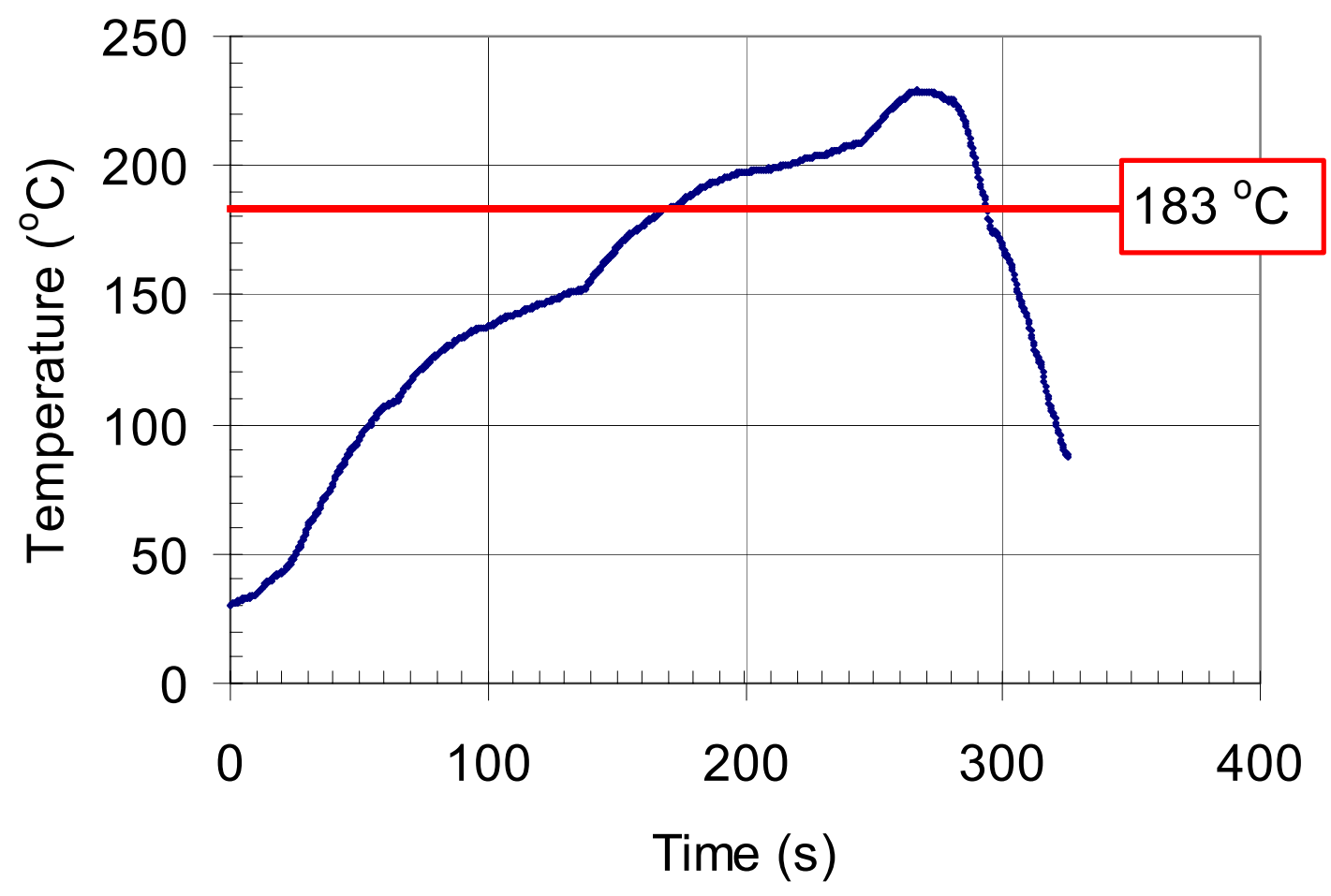

Figure A-30 Material C, Time Above $183^{\circ} \mathrm{C}$ High profile

Table A-59 Material C, reflow parameters for Time Above $183^{\circ} \mathrm{C}$ High profile

\begin{tabular}{c|c|c|c|c}
$\begin{array}{c}\text { Ramp Rate } \\
\left({ }^{\circ} \mathrm{C} / \mathrm{s}\right)\end{array}$ & $\begin{array}{c}\text { Soak Temp } \\
\left({ }^{\circ} \mathrm{C}\right)\end{array}$ & $\begin{array}{c}\text { Soak Time } \\
(\mathrm{s})\end{array}$ & $\begin{array}{c}\text { Time above } 183^{\circ} \mathrm{C} \\
(\mathrm{s})\end{array}$ & $\begin{array}{c}\text { Peak Temp } \\
\left({ }^{\circ} \mathrm{C}\right)\end{array}$ \\
\hline \hline 1.9 & 140 & 45.3 & 125.6 & 229
\end{tabular}

Table A-60 Material C, oven set points for Time Above $183^{\circ} \mathrm{C}$ High profile

\begin{tabular}{c|c|c|c|c|c|c|c}
$\begin{array}{c}\text { Zone \#1 } \\
\left({ }^{\circ} \mathrm{C}\right)\end{array}$ & $\begin{array}{c}\text { Zone \#2 } \\
\left({ }^{\circ} \mathrm{C}\right)\end{array}$ & $\begin{array}{c}\text { Zone \#3 } \\
\left({ }^{\circ} \mathrm{C}\right)\end{array}$ & $\begin{array}{c}\text { Zone \#4 } \\
\left({ }^{\circ} \mathrm{C}\right)\end{array}$ & $\begin{array}{c}\text { Zone \#5 } \\
\left({ }^{\circ} \mathrm{C}\right)\end{array}$ & $\begin{array}{c}\text { Zone \#6 } \\
\left({ }^{\circ} \mathrm{C}\right)\end{array}$ & $\begin{array}{c}\text { Zone \#7 } \\
\left({ }^{\circ} \mathrm{C}\right)\end{array}$ & $\begin{array}{c}\text { Belt Speed } \\
(\mathrm{in} / \mathrm{min})\end{array}$ \\
\hline \hline 129.3 & 150.3 & 154.6 & 202.4 & 213.7 & 212.7 & 261.3 & 23.2
\end{tabular}




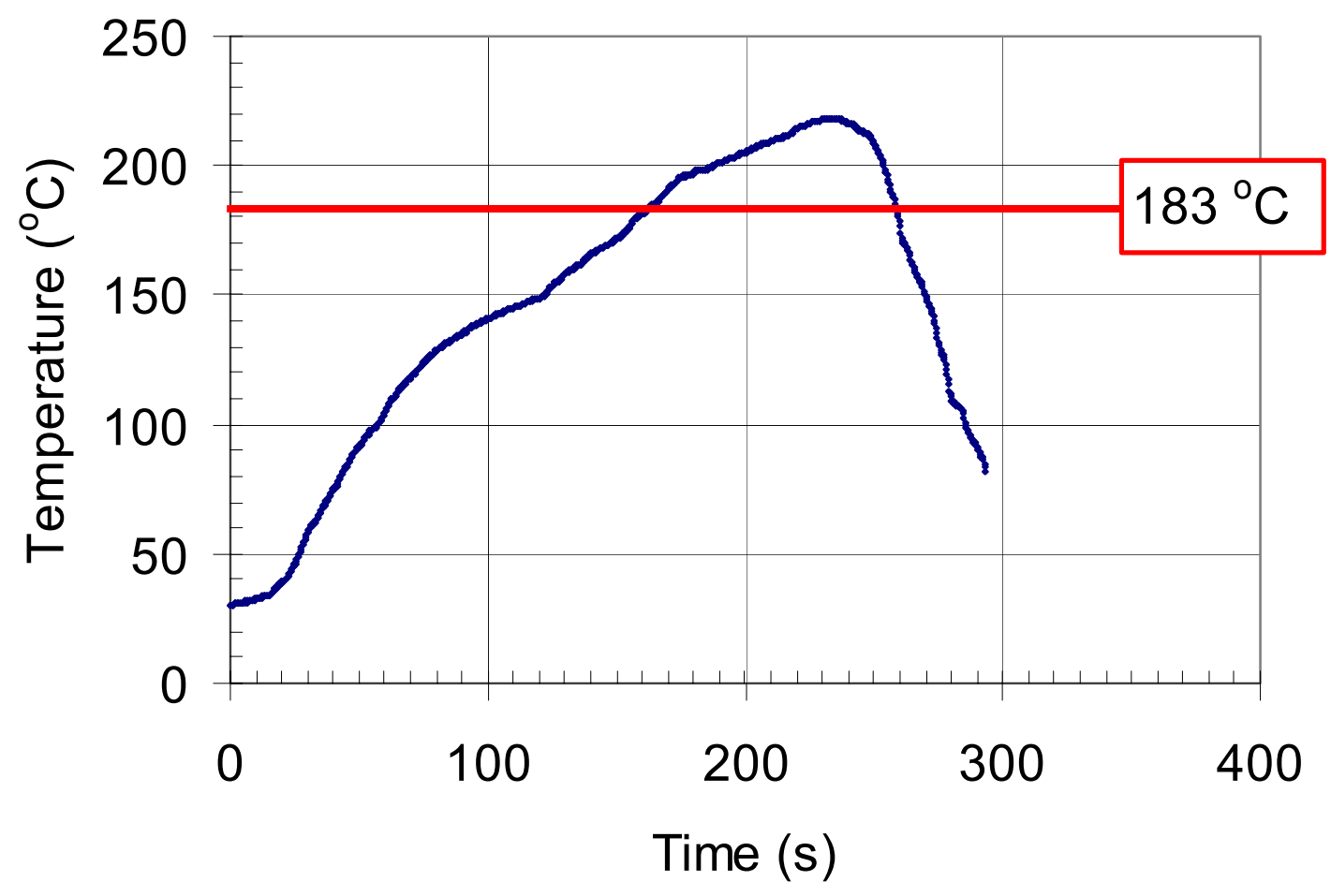

Figure A-31 Material C, Peak Temperature Low profile

Table A-61 Material C, reflow parameters for Peak Temperature Low profile

\begin{tabular}{c|c|c|c|c}
$\begin{array}{c}\text { Ramp Rate } \\
\left({ }^{\circ} \mathrm{C} / \mathrm{s}\right)\end{array}$ & $\begin{array}{c}\text { Soak Temp } \\
\left({ }^{\circ} \mathrm{C}\right)\end{array}$ & $\begin{array}{c}\text { Soak Time } \\
(\mathrm{s})\end{array}$ & $\begin{array}{c}\text { Time above } 183{ }^{\circ} \mathrm{C} \\
(\mathrm{s})\end{array}$ & $\begin{array}{c}\text { Peak Temp } \\
\left({ }^{\circ} \mathrm{C}\right)\end{array}$ \\
\hline \hline 1.9 & 140 & 40.6 & 96.5 & 218.1
\end{tabular}

Table A-62 Material C, oven set points for Peak Temperature Low profile

\begin{tabular}{c|c|c|c|c|r|r|r}
$\begin{array}{c}\text { Zone \#1 } \\
\left({ }^{\circ} \mathrm{C}\right)\end{array}$ & $\begin{array}{c}\text { Zone \#2 } \\
\left({ }^{\circ} \mathrm{C}\right)\end{array}$ & $\begin{array}{c}\text { Zone \#3 } \\
\left({ }^{\circ} \mathrm{C}\right)\end{array}$ & $\begin{array}{c}\text { Zone \#4 } \\
\left({ }^{\circ} \mathrm{C}\right)\end{array}$ & $\begin{array}{c}\text { Zone \#5 } \\
\left({ }^{\circ} \mathrm{C}\right)\end{array}$ & $\begin{array}{c}\text { Zone \#6 } \\
\left({ }^{\circ} \mathrm{C}\right)\end{array}$ & $\begin{array}{c}\text { Zone \#7 } \\
\left({ }^{\circ} \mathrm{C}\right)\end{array}$ & $\begin{array}{c}\text { Belt Speed } \\
(\text { in/min })\end{array}$ \\
\hline \hline 128 & 154 & 155 & 187 & 233 & 224 & 237 & 26.5
\end{tabular}




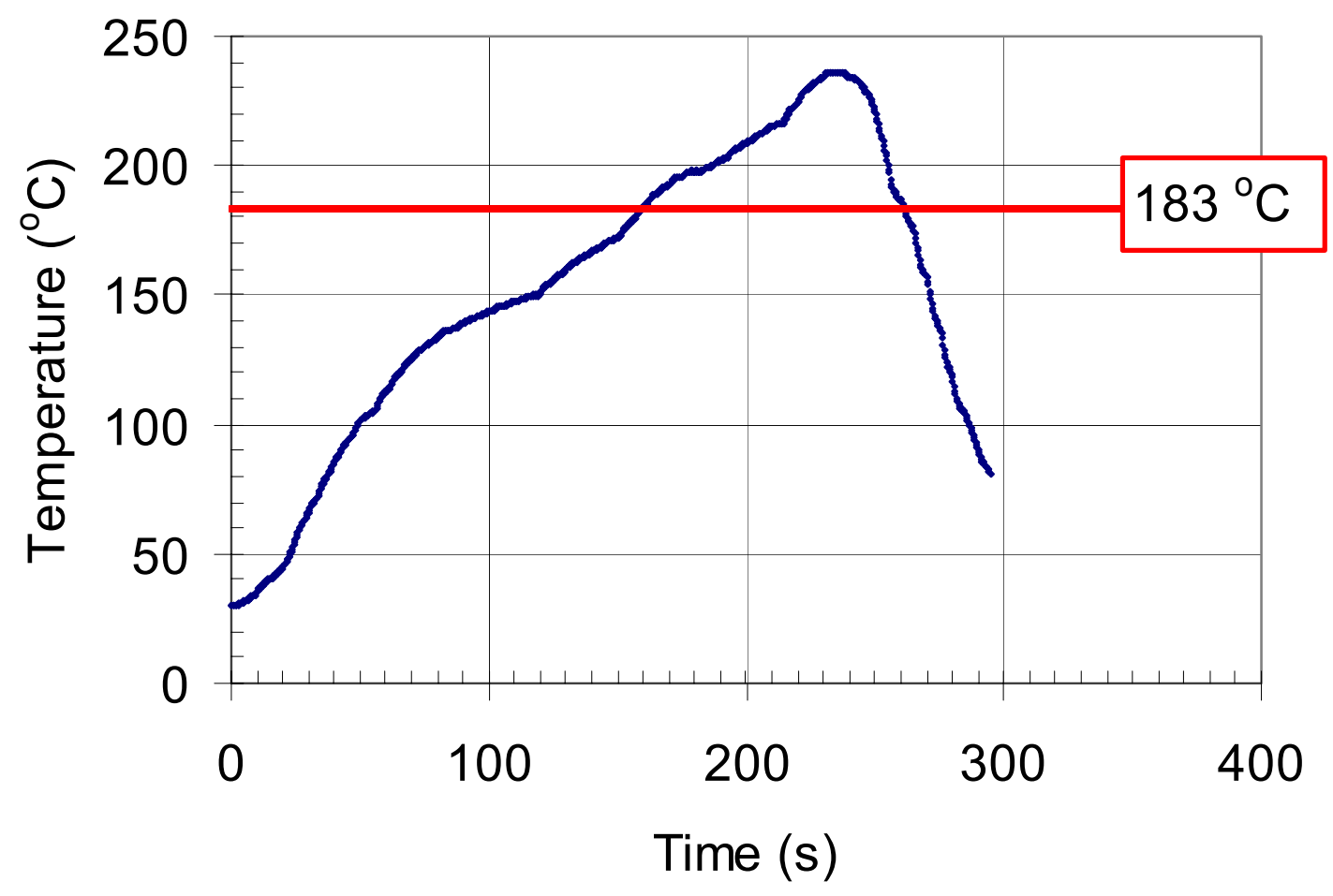

Figure A-32 Material C, Peak Temperature High profile

Table A-63 Material C, reflow parameters for Peak Temperature High profile

\begin{tabular}{c|c|c|c|c}
$\begin{array}{c}\text { Ramp Rate } \\
\left({ }^{\circ} \mathrm{C} / \mathrm{s}\right)\end{array}$ & $\begin{array}{c}\text { Soak Temp } \\
\left({ }^{\circ} \mathrm{C}\right)\end{array}$ & $\begin{array}{c}\text { Soak Time } \\
(\mathrm{s})\end{array}$ & $\begin{array}{c}\text { Time above } 183{ }^{\circ} \mathrm{C} \\
(\mathrm{s})\end{array}$ & $\begin{array}{c}\text { Peak Temp } \\
\left({ }^{\circ} \mathrm{C}\right)\end{array}$ \\
\hline \hline 2 & 140 & 43.6 & 102.4 & 236
\end{tabular}

Table A-64 Material C, oven set points for Peak Temperature High profile

\begin{tabular}{c|c|c|c|c|c|c|c}
$\begin{array}{c}\text { Zone \#1 } \\
\left({ }^{\circ} \mathrm{C}\right)\end{array}$ & $\begin{array}{c}\text { Zone \#2 } \\
\left({ }^{\circ} \mathrm{C}\right)\end{array}$ & $\begin{array}{c}\text { Zone \#3 } \\
\left({ }^{\circ} \mathrm{C}\right)\end{array}$ & $\begin{array}{c}\text { Zone \#4 } \\
\left({ }^{\circ} \mathrm{C}\right)\end{array}$ & $\begin{array}{c}\text { Zone \#5 } \\
\left({ }^{\circ} \mathrm{C}\right)\end{array}$ & $\begin{array}{c}\text { Zone \#6 } \\
\left({ }^{\circ} \mathrm{C}\right)\end{array}$ & $\begin{array}{c}\text { Zone \#7 } \\
\left({ }^{\circ} \mathrm{C}\right)\end{array}$ & $\begin{array}{c}\text { Belt Speed } \\
(\text { in/min })\end{array}$ \\
\hline \hline 130.8 & 155.2 & 155.4 & 185 & 230.1 & 229.2 & 273.3 & 26.4
\end{tabular}




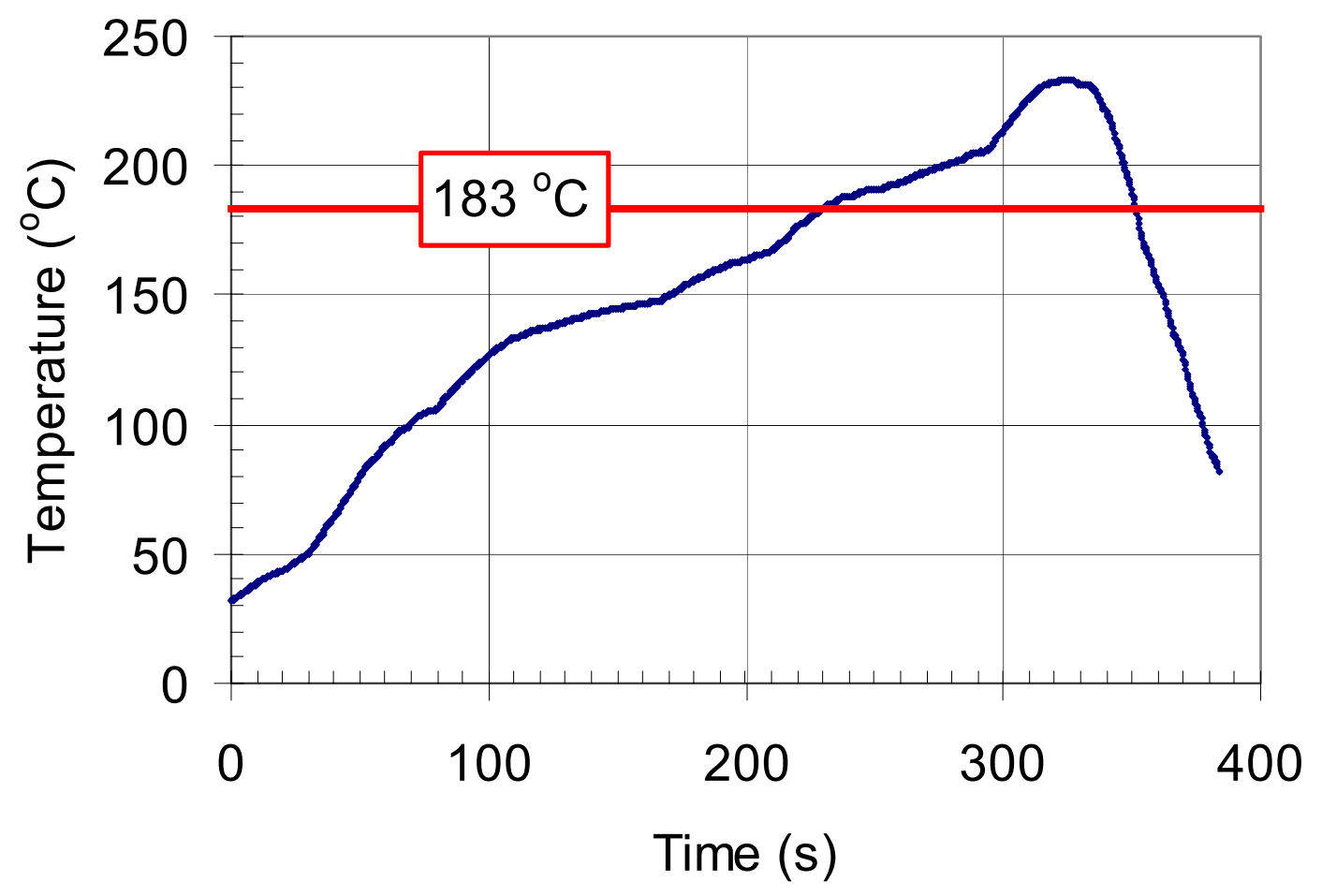

Figure A-33 Material C, Parametric Optimized profile

Table A-65 Material C, reflow parameters for Parametric Optimized profile

\begin{tabular}{c|c|c|c|c}
$\begin{array}{c}\text { Ramp Rate } \\
\left({ }^{\circ} \mathrm{C} / \mathrm{s}\right)\end{array}$ & $\begin{array}{c}\text { Soak Temp } \\
\left({ }^{\circ} \mathrm{C}\right)\end{array}$ & $\begin{array}{c}\text { Soak Time } \\
(\mathrm{s})\end{array}$ & $\begin{array}{c}\text { Time above } 183{ }^{\circ} \mathrm{C} \\
(\mathrm{s})\end{array}$ & $\begin{array}{c}\text { Peak Temp } \\
\left({ }^{\circ} \mathrm{C}\right)\end{array}$ \\
\hline \hline 1.5 & 140 & 55.7 & 122.3 & 233.2
\end{tabular}

Table A-66 Material C, oven set points for Parametric Optimized profile

\begin{tabular}{c|c|c|c|c|c|c|c}
$\begin{array}{c}\text { Zone \#1 } \\
\left({ }^{\circ} \mathrm{C}\right)\end{array}$ & $\begin{array}{c}\text { Zone \#2 } \\
\left({ }^{\circ} \mathrm{C}\right)\end{array}$ & $\begin{array}{c}\text { Zone \#3 } \\
\left({ }^{\circ} \mathrm{C}\right)\end{array}$ & $\begin{array}{c}\text { Zone \#4 } \\
\left({ }^{\circ} \mathrm{C}\right)\end{array}$ & $\begin{array}{c}\text { Zone \#5 } \\
\left({ }^{\circ} \mathrm{C}\right)\end{array}$ & $\begin{array}{c}\text { Zone \#6 } \\
\left({ }^{\circ} \mathrm{C}\right)\end{array}$ & $\begin{array}{c}\text { Zone \#7 } \\
\left({ }^{\circ} \mathrm{C}\right)\end{array}$ & $\begin{array}{c}\text { Belt Speed } \\
(\mathrm{in} / \mathrm{min})\end{array}$ \\
\hline \hline 117.5 & 149.6 & 149.7 & 171.9 & 214.1 & 210.8 & 265.1 & 19.6
\end{tabular}




\section{Material E Reflow Profiles}

The reflow profile characterization for Material E used a ramp type profile as the basis for investigation. The 10 profiles used for experimentation are presented in Figures A-34 through A-43. The reflow parameters and The BTU Paragon oven setpoints that describe these profiles are presented in Tables A-67 through A-86. Replicates of 4 die were assembled for each profile, and these assemblies were analyzed for underfill voiding, resistance, and phase ratio. 


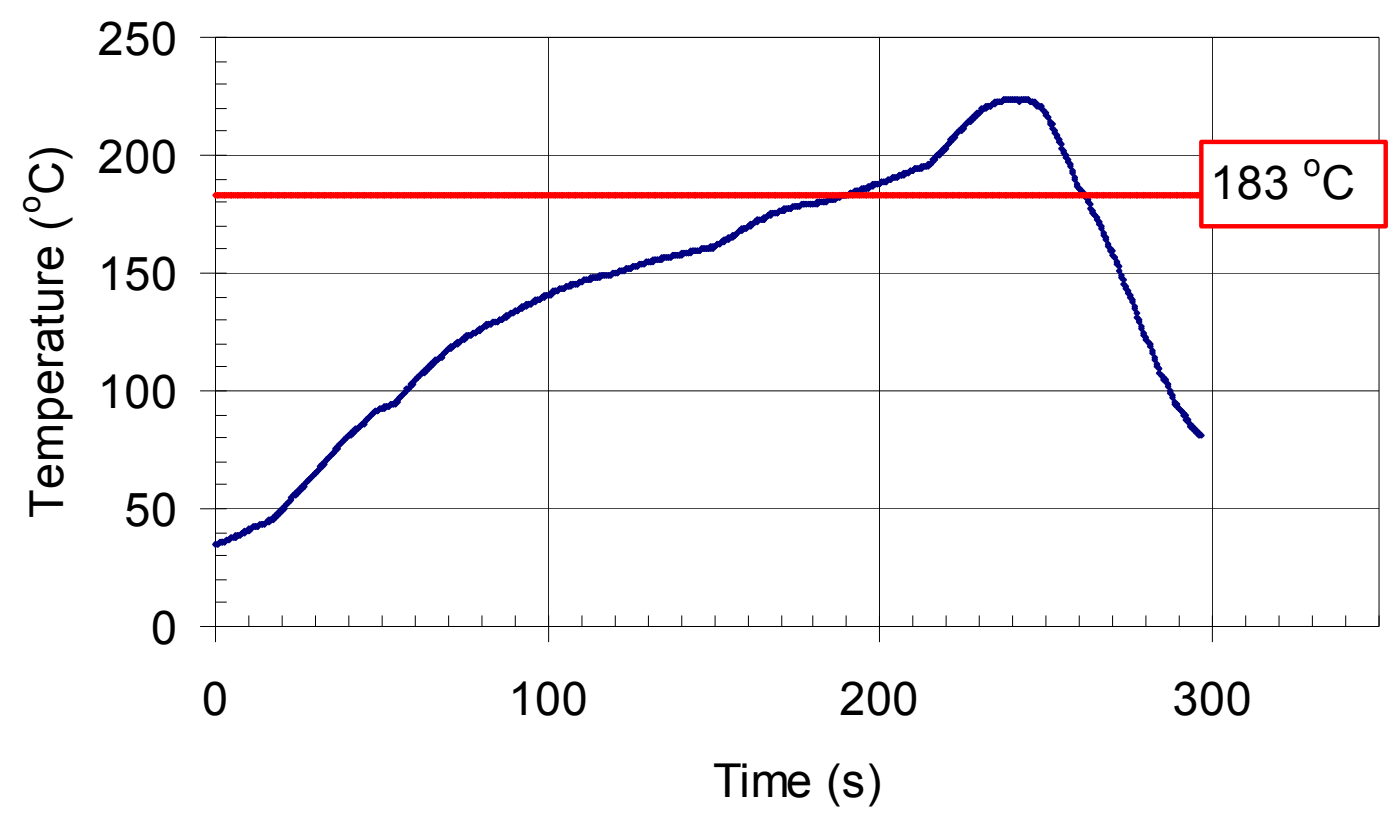

Figure A-34 Material E, Baseline Reflow profile

Table A-67 Material E, reflow parameters for Baseline profile

\begin{tabular}{c|c|c|c|c}
$\begin{array}{c}\text { Ramp Rate } \\
\left({ }^{\circ} \mathrm{C} / \mathrm{s}\right)\end{array}$ & $\begin{array}{c}\text { Soak Temp } \\
\left({ }^{\circ} \mathrm{C}\right)\end{array}$ & $\begin{array}{c}\text { Soak Time } \\
(\mathrm{s})\end{array}$ & $\begin{array}{c}\text { Time above } 183{ }^{\circ} \mathrm{C} \\
(\mathrm{s})\end{array}$ & $\begin{array}{c}\text { Peak Temp } \\
\left({ }^{\circ} \mathrm{C}\right)\end{array}$ \\
\hline \hline 1.8 & 165 & 71.5 & 67.2 & 225.2
\end{tabular}

Table A-68 Material E, oven set points for Baseline profile

\begin{tabular}{c|c|c|c|c|c|c|c}
$\begin{array}{c}\text { Zone \#1 } \\
\left({ }^{\circ} \mathrm{C}\right)\end{array}$ & $\begin{array}{c}\text { Zone \#2 } \\
\left({ }^{\circ} \mathrm{C}\right)\end{array}$ & $\begin{array}{c}\text { Zone \#3 } \\
\left({ }^{\circ} \mathrm{C}\right)\end{array}$ & $\begin{array}{c}\text { Zone \#4 } \\
\left({ }^{\circ} \mathrm{C}\right)\end{array}$ & $\begin{array}{c}\text { Zone \#5 } \\
\left({ }^{\circ} \mathrm{C}\right)\end{array}$ & $\begin{array}{c}\text { Zone \#6 } \\
\left({ }^{\circ} \mathrm{C}\right)\end{array}$ & $\begin{array}{c}\text { Zone \#7 } \\
\left({ }^{\circ} \mathrm{C}\right)\end{array}$ & $\begin{array}{c}\text { Belt Speed } \\
(\text { in/min })\end{array}$ \\
\hline \hline 126.8 & 151.3 & 157.5 & 167.9 & 204.7 & 204.1 & 268.8 & 25.9
\end{tabular}




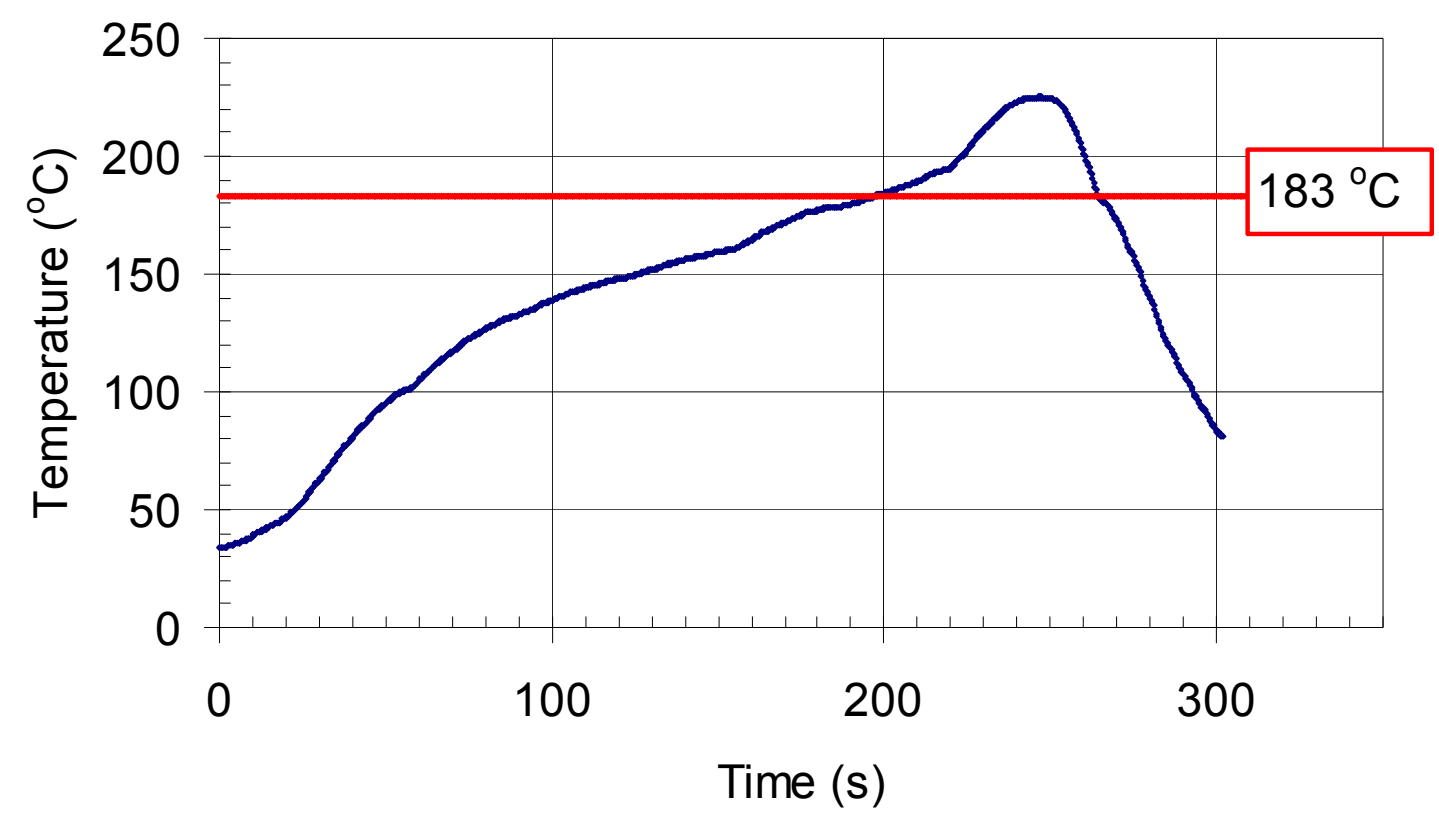

Figure A-35 Material E, Ramp Rate Low reflow profile

Table A-69 Material E, reflow parameters for Ramp Rate Low profile

\begin{tabular}{c|c|c|c|c}
$\begin{array}{c}\text { Ramp Rate } \\
\left({ }^{\circ} \mathrm{C} / \mathrm{s}\right)\end{array}$ & $\begin{array}{c}\text { Soak Temp } \\
\left({ }^{\circ} \mathrm{C}\right)\end{array}$ & $\begin{array}{c}\text { Soak Time } \\
(\mathrm{s})\end{array}$ & $\begin{array}{c}\text { Time above } 183{ }^{\circ} \mathrm{C} \\
(\mathrm{s})\end{array}$ & $\begin{array}{c}\text { Peak Temp } \\
\left({ }^{\circ} \mathrm{C}\right)\end{array}$ \\
\hline \hline 1.6 & 165 & 69.3 & 72.3 & 223.7
\end{tabular}

Table A-70 Material E, oven set points for Ramp Rate Low profile

\begin{tabular}{c|c|c|c|c|c|c|c}
$\begin{array}{c}\text { Zone \#1 } \\
\left({ }^{\circ} \mathrm{C}\right)\end{array}$ & $\begin{array}{c}\text { Zone \#2 } \\
\left({ }^{\circ} \mathrm{C}\right)\end{array}$ & $\begin{array}{c}\text { Zone \#3 } \\
\left({ }^{\circ} \mathrm{C}\right)\end{array}$ & $\begin{array}{c}\text { Zone \#4 } \\
\left({ }^{\circ} \mathrm{C}\right)\end{array}$ & $\begin{array}{c}\text { Zone \#5 } \\
\left({ }^{\circ} \mathrm{C}\right)\end{array}$ & $\begin{array}{c}\text { Zone \#6 } \\
\left({ }^{\circ} \mathrm{C}\right)\end{array}$ & $\begin{array}{c}\text { Zone \#7 } \\
\left({ }^{\circ} \mathrm{C}\right)\end{array}$ & $\begin{array}{c}\text { Belt Speed } \\
(\text { in/min })\end{array}$ \\
\hline \hline 116.5 & 150 & 160.2 & 167.7 & 206.9 & 205.1 & 266.8 & 26.1
\end{tabular}




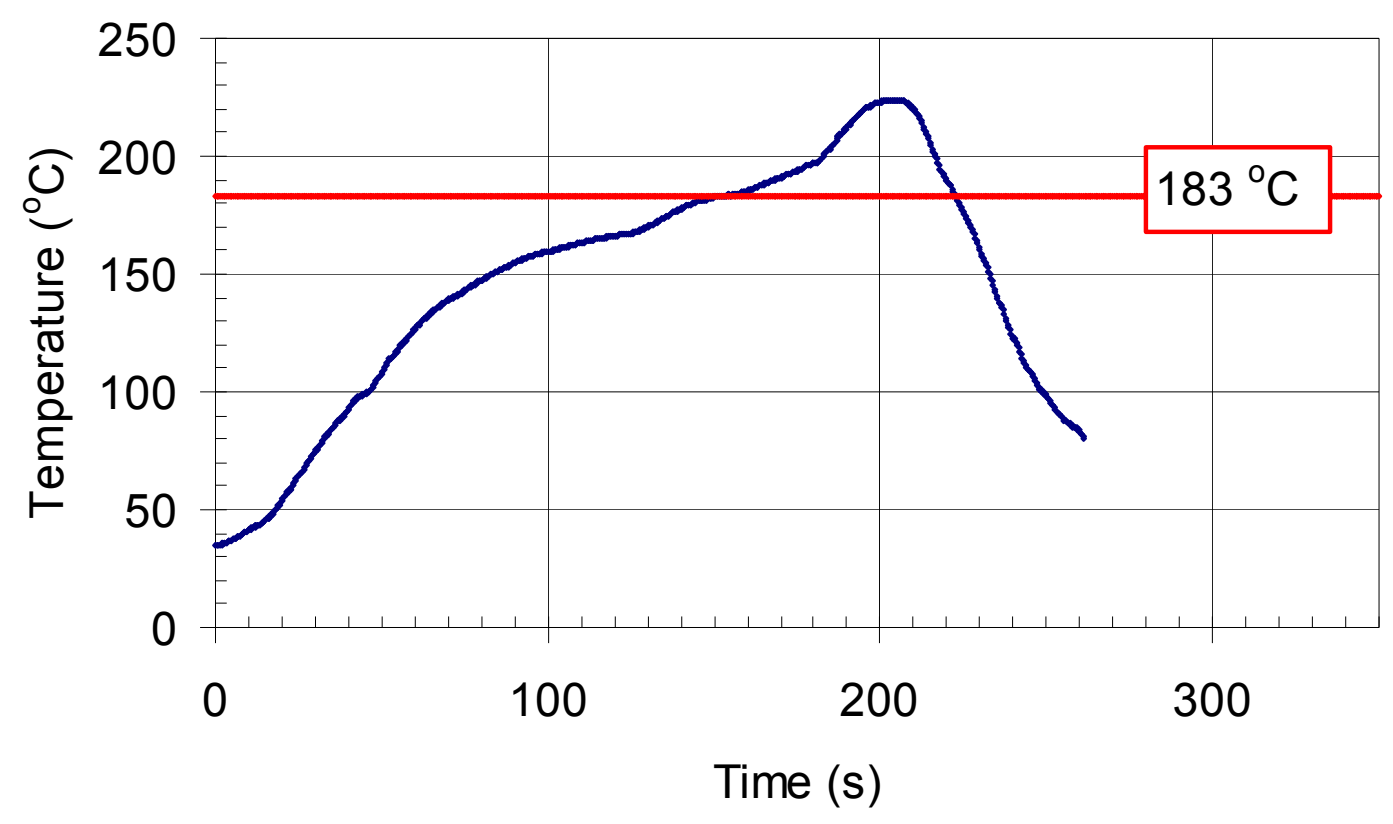

Figure A-36 E, Ramp Rate High reflow profile

Table A-71 Material E, reflow parameters for Ramp Rate High profile

\begin{tabular}{c|c|c|c|c}
$\begin{array}{c}\text { Ramp Rate } \\
\left({ }^{\circ} \mathrm{C} / \mathrm{s}\right)\end{array}$ & $\begin{array}{c}\text { Soak Temp } \\
\left({ }^{\circ} \mathrm{C}\right)\end{array}$ & $\begin{array}{c}\text { Soak Time } \\
(\mathrm{s})\end{array}$ & $\begin{array}{c}\text { Time above } 183{ }^{\circ} \mathrm{C} \\
(\mathrm{s})\end{array}$ & $\begin{array}{c}\text { Peak Temp } \\
\left({ }^{\circ} \mathrm{C}\right)\end{array}$ \\
\hline \hline 2 & 165 & 67.7 & 71.9 & 223.8
\end{tabular}

Table A-72 Material E, oven set points for Ramp Rate High profile

\begin{tabular}{c|c|c|c|c|c|c|c}
$\begin{array}{c}\text { Zone \#1 } \\
\left({ }^{\circ} \mathrm{C}\right)\end{array}$ & $\begin{array}{c}\text { Zone \#2 } \\
\left({ }^{\circ} \mathrm{C}\right)\end{array}$ & $\begin{array}{c}\text { Zone \#3 } \\
\left({ }^{\circ} \mathrm{C}\right)\end{array}$ & $\begin{array}{c}\text { Zone \#4 } \\
\left({ }^{\circ} \mathrm{C}\right)\end{array}$ & $\begin{array}{c}\text { Zone \#5 } \\
\left({ }^{\circ} \mathrm{C}\right)\end{array}$ & $\begin{array}{c}\text { Zone \#6 } \\
\left({ }^{\circ} \mathrm{C}\right)\end{array}$ & $\begin{array}{c}\text { Zone \#7 } \\
\left({ }^{\circ} \mathrm{C}\right)\end{array}$ & $\begin{array}{c}\text { Belt Speed } \\
(\text { in/min })\end{array}$ \\
\hline \hline 131.1 & 173.9 & 173.3 & 173.5 & 209.5 & 208.8 & 271.1 & 31
\end{tabular}




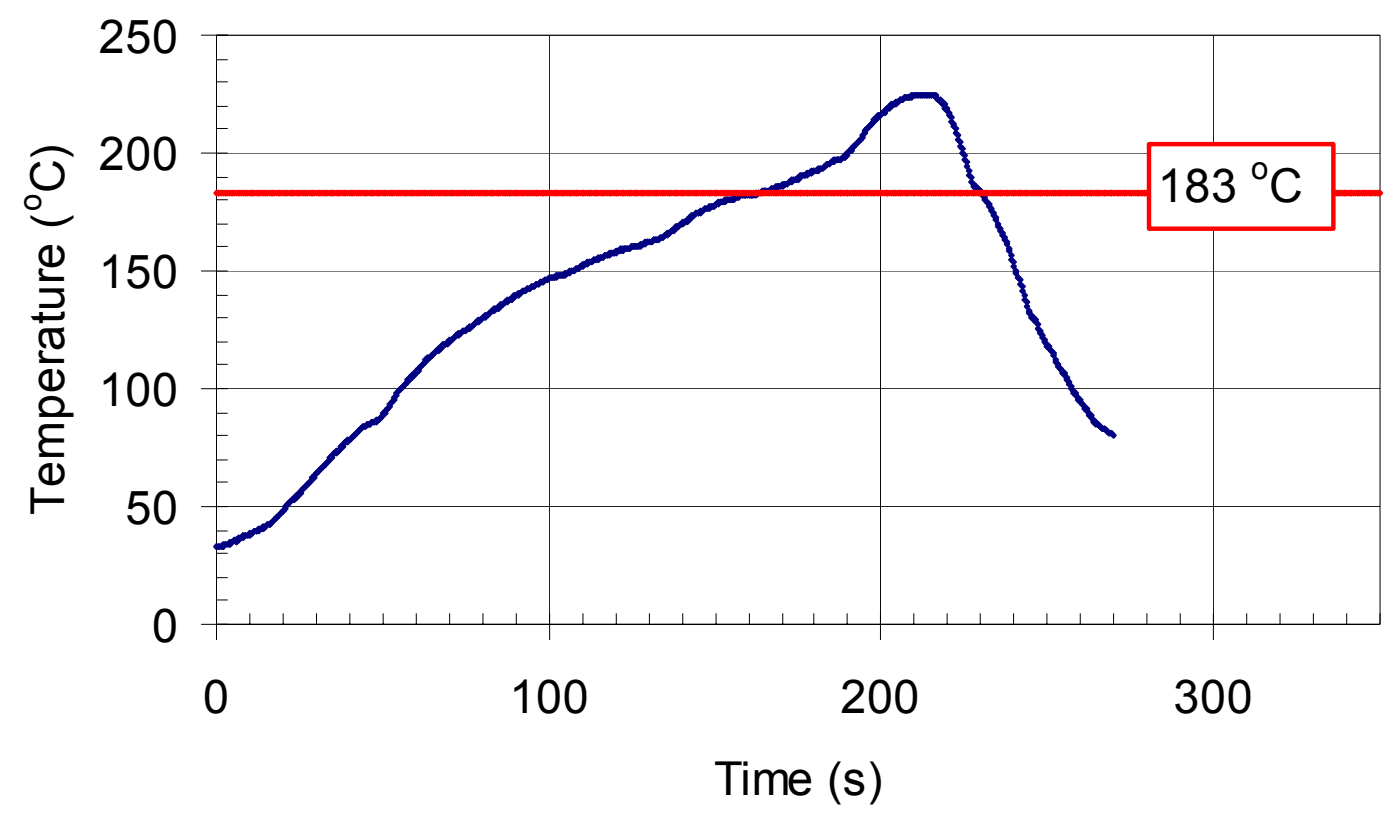

Figure A-37 Material E, Soak Time Low reflow profile

Table A-73 Material E, reflow parameters for Soak Time Low profile

\begin{tabular}{c|c|c|c|c}
$\begin{array}{c}\text { Ramp Rate } \\
\left({ }^{\circ} \mathrm{C} / \mathrm{s}\right)\end{array}$ & $\begin{array}{c}\text { Soak Temp } \\
\left({ }^{\circ} \mathrm{C}\right)\end{array}$ & $\begin{array}{c}\text { Soak Time } \\
(\mathrm{s})\end{array}$ & $\begin{array}{c}\text { Time above } 183{ }^{\circ} \mathrm{C} \\
(\mathrm{s})\end{array}$ & $\begin{array}{c}\text { Peak Temp } \\
\left({ }^{\circ} \mathrm{C}\right)\end{array}$ \\
\hline \hline 1.8 & 165 & 56.1 & 67.3 & 224.7
\end{tabular}

Table A-74 Material E, oven set points for Soak Time Low profile

\begin{tabular}{c|c|c|c|c|c|c|c}
$\begin{array}{c}\text { Zone \#1 } \\
\left({ }^{\circ} \mathrm{C}\right)\end{array}$ & $\begin{array}{c}\text { Zone \#2 } \\
\left({ }^{\circ} \mathrm{C}\right)\end{array}$ & $\begin{array}{c}\text { Zone \#3 } \\
\left({ }^{\circ} \mathrm{C}\right)\end{array}$ & $\begin{array}{c}\text { Zone \#4 } \\
\left({ }^{\circ} \mathrm{C}\right)\end{array}$ & $\begin{array}{c}\text { Zone \#5 } \\
\left({ }^{\circ} \mathrm{C}\right)\end{array}$ & $\begin{array}{c}\text { Zone \#6 } \\
\left({ }^{\circ} \mathrm{C}\right)\end{array}$ & $\begin{array}{c}\text { Zone \#7 } \\
\left({ }^{\circ} \mathrm{C}\right)\end{array}$ & $\begin{array}{c}\text { Belt Speed } \\
(\text { in/min })\end{array}$ \\
\hline \hline 108.8 & 153.3 & 162.5 & 173.1 & 213.2 & 209.5 & 270.3 & 29.9
\end{tabular}




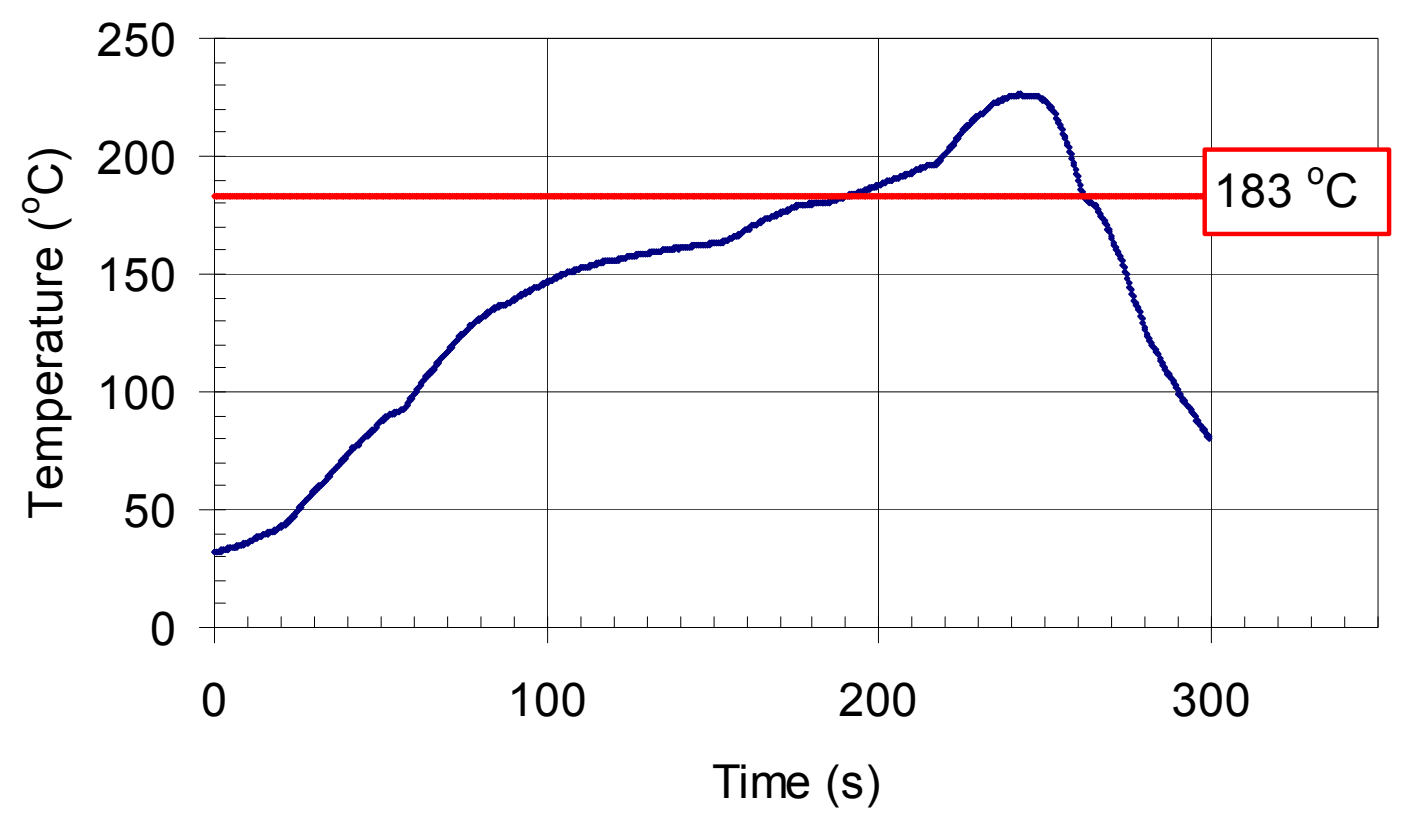

Figure A-38 Material E, Soak Time High Reflow Profile

Table A-75 Material E, Reflow Parameters for Soak Time High Profile

\begin{tabular}{c|c|c|c|c}
$\begin{array}{c}\text { Ramp Rate } \\
\left({ }^{\circ} \mathrm{C} / \mathrm{s}\right)\end{array}$ & $\begin{array}{c}\text { Soak Temp } \\
\left({ }^{\circ} \mathrm{C}\right)\end{array}$ & $\begin{array}{c}\text { Soak Time } \\
(\mathrm{s})\end{array}$ & $\begin{array}{c}\text { Time above } 183{ }^{\circ} \mathrm{C} \\
(\mathrm{s})\end{array}$ & $\begin{array}{c}\text { Peak Temp } \\
\left({ }^{\circ} \mathrm{C}\right)\end{array}$ \\
\hline \hline 1.8 & 165 & 85.1 & 71.2 & 226.2
\end{tabular}

Table A-76 Material E, Oven Setpoints for Soak Time High Profile

\begin{tabular}{c|c|c|c|c|c|c|c}
$\begin{array}{c}\text { Zone \#1 } \\
\left({ }^{\circ} \mathrm{C}\right)\end{array}$ & $\begin{array}{c}\text { Zone \#2 } \\
\left({ }^{\circ} \mathrm{C}\right)\end{array}$ & $\begin{array}{c}\text { Zone \#3 } \\
\left({ }^{\circ} \mathrm{C}\right)\end{array}$ & $\begin{array}{c}\text { Zone \#4 } \\
\left({ }^{\circ} \mathrm{C}\right)\end{array}$ & $\begin{array}{c}\text { Zone \#5 } \\
\left({ }^{\circ} \mathrm{C}\right)\end{array}$ & $\begin{array}{c}\text { Zone \#6 } \\
\left({ }^{\circ} \mathrm{C}\right)\end{array}$ & $\begin{array}{c}\text { Zone \#7 } \\
\left({ }^{\circ} \mathrm{C}\right)\end{array}$ & $\begin{array}{c}\text { Belt Speed } \\
(\mathrm{in} / \mathrm{min})\end{array}$ \\
\hline \hline 111.3 & 166.2 & 165.8 & 166.6 & 206 & 205.5 & 268.4 & 26.1
\end{tabular}




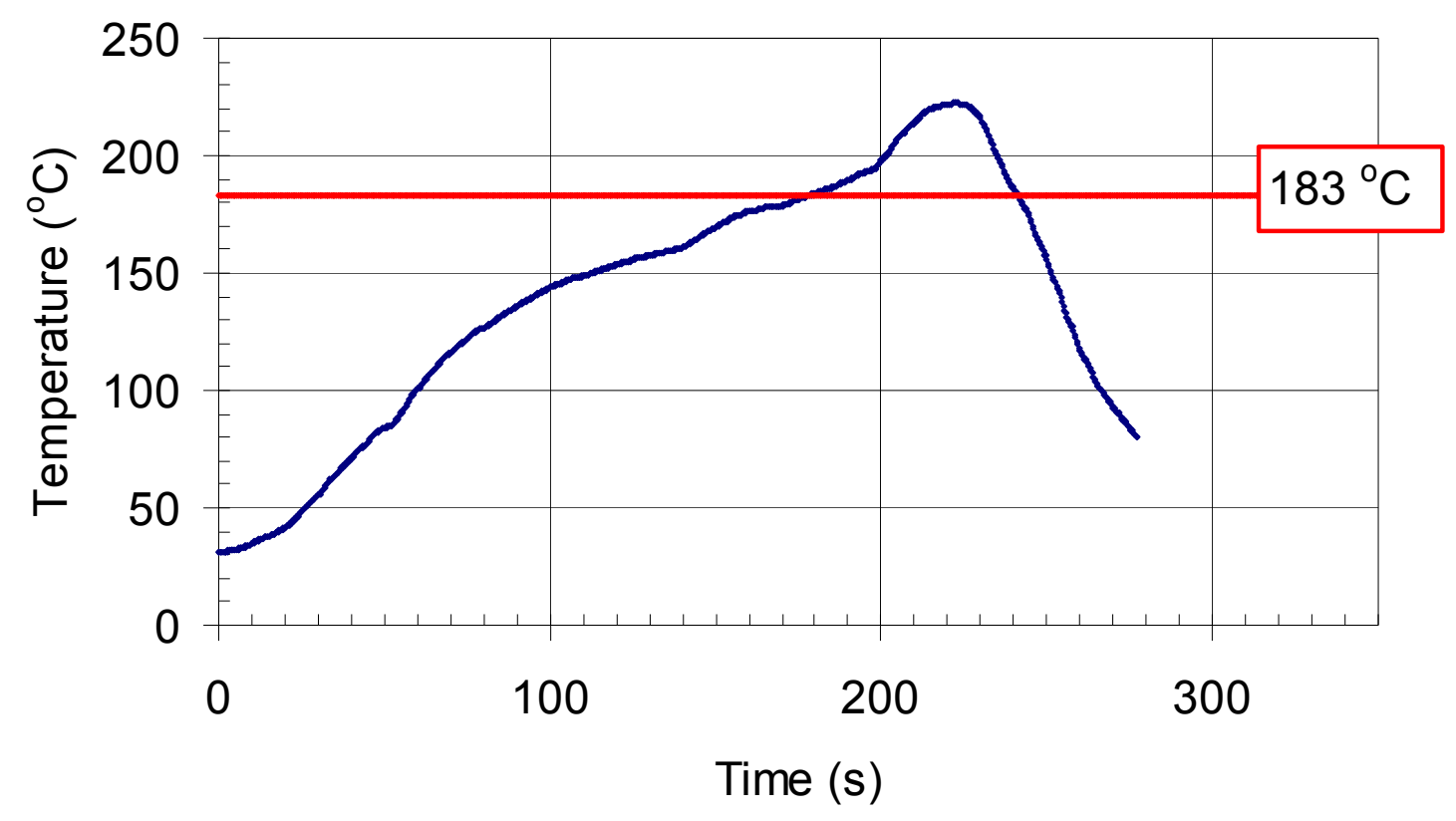

Figure A-39 Material E, Time Above $183{ }^{\circ} \mathrm{C}$ Low Reflow Profile

Table A-77 Material E, Parameters for Time Above $183^{\circ} \mathrm{C}$ Low Reflow Profile

\begin{tabular}{c|c|c|c|c}
$\begin{array}{c}\text { Ramp Rate } \\
\left({ }^{\circ} \mathrm{C} / \mathrm{s}\right)\end{array}$ & $\begin{array}{c}\text { Soak Temp } \\
\left({ }^{\circ} \mathrm{C}\right)\end{array}$ & $\begin{array}{c}\text { Soak Time } \\
(\mathrm{s})\end{array}$ & $\begin{array}{c}\text { Time above } 183{ }^{\circ} \mathrm{C} \\
(\mathrm{s})\end{array}$ & $\begin{array}{c}\text { Peak Temp } \\
\left({ }^{\circ} \mathrm{C}\right)\end{array}$ \\
\hline \hline 1.8 & 165 & 65.7 & 62.9 & 222.4
\end{tabular}

Table A-78 Material E, Oven Setpoints for Time Above $183^{\circ} \mathrm{C}$ Low Reflow Profile \begin{tabular}{c|c|c|c|c|c|c|c}
$\begin{array}{c}\text { Zone \#1 } \\
\left({ }^{\circ} \mathrm{C}\right)\end{array}$ & $\begin{array}{c}\text { Zone \#2 } \\
\left({ }^{\circ} \mathrm{C}\right)\end{array}$ & $\begin{array}{c}\text { Zone \#3 } \\
\left({ }^{\circ} \mathrm{C}\right)\end{array}$ & $\begin{array}{c}\text { Zone \#4 } \\
\left({ }^{\circ} \mathrm{C}\right)\end{array}$ & $\begin{array}{c}\text { Zone \#5 } \\
\left({ }^{\circ} \mathrm{C}\right)\end{array}$ & $\begin{array}{c}\text { Zone \#6 } \\
\left({ }^{\circ} \mathrm{C}\right)\end{array}$ & $\begin{array}{c}\text { Zone \#7 } \\
\left({ }^{\circ} \mathrm{C}\right)\end{array}$ & $\begin{array}{c}\text { Belt Speed } \\
(\text { in/min })\end{array}$ \\
\hline \hline 105.8 & 157 & 163.1 & 167.6 & 206.1 & 205.2 & 269.5 & 28.8
\end{tabular} 


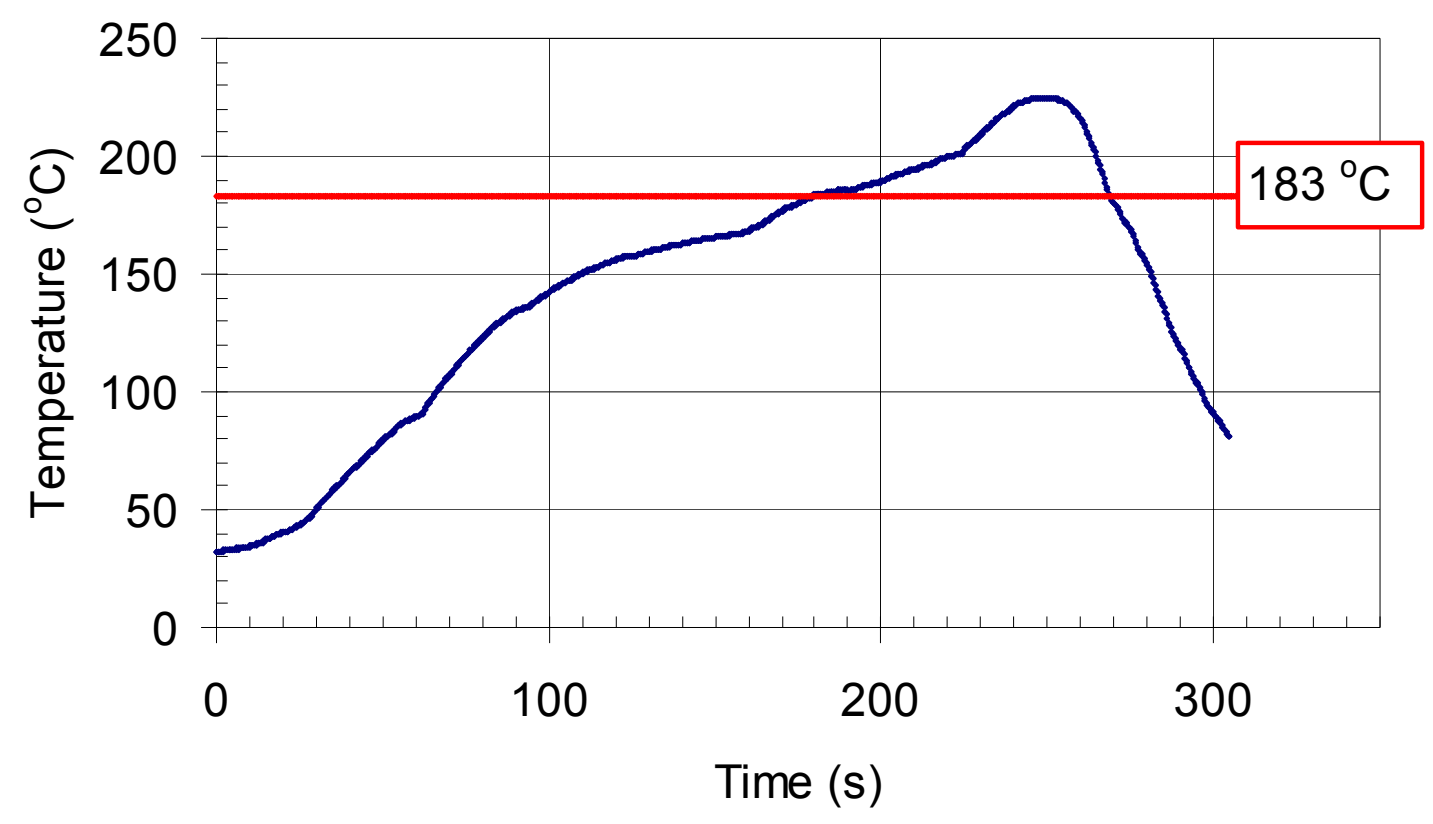

Figure A-40 Material E, Time Above $183^{\circ} \mathrm{C}$ HIgh Reflow Profile

Table A-79 Material E, Parameters for Time Above $183{ }^{\circ} \mathrm{C}$ High Reflow Profile \begin{tabular}{c|c|c|c|c}
$\begin{array}{c}\text { Ramp Rate } \\
\left({ }^{\circ} \mathrm{C} / \mathrm{s}\right)\end{array}$ & $\begin{array}{c}\text { Soak Temp } \\
\left({ }^{\circ} \mathrm{C}\right)\end{array}$ & $\begin{array}{c}\text { Soak Time } \\
(\mathrm{s})\end{array}$ & $\begin{array}{c}\text { Time Above } 183^{\circ} \mathrm{C} \\
(\mathrm{s})\end{array}$ & $\begin{array}{c}\text { Peak Temp } \\
\left({ }^{\circ} \mathrm{C}\right)\end{array}$ \\
\hline \hline 1.8 & 165 & 70 & 89.3 & 224.9
\end{tabular}

Table A-80 Material E, Oven Setpoints, Time Above $183{ }^{\circ} \mathrm{C}$ High Reflow Profile

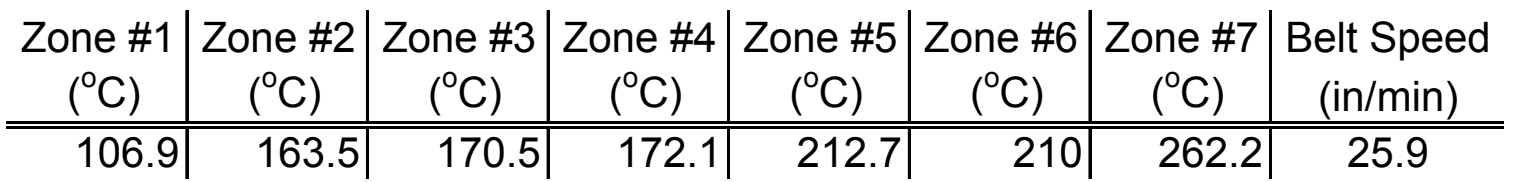




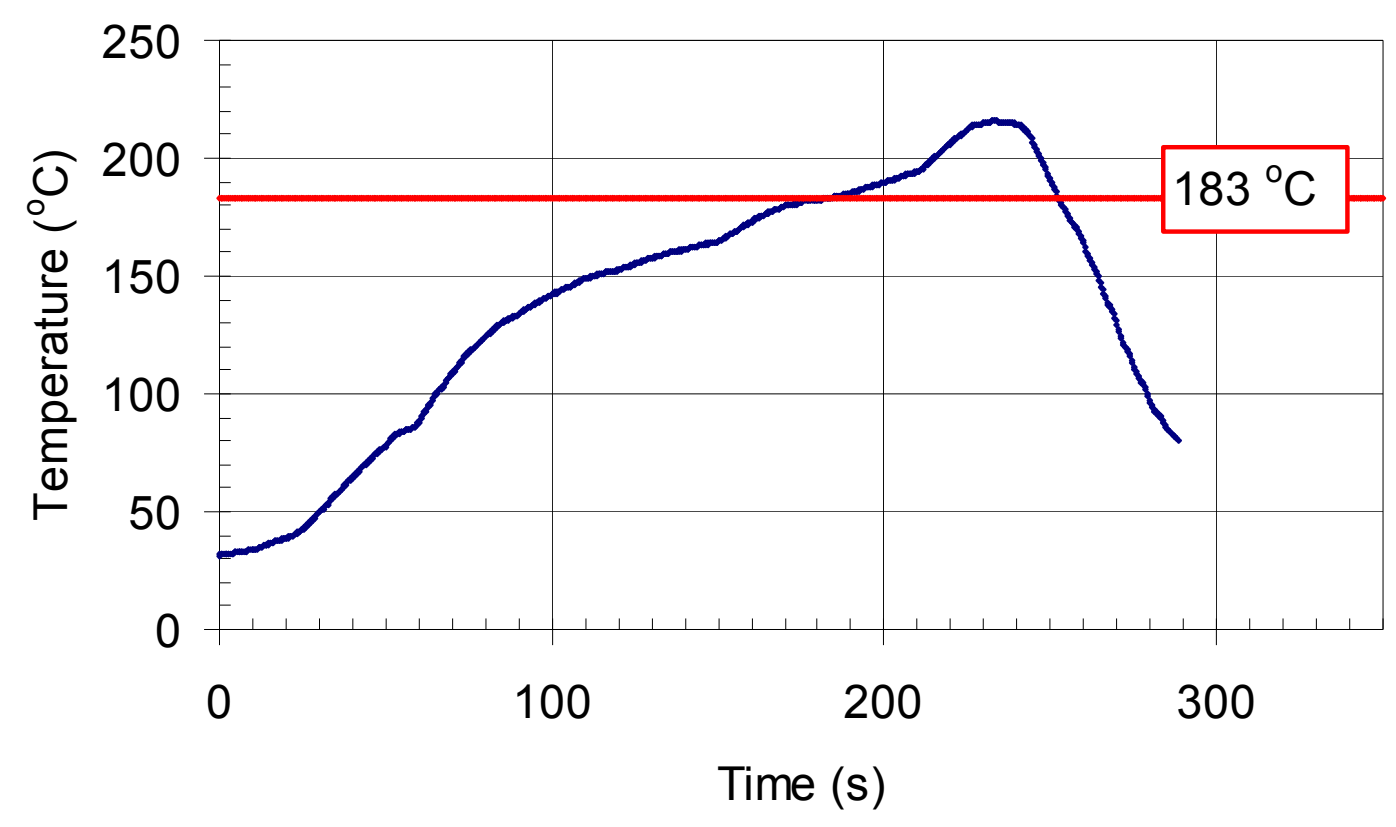

Figure A-41 Material E, Peak Temperature Low Reflow Profile

Table A-81 Material E, Reflow Parameters for Peak Temperature Low Profile

\begin{tabular}{c|c|c|c|c}
$\begin{array}{c}\text { Ramp Rate } \\
\left({ }^{\circ} \mathrm{C} / \mathrm{s}\right)\end{array}$ & $\begin{array}{c}\text { Soak Temp } \\
\left({ }^{\circ} \mathrm{C}\right)\end{array}$ & $\begin{array}{c}\text { Soak Time } \\
(\mathrm{s})\end{array}$ & $\begin{array}{c}\text { Time Above } 183{ }^{\circ} \mathrm{C} \\
(\mathrm{s})\end{array}$ & $\begin{array}{c}\text { Peak Temp } \\
\left({ }^{\circ} \mathrm{C}\right)\end{array}$ \\
\hline \hline 1.8 & 165 & 70.2 & 69.5 & 215.8
\end{tabular}

Table A-82 Material E, Oven Setpoints for Peak Temperature Low Profile

\begin{tabular}{c|c|c|c|c|c|c|c}
$\begin{array}{c}\text { Zone \#1 } \\
\left({ }^{\circ} \mathrm{C}\right)\end{array}$ & $\begin{array}{c}\text { Zone \#2 } \\
\left({ }^{\circ} \mathrm{C}\right)\end{array}$ & $\begin{array}{c}\text { Zone \#3 } \\
\left({ }^{\circ} \mathrm{C}\right)\end{array}$ & $\begin{array}{c}\text { Zone \#4 } \\
\left({ }^{\circ} \mathrm{C}\right)\end{array}$ & $\begin{array}{c}\text { Zone \#5 } \\
\left({ }^{\circ} \mathrm{C}\right)\end{array}$ & $\begin{array}{c}\text { Zone \#6 } \\
\left({ }^{\circ} \mathrm{C}\right)\end{array}$ & $\begin{array}{c}\text { Zone \#7 } \\
\left({ }^{\circ} \mathrm{C}\right)\end{array}$ & $\begin{array}{c}\text { Belt Speed } \\
(\text { in/min })\end{array}$ \\
\hline \hline 103 & 163.2 & 164.5 & 171.6 & 209.3 & 202.1 & 252.7 & 27.6
\end{tabular}




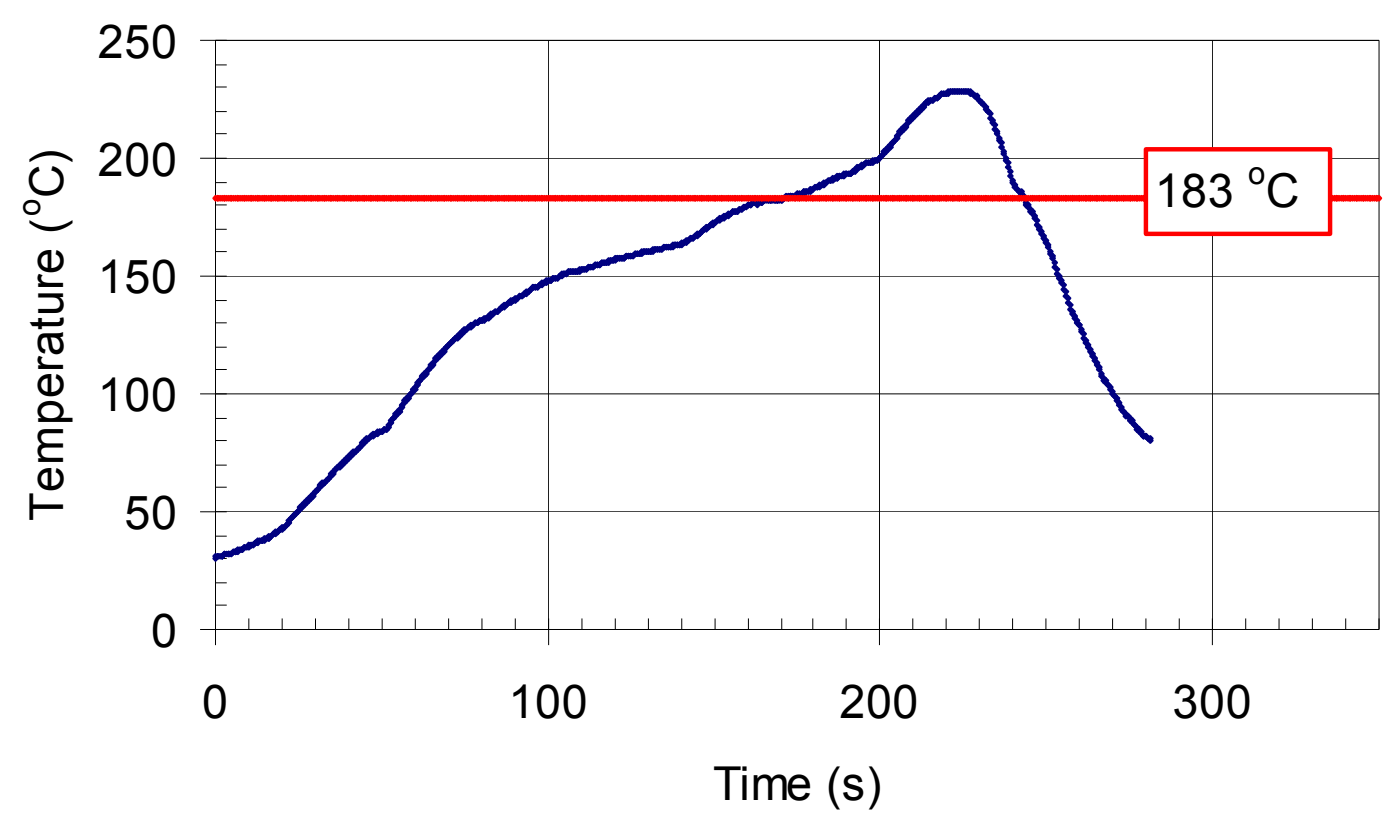

Figure A-42 Material E, Peak Temperature Low Reflow Profile

Table A-83 Material E, Reflow Parameters for Peak Temperature High Profile

\begin{tabular}{c|c|c|c|c}
$\begin{array}{c}\text { Ramp Rate } \\
\left({ }^{\circ} \mathrm{C} / \mathrm{s}\right)\end{array}$ & $\begin{array}{c}\text { Soak Temp } \\
\left({ }^{\circ} \mathrm{C}\right)\end{array}$ & $\begin{array}{c}\text { Soak Time } \\
(\mathrm{s})\end{array}$ & $\begin{array}{c}\text { Time Above } 183{ }^{\circ} \mathrm{C} \\
(\mathrm{s})\end{array}$ & $\begin{array}{c}\text { Peak Temp } \\
\left({ }^{\circ} \mathrm{C}\right)\end{array}$ \\
\hline \hline 1.8 & 165 & 67.7 & 72 & 228.5
\end{tabular}

Table A-84 Material E, Oven Setpoints for Peak Temperature High Profile

\begin{tabular}{c|c|c|c|c|c|c|c}
$\begin{array}{c}\text { Zone \#1 } \\
\left({ }^{\circ} \mathrm{C}\right)\end{array}$ & $\begin{array}{c}\text { Zone \#2 } \\
\left({ }^{\circ} \mathrm{C}\right)\end{array}$ & $\begin{array}{c}\text { Zone \#3 } \\
\left({ }^{\circ} \mathrm{C}\right)\end{array}$ & $\begin{array}{c}\text { Zone \#4 } \\
\left({ }^{\circ} \mathrm{C}\right)\end{array}$ & $\begin{array}{c}\text { Zone \#5 } \\
\left({ }^{\circ} \mathrm{C}\right)\end{array}$ & $\begin{array}{c}\text { Zone \#6 } \\
\left({ }^{\circ} \mathrm{C}\right)\end{array}$ & $\begin{array}{c}\text { Zone \#7 } \\
\left({ }^{\circ} \mathrm{C}\right)\end{array}$ & $\begin{array}{c}\text { Belt Speed } \\
(\text { in/min })\end{array}$ \\
\hline \hline 103.4 & 163.7 & 166.3 & 169.5 & 211 & 210.2 & 275.7 & 28.3
\end{tabular}




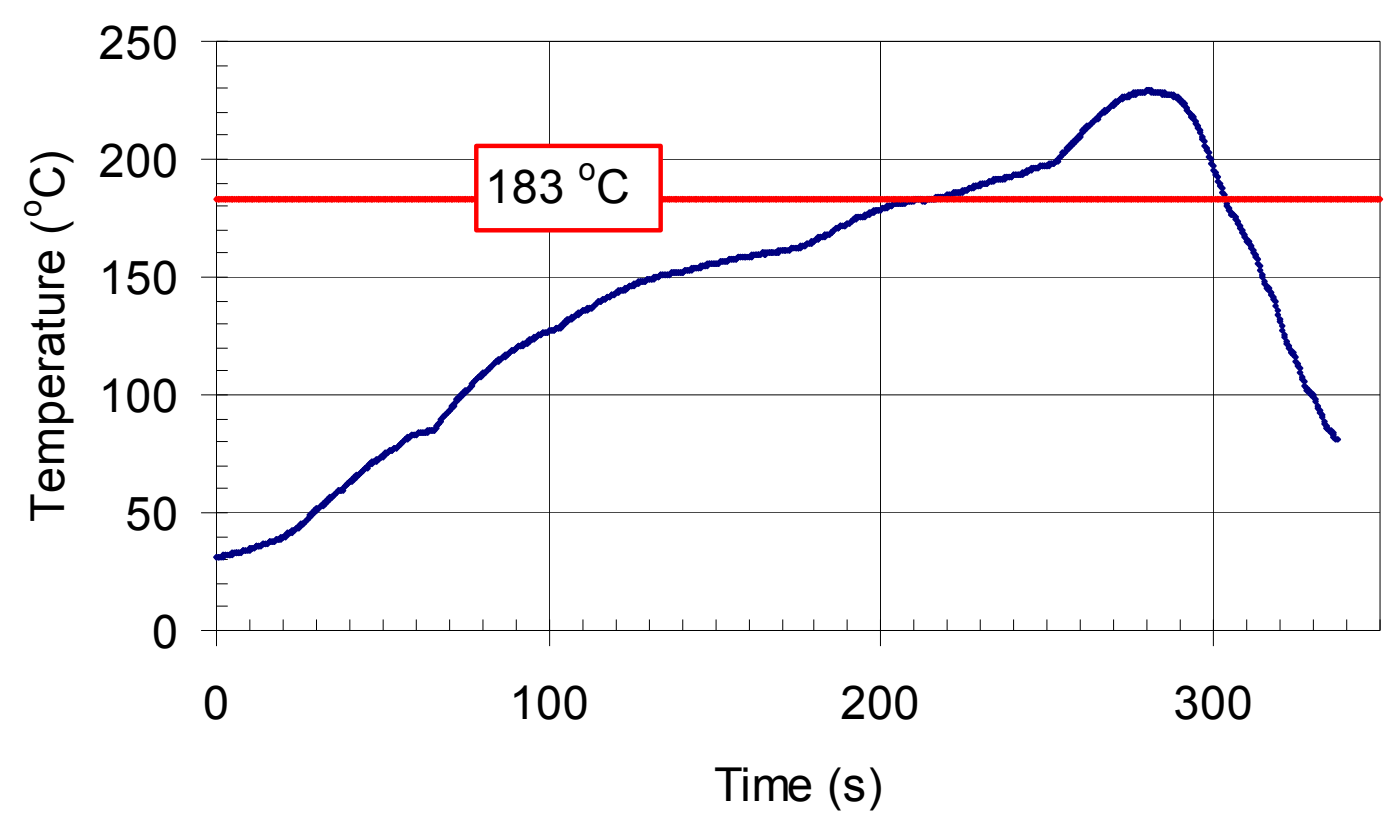

Figure A-43 Material E, Parametric Optimized Reflow Profile

Table A-85 Material E, Reflow Parameters for Parametric Optimized Profile

\begin{tabular}{c|c|c|c|c}
$\begin{array}{c}\text { Ramp Rate } \\
\left({ }^{\circ} \mathrm{C} / \mathrm{s}\right)\end{array}$ & $\begin{array}{c}\text { Soak Temp } \\
\left({ }^{\circ} \mathrm{C}\right)\end{array}$ & $\begin{array}{c}\text { Soak Time } \\
(\mathrm{s})\end{array}$ & $\begin{array}{c}\text { Time Above } 183{ }^{\circ} \mathrm{C} \\
(\mathrm{s})\end{array}$ & $\begin{array}{c}\text { Peak Temp } \\
\left({ }^{\circ} \mathrm{C}\right)\end{array}$ \\
\hline \hline 1.5 & 165 & 83.2 & 87.7 & 228.9
\end{tabular}

Table A-86 Material E, Oven Setpoints for Parametric Optimized Profile

\begin{tabular}{c|c|c|c|c|c|c|c}
$\begin{array}{c}\text { Zone \#1 } \\
\left({ }^{\circ} \mathrm{C}\right)\end{array}$ & $\begin{array}{c}\text { Zone \#2 } \\
\left({ }^{\circ} \mathrm{C}\right)\end{array}$ & $\begin{array}{c}\text { Zone \#3 } \\
\left({ }^{\circ} \mathrm{C}\right)\end{array}$ & $\begin{array}{c}\text { Zone \#4 } \\
\left({ }^{\circ} \mathrm{C}\right)\end{array}$ & $\begin{array}{c}\text { Zone \#5 } \\
\left({ }^{\circ} \mathrm{C}\right)\end{array}$ & $\begin{array}{c}\text { Zone \#6 } \\
\left({ }^{\circ} \mathrm{C}\right)\end{array}$ & $\begin{array}{c}\text { Zone \#7 } \\
\left({ }^{\circ} \mathrm{C}\right)\end{array}$ & $\begin{array}{c}\text { Belt Speed } \\
(\mathrm{in} / \mathrm{min})\end{array}$ \\
\hline \hline 95 & 146.8 & 162.6 & 165.9 & 204.9 & 204.5 & 268.1 & 22.4
\end{tabular}




\section{REFERENCES}

Baldwin, Daniel F., Thorpe, Ryan, and Brian J. Lewis, "Low-Cost HighThroughput Flip Chip Processing: Reliability Based on No-Flow Underfills", Advanced Packaging, Jan. 2000, pp. 36-44.

Baldwin and Pascarella, "Manufacturability of Underfill Processing for Low Cost Flip Chip", ASME, EEP-Vol 21, 1997.

Blake, T. D., "Dynamic Contact Angles and Wetting Kinetics", Wettability, New York M. Dekker, Chap. 5, pp. 251-309, 1993

George E.P. Box, Willam G. Hunter, J. Stuart Hunter, "Statistics for Experimenters - An Introduction to Design, Data Analysis, and Model Building", 1978

Busch, S.C.; Lu, J.; Smith, B; Baldwin, D.F., "Coating and Dicing of Wafer Applied Underfills for Low-Cost Flip Chip Processing", Proceeedings of the International Symposium on Advanced Packaging Materials Processes, Properties and Interfaces, pp. 175-9, 2000

Cox, R. G., "The Dynamics of the Spreading of Liquids on a Solid Surface Part 1. Viscous Flow", Journal of Fluid Mechanics, Vol. 168, pp. 169-194, 1986

De Gennes P. G., "Wetting: Statics and Dynamics", Review of Modern Physics, Vol. 57, No. 3, Part I, pp. 827-863, 1985

De Ruijter, M. J., J. De Coninck, T. D. Blake, A. Clarke, and A. Rankin, "Contact Angle Relaxation during the Spreading of Partially Wetting Drops", Langmuir, Vol. 13, No. 26, pp. 7293-7298, 1997

Dussan, V., and B. Elizabeth, " The Moving Contact Line: The Slip Boundary Condition", Journal of Fluid Mechanics, Vol 77, pp. 665-684, 1976

Fan, S.H., et al., "The effect of reflow condition on the characteristics of PBGA solder joint", Proceedings of the $2^{\text {nd }}$ Electronics Packaging Technology Conference, 1998, p 264-8

Fasser, Y., D. Brettner, "Process Improvement in the Electronics Industry", 1992

Frear, D., et al., "The Mechanics of Solder Alloy Interconnects", 1994

Hayter, Anthony J. "Probability and Statistics for Engineers and Scientists", 1995.

Han, S., "Experimental and Analytical Study on the Flow of Encapsulant During Underfill Encapsulation of Flip Chips", ECTC 1996, pp 327-34 
JEDEC Standard, "Accelerated Moisture Resistance-Unbiased Autoclave", JESD22-A102-C, Electronic Industries Association, March 1991.

JEDEC Standard, "Thermal Cycling", JESD22-A104-A, Electronic Industries Association, December 1989.

Kistler, S., "Hydrodynamics of Wetting", Wettability, New York M. Dekker, Chap. 6, pp. 311-427, 1993

Kim, C., "No-Flow Underfill Process Modeling and Analysis for Low Cost, High Throughput Flip Chip Assembly", IEEE Transactions on Electronics Packaging Manufacturing, v 26, n 2, April 2003, p156-65

Lau, J., “Flip Chip Technologies”, McGraw-Hill, 1996.

Lau, J., "Low Cost Flip Chip Technologies”, McGraw-Hill, 2000

Lau, J., et al., "Effects of Underfill Material Properties on the Reliability of Solder Bumped Flip Chip on Board with Imperfect Underfill Encapsulants", Proceedings of the 49th Electronic Components and Technology Conference, 1999.

Lazarakis, T., "Processing of no-flow fluxing underfills for flip chip assembly" MSME Thesis, School of Mechanical Engineering, Georgia Tech, Atlanta, GA, 2002

Leider, P., Bird, B., "Squeezing Flow Between Parallel Disks. I. Theoretical Analysis", Ind. Eng. Chem., Fundam., Vol. 13, No. 4, 1974

Milner, D., "High throughput flip chip assembly process application and assessment using no-flow underfills" MSME Thesis, School of Mechanical Engineering, Georgia Tech, Atlanta, GA, 2001

Nguyen, L.; Nguyen, H.; Negasi, A.; Tong, Q.; Hong, S.H.; "Wafer-level Underfill - Processing and Reliability", Electronics Manufacturing Technology Symposium, pp. 53-62, 2002

Pascarella, N., "Compression Flow Modeling of Underfill Encapsulants for Low Cost Flip Chip Assembly"', IEEE Transactions on Components, Packaging, and Manufacturing technology, Vol. 21, No. 4, 1998

Chanchani, Rajen, "Modeling and Simulation - The Effects of Grain Coarsening on Local Stresses and Strains in Solder Microstructure", International Symposium on Advanced Packaging Materials, 1999, pp. 136-143

Shi, S.H.; Yamashita, T.Y.; Wong, C.P., "Development of the Wafer Level Compressive-Flow Underfill Encapsulant", Proceeedings of the International 
Symposium on Advanced Packaging Materials Processes, Properties and Interfaces, pp. 337-43, 1999

S.H. Shi, Q. Yao, J. Qu, and C.P. Wong, "Study on the Correlation of Flip-Chip Reliability with Mechanical Properties of No-Flow Underfill Materials", 2000 Symposium on Advanced Packaging Materials, pp. 271-277

A. Shubert, et al., "Experimental and Numerical Reliability Investigations of FCOB Assemblies with Process-induced Defects", Electronic Components and Technology Conference, 2000, pp. 624-632

R.E. Smallman, R.J. Bishop, "Modern Physical Metallurgy \& Materials Engineering", Sixth Edition, 1999.

Thorpe, Ryan, and Daniel F. Baldwin, "High Throughput Flip Chip Processing and Reliability Analysis Using No-Flow Underfills", Advances in Electronic Packaging, ASME, 1999, vol. 26-2, pp. 1323-1330.

Thorpe, Ryan and Daniel Baldwin Ph.D., "A reliability and failure mode analysis of no-flow underfills for low cost flip chip assembly", Electronic Components and Technology Conference, 2000

Thorpe, R. "High Throughput Flip Chip Assembly Process and Reliability Analysis Using No-Flow Underfill Materials" MSME Thesis, School of Mechanical Engineering, Georgia Tech, Atlanta, GA, 2001

Töpper, M.; et al., "Wafer Level Packaging Using Double Balls", International Symposium on Advanced Packaging Materials, 2000, pp. 198-200

Tummala, R., “Fundamentals of Microsystems Packaging”, McGraw-Hill, 2001.

Tummala, R, Eugene Rymaszewski, Alan Klopfenstein, "Microelectronics Packaging Handbook", Second Edition, Part I, II, III, 1997.

Voinov, O. V., "Hydrodynamics of Wetting", Fluid Dynamics, Vol. 11, pp. 714-721, 1976

Wang, T.H. Chew, Colin Lum, Y.X. Chew, P. Miao and L. Foo, "Assessment of Flip Chip Assembly and Reliability via Reflowable Underfill”, Electronic Components and Technology Conference, 2001

C.P. Wong, D. Baldwin, M.B. Vincent, B. Fennell, L.J. Wang, and S.H. Shi, "Characterization of a No-Flow Underfill Encapsulant During the Solder Reflow Process", Electronic Components and Technology Conference, 1998. pp. 12531259 
C.P. Wong editor, "Polymers for Electronic and Photonic Applications", Boston Academic Press, 1993

Young T., Philos. Trans. R. Soc. London 95, 65, 1805 